\title{
Governance of international adaptation finance for local climate change adaptation
}

Citation for published version (APA):

Manuamorn, O. (2020). Governance of international adaptation finance for local climate change adaptation: an analysis of adaptation fund projects. [Doctoral Thesis, Maastricht University]. Boekenplan Maastricht. https://doi.org/10.26481/dis.20201117om

Document status and date:

Published: 01/01/2020

DOI:

10.26481/dis.20201117om

Document Version:

Publisher's PDF, also known as Version of record

\section{Please check the document version of this publication:}

- A submitted manuscript is the version of the article upon submission and before peer-review. There can be important differences between the submitted version and the official published version of record.

People interested in the research are advised to contact the author for the final version of the publication, or visit the DOI to the publisher's website.

- The final author version and the galley proof are versions of the publication after peer review.

- The final published version features the final layout of the paper including the volume, issue and page numbers.

Link to publication

\footnotetext{
General rights rights.

- You may freely distribute the URL identifying the publication in the public portal. please follow below link for the End User Agreement:

www.umlib.nl/taverne-license

Take down policy

If you believe that this document breaches copyright please contact us at:

repository@maastrichtuniversity.nl

providing details and we will investigate your claim.
}

Copyright and moral rights for the publications made accessible in the public portal are retained by the authors and/or other copyright owners and it is a condition of accessing publications that users recognise and abide by the legal requirements associated with these

- Users may download and print one copy of any publication from the public portal for the purpose of private study or research.

- You may not further distribute the material or use it for any profit-making activity or commercial gain

If the publication is distributed under the terms of Article $25 \mathrm{fa}$ of the Dutch Copyright Act, indicated by the "Taverne" license above, 


\section{Governance of International}

\section{Adaptation Finance for Local Climate}

Change Adaptation: An Analysis of

Adaptation Fund Projects 
C2020 Ornsaran Manuamorn

ISBN 9789086665204

Publisher: Boekenplan, Maastricht

All rights reserved. No part of this publication may be reproduced, stored in a retrieval system, or transmitted in any form, or by any means, electronic, mechanical, photocopying, recording or otherwise, without the prior permission in writing, from the author. 


\title{
Governance of International
}

\section{Adaptation Finance for Local Climate Change Adaptation: An Analysis of Adaptation Fund Projects}

\author{
Dissertation
}

to obtain the degree of Doctor at Maastricht University, on the authority of the Rector Magnificus Prof. Dr. Rianne M. Letschert in accordance with the decision of the Board of Deans, to be defended in public on Tuesday, 17 November 2020 at 10:00 hours

by 


\section{Supervisors:}

Prof. Dr. Shyama V. Ramani

Dr. Robbert Biesbroek, Wageningen University

\section{Assessment Committee:}

Prof. Dr. René Kemp (Chairman)

Prof. Dr. James D. Ford, University of Leeds

Dr. Michal Natorski

Dr. Lisa Schipper, The Oxford University Centre for the Environment 
In memory of my mother Somrudee Disyabutra 



\section{Acknowledgements}

Completing this Ph.D. has been a long-time passion of mine. I am grateful for the opportunity to conduct Ph.D. research on a topic that bridges my professional experience with academic curiosity at an institution that is at the center of science-policy interface. I also feel privileged to have been supported throughout the five-year journey by so many wonderful people. If I had omitted anyone in this acknowledgement, it was not out of intention.

First and foremost, I am deeply grateful to my supervisors Prof. Dr. Shyama Ramani and Dr. Robbert Biesbroek for their intellectual guidance, constant encouragement, and uplifting friendship throughout the process. Prof. Ramani, I especially thank you for believing in this research project from day one, and for guiding it through with your contagious passion for using knowledge to improve the lives of the poor. Dr. Biesbroek, I am deeply grateful for your dedicated mentorship and thorough attention, both of which had been an invaluable compass for me to shape this research and navigate the world of adaptation scholarship. I also owe gratitude to Dr. Mindel van de Laar, whose support, motivation, and practical advice made this Ph.D. journey smooth and rewarding.

This research would not have been completed without the interviews that I conducted with staff of the implementing entities of the Adaptation Fund. I am thankful for all the interviewees for their time and insights, and for colleagues at the Adaptation Fund Secretariat, particularly Mikko Ollikainen and Cristina Dengel, for support in arranging the interviews. I am also thankful to the members of the assessment committee-Prof. Dr. René Kemp, Prof. Dr. James D. Ford, Dr. Michal Natorski, and Dr. Lisa Schipper-for their insightful comments that helped enrich the final version of the dissertation. 
I feel lucky to have been part of a special program like GPAC ${ }^{2}$. I would like to thank the GPAC $^{2}$ staff, instructors and friends who in many ways accompanied me throughout the Ph.D. journey. I am very grateful to Dr. Victor Cebotari, my instructor and co-author, who adeptly guided me to work with the QCA methodology, a task which would have been so daunting for me without his guidance. The GPAC $^{2}$ coordinators and extended team, particularly Charlotte Keijser, Cristina Mancigotti, Romy Kunen, and Herman Pijpers, are warmly acknowledged for always being so helpful. Their kindness and attention to me as a Ph.D. fellow always made coming to Maastricht sessions a pleasure. I also feel privileged to have been part of the 2015 cohort together with many wonderful fellows, including Silke Heuser, Erich de la Fuente, Kenroy Roach, and Marisa Foraci. Their friendship made our joint times in Maastricht very memorable. Special thanks go to Silke and Erich with whom I exchanged notes we took for each other and spent hours contemplating the ups and downs of a Ph.D. life.

So many friends and colleagues outside the $\mathrm{GPAC}^{2}$ program also helped make my Ph.D. journey less lonely through their generous and caring acts. For being great hosts to my trips to Maastricht and stopovers in-between, listening to my Ph.D monologue during meals, coffees, and walks, or providing shoulders to laugh and cry on, I want to express sincere thanks to Sopaporn Yong Kurz, Thippaya Chintakovid, Ruangkhao Ryce Chanchai, Porpot Changyawa, Kunakorn Vanichvirun, Naeeda Crishna Morgado, Willem van der Muur, Leela Raina, Rolande Pryce, Sooksiri Chamsuk and Shuan SadreGhazi.

Sometimes a chance encounter brings unique conversations that greatly influence one's life. I owe thanks to Dr. Joseph Mwaura from Kenya who holds a special place in the beginning of my Ph.D. journey. Our surreal conversation in Oxford in August 2014 was a turning point for me to translate a Ph.D. ambition into a real one. I am also thankful to Dr. Thomas Downing at the 
Oxford Adaptation Academy for connecting me to Dr. Biesbroek-a chance introduction that turned into a rewarding collaboration.

Most importantly, a Ph.D. is always undertaken with the support of closest people in one's life. Heartfelt thanks go to my husband Frederico Gil Sander, whose encouragement, intellectual companionship, Excel advice, and cooking have enabled me to pursue this dream.

Finally, my deepest gratitude goes to my father Somchai Manuamorn who always loves me unconditionally. I know this makes you proud. 


\section{List of abbreviations and acronyms}

$\begin{array}{ll}\text { AF } & \text { Adaptation Fund } \\ \text { AFB } & \text { Adaptation Fund Board } \\ \text { AIS } & \text { Agricultural innovation system } \\ \text { CBA } & \text { Community-based adaptation } \\ \text { CBO } & \text { Community-based organization } \\ \text { CDM } & \text { Clean Development Mechanism } \\ \text { CER } & \text { Certified Emission Reduction } \\ \text { CIVICUS } & \text { World Alliance for Citizen Participation } \\ \text { COP } & \text { Conference of the Parties } \\ \text { CSA } & \text { Climate-smart agriculture } \\ \text { CSO } & \text { Civil society organization } \\ \text { DA } & \text { Designated Authority } \\ \text { DAC } & \text { Development Assistance Committee } \\ \text { EE } & \text { Executing Entity } \\ \text { FAO } & \text { Food and Agriculture Organization of the United Nations } \\ \text { fsQCA } & \text { Fuzzy-set Qualitative Comparative Analysis } \\ \text { GCF } & \text { Green Climate Fund } \\ \text { GCI } & \text { Government Closeness Index } \\ \text { CRI } & \text { Global Climate Risk Index } \\ \text { GDP } & \text { Gross Domestic Product } \\ \text { GEF } & \text { Global Environment Facility } \\ \text { GHG } & \text { Greenhouse gas } \\ \text { LDCs } & \text { Least Developed Countries } \\ \text { LDCF } & \text { Least Developed Countries Fund } \\ \text { MDB } & \text { Multilateral Development Bank } \\ \text { MIE } & \text { Multilateral Implementing Entity } \\ \text { NAPA } & \text { National Adaptation Programme of Action } \\ \text { ND-GAIN } & \text { Notre Dame Global Adaptation Initiative } \\ & \end{array}$


NGO Non-governmental organization

NIE National Implementing Entity

ODA Official Development Aid

OECD Organisation for Economic Co-operation and Development

PPCR Pilot Programme for Climate Resilience

QCA Qualitative Comparative Analysis

R\&D Research and development

RIE

Regional Implementing Entity

SCCF

Special Climate Change Fund

SDGs Sustainable Development Goals

SIDS Small Island Developing States

UNDP United Nations Development Programme

UNEP United Nations Environment Programme

UNFCCC United Nations Framework Convention on Climate Change

WFP World Food Programme 


\section{Table of contents}

Acknowledgements ....................................................................ii

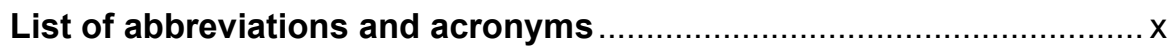

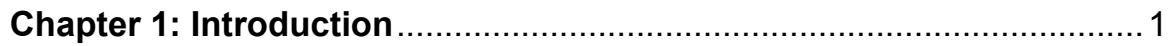

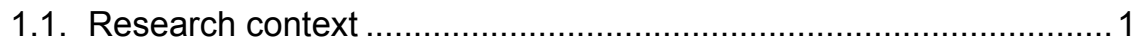

1.2. Problem outline and key knowledge gaps ................................... 7

1.3. Objective and research questions ............................................... 11

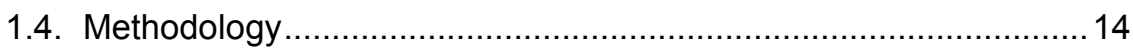

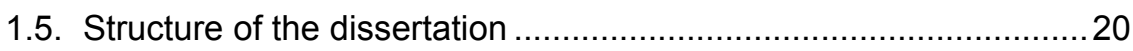

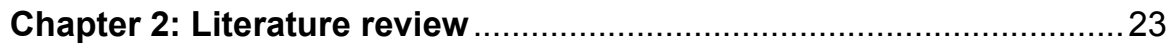

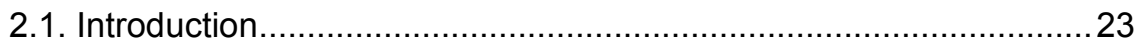

2.2. The rise of adaptation in global climate policy .............................. 23

2.3. Global discourses on climate and development, local communities, and international adaptation finance......

2.4. Different perspectives used to study international adaptation finance

2.5. Access modalities to international adaptation finance ....................52

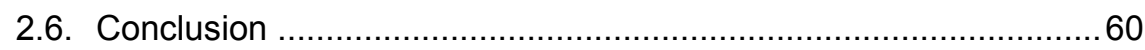

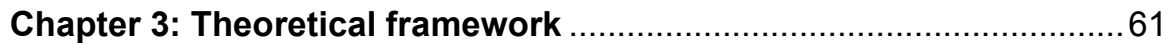

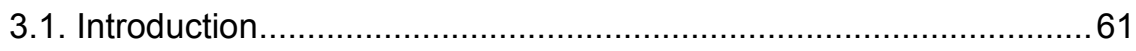

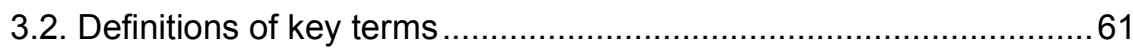

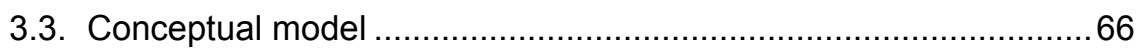

3.4. Theoretical mechanisms .......................................................... 69

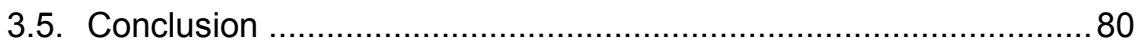

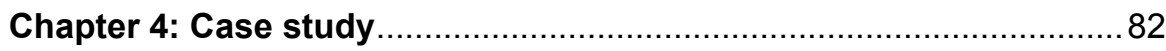


4.1. Introduction

4.2. History, operations and recent developments of the AF 82

4.3. An overview of the AF portfolio ....................................... 88

4.4. Previous assessments of the AF ..................................... 92

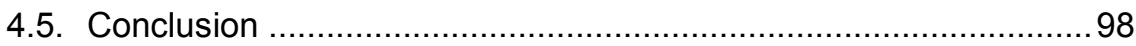

Chapter 5: Do direct access and indirect access adaptation projects differ in their focus on local communities? A systematic analysis of 63 Adaptation Fund projects 99

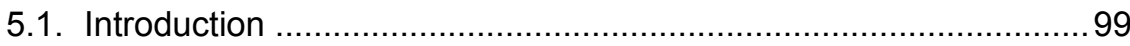

5.2. Conceptual framework for assessing community focus in adaptation projects 103

5.3. Data and methods 111

5.4. Results 118

5.5. Discussion 126

5.6. Conclusion 130

Chapter 6: What makes internationally-financed adaptation projects focus on local communities? A configurational analysis of $\mathbf{3 0}$ Adaptation Fund projects 132

6.1. Introduction 132

6.2. Theoretical framework 135

6.3. Method 145

6.4. Results 155

6.5. Discussion 163

6.6. Conclusion 169

Chapter 7: Do access modalities to international adaptation finance matter for the promotion of agricultural innovations?: An analysis of 36 Adaptation Fund projects 191

7.1. Introduction 191 


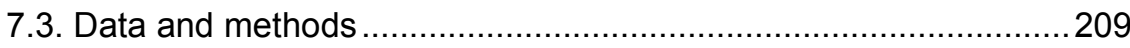

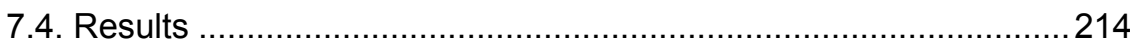

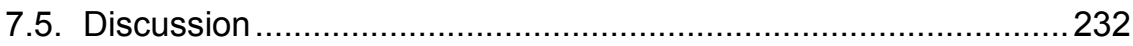

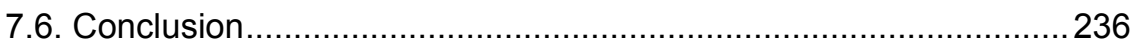

Chapter 8: Conclusions, discussion and reflections ……..............2238

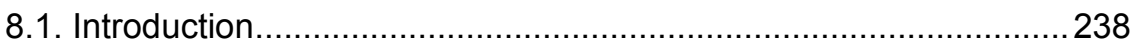

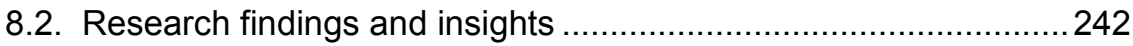

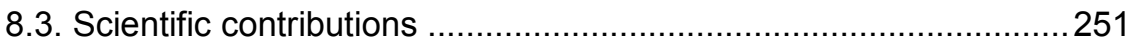

8.4. Reflections on the research design and study limitations ..............257

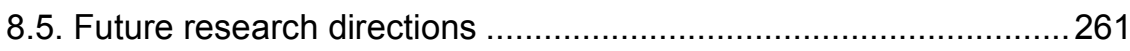

8.6. Policy implications and recommendations ...................................264

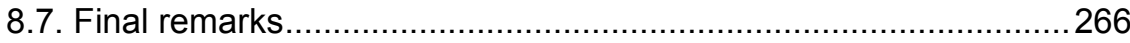

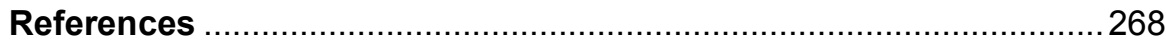

Annex A. Supplementary Material 1: Adaptation Fund Projects

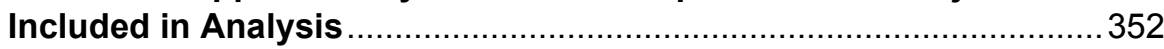

Annex B. Supplementary Material 2: Adaptation Fund Project/

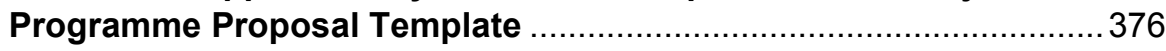

Annex C. Supplementary Material 3: Codebook for the Assessment of the Level of Community Focus in Adaptation Fund projects ............. 384

Annex D. Supplementary Material 4: Codebook for classifying the choices of agricultural innovations for climate change adaptation financed by Adaptation Fund Projects

Annex E.Supplementary Material 5: A systematic literature review of the drivers of dissemination, adoption and diffusion of agricultural innovations for climate change adaptation

Annex F. Supplementary Material 6: Letter of invitation for semistructured interview.

Annex G. Supplementary Material 7: Semi-structured interview guides. 
Annex H. Summary of the Dissertation .............................................. 467

Annex I. Addendum on Valorization of the Dissertation ....................470

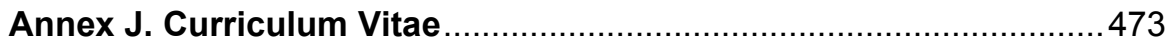

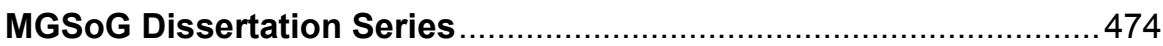

\section{Figures}

Figure 1.1: A simplified representation of access modalities to the AF......11

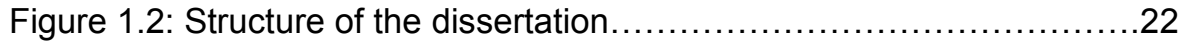

Figure 2.1: The architecture of the direct and indirect access modalities to

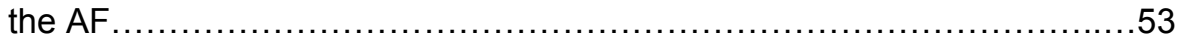

Figure 3.1: Overall conceptual model of the dissertation....................68

Figure 4.1: Roles of different parties in accessing AF resources............87

Figure 4.2: Approved AF projects by access modality as of May $2017 \ldots \ldots .89$

Figure 4.3: Type of funded adaptation actions in AF projects as of May

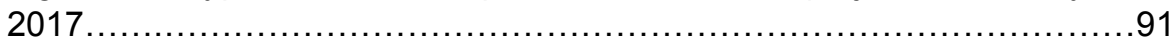

Figure 5.1: Roles played by community-level stakeholders throughout

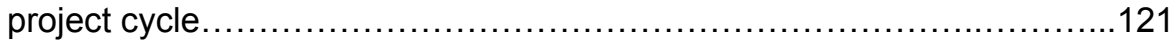

Figure 5.2: Biophysical and socioeconomic dimensions of climate vulnerability addressed by AF projects................................123

Figure 5.3a: Type of organizations that serve as EEs of AF projects......125

Figure 5.3b: Type of organizations that EEs of AF projects partner with...125

Figure 7.1: A conceptual framework on the potential role of access modalities to the $A F$ in shaping the project design to promote agricultural

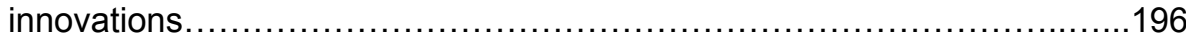

Figure 7.2: Thematic Areas of Disseminated Agricultural Innovations in AF projects................................................................

Figure 8.1: Relations between knowledge gaps, research strategies and

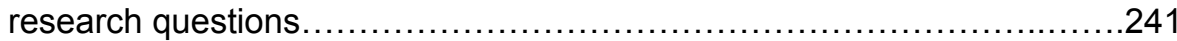

Figure S3.1: A typology of participation in climate change adaptation......406 
Figure S5.1: A systematic literature review to identify the divers of dissemination, adoption, and diffusion of agricultural innovations for climate change adaptation in development countries. ... .443

\section{Tables}

Table 5.1: Summary of dimensions, indicators and measurements of community-focused adaptation.

Table 6.1: Summary of data sources, measurements and calibration thresholds.

Table 6.2: Analysis of necessary conditions for stronger and weaker community focus in AF projects.

Table 6.3: Fuzzy-set analysis of sufficient conditions for stronger and weaker community-focus in AF projects (parsimonious solutions)..........162

Table A1: Summary of raw and fsQCA scores for the 30 cases.

Table A2: Data Sources, Measurements, and fsQCA Calibrations of the Outcome and Conditions.

Table C1: Truth table for the presence of outcome (Stronger community focus).

Table C2: Truth table for the absence of outcome (Weaker community focus) 189

Table 7.1: Typology of potential choices of agricultural innovations for climate change adaptation used in this study 198

Table 7.2: Drivers for the dissemination, adoption and diffusion of agricultural innovations in developing countries.

Table 7.3: Summary of conducted interviews. 212

Table S1.1: All Adaptation Fund projects approved as of May 2017........353

Table S3.1: List of adaptation activities financed by AF projects. 394

Table S4.1: Examples of typologies of climate change adaptation actions in the agricultural sector. .433

Table S5.1: Configuration of the search query. 441

Table S5.2: Inclusion and exclusion criteria for the selection of articles...442 
Table S5.3: Factors influencing the dissemination of agricultural innovations for climate change adaptation through public programs in developing countries. 444

Table S5.4: Factors influencing the adoption of agricultural innovations for climate change adaptation through public programs in developing countries 448 


\section{Chapter 1: Introduction}

Local communities in developing countries are facing a disproportionate burden in adapting to the negative impacts of climate change. There is an international consensus that developed countries will help finance climate change adaptation in developing countries, including by directing part of the resources of multilateral climate funds to support locally driven and innovative adaptation actions at the community level. This dissertation explores whether the governance arrangements through which recipient developing countries access such financing influence if and how financial resources are invested in community-focused and innovative adaptation projects. Section 1.1 presents the overall research context in more detail, while Section 1.2. identifies the specific knowledge gaps central to the dissertation. Section 1.3. elaborates on the research objective and presents the research questions. Section 1.4. positions the research methodology, describes the case study and provides an overview of methods used in this dissertation. The chapter concludes with a description of the structure of the dissertation in Section 1.5.

\subsection{Research context}

\subsubsection{Global policy context}

In the last two decades, climate policy debates have shifted from being predominantly concerned with mitigating future climate change through reducing greenhouse gas ( $\mathrm{GHG}$ ) emissions towards recognizing the need to adapt to an already changing climate (Ford, 2007; Hall \& Persson, 2017; Huq $\&$ Toulmin, 2006; Schipper, 2006). Three trends are evident within this global policy context. First, it is recognized that developing countries are more vulnerable to the potential negative impacts of climate change compared to developed countries (Brooks et al. , 2005; Füssel, 2010; IPCC, 2014a), and 
that a disproportionate burden of adaptation will fall on the poor, natural resource-dependent and marginalized populations (Levy \& Patz, 2015; Mearns \& Norton, 2010; Olsson et al., 2014; Thomalla et al., 2006). This uneven adaptation burden is recognized both as global climate injustice (Colenbrander et al., 2018) and a barrier for achieving global sustainable development goals (Szabo et al., 2016). Second, international climate negotiations and development organizations have dedicated more policy attention to supporting climate change adaptation in developing countries (Adger et al., 2003; Ayers \& Huq, 2009; Lesnikowski et al., 2017). The 2015 Paris Agreement calls for such adaptation to be country-driven, gendersensitive and participatory, taking into consideration "particularly vulnerable" countries, groups and communities (UNFCCC, 2015a). Third, there is also an increasing policy support for locally driven approaches to climate change adaptation, due to their potential to identify solutions that are context-specific, cost-effective, socially acceptable, and when implemented in conjunction with wider governance reforms, more inclusive of the poor and vulnerable communities (Cutter et al., 2012; Mfitumukiza et al., 2020; Mimura et al., 2014).

Adapting to climate change is costly for both governments and local communities (UNEP, 2016; World Bank, 2009). As climate change amplifies existing development challenges of developing countries, these actors will have to incur the costs of adaptation beyond baseline development investments (Narain et al., 2011). Global estimates of adaptation costs in developing countries range between USD 280-500 billion annually by 2050 (UNEP, 2016). Given the predominant share of historical emissions of developed countries, there is an international consensus that they should help finance these adaptation costs (Bowen, 2011; Streck, 2012; UNFCCC, 2015a). In 2009, developed countries pledged through the Copenhagen Accord to provide developing countries with USD 30 billion in "new and additional" fast-start climate finance for 2010-2012, with a goal of mobilizing 
long-term climate finance of USD 100 billion per year by 2020 (Stadelmann et al., 2011). The Paris Agreement reaffirms that developed countries should take a lead in mobilizing climate finance flows consistent with the long-term low-carbon and climate-resilient development pathways (UNFCCC, 2015a). Prior to 2025, the Parties to the Paris Agreement agree to set "a new collective quantified goal from a floor of USD 100 billion per year, taking into account the needs and priorities of developing countries" (UNFCCC, 2016, p.8). For adaptation needs and priorities, many developing countries explicitly call for more international climate finance to be channeled towards local actions, and for more active participation of local communities in directing fund use (Figueres, 2004; IIED, 2014, 2015).

Efforts to mobilize international climate finance has led to the proliferation of multilateral climate funds, which are specialized vehicles designed to mobilize, pool and deliver such financing to developing countries (Bécault \& Marx, 2017; Nakhooda et al., 2013; Parker et al., 2014). Three multilateral climate funds for adaptation were established at the 7 th session of the Conference of the Parties (COP7) of the United Nations Framework Convention on Climate Change (UNFCCC) in Marrakech in 2001: the Special Climate Change Fund (SCCF), the Least Developed Countries Fund (LDCF), and the Adaptation Fund (AF) under the Kyoto Protocol (GEF, 2011; Schipper, 2006). After the 2009 Copenhagen Accord, these funds were expected to be important instruments for fast-start and long-term climate finance focusing on adaptation activities. At the COP16 in Cancun in 2010, parties to the UNFCCC also established the Green Climate Fund (GCF), which is mandated to make an ambitious contribution towards the USD 100 billion goal by mobilizing resources from public and private sectors and directing at least $50 \%$ of the resources towards adaptation (Fridahl \& Linnér, 2016). In parallel, multilateral climate funds for adaptation have also been established outside the UNFCCC framework, including the Pilot Programme for Climate Resilience (PPCR), administered by the World Bank as a joint 
initiative of six multilateral development banks (MDBs), and the Adaptation for Smallholder Agriculture Programme, managed as a trust fund by the International Fund for Agricultural Development. The multiplication of these specialized climate funds-along with parallel bilateral and multilateral aid programs that channel adaptation-marked Official Development Aid (ODA) as international adaptation finance-has resulted in a highly decentralized, fragmented, and cumbersome global adaptation finance system (Bécault \& Marx, 2017; Ciplet et al., 2013; Streck, 2012), with limited consistency and transparency in the reporting and monitoring of its volume, additionality, intermediary channels, recipients, and end uses (Donner et al., 2016; Khan et al., 2019; Michaelowa \& Michaelowa, 2011; Stadelmann et al., 2011b).

\subsubsection{Literature context}

In parallel to these global climate policy developments, scholars have increasingly used "climate finance" as a lens to study three aspects of climate change adaptation. First, within the international development community, Zadek (2011) notes that "climate finance has become the analytic norm for thinking about resourcing the challenge of climate change" (p.1059), providing a framework to determine "...at least in theory, what are (and therefore who will pay for) the 'incremental costs' associated with mitigationand adaptation-focused investments" (p.1059). Second, there is a growing literature on climate finance effectiveness, which is "primarily a policy-based discussion concerning how international and national funding architectures shape outcomes" (Barrett, 2013, p. 1820), and a subset of this literature assesses multilateral climate funds for adaptation. Key issues discussed are the funds' architectures and processes (such as access modalities, resource allocations, and result management) (Nakhooda et al., 2014; Parker et al., 2014; Remling \& Persson, 2015); their outputs (such as funding allocation patterns and stakeholder engagement) and outcomes (such as capacity 
building, creating an enabling environment and catalyzing innovations) (Canales Trujillo \& Nakhooda, 2013; Nakhooda et al., 2014); and their adherence to broad principles (such as equity, efficiency, and accountability) (Nakhooda et al., 2014; Persson \& Remling, 2014; Terpstra et al., 2013). While scholars propose frameworks to assess the effectiveness of these funds (Fenton et al., 2015; Nakhooda et al., 2014), currently there is no universally agreed metric to assess overall effectiveness of international adaptation finance (Buchner et al. 2012; Christiansen et al., 2018; Stadelmann et al., 2015). Third, in addition to climate finance studies, scholars also apply the climate finance lens to other research areas such as adaptation governance. For example, Dzebo \& Stripple (2015) use the governance structures and procedures of multilateral climate funds-which span global, national and local domains-to demonstrate the emergence of transnational adaptation governance through the projects they fund. Despite the growing body of literature in each of these three strands, climate finance "remains under-researched and under-theorized, and stands in need of further integration of and dialogue between different approaches to the topic" (Pickering, 2017, p.2).

A question of how a global climate financing mechanism like multilateral climate funds can meaningfully support local climate change adaptation is an under-researched topic that cut across the above three strands of literature. First, from the resourcing perspective, these funds have played an increasingly important role in financing adaptation investments in developing countries in recent years. The UNFCCC estimates that "adaptation finance channeled through core multilateral climate funds has so far reached over 20 million direct beneficiaries" (UNFCCC, 2018, p.81), and could be as high as 290 million if both direct and indirect beneficiaries are combined (UNFCCC, 2018 , p.100). Second, from the climate finance effectiveness perspective, the literature thus far "leaves community level implementation largely absent" (Barrett, 2013, p.1820) from the adaptation finance effectiveness discussion, 
even though it emphasizes the need for global climate funds to deliver more finance to the most vulnerable local communities. Third, from the governance perspective, these funds are an increasingly important actor in the global governance of adaptation (Dzebo \& Stripple, 2015; Nakhooda et al., 2014), and their comparatively small annual flows compared to the bilateral and MDB channels "belie the significant influence that these funds have had as a core component of the global public finance architecture" (Nakhooda et al., 2014, p.21). However, current literature has hardly moved beyond simply describing the architectures and processes of multilateral climate funds and the broad patterns of funding allocations (Amerasinghe et al., 2017; Bird et al., 2011; Nakhooda et al., 2014; Parker et al., 2014), to systematically examine how these governance arrangements shape actual investments in communitylevel adaptation under different recipient country contexts.

As a result, important questions remain about the role of international adaptation finance in supporting local adaptation to climate change in developing countries, and what forms of climate finance governance is needed to connect global, national and local adaptation processes for the benefit of vulnerable communities. Answering these questions is important and timely for the study and practice of climate finance, adaptation governance and international development, and calls for research that explicitly connect these three themes. Addressing this research gap, which is discussed in Section 1.2 in more detail, is the objective of this dissertation. By examining the experience of a multilateral climate fund in financing adaptation projects, this dissertation aims to understand and explain if and how the governance of international adaptation finance shapes local climate change adaptation actions at the project level in developing countries. 


\subsection{Problem outline and key knowledge gaps}

Within the above research context, four specific knowledge gaps are central in this dissertation.

First, there is limited knowledge on how much international adaptation finance has reached local communities (Fenton et al., 2014; Figueres, 2004), largely due to the lack of a standardized definition and methodology to assess the level of community focus in internationally-financed adaptation projects. Soanes et. al. (2017) make a preliminary estimate that between 2003-2016 less than $10 \%$ of global climate finance (for both adaptation and mitigation purposes) was flowing to local level i.e. entities below the district administration including local governments, community-based organizations (CBOs), local non-governmental organizations (NGOs), households and microfinance institutions. However, what fraction of this locally-oriented climate finance has actually reached local communities, what adaptation activities are financed, and if participatory processes are used remain largely unknown (Soanes et al., 2017). To address this knowledge gap, new initiatives, such as the Adaptation Finance Accountability Initiative launched in 2012, have been established to better track how international adaptation finance is allocated domestically and whether it benefits local communities (Wilkinson et al., 2014). The initiative's partners and other scholars have piloted approaches to track adaptation finance at the local level in selected countries (Fenton et al., 2015; Wilkinson et al., 2014). However, the lack of a common definition and methodology to assess community-focused projects at a large scale contributes to the difficulty in systematically tracking community-bound international adaptation finance globally.

Second, there is also a limited understanding of how international adaptation finance has stimulated community-level adaptation innovations to date. As climate change presents new challenges to vulnerable local communities 
around the world, it is recognized that innovations are needed to enhance the effectiveness of local adaptation actions (Aase et al., 2013; FAO, 2016). Multilateral climate funds are expected to play an important role in financing these innovations (Adaptation Fund, 2017; Canales Trujillo \& Nakhooda, 2013; GCF, 2019; Meinzen-Dick et al., 2013; Nakhooda et al., 2014), due to their capacity to create a new collaborative space between scientific, private sector and civil society actors, and to leverage larger financing from other public and private sources for up-scaling innovations (Nakhooda et al., 2014). In reality, these funds are financing a large number of projects in climatevulnerable communities (such as farming communities) where the need for innovation to build adaptive capacity is evident (Parker et al., 2014). However, whether and how these funds have invested in adaptation innovations in these communities remains under-researched, partly due to the inadequate tracking of the international adaptation finance that has reached them in the first place.

Third, whether climate finance governance matters for international adaptation finance to stimulate community-focused and innovative adaptation is poorly understood. Currently, developing countries access multilateral climate funds through two access modalities-the direct access modality and the indirect access modality-which represent two different governance models of international adaptation finance. However, the implications of these two models on local climate change adaptation in recipient countries have not been adequately studied in academic research.

Historically, climate funds have been solely accessed through international intermediaries such as MDBs and United Nations agencies (UNFCCC, 2018, p.91), which are accredited as multilateral or regional implementing entities (MIEs or RIEs) of the funds. Such arrangement is characterized as the "indirect access", or sometime referred to as the "multilateral access", modality (UNDP, 2012), due to the indirect nature by which funds flow to 
developing country recipients. Since 2008 , there has been a significant push for a "direct access" modality (UNFCCC, 2018, p.91), by which developing countries access financing from multilateral climate funds directly through their own accredited national implementing entities (NIEs). While direct access is not new to development finance, it is considered innovative for international adaptation finance, and is pioneered by the AF (Adaptation Fund, 2017; Ballesteros et al., 2010; Brown et al., 2010) and subsequently adopted by the GCF.

Given the interest in direct access as a novel and more country-driven global climate financing mechanism when compared to indirect access (Brown et al., 2010; Craeynest et al., 2010; Druce et al., 2013; Schäfer et al., 2014), it is perhaps surprising that little attention has been given to comparing the projects funded by the two modalities in practice, even though it has been since 2010 that they are operating in parallel. In reality, the two access modalities differ on two key governance dimensions (Figure 1.1). First, the direct access modality is structurally more decentralized to the national level when compared to the indirect access modality. Second, direct access projects are managed by national institutions accredited as NIEs, while indirect access projects are managed by global and regional institutions serving as MIEs or RIEs on behalf of the recipient countries. These differences in the types of organizations could influence decision-making on project investment (Scoville-Simonds, 2016; UNFCCC, 2018). With regards to community-focused and innovative adaptation, there is also literature, as further elaborated in Chapters 2 and 3, which suggests that direct access could make a difference in project design in these two aspects, particularly by promoting more community-focused adaptation and locally relevant innovations. However, there has been no study to date that empirically tests these claims. In this dissertation, I argue that the two access modalities should be explicitly conceptualized as different governance models of 
international adaptation finance that could potentially shape local adaptation differently in order to test the claims.

Finally, more knowledge is needed to develop policy approaches to promote community-focused and innovative adaptation under both access modalities to international adaptation finance, while taking into account different recipient country contexts. While vulnerable communities are among the intended beneficiaries of international adaptation finance, they cannot access multilateral climate funds by themselves under the current global climate finance architecture (Lebel et al., 2017). For community needs be prioritized for funding, higher-level actors, including the funds' implementing entities, endorsing governments and civil society organizations (CSOs), must actively champion that bottom-up approaches be included in internationally-financed adaptation projects. As direct access and indirect access projects will continue to operate in parallel, more knowledge is needed on how "community-focused" and "innovative" adaptation could be supported through investment under both access modalities, while recognizing that the pathways to these outcomes could vary in different recipient countries. Except some studies that discuss the role of the AF with regards to community adaptation (Fenton et al., 2014) and innovation (Canales Trujillo \& Nakhooda, 2013), access modalities to international adaptation finance, community-level adaptation, and innovation are not systematically considered together in the literature. I argue that more research on this is required to understand the ways through which community-focused and innovative adaptation could be effectively promoted by international adaptation finance. 


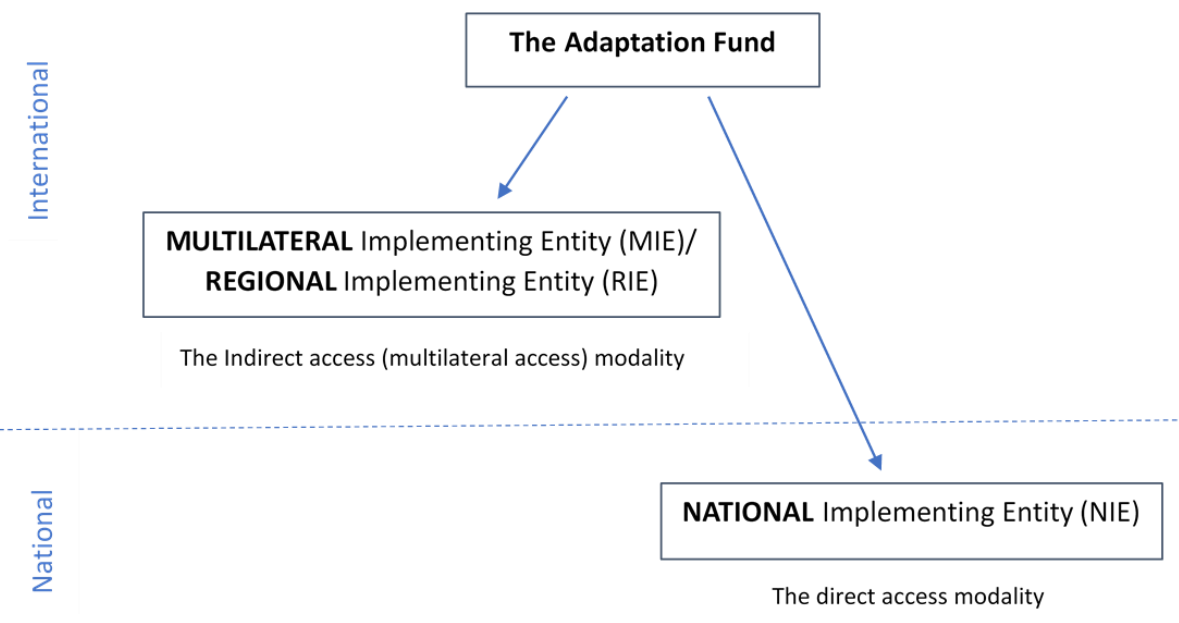

Figure 1.1: A simplified representation of access modalities to the AF (See a more detailed representation in Chapter 2)

Source: Author.

\subsection{Objective and research questions}

As discussed above, the central objective of this dissertation is to understand and explain if and how the governance of international adaptation finance shapes local climate change adaptation actions at the project level in developing countries. This dissertation conceptualizes the direct access and indirect access modalities to multilateral climate funds as representing two models of international adaptation finance governance. Given the dissertation's main interest in community-focused and innovative adaptation, the main research question $(R Q)$ of the dissertation is:

$R Q:$ How do access modalities to international adaptation finance shape the level of community focus and the promotion of adaptation innovations in the design of projects in recipient countries? 
Five research sub-questions (sub-RQ) are formulated to answer the main $R Q$. The questions are organized along the two aspects of the dependent variable.

1) Level of community focus in project investment

Sub-RQ1: How can the level of community focus in adaptation projects be defined and measured?

This question responds to the recognized need for more financing for community adaptation initiatives. To empirically investigate how internationally-financed adaptation projects vary in their level of focus on vulnerable communities, it is necessary to define the concept of "communityfocused adaptation" more precisely and develop operational indicators to measure it.

Sub-RQ2: Are direct access and indirect access projects equally communityfocused?

The newly developed definition and indicators are used to systematically compare the level of community focus in direct access and indirect access adaptation projects financed by the same multilateral climate fund. The comparative analysis will provide empirical insights on whether there is a difference in the level of community focus between both types of projects.

Sub-RQ3: What explains the difference in the level of community focus in direct access and indirect access adaptation projects?

This question recognizes that any observed difference in the level of community focus between direct access and indirect access adaptation projects cannot be solely attributed to the modalities. Other contextual conditions of the recipient countries, such as the level of climate vulnerability 
and domestic governance factors, could interact with the access modalities to jointly shape the community-focused project design. This question therefore aims to examine under which conditions multilateral climate funds invest in highly versus weakly community-focused adaptation projects under both access modalities. This analysis will provide insights on multiple pathways through which international adaptation finance could promote highly community-focused adaptation.

2) Promotion of adaptation innovations

Sub-RQ 4: Are there differences in the design of direct access and indirect access projects to promote adaptation innovations?

This question responds to the need for more knowledge on how multilateral climate funds have supported community-level adaptation innovations, and whether climate finance governance matters for how the support is designed at the project level. In particular, the question aims to investigate whether NIEs of direct access projects and MIEs/RIEs of indirect access projects design their projects to promote innovations differently and to what effect this matters. The promotion of innovation is defined as a combination of two design elements: 1 ) the choice (s) of agricultural innovations financed by each project; and 2) the project's implementation plan with regards to the innovations. This sub-question is answered with a focus on projects that promote agricultural innovations for climate change adaptation for local communities.

Sub-RQ 5: What explains differences in the design to promote adaptation innovations of direct access and indirect access projects, if they exist?

Similarly to the analysis on the level of community focus, any observed differences in the project design to promote adaptation innovations cannot be 
attributed to the role of access modalities alone. The objective of this question is therefore to identify other contextual factors in recipient countries that could interact with the access modalities to shape the approach taken by both types of projects to promote agricultural adaptation innovations for local communities.

\subsection{Methodology}

Obtaining answers to the above research questions requires identifying theoretical perspectives that establish plausible causal relationships between climate finance governance and adaptation design characteristics. It also calls for an exploration of the empirical reality from internationally-financed adaptation projects through which these relationships could be observed. This has led to a research strategy that cycles between established theories and project data. To accomplish this strategy, several research methods are used in this dissertation to answer individual research questions, together resulting in the overall insights on the main research question. This section describes the research perspectives, research design, the chosen case study, and the multi-method approach adopted in this dissertation.

\subsubsection{Positioning the research methodology}

There are four elements of the methodology that positions my research: a realist research perspective, a comparative method, and the theoretical foci on governance and on the project design.

First, the dissertation adopts a realist research perspective, which is rooted in a pragmatic claim to knowledge (Blumberg et al., 2011; Creswell, 2003). Conceptualizing knowledge creation through action and interaction precipitated by a problematic situation (Corbin \& Strauss, 2008), pragmatism in research is characterized as being concerned with consequences of 
actions, problem-centered, pluralistic, and real world practice-oriented (Creswell, 2003). As an important approach in social science research (Sayer, 2000), the realist perspective provides a middle ground for combing the positivist paradigm of scientifically testing theory-informed hypotheseswhich by itself could be insensitive to contexts-with interpretivist research, in which knowledge is considered socially-constructed, situated and subject to interpretations (Blumberg et al., 2011). The realist perspective guides the dissertation's use of both deductive and inductive research strategies; the former to construct analytical categories and develop frameworks to test hypotheses, and the latter to incorporate categories, hypotheses and conclusions from iterative data examination. This pragmatist approach also "opens the door to multiple methods, different worldviews, and different assumptions, as well as to different forms of data collection and analysis in the mixed methods study" (Creswell, 2003, p.12). The approach is therefore considered appropriate for guiding this dissertation, which builds on, and aims to contribute to, multiple fields of social science including climate finance, adaptation governance and international development.

Second, the dissertation adopts a comparative method to study how internationally-financed adaptation projects in different countries are shaped by climate finance governance. Current adaptation research has until recently been dominated by in-depth, qualitative, single or small-N studies (Biesbroek et al., 2018), resulting in the state of adaptation knowledge which is predominantly context-specific. To build a more systematic understanding of how climate change adaptation is taking place globally, scholars have increasingly applied systematic approaches to study the patterns of adaptation actions across countries using large- $\mathrm{N}$ samples (more than 20 cases) (Berrang-Ford et al., 2011; Biagini et al., 2014; Conevska et a., 2018; Ford et al., 2015; Ford et a., 2011; Lesnikowski et al., 2013). The comparative, cross-country analysis of adaptation projects in this dissertation is consistent with, and will further expand the insights from, this growing body 
of systematic adaptation studies. In this dissertation, I make use of adaptation project documents to investigate planned adaptation actions at the local level.

Third, the dissertation examines how international adaptation finance shapes local adaptation projects from a governance perspective. While there are many non-governance variables which could be taken into account-some of which are analyzed in this dissertation (e.g. the level of climate vulnerability, the capacity of national research institutes etc.)-the governance-centric analytical framework aims to bring the under-researched governance aspects of international adaptation finance to the center of the discussion. By framing the two access modalities to multilateral climate funds as the main explanatory variable, the dissertation aims to unpack these two governance models of international adaptation finance more meaningfully, and explore their importance in shaping local adaptation both theoretically and empirically. In Chapter 2, I elaborate the choice of a governance-centric approach in more detail.

Finally, the dissertation defines its two aspects of the dependent variablethe level of community focus in project investment and the promotion of adaptation innovations - as patterns in project design which are observable and interpretable. Three rationales underlie this research focus on project design.

First, much of the current literature has focused on assessing the outputs (such as spending patterns, stakeholder engagement), outcomes (such as capacity building) and impacts (reduced vulnerability) of adaptation projects without critically examining how the projects are designed and governed in the first place. This creates a major knowledge gap, considering that projects are a key construct through which climate vulnerability and adaptation are framed in developing countries (Lebel et al., 2018). For example, Lebel et al. (2018) analyze 12 internationally-financed adaptation projects in Lao PDR 
and Cambodia and find that those using the infrastructure, information, and capacity frames during the design stage prioritize adaptation solutions based on expert knowledge. On the other hand, the framing of climate vulnerability as resulting from local communities' lack of secure access to resources leads to project-financed adaptation solutions that address the distribution of resources and power. The authors also find that the frames used in project design can influence how adaptation projects are governed, for example, through assigning roles to actors based on the types of solutions prescribed. Given that international adaptation finance delivery is highly projectized, scholars call for more research on adaptation project design in this context. More understanding is particularly needed on how the political economy of adaptation framing, resource allocation, and power relations among project stakeholders could affect the choices of adaptation actions, which, in turn, shape pathways to outcomes and impacts (Lebel et al., 2018; Sovacool et al., 2017).

Second, as of May 2017 when I collected project data for this dissertation, most adaptation projects financed by the two multilateral climate funds operating both direct access and indirect access modalities (i.e. the AF and the GCF) were still in the early stages of approval and implementation. This was particularly the case for direct access projects, as more NIEs became successfully accredited by the funds after 2013 (UNFCCC, 2018, p.92). Such a data landscape would not have supported a meaningful comparative assessment of adaptation outcomes and impacts from direct access and indirect access projects, but it does offer a unique opportunity to compare their design characteristics concerning local adaptation. Insights from such comparison is relevant to the development of a meaningful monitoring and evaluation framework of community-based adaptation (CBA) initiatives (Faulkner et al., 2015). They could also inform future outcome and impact research, and outcome-based approaches to adaptation tracking (Christiansen et al. 2018; Ford et al., 2013). 
Finally, the standardized international climate finance tracking methodologies (e.g. the Rio Markers used by bilateral donors and the joint methodology used by MDBs) currently track international adaptation finance from projects globally at the design stage, but do not mark the community-bound portion of project financing (IADB et al., 2017; OECD, 2016). Given the need to better track the beneficiaries of multiple adaptation funding streams, understanding how much international adaptation finance is community-bound at the design stage in a critical step to enhance these existing tracking methodologies, and could contribute to a future comprehensive adaptation finance effectiveness metric (Ford et al., 2015).

\subsubsection{Research design}

The embedded case study approach serves as the principal research design for all three empirical chapters (Chapters 5, 6 and 7) of this dissertation. A case refers to "a phenomenon of scientific interest...that the investigator chooses to study with the aim of developing theory (or "generic knowledge") regarding the causes of similarities or differences among instances (cases) of that class of events" (George \& Bennett, 2005, pp.17-18). A case study approach aims to study a social phenomenon in its context. The embedded case study approach refers to a case study that involves more than one subunit of analysis, and usually employs both qualitative and quantitative methods that may be applied within the sub-units (Scholz \& Tietje, 2002). Knowledge integration within an embedded case study can be structured along three levels: the process of explaining data and results at the sub-unit level (e.g. sub-projects) leads to conceptualization and knowledge integration at the synthesis level, which then creates an encompassing understanding at the overall case level (Scholz \& Tietje, 2002).

While the objective of comparing projects in Chapter 5 is descriptive, that of Chapters 6 and 7 is explanatory, and to a large extent, draws on Mill's Method 
of Agreement (Mill, 1843) as an overarching method for identifying causation i.e. when two or more projects from different countries exhibit the same dependent variable characteristics (high/low community focus in Chapter 6 , and the promotion of locally-relevant innovations in Chapter 7), the analysis seeks to identify their common explanatory factors. By employing Qualitative Comparative Analysis (QCA) in Chapter 6, the dissertation also combines the Method of Agreement with the Method of Difference (Mill, 1843) to eliminate irrelevant factors and combine relevant conditions to obtain a causal path for the occurrence (and absence) of an outcome. (See more detail in Chapter 6). Each chapter also employs a different sampling strategy, which is discussed in more detail in the method section of each chapter.

\subsubsection{The case study}

The AF under the Kyoto Protocol is the case studied in this dissertation and its individual projects are the sub-units of analysis. Apart from being the fund that introduced the direct access modality to international adaptation finance, the $\mathrm{AF}$ is chosen as the case for three reasons. First, compared to the GCF which has also introduced direct access more recently, the AF has financed a higher number of direct access versus indirect access adaptation projects, thus offering more cases for comparative analysis. Second, while the AF is mandated to prioritize most vulnerable local communities, it does not have a dedicated community-financing program like other funds, for example, the CBA pilot program of the GEF Small Grant programs (Huq \& Faulkner, 2013). We could therefore expect to see the differences in the level of community focus and innovation promotion designs at the project level, thus ensuring sufficient variation in the research's dependent variable. In addition, the focus of the research design on just the AF automatically controls for a set of AFspecific factors that would likely have biased a comparison of direct access and indirect access projects from different funds. 


\subsubsection{Research methods}

Within the overall embedded case study research design, I use a multimethod approach to combine different research methods and data sources to answer a particular research question (Creswell, 2003; Greene et al., 1989; McKendrick, 1999). In congruence with the realist research perspective, multi-method research "employs strategies of inquiry that involve collecting data either simultaneously or sequentially to best understand research problems" (Creswell, 2003, p.18), and is used within a case study framework to build a comprehensive understanding of the case (Fetters et al., 2013). Among the particular reasons a multi-method approach is adopted by researchers (Greene et al., 1989; McKendrick, 1999), I use it in this dissertation primarily for complementarity, triangulation, development (i.e. using the results from one method to inform the other) and expansion (i.e. building new insights on the phenomenon). The multiple methods used, both sequentially and concurrently (Fetters et al., 2013), in this dissertation include systematic reviews (Berrang-Ford et al., 2015; Gough et al., 2012), content analysis (Saldaña, 2013), QCA (Ragin, 2000, 2009), and semi-structure interviews (Blumberg et al., 2011; Creswell, 2003). The choice of when and where to use each method is based on its match with the research problem being investigated through each research question (Creswell, 2003, p. 21). Each empirical chapter in this dissertation contains a section that discusses the methods adopted in more detail.

\subsection{Structure of the dissertation}

Following this introduction chapter, the body of the dissertation is organized into seven chapters. Chapter 2 presents a review of literature related to the dissertation's focus, followed by Chapter 3 which develops a theoretical framework to guide the analyses. Chapter 4 provides a detailed background on the AF as the case study. Three empirical chapters subsequently address 
research sub-questions. Chapter 5 proposes a new framework to assess the level of community focus in adaptation projects (Sub-RQ1) and applies the framework to systematically assess and compare AF projects from the direct access and indirect access modalities (Sub-RQ2). Chapter 6 assesses the conditions that influence the level of community focus in AF projects and identifies specific configurations of conditions that lead to a stronger or weaker community focus in project design (Sub-RQ3). Chapter 7 examines if there are any differences in how direct access and indirect access AF projects are designed to promote agricultural innovations for local communities (Sub$R Q 4$ ), and what explains the differences, if they exist (Sub-RQ 5). Chapter 8 synthesizes the overall findings of the dissertation and discusses their theoretical and policy contributions. The overall structure of the dissertation is depicted in Figure 1.2.

Chapters 5 and 6 have been published, and Chapter 7 will be submitted, as independent journal papers. As such, some repetition of introductory information and key concepts and acronyms are to be expected when reading through them in the context of this book. 


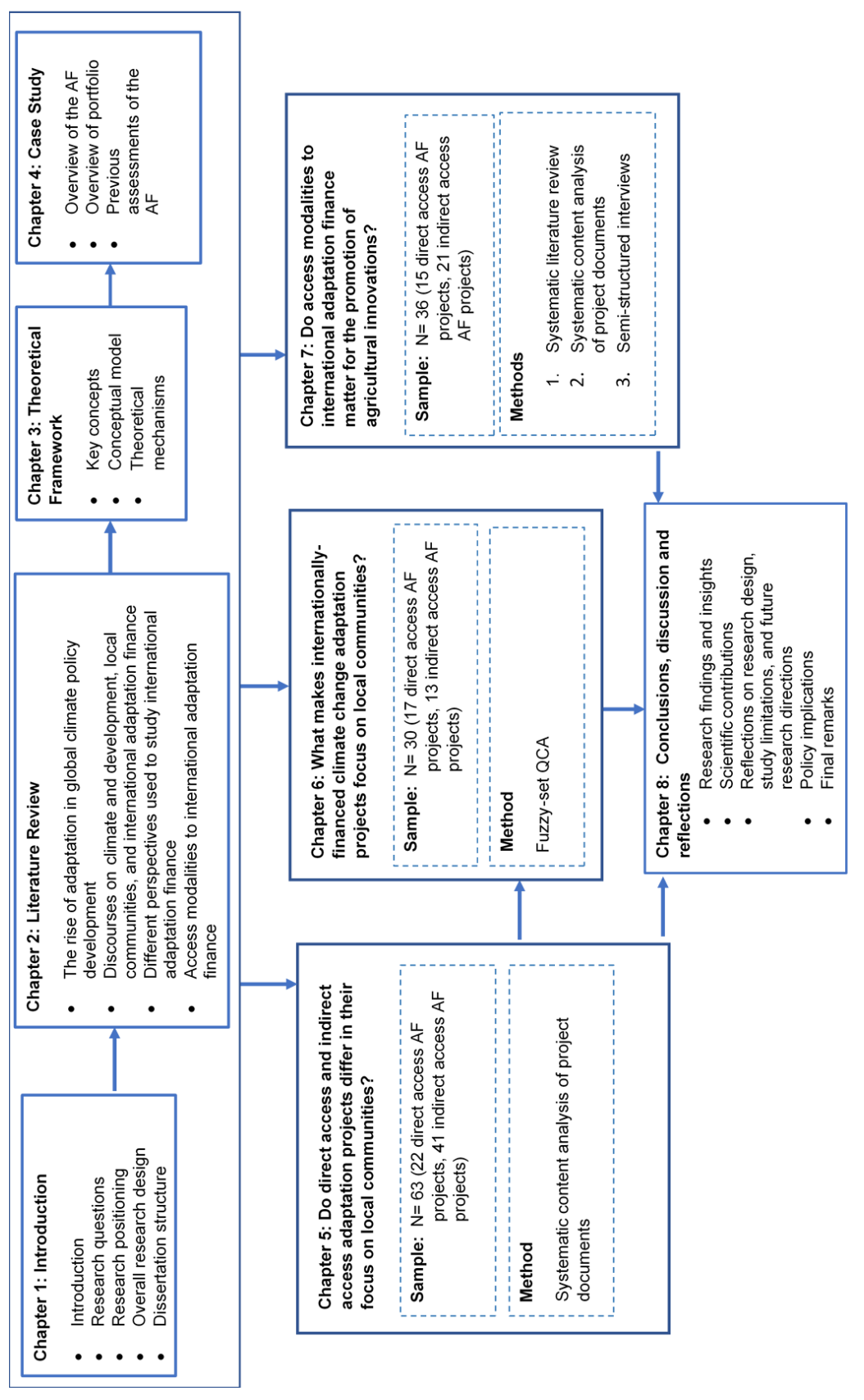

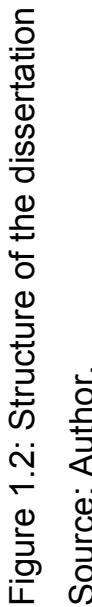




\section{Chapter 2: Literature review}

\subsection{Introduction}

This chapter reviews the key areas of literature and discourses relevant to the dissertation. Section 2.2. discusses the rise of the adaptation agenda in global climate policy. Section 2.3 presents three global discourses that shape the thinking and inquiry in this dissertation. The first discourse relates to the relationship between climate change adaptation and development (Section 2.3.1). The second relates to the growing prominence of CBA as an influential approach to operationalize development-compatible adaptation at the local level (Section 2.3.2). The third relates to the role of international adaptation finance in supporting developing countries (Section 2.3.3). Section 2.4. presents three perspectives-political economy, ethics, and governanceused to study international adaptation finance to date, and discusses the reasons why I choose the governance perspective for this dissertation. Section 2.5. summarizes a key global debate on the governance of international adaptation finance which centers on the issue of alternative access modalities to multilateral climate funds, and how they could influence local adaptation actions at the project level in recipient countries. Section 2.6 provides an overall conclusion to the chapter.

\subsection{The rise of adaptation in global climate policy}

In the early 1990s, global climate negotiations under the UNFCCC were characterized by a mitigation-adaptation divide, in which adaptation received little attention and was sometimes pitched against mitigation (Pielke et al., 2007; Schipper, 2006). Key reasons for this include a perception that adaptation could be delayed until the effects of mitigation are evident; a concern that more attention to adaptation could create complacencies for 
mitigation; a fear among developing countries that discussing adaptation could derail developed-country mitigation commitments, and a concern by developed countries that adaptation is linked to the issues of liability and compensation (Ciplet et al., 2013; Schipper, 2006). The marginalization of the adaptation agenda was also reflected by the relatively little attention it received in the First Assessment Report (FAR) (1990) and the Second Assessment Report (SAR) (1996) of the IPCC. The turning point came with the 2001 Third Assessment Report (TAR), which concluded that adaptation is necessary to complement mitigation. The 2007 Fourth Assessment Report (AR4) further established that despite mitigation efforts the climate system is unequivocally warming and emphasized the need for more extensive adaptation (IPCC, 2007). The 2014 Fifth Assessment Report (AR5) further called attention to sectoral and regional impacts of climate change and to adaptation options, planning, and implementation at various scales (IPCC, 2014b).

While the TAR raised the political status of adaptation (Pelling, 2011), a series of UNFCCC processes and agreements since early 2000s also helped establish adaptation as a key pillar in global climate policy. Shortly after the TAR, the Buenos Aires Programme of Work on Adaptation and Response measures was created in 2004, calling for developed countries to contribute more financing to support adaptation actions in developing countries, and for the GEF to help these countries elaborate adaptation strategies as part of the national communication process (UNFCCC, 2005). Between 2005-2006, the Nairobi Work Programme on Impacts, Vulnerability and Adaptation to climate change was also created - and is still operational today-to assist developing countries, particularly Least Developed Countries (LDCs) and Small Island Developing States (SIDS), to assess climate change impacts and vulnerability and make informed adaptation decisions (UNFCCC, 2020). Reflecting the growing sense of urgency for adaptation actions, the 2007 Bali Action Plan-adopted at the UNFCCC COP13-formally recognized 
adaptation as a key pillar of climate policy, along with mitigation, technology transfer and finance (UNFCCC, 2007), thus making 2007 another pivotal turning point for adaptation (Klein et al., 2017, p.7). The 2009 Copenhagen Accord then included a pledge for "new and additional" global climate finance, much of which is supposed to be directed towards adaptation. The 2010 Cancun Adaptation Framework further emphasized that "adaptation must be addressed with the same priority as mitigation and requires appropriate institutional arrangements to enhance adaptation action and support" (UNFCCC, 2010, p.3). The 2015 Paris Agreement further strengthened the adaptation pillar of the global climate policy with regards to adaptation targetsetting, institutional frameworks and financing (Lesnikowski et al., 2017).

\subsection{Global discourses on climate and development, local communities, and international adaptation finance}

\subsubsection{Climate change adaptation and development}

Climate change adaptation in human systems is generally understood as "the process of adjustment to actual or expected climate and its effects, in order to moderate harm or exploit beneficial opportunities" (IPCC, 2018, p.542). While human societies have been adapting to climate risks throughout history, climate change adaptation responds to three specific forms of stimuli associated with a changing climate: 1 ) long-term change in average climatic conditions (e.g. rising temperatures, sea level rise, changing precipitation regimes); 2) increased variability in the annual or seasonal weather conditions (e.g. the start, duration, and seasonal distribution of monsoons), and 3) increased frequency and magnitude of extreme weather events (e.g. floods, droughts, storms, heat waves etc.) (IPCC, 2014a, 2018b; Smit \& Skinner, 2002). Adaptation actions can take technological, economic, legal and institutional forms; be reactive, concurrent or anticipatory to the climate stimuli; autonomous (spontaneous) or planned; and undertaken by 
individuals, groups or institutions (Smit et al., 2000). Adaptation can occur through top-down and bottom-up processes or a combination (Archer et al., 2014; Butler et al., 2015; Dannevig et al., 2012; Sharma et al., 2014).

The concept of adaptation is closely related to vulnerability, adaptive capacity, and maladaptation (Adger, 2006; Smit \& Wandel, 2006). In the climate change literature, vulnerability of any system is commonly defined as a function of its exposure and sensitivity to climate hazards, including variability and extremes, and its adaptive capacity (Adger, 2006; Adger et al., 2005; Pelling, 2011; Smit \& Wandel, 2006), or the ability of a system to adjust to climatic stress to lesson harm or capture new opportunities (Engle, 2011; IPCC, 2018a; Smit \& Wandel, 2006). In other words, adaptive capacity "affects vulnerability by modulating exposure and sensitivity" (Engle, 2011. p.649). On the other hand, adaptation that inadvertently increases, or simply redistributes, vulnerability to climate change is called maladaptation (Atteridge \& Remling, 2018; Barnett \& O'Neill, 2010; IPCC, 2018a). Pathways to maladaptation include actions that increase GHG emissions, disproportionally burden the most vulnerable; have high opportunity costs; reduce incentives to adapt; and/or limit future choices (Atteridge \& Remling, 2018, p.2, summarizing Barnett \& O'Neill, 2010). Work et al. (2019) highlight the potential for poorly-designed climate and development projects to collectively produce maladaptive results at the landscape scale, especially when they involve collusion between government and international partners and promote local resource use conflicts. To avoid maladaptation, Magnan et al. (2016) advocate for decision makers and stakeholders to anticipate the risk of maladaptation in the planning agenda, and call for context-specific guidelines to help practitioners design adaptation investments with low risk of maladaptation.

Climate change adaptation has been recognized within the global climate policy context not just an environmental problem but a development problem 
(Adger et al., 2003; World Bank, 2009). As climate change is expected to disproportionally impact countries with low levels of socio-economic development and weak governance (Berrang-Ford et al., 2014; Brooks et al., 2005; IPCC, 2014), adaptation has become increasingly branded as a developing country issue, and supporting adaptation has also become synonymous with pursuing development (Ayers \& Dodman, 2010; Schipper, 2006; World Bank, 2009). Development in the context of climate change was initially defined as primarily economic development but over the years has been framed more broadly as human security and human rights (Adger, 2010; Barnett, 2003; Cameron et al. , 2013; Kates, 2000; Lesnikowski et al., 2017; Stern, 2007). The AR4 positions adaptation as necessary actions for sustainable development pathways, while the 2007 Bali Action Plan links adaptation to climate-resilient development (UNFCCC, 2007). Within this context, key discourses on climate change adaptation and development have emerged around two aspects: the relationship between adaptation and development, and how to make development and adaptation compatible (Ayers \& Dodman, 2010).

Broadly speaking, two divergent perspectives shape the discourses on adaptation and development linkages. The first perspective-referred to as the adaptation approach (Schipper, 2007) or the adaptation plus development approach (Ayers \& Dodman, 2010)—considers adaptation as additional to development. This perspective is prevalent within the UNFCCC negotiations and among international development organizations, as reflected in their approach to estimate additional adaptation costs on top of baseline development investments (Narain et al., 2011; World Bank, 2010). The perspective reflects the UNFCCC's narrow framing of adaptation as response to anthropogenic climate change, rather than climate variability (including change), and places the emphasis on technology-based adaptation measures as stand-alone or additional measures to development (Ayers \& Dodman, 2010). While this perspective provides a rationale for 
mainstreaming adaptation into development (Schipper, 2007), it tends to define mainstreaming narrowly as technical efforts to modify existing infrastructure or development projects to ensure that they withstand the future climate based on projections (ADB, 2012; Ayers et al., 2014; Dasgupta et al., 2011). This type of mainstreaming is called "climate proofing" or "mainstreaming minimum" (Klein, 2010, p.39).

The second perspective-referred to as the vulnerability reduction approach or the adaptation as development approach-considers adaptation as indistinguishable from development (Ayers \& Dodman, 2010). The perspective conceives adaptation as synonymous with good development, and puts an emphasis on investments that improve overall development indicators (e.g. poverty, education, health etc.) to reduce the structural causes of social vulnerability to both climatic and non-climatic stresses (Ribot, 2010; Schipper, 2007). This perspective underlines approaches such as CBA, which implements development activities to address multiple stressors that underlie the climate vulnerability of the poor (Ayers \& Dodman, 2010). Like the adaptation plus development perspective, this vulnerability/developmentcentric perspective also emphasizes the mainstreaming of adaptation with development policies, but defines mainstreaming more broadly as "an approach that considers the role of development in achieving vulnerability reduction to both climate and other risks for the most vulnerable people" (Ayers et al., 2014, p.41). This approach is referred to as "mainstreaming plus", and could include actions such as strengthening institutional framework for equitable access to resources, or removing financial, institutional, and knowledge barriers for people and organizations to adapt (Klein, 2010, p.40).

The two divergent perspectives on adaptation and development linkages broadly reflect the two interpretations of vulnerability (O'Brien et al., 2007); first, as "outcome vulnerability", or the net impact of the projected climate change, reflecting the influence of a scientific framing of the climate problem; 
and second, as "contextual vulnerability", or the state of a system generated by the interaction of climate change and the social-ecological conditions in which it occurs, reflecting a human-security framing (O'Brien et al., 2007). The two framings of vulnerability have practical consequence on adaptation since they influence what actions get counted as adaptation and therefore where adaptation finance should go (Huq \& Burton, 2003; O'Brien et al., 2007).

Increasingly, scholars have made a case for bridging the two perspectives on adaptation and development linkages. For example, McGray et al. (2007) find that most projects in developing countries fall in-between the two positions, and propose that adaptation approaches be framed as a continuum between climate change-oriented to development/vulnerability-oriented approaches. Scholars also argue that capacities associated with fundamental development goals (income, health, education level etc.) and those with the adaptation goals of managing and reducing specific climate threats (adoption of technologies, use of climate information etc.) are related but not necessarily the same (Eakin et al., 2014; Lemos et al., 2016), and emphasize the symbiotic relationships between adaptation and development capacities. For example, Lemos et al. (2016) find that in the case of Brazil baseline development indicators are positively correlated with adaptation; higher households' economic indicators (such as wealth) are associated with a higher climate adaptive capacity (e.g. the ability to adopt irrigation). Eakin et al. (2014) argue that the two domains of development and adaptation capacities "must be addressed explicitly, simultaneously and iteratively if climate change adaptation and sustainable development goals are to be attained" (p.1).

At the same time, it is also recognized that not all development efforts are good for adaptation (Ayers \& Dodman, 2010), and vice versa (Eriksen et al., 2011). For example, poverty reduction efforts (e.g. the conversion of 
mangrove forests into shrimp farms) could provide economic gains but increase climate vulnerability (e.g. coastal communities for vulnerable to storm surges) (Klein, 2010, p.40). This recognition of the potential conflict between development and adaptation goals underlies the discourses on how to ensure that development and adaptation are compatible. Several avenues for compatibility are discussed in the literature. First, some scholars identify key principles for integrating adaptation with sustainable development goals, including the sensitivity to context, the acknowledgement of different values and interests, the use of local knowledge, and the consideration of feedbacks between local and global processes (Eriksen et al., 2011). Second, there is a call for more mainstreaming of climate change adaptation objectives into development policies and international development assistance (Agrawala \& Van Aalst, 2008; Ayers et al., 2014; Reid \& Huq, 2014; Saito, 2013; Sietz et.al, 2011; Wright et al., 2014). Third, locally-driven adaptation has also been increasingly seen as a particularly important approach to integrate contextspecific development and adaptation objectives (Nalau et., 2015).

In many ways, the dissertation adopts the conceptual separation between development and adaptation; while it is certain that climate change adaptation cannot be achieved without investments that improve overall development indicators and reduce the structural causes of vulnerability, it is also argued that development investments per se are unlikely to be adequate to build specific capacities to address specific climate threats without applying an explicit adaptation lens. This argument also underlies the dissertation's stance on the need to track adaptation finance separately from development finance, which is discussed in Section 2.3.3.

\subsubsection{Community-based adaptation}

While there are many approaches to locally-driven adaptation involving cities, municipalities, districts and communities (Adhikari \& Taylor, 2012; Betsill \& 
Bulkeley, 2006; Castán Broto \& Bulkeley, 2013; Nordgren et al., 2016), CBA has emerged as a particularly prominent area of research and practice that significantly shapes climate change adaptation and development linkages at the local level in developing countries. As a discourse, CBA is "an attempt to break away from hegemonic discourses of climate change vulnerability and adaptation (Kirkby et al., 2017, p.3)" that focusses on top-down technocratic approaches, to one which is contextualized, bottom-up, participatory and explicitly pro-poor (Kirkby et al., 2017). By responding to the needs of the most vulnerable and promoting participatory development, CBA is "becoming a mainstream entry point for development agencies to engage with adaptation to climate change at the local level" (Dodman \& Mitlin, 2013, p.642). Initial advocates of CBA were the NGO community and field-based development practitioners working ot the front line in poor and largely rural communities. In the last decade, the supporters of CBA have grown substantially to include other key actors in the international community including representatives of the UNFCCC, other UN agencies, multilateral and bilateral donors, government officials, and the research community. Among all UNFCCC member countries, 100 parties consider CBA a major adaptation approach (UNFCCC, 2015b), signifying the acceptance of the approach by a large number of governments.

Despite its popularity, the term CBA remains a broad umbrella concept for many community-level interventions but lacks a common definition and conceptual clarity (Dodman \& Mitlin, 2013; Kirkby et al., 2017; Schipper et al., 2014). McNamara \& Buggy (2017) conduct a systematic review of academic CBA literature and argue that the definition by Ayers \& Forsyth (2009) below is the most comprehensive. In this dissertation, I also adopt their definition as a starting point to develop indicators to assess the level of community focus in adaptation projects (See Chapter 5). 
"Community-based adaptation operates at the local level in communities that are vulnerable to the impacts of climate change. It identifies, assists, and implements community-based development activities that strengthen the capacity of local people to adapt to living in a riskier and less predictable climate. Moreover, community-based adaptation generates adaptation strategies through participatory processes, involving local stakeholders and development and disaster risk reduction practitioners. It builds on existing cultural norms and addresses local development concerns that make people vulnerable to the impacts of climate change in the first place" (Ayers \& Forsyth, 2009, p. 24).

While CBA projects could look like normal development activities, they differ by explicitly considering the potential impacts of climate change on community livelihoods. A development project that only addresses current climatic vulnerability but not the long-term impacts of climate change is not considered CBA (Fenton et al., 2014; Reid et al., 2010). CBA also requires the integration of scientific and local knowledge for improving the understanding of climate risks and vulnerabilities at the local level (CARE, 2010; Ensor \& Berger, 2009; Huq \& Reid, 2007; Reid et al., 2009, 2010; UNDP, 2010). The kinds of scientific knowledge used in CBA come from sources such as climate change models, weather stations, and remotesensing observations, while the relevant local knowledge comes from the communities' experience with past climate hazards and how they adapted to them (Reid et al. 2010). Lebel (2013) classifies such local knowledge emerging from communities' climate-related experience into four categories: land and water management, physical infrastructure, livelihood strategies, and social institutions. Other scholars highlight the importance of other types of local knowledge-referred to as "indigenous knowledge" or "traditional knowledge" (Naess, 2013)—which also plays a key role in shaping the preferences for adaptation actions at the community level. These often 
non-climate specific forms of local knowledge include goals, preferences, cultures, values, beliefs, experiences, practices, and technologies (Ensor \& Berger, 2009; Kettle et al., 2014; Naess, 2013).

Despite its premise, CBA is subject to five main lines of criticisms. First, given its reliance on historically-informed local knowledge, CBA is questioned for its ability to adequately address long-term climate risks and new normals, and for its potential to prejudice against larger-scale adaptation options needed to deal with unprecedented and disruptive climate change (Ayers \& Forsyth, 2009; Dodman \& Mitlin, 2013). Second, Forsyth (2013) argue that "'community based' approaches tend to imply that vulnerabilities-and solutions to risks-are located locally" (p.6), resulting in a tendency to treat communities as panaceas while downplaying the roles of enabling and constraining factors above the community level (Dodman \& Mitlin, 2013; Forsyth, 2013; Mohan \& Stokke, 2000). Third, Sabates-Wheeler et al. (2008) argue that early CBA projects adopted an over-simplified view of livelihood diversification as a risk management strategy, without adequately disaggregating community members into sub-groups based on poverty and vulnerability statuses and considering other options for livelihood transformation (such as intensification and migration). Fourth, some scholars argue that the concept of community is poorly defined, and is often used to morally justify interventions as people-centered, while assuming the notions of collectiveness and harmony that ignore the power politics and structural inequities between sub-groups (McDonnell, 2019; Titz et al., 2018). Given that real-life communities are heterogenous and, in many cases, transient, CBA faces a difficulty in defining a "community" and its members, and therefore, a challenge in being representative and inclusive (Buggy \& McNamara, 2016; Kepe, 1999; McDonnell, 2019; Schipper et al., 2014). It is also well-established in the literature that participation as a governance process is not devoid of norms, expectations, framings, and ideologies (Lebel et al., 2018; Sprain, 2017). If implemented uncritically in this context, CBA- 
similarly to its predecessor participatory development approaches-could be subject to the well-recognized pitfalls of participation including elite capture, exclusions, and the political uses of the "local" by hegemonic interests (Ayers, 2010; Cleaver, 1999; Cooke \& Kothari, 2001; Dodman \& Mitlin, 2013; Few et al., 2007; Forsyth, 2013; Mohan \& Stokke, 2000; Sprain, 2017). Fifth, as CBA is substantially based on localized perceptions of risks, it could be difficult to make CBA practices transferrable to risks and policies wider than the scale of communities (Ayers \& Forsyth, 2009).

As a field of action-oriented research, the CBA literature has also expanded significantly in the recent decade. Broadly speaking, the landscape of CBA literature to date has been dominated by the description of its theory and practice (Ensor \& Berger, 2009; Kirkby et al., 2017; Reid, 2016; Reid et al., 2009); the multiplication of how-to operational guidelines and tools (CARE, 2010; Magee, 2013; UNDP, 2010, 2015; Webb et al., 2015); the stock-taking of implementation experiences from a portfolio of projects (McNamara, 2013) or in-depth case studies (Baas \& Ramasamy, 2008; Simane \& Zaitchik, 2014); and the discussion on approaches for CBA mainstreaming and upscaling (Archer et al., 2014; Fenton et al., 2014; Gogoi et al., 2014; Regmi \& Star, 2014, 2015; Reid \& Huq, 2014; Schipper et al., 2014). Four key themes have emerged in recent CBA literature.

First, there is a push for CBA projects to integrate innovation, learning and multi-sectoral approaches to climate change adaptation (McNamara \& Buggy, 2017). Adaptation pilot projects at the community level are widely seen as important "laboratories of innovation" (Gogoi et al., 2014, p. 368), which simultaneously provide vulnerable local communities with an experimental space, and policy makers with demonstration cases for mainstreaming these innovations into adaptation policies and practices beyond the community level. 
Second, researchers have begun to assess the performance of CBA from various perspectives. For example, Huq \& Faulkner (2013) find that a CBA project in Namibia has contributed to increased food security during severe droughts, and to community perceptions of increased ability to adapt to increasing drought and flood events. Based on case studies from Timor Leste and Solomon Islands, Ensor et al. (2016) finds support to the claim that CBA projects can build resilience-defined as a combination of characteristics (e.g. high diversity, acceptance of uncertainty and change, preparedness and planning, learning etc.) of a social-ecological system (Bahadur et al., 2013) - particularly by focusing on local decision-making, bridging or synthesizing scientific and local knowledge, and using mixed methods that pay attention to landscape functions and ecosystem services important for local communities. However, Ensor et al. (2016) also caution that this strength vis-à-vis resilience should not mean that CBA projects ignore the question of who is benefiting from resilience and inadvertently reinforce unjust structures and power relations and forgoing transformative opportunities. This caution also reflects the broader concern in the literature that many current adaptation initiatives, particularly donorfinanced ones in developing countries, tend to emphasize incremental adaptation through educational or behavioural campaigns targeting local communities (Burch et al., 2017), rather than investing in transformative adaptations that are truly new, adopted at a large-scale, or transform places and shift locations (Kates, Travis, \& Wilbanks, 2012). These transformations may be necessary where vulnerabilities and risks are sizable, and the potential impacts of climate change too disruptive to the current natural and human systems (Dodman \& Mitlin, 2013; Kates et. al., 2012; Noble et al., 2014; Pelling et al., 2015).

initiatives in the Pacific islands and find that they perform well in terms of suitablity to the community context and priorities. On the other hand, sustainability post-project cycle is a major concern, indicating the limited 
extent that these CBA initiatives are mainstreamed in the national policy and planning processes of the host countries. Drawing on the evaluation, the scholars also suggest four optimization points for future CBA initiatives: local approval and ownership, shared access to and benefit from initiatives, integration of local realities, and systems-thinking and forward planning.

Third, scholars increasingly discuss the limits of analyzing CBA as autonomous, bottom-up community actions. Given that community-level vulnerability is caused by both climate and non-climate stressors at multiple scales, Dodman \& Mitlin ( 2013) argue that CBA so far has not given sufficient attention to building a bridge with the macro-level enabling governance factors above the community level. These factors include, among others, the institutional and policy context and adaptation co-management across scales (McNamara \& Buggy, 2017; Reid, 2016). Despite this recognition of the need for complementarity between bottom-up and top-down approaches, there is still limited research that analyzes CBA projects as planned initiatives in the context of multi-level governance. Spires et al. (2014) find that only $4.4 \%$ of the CBA literature they systematically reviewed discusses CBA in developing countries as planned adaptation, even though these projects are most often implemented and financed by external partners, including international funders and civil society actors, and supported by national and sub-national governments (Adhikari \& Taylor, 2012; Spires et al., 2014).

Finally, scholars also draw more attention to the role of the barriers in CBA planning and implementation. Spires et al. (2014) find that the most pervasive barriers relate to poor coordination within and between the organizations that plan and implement CBA, limited knowledge and information on climate change, and ineffectual communication between stakeholders involved in CBA actions. Others also recognize inadequate financing as another key barrier for up-scaling CBA initiatives in developing countries (Fenton et al., 2014; Figueres, 2004). Drawing on an assessment of actual CBA project 
documents, Piggott-McKellar et al.( 2019) also highlight the prevalence of cognitive and behavioral barriers to CBA. These barriers-which refer to issues such as community members' reluctance to implement unknown technologies, lack of interest and commitments by project staff, internal community conflicts, and cultural and religious values that are not in line with project objectives-raise a concern of the continued dominance of top-down approaches in projects that are labeled as CBA (Piggott-McKellar et al., 2019).

\subsubsection{The role of International adaptation finance in developing countries}

Notwithstanding the ongoing debates on the adaptation and development linkages and on CBA as an approach to promote such linkages, it is recognized that developing countries will bear a disproportionate burden of adapting to the impact of climate change, and that adaptation actions are urgently needed to protect the vulnerable populations in these countries (Brooks et al., 2005; Füssel, 2010; IPCC, 2014a). There is also an international consensus that developed countries should take a lead in mobilizing climate finance flows to help finance climate actions in developing countries (UNFCCC, 2015a). In this context, another global discourse has emerged around the role that international adaptation finance as a form of climate finance can play in supporting development-compatible adaptation actions, taking into consideration "particularly vulnerable" developing countries and the vulnerable groups and communities within the countries (UNFCCC, 2015a).

Climate finance can be broadly understood as "the financial resources dedicated to adapting to and mitigating climate change globally, including in the context of financial flows to developing countries" (UNFCCC, 2018, p.21). Climate finance is classified according to two objectives: mitigation finance supports actions that reduce GHG emissions, specifically for the world to 
remain within a $2^{\circ} \mathrm{C}$ global temperature rise above pre-industrial levels and pursuing efforts to limit the rise to $1.5^{\circ} \mathrm{C}$ (de Coninck et al., 2018), while adaptation finance funds actions that reduce harms and capture benefits from climate change which is already happening (Bird \& Glennie, 2011). Adaptation finance can generate mitigation co-benefits and vice versa. Mitigation and adaptation financial flows can be domestic (i.e. within countries) and international (i.e. between countries) and come from public and private sources (Betzold \& Weiler, 2018; Buchner et al., 2015). Global climate finance is estimated by summing up all domestic and international flows for both mitigation and adaptation objectives. In 2016, the total global climate finance flows are estimated to range from USD 455 billion (Oliver et al., 2018) to USD 681 billion (UNFCCC, 2018). Global adaptation finance (international and domestic) largely comes from public financing, with grant instruments dominating international adaptation finance, while both domestic and international mitigation finance comes from diverse public and marketbased sources including loans, equity, grants etc. (Buchner et al., 2015; UNFCCC, 2018).

As a form of climate finance, international adaptation finance refers to the component of global climate finance that originates from public resources of developed countries to fund adaptation activities in developing countries as part of an international commitment under the UNFCCC (UNFCCC, 2018). Three main mechanisms channel this public international adaptation finance towards developing-country recipients (OECD, 2018; UNFCCC, 2018): 1) bilateral development agencies, including those of donor countries which have established own climate funds (e.g. the United Kingdom's international Climate Fund, the Nordic Development Fund, the German International Climate Initiative and the European Union's Global Climate Change Alliance), and those which have not established climate funds but provide climaterelated aids to developing countries (e.g. the Agence Française de Développement, the United States Agency for International 
Development); 2) multilateral development banks (MDBs), such as the World Bank, the Asian Development Bank and the African Development Bank, which commit their own resources raised through capital markets to finance climate adaptation actions in developing countries; and 3) multilateral climate funds, comprising those administered by the operating entities of the Financial Mechanism of the UNFCCC (e.g. the SCDF, the LDCF) and the Kyoto Protocol (the AF) and other non-UNFCCC funds (e.g. the PPCR). In terms of relative volume, the majority of the international adaptation finance has been channeled through the bilateral and MDB mechanisms, with less than $5 \%$ handled through multilateral climate funds to date (UNEP, 2016). In 2016, the UNFCCC estimates that the three mechanisms channelled a combined sum of USD 21.1 billion of international adaptation finance commitments toward developing countries; the bilateral initiatives channelled the largest annual flow of USD 14.73 billion, followed by the MBDs with USD 5.9 billion, and the multilateral climate funds with USD 0.5 billion (UNFCCC, 2018).

Conceptually, international adaptation finance can be distinguished from development finance known as official development aid (ODA). International adaptation finance originates from an international commitment to address climate injustice, has climate-specific objectives, and is governed largely by the UNFCCC mechanisms (Bird \& Glennie, 2011; Birdsall \& De Nevers, 2012). On the other hand, ODA comes from voluntary public contributions to support broader development and poverty reduction goals, is politically determined by donor countries, and is pre-eminently influenced by the Development Assistance Committee (DAC) of the Organisation for Economic Co-operation and Development (OECD) (Bird \& Glennie, 2011). However, these conceptual differences are blurred in practice. In many donor countries, there is no separate decision-making process between international adaptation finance and development finance (Betzold \& Weiler, 2018, p.209). Like development finance, the allocation of international adaptation finance is 
shaped by the bureaucratic politics between aid, environment and finance ministries within donor countries (Pickering et al., 2015). As these donors rely heavily on their aid budgets to fulfill climate pledges, most public international adaptation finance to date has come in the form of adaptation-marked ODA (Betzold \& Weiler, 2018; Scoville-Simonds, 2016). In addition, international adaptation finance and development finance also share some similar guiding principles (e.g. accountability, national ownership) (Bird \& Glennie, 2011), and could be spent at the project level in an indistinguishable way (Bird \& Glennie, 2011; Wilkinson et al., 2014).

The relationships between development and adaptation finances have been at the center of an unresolved debate between developed and developing countries within the UNFCCC and other international development fora. Apart from being linked the divergent perspectives on the adaptation-development relationships discussed earlier in section 2.3.1, this contentious debate also reflects the differences in how countries interpret the UNFCCC principles for fair, effective and efficient climate finance delivery (Bécault \& Marx, 2017). On the one hand, developing countries favor a clear distinction between international adaptation finance and ODA to ensure that developed countries fulfill their obligations of providing new and additional climate finance (Bécault \& Marx, 2017). On the other hand, developed countries emphasize the efficiency and effectiveness of mainstreaming adaptation into development planning, thus adaptation finance into development assistance (Bécault \& Marx, 2017; Chan \& Amerasinghe, 2018; Samuel Fankhauser \& Burton, 2011). Interestingly, while the 2015 Paris Agreement reaffirms the commitment of developed countries to provide climate finance to developing countries, it no longer specifies that climate finance has to be new and additional to development finance (UNFCCC, 2015a). It remains unclear how such change will reshape this developed and developing-country debate. 
Scholarly positions on the relationships between international adaptation finance and development finance vary. For example, Fankhauser \& Burton (2011) argue that the best use of adaptation finance in the short run may be to finance less tangible developmental activities that increase adaptive capacity, but this approach is constrained by the "fixation" on additionality of investments (p.1046). In line with the position of developing countries, Ayers \& Huq (2009) argue that the distinction between international adaptation finance and development finance is necessary for the tracking purpose, but efforts are required to ensure that on-the-ground use of adaptation and development finances are complementary. Klein (2010) argues that mainstreaming international adaptation finance with development projects makes sense from an operational perspective but cautions about the risk of mainstreaming being used to by donors to relabel existing development aid as adaptation without providing new and additional climate finance. Other scholars involved in this debate question the whole conception of climate finance altogether. For example, Zadek, (2011) argue that "climate finance is the wrong lens through which to understand, let alone design, solutions to the climate challenge" (P.1606). With the unrealistic 100 billion-above-ODA-goal inhibiting its effective mobilization, climate finance runs the risks of repeating the shortcomings of large-scale international public resource transfers (e.g. bureaucratization) and should be reformulated as sustainable economic development finance more broadly (Zadek, 2011).

In this dissertation, I take the same starting point as Ayers \& Huq (2009) that tracking international adaptation finance as separate from development finance is necessary for three reasons. First, the separation ensures the needed visibility of the adaptation agenda in the context of competing development challenges. Second, given the general understanding that climate finance should be new and additional to development finance, the separation is necessary for the developing-country beneficiaries and civil society to monitor that international adaptation finance complements, rather 
than replaces, development finance, and therefore hold developed countries accountable to international commitments. Third, despite the current weaknesses in the global climate finance reporting and monitoring system, the separation still allows for a more systematic monitoring and reporting of international adaptation finance channeled through multiple mechanisms, and therefore, contributes to more transparency in the use of resources from these mechanisms against adaptation objectives. At the operational level, I also agree with both Ayers \& Huq (2009) and Klein (2010) that on-the-ground use of adaptation and development finances should be complementary, particularly by mainstreaming the adaptation objectives to the design of projects/programs at the local level.

\subsection{Different perspectives used to study international adaptation finance}

Within the context of the relationship between international adaptation finance and development finance discussed above, research on international adaptation finance is shaped by three perspectives: political economy, ethics, and governance. These perspectives are discussed below.

\subsubsection{Political economy of international adaptation finance}

A large number of studies estimate the adaptation costs in developing countries (Mekonnen, 2014; Narain et al., 2011; Smith et al., 2011; UNEP, 2016; UNFCCC, 2010), tracks international adaptation finance flows (Buchner et al., 2015; OECD, 2018; UNFCCC, 2018), and assess their adequacy against the estimated costs (Fankhauser et al., 2016; Flåm \& Skjærseth, 2009). For example, Smith et al. (2011) review global estimates of adaptation costs in developing countries and find that additional investments of USD 26-230 billion will be needed annually by 2030. A recent report concludes that these costs could reach between USD 280-500 billion 
by 2050 (UNEP, 2016). While these estimates are highly uncertain and may not reflect the true adaptation costs and financing gap (Fankhauser et al., 2016), they indicate a very high cost of adaptation globally. There is a consensus that current public international adaptation finance flows are inadequate to meet the adaptation costs in developing countries (Fankhauser et al,, 2016; Flåm \& Skjærseth, 2009). For example, the UNFCCC estimates that public international adaptation finance flows to developing countries through bilateral initiatives, MDBs, and multilateral climate funds amounted to USD 21.1 billion in 2016 (UNFCCC, 2018), or a fraction of the estimated global adaptation costs, particularly if compared to the upper-bound estimates. This recognized public financing gap leads to a discussion on ways to mobilize more adaptation finance from the private sector (Pauw, 2015; Pauw et al., 2015; Tompkins \& Eakin, 2012), and from South-South finance (Ha et al., 2016).

A related body of literature looks at the question of additionality, reporting and transparency of international adaptation finance (Brown et al., 2010; Schalatek et al., 2010; Stadelmann et al., 2011). Three key issues stand out from this subset of literature. First, given that "new and additional" to what has never been clearly defined, there is no commonly agreed baseline by which the additionality of international adaptation finance to development finance is measured, and the overlap between development and adaptation finances at the project level continues to complicate the measurement of international adaptation finance (Donner et al., 2016; Stadelmann et al., 2011). Second, there is a lack of harmonized definition and reporting of adaptation finance across provider institutions, which contribute to inconsistent reporting and data gaps on adaptation finance (Hall, 2017; UNEP, 2016; UNFCCC, 2018). Third, at the project level, researchers and climate finance transparency initiatives have questioned the unclear rationale why many donor-financed project activities on the ground are labelled as adaptation as opposed to regular development activities (Adaptation Watch, 
2015; Donner et al., 2016; Wilkinson et al., 2014), a pattern which suggests a high possibility of over-reporting, miss-labelling, and double-counting (Adaptation Watch, 2015; Dasgupta et al., 2015; Michaelowa \& Michaelowa, 2011). Despite the common use of the Rio-Markers by most bilateral donors to report their international adaptation finance commitments, the high discretion in how these markers are applied at the project level impedes a meaningful comparison of each donor's performance with regards to financing adaptation in developing countries (Roberts \& Weikmans, 2017). All of these issues point to a broader transparency gap in the current global adaptation finance system (Adaptation Watch, 2015).

From a resource allocation perspective, researchers also assess how political economy factors such as recipient vulnerability, recipient merit, and donor interest determine the allocation of international adaptation finance flows to different recipient countries (Betzold \& Weiler, 2018; Robinson \& Dornan, 2017). Examining bilateral adaptation aids between 2010-2015, Betzold \& Weiler (2018) find that a combination of these three factors determine international adaptation finance allocations; in particular, more bilateral adaptation aids have been allocated to recipients with higher physical exposure to climate hazards, good governance, and high political and economic significance to bilateral donors. Using the data on bilateral adaptation aids between 2010-2014, Robinson \& Dornan (2017) find that, as a group of countries, SIDs are not disadvantaged in receiving international adaptation finance, which is contrary to a widespread perception, but the distribution of such finance is highly concentrated among a limited group of SIDS countries. SIDS countries with good governance are also more likely to receive international adaptation finance (Robinson \& Dornan, 2017). 


\subsubsection{Ethics of international adaptation finance}

Another group of studies apply the concepts of procedural and distributive justice to study international adaptation finance; the former describes the normative criteria for the allocation of costs and benefits, while the latter refers to the ethical implications of power relations in planning and decision-making processes (Colenbrander et al., 2018; Grasso, 2010, 2011; Khan et al., 2019; Paavola \& Adger, 2006). Early studies examine the principles to guide an international framework for fair international adaptation finance, including the avoidance of dangerous climate change, the burden-sharing among contributing developed countries, the prioritization of the most vulnerable recipient countries in the distribution of assistance, and the equal participation of all in decision making (Dellink et al., 2009; Grasso, 2010; Paavola \& Adger, 2006). Recently, scholars examine new issues arising from the operationalization of international climate finance pledges, including the balance between mitigation and adaptation finance, the proportionality of available finance to the adaptation needs of the most vulnerable (Morgan \& Waskow, 2014), the transparency, accountability, and legitimacy of adaptation finance mechanisms (Ballesteros et al., 2010; Lebel et al., 2017; Schalatek, 2012; Terpstra et al., 2013), and the ethical rationales for recipient versus donor control of international adaptation finance (Duus-Otterström, 2016). Some argue that multilateral mechanisms and processes under the UNFCCC need to be strengthened, including by dedicating a renewed attention to justice issues in climate finance distribution, governance, and North-South collaboration (Khan et al., 2019), for international adaptation finance to achieve just, as well as effective, international outcomes (Winkler \& Beaumont, 2010).

Recently, scholars have departed from the focus on international-level climate justice and turned more attention to a multi-scalar approach (Barrett, 2013; Colenbrander et al., 2018). Such approach conceptualizes climate 
justice as a top-down, accumulative process-with the primary actors being states at the global level, developing-country states at the national level, and households and communities at the local level-and examines the groundlevel implementation of adaptation projects "as an observable and measurable proxy for climate justice" (Barrett, 2013, p 2016). From this multiscalar perspective, climate justice is considered achieved if the intra-state distribution of adaptation finance is directed towards the most climatevulnerable regions and groups within recipient countries (Barrett, 2013a, 2013b, 2015). When multilateral climate funds are involved, scholars also argue that just adaptation outcomes are more likely if local groups can directly access these funds (Colenbrander et al., 2018), and when gender equity is explicitly addressed in project design (Wong, 2016).

\subsubsection{Governance of international adaptation finance}

Governance can be broadly understood as "the process of steering society and the economy through collective action and in accordance with some common objectives" (Torfing, 2012, p.14). Often with the involvement of public authorities, such steering entails "the setting, application, and enforcement of the rules of the games" (Kjaer, 2004, p.12), and therefore encompasses the ideas of power, responsibility, legitimacy and accountability in collective actions (Kjaer, 2004; Madzwamuse, 2011). Explaining the governance of the European Union, Eising \& Kohler-Koch (2003) define governance as "the ways and means in which the divergent preferences of citizens are translated into effective policy choices, about how the plurality of societal interests are transformed into unitary action and the compliance of social actors is achieved" (p.13). While stressing different elements, these definitions share a common idea of the steering of diverse societal actors towards a common goal. 
Much of the early literature on governance focuses on the state's role in steering the society but more recently studies have also conceptualized governance as broader than government. This government-plus view of governance still recognizes the important role of the state but focuses on how a plurality of state and non-state actors interact in complex processes, which are both formal and informal, across scales towards a common goal (Gjaltema et al., 2019; Kjaer, 2004; Torfing, 2012). Based on the degree of formality of institutions and the relative dominance of state versus non-state actors, scholars characterize governance into three ideal-type modes: bureaucratic hierarchies (formal institutions, dominant state actors), markets (formal and informal institutions, dominant non-state actors), and networks (largely informal institutions, participation of state and non-state actors) (PahlWostl, 2009; Thompson et al., 1991).

At another extreme end, the term "governance without government" is used in the literature to refer to the steering and control of societies with little or no direct involvement of the state actors in the public sector (Torfing, 2012, p.3). Reflecting the growing complexity of governance problems, the term "metagovernance" has also been coined in the literature to describe the governance of governance or the organization of self-organization (Gjaltema et al., 2019). However, Gjaltema et al. (2019) argue that meta-governance is better understood as the coordination of different governance modes to overcome governance failures.

International adaptation finance is part of a complex set of mechanisms of global climate governance (Bécault \& Marx, 2017). In its broad sense, climate governance refers to "all purposeful mechanisms and measures aimed at steering social systems towards preventing, mitigating or adapting to the risks posed by climate change" (Jagers \& Stripple, 2003, p 385). While "new and additional" climate finance has been a key element in the UNFCCC since its beginning (UNFCCC, 1992), arguably the mechanisms and measures 
associated with climate finance have been at the centre of global climate governance since the 2009 Copenhagen Accord had mandated specific mobilization goals. For adaptation, scholars argue that mobilizing and transferring finance has become an important mode of current global adaptation governance (Hall \& Persson, 2017). Given the purposefulness and institutional complexity of climate finance, Pickering et al. (2017) argue that climate finance governance is a sub-system which can be distinguished from, but is closely integrated with, the broader system of global climate governance that centres on the UNFCCC. Within this context, the literature on the governance of international adaptation finance tends to focus on the structures, systems and processes related to the control over climate finance decision-making and their implications on climate finance effectiveness and justice. The literature generally discusses these issues at two levels.

First, at the macro-structural level, scholars analyze the entire UNFCCCbased global climate finance governance, including its normative framework, overall architecture, division of responsibilities between countries and financing mechanisms, and the geographical coverage of the entire system (Amerasinghe et al., 2017; Ballesteros et al., 2010; Bécault \& Marx, 2017). According to Bécault \& Marx (2017), the current UNFCCC-based global climate finance governance construct is characterized by a weak and contested normative framework on what constitutes a fair, equitable, and effective provision of climate finance to developing countries, and a highly divergent financing architecture comprising several multilateral climate funds. The system also exhibits a relative geographical concentration of climate finance beneficiaries, with middle-income countries such as those in East Asia taking a large share of climate finance (for both mitigation and adaptation), and with adaptation finance going to the most vulnerable countries (e.g. LDCs and SIDs) being relatively small. Building on Ostrom (2010), Bécault \& Marx (2017) also characterizes the system as multi-level governance, since it encompasses vertically and horizontally integrated 
actors across issues and scales, and as being weakly polycentric, due to the presence of a certain degree of autonomy and independence of sub-units, but note that to determine how the entire system fares in terms of polycentricity would require a more in-depth empirical analysis.

At the micro-institutional level, the literature on the governance of international adaptation finance discusses the structures and processes of individual multilateral climate funds for adaptation, mainly the AF, the GCF, and the GEF (Bowman \& Minas, 2019; Canales Trujillo \& Nakhooda, 2013; Möhner \& Klein, 2007; Nakhooda et al., 2014; Parker et al., 2014). Key issues discussed in relation to these funds range from capital mobilization, management board composition, oversight by the UNFCCC COP (Bowman \& Minas, 2019; Dodman \& Mitlin, 2013; Fridahl \& Linnér, 2016; ScovilleSimonds, 2016; Winkler \& Dubash, 2016), to post-capitalization set-ups related to the allocation and use of funds in recipient countries (Fridahl \& Linnér, 2016; Nakhooda et al., 2014; Rai et al., 2015; Schalatek, 2012). Acknowledging that the global climate finance governance will remain highlyfragmented, scholars generally call for more mobilization of international adaptation finance through the individual funds and improved coordination among funds and between funds and countries (Amerasinghe et al., 2017). The literature also calls for each fund to improve governance in terms of increased operational efficiencies and accountability, strengthened capacity and ownership of developing-country recipients, equitable fund allocations, and enhanced participation of local communities as partners and beneficiaries (Amerasinghe et al., 2017). Except for some recent studies (Barrett, 2015; Lebel et al., 2017; Sovacool et al., 2017), this body of literature tends to use the term governance in a broad sense. There is still a lack of a systematic application of concepts and theories from the governance literature, such as multi-level governance (Hooghe \& Marks, 2003), polycentric governance (Ostrom 2010), and decentralization and devolution 
(Bardhan, 2002; Fisher, 1999), to characterize and examine the performance of the governance of each fund.

2.4.4. Rationale for the dissertation's use of the governance perspective

This dissertation analyzes international adaptation finance that flows to developing countries through the mechanism of multilateral climate funds. Given the different perspectives that can be used to study the role of these funds in channeling international adaptation finance, I use the governance perspective in this dissertation for five reasons. First, understanding why so little of international adaptation finance has reached the local level to date requires more research on how the resource is linked through a cascade of institutions and actors to the actual implementation of adaptation, which is essentially a governance issue (Adger et al. ,2009).

Second, multilateral climate funds offer a unique entry point to study international adaptation finance from the perspective of access modalities as different governance models. Currently, developing countries primarily access both development finance (ODA) and international adaptation finance (see section 2.3.3.) indirectly through multilateral and bilateral development agencies (e.g. indirect access). The only portion of international adaptation finance that goes through multilateral climate funds is unique in the sense that it can be accessed through two alternative models i.e. indirect access and direct access (through national entities) (see the discussion in section 2.5.). This variation in governance models provides a setting for the comparative analyses in this dissertation.

Third, the multilevel governance of multilateral climate funds also provides a setting to examine the multilevel governance of adaptation processes themselves. While the earlier adaptation literature tends to draw the analytical boundaries of adaptation governance issues as either national and local 
when analyzing initiatives involving state and non-state actors (Juhola \& Westerhoff, 2011; Mickwitz et al., 2009; Næss et al., 2005), or as international when analyzing the UNFCCC processes (Jordan et al., 2015), these mutually exclusive views provide inadequate frameworks to how global processes are shaping local adaptation. With their unique structures and processes involving a broader range of state and non-state, as well as international and local, actors, multilateral climate funds signify the emergence of a new era of transnational adaptation governance (Dzebo \& Stripple, 2015), and, therefore, offer an analytical setting which captures adaptation governance that simultaneously spans international, national, sub-national and local jurisdictions.

Fourth, in climate change adaptation studies, governance is generally used as an umbrella concept to capture both the institutional design of decisionmaking mechanisms, and the processes to manage the relationships between the expanding networks of adaptation actors towards a common goal (Nieuwaal et al., 2009). By extending this lens to study international adaptation finance, one can pay attention to both the institutional design (e.g. access modalities) and processes (e.g. community consultations in project design) which carry important implications for how the finance is used at the local level.

Finally, a governance perspective could also provide relevant insights to the important political economy and ethical questions in international climate finance. For example, one of the key sources of legitimacy for multilateral climate funds comes from a justification that they will deliver adaptation benefits to vulnerable local populations (Lebel et.al., 2017). Understanding what governance arrangements can enable the funds to reach more local beneficiaries under different country contexts can inform policy actions that simultaneously enhance the funds' legitimacy and climate finance effectiveness at the local level. 


\subsection{Access modalities to international adaptation finance}

Given my choice of using the governance perspective in this dissertation, I now turn to a key global debate on how the governance of individual multilateral climate funds can be arranged to support local adaptation. Such debate centres on the issue of access modality, which is the main subject investigated in the empirical chapters of this dissertation (Chapters 5,6,7).

Among all the multilateral climate funds for adaptation, two funds-the AF and the GCF-offer options for developing countries to access their resources via the direct access modality and the indirect access modality. Figure 2.1 illustrates the two modalities under the AF structure. Much of the literature discusses the innovativeness of the direct access modality-which was pioneered by the AF and subsequently adopted by the GCF-and compares its advantages and disadvantages with the indirect access modality. The debate on these alternative access modalities to multilateral climate funds encapsulates a wide range of issues including climate justice, accountability, ownership, capacity, participation and transaction costs, as well as their trade-offs. 


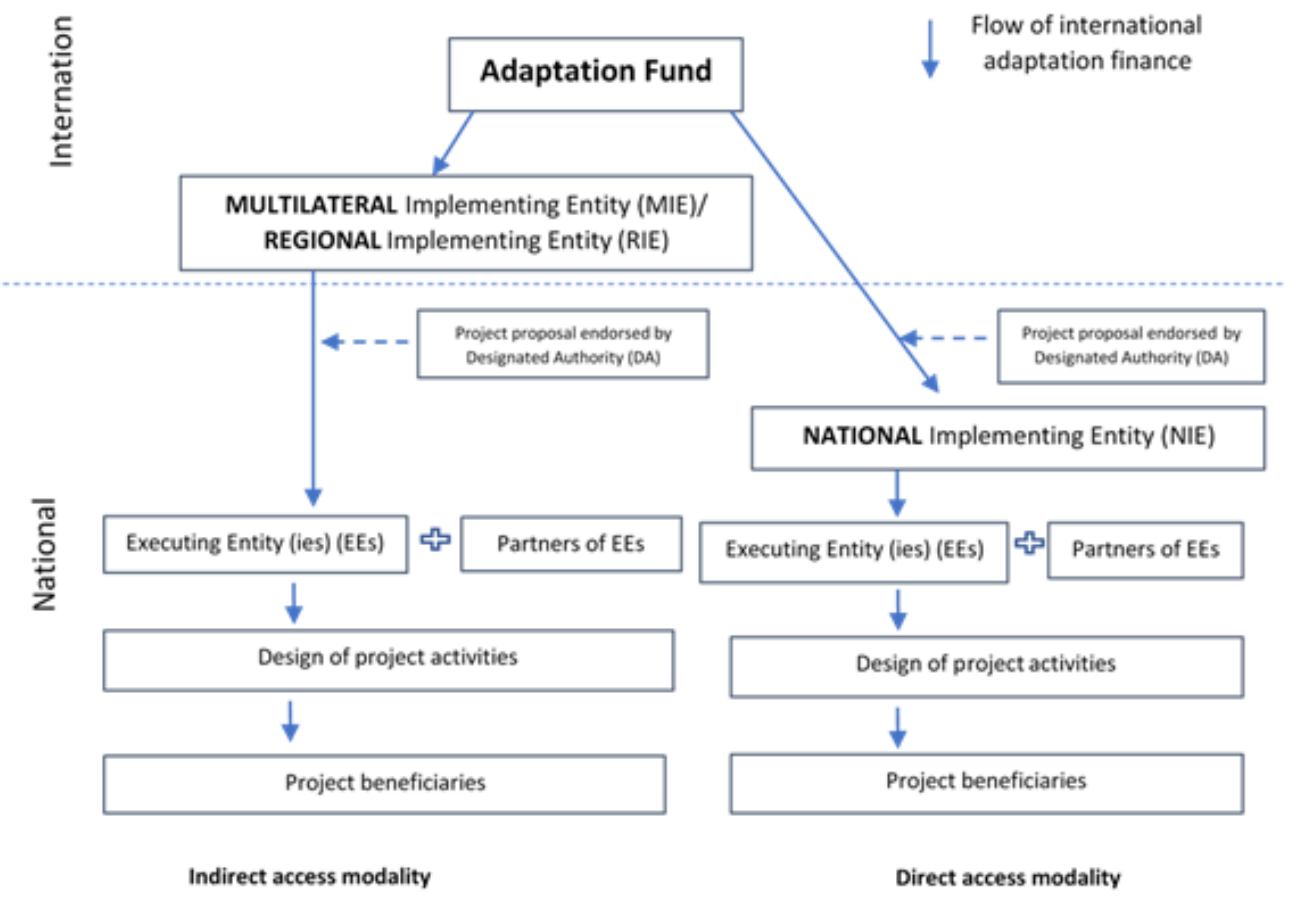

Figure 2.1: The architecture of the direct access and indirect access modalities to the AF

Source: Author.

2.5.1. The indirect access modality

The "indirect access" modality had been the norm in international adaptation finance (as well as development finance) and remains the most dominant access modality today (Duus-Otterström, 2016; Schäfer et al., 2014; UNFCCC, 2018). Under this modality, developing countries access funding through multilateral implementing entities (MIEs) and/or regional implementing entities (RIEs), which identify, develop, implement and monitor projects for developing countries in collaboration with national and local executing entities (EEs) (Figure 2.1). Funded projects use the implementing entities' institutional capacities and systems that comply with the AF standards for financial and project management, anti-corruption, grievance 
redress, inspection and social and environmental protection (AFB, 2008). The modality also has other names in the literature. It is sometimes called "multilateral access" since much of the funds that flow to developing countries indirectly go through multilateral intermediaries (UNDP, 2012). More recently, the modality has been referred to as "internationally-intermediated access" or "intermediary access", recognizing that not all indirect access projects are multilateral (Schäfer et al., 2014). As international adaptation finance comes from donors' public treasuries, indirect access supposedly assures donors with higher accountability and transparency through systems of the MIEs and RIEs and arguably allows more donor control of climate finance. This leads to the modality to be sometimes called "direct interventions" from the donor perspective, as opposed to "direct transfers" in the case of direct access (Brunner \& Enting, 2014).

Literature that explicitly discusses the advantages and disadvantages of the indirect access modality is scarce compared to studies that focus on direct access. In this limited literature, several rationales are provided to explain why developing countries may choose the indirect access modality in accessing multilateral climate funds. First, accessing the funds through international intermediaries helps bridge the current national capacity gaps by allowing developing countries with limited institutional capacity to use the capacity of multilateral institutions. Second, the modality could help ensure the synergies of the funded projects with other internationally-funded climate initiatives, such as the implementation of National Adaptation Programmes of Action (NAPA) projects funded by the LDCF. Third, the modality helps developing countries harness the international expertise of MIEs/RIEs with regards to specific adaptation needs (e.g. coastal adaptation) (IGES, 2011; Schäfer et al., 2014), while having the potential to promote healthy competition among international agencies to offer the expertise based on comparative advantage (IGES, 2011). From the recipient country's perspective, there could also be other positive implications from developing 
working relationships with well-known international and regional organizations (Schäfer et al., 2014). From the perspective of donors, the indirect access modality represents a way for donor countries to delegate control of climate finance to international or regional organizations. This reduces the transactions costs that could arise from information asymmetries and contract enforcement between the donors and implementing entities, as well as from limited institutional capacities of recipient-country institutions (Brunner \& Enting, 2014).

Despite the above advantages for developing countries to use the service of $\mathrm{MIEs} / \mathrm{RIEs}$, the literature also discusses several disadvantages of the indirect access modality. From a climate justice perspective, developing countries generally perceive climate finance as their polluter-pay entitlements justified by historical contributions of developed countries to climate change (AFB, 2015; Bird et a., 2011; Ciplet et al., 2012; Harmeling \& Kaloga, 2011), and believe that the ownership and control of international climate finance should be transferred to recipient-country national systems (Bird et al., 2011). Channeling climate finance through international systems falls short of this entitlement principle. The dominant use of the indirect access modality also would mean that much of international adaptation finance continue to flow through a structure that largely reproduces that of traditional ODA, the ineffectiveness of which is well-known (Doucouliagos \& Paldam, 2009). Some scholars further suggest that the ineffectiveness of ODA had contributed to, or at least did not help improve, the socio-economic processes that sustain inequalities and climate vulnerabilities in developing countries in the first place (Colenbrander et al., 2018; Scoville-Simonds, 2016).

From an aid effectiveness perspective, the disadvantages of the indirect access modality have been mentioned in relation to the issues of national ownership and operational efficiency. For national ownership, scholars criticize the indirect access modality as being donor-driven, allowing more 
opportunities for donors and MIEs/RIEs to impose their own agenda above national priorities (Craeynest el al., 2010). MIEs/RIEs may also have a tendency to work within their own structure and this could limit the engagement of domestic entities (IGES, 2011; Schäfer et al., 2014). For operational efficiency, the use of third-party intermediaries-while potentially saving transaction costs from the donor perspective-creates another set of high transaction costs from complicated multilateral procedures that parallel national systems, requirements for co-financing (in the case of the GEF) and high administrative fees charged by the implementing entities (Brunner \& Enting, 2014; UNFCCC, 2008b). Experiences from actual AF projects indicate that project management fees (comprising implementing entity (IE) management and execution fess) charged by MIEs are consistently higher than those charged by NIEs (around 1.5 times), and this fee differential may have contributed to the increased interest in the direct access modality (Bird, 2014; Schäfer et al., 2014).

\subsubsection{The direct access modality}

The term "direct access" generally means that "developing countries directly accessing international public financing in order to implement national and local actions to address climate change" (Bird et al. , 2011, p 3). The term implies the transfer of responsibility, capacity and fiduciary risks in managing climate finance to the national level (Bird et al., 2011; Druce et al., 2013), though it remains debatable if the modality also means the transfer of full financial ownership of climate finance to developing countries (Bird et al., 2011).

The direct access modality represents a call for democratizing governance of global climate finance (AFB, 2015; Bird et a., 2011; Ciplet et al., 2012; Harmeling \& Kaloga, 2011). While not being new to development finance, direct access is innovative for international adaptation finance (Ballesteros et 
al., 2010; Brown et al., 2010). Under direct access, all the functions of a MIE or RIE discussed above are performed by NIEs (Figure 2.1), which are "national legal entities nominated by Parties that are recognized by the Board as meeting the fiduciary standards and demonstrating ability to comply, as a minimum, with the environmental and social policy and the gender policy approved by the Board" (AFB, 2017, p.6). Government actors still play a predominant role within the direct access modality. For example, Harmeling \& Kaloga (2011) describe the AF's direct access model as a "government run model" (p.27) as the Designated Authorities (DAs), which represent national governments, need to endorse both the NIE applications and the project/program proposals.

Two forms of direct access modalities can be distinguished: "ordinary direct access" and "enhanced direct access" (Müller, 2013; Schäfer et al., 2014). In technical terms, the AF's direct access modality is characterized as ordinary direct access, whereby only implementation and execution authorities are decentralized to the national level, while fund oversight, management and approval functions remain with the AF (Müller, 2013). Under enhanced direct access, all the functions except oversight are decentralized to a national entity, representing a deeper devolution of decision-making power (Müller, 2013; Schäfer et al., 2014; UNDP, 2012). In this situation, NIEs will become national funding entities (NFEs) as they will have the delegated authority to make funding decisions by approving project proposals (Müller 2013), in addition to the implementation and execution-related tasks delegated to them under ordinary access. This modality of enhanced direct access is not yet practiced across the board by the AF or the GCF. What the AF considers as the closest manifestation of enhanced direct access in its portfolio happens at the project level in a direct access project in South Africa. Implemented by the South African National Biodiversity Institute (SANBI) as the NIE, the project operates a small grants facility through which decision-making on subproject allocations is made locally (Schäfer et al., 2017, p.130), thus exhibiting 
the characteristics of enhanced direct access. To date, there has been no research to analyze whether the practice of enhanced direct access at the project level is happening more under direct access projects versus indirect access projects. This is investigated as part of Chapter 5 .

The direct access modality responds to developing-country criticisms of prolonged procedures and imposing priorities of international implementing entities experienced through the GEF (Horstmann, 2011). It also reflects a call for country-driven project identification, the presence of a financial mechanism at the country level, and greater attention to capacity building (Horstmann, 2011). The most commonly cited pragmatic arguments for direct access in the literature are that it would promote national ownership of internationally-funded adaptation activities, reduce transaction costs by removing intermediaries, enhance responsiveness and accountability of investments to local populations, and increase national and sub-national institutional capacity for adaptation (Brown et al., 2010; Druce et al., 2013; Masullo et al., 2015; Schalatek, 2012).

Scholars also consider the advantages of the direct access modality from an ethical standpoint. For example, Duus-Otterström (2016) examines three ethical arguments for recipient control of domestic allocation of international adaptation finance; the arguments are epistemic (i.e. countries know best), entitlement (i.e. adaptation finance belongs to developing countries), and legitimacy (i.e. only national governments can decide who to be protected and how) (Müller, 2011). As direct access represents more recipient control of international adaptation finance, these arguments apply to the modality. Duus-Otterström (2016) posits that there is good case for recipient control based on the three arguments in democratic countries, but "does not rule out the possibility that recipient control might be justified all things considered ( $p$. 668)" in all countries including non-democratic ones. To enhance climate equity, scholars call for the $\mathrm{AF}$ and other multilateral climate funds to move 
beyond government-centric direct access to allow the targeted beneficiaries themselves (e.g. local communities, $\mathrm{CBOs}$ etc.) to directly access international adaptation finance (Colenbrander et al., 2018; Schalatek, 2012). For the reason of genuine country ownership through direct access, Müller (2008) also argues that the AF "should be the main instrument for the purpose of raising and managing of international adaptation finance for developing countries" (p.4).

Operationalizing the direct access modality has been challenging in practice. While there is a strong demand for direct access, developing-country institutions generally face high capacity constraints in gaining accreditation as NIEs. Most direct access applicants face a resource-intensive and timeconsuming process that involves demonstrating an extensive amount of historical documentary evidence, while some have to invest in making adjustments to their systems (e.g. procurement, safeguards, project management, and human resource management) before receiving NIE accreditation (Bugler \& Rivard, 2012; Masullo et al. 2015; Schäfer et al., 2014). Reflecting the rigorous accreditation requirements, few developingcountry national institutions, especially from least developed countries, were able to meet the NIE accreditation requirements in the early years, resulting in the AF portfolio being dominated by indirect access projects until around 2013, after which the number of successfully-accredited NIEs started to rise (UNFCCC, 2018). From a global perspective, these capacity gaps have led some to question if direct access would lead to globally equitable access to climate finance given asymmetric country capacities (Schäfer et al., 2014).

As indicated in the discussion on the ethical rationales for direct access, scholars also argue that the effectiveness, efficiency, and equity outcomes of the direct access modality depend on the choice of NIE and the presence of broader democratic conditions that ensure meaningful involvement of local groups in public decision-making in the first place (Duus-Otterström, 2016; 
Masullo et al., 2015; Schalatek, 2012). The right choice of NIE depends on the social and political context of the recipient country. While some successful NIEs derive their credibility from being a government agency with extensive experience in handling international development finance, others are chosen due to their independence from the government (Bugler \& Rivard, 2012).

The uses of direct and indirect access modalities are not mutually exclusive. Schäfer et al. (2014) point out that many developing countries that currently use an international intermediary for accessing the AF also wish to accredit their own NIEs and would therefore benefit from a more purposefully managed transition to direct access. In this context, Bird et al., (2011) argue that the indirect access and direct access modalities are better conceived not as alternatives, but as an integrated package of services to developing countries. Multilateral institutions could help countries without NIEs secure immediate financing for high-priority adaptation actions, while simultaneously supporting readiness activities and technology transfer that facilitate longterm national direct access (Bird et al., 2011).

\subsection{Conclusion}

In sum, this chapter discusses the rise of the adaptation agenda in global climate policy, and the global discourses on climate and development, local communities and climate change adaptation, and international adaptation finance. After presenting the governance perspective I use in this dissertation, I discuss a key debate on the governance of international adaptation finance, which centers on the issue of alternative access modalities to multilateral climate funds, and how they could influence local adaptation actions at the project level in recipient countries. The remaining chapters of the dissertation turn to the theoretical and empirical examination of the influence of the access modalities on internationally-financed adaptation projects. 


\section{Chapter 3: Theoretical framework}

\subsection{Introduction}

The central inquiry in this dissertation is whether and how the governance models of international adaptation finance lead to different project design with regards to the level of focus on local communities, and the promotion of adaptation innovations for these communities. Answering this question requires the clarification of key terms, a conceptual model, and the identification of the theoretical mechanisms that link the governance models of international adaptation finance to the community-focused and innovative adaptation project design. Drawing on the literature review in Chapter 2, Section 3.2. defines the key terms used in this dissertation. Section 3.3. develops an overall conceptual model that links the key concepts, while Section 3.4 identifies the theoretical mechanisms that explain why access modalities to international adaptation finance matter for community-focused and innovative adaptation. Section 3.5 provides a short conclusion.

\subsection{Definitions of key terms}

\subsubsection{International adaptation finance}

In this dissertation, the term "international adaptation finance" refers to the component of global climate finance that originates from public resources of developed countries to fund adaptation activities in developing countries as part of an international commitment under the UNFCCC (UNFCCC, 2018). In practice, this international financial transfer, which could take the forms of grants and loans, could be used by developing countries to fund a wide range of climate change adaptation actions, ranging from the climate-proofing of infrastructure, ecosystem restoration, the pilot-testing of agricultural 
innovations to the building of human and institutional capacities in locations and sectors vulnerable to climate change.

While international adaptation finance flows through one of three mechanisms as explained in Chapter 2, I choose multilateral climate funds as the analytical entry point for this dissertation. From the climate finance governance perspective, these funds represent a "new kind of funding institution in the emerging field of climate finance governance" (Bowman \& Minas, 2019, p.342). In particular, the funds are the only international adaptation finance mechanism among the three that operates both the direct access and indirect access modalities within the same funding structure, thus allowing their comparison as two different models of how international adaptation finance reaches countries and local beneficiaries. In addition, it is recognized that these funds have a strategic role in pioneering innovative climate investments (Nakhooda et al., 2014), thus making them highly relevant actors for the analysis on the promotion of adaptation innovations.

\subsubsection{Governance models of International adaptation finance}

As discussed in Chapter 2, the term governance of international adaptation finance could be used in the macro-structural sense, when it refers to the entire UNFCCC-based global climate governance system, and in the microinstitutional sense, when it refers to individual multilateral climate funds. In this dissertation, I use the term in the micro-institutional sense. Specifically, the governance of international adaptation finance is defined as the institutional architecture, systems and processes of decision making related to access to resources, planning, implementation, reporting and accountability which are used by an institution, government or other entity in managing climate finance from multilateral climate funds for the purpose of climate change adaptation (Rai, Kaur, et al., 2015; Schalatek, 2012). In other words, this dissertation is primarily concerned with the climate finance 
governance phase during which developing-country recipients make use of the mobilized international adaptation finance via these funds, with each individual fund considered as an independent governing unit.

In this dissertation, the two "governance models of international adaptation finance" in the above phase refer to the direct access and indirect access modalities to multilateral climate funds for adaptation (refer to Figure 2.1). Under the direct access modality, the finance flows from the AF directly to national organizations accredited as NIEs, while under the indirect access modality, finance flows from the $A F$ to developing countries through intermediary international organizations, serving as MIEs or RIEs. Indirect access allows developing countries with limited institutional capacities, adaptation expertise, and climate finance experience to tap into those of international organizations, while direct access is pioneered by the AF to enable recipient countries to manage their own projects, strengthen country ownership and build national institutional capacities in climate finance (Adaptation Fund, 2012; Brown et al., 2010b).

\subsubsection{Community-focused adaptation}

The term "community-focused adaptation" is used to reflect the level of focus on vulnerable local communities in an adaptation project, which is the first project design aspect being studied in this dissertation. Here, I use the term "community-focused adaptation" to refer to climate change adaptation investment that takes place at the local level in a place-based context and puts the climate-vulnerable communities at the center of such investment both as decision-makers and beneficiaries. In other words, communityfocused adaptation conveys that notion of adaptation centered on the priorities and methods chosen by the communities. While many terms could have been used to refer to this type of adaptation investment, I choose to use the term "community-focused" adaptation for three reasons. 
First, the term signifies its distinction from, yet proximity to, CBA, which has become a much debated approach and a field of action research in its own right (Ayers \& Forsyth, 2009; Kirkby et al., 2017). Second, the term reflects a recognition that there are in theory other paths to community-focused adaptation in addition to CBA. For example, community-focused adaptation can result from projects that adopt approaches, such as ecosystem-based adaptation, farmer field school, rural development, which are operationalized in a community-focused manner. Third, the term "community-focused" adaptation also arguably represents a broader concept than "communitydriven" adaptation, in that community-focused adaptation can simultaneously involve having the community at the "driving" seat in adaptation decisionmaking, as well as other ways to prioritize local communities within a project context, for example, a high ratio of community-level budget to overall project budget.

The term community-focused adaptation also reflects an integration of three key concepts-community, climate change adaptation, and the focus of adaptation investment on local communities. I briefly discuss the concepts here.

The concept of community is highly contested and subject to interpretations (Buggy \& McNamara, 2016; Kepe, 1999; Titz et al., 2018). The term community is used in this dissertation to refer to vulnerable groups of individuals and households in villages, communes, neighborhoods, and settlements in climate-vulnerable locations (Ayers \& Forsyth, 2009 and Reid et al, 2010). Populations living in these settings are often conceptualized as place-based local communities such as rural communities, farming communities, coastal communities (Adaptation Fund, 2013; GCF, 2018; Rawlani \& Sovacool, 2011).These communities are recognized as internally diverse, hierarchical, and dynamic and do not always have stable populations and boundaries (Buggy \& McNamara, 2016; Kirkby et al, 2017). At the same 
time, they are also characterized as sharing common characteristics, beliefs and/or actions that shape both the collective exposure to climate change (Agrawal, 2008), as well as the ability to adapt to it (Dodman \& Mitlin, 2013).

As for climate change adaptation, I follow the IPCC in defining adaptation as "the process of adjustment to actual or expected climate and its effects, in order to moderate harm or exploit beneficial opportunities" (IPCC, 2018, p.542). As the adaptation projects analyzed in this dissertation take place with the intention to address climate change and involve external financing, they are considered as planned and anticipatory adaptation, rather than as autonomous (spontaneous) adaptation by the communities (Smit et al., 2000; Spires et al., 2014).

There is currently no agreed set of definitions and design principles to define and measure the level of focus of adaptation investment on local communities. A key objective of this dissertation is therefore to identify and test operational indicators for community-focused adaptation, as part of an effort to develop an operational methodology to track community-bound climate finance. This is the subject of Chapter 5.

\subsubsection{The promotion of adaptation innovations}

Adaptation innovation is defined in this dissertation as anything new to the adopting units, systems, geographies, which is introduced with an objective to reduce the vulnerability to climate change, including variabilities and extremes. This builds on Rogers (2003), who defines innovation as an idea, practice, or object perceived as new by an individual or other unit of adoption, as well as the IPCC's definition of climate change adaptation discussed in Section 3.2.3. This definition also reflects an understanding that innovation is context-specific (Sørensen \& Torfing, 2011), in that a business-as-usual 
product or practice in one context can become an innovation when introduced to other adopting systems and geographies.

As discussed in Chapter 7, the "promotion of adaptation innovations" by AF projects, which is the second project design aspect studied in this dissertation, is defined as a combination of two design elements: 1) the choice(s) of agricultural innovations financed by each project; and 2) the project's implementation plan with regards to the innovations. Due to the importance of adaptation innovations in building the adaptative capacity of vulnerable agricultural communities in developing countries (Aase et al., 2013; FAO, 2016), and the prominent roles of the AF in this context (Lipper et al., 2014), Chapter 7 investigates how direct access and indirect access $\mathrm{AF}$ projects are designed to promote adaptation innovations by analyzing $\mathrm{AF}$ agricultural projects.

\subsection{Conceptual model}

Using the $\mathrm{AF}$ as the case study, the dissertation analyzes the design differences in direct access and indirect access projects with regards to the level of community-focused adaptation project investment, and the promotion of agricultural adaptation innovations in the targeted local communities. There are two groups of explanatory variables for the observed variations in these two aspects of project design as outcomes: the role of access modalities, and the role of recipient country context. Figure 3.1 below illustrates the overall conceptual model of the dissertation.

First, the role of the direct access and indirect access modalities to the AF is considered in explaining the two outcomes. According to the AF operational guideline (AFB, 2008), NIEs, MIEs and RIEs all have the same roles and responsibilities with regards to designing, implementing, and monitoring $A F$ projects. But from a governance perspective, the two modalities are distinctly 
different. Two main observations - the first being structure-based, and the second organization-based-provide a rationale to conceptualize the modalities as two different governance models of international adaptation finance.

Structurally, the direct access modality is more decentralized to the national level when compared to the indirect access modality. This, in turn, creates a "shorter distance" between the global climate finance mechanism and local realities. From the perspective of organizational type, the two modalities are led by very different types of organizations. Direct access projects are managed directly by developing countries through NIEs, and indirect access projects by global and regional institutions serving as MIEs or RIEs on behalf of the recipient countries. These are distinctly different organizations in terms of history, characteristics, capacities, preferences and networks. It its recent assessment of global climate finance, the UNFCCC observes that "the operational priorities, experience and networks of the implementing entities through which climate finance is accessed can influence greatly how funds are spent" (UNFCCC, 2018, p.91). Together, these structural and organizational differences provide a conceptual ground to explore how the two access modalities, as two governance models of international adaptation finance, could potentially have different implications on the design of community-focused and innovative adaptation at the project level.

Second, the conceptual model also considers the role of other contextual factors in the recipient countries in shaping the outcomes, either independently or by acting in conjunction with the access modalities. This reflects a recognition that any observed differences in the community-focused and innovative adaptation project design outcomes are unlikely to be explained by the role of the modalities alone. The set of recipient country contextual factors that could affect each project design aspect is discussed briefly in the sections below, and elaborated further in the relevant empirical 
chapters (Chapter 6 for the level of community-focused adaptation investment, and Chapter 7 for the promotion of adaptation innovations).

Figure 3.1. depicts the overall conceptual framework for the dissertation in terms of its key components. Component 1 refers to the two project design aspects that are the outcomes of interest of the dissertation. Component 2 refers to the role of access modalities to international adaptation finance, and Component 3 to the role of recipient country context, in explaining outcome variations.

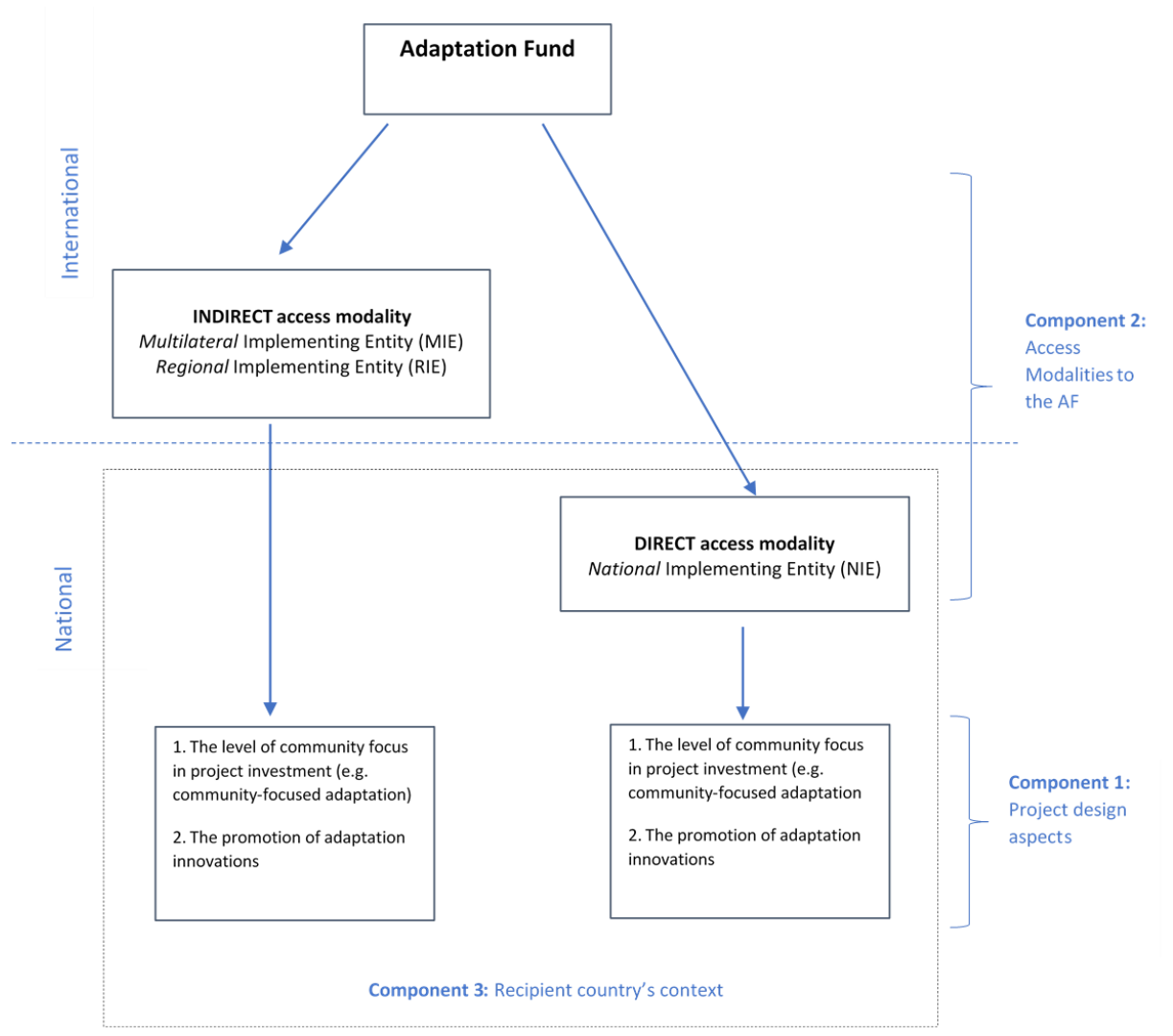

Figure 3.1: Overall conceptual model of the dissertation

Source: Author. 


\subsection{Theoretical mechanisms}

3.4.1. Why do access modalities matter for community-focused adaptation?

There are two main theoretical grounds to hypothesize why the two access modalities could perform differently with regards to the outcome of the level of community-focused adaptation in project design. The first corresponds to the structural difference between the two access modalities, and the second to the nature of organizational differences between NIEs and MIEs/RIEs. The literature on decentralization, subsidiarity and development provides relevant arguments to develop hypotheses related to the structural difference, while the literature on aid effectiveness forms the basis for developing hypotheses related to the organizational differences.

3.4.1.1. Decentralization, subsidiarity and development perspective

Decentralization is one of the most important reforms undertaken globally to promote good governance (Bardhan, 2002; Faguet, 2014). The most prominent argument for decentralization in the context of development studies is that "it will improve the accountability and responsiveness of government by altering its structure so as to increase citizen voice and change the deep incentives that public officials face" (Faguet, 2014, p.2). The part of the structure altered refers to the shorter distance between the authority and the citizens as a result of decentralization reforms. Some studies find that decentralization is associated with improved development outcomes, defined as improved delivery of public services (Ghuman \& Singh, 2013; Mehrotra, 2006) or improved natural resource management (Agrawal \& Ribot, 1999), as well as with international aid effectiveness defined as the effect of aid on economic growth (Lessmann \& Markwardt, 2016). These positive relationships are often explained as resulting from the effect of decentralization on improving government accountability to local populations, 
including by devolving decision-making power to them or local governments in some cases (Agrawal \& Ribot, 1999; Ghuman \& Singh, 2013). Another important argument in favor of the short distance created by decentralization draws from the related principle of subsidiarity, which argues that, given the heterogenous preferences of populations, the optimal location of decisionmaking on the provision of public goods is at the most disaggregate level of competent authorities (Casey, 2018).

As the direct access modality represents the decentralization of the governance of international adaptation finance to the national level, there are three major arguments as to why it could lead to more community-focused adaptation projects. The first two flow from the decentralization and development theory, while the third from the related subsidiarity principle.

First, the shorter distance between NIEs and project beneficiaries in the direct access modality is argued to facilitate community participation in the entire project process, thus making the project design more accountable to local populations. Reflecting this short distance argument, Fenton et al. (2014) argue that direct access could bring vulnerable communities "closer into the process of conceptualizing, formulating, and ultimately implementing and evaluating adaptation" (p. 394). For civil society in particular, Ballesteros et al. (2010) argue that "the involvement of national institutions through "direct access" may, in certain national contexts, lead to greater civil society participation in the AF project cycle" (p.28), thus contributing to making the process more locally accountable.

Second, the shorter distance between NIEs and local realities in the direct access modality could also help direct access projects perform better on the devolution of decision-making to the local level when compared to indirect access projects. The term "devolution" here indicates a deeper transfer of power from the center when compared to decentralization (Bardhan, 2002; 
Barrett, 2015; Fisher, 1999). While the direct access modality is more decentralized to the national level when compared to indirect access, devolved decision-making can also take place under both modalities. However, it could be argued that the direct access modality is more likely to further devolve decision-making downwards to the local level. By removing international intermediaries in the climate fund-recipient-country relationship, the direct access modality enables NIEs to lead in identifying adaptation priorities, conducting public consultations and designing implementation arrangements, including choosing partner EEs (refer to Figure 2.1). This likely expands opportunities for subnational actors, including local authorities, civil society, and $\mathrm{CBOs}$, to be engaged not just as consulted stakeholders but formally as EEs or partners of EEs. Some governments, such as Mali and Tanzania, are pursuing direct access to international climate funds as a strategy to finance their own devolved domestic climate finance entities (Hesse, 2016). Harmeling \& Kaloga (2010) review eight projects considered by the AF Board in 2010 and find that the seven indirect access projects exclusively used government agencies as EEs, while a direct access project in Senegal was the only one which involved NGOs as EEs. Despite this early finding, there has been no research to date that systematically assess whether NIEs are more likely to devolve decision-making downwards when compared to MIEs/RIEs.

Third, from the related subsidiarity perspective, it can be argued that direct access is also likely better in responding to heterogenous local adaptation needs. With the indirect access modality, there has been a concern that that "due to multilateral agencies' limited understanding of local context, the projects they implemented would be less effective" (Persson, 2011). In the context of externally-financed adaptation projects, Lebel et al. (2018) also argue that the ability to meet local adaptation needs and objectives is constrained when external actors have too much influence in project governing structures, and when initial project plans written from afar are 
followed too strictly. In this sense, the superior local knowledge of the NIEs, which includes the knowledge on characters, needs and preferences of local populations, could make them a better organization to deliver customized adaptation investment (as public goods) to local communities with differentiated needs.

Based on the above theoretical arguments, I therefore hypothesize in this dissertation that direct access projects would generally perform better on being community-focused, including by enhancing community participation in the project process and by devolving more decision-making to them. This hypothesis is tested in Chapter 5 using more precisely defined indicators. From a development intervention evaluation perspective, it should be noted that the indicators in Chapter 5 are also informed by the Organisation for Economic Co-operation and Development (OECD) Development Assistance Committee (DAC) evaluation criterion of relevance, which evaluates the extent to which an intervention's objectives and design respond, among others, to beneficiary needs (OECD, 2019).

\subsubsection{Aid effectiveness perspective}

The aid effectiveness literature defines national ownership as a key indicator of international aid effectiveness (Doucouliagos \& Paldam, 2009; Huang \& Pascual, 2017; Müller, 2014). For aid recipient countries, ownership means that they define the agenda, priorities, and program of aid use independently of the external funding sources (Castel-Branco, 2008). For recipients of international adaptation finance, such ownership is manifested through three elements: 1) mainstreaming, or alignment of climate finance with national strategies and priorities; 2 ) decision-making responsibilities vested in national institutions; and 3) the use of national systems for ensuring accountability (Brown et al., 2013). With national organizations being the lead organizations, the direct access modality is characterized by the last two elements and is 
also argued to lead to the first. For example, Craeynest et al. (2010) argues that the direct access modality "enhances country ownership and thus offers greater potential for alignment with national needs and priorities, rather than pursuing projects and programmes that fit the requirements of intermediary bodies" (p.15). Such greater potential for alignment with national needs and priorities could theoretically lead to more mainstreaming of the AF-financed community-level adaptation activities with national policy and planning processes under the direct access modality. This form of mainstreaming is recognized as being critical for community-level adaptation projects to move beyond being stand-alone, small-scale initiatives to become an approach that delivers transformed resilience at a large scale (Huq \& Faulkner, 2013).

Building on the above expectation on enhanced national ownership in the direct access modality, I therefore hypothesize that there is more mainstreaming of AF-financed community adaptation activities in the national policy and planning processes in projects led by NIEs when compared to those led by MIEs/RIEs. This hypothesis is also tested using more precise indicators in Chapter 5. The indicators are also informed by the OECD/DAC evaluation criterion of coherence, which evaluates the compatibility of an intervention with other interventions (particularly policies) in a country, sector, or institution (OECD, 2019).

3.4.2. Why does the recipient country's context matter for communityfocused adaptation?

Country-level contextual conditions could influence adaptation approaches taken within each AF recipient country, and in theory, could also affect the level of community focus in an AF-financed adaptation project within the country. Scholarly literature has identified two groups of such relevant country-level contextual conditions. The first group relates to the level of climate change impacts that a country faces, which could act as a catalyst for 
its government to take actions to protect its vulnerable citizens (Ahmed et al., 2015; Conevska et al., 2018). The second group of conditions relates to the enabling governance environment for community-focused adaptation approaches, such as the balance between top-down and bottom-up approaches in the government structure (Brockhaus \& Kambiré, 2009), or the enabling environment conductive to civil society participation in adaptation policy making (Adhikari and Taylor, 2012; Agrawal and Perrin, 2009; Chu et al., 2016), including through community association and networking (Adger, 2003). These country-level conditions could act independently, or in conjunction with the access modalities, to shape the community-focused design of AF projects. For example, while the direct access modality decentralizes the governance of international adaptation finance from the international to national levels, it is possible that the impact of direct access in enhancing community-focused adaptation is magnified in recipient countries which are already decentralized to begin with. This is because the AF's access modality remains largely government-driven, given that the large amount of NIEs are government agencies and that all AF project/program proposals need to be endorsed by the Designated Authority (DA) representing national governments. Arguably, the NIEs and DAs from decentralized countries are less likely to have a disconnect with local realities, which is often cited as a key governance barrier for bottom-up adaptation approaches (Kuruppu \& Willie, 2015).

In this dissertation, I therefore hypothesize that countries with higher exposure to climate risks, more government decentralization, and by association government closeness to local realities, and a more conducive governance environment for civil society, are more likely to support AF projects with a stronger community focus. I also expect to see some interactions between these contextual factors in shaping the communityfocus project design outcome. Chapter 6 will test these hypotheses using a QCA methodology. 
It is recognized that the above hypotheses are generalized and do not fully capture the political economy of climate change adaptation and development finance. For example, national-level government actors cannot always be assumed to represent the interests of their populations. For vulnerable minorities such as indigenous peoples, existing national-level state entities that are already discriminatory are likely not the most appropriate avenue for delivering international adaptation finance. In many cases, national policies to promote climate resilience, especially those designed by technocratic elites, can also end up favouring elites (such as landowners), while excluding the most vulnerable (such as the landless, and displaced peasants) (Sovacool et al., 2019). Such a disconnect between the government and its vulnerable populations can exist even in decentralized countries and could lead to cases whereby direct-access projects are not community-focused. However, the purpose of developing the generalized hypotheses here is to facilitate the initial comparison of the design patterns of direct access and indirect access projects at the AF portfolio level. This in no way precludes subsequent in-depth research that examines individual projects and their implementation and impacts with an explicit consideration of the political economy issues.

3.4.3. Why do access modalities matter for the promotion of adaptation innovations?

While it is recognized that public climate finance should support climaterelated innovations (Bowen, 2011; Hogarth, 2012), exploring the influence of different access modalities to public international adaptation finance on the promotion of innovations is a highly exploratory topic. Given that there is very limited literature on this, I draw insights from the existing literature to develop two sets of hypotheses. First, I combine insights from the decentralization literature discussed above with those from innovation studies to hypothesize how the structural difference between the direct and indirect access 
modalities could affect the promotion of adaptation innovations at the project level. Second, I draw on the literature on aid effectiveness, as well as on climate change adaptation, to hypothesize the potential project design differences due to the organizational differences between NIEs and MIEs/RIEs.

\subsubsection{Decentralized innovation platform perspective}

An innovation platform refers to a space in which "all key actors from a sector or a geographical location (territory, watershed, province) are convened...to create a support network that can foster an effective combination of technical, social, economic and institutional innovations" (Klerkx et al., 2013. p. 186). Increasingly common in research and development initiatives on agricultural innovations, innovation platforms represent a participatory model whereby a wide range of stakeholders, including experts, government bodies, producer associations, private sector, and financial sector, can engage with local stakeholders to identify problems and prioritize innovative solutions to promote agricultural development (Pamuk et al., 2014). Within an innovation platform, there could also be innovation champions, or key individuals who make decisive contributions to innovation by inventing or advocating a particular technology (technology champion), exerting political effort (power champion), creating a receptive environment (process champion), and bridging relationships (network champion) (Klerkx et al., 2013). These innovation champions are also referred to as facilitators, intermediaries, conveners, brokers, entrepreneurs, or promotors (Totin et al., 2018).

In the context of the AF, a direct access project that aims to promote innovation could be conceptualized as an innovation platform which is structurally more decentralized to the national level when compared to an indirect access project with the same objective. There are three main arguments why this higher level of decentralization could matter for the 
approach to promote agricultural adaptation innovations at the project level. First, the shorter distance between NIEs and local realties in a direct access project platform is likely to facilitate more active local consultation during the project design (Fenton et al., 2014), thus contributing to the choice of disseminated innovations being more responsive to local needs. Such closer community consultation also encourages on-demand co-production of climate adaptation technologies which enhances its adoption by users (Chhetri et al., 2012).

Second, the logic of subsidiarity also applies to AF projects in the context of innovation promotion. From a public goods perspective, an AF-financed adaptation innovation is essentially a publicly-funded service to the project beneficiaries, as opposed to a privately-supplied service through markets. Given the heterogeneity in the preferences of local populations and in delivery challenges across localities, the subsidiarity principle would suggest that a nationally-led innovation platform represented by a direct access project is a more optimal location of decision-making on locally appropriate innovations, when compared to an internationally-led platform represented by an indirect access project.

Third, the literature on agricultural innovation systems (AIS) increasingly highlights the important role of innovation brokers in articulating problems, building networks, supporting negotiation and learning, and dealing with the dynamics of power and conflict (Klerkx et al., 2012; Totin et al., 2018). For local communities, these brokers also play a very important role in connecting them to other actors in the AIS to ensure necessary access to resources and information to adopt innovation (Klerkx et al., 2012; Meinzen-Dick et al., 2013). Given that NIEs are more embedded in the national and local contexts when compared to MIEs/RIEs, they are arguably better-placed to perform these brokering roles, or to choose, based on a superior knowledge of local institutional capacities and networks, to partner with appropriate EEs that can 
effectively perform these roles. On the other hand, it could be also be argued that, as a broker of knowledge for innovation, MIEs and RIEs are better positioned to facilitate international transfer of global knowledge and technologies to local communities, given their superior international networks and global and regional expertise.

Given the above arguments, I therefore hypothesize that direct access projects have more potential to promote locally relevant agricultural innovations. Examples of these innovations are when the AF projects disseminate innovations developed by national or local research institutes, when internationally-developed crop varieties are adapted to meet local agronomic and agroecological constraints (Lybbert \& Sumner, 2012), or when scientific information is delivered to farmers in local language and in a way that enhances the effectiveness of indigenous farming practices (FAO, 2014). Chapter 7 investigates if direct access projects promote more locally relevant agricultural innovations when compared to indirect access projects. As in Chapter 5 , the analysis on locally relevant innovations in Chapter 7 is also informed by the OECD/DAC evaluation criterion of relevance to beneficiary needs (OECD, 2019).

\subsubsection{Aid effectiveness perspective}

Farm-level decisions to adapt to climate change is also shaped by nonclimate factors, including commodity prices, change in resource use rights, government subsidies and support programs (Smit \& Skinner, 2002). To be effective in this context, it is recognized that a project to promote agricultural innovations for adaptation, including through the transfer and diffusion of adaptation technologies (Trærup \& Stephan, 2015), should build on broader policies that address both climate and non-climate drivers of farm-level adaptive decisions (Smit \& Skinner, 2002), as well as on broader social and economic development goals embedded in national and sectoral policies 
(Trærup \& Stephan, 2015). In other words, the project-level effort to promote adaptation innovations should be mainstreamed with national and sectoral policy processes to create an enabling environment for innovation dissemination, adoption and diffusion.

From an aid effectiveness perspective, it can be argued that direct access could ensure more policy mainstreaming of AF-financed agricultural innovations, thus contributing to the long-term sustainability of project benefits, in two ways. First, given that policy mainstreaming occurs at the domestic level, Hogarth (2012) argues that climate finance for innovations should flow through national entities, since they are in a better position to work closely with governments "to formulate clear, long-term goals; establish a diverse mix of policy instruments necessary to guide socio-technical transitions; and align and mainstream climate change programmes into development strategies" (Hogarth, 2012, p.272). Second, enhanced national ownership through direct access could also ensure more continuation of country's financing support for the long-term diffusion (up-scaling) of AFfinanced agricultural innovations. As donors like the AF cannot guarantee funding beyond a certain timeframe, typically between 3-5 years, it is common that situations in recipient countries revert to the pre-project conditions after external funding expires (Nunn, 2013). National ownership though direct access could ensure that externally funded interventions are considered national priorities and embedded with long-term policy interventions, and therefore increases the likelihood that governments will continue to finance them with its own budgets.

Given this aid effectiveness perspective, I therefore hypothesize that to see more policy mainstreaming of AF-financed agricultural innovations in the case of direct access projects. Key indicators of such policy mainstreaming are the alignment of AF-financed innovative activities with national development or sectoral strategies, and a clear financial sustainability plan made by recipient 
governments for the continued diffusion of AF-disseminated innovation beyond the initial AF project period. Both indicators reflect the coherence criterion of the OECD/DAC evaluation criteria for development interventions.

3.4.4. Why does the recipient country's context matter for the promotion of adaptation innovations?

Totin et al. (2018) note "the growing consensus that efforts to catalyse positive change in agricultural and food systems through innovation platforms must pay attention to the variety of institutional contexts in which they are embedded" (p.38). Given that innovation is highly context-specific, factors that could influence the approach each AF project uses to promote innovation is also likely specific to the type of agricultural innovation, the targeted populations and the socio-technological context of the AF recipient countries. Some key country factors which could influence the project-level innovation promotion approach include agro-ecological settings (Bocco \& Napoletano, 2017), economic feasibility (Trærup \& Stephan, 2015), a national agricultural innovation strategy (Moreddu \& Van Tongeren, 2013), the capacities of national agricultural research and technological institutions (Adenle et al., 2015; Chhetri et al., 2012; World Bank, 2006), the extent of climate and agricultural policy integration (Brooks \& Loevinsohn, 2011; Leimona et al., 2015; Schmidt, 2019), the prevailing forms of traditional knowledge and social institutions (Lebel, 2013), and the country's exposure to international knowledge flows (Lebel, 2013). In Chapter 7, I take an exploratory approach to conduct semi-structured interviews with NIEs and MIEs/RIEs to explore the importance of these contextual factors.

\subsection{Conclusion}

In this Chapter, I develop an overall conceptual model that links the governance models of international adaptation finance, defined as the direct 
access and indirect access modalities to the AF, to the two project design outcomes of the level of community focus and the promotion of adaptation innovations. I make two main theoretical arguments to guide further empirical examination of the linkage between the access modalities and the outcomes. Drawing on the literature on decentralization, subsidiarity and development, I hypothesize that the direct access modality, by being more decentralized to the national level, is more likely to promote community-focused and locallydriven innovative project design. Drawing on the aid effectiveness literature, I hypothesize that direct access projects are more likely to be mainstreamed with national policies as a result of enhanced national ownership. While the access modalities are the main explanatory variable in the study, the conceptual model also recognizes the potential role of contextual factors in AF recipient countries in shaping the two outcomes. The role of these contextual factors are also investigated in Chapters 6 and 7. In the following sections of the dissertation, Chapter 4 provides more background information on the AF as the case study, followed by Chapters 5,6 , and 7 which present empirical analyses using AF data. 


\section{Chapter 4: Case study}

\subsection{Introduction}

This dissertation selects the AF under the Kyoto Protocol as the case study and its projects as sub-units of analysis. As a background to the case study, section 4.2. describes the history, operations, and recent developments of the AF. Section 4.3. provides an overview of the AF portfolio of adaptation investments under both access modalities. Section 4.4. summarizes key findings from the previous assessments on the AF processes and projects. Section 4.5. provides a short summary.

\subsection{History, operations and recent developments of the AF}

The AF was established under the Kyoto Protocol of the COP7 in Marrakesh in 2001. The Fund became officially launched in 2007 and sent out its first call for proposals in 2010. The AF has the objective to finance concrete and country-driven adaptation projects and programs that help vulnerable communities in developing countries to adapt to climate change (UNFCCC, 2009). The AF's explicit prioritization of vulnerable communities as a strategic priority is considered a unique feature that distinguishes it from other funds such as the GEF-administered LDCF and the World Bank-administered PPCR (AFB, 2015). An adaptation project/ programme is defined in the AF operational policies and guidelines as:

"a set of activities aimed at addressing the adverse impacts of and risks posed by climate change. The activities shall aim at producing visible and tangible results on the ground by reducing vulnerability and increasing the adaptive capacity of human and natural systems to respond to the impacts of climate change, including climate 
variability. Adaptation projects/programmes can be implemented at the community, national, regional and transboundary level. Projects/programmes concern activities with a specific objective(s) and concrete outcome(s) and output(s) that are measurable, monitorable, and verifiable" (AFB, 2017, p.3).

The AF is overseen by the Adaptation Fund Board (AFB), composed of 16 members and 16 alternates representing Parties to the Kyoto Protocol; about 69 percent of the board members represent developing countries. Each board member represents a constituent of countries, with the following five constituent groups: the five United Nations regional groups (two representatives from each), SIDS (one representative), LDCs (one representative), Annex I Parties to the UNFCCC (two representatives), and non-Annex I Parties to the UNFCCC (two representatives) (Adaptation Fund, 2019b). Housed by the GEF, the AFB Secretariat is based in Washington DC and provides research, advisory, administrative, and an array of other services to the Board. The AF is financed in part by government and private donors, and also by a two percent share of proceeds of Certified Emission Reductions (CERs) issued under the Kyoto Protocol's Clean Development Mechanism (CDM) projects. The World Bank serves as the interim trustee of the $A F$, performing the functions of selling the CER certificates and manages the $A F$ trust fund. While there was at one point an expectation that the $A F$ would be primarily replenished by the monetized CERs (Müller, 2006), in practice the AF has been financed from more donor contributions compared to monetized CERs, whose prices have declined significantly in recent years. As of September 2019, the AF has received a total contribution of USD 859.53 million, with the top five contributors being Germany (USD 362.77 million), CER sales proceeds (USD 201.6 million), Sweden (USD 114.02 million), Spain (USD 57.05 million), and Belgium (USD 29.82 million) (World Bank, 2020). 
As a UNFCCC fund, the AFB is fully accountable to the Conference of the Parties serving as the meeting of the Parties to the Kyoto Protocol (CMP) under the UNFCCC. Among key functions of the AFB are to develop strategic priorities, policies and guidelines for the CMP's adoption; develop and decide on specific operational policies and guidelines; decide on projects, including the allocation of funds, in line with the AF principles, criteria, modalities, policies and programs; and monitor and review implementation of the AF operations (UNFCCC, 2013).

Countries eligible for AF financing are defined as "developing country Parties to the Kyoto Protocol that are particularly vulnerable to the adverse effects of climate change including low-lying and other small island countries, countries with low-lying coastal, arid and semi-arid areas or areas liable to floods, drought and desertification, and developing countries with fragile mountainous ecosystems" (AFB, 2017, p.2). This reflects a decision by the AFB to keep the definition of eligible countries sufficiently broad so that every developing country can be eligible (Harmeling \& Kaloga, 2011). In all eligible countries, the AF finances stand-alone adaptation projects on the basis of the full costs of adaptation, defined as "the costs associated with implementing concrete adaptation activities that address the adverse effects of climate change" (AFB, 2017, p.3). Unlike the GEF which finances incremental adaptation costs and requires co-financing, the AF does not require cofinancing for its projects. However, countries may decide to use other sources of financing in a parallel manner to the AF resources. Some multilateral development banks may consider the $\mathrm{AF}$ as a potential source of cofinancing.

Nominating a DA is the first step for a developing country to establish a relationship with the AF. The DA is an officer from a recipient-country's government, who serves as the focal point person between the governance and the AFB and the AFB Secretariat. After having installed a DA, each 
country can choose between the service of MIEs/RIEs under the indirect access modality, or of NIEs under the direct access modality, in accessing the AF resources. As of September 2019, the AF has accredited 31 NIEs from 31 countries (Adaptation Fund, 2019a). The organizational nature of the NIEs vary, ranging from government ministries, agricultural banks, research institutions, microfinance institutions to NGOs. How a country chooses between the access modalities is not yet widely researched, but likely shaped by its context, capacities, and preferences.

According to the AF operational guidelines, the options of submitting different projects/programmes through an NIE and through a MIE/RIE are not mutually exclusive (AFB, 2017, p.5). For example, Argentina and Peru simultaneously access the AF through MIEs and NIEs. Under both access modalities, the key responsibilities of the DAs are to endorse, on behalf of the national government: 1) accreditation applications of NIEs; 2) accreditation applications of RIEs; 3 ) projects and programs proposed by all types of implementing entities (IEs); and 4) the consistency between the project/program proposals and the government's national and regional priorities (AFB, 2017a). The latter responsibility suggests that the DA has an important role in ensuring national ownership of AF projects (Bird, 2014).

Eligible countries go through the following process to access the AF resources. A proposal must be submitted at least nine weeks prior to an AF Board meeting. Regular adaptation project and program proposals (i.e. those that request funding exceeding USD 1 million) would undergo either a onestep or a two-step approval process. A small-sized project (less than USD 1 million) would undergo a one-step process. In case of the one-step process, the proponent would directly submit a fully developed project proposal. In the two-step process, the proponent would first submit a brief project concept, which would be reviewed by the Project and Program Review Committee (PPRC) and would be endorsed, not endorsed or rejected by the AFB. In the 
second step, the fully-developed project/program document would be reviewed by the PPRC, and would be approved, not approved or rejected by the AFB (AFB, 2017a). To assist developing countries in developing projects, Project/Program Formulation Grants are available to NIEs upon endorsement of the concept. Up to $50 \%$ of the AF's resources can be accessed by MIEs, while $50 \%$ is reserved for access by NIEs and RIEs combined. There is also a maximum cap of USD 10 million per country.

Another key actor in the AF project cycle is the EEs. The AF's official document on the roles and responsibilities of IEs and EEs broadly state that both types of entities shall assist eligible countries "with the identification, preparation, and implementation of activities that would enable them to adapt to the adverse effects of climate change", and both "are fully accountable for the management, operation, and use of funds for activities approved by the Adaptation Fund Board based on fiduciary standards to be established by the Adaptation Fund Board" (AFB, 2008, p.1). In the AF's operational policies and guidelines, the role of EEs is further specified as "organizations that execute adaptation projects and programmes supported by the Fund under the oversight of Implementing Entities" (AFB, 2017, p.7). In practice, the relationships between IEs and EEs could vary in different countries. During project development, IEs can propose projects to the AFB then identify EEs to execute; EEs can propose projects to the AFB via IEs, or IEs and EEs can collaboratively develop a project proposal for the AFB. There have also been cases where the NIE has opened a call for proposals by prospective EEs and then selected among those. Regardless of the project development approach, ideally the IEs should involve also the DA from the beginning. Once proposals are approved by the AFB, financing will flow through the IEs to the EEs during the implementation phase. The IEs will serve as the focal point vis-à-vis the AFB and the AFB Secretariat. On behalf of the AF, NIEs or MIEs/RIEs will supervise the EEs in implementing the activities on the ground, and in doing so will bear all financial, monitoring and reporting responsibilities 
for the project (AFB, 2017a). The general principle is that NIEs and MIEs/RIEs should not execute projects, in order to keep the implementation (oversight) and execution (practical management) roles separate. In some cases, however, the IEs may have some execution roles (Figure 4.1).

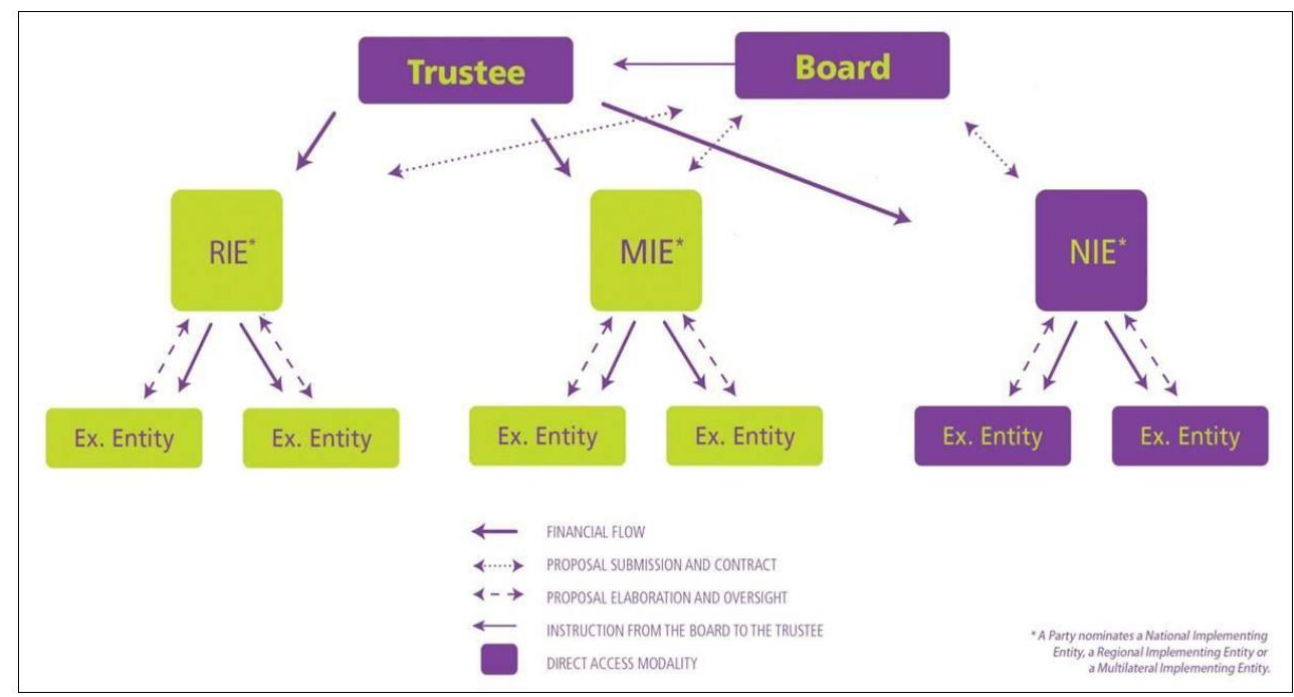

* A party nominates a National Implementing Entity, a Regional Implementing Entity or a Multinational Implementing Entity

Figure 4.1: Roles of different parties in accessing AF resources Source: AFB, 2017, p.6.

After 10 years of operations, the AF launched in 2017 a new mid-term operational strategy (2018-2022) which places innovation, action and learning as the key pillars for its future operations (Adaptation Fund, 2017). In December 2018, the AF also launched innovation grants, with an objective to build national capacity to accelerate the deployment of innovative adaptation practices on the ground (Adaptation Fund, 2018a). While the AF has supported the piloting of innovations since the beginning of its operations, it is expected that both the new mid-term strategy and the innovation grants will enable the AF to finance and upscale innovative adaptation practices that 
target vulnerable populations, while capturing and communicating the lessons learned from these investments in a more systematic way.

In December 2019, the Conference of the Parties serving as the meeting of the Parties to the Paris Agreement (CMA) decided at the COP24 in Poland that the AF shall serve the Paris Agreement, effective January 2019. This decision reflects a transition by which the Paris Agreement will replace the Kyoto Protocol after the end of its second commitment period in 2020. The decision carries two main implications for the AF. First, developing and developed country Parties to the Paris Agreement are now eligible for membership on the AFB. Second, the AF will continue to receive a share of proceeds from CDM projects under the Kyoto Protocol until a similar mechanism becomes available under the Paris Agreement, which is when the AF shall exclusively serve the Paris Agreement (Adaptation Fund, 2018b).

\subsection{An overview of the AF portfolio}

As of May 2017 when data were collected for this dissertation, the AF had committed approximately USD 416.1 million of grant financing to 63 adaptation projects (22 direct access and 41 indirect access projects) (See Supplementary Material 1 for more detail of the 63 projects). The projects are distributed relatively equally between developing countries from the AsiaPacific (23), African (20) and Latin American and Caribbean (19) regions, with only one project in Eastern Europe (Georgia). With an investment cap of USD 10 million per country, the average size of a project is USD 6.6 million; direct access projects have an average size of USD 6.8 million and indirect accessprojects of USD 6.5 million. The biggest project (Mongolia) received USD 9.99 million, while the smallest project (India) received USD 0.69 million, both of which are direct access projects. Indirect access projects dominated the earlier years of the AF's operation while direct access projects have increased starting from 2013 onwards (Figure 4.2). This reflects the effect of the 50\% 
cap for financing for MIE/RIE project proposal introduced by the AF Board in 2010 , as well as the increasing success of NIEs in accreditation and proposal submission since 2013.

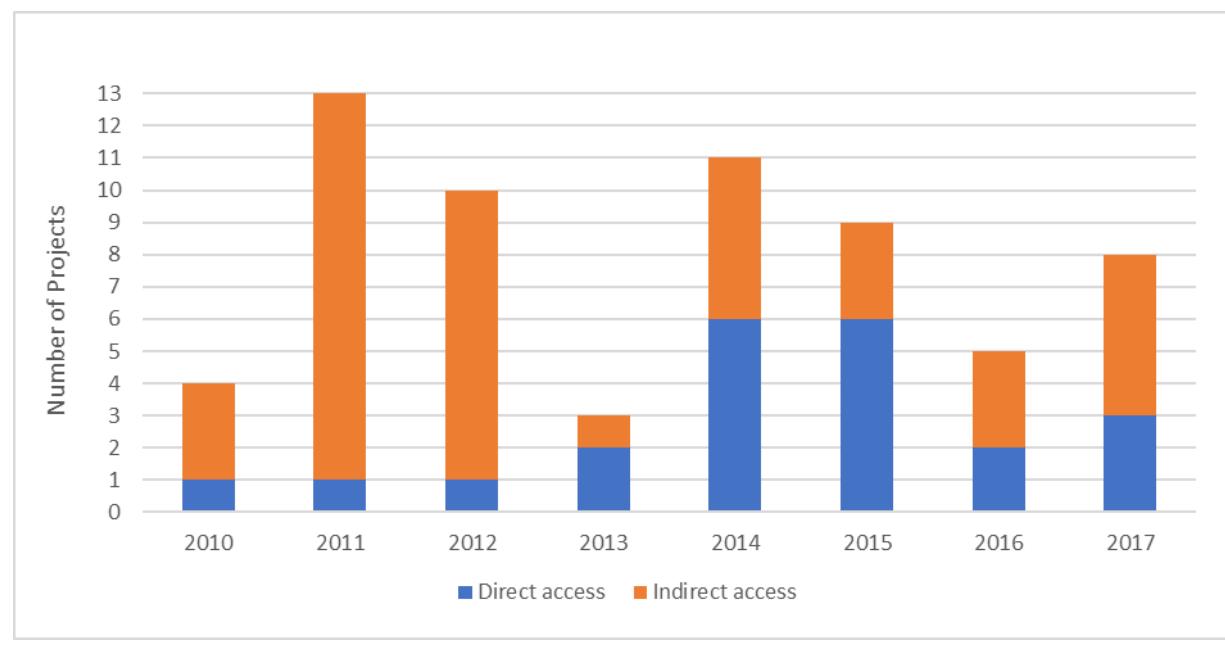

Figure 4.2: Approved AF projects by access modality as of May 2017 Source: Author's analysis

While the AF's mandate focuses on concrete adaptation actions, in practice it also supports the strengthening of the broader enabling environment. There are no prescribed sectors for these project activities but so far the AF has financed adaptation in relation to water resource management, agriculture, disaster risk reduction, food security, forest-dependent populations, fragile ecosystems, rural development, and integrated coastal zone management (AFB, 2015; Conevska et al., 2019; Parker et al., 2014). The AF also explicitly supports demonstrative projects that pilot new adaptation approaches, and requires that all projects include a knowledge management component to synthesize and share learning for potential upscaling and replication (AFB, 2015). In terms of adaptation activities, most AF projects respond to the adaptation needs from increased intensity and frequency of extreme events (including floods, droughts, and tropical storms) and long-term issues 
including warming trends and sea level rise (AFB, 2015). According to the AF's self-conducted portfolio review, nearly $70 \%$ of all project spending went to structural/physical outputs (e.g. water management infrastructure, ecosystem restoration), while institutional (e.g. improvement in planning, laws and regulations etc.) and social adaptation options (e.g. human capacity building, sustainable livelihood strategies) dominate in terms of the number of outputs (AFB, 2015).

To develop a more detailed picture of the type of funded adaptation activities financed by AF projects by access modality, I apply an adaptation typology from Biagini et al. (2014) to conduct an overall review of the $63 \mathrm{AF}$ projects approved as of May 2017. This portfolio review shows that investments in human capital and institutional capacity development are most common adaptation activities financed in projects under both modalities. Investment in physical infrastructure (e.g. irrigation systems, flood protection structures etc.), green infrastructure (e.g. watershed rehabilitation), new behavior and practices (e.g. crop and soil management techniques), and improved adaptation planning also received strong support across all projects (Figure 4.3). 


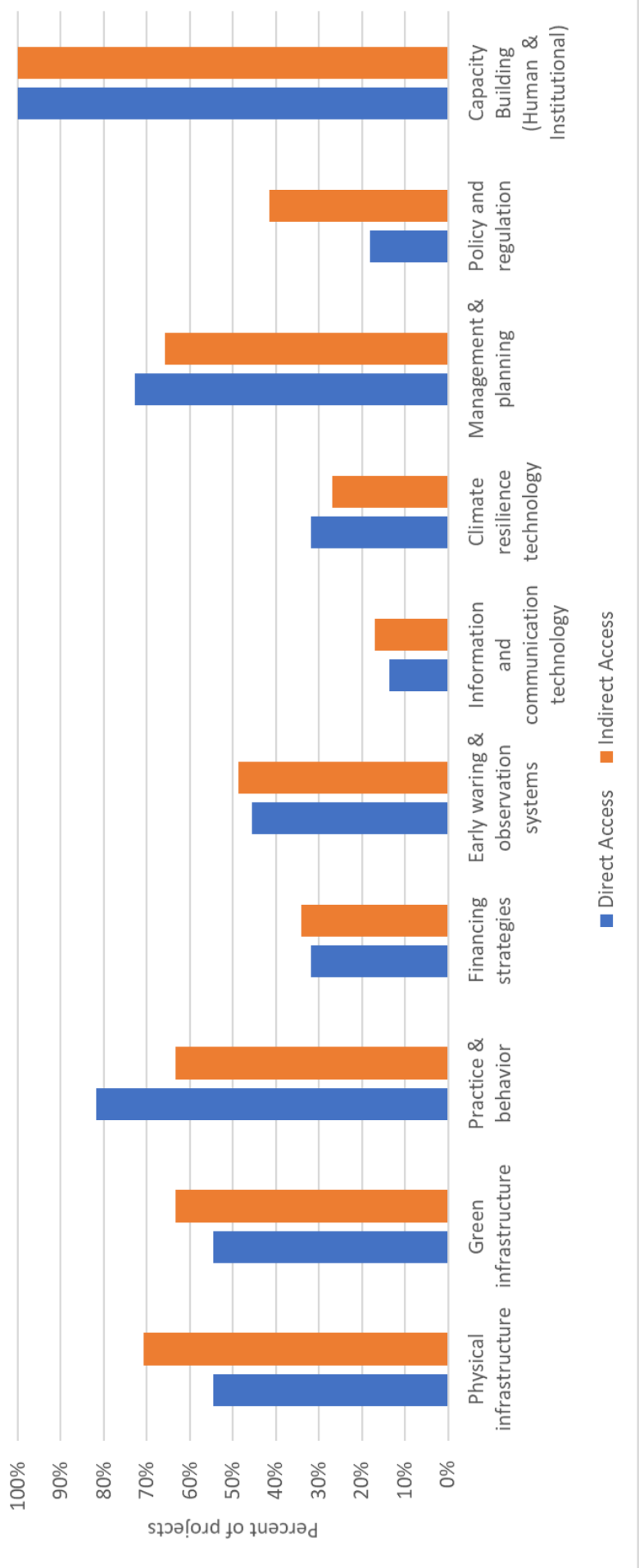

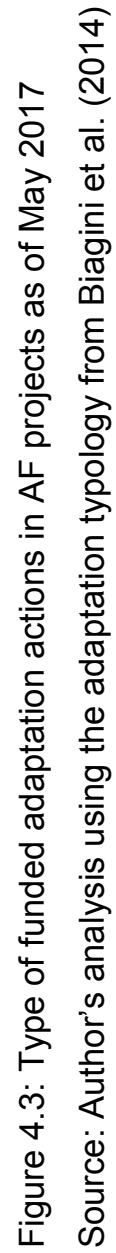




\subsection{Previous assessments of the AF}

Previous assessments of the AF provide a relevant context to this dissertation's examination of the AF's role is financing community-level and innovative adaptation through both access modalities. These assessments generally focus on the processes surrounding the AF's creation and its operational experience from the first generation of projects and programs (Canales Trujillo \& Nakhooda, 2013; Harmeling \& Kaloga, 2011; Horstmann, 2011; Levaggi, 2014; Remling \& Persson, 2015; Stadelmann et al., 2013). As a background to the subsequent analysis of AF projects in this dissertation, this section summarizes key findings from the previous assessments of the AF.

\subsubsection{Political economy of the AF}

Many scholars discuss the political economy of the AF's creation, highlighting the contentious North-South battles over how the AF would be governed (Grasso, 2011; Harmeling \& Kaloga, 2011; Horstmann \& Abeysinghe, 2011; Müller, 2006). On the one hand, developed countries strongly preferred the GEF to be the operating entity of the AF, citing the GEF's ability to support the mainstreaming of adaptation with national policies while ensuring nonduplication of the AF with existing GEF-managed funds (Harmeling \& Kaloga, 2011). On the other hand, developing countries strongly argued for a new operating entity of the AF under the authority of the UNFCCC COP, with less dominance of multilateral institutions and donor countries (Grasso, 2011; Harmeling \& Kaloga, 2011; Müller, 2006), and with a policy to finance full costs of adaptation rather than incremental costs as practiced by the GEF (Horstmann \& Abeysinghe, 2011). Developing countries also called for direct access to the AF-a demand that reflects their long-standing criticisms of prolonged procedures and imposing priorities of international implementing entities experienced through the GEF (Horstmann, 2011), and a desire for 
country-driven project identification, a financial mechanism which is present at the country level, and greater attention to capacity building (Horstmann, 2011). This North-South contention reflects an international political economy in which developing countries increasingly demanded a more country-led operating instrument of global climate finance (Ciplet et al., 2013; Harmeling \& Kaloga, 2011). Reflecting a compromised outcome favorable to developing countries, the AF was finally designed with a management board with developing-country majority, direct access by developing countries, resource mobilization through monetized CERs that help reduce donor and ODA dependence, and the GEF providing only secretariat service to the otherwise functionally-independent AFB Secretariat (Harmeling \& Kaloga, 2010; Horstmann, 2011; UNFCCC, 2008a).

\subsubsection{Operationalization of the $\mathrm{AF}$}

Other studies review the operationalization of the AF following its creation, focusing on the actual experience with the direct access modality on the ground (Brown et al., 2010; Bugler \& Rivard, 2012; Canales Trujillo \& Nakhooda, 2013; Craeynest et al., 2010; Harmeling \& Kaloga, 2010; Schäfer et al., 2014).

In general, these assessments find that the operationalization of direct access to the $\mathrm{AF}$ has been challenging in practice, with several lessons learned being documented. For example, the direct access modality seems to have contributed to lower project administrative costs, but understanding the full implications of the modality on the broader set of transactions cots requires more analysis. Experience from actual AF projects indicates that project management fees (comprising IE management and execution fess) charged by MIEs are consistently higher on average than those charged by NIEs (around 1.5 times), and this fee differential may contribute to the increased interest in the direct access modality (Bird, 2014; Schäfer et al., 2014). But 
while reducing the administrative costs compared to projects implemented by third-party international intermediaries, direct access also incurs another set of transactions costs from the lengthy accreditation process, high capacity building needs of NIE applicants, and the time and technical support required for accredited NIEs to develop qualified project proposals (AFB, 2015; Brown et al., 2010; Masullo et al., 2015; Schäfer et al., 2017). The AF itself documents that, in some cases, project management involving multiple subnational and local institutions also increases administrative costs of direct access projects during the implementation phase (AFB, 2014).

In addition, early experience suggests that the successful accreditation of an NIE carries long-term benefits for the recipient country beyond the immediate AF project that the NIE implements. In the case of Senegal, the success of the Centre de Suivi Écologique (CSE) in 2010 in being the first NIE accredited globally has created an incentive for other domestic institutions to improve their institutional capabilities after seeing the benefits for the CSE (Bugler \& Rivard, 2012). NIEs accredited by the AF can also expedite their access to other funding sources. This is demonstrated when the GCF has used a "fast track" process to accredit $14 \mathrm{NIEs}$ and 6 RIEs of the AF as its own implementing entities to date (Adaptation Fund, 2017; GCF, 2019a).

Apart from the access modality, scholars also assess other aspects of the operational procedures of the AF. Amerasinghe et. al., (2017) find the AF to have the most nimble project approval process among climate funds, with the AF taking on average eight (one-step projects) to 12 (two-step projects) months compared to between 10 to 28 months for other funds. Grimm et al. (2018) find the AF favorable in terms of institutional capacity building, Board procedure, environmental, social, and gender policies, and stakeholder engagement, but recognize that there could be a greater scope for collaboration between the $\mathrm{AF}$ and civil society. At the same time, a recent assessment by UNFCCC (2018) finds that overall "the costs associated with 
the $\mathrm{AF}$ are relatively high because it accredits a wide range of national and regional implementing entities, and has its own legal personality" (p.90). Looking forward, scholars call for a clearer division of labor between the AF and the GCF and more harmonization of standards and procedures (Amerasinghe et al., 2017; Grimm et al., 2018). Amerasinghe et al. (2017) suggests that the $A F$ focuses on its niche on small-scale adaptation projects, while the GCF focuses on "larger, more transformative, or financially innovative approaches" (p.8).

\subsubsection{Equity, efficiency and effectiveness of the AF}

Using early AF projects as case studies, a group of studies examine the principles that guide the AF's allocations and assess the Fund's adequacy in responding to the need of the most vulnerable countries and communities. While some scholars find that the AF's direct access modality contributes to higher focus on local communities (Fenton et al., 2014), the studies generally find that, as a global financing mechanism, the AF does not respond adequately to the needs of the most vulnerable both from the international and within-country allocation perspectives (Conevska et al., 2019).

From the international allocation perspective, Stadelmann et al. (2013) assess all project proposals (39) considered by the AF portfolio as of 2011 against a set of equity and efficiency indicators. They find that projects approved or endorsed by the AFB rank high according to one costeffectiveness indicator (absolute economic savings), but low on other equity indicators (i.e. country-level vulnerability index, equal funding per capita, and gross domestic product (GDP)) and cost-effectiveness indicators (i.e. relative economic savings and human lives savings). Reviewing a larger portfolio of 46 project proposals (of which 25 were approved) as of 2012, Persson \& Remling (2014)—though recognizing that proposals from LDC and/or SIDS countries were slightly more successful than others-argue that the AF 
allocation in general has not prioritized the most vulnerable countries, when comparing the approved countries to the available national-level vulnerability indices. Instead, the AF allocation appears to be mostly guided by a rationale of international equity, whereby all countries are entitled to an equal lump sum (e.g. a national cap of USD 10 million for all) and funds are available on a first-come, first-serve basis to any eligible countries that submit a technicallyqualified proposal (Persson \& Remling, 2014). Conevska et al. (2019) also find that the AF is technically inadequate-from the perspective of priorities, eligibility, and disbursement of finance-to respond to the need of developing countries. Three key reasons for this are the lack of a sector-based approach when prioritizing adaptation projects; the practice of financing capacity building only in addition to concrete adaptations, which may not respond to countries with heterogenous adaptation needs; and the USD 10 million country cap which are perceived by many recipient countries to be too small to finance sustainable concrete adaptation projects (Conevska et al., 2019).

For within-country allocations, scholars find that there are no operationalized definition and standard indicators of vulnerability for AF projects (Horstmann, 2011; Persson \& Remling, 2014). In practice, this allows each project proponent to use its own rationale to justify the selection of "particularly vulnerable" beneficiaries (Horstmann, 2011; Persson \& Remling, 2014). When comparing project-level justifications for beneficiary selection, Remling \& Persson (2015) find that "a wide variety of interpretations of 'vulnerability' have been made and that there is no common ground regarding who the vulnerable entity is. Generally, proposals focus on impact-focused adaptation (measures against sensitivities and exposures) and climate risk specifically, rather than vulnerability-focused adaptation and underlying (often social) causes of vulnerabilities more generally" (p.29).

The AFB Secretariat provides responses to some of the findings of these assessments (Levaggi, 2014). Responding to Stadelmann et al. (2013), the 
AFB Secretariat clarifies that non-approved proposals can get resubmitted and are mostly finally approved by the Board. Given this, the Secretariat argues the authors have likely statistically overstated rejections by analyzing proposals considered at only a few Board meetings, while also overcounting the same proposals resubmitted to different Board meetings as different proposals (Levaggi, 2014). On the other hand, the AFB Secretariat's response confirms that project approvals are based on technical quality rather than country characteristics (Levaggi, 2014), thereby supporting the conclusion of Persson \& Remling (2014) that the guiding principle for project approvals is first-come, first-serve international equity among technically qualified proposals. Until the present, there has not yet been a repeated systematic analysis of the current AF portfolio against equity and efficiency indicators.

\subsubsection{Adaptation Fund and innovations}

In assessing the effectiveness of the AF, Canales Trujillo and Nakhooda (2013) find that many AF projects finance a wide range of in technologies and practices in recipient countries, including weather monitoring systems and early warning systems, hydrological monitoring systems for river basins, new land management techniques, climate-resilient crop varieties, options for income diversification etc. While many of these activities seek to support community-level resilience, it is less clear about the approach by which AF projects support individual capacity to innovate or promote autonomous innovation. Recognizing that innovation is highly context-specific, the authors note that "further study of country level interventions are necessary to offer more definitive insights into how the Adaptation Fund has been supporting innovation in practice, and what the outcomes of its support are likely to be" (Canales Trujillo and Nakhooda, 2013, p.26). 


\subsection{Conclusion}

In this chapter, I discuss the AF as the case study and its projects as subunits of analysis of the dissertation. I review the history and recent developments of the AF and provide an overview picture of the AF portfolio as of May 2017, showing the distribution of projects between the direct access and indirect access modalities and the types of funded adaptation actions. I also summarize previous studies on the AF, which so far have focused on the challenges facing its operationalization, and on the equity, efficiency and effectiveness of the Fund. The review of these studies shows that there has been no academic research that systematically assesses the AF portfolio in recent years. There is also limited knowledge on the AF's approach to support innovations. The next three chapters of the dissertation aim to fill these knowledge gaps by undertaking theoretically-guided empirical analyses of AF projects, with the objective to understand if and how the access modalities shape the community-focused and innovative project design under different recipient country contexts. 


\section{Chapter 5: Do direct access and indirect access adaptation projects differ in their focus on local communities? A systematic analysis of 63 Adaptation Fund projects ${ }^{12}$}

\subsection{Introduction}

The Adaptation Fund (AF) is recognized for pioneering the direct access modality, which allows national institutions in developing countries to access international adaptation finance directly without using international intermediaries such as multilateral development banks (Adaptation Fund, 2012; Schäfer et al., 2014). Direct access is not new to development finance but is innovative for international adaptation finance (Brown et al., 2010). The AF was the first multilateral climate fund to pioneer direct access on a regular basis, along with providing indirect access through international intermediaries. The AF's introduction of direct access reflects an international political economy in which developing countries increasingly demand a more country-led operating instrument of global climate finance (Harmeling \& Kaloga, 2011; Horstmann, 2011).

\footnotetext{
${ }^{1}$ This chapter has been accepted for publication as: Manuamorn, O.P. and Biesbroek, R. (2020), Do direct access and indirect access adaptation projects differ in their focus on local communities? A systematic analysis of 63 Adaptation Fund projects. Regional Environmental Change.

2 The following author statement describes the contributions of the authors to the paper: Ornsaran Pomme Manuamorn: Conceptualization, Methodology, Validation, Formal analysis, Investigation, Resources, Data Curation, Writing - Original Draft, Writing - Review \& Editing, Visualization, Supervision, Project administration; Robbert Biesbroek, Ph.D.: Conceptualization, Investigation, Validation, Writing Review \& Editing, Supervision
} 
Access modality refers to "the institutional architecture through which funding decisions are made and finance flows" (Bird, 2014, p.6). As such, it constitutes a key governance context shaping the fund-recipient relationships and the characteristics of adaptation projects being financed. Under the indirect access modality, developing countries access AF funding through international organizations accredited as multilateral implementing entities (MIEs) or regional implementing entities (RIEs). MIEs and RIEs identify, develop, implement and monitor projects for developing countries in collaboration with executing entities (EEs), which could be national, subnational or local organizations, and are accountable for the overall fund use on behalf of the recipient countries (AFB, 2008). Under the direct access modality, all of these functions of MIEs or RIEs are performed by national institutions accredited as national implementing entities (NIEs). According to the AF operational guideline (AFB, 2008), NIEs, MIEs and RIEs all have the same roles and responsibilities with regards to designing, implementing, and monitoring AF projects. But while the roles and responsibilities of these implementing entities are the same on paper, in practice the direct access modality is structurally more decentralized to the national level. At the same time, the knowledge, capacity, and incentives of national and international organizations vary, and these differences could carry implications for how adaptation interventions are designed and implemented.

Direct access generates a strong interest from the international climate community but the current discourse on the advantages and challenges of the modality is shaped by divergent views. Some donors perceive direct assess as potentially accelerating climate finance delivery but not as a default option due to concerns about transparency, accountability and risk management at the recipient-country level (Bird et al., 2011). Developing countries and civil society, on the other hand, praise the modality for being country-driven and argue that it should be a key design principle of future global climate financing mechanisms (IIED, 2014; UNFCCC, 2010a). The 
latter position has gained some momentum with the adoption of direct access by the Green Climate Fund (GCF, 2015). However, indirect access had been the norm in international adaptation finance and remains the most dominant access modality today (Duus-Otterström, 2016).

Much of the current literature on direct access discusses its key features and the implications on the recipient country-fund relationships (Bird, 2014; Brown et al., 2010; Druce et al., 2013; Harmeling \& Kaloga, 2010). Some scholars examine supportive and opposing arguments for the modality (Craeynest et al., 2010; Duus-Otterström, 2016). Recent studies begin to assess the operationalization experience of the modality (Druce et al., 2013; Masullo et al, 2015; Schäfer et al., 2014; UNDP, 2012), focusing on lessons learned from accredited national institutions and making recommendations to improve the AF accreditation procedures to accelerate direct access. Given the interest in direct access as a novel mechanism to channel international adaptation finance to developing countries when compared to indirect access, it is surprising that little attention has been given to comparing the projects funded by the two modalities in practice, even though it has been since 2010 that they are operating in parallel.

This chapter compares direct access and indirect access AF projects on their adaptation investment at the community level. The analysis that follows is guided by the following empirical research question: are direct access and indirect access projects equally community-focused? Three reasons provide the rationale for this comparison. First, the AF has been recognized for its success in reaching the most climate-vulnerable populations including local communities and marginalized groups (Fenton et al., 2014). But while the direct access modality has been credited as a key factor for such success (Fenton et al., 2014), there has been no research which compares the level of community focus of direct access and indirect access projects within the AF portfolio. Second, while the AF's mandate prioritizes most vulnerable local 
communities, the AF does not have a dedicated community-financing window like other funds, for example, the community-based adaptation (CBA) pilot program of the Global Environment Facility Small Grant programs (Huq \& Faulkner, 2013). We could therefore expect to see the different degrees of emphasis on community-based approaches in AF projects as a result of context-specific negotiation among stakeholders. Third, the focus of the research design on just the AF automatically controls for a set of AF-specific factors that would likely have biased a comparison of direct access and indirect access projects from different climate funds. However, since there is currently no standard methodology to systematically report and track community-level adaptation financing (Fenton et al. 2014), a new framework needs to be developed for the proposed project comparison.

The purpose of this chapter is therefore three-fold. First, it develops a new framework to assess the level of community focus in adaptation projects. Second, it tests the framework by assessing the level of community focus in AF projects. Third, it compares if direct access and indirect access projects differ in terms of the level of community focus. Answering this third question is highly relevant to the study of international adaptation finance. Given that the $\mathrm{AF}$ is seen as a potential model for other multilateral climate funds (Horstmann, 2011), findings from this assessment could inform the operations of those funds, particularly the GCF which has adopted the direct access modality, accredited $14 \mathrm{NIEs}$ and 6 RIEs of the AF as its own implementing entities, and is financing the up-scaling of $\mathrm{AF}$ projects in various countries. We argue that a meaningful systematic comparison of direct access and indirect access projects is only recently enabled by the AF's approval of more direct access projects since 2013, thus adding more comparison cases from the direct access side. While recent papers perform qualitative analysis of AF projects (Persson \& Remling, 2014; Remling \& Persson, 2015), to the best of our knowledge this is the first study that 
systematically compares the two modalities on the design characteristics of adaptation projects.

The chapter is organized as follows. Section 5.2 proposes a conceptual framework to assess the level of community focus in adaptation projects, drawing from the literature on climate finance tracking, CBA, participatory development, and decentralization. Section 5.3 describes the chapter's methodology and data analysis. Section 5.4 presents the results from the systematic analysis of 63 AF projects. Section 5.5 discusses the findings. Section 5.6 provides a conclusion.

\subsection{Conceptual framework for assessing community focus in adaptation projects}

There is currently no established framework and methodology to assess climate finance for community-focused adaptation. Based on a search of the recent climate finance tracking literature, we identify two seminal papers by Fenton et al. (2015) and Soanes et al. (2017) that seek to develop such a framework and identify its key components. The three key components similarly identified by both papers are: 1) a definition of who are communitylevel beneficiaries of adaptation finance; 2) a quantitative tracking of each project's financial investment in activities that generate direct adaptation benefits for these beneficiaries; and 3) an assessment of the qualitative characteristics of the project processes and activities that reflect key design principles of community-focused adaptation. We use these three components as a starting point to further elaborate our framework to assess the level of community focus in adaptation projects. The following section discusses the definition of community-level beneficiaries (5.2.1), which forms the basis for our design of quantitative tracking (5.2.2.) and qualitative assessment (5.2.3) of community-focused adaptation in this chapter. 
5.2.1. Community-level beneficiaries of international adaptation finance

We further consult the CBA literature to understand who can be defined as community-level beneficiaries of international adaptation finance and use such definition to guide the coding of AF project documents (See section 3.2). Drawing on the CBA literature, we define beneficiaries of international adaptation finance at the community level to comprise groups of households, villages, communes, neighbourhoods, and settlements in climate-vulnerable locations (Ayers \& Forsyth, 2009; Reid et al., 2010). Populations living in these settings are often conceptualized as place-based local communities such as rural communities, farming communities, coastal communities etc. They are recognized as being internally diverse and do not always have stable populations and boundaries (Buggy \& McNamara, 2016; Kirkby et al, 2017), but at the same time share common characteristics, beliefs and/or actions that shape their collective exposure to climate change (Agrawal, 2008), as well as the ability to adapt to it (Dodman \& Mitlin, 2013). Community actors, such as individual community members, smallholder producer groups, women groups, community leaders and community-based organizations (CBOs) etc., can be distinguished from other local but more upwardly-located actors such as cities, municipalities, and districts. Internationally-funded adaptation projects that support bottom-up approaches usually target these community actors as project beneficiaries in practice (Adaptation Fund, 2013, 2014; GCF, 2018; Huq \& Faulkner, 2013). Apart from promoting technical adaptation measures that build on local knowledge and practices, project activities usually incorporate on-site capacity building for these community actors.

It should be noted that the use of the above definition of community-level beneficiaries does not presuppose the notions of harmony and equality that ignore the power politics and structural inequities between community subgroups (McDonnell, 2019; Titz et al., 2018). It is well recognized that bottom- 
up approaches such as CBA face a difficulty in defining a real-life community and its members, that community power relations are unequal, and that the notion of community can be used to morally justify external interventions as people-centered, while the benefits are in fact captured by local elites (Buggy \& McNamara, 2016; Kepe, 1999; McDonnell, 2019; Schipper et al., 2014). The purpose of defining community-level beneficiaries in this study is primarily to understand who are targeted for AF community-level interventions in order to initially compare the design of direct access and indirect access projects, without precluding future studies that will assess them with more critical perspectives.

\subsubsection{Financial investment at the community level}

Quantifying the amount of adaptation finance designated for local actions is fundamental to tracking adaptation finance at the local level (Fenton et al., 2015; Soanes et al., 2017). Building on Fenton et al. (2015) and Soanes et al. (2017), we therefore track the amount of project funding within each AF project that flows to community-level activities, which are defined as AF project activities that generate direct benefits for community-level beneficiaries as discussed above. Examples are the introduction of climateresilient agricultural technologies to farming communities, the construction of new village water harvesting infrastructure, capacity building for villagers and CBOs for community-based resource management etc. (see Supplementary Material 3). Excluded from community-level investment are AF project activities that build infrastructure above the community scale, conduct technical analyses, improve capacity of government institutions and/or strengthen overall policy and regulatory frameworks. 
5.2.3. Qualitative characteristics of community-focused adaptation

Drawing from the literature on $\mathrm{CBA}$ and participatory development, we propose to assess each $\mathrm{AF}$ project for three qualitative characteristics that reflect the key design principles of community-focused adaptation: 1) the level of community participation during project design and implementation; 2) the level of devolution of decision-making power to community-level actors; and 3 ) the design for policy adoption and replicability of community adaptation activities.

\subsubsection{Community participation}

Here we refer to participation as public participation in the context of climate change adaptation, which Few et al., (2007) describe as "securing the active involvement of a broad range of stakeholders in decision-making and action for anticipatory adaptation through processes coordinated by governments and other agencies" (p. 47). Public participation is often used interchangeably with stakeholder participation since the focus is on engaging those with stakes in the decision-making rather than a general public (Reed, 2008). The participatory development movement calls for bottom-up involvement of beneficiaries as informed participants in the design and management of development projects that affect them (Chambers, 1983, 1994; Mansuri \& Rao, 2003; United Nations, 2008). Cleaver (1999) summarizes the two strands of arguments for participatory development; the first are efficiency arguments which espouse participation as means to achieve better project outcomes. Here participation is seen as a pragmatic way to identify development priorities by asking the beneficiaries themselves, resulting in a project which is more relevant, targeted and accepted. The second are empowerment arguments which see participation as a desirable end. Here participation is considered a transformational process that builds capacities of the individuals to improve their lives and affect positive social change 
(Cleaver, 1999). In practice, the two strands are often used jointly in justifying participatory development projects.

Literature on public participation in environmental decision making provides various typologies of stakeholder participation (Reed, 2008). Building on Pretty et al. (1995) and Conde et al. (2005), Carter et al. (2007) present a typology of participation in decision-making on climate change adaptation, which can be simplified into three ladders: 1) self-mobilization is the most active form of public participation that takes place when local stakeholders initiate and control the project and solicit external assistance; 2) partnership is the second most active form of participation, which represents when local stakeholders act as equal partners to the project proponent and contribute own resources, ideas, and leadership to the consultative process; and 3) consultation is considered the most basic form of public participation, which takes place when local stakeholders collaborate in a process driven by a thirdparty, are dependent on external resources, and their inputs are used to tailor the pre-identified project design and ensure relevant results.

Community-focused adaptation requires active participation of community stakeholders in project design and implementation (Dodman \& Mitlin, 2013; Forsyth, 2013; Lasage et al., 2015; Sherman \& Ford, 2014). During the project design phase, participatory consultation approaches could help ensure that the proposed externally-financed interventions address the most relevant local adaptation needs and that the selection of project beneficiaries is inclusive (Kirkby et al., 2015; Reed, 2008; van Aalst et al., 2008). Continued community participation in project implementation is also important for ensuring project effectiveness, transparency and accountability. Stakeholder participation is particularly central to community-focused adaptation initiatives that adopt the CBA approach. CBA generates adaptation strategies through participatory processes involving both local stakeholders and external experts, with an objective to synthesize scientific knowledge from external 
experts with local knowledge and customs to identify locally-appropriate adaptation options (Ayers \& Forsyth, 2009; Piccolella, 2013; Reid et al., 2010). These processes draw heavily on participatory approaches and methods developed in the fields of disaster risk reduction, community development and farmer-led participatory research (Reid et al., 2010). However, scholars caution that participation processes are not devoid of norms, expectations, framings, and ideologies (Lebel et al., 2018; Sprain, 2017), and If implemented uncritically, could be captured by elites, exacerbate hierarchies and exclusions, and result in undemocratic outcomes (Sprain, 2017).

\subsubsection{Devolved decision-making}

The terms devolution and decentralization are often used interchangeably in discussing bottom-up approaches to climate change adaptation, but we argue that they should be distinguished in this context. Devolution can be broadly understood as the relocation of power, construed as capacity or authority in decision-making, from a center to local-level entities such as local governments or communities (Bardhan, 2002; Fisher, 1999). Decentralization generally refers to the transfer of power and resources-political, fiscal or administrative-away from the central government to non-central government entities (Schneider, 2003), which can occur with or without relocating the decision-making power (Bardhan, 2002; Fisher, 1999). While other definitions of decentralization include some degree of power transfer, it is understood that devolution represents a firmer and more institutionalized transfer of power to localities when compared to decentralization (Barrett, 2015). Decentralization without devolution is sometimes referred to as "deconcentration", involving merely shifting the workloads from a central authority to local bureaucracies while decision-making power remains centralized (Regmi \& Star, 2014; Tacconi, 2007). 
While decentralization in the overall government structure is considered a promising approach to promote bottom-up climate change adaptation (Brockhaus \& Kambiré, 2009; Scanlon \& Nobbe, 2010), recent literature emphasizes that community-focused adaptation also requires devolved decision-making to the local level in an actual project setting (Regmi \& Star, 2014). This is because community participation processes alone do not guarantee that an externally-financed adaptation project would be locally responsive. In many cases, community participation processes only engage community stakeholders as feedback providers to confirm a pre-determined project design (UNDP, 2014), and can fail to genuinely involve communities in adaptation interventions (Mikulewicz, 2018; Sherman \& Ford, 2014). Apart from community participation, it is argued that an explicit transfer of decisionmaking power to the communities is required for them to truly determine the methods and goals of adaptation that build on their own knowledge, livelihood practices and preferences (Dodman \& Mitlin, 2013; Kirkby et al., 2015; Regmi \& Star, 2014).

In the context of climate finance, there are calls for multilateral climate funds to move beyond the decentralization of implementation-related tasks and community consultation to devolve the actual decision-making power on project fund use to the local level (Bosma et al., 2018). This involves, for example, relocating funding approval functions, in addition to implementation and execution authorities, to NIEs and their project executing entities (EEs) (Müller, 2013), and having more downwardly-accountable local actors, such as CBOs and local NGOs, to formally serve as EEs and partners of EEs (AFB, 2008). Comparing decentralized and devolved systems for subnational allocation of domestic climate finance in Kenya, Barrett (2015) find that the devolved structures outperformed the decentralized ones in targeting adaptation finance resources at local vulnerable communities. 


\subsubsection{Design for policy adoption and replicability}

Apart from being participatory and devolutionary, we argue that a communityfocused adaptation project should also be designed from the onset to ensure the long-term adoption of adaptation actions and the replicability of benefits they deliver (Schipper et al., 2014). Huq \& Faulkner (2013) argue that such concern for time scale (i.e. the ensured community climate resilience after the project has finished), and geographical scale (i.e. the replicability of resilience beyond immediate project boundaries), are key design features that enable CBA initiatives to deliver "transformed resilience" results.

Apart from stressing the importance of capacity building for climatevulnerable local communities (Kirkby et al., 2017), the recent CBA literature also calls for community adaptation initiatives to maximize their long-term adaptation benefits and replicability through two types of mainstreaming (Huq \& Faulkner, 2013; McNamara \& Buggy, 2017; Reid \& Huq, 2014). First, policy mainstreaming generally refers to the integration of adaptation objectives into government policy-making (Klein, 2010; Uittenbroek et al., 2013). An example of CBA policy mainstreaming is when community adaptation concerns and practices are vertically integrated into policy processes above the community level (McNamara \& Buggy, 2017; Regmi \& Star, 2014; Saito, 2013). The policy mainstreaming of community-based approaches, which is sometimes referred to as "scaling-up" (Fenton et al., 2014; Huq \& Faulkner, 2013), reflects the institutionalization of these approaches into long-term structures beyond a project's life. Second, geographical mainstreaming, or "scaling out", concerns the horizontal expansion of successful community adaptation practices to different locations (Huq \& Faulkner, 2013), leading to a replication of community best practices at a larger scale. While the two types of mainstreaming processes can and often take place in a complementary manner, they should be conceptually distinguished as the knowledge, skills and enabling conditions required may differ (Huq \& Faulkner, 2013). 


\subsection{Data and methods}

\subsubsection{Sample}

We make use of the publicly available database of AF projects for analysis. As of May 2017, the AF had approved 63 projects from 53 countries, comprising 41 indirect access projects and 22 direct access projects (see Supplementary Material 1). All AF projects have approved proposal documents which follow the same standardized template and contain detailed project information (see Supplementary Material 2). This facilitates a systematic comparison across projects and components (Ford \& BerrangFord, 2016).

\subsubsection{Operational indicators for assessment}

5.3.2.1. Indicator of financial investment at the community level

As discussed in Section 5.2, community-level project activities are defined as project activities that generate direct adaptation benefits to, as well as build capacity of, groups of households, villages, communes, neighbourhoods, and settlements in climate-vulnerable locations. To operationalize the tracking of financing bound for these activities within a given AF project, we use the granular approach of the climate finance tracking methodology jointly developed by multilateral development banks to identify project components and sub-components that invest in the community-level activities and track the budget attached to them (IADB et al., 2017). We exclude project administration fees charged by AF implementing entities to identify the true fraction reaching community actors. An AF project that invests more in activities with direct adaptation benefits to local communities as a percentage of the total project budget (indicator F1) is considered more communityfocused (Table 5.1). 


\subsubsection{Community participation indicators}

We propose four indicators to operationalize the assessment of community participation in AF projects (Table 5.1). The first two indicators assess the level of participation of community-level stakeholders-defined as community members, community leaders, community groups, $\mathrm{CBO}$ s and local resource persons - in the design and implementation of each AF project. The latter two indicators assess if each project exhibits efficiency gains from community participation. We do not include indicators to assess the empowerment effect of participation as this would require a longer time horizon and an in-depth analysis which is beyond the scope of this chapter.

The first two indicators for the level of community participation are: P1) the type of stakeholder participation, defined as self-mobilization, partnership, and consultation; and P2) the number of roles played by community stakeholders throughout the project cycle, with the potential nine roles comprising baseline development, vulnerability and adaptation assessment, project identification and proposal development, project implementation, support and outreach to local project participants, technical support and institutional support, monitoring and evaluation, capacity development, and lesson distillation and documentation. A project is considered to have a higher level of community participation if community-level stakeholders are consulted during the project design phase in a way that more resembles selfmobilization, and if they are involved in a higher number of roles throughout the project cycle.

The two indicators for efficiency gains from participation are: P3) the dimensions of climate vulnerability of project beneficiaries, which refers to the biophysical and socioeconomic characteristics (i.e. livelihood sources, age, economic status, gender, health status, location and geography, and social status) that make a community and its members vulnerable to climate 
change; and P4) the sub-categories of beneficiaries (e.g. women, elderly, ethnic minorities, disabled, landless labourers, single-headed households) within each dimension of vulnerability (See Supplementary Material 3). While the indicator $\mathrm{P} 3$ reflects the diversity of lens used to identify sources of climate vulnerability, the indicator $\mathrm{P} 4$ reflects the higher inclusivity in project design. For example, a project that deals with livelihood source-related climate vulnerability, such as crop production, could identify different sub-categories of beneficiaries, such as female, elderly, and ethnic minority farmers, to tailor adaptation activities to match each sub-group's differentiated needs. In this chapter, we assume that a project that targets a higher number of vulnerability dimensions and sub-categories of beneficiaries is more inclusive, reflecting the efficiency gains from the project proponent having solicited the diverse adaptation priorities from the community stakeholders themselves.

Finally, we consider a project to be more participatory overall, if it exhibits both a higher level of community participation during project design and implementation, as well as higher efficiency gains from such participation.

\subsubsection{Devolved decision-making indicators}

We use three indicators to operationalize the assessment of the level of devolved decision-making in AF projects: D1) the type of organizations that serve as EEs, using a typology of international, national, sub-national and local organizations; D2) the type of organizations that EEs partner with, using the same organizational typology as the indicator D1; and D3) the existence of mechanisms within a given project design that enable local decisionmaking on funding approvals and/or adaptation choices. An example is a small grant facility, which devolves local decision-making on funding approvals to the grantees. Another example is a call for proposals from local communities, which solicits adaptation choices directly from the communities, while the decision-making on funding approvals remains with the AF. 
However, an AF project that involves a call for proposals is still more devolved than ones without. The AF framework allows for both the partnership with local organizations and the use of mechanisms for local decision-making. Whether and how much each project uses both is the decision of the NIE and MIE/RIE. For this paper, a project is considered more devolutionary if it involves a higher number of local organizations, such as CBOs and local NGOs, as EEs and EE partners, and uses a higher number of mechanisms for local decision-making (Table 5.1).

\subsubsection{Indicators for design for policy adoption and replicability}

We use the level of policy mainstreaming of community-level project activities (M1) to measure the concern in project design for policy adoption, and the level of geographical mainstreaming of these activities (M2) to measure the concern for replicability. For geographical replication, we also differentiate between the action cases, whereby concrete replication activities already take place within the current AF project, and the intention cases, which indicate a recognition of the need for replication but such action has not yet taken place. An action case is considered to represent a clearer plan for replication than an intension case (Table 5.1). A project which mainstreams community-level adaptation with policies and makes a clearer plan for geographical replication is considered to exhibit more design for policy adoption and replicability. 
Table 5.1: Summary of dimensions, indicators and measurements of community-focused adaptation

\begin{tabular}{|c|c|c|c|}
\hline Dimension & Indicator & $\begin{array}{l}\text { Indicator } \\
\text { description }\end{array}$ & Measurement \\
\hline $\begin{array}{l}\text { 1. Financial } \\
\text { investment at } \\
\text { the community } \\
\text { level }\end{array}$ & $\mathrm{F} 1$ & $\begin{array}{l}\text { Budget for project } \\
\text { activities that } \\
\text { generate direct } \\
\text { adaptation benefits } \\
\text { to community-level } \\
\text { beneficiaries }\end{array}$ & $\begin{array}{l}\text { Community-level project } \\
\text { budget / total project budget } \\
(\%) \\
\text { Conversion of \% into scores: } \\
\text { High (3), Medium (2), and } \\
\text { Low (1) }\end{array}$ \\
\hline \multirow{6}{*}{$\begin{array}{l}\text { 2. Community } \\
\text { participation }\end{array}$} & \multicolumn{3}{|c|}{ Level of community participation } \\
\hline & $\mathrm{P} 1$ & $\begin{array}{l}\text { Type of public } \\
\text { participation of } \\
\text { community-level } \\
\text { stakeholders during } \\
\text { project design }\end{array}$ & $\begin{array}{l}\text { Self-mobilization }(\text { score }=3 \text { ) } \\
\text { Partnership }(\text { score }=2) \\
\text { Consultation }(\text { score }=1)\end{array}$ \\
\hline & $\mathrm{P} 2$ & $\begin{array}{l}\text { Roles performed by } \\
\text { community-level } \\
\text { stakeholders } \\
\text { throughout project } \\
\text { cycle }\end{array}$ & Number of roles (1-9) \\
\hline & \multicolumn{3}{|c|}{ Efficiency gains from community participation } \\
\hline & P3 & $\begin{array}{l}\text { Dimensions of } \\
\text { vulnerability of } \\
\text { project } \\
\text { beneficiaries }\end{array}$ & Number of dimensions (1-7) \\
\hline & $\mathrm{P} 4$ & $\begin{array}{l}\text { Sub-categories of } \\
\text { beneficiaries within } \\
\text { each dimension of } \\
\text { vulnerability }\end{array}$ & $\begin{array}{l}\text { Number of sub-categories } \\
(1-25)\end{array}$ \\
\hline \multirow[t]{3}{*}{$\begin{array}{l}\text { 3. Devolved } \\
\text { decision- } \\
\text { making }\end{array}$} & D1 & $\begin{array}{l}\text { Type of } \\
\text { organizations that } \\
\text { serve as project EE }\end{array}$ & $\begin{array}{l}\text { International }(\text { score }=0) \\
\text { National }(\text { score }=0) \\
\text { Sub-national }(\text { score }=1) \\
\text { Local }(\text { score }=2)\end{array}$ \\
\hline & $\mathrm{D} 2$ & $\begin{array}{l}\text { Type of } \\
\text { organizations that } \\
\text { serve as partners } \\
\text { of EE }\end{array}$ & $\begin{array}{l}\text { International }(\text { score }=0) \\
\text { National }(\text { score }=0) \\
\text { Sub-national }(\text { score }=1) \\
\text { Local }(\text { score }=2)\end{array}$ \\
\hline & D3 & $\begin{array}{l}\text { Mechanisms to } \\
\text { allow local } \\
\text { decision-making on }\end{array}$ & $\begin{array}{l}\text { Yes (1) } \\
\text { No (0) }\end{array}$ \\
\hline
\end{tabular}




\begin{tabular}{|l|c|l|l|}
\hline Dimension & Indicator & $\begin{array}{l}\text { Indicator } \\
\text { description }\end{array}$ & Measurement \\
\hline & $\begin{array}{l}\text { funding approvals } \\
\text { and adaptation } \\
\text { choices }\end{array}$ & \\
\hline $\begin{array}{l}\text { 4. Design for } \\
\text { policy adoption } \\
\text { and replicability }\end{array}$ & M1 & $\begin{array}{l}\text { Level of policy } \\
\text { mainstreaming of } \\
\text { community-level } \\
\text { project activities }\end{array}$ & $\begin{array}{l}\text { Yes (1) } \\
\text { No (0) }\end{array}$ \\
\cline { 2 - 4 } & M2 & $\begin{array}{l}\text { Level of } \\
\text { geographical } \\
\text { mainstreaming of } \\
\text { community-level } \\
\text { project activities }\end{array}$ & $\begin{array}{l}\text { Yes - action case (2) } \\
\text { Nes - intention case (1) }\end{array}$ \\
\hline
\end{tabular}

\subsubsection{Systematic content analysis}

Guided by the conceptual framework in Section 5.2., we combine deductive and inductive strategies to develop a coding system to systematically review the content of $63 \mathrm{AF}$ project documents for all indicators in Table 5.1.

For the level of financial investment at the community level (F1), we first look for activities that directly target groups of households, villages, communes, neighbourhoods, and settlements in climate-vulnerable locations. Once these activities are identified in the project documents, we extract the budget bound for them from each document based on the approach discussed in Section 5.3.2.1., and then calculate the community-level budget as a percentage of total project budget for the 63 projects.

For the indicators of community participation (P1-P4), devolved decisionmaking (D1-D3) and design for long term adoption and replicability (M1-M2), we first consult the literature to identify relevant categories and subcategories and turn them into a preliminary set of codes for each indicator. For example, we integrate insights from the social vulnerability literature, which focuses on local-scale, bottom-up assessments of socioeconomic drivers of both vulnerability to climate change and responses to its impacts 
(Bohle et al., 1994; Mearns \& Norton, 2010; Noble et al., 2014), to define the seven categories to code the dimensions of climate vulnerability faced by community-level project beneficiaries: economic status, gender, age, social status, health status, livelihood source, and location and geography. We then test these codes with a sample of six AF project documents, resulting in incorporation of new codes emerging from the data. To extract information for every code, we review the structure of the AF project proposal template and identifiy sections with relevant information. To ensure that relevant information outside the pre-identified sections is also captured, we conduct a general search of the documents with relevant key words drawn from both the literature and a review of sample project documents (see Supplementary Material 3 for more detail). We analyze the coding results using Atlas.ti 7. We use the Codes-Primary Documents Table function to extract coded information for all indicators, except the indicator P4 where we use the CodeCo-occurrence Table. We tabulate the results for every indicator by access modality to assess the differences between direct access and indirect access projects.

\subsubsection{Limitations}

Given the study's data and methodology, some limitations should be noted. First, it is a systematic assessment of project proposals which represent how the projects are designed but do not capture changes during project implementation or project outcomes. As more projects mature, future research could analyze project evaluation documents and conduct in-depth case studies to assess the differences between direct access and indirect access projects in practice.

Second, the use of project design documents as the main data source means that community level perspectives are missing. It is recognized that community participation and devolved decision-making cannot be fully 
captured by analyzing project documents, and that the indicators used in this study do not reflect the differences in power that define whether we can consider community participation and decision-making processes equitable. Further in-depth study of existing or recently completed projects on the ground will complement this study to shed more lights in this aspect.

Third, the quality of project documents varies. While some projects provide comprehensive information with well-crafted texts, others are less extensive and at times less eloquently written. MIEs and RIEs are likely to be more adept in writing project proposals that meet AF criteria as well as international discourses on participation than NIEs. This could have resulted in systematic overreporting by MIEs and RIEs and underreporting by NIEs, especially those less familiar with project proposal preparation. However, this risk is mitigated by the fact that all the project proposals followed similar guidelines, ensuring that the same minimum extent of information is covered by each proposal. The inclusion of 63 projects in the analysis also ensures that our results are based on a relatively large sample of documents, thus mitigating the potential effects of varying document quality.

\subsection{Results}

5.4.1. Financial investment at the community level

As of May 2017, the AF had committed a grand total of USD 416.1 million of grant financing to 63 adaptation projects (22 direct access and 41 indirect access projects). The projects are distributed relatively equally between developing countries from the Asia-Pacific (23), African (20) and Latin American and Caribbean (19) regions, with only one project in Eastern Europe (Georgia). With an investment cap of USD 10 million per country, the average size of a project (including execution and management fees) is USD 6.6. million; direct access projects have an average size of USD 6.8 million 
and indirect access projects of USD 6.5 million. The biggest project (Mongolia) had received USD 9.99 million, while the smallest project (India) had received USD 0.69 million, both of which are direct access projects. After excluding the execution and management fees from the total amount of project financing, we find that the average size (the total component cost only) of a direct access project is USD 6 million, compared to USD 5.5 million for an indirect access project. This suggests that, on average, direct access projects have slightly lower combined execution and management fees (12\%) than indirect access projects (15\%).

For the indicator F1, we find that the level of financial investment in at the community level is higher in direct access projects compared to indirect access projects. On average, direct access projects invest $77.2 \%$ of project budget from the total component cost at the community level compared to $69.7 \%$ in indirect access projects. Three direct access projects invest $100 \%$ of their total component cost in community-level activities compared to two indirect access projects.

\subsubsection{Qualitative characteristics of community-focused adaptation}

\subsubsection{Community participation}

Overall, we find that direct access projects are more participatory than indirect access projects, due to a higher level of community participation, measured by the indicators $\mathrm{P} 1$ and $\mathrm{P} 2$, and higher efficiency gains from community participation, measured by the indicators $\mathrm{P} 3$ and $\mathrm{P} 4$.

For the type of public participation during project design (P1), we find no projects reporting their consultative process in a way that is consistent with self-mobilization. The most dominant form of public participation reported by most projects in both modalities-comprising $100 \%$ of the indirect access 
projects and $90 \%$ of direct access projects-is consultation. However, we find that $10 \%$ of direct access projects reported their consultative process in a way that is consistent with partnership, while none of indirect access projects did.

When comparing the number of roles played by community-level stakeholders throughout the project cycle (P2), we find that on average these stakeholders play four roles per project in both modalities. However, when each role is compared between modalities, a higher proportion of direct access projects involve community-level stakeholders across the roles (Figure 5.1). The biggest difference is found in monitoring and evaluation, whereby $82 \%$ of direct access projects report the involvement of communitylevel stakeholders compared to only $41 \%$ of indirect access projects. This is followed by the difference in community involvement in vulnerability and adaptation assessment, whereby $86 \%$ of direct access projects report the involvement of community-level stakeholders compared to only $63 \%$ of indirect access projects (Figure 5.1). 


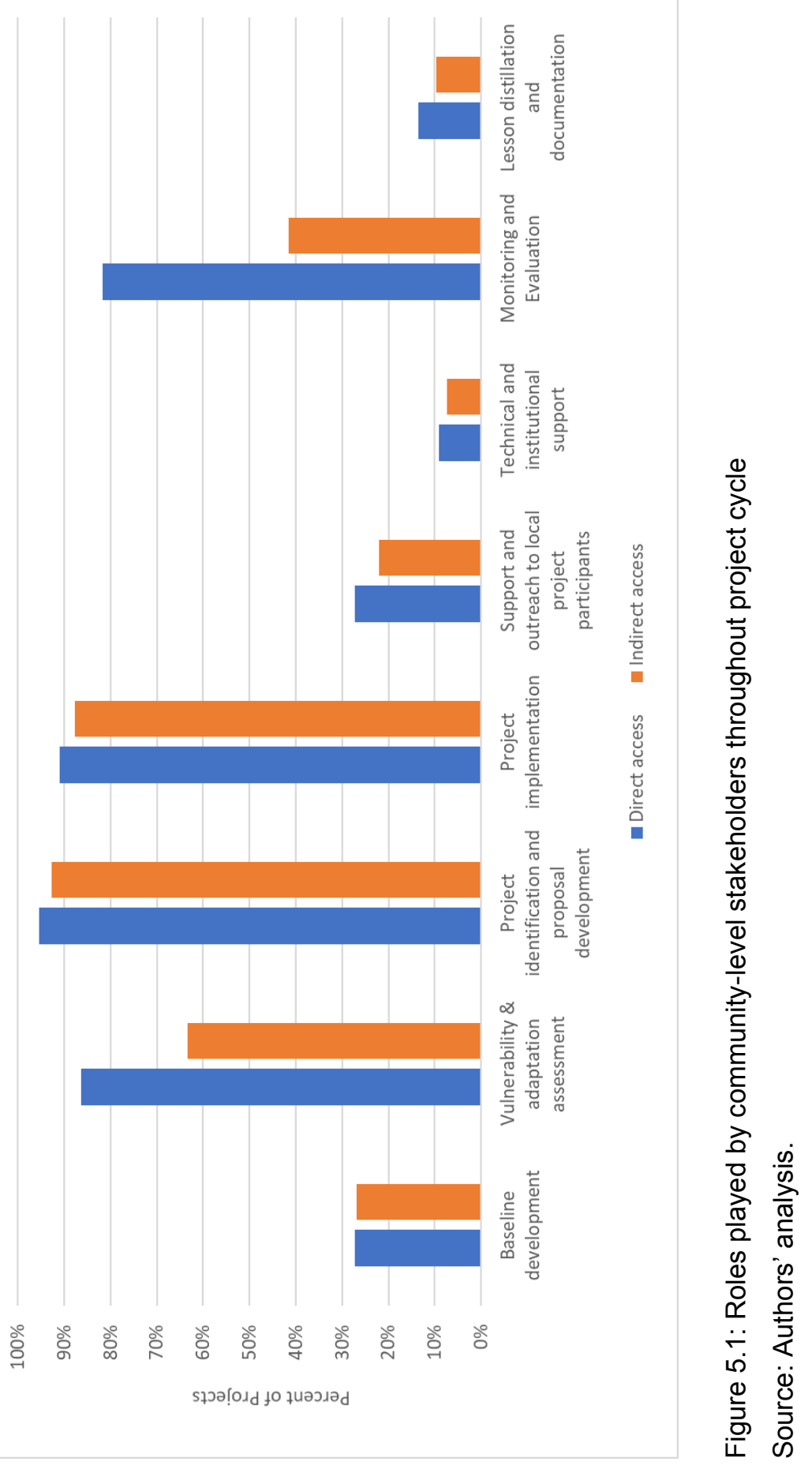


As the first indicator for efficiency gains from community participation (P3), we find that five out of seven key dimensions of climate vulnerability are addressed by more direct access projects than indirect access projects. These five dimensions are livelihood sources, age, economic status, gender and social status. Only two dimensions of vulnerability-health status and location and geography-are covered by more indirect access projects (Figure 5.2).

As the second indicator for efficiency gains from community participation (P4), we find that on average direct access projects target six sub-categories of beneficiaries per project, while indirect access projects target five subcategories per project. We interpret this higher number of sub-categories of beneficiaries to reflect more inclusivity in the project design, suggesting more efficiency gains from community participation. However, in terms of the dominant sub-categories of project beneficiaries, we find that the poor, smallholder farmers, women, children and youth are the most targeted subcategories in both access modalities. 

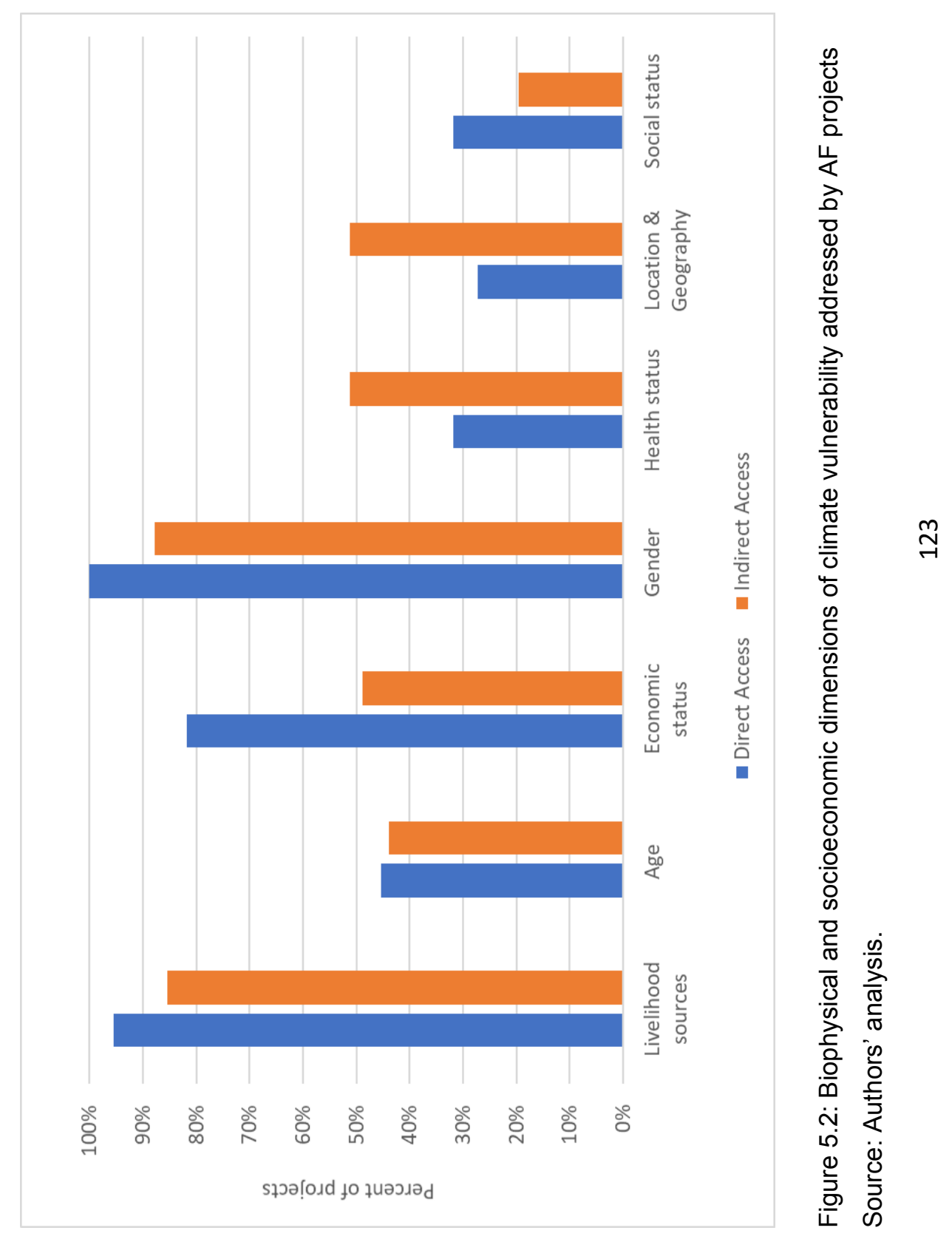


\subsubsection{Devolved decision-making}

Overall, we find that direct access projects are more devolutionary than indirect access projects, as measured by the three indicators for devolved decision-making. While national-level organizations are the most common EEs for both direct access and indirect access projects, a higher proportion of direct access projects are executed by sub-national and local organizations (D1); we find no indirect access project with local organizations officially assigned as its EEs (Figure 5.3a). The EEs of more direct access projects $(82 \%)$ than indirect access projects $(71 \%)$ also partner with local organizations, while the EEs of more indirect access projects partner with national and sub-national organizations than direct access projects (D2) (Figure 5.3b). We also find that $27 \%$ of direct access projects employ mechanisms to allow local decision-making on funding approvals and adaptation choices (D3) compared with $17 \%$ in indirect-asses projects. In terms of the type of mechanisms used, direct access projects operationalize more small grant facilities, while indirect access projects use more calls for adaptation proposals from local stakeholders including communities and CBOs. 


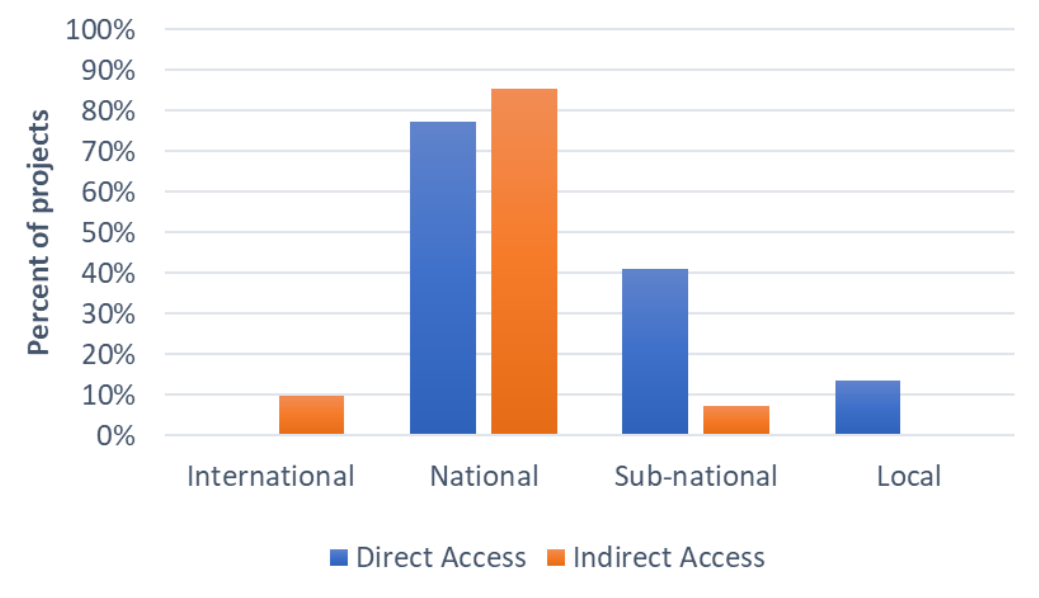

Figure 5.3a: Type of organizations that serve as EEs of AF projects Note: A project can have multiple EEs

Source: Authors' analysis.

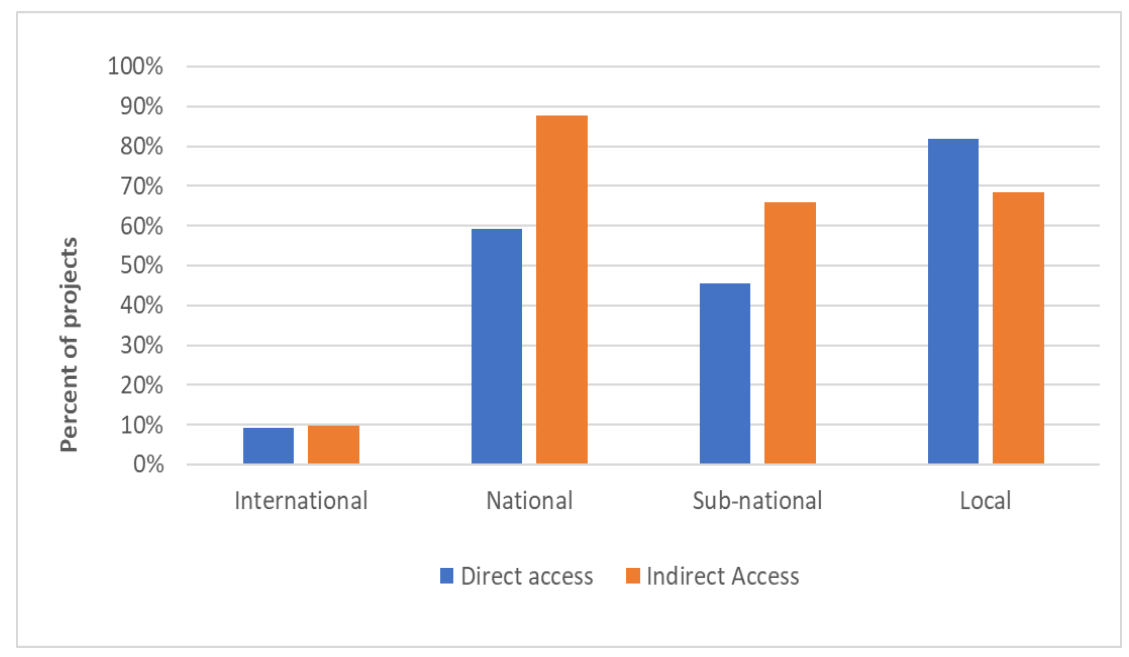

Figure 5.3b: Type of organizations that EEs of AF projects partner with Note: An EE can have multiple partners

Source: Authors' analysis. 


\subsubsection{Design for policy adoption and replicability}

We find no difference between direct access and indirect access projects with regards to how they are designed to promote the policy adoption and replicability of community adaptation actions through policy and geographical mainstreaming. All project proposals report the integration of the financed community adaptation activities with some form of national, regional and/or sectoral policies (M1). While we find that the design for geographical mainstreaming (M2) varies between both access modalities, the overall results show a similar pattern; $68 \%$ of direct access projects are the intention cases compared to $64 \%$ of indirect access projects, and $37 \%$ of indirect access projects are action cases compared to $31 \%$ of direct access projects.

\subsection{Discussion}

Much of the current climate finance literature focuses on the AF's effort to introduce direct access and how the modality changes recipient country-fund relationships vis-à-vis indirect access. Our findings move beyond this emphasis to build an initial understanding of the design characteristics of adaptation projects under both access modalities. They also offer a glimpse of how much national and international implementing entities of the AF have directed financial resources towards local communities, while engaging subnational institutions and local stakeholders in the process. These findings complement the growing research that systematically analyzes the portfolios of international climate funds to understand how global and local processes interact to shape adaptation processes in developing countries (Biagini et al., 2014; Conevska et al., 2018; Remling \& Persson, 2015). By establishing empirical knowledge from the AF's operationalization of the two modalities, which arguably represent different models of climate finance governance, the chapter's findings inform the policy discourse on how to improve institutional arrangements of international climate finance to support local adaptation 
(Bird, 2014; Brown et al., 2013; Nakhooda et al., 2014). The empirical findings here could also inform future theory building on the role of a decentralized climate finance governance model such as the direct access modality in shaping local climate actions.

The findings on community participation provide insights on how climate vulnerability is framed in developing countries. The main vulnerable groups we find being targeted by the AF projects in both access modalities are rural populations, particularly smallholder farmers, women, youth and the elderly, which reflect the same pattern as seen in the Intended Nationally Determined Contributions (UNFCCC, 2015b). These findings differ from those of Remling \& Persson (2015), who analyze 27 AF project proposals approved by the end of 2012 and find limited focus on social aspects of vulnerabilities such as gender and ethnicity. On the contrary, we find that women are one of the most commonly targeted beneficiaries. Projects from Ecuador, Guatemala, Belize, Nepal, India, Lao PDR, Honduras, Panama, and Paraguay also explicitly target marginalized groups including ethnic minorities, indigenous populations and low-caste communities. These different results could be driven by the different content analysis methodology. It could also reflect post2012 changes in AF policies, particularly the new requirement that proposals strongly consider gender equality and women empowerment (TANGO International and ODI, 2015).

Our results on devolved decision-making provides some initial support to an expectation that the direct access modality could promote subnational devolution of climate finance decision-making (Bosma et al., 2018). Devolution is broadly defined in this chapter as the presence of more subnational and local organizations, as well as the transfer of decisionmaking power on funding approvals and adaptation choices to them, within the formal decision-making structure of an internationally-financed adaptation project. Future research could examine if this process-based devolution fully 
reflects the theoretical construct and performance expectations of a devolved structure, or whether it is more in line with decentralization or deconcentration, and what are the implications of these different governance variants for bottom-up climate change adaptation.

Finally, our findings on the design for the policy adoption and replicability of community adaptation actions do not lend support to some of the literature that expects the direct access modality to promote more policy and geographical mainstreaming of community adaptation approaches when compared to indirect access (Craeynest et al., 2010). Two factors should be considered here. First, the AF requires that all projects report clear linkages to national and subnational policies. In each country, the AF's designated national authority also has to endorse a project proposal, a process which is similar in both access modalities. These requirements ensure that all AF projects are integrated with national policy processes. Second, while NIEs are well-placed to promote policy integration, MIEs can also do so in indirect access projects. For example, the United Nations Development Programme (UNDP) had played an active role in supporting the National Adaptation Programme of Action (NAPA) in many developing countries while also serving as a MIE of the AF. These dual roles have contributed to the strong integration of the UNDP-implemented AF projects with national adaptation priorities formulated in NAPAs (Schäfer et al., 2014). In some countries, it is the process of AF project preparation itself that catalyzes adaptation policy mainstreaming. For example, the process of developing the UNDP-implemented AF project in Honduras helps initiate the integration of adaptation objectives into the country's national development and water policies (TANGO International and ODI, 2015).

While providing a useful insight about AF projects, it is recognized that the binary mainstreaming indicators used in this study do not capture any qualitative differences in the mainstreaming processes between countries, or 
whether and how the processes evolve during project implementation. Understanding these dynamics and how they unfold over time requires future research with an in-depth case study approach. In addition, it is recognized that national-level government actors cannot always be assumed to represent the interests of their populations, and that national policies to promote climate resilience, especially those designed by technocratic elites, can end up favouring elites (such as landowners), while excluding the most vulnerable (such as the landless, and displaced peasants) (Sovacool et al., 2019). These political economy issues need to be taken into account in fully understanding the interplay between policy mainstreaming and the sustainability of community level adaptation actions, and more broadly, in analyzing the relationship between state and citizens in shaping the local use of international adaptation finance.

Two considerations should inform the interpretation of the chapter's findings. First, our research intention and findings are not normative in the sense that we do not imply that one modality is better than the other. Multiple modalities are going to be needed to address the range of climate financing needs and readiness of developing countries and could co-exist within a single country (Müller \& Pizer, 2014). Choosing an access modality is likely a country's decision shaped by context, capacities, and preference (Biesbroek et al, 2018). Second, the chapter's objective is descriptive which means that we cannot attribute the observed differences between direct access and indirect access projects solely to the modalities. While the modalities could play a role for the financial, participatory and devolutionary differences between direct access and indirect access projects, they are likely to do so in conjunction with other potential contributing factors, such as the experience of extreme weather events motivating countries to apply for financing to protect vulnerable localities (Conevska et al., 2018), the balance between top-down and bottom-up approaches in recipient countries' government structure, and other enabling conditions for community mobilization such as the governance 
of civil society. Explaining the causation requires further research that aggregates all indicators used in this study to determine and compare the overall level of community focus of AF projects, and uses a different research design, such as a Qualitative Comparative Analysis (QCA) methodology, to determine the conditions that explain the occurrence and non-occurrence of the community focus outcome. Such QCA analysis is the subject of Chapter 6.

\subsection{Conclusion}

The chapter assesses if direct access and indirect access adaptation projects are different in terms of their focus on vulnerable local communities using the AF as the case study. We propose a new framework to assess the level of community focus in adaptation projects, using a combination of financial, participatory, devolutionary, and design for long term adoption and replicability criteria. We find that direct access projects are more communityfocused than indirect access projects because they exhibit higher communityoriented financial, participatory, and devolutionary characteristics. We find no difference between the direct access and indirect access projects with regards to how they are designed to promote the policy adoption and replicability of community adaptation actions through policy and geographical mainstreaming.

Recognizing that our findings are based on project documents that provide partial views, we draw the following initial observations that could have important policy implications for international climate funds and developing countries. While we find that direct access projects are on average more community-focused than indirect access projects, community-focused adaptation projects are present under both access modalities to the $\mathrm{AF}$, and many MIEs that implement indirect access projects also engage sub-national institutions and local stakeholders as actively as, or even more than, some 
NIEs. This suggests that while the direct access modality has the potential to enhance climate finance outcomes at the community level, this potential does not necessarily and automatically materialize in all cases. On the other hand, while some indirect access projects perform well on financial investment at the community level, community participation, and devolved decision making, many show gaps. This finding should serve to remind MIEs to take extra care in improving project design in these aspects.

To accelerate the delivery of international adaptation finance to local level, policy could aim to build capacity of both direct access and indirect access entities to further engage other subnational and local stakeholders in fund use. Capacity building for community members as well as organizations that support them such as $\mathrm{CBO}$ s is also essential to ensure that they can meaningfully participate in the identification and design of internationallyfinanced adaptation projects. At the same time, it is important to recognize that capacity building alone is not a panacea, especially if implemented without adequate consideration of differentiated dimensions of vulnerability thus adaptation needs, and of the unequal initial capacities and access to resources within a community. Beyond capacity building, community stakeholders also need to be empowered to meaningfully participate as decision makers and beneficiaries in both access modalities by more active use of concrete mechanisms such as a small grant facility and a call for proposals from local communities as discussed in this chapter. Finally, as NIEs, MIEs and RIEs of the AF have gained experience and lessons learned from engaging sub-national stakeholders during project design and implementation, more knowledge sharing among them should be facilitated, with a view to inform the design of future internationally-financed adaptation projects under different country contexts. 


\section{Chapter 6: What makes internationally- financed adaptation projects focus on local communities? A configurational analysis of 30 Adaptation Fund projects ${ }^{3} 4$}

\subsection{Introduction}

Developing countries are vulnerable to the negative impacts of climate change (Füssel, 2010; IPCC, 2014a, 2018b). The poor, natural resourcedependent, and marginalized populations will bear a disproportionate burden of adapting to these impacts (Mearns and Norton, 2010; Olsson et al., 2014; Thomalla et al., 2006). Recognizing this as global climate injustice and a barrier for achieving sustainable development, the Paris Agreement calls for stronger international commitments to support adaptation for the most vulnerable populations (United Nations, 2015a). Particularly vulnerable groups include women, children elderly, minorities, people with disabilities etc., who live in vulnerable locations such as coastal zones, flood plains, rural areas, and informal settlements in disaster-prone urban areas (Levy \& Patz,

\footnotetext{
${ }^{3}$ This paper has been published as: Manuamorn, O.P., Biesbroek, R., Cebotari, V. (2020). What makes internationally-financed climate change adaptation projects focus on local communities? A configurational analysis of 30 Adaptation Fund projects. Global Environmental Change, 61, 102035.

${ }^{4}$ The following author statement describes the contributions of the authors to the paper: Ornsaran Pomme Manuamorn: Conceptualization, Methodology, Validation, Formal analysis, Investigation, Resources, Data Curation, Writing - Original Draft, Writing - Review \& Editing, Visualization, Supervision, Project administration; Robbert Biesbroek, Ph.D.: Conceptualization, Validation, Investigation, Resources, Writing - Review \& Editing, Supervision; and Victor Cebotari, Ph.D.: Methodology, Validation, Formal analysis, Investigation, Resources, Writing - Original Draft (Methodology), Writing - Review \& Editing
} 
2015; Olsson et al., 2014). Within this context, the paradigm that supports local adaptation has also gained prominence (Nalau et al., 2015). For example, community-based adaptation (CBA) has been increasingly adopted to operationalize local adaptation (Fenton et al. 2014). The CBA approach places the climate-vulnerable populations at the center of adaptation decision-making and capitalizes on their local knowledge for building adaptive capacity (Dodman and Mitlin 2013). Kirkby et al. (2015) estimate that developing countries in Africa, Asia and the Pacific Islands have implemented thousands of CBA projects in recent years.

Despite the increased policy support, inadequate financing remains a key barrier to community adaptation efforts in developing countries (Schipper et al., 2014). There is much interest in the role that international adaptation finance could play to close the financing gap (Fenton et al., 2014; UNEP, 2016). As a component of global climate finance, international adaptation finance mostly originates from public resources of developed countries and flows to developing countries to fund adaptation actions (Buchner et al., 2015), as part of an international commitment to address global climate injustice (Cameron et al., 2013; Hall and Persson, 2017). Bilateral aid programs, multilateral development banks, and specialized multilateral climate funds are three mechanisms that channel public international adaptation finance towards developing-country recipients (OECD, 2018). But while public international climate finance commitments have recently increased by 44\% between 2013 and 2017 (OECD, 2018), Soanes et. al. (2017) estimate that between 2003 and $2016<10 \%$ of climate finance was flowing to local level i.e. entities below the district administration including local governments, community-based organizations (CBOs), local nongovernmental organizations (NGOs), households and microfinance institutions. 
Some international funding mechanisms have been more successful in channeling resources towards local actions than others. The Adaptation Fund (AF) under the Kyoto Protocol is recognized as a successful example (Fenton et. al., 2014). Fenton et al. (2014) argue that the AF has performed well on integrating local-level adaptation investment in its portfolio because of: 1) its mandate which is centered on vulnerable populations; 2) a requirement that project proposals prioritize particularly vulnerable communities; and 3) the option of direct access that provides funding directly to national institutions. But while these fund-related characteristics are important in shaping the AF's portfolio, contextual conditions of recipient countries could also influence funding allocations at the project level (Rai et al., 2015; Terpstra et al., 2013). For example, studies have showed that a country's administrative tradition (Biesbroek et al., 2018) and level of decentralization (Brockhaus \& Kambiré, 2009) could affect the policy approach that a government takes to support climate change adaptation across scales. As all proposed AF projects need to be endorsed by national governments of recipient countries, these countrylevel governance conditions are likely to be relevant in explaining whether the government agencies take a strong community focus (or not) in these projects. These contextual conditions could also interact with the AF's fundrelated characteristics to shape the project design. Understanding such interaction requires a configurational research approach which accounts for the interdependence among factors in shaping an outcome.

This paper assesses under which conditions multilateral climate funds intensify or moderate the focus on local communities in their adaptation investment at the project level. Using the AF as the case study, the paper systematically compares $30 \mathrm{AF}$ projects to analyze the contextual conditions for a stronger or weaker community focus in the design of each project. To systematically analyze the influence of multiple contextual conditions, we use a Qualitative Comparative Analysis (QCA) methodology. The methodology models the evidence in a configurational way to determine the conditions and 
their combination that explain the occurrence of the outcome and its nonoccurrence. The ability to capture complex causal patterns enables us to better understand and specify the contexts under which the varying degrees of community focus in AF projects are shaped. To the best of our knowledge, this is the first paper that uses the QCA methodology to study international adaptation finance.

The paper is structured as follows. The next section develops a theoretical framework in which we define what we mean by community focus in AF projects and elaborate on the contextual conditions which could theoretically influence the outcome. Section 6.3 describes the data collection processes, discusses the QCA methodology, and presents the operationalization of data for the fuzzy-set analysis. Section 6.4 presents the main findings from the analysis of necessary and sufficient conditions for a stronger or weaker community focus in AF projects. The paper then discusses the key findings and their implications and provides a conclusion.

\subsection{Theoretical framework}

\subsubsection{Outcome: Community focus in AF projects}

Following Ayers and Forsyth (2009) and Reid et al. (2010), we define vulnerable communities as groups of individuals and households in villages, communes, neighborhoods, and settlements in climate-vulnerable locations. These communities are internally diverse but at the same time share common characteristics, beliefs and/or actions that shape their collective exposure to climate change (Agrawal, 2008). While these local communities are highly vulnerable to climate change, they are also believed to "have the skills, experience, local knowledge and networks to undertake locally appropriate activities that increase resilience and reduce vulnerability to a range of factors including climate change" (Dodman and Mitlin 2013; pp. 640-641), and are 
therefore a focus of adaptation interventions. As community actors such as $\mathrm{CBOs}$, community leaders, and community members can be distinguished from other local but more upwardly-located actors such as cities, municipalities, and districts, we consider communities as the most local level of beneficiaries of international adaptation finance.

Building on the literature on CBA (Forsyth, 2013; Kirkby et al., 2017) and climate finance tracking at the local level (Fenton et al., 2015; Soanes et al., 2017), we define three dimensions to assess the level of community focus in AF projects: 1) the level of financial investment in community-level adaptation activities; 2) the level of community participation in project design and implementation; and 3) the level of devolved decision-making to the community level.

\subsubsection{Financial investment at the community level}

Financial resources available to local communities are critical for the implementation of adaptation actions. We therefore track the amount of funding within each AF project that flows to activities which generate direct adaptation benefits for community-level beneficiaries (Fenton et al., 2015; Soanes et al., 2017). Examples of these activities are the introduction of climate-resilient agricultural technologies to farming communities, the construction of new village water harvesting infrastructure, and capacity building for villagers and $\mathrm{CBOs}$ for community-based resource management. Excluded from these community-level investments are AF project activities that build infrastructure above the community scale, conduct technical analyses, improve the capacity of government institutions and/or strengthen overall policy and regulatory frameworks. An AF project that invests more in activities with direct adaptation benefits to local communities as a percentage of the total project budget is considered as the first indicator of being more community-focused. 


\subsubsection{Community participation}

Community-focused adaptation requires active participation of community stakeholders in project design and implementation (Dodman \& Mitlin, 2013; Forsyth, 2013; Lasage et al., 2015; Magee, 2013). The CBA literature emphasizes the importance of community participation processes in the project design phase for synthesizing scientific knowledge from external experts with local knowledge and customs to identify locally-appropriate adaptation options (Ayers \& Forsyth, 2009; Piccolella, 2013; Reid et al., 2010), and for ensuring that that the selection of project beneficiaries is inclusive (Kirkby et al., 2015). It also highlights the need for project financiers to use various cultural and linguistic styles to create equitable participation space for different sub-groups of community members (Roncoli et al.,2011). After project activities have been initiated, continued community participation in project implementation keeps the financier-beneficiary feedback loops open, allowing for adaptive management, and meaningful evaluation of lessons. We therefore consider an AF project with a higher level of community participation during project design and implementation as the second indicator of being more community-focused.

\subsubsection{Devolved decision-making}

Recent literature emphasizes that community-focused adaptation also requires the devolution of decision-making power to the local level (Regmi \& Star, 2014). This is because community participation processes alone do not guarantee that an externally-financed adaptation project would be locally responsive. In many cases, community participation processes only engage community stakeholders as feedback providers to confirm a pre-determined project design (UNDP, 2014), and are therefore of tokenistic value. For local communities to truly determine the methods and goals of adaptation that build on their knowledge, practices and preferences (Dodman \& Mitlin, 2013; 
Kirkby et al., 2015), there are calls for international climate funds to move beyond community consultation to devolve decision-making on fund use to the local level (Bosma et al., 2018). This involves, for example, having local and downwardly-accountable actors such as $\mathrm{CBO}$ s to formally serve as project executing entities (EEs) of internationally-financed adaptation projects (AFB, 2008), and relocating funding approval functions, in addition to implementation and execution authorities, to them (Müller, 2013). We therefore consider an AF project which devolves more decision-making to community-level actors as the third indicator of being more communityfocused.

\subsubsection{Conditions enabling community focus in internationally-financed adaptation projects}

Multilateral climate funds like the AF are channelling resources to local project beneficiaries through national governments, international organizations and civil society organizations. As local communities cannot access the AF directly, they rely on these higher-level actors to adopt inclusive adaptation planning, and to actively champion for community adaptation needs to be prioritized for AF financing. Understanding the contextual conditions that could influence these higher-level actors' willingness and capacity to do so is therefore relevant to understanding what makes $\mathrm{AF}$-financed projects invest in community-focused adaptation. Scholarly literature has identified three groups of such relevant contextual conditions.

The first group relates to the level of climate change impacts on developing countries, which could act as a catalyst for governments to take actions to protect its vulnerable citizens (Ahmed et al., 2015; Conevska et al., 2018). In this study, we use past climate-related losses (condition 1) and projected future climate risks (condition 2 ) to respectively represent the observed and projected climate vulnerability of AF recipient countries. 
The second group of conditions is related to the enabling governance environment for community-focused adaptation approaches. In general, the level of government decentralization (Brockhaus \& Kambiré, 2009) and the role of civil society (Adhikari \& Taylor, 2012; Agrawal \& Perrin, 2009; Chu et al., 2016) were found to be important in previous studies, but they have not been sufficiently operationalized for cross-country comparison. In this study, we use government structure (condition 3 ) and governance of civil society (condition 4) to represent the AF recipient countries' enabling governance environment for community-focused adaptation approaches.

Finally, the governance of international adaptation finance itself--particularly how finance is distributed from multilateral climate funds to recipient countries through national or international implementing entities--could also influence decision-making at the project level (Scoville-Simonds, 2016; UNFCCC, 2018). It its recent assessment of global climate finance, the UNFCCC observes that "the operational priorities, experience and networks of the implementing entities through which climate finance is accessed can influence greatly how funds are spent" (UNFCCC, 2018, p.91). As the last condition in this QCA study, we therefore include the type of access modality which each recipient country uses to access AF resources (condition 5) to represent the governance of international adaptation finance.

The following sub-sections describe the theoretical expectations on the role of each contextual condition in explaining the level of community focus in AF projects.

6.2.2.1. Condition 1: Past climate-related losses

Past climate-related extreme events represent a country's level of climate vulnerability, and are found to be a key predictor of national-level adaptation actions (Berrang-Ford et al., 2014). Given that governments have moral and 
legal obligations to protect citizens from harms (Cameron et al., 2013), these extreme events could act as focusing events for governments to take protective actions (Jones \& Baumgartner, 2005). In reality, increasing losses from climate-related extremes have indeed provided an impetus for governments to implement adaptation policy and actions (Ahmed et al., 2015; Berrang-Ford et al., 2011; McEvoy et al., 2010). The impetus also drove developing-country governments with budget constraints to seek international adaptation finance. Reviewing 96 adaptation projects from 2004-2015 that targeted food systems, Conevska et al. (2018) find that the impact of extreme weather events was the most cited motivation for governments seeking financing from UNFCCC mechanisms for these projects.

Given that the negative climate change impacts are experienced primarily at the local level, there is evidence that, when governments take adaptation actions, they increasingly pay attention to reducing the vulnerability of local communities living in locations where negative climate impacts have been experienced. For example, developing-country governments have identified local communities such as rural households and smallholder farmers in climate-vulnerable regions as priority groups to benefit from adaptation policy actions (UNFCCC, 2015b). Among all UNFCCC member countries, 100 parties also consider CBA as a major adaptation approach to be upscaled in their countries (UNFCCC, 2015b). Such increasing prioritization of local communities can also be observed in the use of international adaptation finance at the project level (Conevska et al., 2018).

The above discussion suggests that there are precedents of past extreme weather events acting as a catalyst for developing-country governments to protect its citizens, including by seeking international adaptation finance. At the same time, there is evidence that local communities have received increasing attention from these governments as prioritized vulnerable groups, including by being targeted as the primary beneficiaries of internationally- 
financed adaptation projects. Given these two precedents, we therefore hypothesize that governments of countries which experienced higher climaterelated losses in the past would have an impetus to protect vulnerable local communities from harms. When they apply for AF finance, they would also have an incentive to influence the design of AF-financed adaptation projects to have a stronger community focus.

\subsubsection{Condition 2: Projected future climate risks}

Exposure to future climate risks is another key indicator of country climate vulnerability (Füssel, 2010). Similar to Hinkel (2011), we understand country climate vulnerability here as a "measure of possible future harm (p. 199)." Similar to experience with past climate risks, exposure to future climate harms can also drive governments to take anticipatory actions to protect citizens. These actions can be seen, for example, when governments use projected future climate risks as a basis to develop an adaptation policy framework (Government of Indonesia, 2016; Ministry of Environment of Jordan, 2013). In reviewing global adaptation experience, Berrang-Ford et al. (2011) also find that government actors particularly at the national level--though more so in developed countries than developing countries--are more likely to plan adaptation actions as response to long-term projected climate change impacts, when compared to individuals and households whose adaptation is largely stimulated by short-term factors such as changing market conditions and extreme weather events.

Projected future climate risks have also informed climate vulnerability assessments at regional and local levels, with results that enable governments to better plan anticipatory adaptation actions at these scales (Barnett, 2011; Chen et al., 2015; Gustafson et al., 2017; Soora et al., 2013). In recent years, climate projections in many developing countries have been downscaled (Gustafson et al., 2017). These advances have given 
governments in these countries an expanded capacity to identify local climate change hotspots, and to combine the science-based data with a communitybased perspective on vulnerability to better support community-level adaptation processes (Gustafson et al., 2017).

The above discussion suggests that the presence of future climate risks could motivate national governments to plan for anticipatory adaptation, and that recent scientific advances have allowed these governments in developing countries to do so more effectively at the local level. Together with the precedent of local communities being an adaptation priority of developingcountry governments as discussed above, these two observations have led us to expect that governments of AF recipient countries with higher overall exposure from projected climate risks would have an impetus to plan for anticipatory adaptation, and when they do so using AF financing, they would have more incentive in directing financing towards community-focused adaptation.

\subsubsection{Condition 3: Government structure}

As a key characteristic of government structure (Treisman, 2002), decentralization generally refers to the transfer of power and resourcespolitical, fiscal or administrative-away from the central government to noncentral government entities (Schneider, 2003). In reality, not all decentralization reforms involve the same degree of power and resource transfer. Reforms that involve the relocation of decision-making power are often characterized as political "devolution" (Bardhan, 2002; Fisher, 1999), while those that involve only the relocation of administrative functions are sometimes referred to as "deconcentration" (Agarwal et al., 2012; Regmi \& Star, 2014; Tacconi, 2007). Regardless of the degree, decentralization is one of the most important reforms undertaken globally to promote good governance (Bardhan, 2002; Faguet, 2014). The most prominent argument 
for decentralization is that "it will improve the accountability and responsiveness of government by altering its structure so as to increase citizen voice and change the deep incentives that public officials face" (Faguet, 2014, p.2). Decentralization is considered a promising mechanism to improve the governance environment needed for bottom-up approaches to climate change adaptation (Brockhaus \& Kambiré, 2009). As the disconnect between national governments and local realities is often cited as a key governance barrier for these approaches (Kuruppu \& Willie, 2015), decentralization could address this disconnect by enhancing participatory governance by vulnerable local communities, thus creating " 'short distances' to local realities which should result in adapted and highly responsive planning" (Brockhaus \& Kambiré, 2009, p.411). This could also lead to more opportunities for mainstreaming adaptation in sub-national government plans (D’Agostino \& Sovacool, 2011). We therefore expect that countries with more government decentralization, and by association government closeness to local realities, are more likely to support AF projects with a stronger community focus.

\subsubsection{Condition 4: Governance of civil society}

Following Anheier et al. (2001), we define civil society as "the sphere of institutions, organisations and individuals located between the family, the state and the market, in which people associate voluntarily to advance common interests (p.3)", highlighting the nature of civil society as "a space for collective action" (Fioramonti \& Kononykhina, 2015). While early literature largely assessed the strength of civil society from its internal characteristics such as density, membership, and legitimacy, recent studies have shifted attention towards assessing civil society strength by analyzing its enabling environment (Fioramonti \& Kononykhina, 2015; Simiti, 2017). In the context of climate change, an enabled civil society is considered an important agent of change in the process of adaptation (Adger, 2003), by raising societal 
awareness about climate change from the bottom up, serving as an intermediary mechanism to help align government policies with community adaptation priorities (Lati, 2008), and directly supporting CBA actions (Adhikari \& Taylor, 2012; Webb et al., 2015). In the context of climate finance, civil society is a key implementation partner of multilateral climate funds including the AF (Adaptation Fund NGO Network, 2012). As a check-andbalance mechanism, civil society is also expected to play a pivotal role in ensuring that the use of climate finance is reaching the poor and most vulnerable communities (Ballesteros et al., 2010; Colenbrander et al., 2018; Peterson Carvalho \& Terpstra, 2015). We therefore expect to see a stronger community focus in $\mathrm{AF}$ projects in recipient countries with a more conducive governance environment for civil society to operate.

6.2.2.5. Condition 5: Governance of international adaptation finance (access modality)

Access modality broadly refers to "the institutional architecture through which funding decisions are made and finance flows" (Bird, 2014, p.6). As such, it constitutes a key governance context shaping the fund-recipient relationships. Two access modalities allow developing-country recipients to access financing from the AF: under the indirect access modality, the recipients access funding through international intermediary organizations accredited by the fund as its multilateral implementing entities (MIEs) or regional implementing entities (RIEs); under the direct access modality, national organizations are accredited as national implementing entities (NIEs) to manage the funding and project implementation. Indirect access has been and remains the most dominant access modality to international adaptation finance today (Duus-Otterström, 2016). It allows developing countries with limited institutional capacities, adaptation expertise, and climate finance experience to tap into those of international organizations. Direct access modalities are considered an innovation in climate finance governance 
pioneered by the $\mathrm{AF}$ to enable recipient countries to manage their own funds and projects, strengthen country ownership and build national institutional capacities in climate finance (Adaptation Fund, 2012; Brown et al., 2010). The role of direct access in ensuring that climate finance is locally accountable has received strong attention (Bosma et al., 2018). It is argued that direct access would shorten the distances between local actors and the NIE-led project design process, thus allowing local priorities to be better captured (Fenton et al., 2014), enhance project ownership among government officials who are more accountable to local populations (Bosma et al., 2018; Craeynest et al., 2010; Müller and Pizer, 2014), and increase opportunities for devolution of funding decision-making to local actors such as civil society and local communities themselves (Bosma et al., 2018). Based on these arguments, we expect to see a stronger community focus in direct access AF projects compared to indirect access projects.

While each of the conditions above could theoretically influence the level of community focus in AF projects independently, it is also possible that they affect the outcome by acting in conjunction. For example, the impact of direct access in enhancing community-focused adaptation could be magnified in recipient countries which are already decentralized. The configurational approach employed in this study allows us to investigate whether such interaction between country decentralization and direct access exists in shaping the community-focused outcome.

\subsection{Method}

\subsubsection{Sampling of cases}

We choose the $\mathrm{AF}$ as the case study for three main reasons. First, while the $\mathrm{AF}$ is prioritizing most vulnerable local communities, the AF does not have a dedicated community-financing program like other funds, for example, the 
CBA pilot program of the Global Environment Facility Small Grant programs (Huq \& Faulkner, 2013). We could therefore expect to see the different degrees of emphasis on community-based approaches at the project level as a result of context-specific negotiation among stakeholders. This ensures sufficient variation in the outcome for our QCA study. Second, compared to the Green Climate Fund which has also introduced direct access more recently, the AF has financed a higher number of direct access versus indirect access adaptation projects, thus offering more cases for comparative analysis. Third, all AF projects have approved project proposal documents which are publicly available in English on its website. Each document provides detailed information about project design which enables a systematic review and comparison.

To identify the sample for this study, we first identify all projects approved by the AF as of May 2017, resulting in 63 projects from 53 countries. We then compare the available country data for the first four theorized conditions (See section 6.2.2) for the 53 countries. Based on data availability, we reduce the sample size to 30 project countries, with a total of 38 approved projects. To avoid country bias in our sample size, we randomly select one project from each of the four countries with more than one project (India, Argentina, Peru, and South Africa). This results in the final sample of 30 projects from 30 countries for our QCA study (See Table A1 in Appendix A for the list of countries and Supplementary Material 1 for more project detail).

\subsubsection{Fuzzy-set analysis and configurational logic}

This study employs a fuzzy-set analysis, which is one technique within the broader QCA methodology (Ragin 2000). The application of fuzzy-set QCA to social sciences is argued to be particularly suitable for studying complex phenomena, as it detaches from the traditional distinction between caseoriented and variable-oriented research (Cebotari \& Vink, 2013). Specifically, 
fuzzy-set analysis assumes conjunctural causation and aims at assessing whether conditions, independently or together in a configuration, explain the presence or absence of the outcome. As a systematic comparative method, fuzzy-set analysis is suitable for small and medium $\mathrm{N}$-samples and combines quantitative information with a case-oriented approach, where good knowledge of each case is needed to explain the link between theory, the cases, and obtained findings (Kirchherr et al., 2016; Pahl-Wostl \& Knieper, 2014).

Fuzzy-set technique revolves around the analysis of subset relations and distinguishes between the necessary and sufficient conditions and their configurational logic (Ragin, 2000, 2009). Fuzzy-set analysis employs several steps. First, the empirical and theoretical evidence feeds in a raw dataset that includes the outcome and conditions for each case. Second, raw values for conditions and the outcome are calibrated into fuzzy-set partial membership scores using evidence-based thresholds. The calibration leads to fuzzy-set membership scores for the outcome and conditions, which are based on values in the interval between [0] (non-membership) and [1] (full membership). Third, the fuzzy-set scores are used in the analyses of necessary and sufficient conditions leading to the presence and absence of the outcome. Based on the logic of subset relations, the status of being a necessary condition implies that the outcome $(\mathrm{Yi})$ is a subset of the condition $(X i)$, where the fuzzy-set scores of the outcome should be lower or equal to the fuzzy-set scores of the condition $(Y i \leq X i)$. Inversely, the status of being a sufficient condition implies that the condition is a subset of the outcome, where the fuzzy-set scores of the condition are lower or equal to the fuzzyset scores of the outcome $(\mathrm{Xi} \leq \mathrm{Yi})$. Specifics related to the outcome, conditions, calibrations, and the analyses of necessary and sufficient conditions, are subsequently presented in greater detail. 


\subsubsection{Operationalization and calibration of measurements}

\subsubsection{Outcome}

The outcome of this study is the community focus in AF projects. Data for the outcome are collected from $30 \mathrm{AF}$ project documents across three dimensions: financial investment in community-level activities, community participation, and devolved decision-making. We develop a codebook to guide our extraction of data for the three dimensions using AtlasTi. (see Supplementary Material 3).

For the financial dimension, we apply the granular approach of the climatefinance tracking methodology jointly developed by multilateral development banks (IADB et al., 2017). Specifically, we identify within each project components and sub-components that invest in community-level activities and track the financing attached to them. Once we extract this from each project document, we calculate the community-level budget as a percentage of total project budget for the 30 projects. We exclude from this calculation project administration fees charged by AF implementing entities to identify the true fraction of financing that reaches community adaptation activities. We then convert the percentages into three categories of scores by looking at the distribution of the percentages of community-based project budget in the 30 projects: the top one-third of projects with highest percentages are classified as having "high" financial investment at the community level, the middle third as "medium" level and the bottom third as "low" level. We then assign the score of 3 to "high" projects, 2 to "medium" projects, and 1 to "low" projects, respectively.

We assess the level of community participation using four indicators: 1) the type of public participation during project consultation (ascendingly ranked as consultation, partnership, and community self-mobilization); 2) the number of 
roles played by community actors throughout the project cycle; 3 ) the number of dimensions of climate vulnerability addressed by the project (e.g. livelihood sources, gender, health status, geography etc.); and 4) the number of beneficiary sub-categories (e.g. the elderly, children, women, ethnic minorities etc.). The level of devolved decision-making in AF projects is assessed using three sub-indicators: 1) the type of organizations that the NIEs or MIEs/RIEs contract to serve as project executing entities (EEs), using the typology of international, national, sub-national, and local organizations; 2) the type of organizations that EEs partner with, using the same organizational typology; and 3) the use of mechanisms for local decisionmaking on project approvals and adaptation choices (such as a small grant facility and calls for proposals from communities). We add the scores of the four community participation sub-indicators to calculate an overall community participation score for each of the 30 projects, and do the same for the overall devolved decision-making score. We then use the same distributional approach as for the financial dimension to rank the 30 projects into "high", "medium" and "low" categories and assign the scores of 3, 2, and 1, respectively (See more explanation of the indicators in Supplementary Material 3).

Finally, we add the financial, participation, and devolved decision-making scores to calculate an overall "community focus" outcome score for each of the 30 project cases. A project with a "community focus" outcome score of 9 indicates that it is characterized by high financial investment at the community level (score $=3$ ), high community participation (score $=3$ ) and high devolved decision-making to community-level actors (score $=3$ ). On the other hand, a project with an outcome score of 3 indicates that the project scores low in all the three categories (i.e. score $=1+1+1$ ). Projects with outcome scores between 4 and 8 indicate that they have different mixtures of low, medium, high scores from three dimensions of community focus (See Table A1 in Appendix A for the 30 outcome scores). 


\subsubsection{Conditions}

For the Condition 1 on "past climate-related losses", we use the 20-year average rankings from the Global Climate Risk Index (CRI), a comprehensive and frequently used database to proxy countries' historical climate exposure in cross-country studies (Berrang-Ford et al., 2014; Betzold \& Weiler, 2018; Tranter \& Booth, 2015). For example, if an AF project in India was approved in 2012, we use the 1992-2011 average CRI ranking for India as a proxy for past climate-related losses affecting the decisions of agencies involved in designing such project. This choice of data ensures that we only capture losses materializing before the date of project approval. An average ranking also better reflects a country's overall exposure to climate extremes than one year of data, and better captures the cases whereby AF project decisions are influenced by a cumulative experience of past extreme events.

Data for the Condition 2 on "projected future climate risks" come from the exposure sub-index of the Notre Dame Global Adaptation Initiative (NDGAIN) Country Index, which measures the degree by which a country is biophysically exposed to future climate hazards (Chen et al., 2015). Betzold and Weiler (2018) used the ND-GAIN exposure sub-index and the CRI sideby-side to respectively measure the impacts of past and future climate vulnerability in recipient countries on bilateral donors' allocation of adaptation finance between these countries. They found both indicators to be statistically significant, with the ND-GAIN exposure sub-index scores correlated with both the selection of recipient countries and the allocated amounts, while the CRI only correlated with recipient selection.

For the Condition 3 on "government structure", we use country scores from the Government Closeness Index (GCI). Using data for mid 2000s (mostly 2005), the $\mathrm{GCl}$ is a global database of indicators that do not only measure how decentralized a country's government is, but also how close a 
decentralized government is to its citizens (Ivanyna \& Shah, 2014). While other global databases, such as the tiers of government (Treisman, 2008) and the Varieties of Democracy dataset (V-Dem Institute, 2018), contain decentralization-related indicators for developing countries, the $\mathrm{GCl}$ was specifically designed to capture most closely the discussed concept of "short distances" between national governments and local populations. We therefore consider the $\mathrm{GCl}$ most fit-for-purpose.

For the Condition 4 on "governance of civil society", we use the Governance Environment Sub-index under the CIVICUS Civil Society Enabling Environment Index launched in 2013. Conceptualizing civil society as a space for collective action, the sub-index focuses on governance indicators most theoretically relevant to rights and freedoms which enable civic participation (Fioramonti \& Kononykhina, 2015).

For the Condition 5 on "access modality", we use Atlas.ti to extract information on the condition from the AF project documents. Projects with MIEs and RIEs are coded as indirect access, and projects with NIEs as direct access. Direct access is assigned the value of 1 and indirect access of 0 (See Table A2 in Appendix $A$ for more information on all the data sources for the five conditions).

\subsubsection{Fuzzy-set data calibration}

For each case, we calibrate fuzzy-set scores on the outcome and the five conditions, thus transforming "raw" data into fuzzy-set membership scores. The fsQCA software calibration tool is used for this procedure (Ragin \& Davey, 2016). The calibration tool uses well-informed threshold values to automatically assign fuzzy-set scores to each measurement. The outcome and four conditions have each three threshold values: the full membership in the set (fuzzy-set score $=1$ ), the non-membership in the set (fuzzy-set score 
$=0$ ), and a crossover point above which a case is closer to full membership and below which a case is closer to non-membership. One condition, the access modality, is binary and we do not calibrate it as the data are already in a 0,1 format. Table 6.1 summarizes the thresholds used to calibrate the raw data into fuzzy-set scores. For the detailed distribution of raw and fuzzyset scores of the 30 project cases, see Appendix A, Table A1. Furthermore, the rationale for choosing these specific calibration thresholds are detailed in Appendix A, Table A2. 


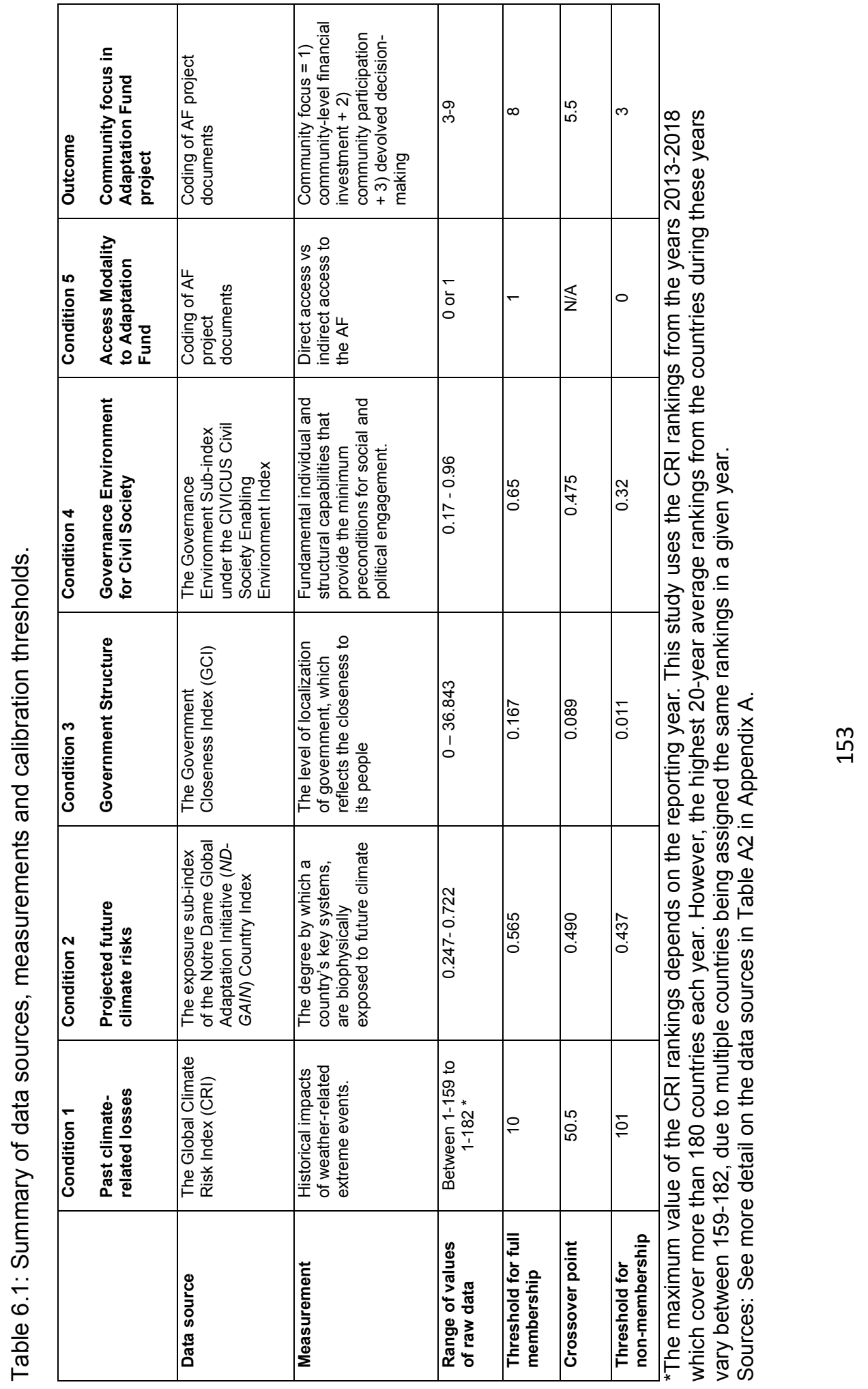




\subsubsection{Research limitations}

Some limitations should be noted given the nature of the study. First, assessing the level of community-focused adaptation is challenging as the concept of community is contested (Kepe, 1999; Titz et al., 2018), and what constitutes community focus is subject to interpretations. While the rich CBA literature significantly shapes the current understanding of key characteristics of community adaptation initiatives, there is no common methodology to assess the level of 'community focus' across projects and countries. Recognizing this complexity, we integrate both quantitative and qualitative perspectives to develop a more informed, and arguably reasonably nuanced, picture of each adaptation project's level of community focus. However, future studies could consider adding more aspects of assessment for a more comprehensive understanding of community-focused adaptation.

Second, the 'community focus' outcome score in this paper represents an overview of each project's community orientation at the design completion stage but not in its actual implementation. As these projects mature, future studies should assess if they also exhibit post-implementation characteristics of meaningful community-level adaptation such as accountability, transparency, sustainability, flexibility, ownership, capacity building, participatory monitoring and evaluation etc. (Faulkner et al., 2015; Fenton et al., 2015; Terpstra et al., 2013).

Third, limited diversity complicates the analysis of community-focused adaptation in this study. Limited diversity refers to when logically possible combinations of conditions are not covered by empirical evidence (Schneider \& Wagemann, 2012, p.328). In this study, 15 of 32 different configurations of conditions are not assigned empirical cases, which impedes a full-fledged conclusion based on observations. Future research could aim to test the observed configurational evidence from this study with more cases. 
Finally, the study is designed to focus on the country-level enabling conditions for internationally financed, community-focused adaptation projects. As a result, it does not capture the importance of regional and local contexts which could also shape the outcome. However, there are severe data limitations to assess regional and local conditions across developing countries. Future research could explore relevant regional and local conditions and potential data sources for them, as well as identify more project cases to provide additional insights on the scale and configurational logic tested in this study. Adding multiple projects for each country would also bring the opportunity to better assess the within-country variations of different community-focused projects.

\subsection{Results}

This section presents the analyses of necessary and sufficient conditions for the presence of the outcome (a stronger community focus in AF projects) and the absence of the outcome (a weaker community focus in AF projects). It must be noted that both analyses employ two parameters of fit. The first parameter is called "consistency" and indicates the degree to which the subset relation is approximated. Values of consistency can range between 0 and 1 , with higher values indicating a better subset relation. There are no clearly defined standards to set the benchmark for consistent subset relations (Schneider \& Wagemann, 2010), but a consistency value of 0.80 is generally seen as the minimum accepted cut-off point for a reliable set analysis for sufficiency (Ragin, 2009). A consistency threshold of 0.9 is advised for necessity (Schneider \& Wagemann, 2012, p.143).

The second parameter of fit is "coverage" and indicates the relation in size of the overlap between the condition set and the outcome set. In the analysis of necessary conditions, the coverage shows the relevance and trivialness of a necessary condition (Schneider \& Wagemann, 2012). Similarly, in the 
analysis of sufficient conditions, the coverage shows how much of the outcome is covered by the sufficient condition at hand (Schneider \& Wagemann, 2012, p.325).

For simplicity, all measurements have been assigned a one-word coding, which is specified when results for the necessary and sufficient conditions are presented. The wording of each condition and the outcomes is outlined in Table 6.2.

\subsubsection{Necessary conditions}

The analysis of necessary conditions includes the presence and absence of all conditions for both the presence and absence of the outcome. Table 6.2 presents the findings of the necessity analysis. We find no necessary condition for the presence of the outcome. However, with a consistency score of 0.91 , we find that the absence of high exposure to future climate risks is a necessary condition for the absence of the outcome. Although the consistency score of 0.91 is relatively high, it is slightly below the perfect consistency score of 1.00 , so we approach this condition as 'quasinecessary'. With a moderate coverage score of 0.52 , we conclude that the absence of high exposure to future climate risks is a nontrivial necessary condition for a weaker community focus in AF projects. However, it does not explain the full variation in the weakness of community focus exhibited by the projects. 
Table 6.2: Analysis of necessary conditions for stronger and weaker community-focus in AF projects

\begin{tabular}{|c|c|c|c|c|c|}
\hline \multirow[t]{2}{*}{ Condition } & \multirow[t]{2}{*}{ Code } & \multicolumn{2}{|c|}{$\begin{array}{l}\text { Stronger community- } \\
\text { focus in AF projects } \\
\text { (Presence of the } \\
\text { outcome) }\end{array}$} & \multicolumn{2}{|c|}{$\begin{array}{l}\text { Weaker community- } \\
\text { focus in AF projects } \\
\text { (Absence of the } \\
\text { outcome) }\end{array}$} \\
\hline & & Consistency & Coverage & Consistency & Coverage \\
\hline \multirow{2}{*}{$\begin{array}{l}\text { Past } \\
\text { climate- } \\
\text { related } \\
\text { losses }\end{array}$} & CLIMPAST & 0.39 & 0.71 & 0.46 & 0.58 \\
\hline & climpast & 0.77 & 0.67 & 0.77 & 0.47 \\
\hline \multirow{2}{*}{$\begin{array}{l}\text { Projected } \\
\text { future } \\
\text { climate risks }\end{array}$} & CLIMFUTURE & 0.42 & 0.87 & 0.29 & 0.42 \\
\hline & climfuture & 0.72 & 0.59 & $0.91^{*}$ & 0.52 \\
\hline \multirow{2}{*}{$\begin{array}{l}\text { Government } \\
\text { structure }\end{array}$} & GOVSTRUCTURE & 0.69 & 0.60 & 0.73 & 0.44 \\
\hline & govstructure & 0.36 & 0.65 & 0.35 & 0.44 \\
\hline \multirow{2}{*}{$\begin{array}{l}\text { Governance } \\
\text { of civil } \\
\text { society }\end{array}$} & GOVCIVIL & 0.59 & 0.69 & 0.61 & 0.50 \\
\hline & govcivil & 0.57 & 0.68 & 0.61 & 0.51 \\
\hline \multirow{2}{*}{$\begin{array}{l}\text { Access } \\
\text { modality }\end{array}$} & MODALITY & 0.47 & 0.64 & 0.38 & 0.36 \\
\hline & modality & 0.53 & 0.55 & 0.62 & 0.45 \\
\hline
\end{tabular}

Source: Authors' analysis.

Note: Uppercase letters refer to the presence of a condition, and lowercase letters to the absence of a condition.

${ }^{*}$ consistency score $\geq .90$.

Nevertheless, our analysis suggests that, without a high degree of vulnerability to future climate harms, countries would not have acted to direct more AF project financing towards local communities. However, given that there is no necessary condition for the presence of the outcome, the opposite is not the case; a higher degree of vulnerability to future climate harms does not guarantee the presence of a stronger community focus in AF projects. This can be interpreted as when countries are highly exposed to future climate risks, whether or not they would design AF projects to have a stronger community focus is not explained by one necessary condition, but a configuration of sufficient conditions. 


\subsubsection{Sufficient conditions for stronger community focus in AF projects.}

The analysis of sufficiency is performed by outlining the logical combinations of all conditions and linking them to the presence or the absence of the outcome. The analysis produces three types of solution terms: conservative, parsimonious, and intermediate. Here, we follow the recommendation of Baumgartner \& Thiem (2017) (p.24) and present the parsimonious solution, as it represents the superset of the intermediate and complex solutions and was found to better reflect analyses exposed to limited empirical diversity. Table 6.3 presents the results of the analysis of sufficient conditions of this study. The conservative solution, which does not use simplifying assumptions in logical minimization, and intermediate solution, whose logical minimization is informed by directional expectations from theories, are also presented in the Appendix B. The truth tables showing all logical combinations for the analysis of sufficient conditions are included in the Appendix C.

We find that the parsimonious solution contains three paths of configurations of sufficient conditions enabling AF projects with a stronger community focus (Table 6.3). The consistency score of the overall solution formula (encompassing the entire solution) is 0.805 , meaning that the claim that these configurations are sufficient for the outcome to occur is supported by empirical evidence. The coverage score of 0.690 indicates that the solution formula explains roughly $69 \%$ of the outcome when it is present. Overall, cases may have membership in more than one configuration, as is the case of projects in Mali, Kenya, Rwanda, and Ethiopia because the memberships in configuration of sets may overlap.

We present the solutions in a configuration format, using the coding of conditions as presented in Table 6.2. Terms in capital letters mean the presence of the condition, while lower-case terms mean the absence of the condition. Furthermore, the sign "* " indicates the logical relation "AND" 
between the conditions. Configuration 1 contains a single condition which by itself is sufficient to explain the presence of the outcome. Configurations 2 and 3 contain the so-called INUS conditions, that is conditions which are themselves insufficient but form a necessary part of an unnecessary but sufficient configuration (Schneider \& Wagemann, 2012). In other words, INUS conditions can be understood as relevant elements in the observed configuration in which the outcome is shaped (Cebotari \& Vink, 2013).

\section{Configuration 1: CLIMFUTURE}

Configuration 1 shows that the presence of higher exposure to future climate risks is individually sufficient to explain the presence of a stronger community focus in AF projects in eight cases. The cases are from Niger, India, Mali, Uganda, Ethiopia, Rwanda, Kenya, and Sri Lanka. In these countries, AF projects are designed to have a stronger community focus regardless of the level of past climate-related losses, the decentralization characteristic of government structure, the governance of civil society, and the access modality to the AF.

\section{Configuration 2: GOVCIVIL * modality}

Configuration 2 shows that indirect access AF projects are designed to have a stronger community focus in countries with a more conducive governance environment for civil society. The presence of conducive civil society governance and the indirect access modality work together as INUS conditions for the outcome to occur, regardless of the level of exposure to past and future climate risks and the prevailing level of government decentralization. This configuration applies to six cases, namely Belize, Ghana, Guatemala, Mali, Paraguay and Lebanon. 
Configuration 3: govcivil * MODALITY

Configuration 3 is the flip side of the Configuration 2 and applies to five cases: Ethiopia, Jordan, Morocco, Rwanda, and Kenya. Despite the absence of conducive civil society governance, direct access AF projects are designed to have a stronger community focus. Here, the weak civil society governance and the direct access modality appear together as INUS conditions that explain the outcome of a stronger community focus in AF projects, independently of the roles of past and future climate risks and the level of government decentralization.

6.4.3. Sufficient conditions for weaker community focus in AF projects.

The analysis of sufficient conditions for the absence of the outcome uses the same five conditions employed in the previous analysis. The fuzzy-set analysis indicates that there are two paths in the parsimonious solution that are sufficient to explain a weaker community focus in AF projects (Table 6.3). The overall solution consistency is high (0.84), suggesting that its claim is empirically supported. At the same time, the overall coverage score of 0.38 means that the solution formula explains roughly $38 \%$ of the outcome of a weaker community focus in AF projects. This suggests that a large part of the negated outcome remains unexplained by the conditions in Configurations 4 and 5. Further research may unveil additional conditions relevant to explaining a weaker community focus in AF projects.

Configuration 4: govcivil * GOVSTRUCTURE * CLIMPAST

Configuration 4 shows that AF projects with a weaker community focus can be found in the context of recipient countries with weak civil society governance, despite these countries having decentralized governments and having experienced high losses from past climate-related extremes. This 
situation applies to projects in Honduras and Colombia and occurs regardless of the countries' exposure to projected future climate risks and the access modality to the AF.

Configuration 5: govstructure * climfuture ${ }^{*}$ climpast ${ }^{*}$ modality

Configuration 5 shows that a configuration of four conditions-centralized government, low exposure to future climate risks, low past climate-related losses and the use of indirect access modality to access AF funding-explains a weaker community focus in AF projects in Egypt and Mauritania, regardless of the governance environment of civil society. 
Table 6.3: Fuzzy-set analysis of sufficient conditions for stronger and weaker community-focus in AF projects (parsimonious solutions)

\begin{tabular}{|c|c|c|c|c|c|c|}
\hline \multirow[b]{2}{*}{ Condition } & \multirow[b]{2}{*}{ Code } & \multicolumn{3}{|c|}{$\begin{array}{l}\text { Stronger community-focus in AF } \\
\text { projects }\end{array}$} & \multicolumn{2}{|c|}{$\begin{array}{l}\text { Weaker community- } \\
\text { focus in AF projects }\end{array}$} \\
\hline & & $\begin{array}{l}\text { Configura } \\
\text { tion } 1\end{array}$ & $\begin{array}{l}\text { Configura } \\
\text { tion } 2\end{array}$ & $\begin{array}{l}\text { Configura } \\
\text { tion } 3\end{array}$ & $\begin{array}{l}\text { Configura } \\
\text { tion } 4\end{array}$ & $\begin{array}{l}\text { Configura } \\
\text { tion } 5\end{array}$ \\
\hline \multirow{2}{*}{$\begin{array}{l}\text { Past climate- } \\
\text { related } \\
\text { losses }\end{array}$} & CLIMPAST & & & & $\mathrm{X}$ & \\
\hline & climpast & & & & & $\mathrm{X}$ \\
\hline \multirow{2}{*}{$\begin{array}{l}\text { Projected } \\
\text { future } \\
\text { climate risks }\end{array}$} & CLIMFUTURE & $\mathrm{X}$ & & & & \\
\hline & climfuture & & & & & $\mathrm{X}$ \\
\hline \multirow[t]{2}{*}{$\begin{array}{l}\text { Government } \\
\text { structure }\end{array}$} & $\begin{array}{l}\text { GOVSTRUCT } \\
\text { URE }\end{array}$ & & & & $\mathrm{X}$ & \\
\hline & govstructure & & & & & $\mathrm{X}$ \\
\hline \multirow{2}{*}{$\begin{array}{l}\text { Governance } \\
\text { of civil } \\
\text { society }\end{array}$} & GOVCIVIL & & $X$ & & & \\
\hline & govcivil & & & $x$ & $\mathrm{X}$ & \\
\hline \multirow{2}{*}{$\begin{array}{l}\text { Access } \\
\text { modality }\end{array}$} & MODALITY & & & $\mathrm{X}$ & & \\
\hline & modality & & $X$ & & & $\mathrm{X}$ \\
\hline Cases & & $\begin{array}{c}\text { Niger, } \\
\text { India, Mali, } \\
\text { Uganda, } \\
\text { Ethiopia, } \\
\text { Rwanda, } \\
\text { Kenya, Sri } \\
\text { Lanka }\end{array}$ & $\begin{array}{c}\text { Belize, } \\
\text { Ghana, } \\
\text { Guatemala, } \\
\text { Mali, } \\
\text { Paraguay, } \\
\text { Lebanon }\end{array}$ & $\begin{array}{c}\text { Ethiopia, } \\
\text { Jordan, } \\
\text { Morocco, } \\
\text { Rwanda, } \\
\text { Kenya }\end{array}$ & $\begin{array}{l}\text { Honduras, } \\
\text { Colombia }\end{array}$ & $\begin{array}{c}\text { Egypt, } \\
\text { Mauritania }\end{array}$ \\
\hline Consistency & & 0.872 & 0.788 & 0.861 & 0.869 & 0.809 \\
\hline $\begin{array}{l}\text { Raw } \\
\text { coverage }\end{array}$ & & 0.421 & 0.318 & 0.238 & 0.254 & 0.145 \\
\hline $\begin{array}{l}\text { Unique } \\
\text { coverage }\end{array}$ & & 0.134 & 0.172 & 0.097 & 0.233 & 0.123 \\
\hline $\begin{array}{l}\text { Solution } \\
\text { consistency }\end{array}$ & \multicolumn{4}{|c|}{0.805} & \multicolumn{2}{|c|}{0.844} \\
\hline $\begin{array}{l}\text { Solution } \\
\text { coverage }\end{array}$ & \multicolumn{4}{|c|}{0.690} & \multicolumn{2}{|c|}{0.378} \\
\hline
\end{tabular}

Source: Authors' analysis.

Note: Uppercase letters refer to the presence of a condition, and lowercase letters refer to the absence of a condition. 


\subsection{Discussion}

We briefly discuss the QCA results, focusing on each of the five conditions and how they relate to community focus in AF projects as the outcome, before discussing the contributions of our work to the debates on international adaptation finance.

When comparing the two conditions representing recipient-country climate vulnerability (Conditions 1 and 2), we find that the exposure to future harms has a stronger explanatory value, as its absence is found to be a necessary condition for a weaker community focus in AF projects, while its presence is also sufficient by itself to explain a stronger community focus in AF projects in eight countries (Niger, India, Mali, Uganda, Ethiopia, Rwanda, Kenya, and Sri Lanka). On the other hand, the accumulated experience from past climaterelated losses does not help explain any case of stronger community focus in AF projects, while its absence only forms part of the observed explanation for a weaker community focus in two AF projects, but for which the projected future climate risks condition also plays a contributing role.

We interpret these findings to support the theoretical expectation that national governments, especially when using international adaptation finance to protect local communities, have more incentives to plan for adaptation as anticipatory actions than as reaction to past climate extremes, which differs from the finding of Conevska et al. (2018). Our finding also expands BerrangFord et al. (2011) by providing new evidence that developing-country governments are also anticipatory adaptation actors, and offers counterevidence to studies that found scientific uncertainties and long timeframes associated with climate projections to be a key barrier for anticipatory adaptation actions (Barnett, 2001; Ford, Berrang-Ford, Bunce, et al., 2015). Three factors could offer explanations for our findings. First, both improved weather monitoring and downscaled climate projections have enabled climate 
vulnerability assessment at sub-national scales, thus allowing AF projects to identify climate hotspots and better target vulnerable groups in these regions. This is evident in the AF project in Sri Lanka, whereby district-level climate vulnerability analyses were used to design adaptation interventions to address increased rainfall variability in the Mahaweli Basin. Second, local communities increasingly perceive changing current climate hazards to be associated with future climate change, thus creating a sense of urgency for actions despite future climate uncertainties. This is evident in the AF project in India, whereby perceptions expressed by hill communities in Uttarakhand during stakeholder consultation have formed the basis for project activities. Third, there has been an increased adoption of the vulnerability-centric framing of adaptation (Dupuis \& Biesbroek, 2013; Hall, 2017), which considers existing development deficits as drivers of social vulnerabilities to future climate change and highlights the need to address these drivers today as anticipatory adaptation. The influence of this framing is present in all eight AF project countries for which the high exposure to future climate risks is a sufficient condition for a stronger community focus.

We do not find the decentralization characteristic of government structure (Condition 3) to be an important condition for community focus in AF projects. While forming part of the sufficient conditions for four cases of AF projects with a weaker community focus, government structure was not part of any configuration of conditions that explains the 19 cases of AF projects with a stronger community focus. On the other hand, the AF projects in Honduras and Colombia exhibit a lower community focus despite the presence of more localized governments, which contradicts the theoretical expectation for the government structure condition. This high decentralization-low community focus anomaly could be potentially explained by the presence of barriers that prevent the decentralization promise for bottom-up adaptation from being realized. These barriers include limited connection and information flows between national and local government actors, unclear division of 
responsibilities in adaptation planning and financing (Brockhaus \& Kambiré, 2009), limited technical capacities among local government agencies (Madzwamuse, 2011), limited integration of civil society in the decentralized processes (Brockhaus \& Kambiré, 2009), and potential capture of decentralized decision-making by local elites (Bardhan, 2002; Persha \& Andersson, 2014).

We find that the conducive governance environment of civil society (condition 4 ) is an important contextual condition for community focus in AF projects. This is evidenced by the presence of this condition in Configuration 2 and its absence in Configuration 3, which together explain a stronger community focus in 11 project cases, and also by its absence in Configuration 4 that explains a weaker community focus in two project cases. In Belize, Ghana, Guatemala, Mali, and Paraguay, our finding indicates that conducive civil society governance plays a key role in shaping indirect access AF projects to have a stronger community focus. Arguably, the conducive governance environment has allowed civil society organizations in these countries to effectively communicate the expectations of targeted project communities to MIEs/RIEs during consultation processes, thus closing the knowledge gap on local realities which could have otherwise inhibited community-focused project design. However, despite the presence of both decentralized governments and high exposure to past climate-related losses, the presence of unconducive civil society governance still contributes to a lower community focus in AF projects in Honduras and Colombia. This is potentially because civil society organizations operating in this environment are unlikely to effectively mobilize and represent vulnerable local communities in AF project consultation processes. These findings support the theoretical expectation for the GOVCIVIL/govcivil condition (condition 3). However, we also find cases of a stronger community focus in AF projects in Ethiopia, Jordan, Morocco, Rwanda, and Kenya, despite the presence of weaker civil society governance. Since all of these cases are direct access projects, the finding 
suggests that the role of the direct access modality should be investigated closely to understand the presence of a stronger community focus in these cases.

It should be noted that Lebanon is a deviant case in our analysis above due to the ambiguous membership (0.52) in Configuration 2 and also a very low membership score in the outcome (0.05). In this ambiguous case, the indirect access project in Lebanon exhibits a low community focus (0.05), despite the country having a conductive governance environment for civil society (0.52). However, the borderline membership of 0.52 barely fulfills the status of having a conductive governance environment in Lebanon, and the influence of this condition appears to be outweighed by a weaker community focus in the project design. This contradicts the pattern seen in other cases under Configuration 2. This therefore suggests that it will be controversial to consider Lebanon as a typical case for either weak or strong community focus in subsequent process tracing analysis of causal mechanisms linked to configurations outlined in this study.

Finally, our finding confirms that the access modality (condition 5) is another important contextual condition. We draw this conclusion because the condition helps explain the presence of a stronger community focus in 11 project cases and the absence of such outcome in two project cases. However, our result also suggests that the MODALITY/modality condition on its own is not sufficient for the presence or absence of the outcome, but it works configurationally with other conditions. For the presence of the outcome, the access modality condition works in conjunction the governance environment for civil society condition. On the one hand, the "GOVCIVIL *modality" configuration indicates that an enabled civil society could help compensate for the long distances between local communities and MIEs/RIEs, leading to indirect access AF projects with a stronger community focus. On the other hand, the "govcivil"MODALITY" configuration suggests 
that the direct access modality helps shorten the vertical distances between AF project consultation processes and local civil society organizations in recipient countries, despite them being otherwise constrained by the overall weak civil society governance environment. In this sense, our finding lends support to the theoretical expectation that the direct access modality could "in certain national contexts, lead to greater civil society participation in the AF project cycle" (Ballesteros et al., 2010, p.28). For the absence of the outcome, the indirect access modality works in conjunction with the low levels of past climate-related losses (condition 1) and projected future climate risks (condition 2) and the presence of a centralized government structure to explain a weaker community focus in AF in two recipient countries. These findings also support the theoretical expectations discussed in section 6.2.2.

Overall, our findings contribute to the adaptation literature in three ways. First, by looking at projects financed by the $A F$, we place these planned community adaptation initiatives in the context of global climate governance, in which mobilizing and transferring finance is an important mode of such governance (Hall \& Persson, 2017). This differs from, but complements, much of the existing literature that discusses these initiatives as local actions shaped largely by within-community characteristics including risk perceptions, local knowledge systems and capacity of local institutions (Alam et al., 2017; Lebel, 2013; Sekine et al., 2009).

Second, we add new insights to the growing body of literature that discusses the limits of stand-alone community adaptation actions and emphasizes the importance of macro-level enabling factors (Adhikari \& Taylor, 2012; Archer et al., 2014; McNamara \& Buggy, 2017; Mimura et al., 2014; Regmi \& Star, 2015; Spires et al., 2014). Our findings bring attention to the role of vulnerability to future climate risks, the governance of civil society and the access modality to international climate funds as three important enabling conditions for internationally-financed, community-focused adaptation. 
Third, while adaptation research has until recently been dominated by indepth, qualitative, single or small-N studies (Biesbroek et al., 2018), this study develops a new and integrated model of assessing community focus in AF projects from the set-theoretic lenses of necessary and sufficient conditions. The methodological innovation of this study is twofold: (a) the fuzzy-set analysis of the community focus in AF projects employs a configurational logic, in which several conditions interrelate and often need to be understood in a conjunctural manner; and (b) to the best of our knowledge, this is the first study to point to a causal asymmetry in the study of community focus in adaptation projects, in that what explains the weaker outcome is not automatically the negation of the conditions, or configuration of conditions, that explains the stronger outcome. The causal asymmetry is often overlooked by studies, as it cannot be captured easily with mainstream data modelling techniques.

This study also makes two contributions to the climate finance literature. First, while previous studies highlighted the potential of the direct access modality in supporting community-level adaptation (Fenton et al., 2014), our findings demonstrate that indirect access adaptation projects could equally focus on local vulnerable communities when working in conjunction with an enabled civil society. In addition, the outcome assessment framework developed for this paper (see Section 6.2.1) could form a basis for developing an operational methodology to track the delivery of global adaptation finance to the community level. The existing standardized tracking methodologies, such as the Rio-Markers used by bilateral donors (OECD, 2016) and the joint climate-finance tracking approach used by multilateral banks (IADB et al., 2017), are not designed to mark community-bounded financing. As a result, there is a major global knowledge gap on the actual amount of global adaptation finance allocations that have reached community-level beneficiaries. A new community-focused methodology is needed to close the 
gap and ensure tracking consistency as part of a transparency mechanism under the Paris Agreement (Lesnikowski et al., 2017).

\subsection{Conclusion}

Using the AF as the case study, this study assesses under which conditions internationally-financed adaptation projects are designed to focus on adaptation investment at the community level. We apply the fuzzy-set QCA methodology to analyze the contextual conditions for a stronger or weaker community focus in AF projects. We find that the absence of high exposure to projected future climate risks is a necessary condition for a weaker community focus in AF projects. We also find that AF projects with a stronger community focus are stimulated by the sole presence of higher exposure to projected future climate risks in a set of countries, and by the complementary roles of civil society and the access modality to the AF in others.

Our findings carry policy implications for global climate finance actors seeking to promote locally inclusive use of international adaptation finance. First, the findings suggest that there are divergent policy pathways to stimulate internationally-financed, community-focused projects in developing countries. While earlier literature highlights the promise of the direct access modality in promoting community-focused adaptation (Fenton et al., 2014), this study shows that access modality by itself does not automatically deliver the community-focused outcome in all country contexts, and works in conjunction with the country context to deliver the outcome only in some countries. The study also shows that community-focused adaptation could be promoted under both direct access and indirect access modalities.

Second, the study shows that country-level enabling conditions matter for shaping the use of international adaptation finance at the project level to be community-focused. While the analysis in this study focuses on the project 
design, the country-level and project-level (access modality) conditions that explain the variation in project design could continue to influence project implementation. For example, in countries where civil society and access modality have complemented each other in driving the community-focused design of AF projects, such collaboration could continue to be important in ensuring that the strong community focus is not diluted throughout the project cycle. However, understanding this collaboration in the context of project implementation, and which policy actions are needed to support it, will require further research.

Finally, when the limited capacity of civil society plays a role in shaping a weak community focus in internationally-financed adaptation projects, particular policy attention should be given to strengthening a conducive environment for civil society to promote bottom-up adaptation approaches. This could include involving civil society actors such as CBOs in local climate awareness campaigns and building their capacity in community engagement and climate finance readiness 


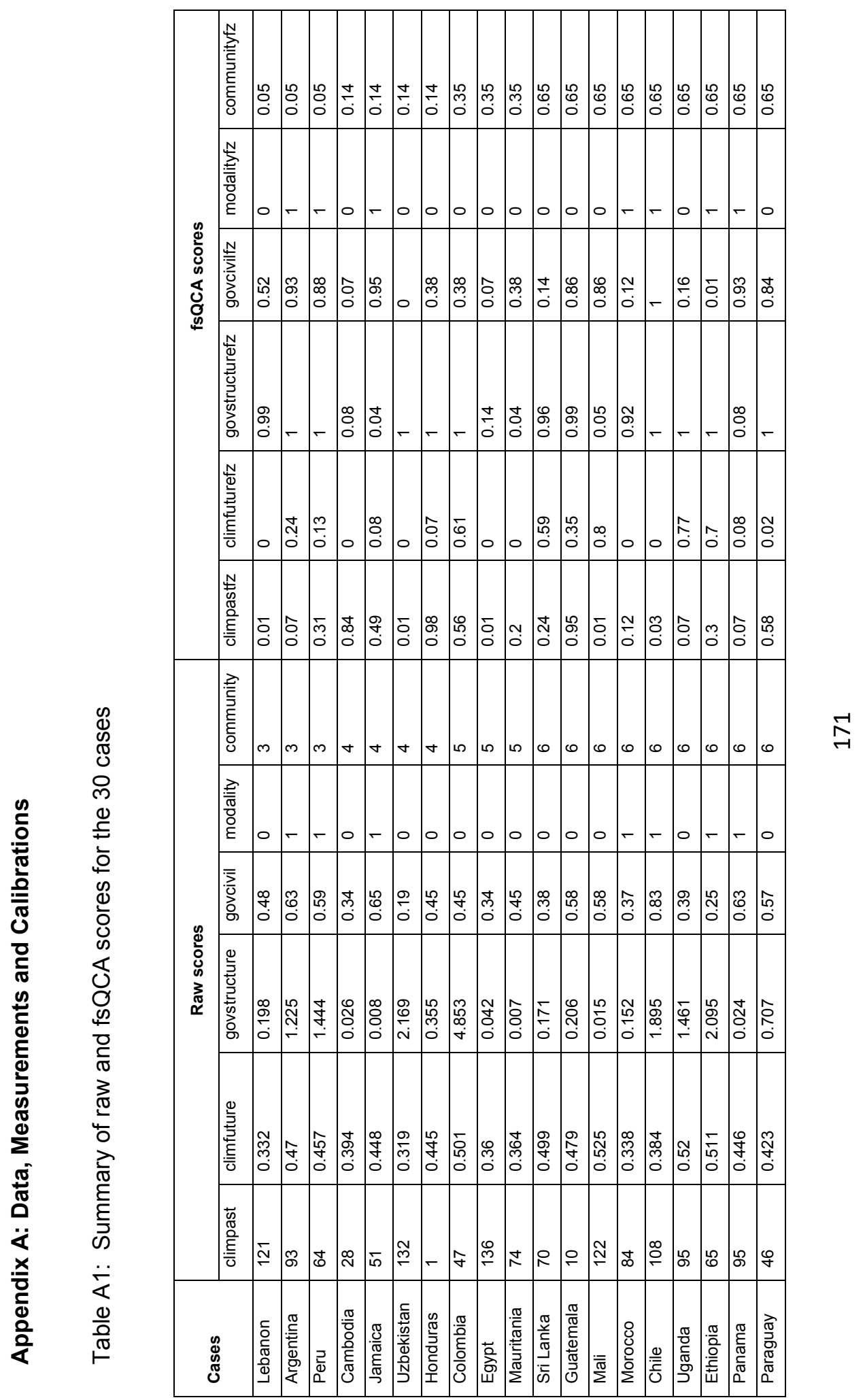




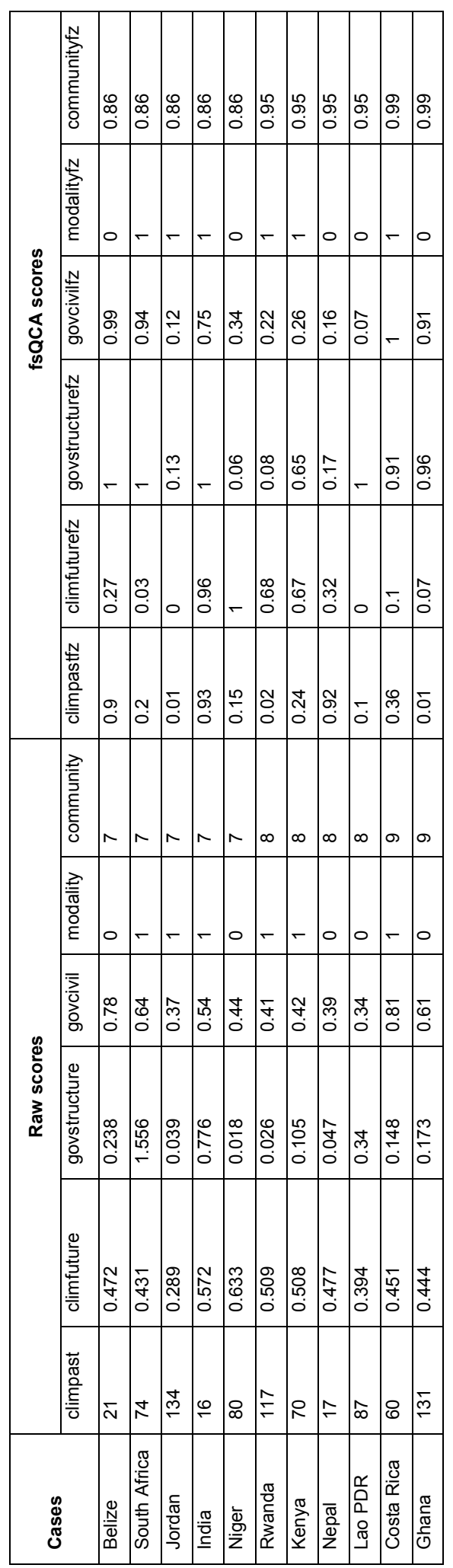




\begin{tabular}{|c|c|c|c|c|c|}
\hline 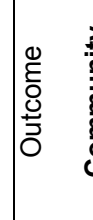 & 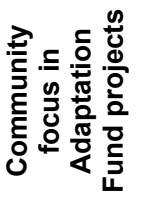 & 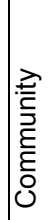 & 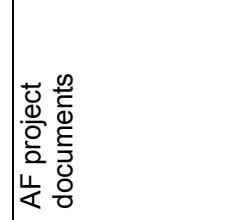 & 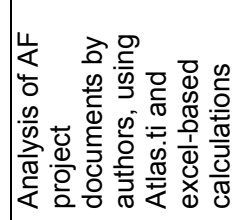 & 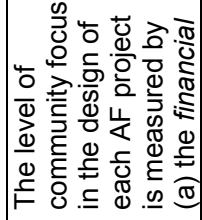 \\
\hline 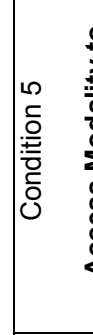 & 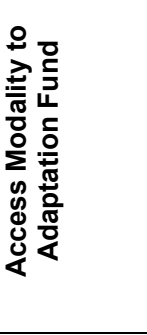 & 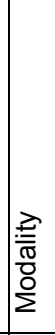 & 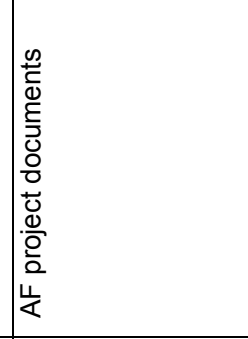 & 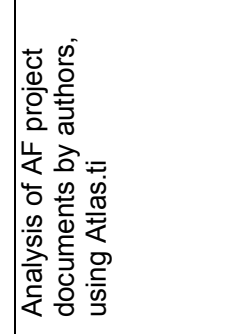 & 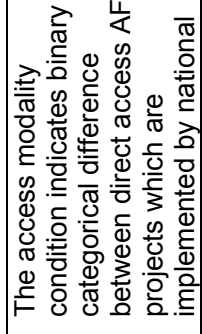 \\
\hline 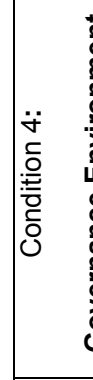 & 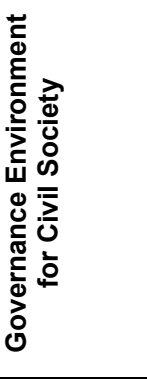 & 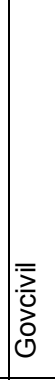 & 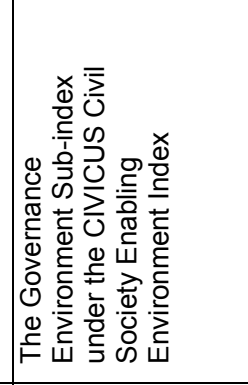 & 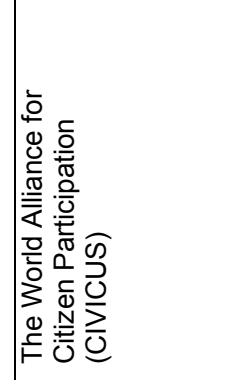 & 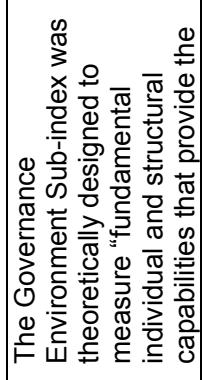 \\
\hline 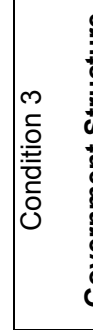 & 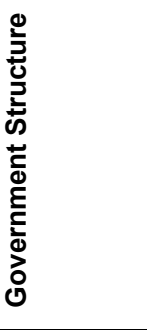 & 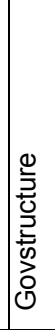 & 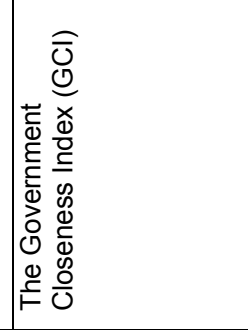 & 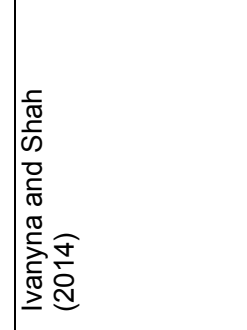 & 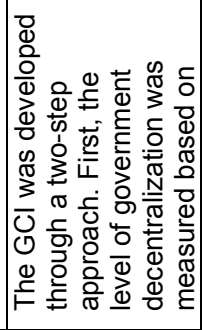 \\
\hline 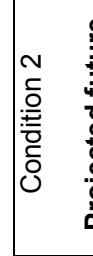 & 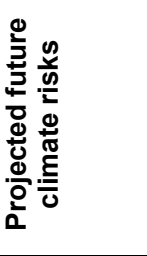 & $\mid$ & 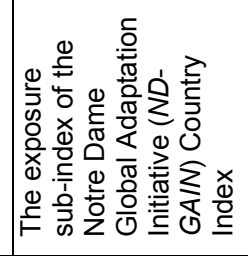 & 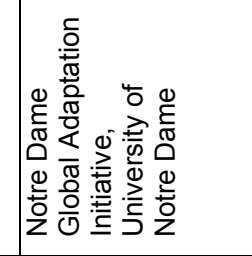 & 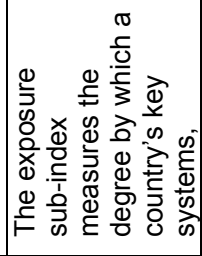 \\
\hline 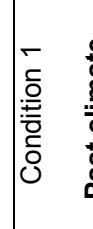 & 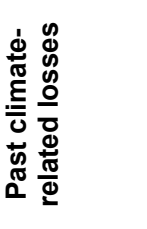 & 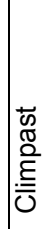 & 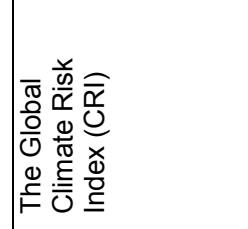 & 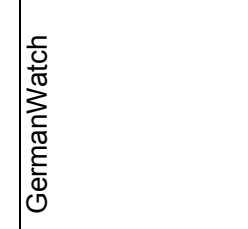 & 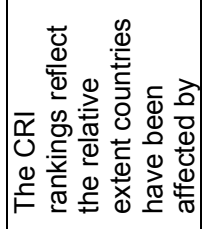 \\
\hline & & ¿ें & 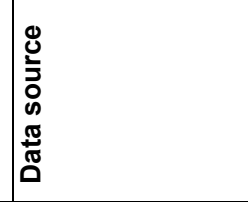 & 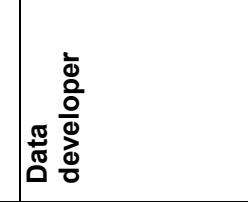 & 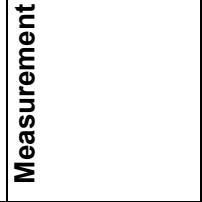 \\
\hline
\end{tabular}




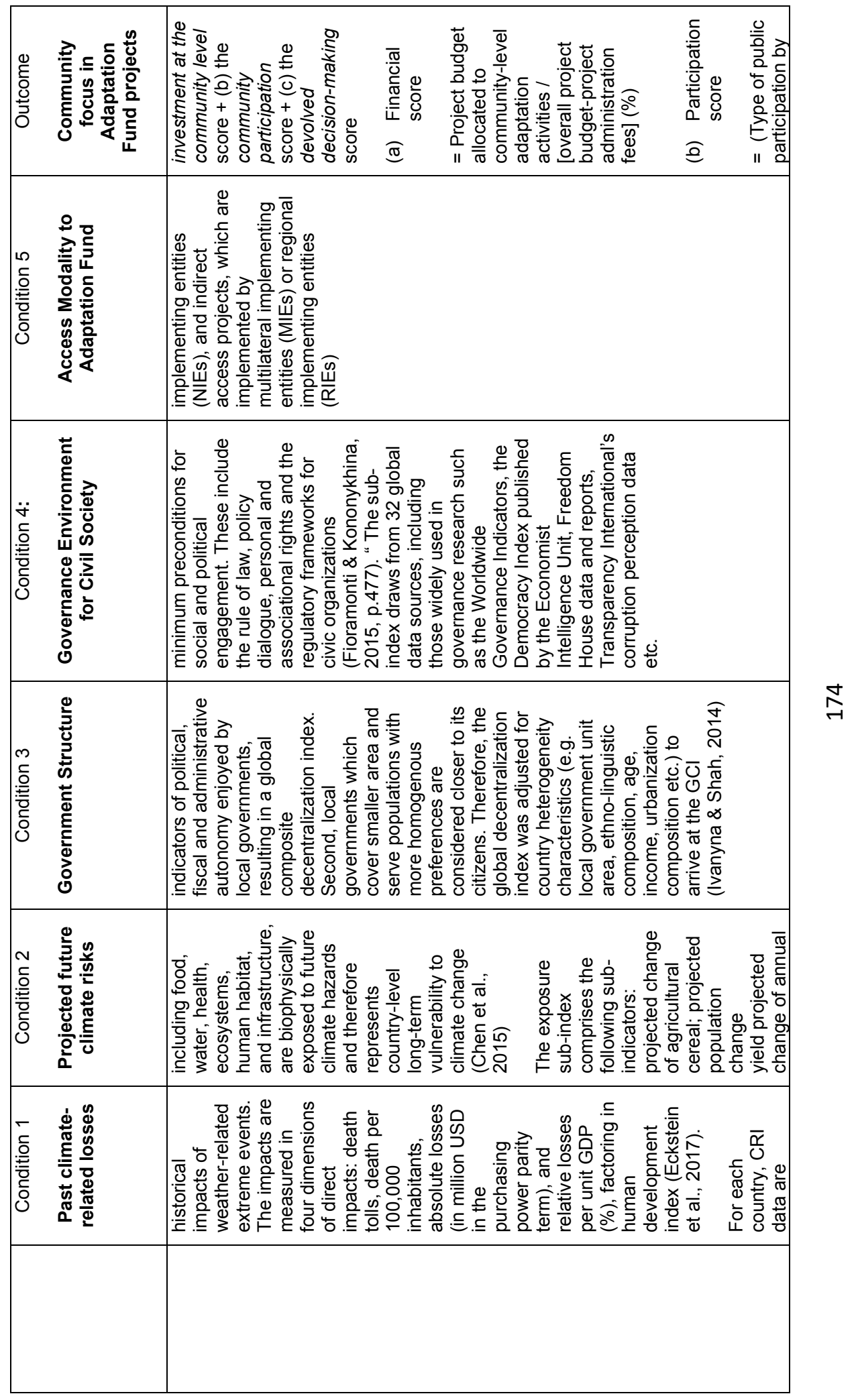




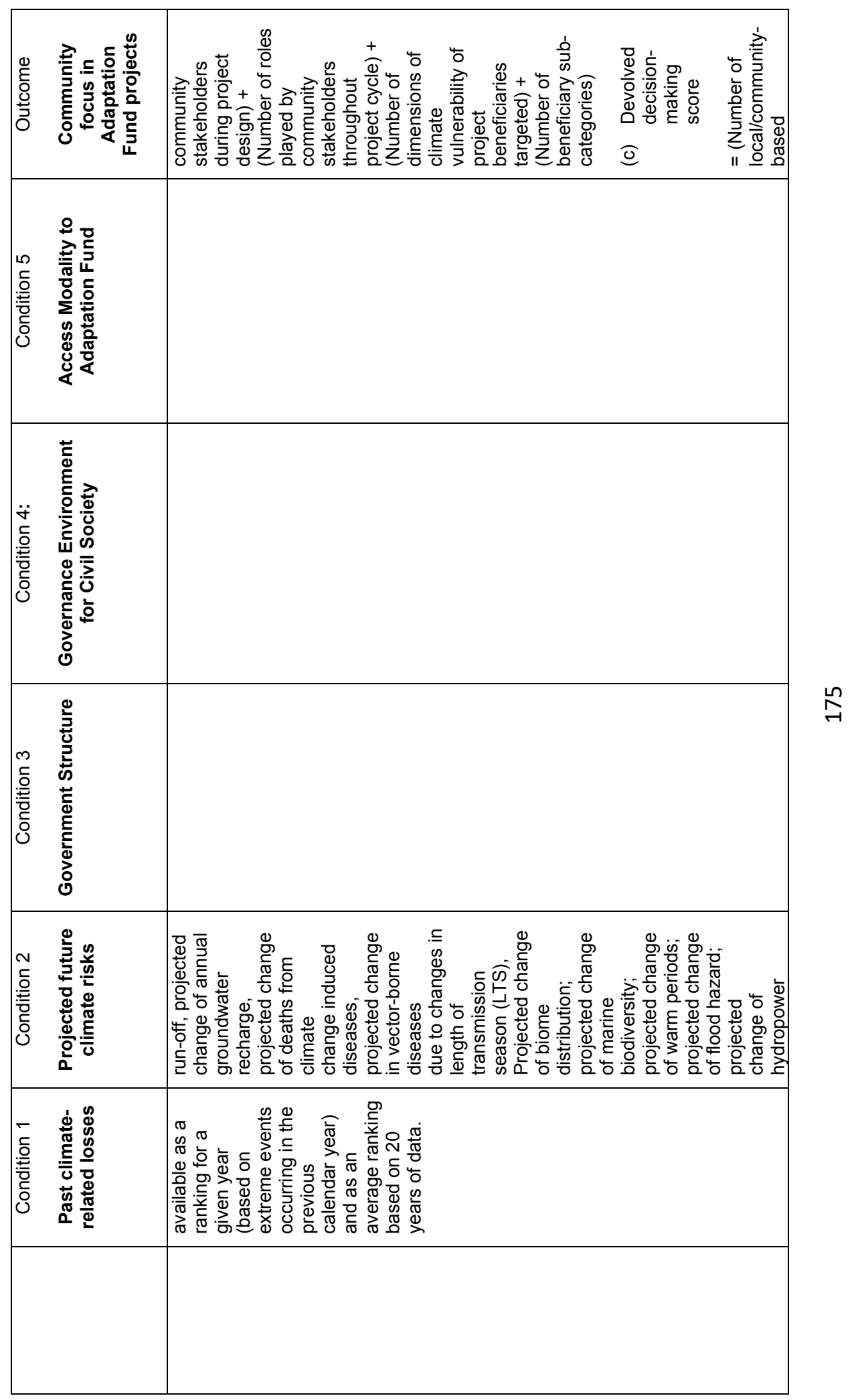




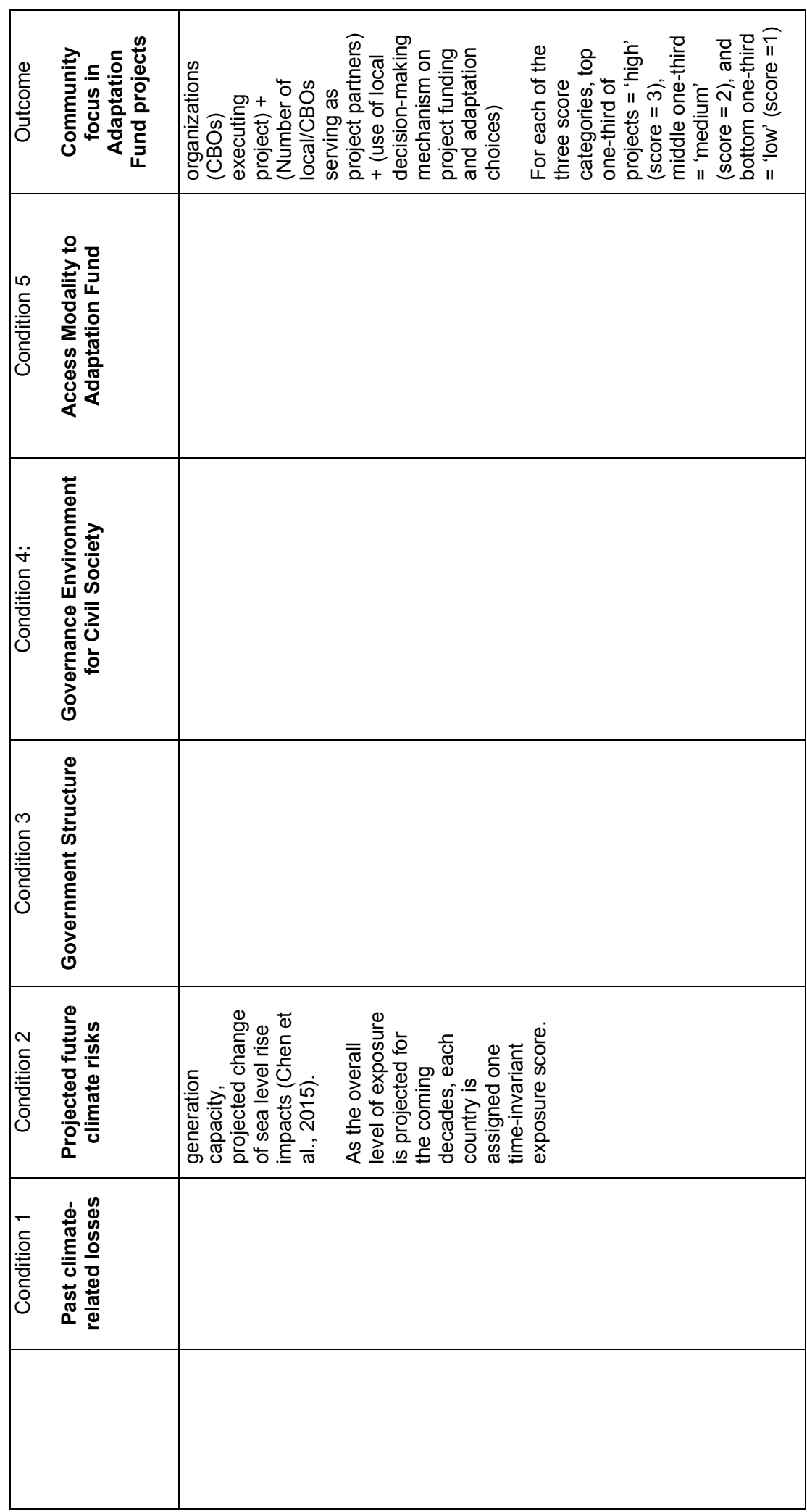




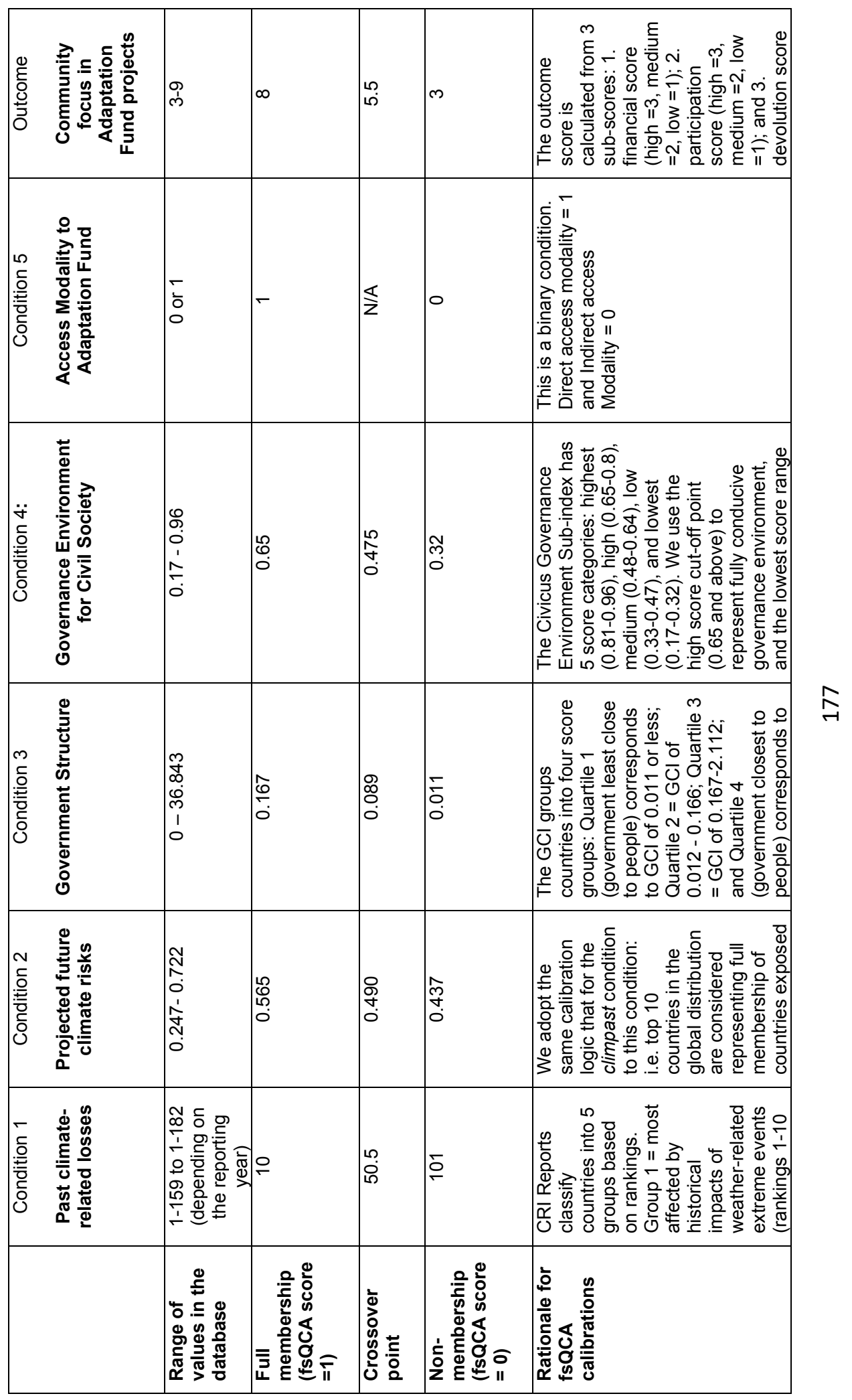




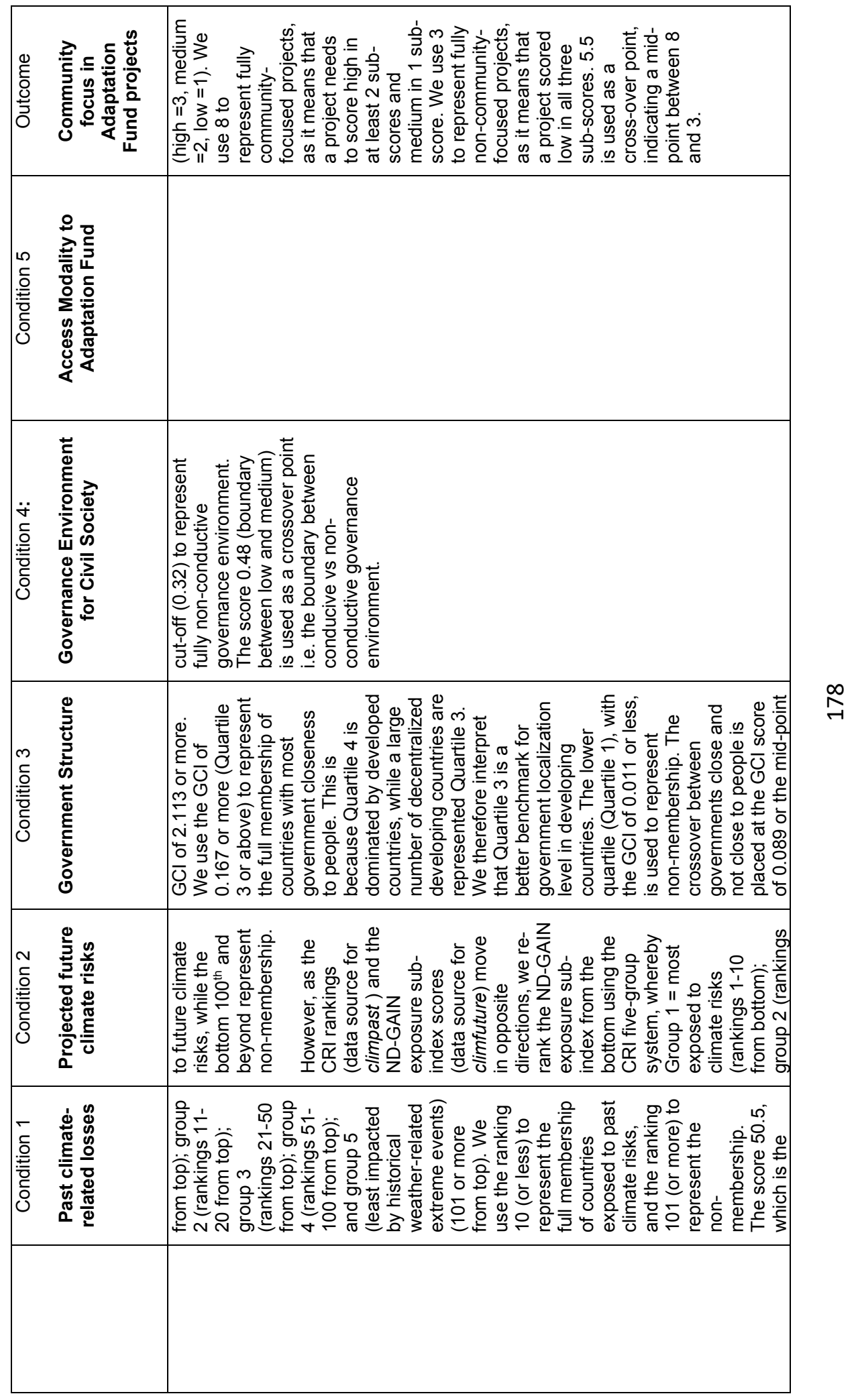




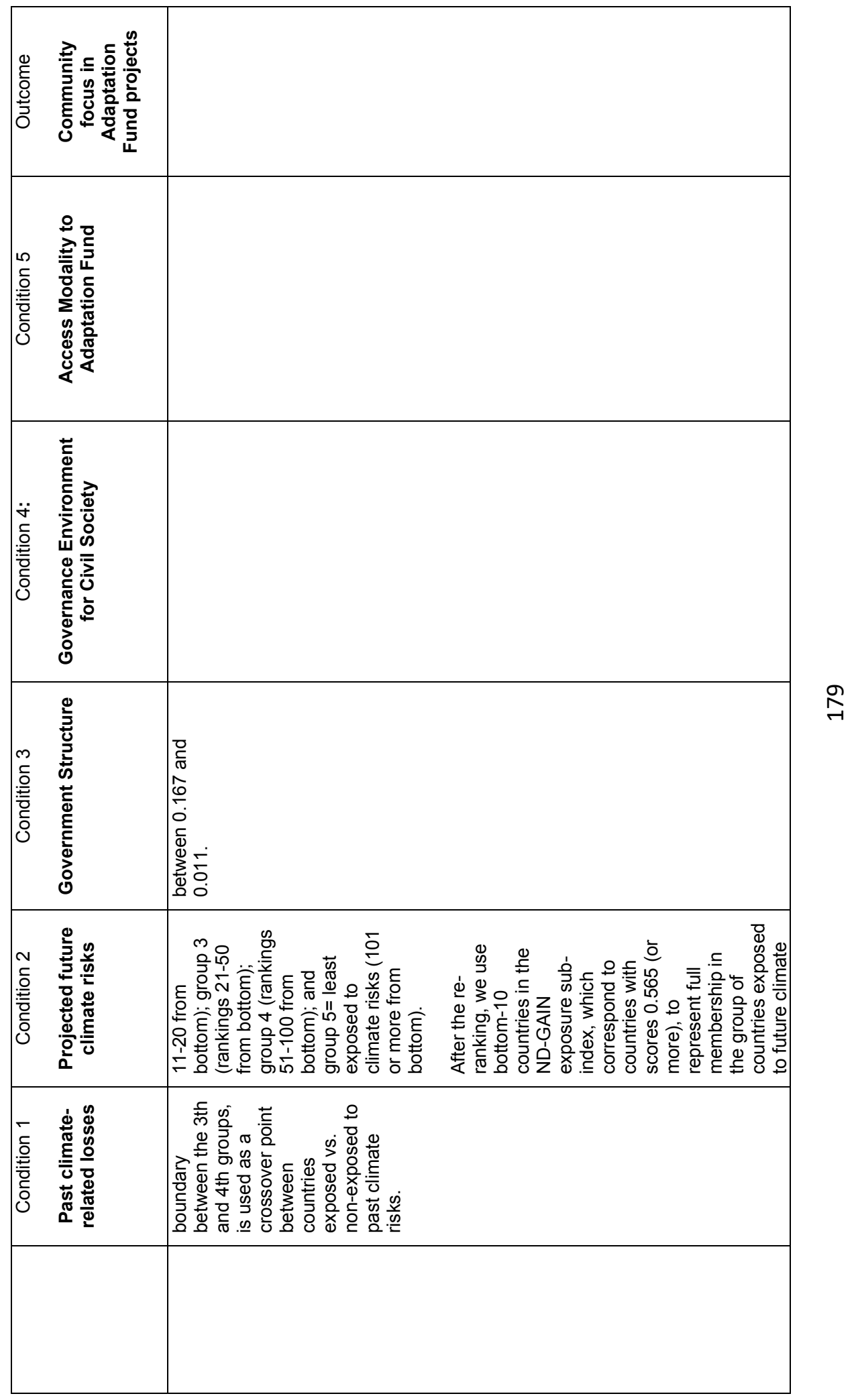




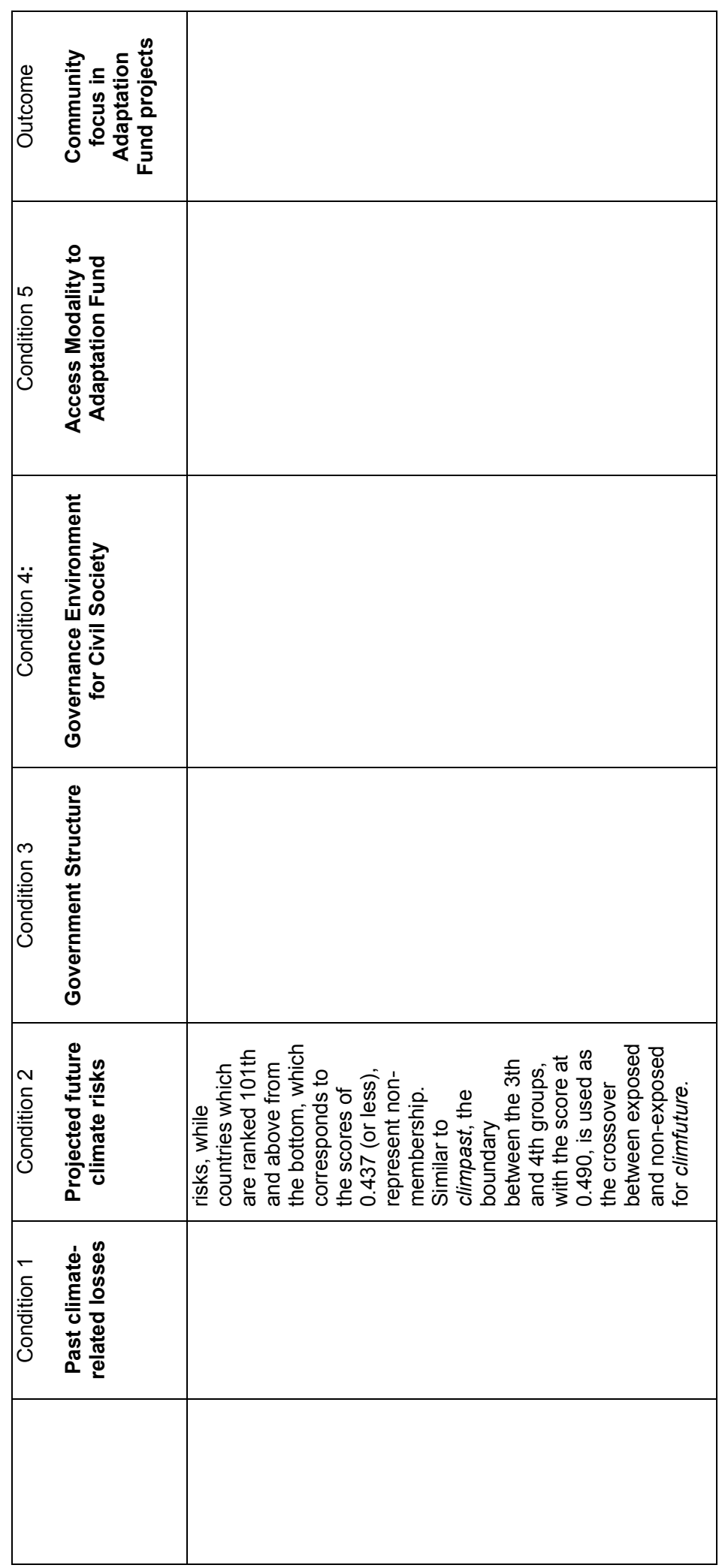

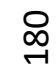




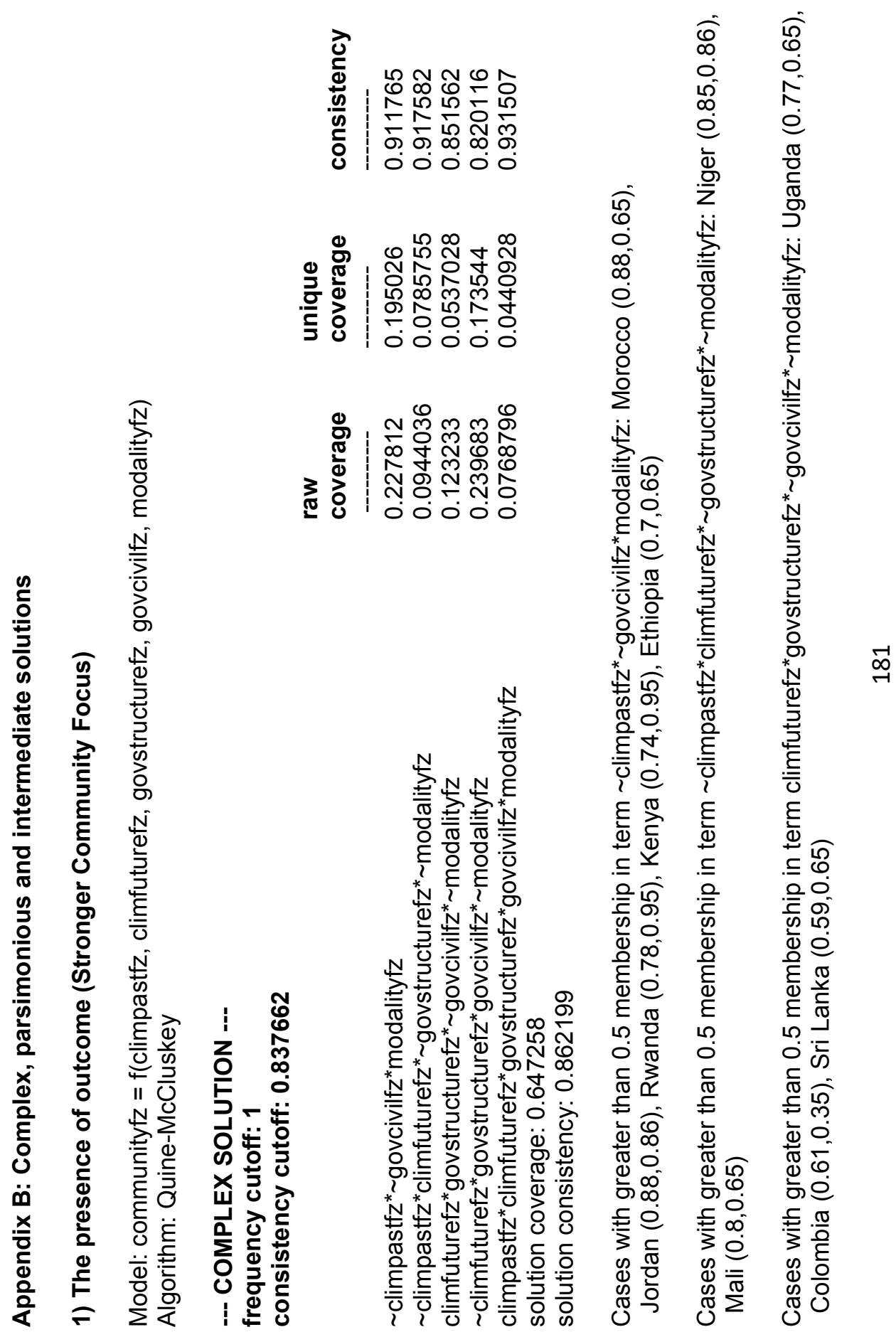




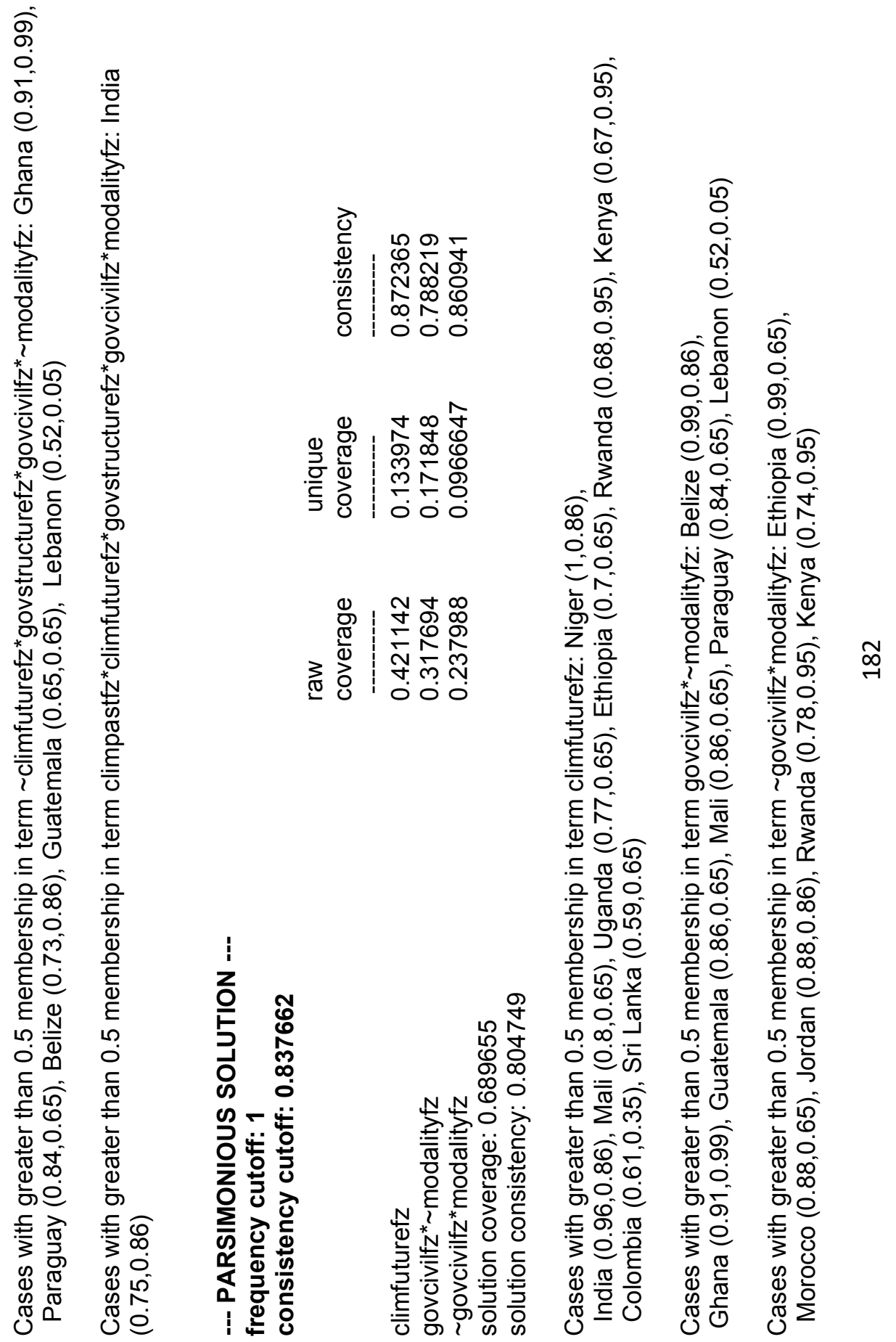



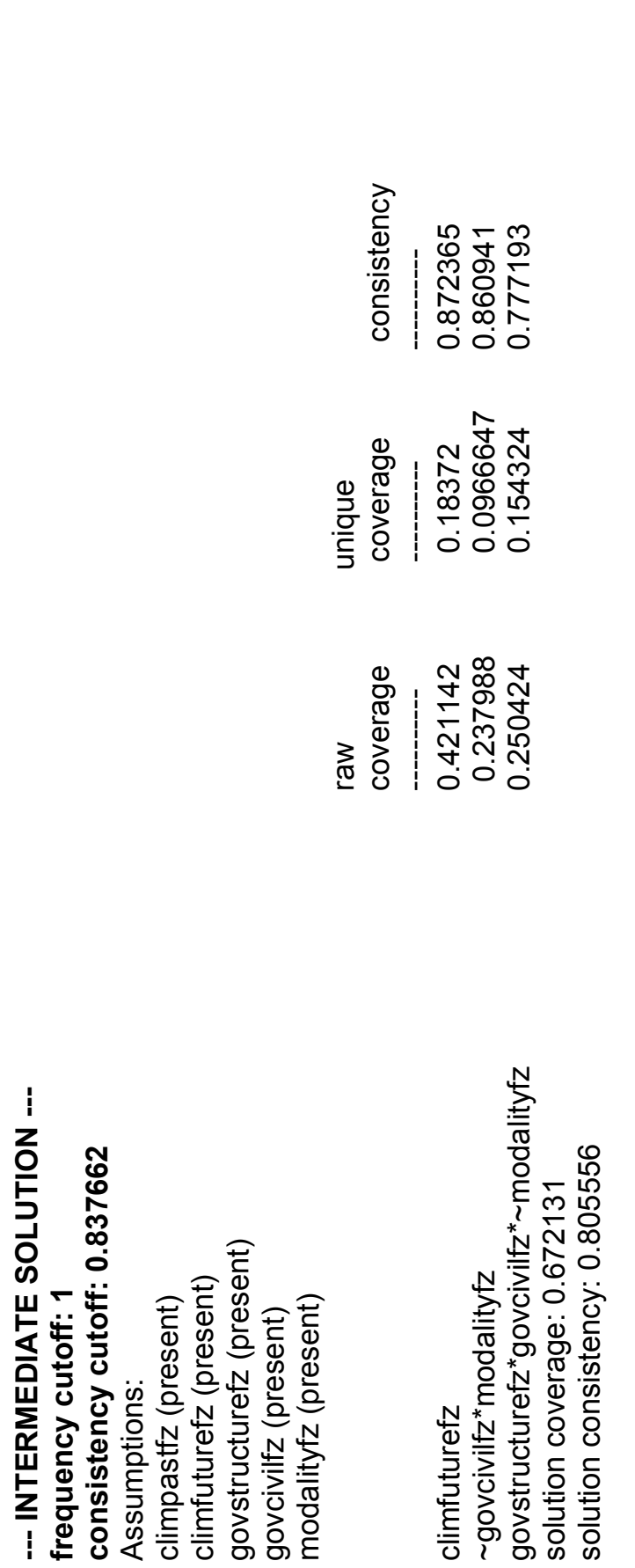

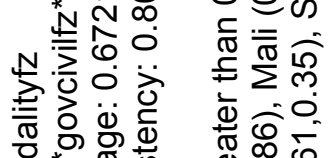

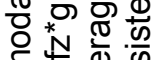

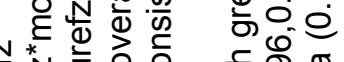
$\stackrel{1}{0}$ तั

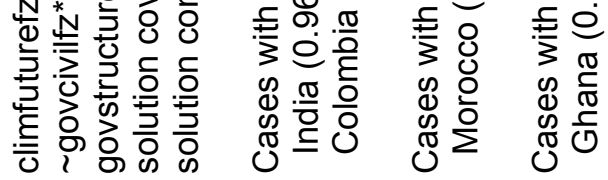

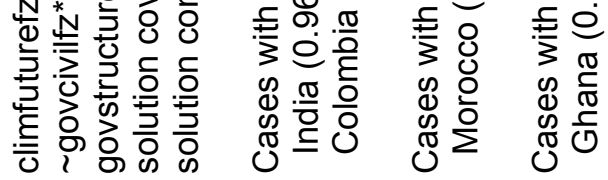

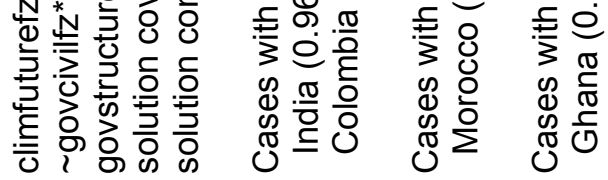

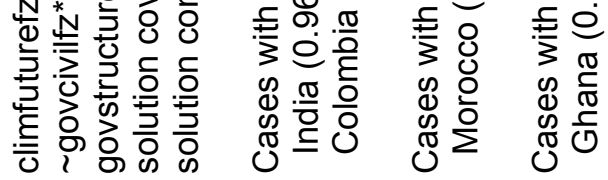

(1)

ब

๑ก กิ่

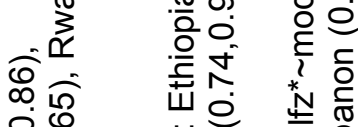

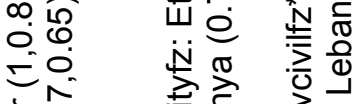
ঠ் 之. ำ

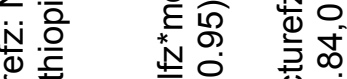
至 है ठी

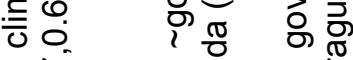

हN ह $\frac{1}{\sigma}$ ह $\stackrel{\Phi}{ \pm}$

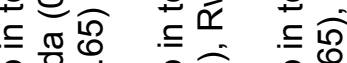

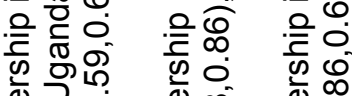

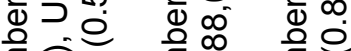
हाँ है है है बֻ

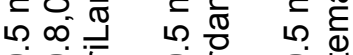
லீㅎํ ส 宅

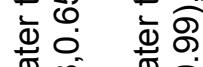
"ত

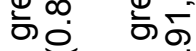

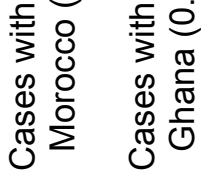




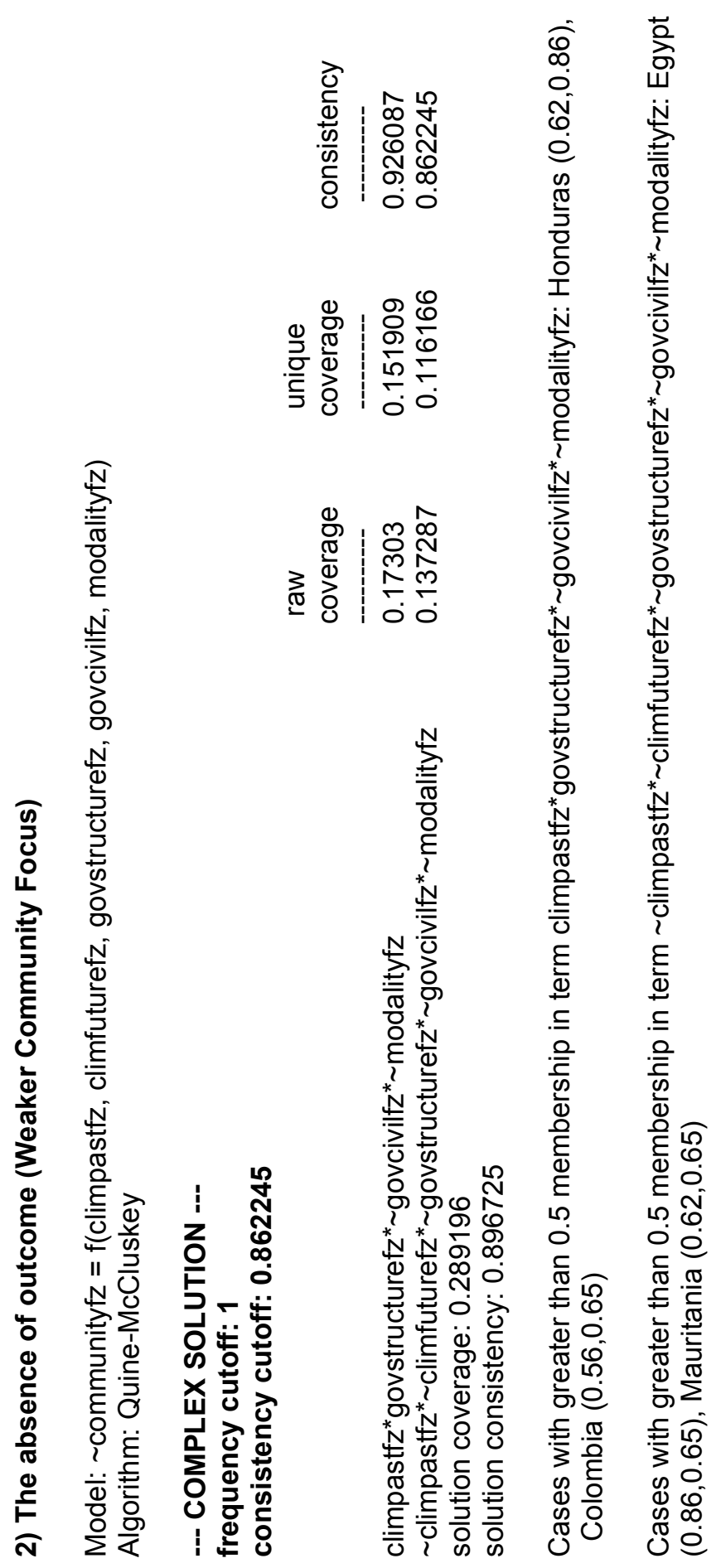




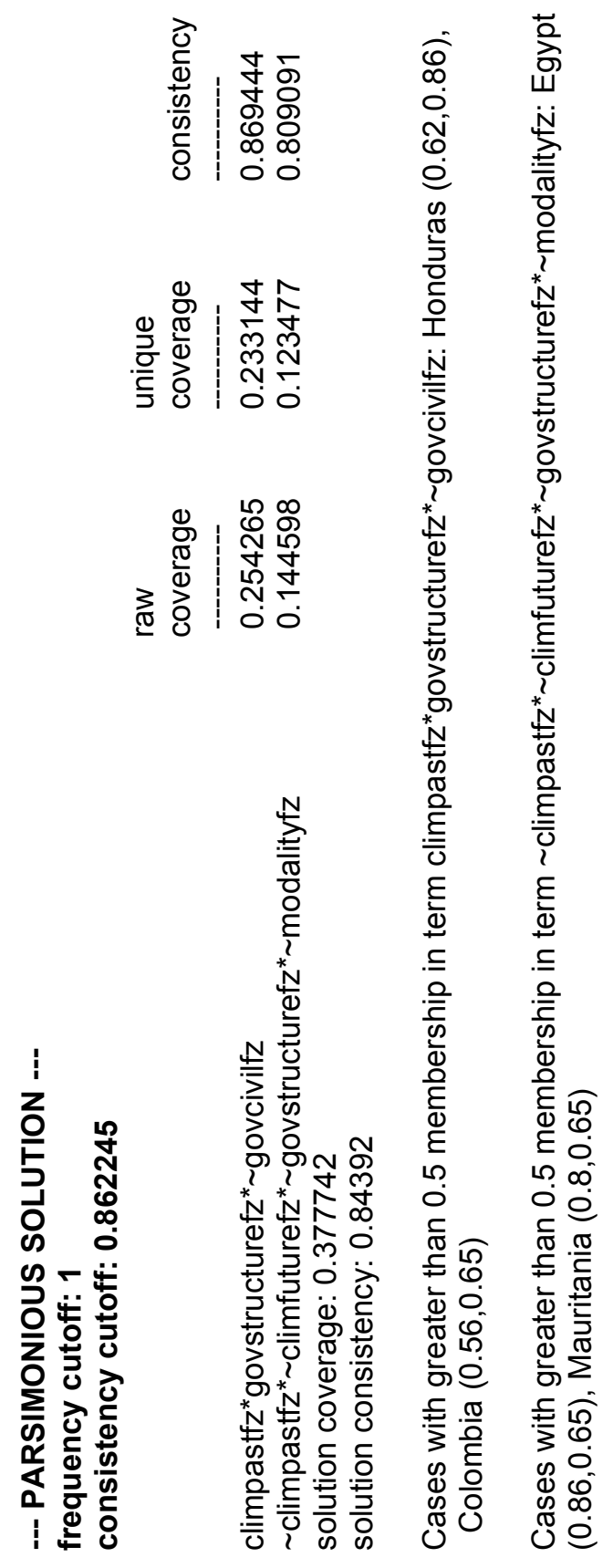




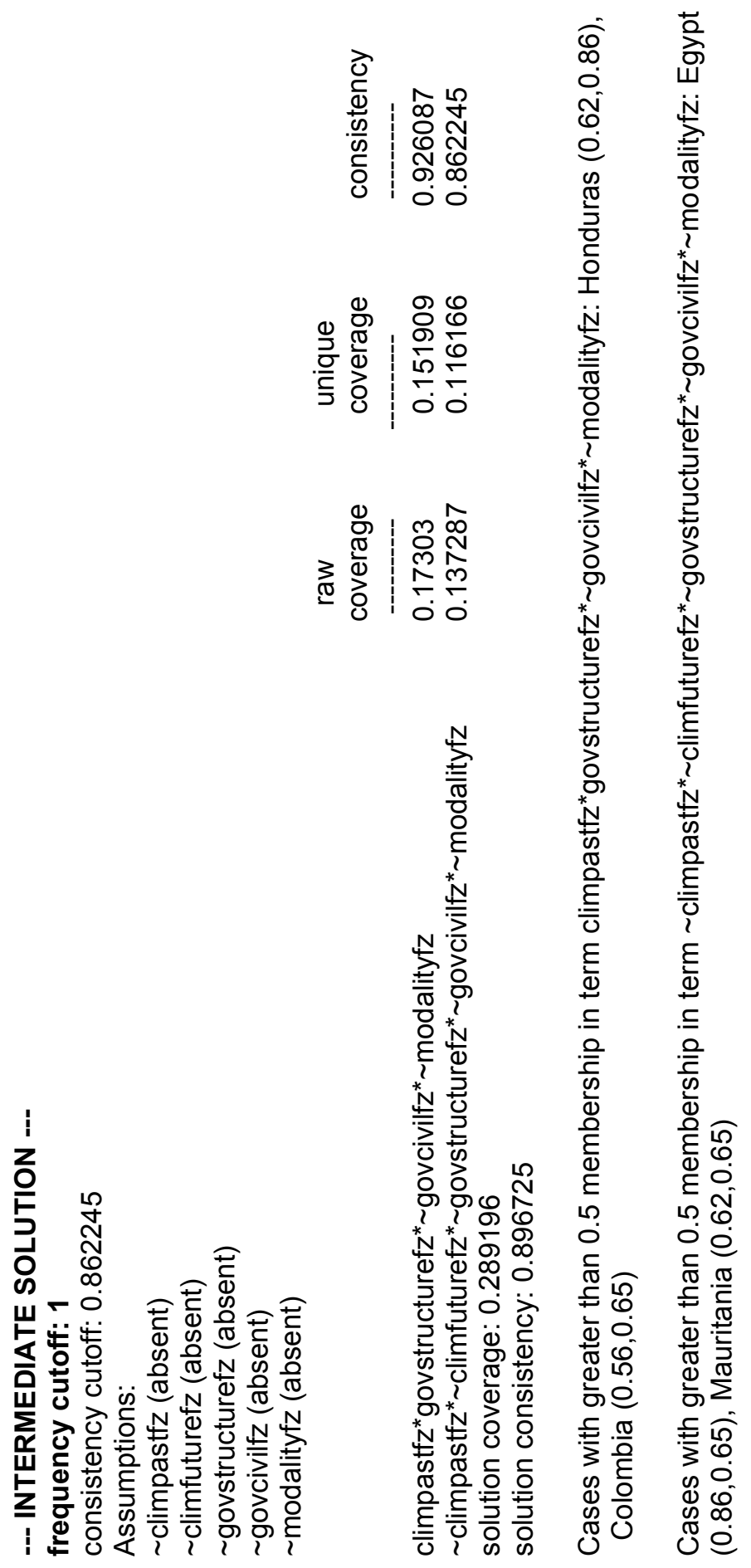




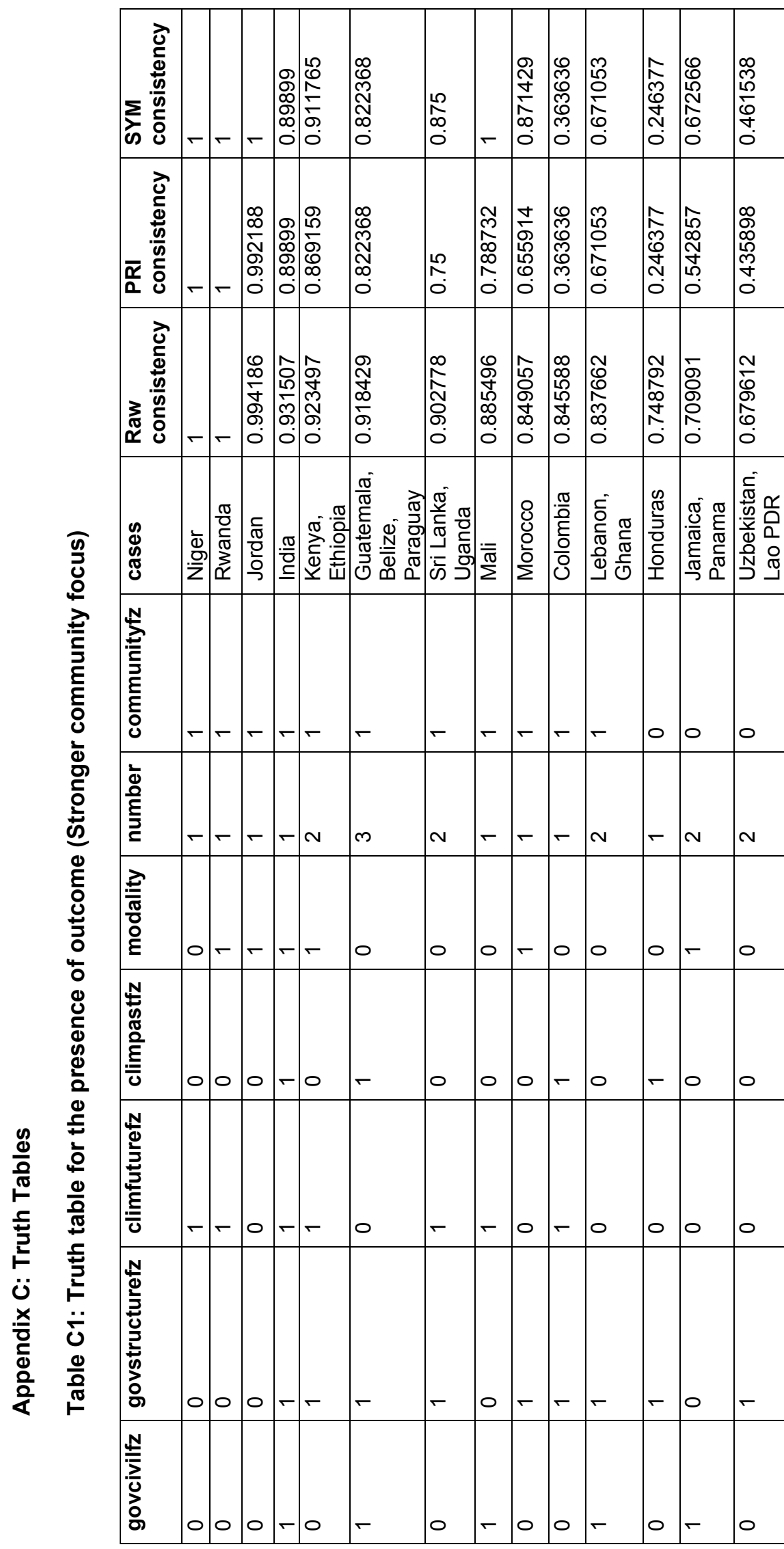




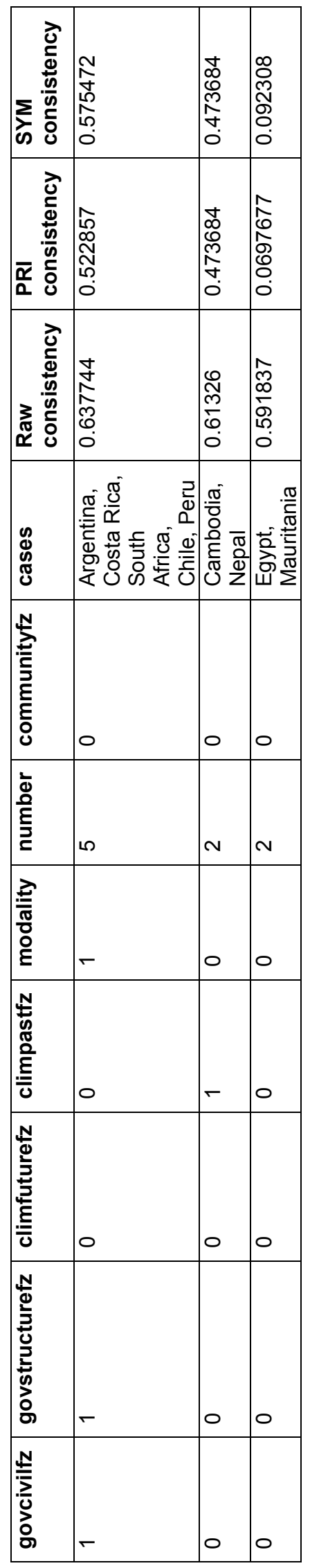




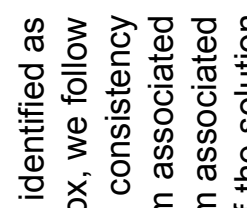

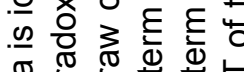

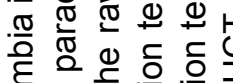

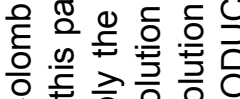

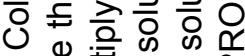

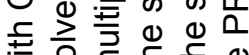

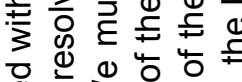

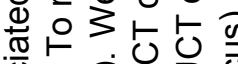

完守争

W 0 吕

重

Ф

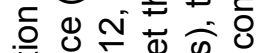

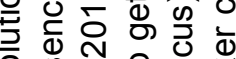

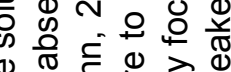

o

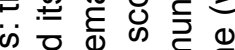

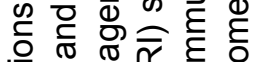

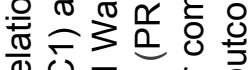

बن 0 잉

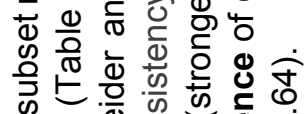

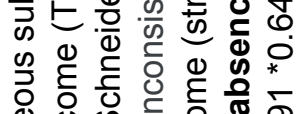

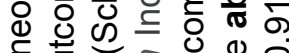

密

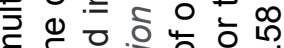

क栲

舟

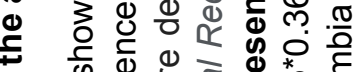

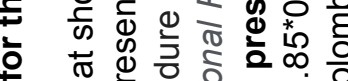

政

o 0

要

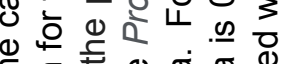

t

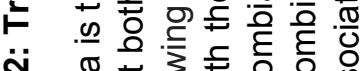

ช

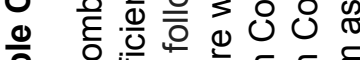

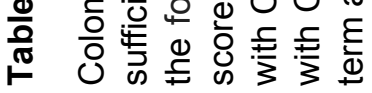

흔

空 $\stackrel{0}{=}$

吕

응

๘

잉

$\stackrel{\square}{\stackrel{0}{\leftrightarrows}}$

()

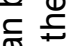

ช

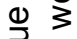

$\frac{\pi}{\sqrt{2}} \cdot \frac{0}{0}$

능

O

뜸 흐

을 兽

त हे ब

亦宅

○े :

무을

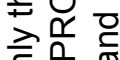

0 잉

穴章

宅导

도

ह

o

赵

$\infty \dot{\oplus} \dot{0}$

क)

응 导

宅

क 0 눙

용 잉

은

ठठ

造导
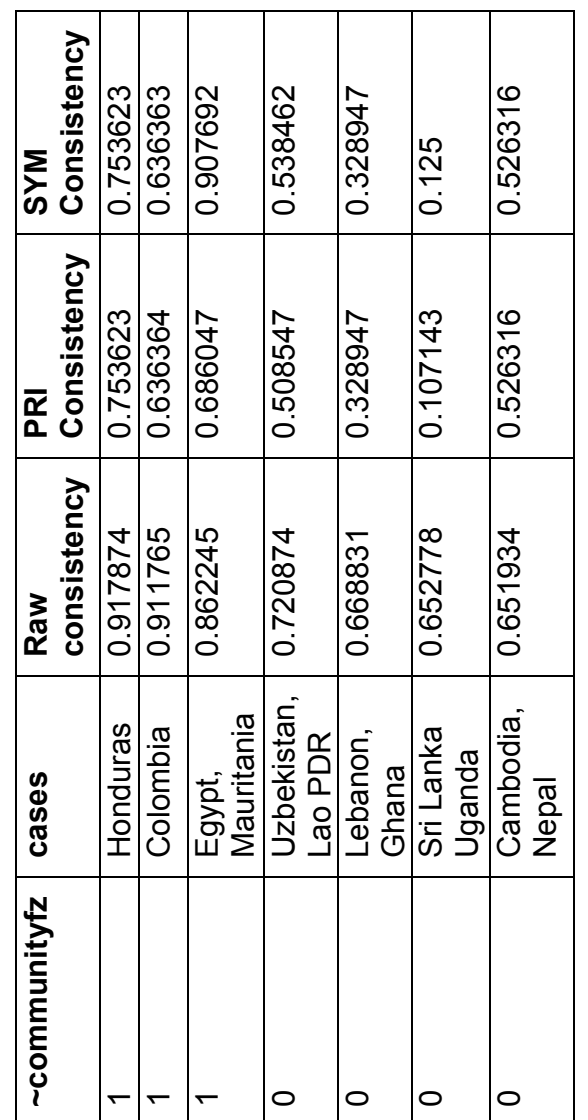

$\underset{\infty}{\infty}$

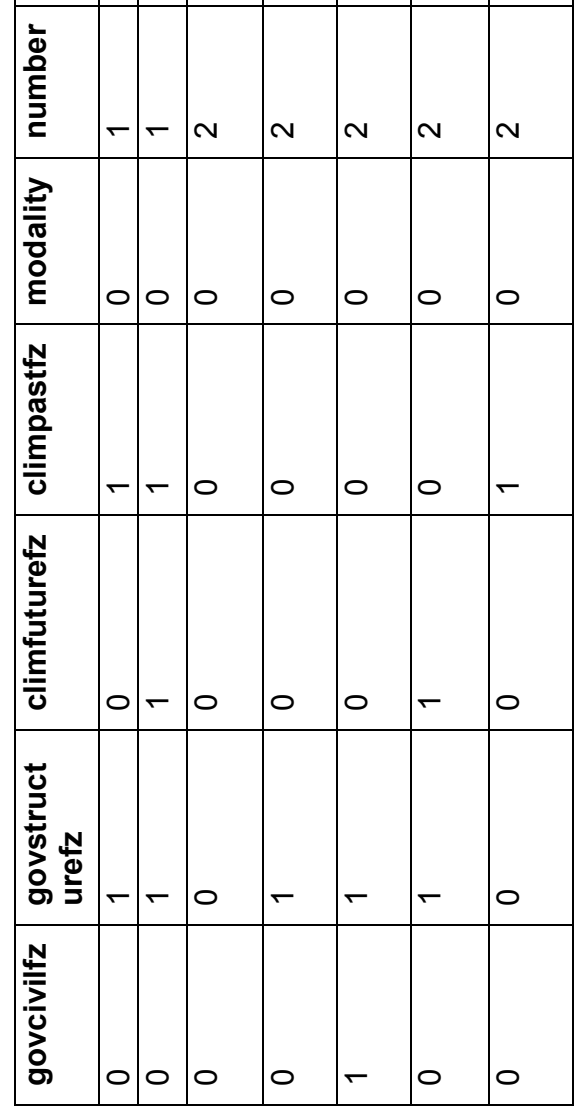




\begin{tabular}{|c|c|c|c|c|c|c|c|c|c|c|}
\hline 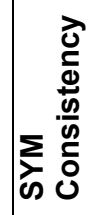 & 贷 & 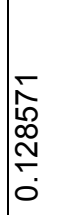 & 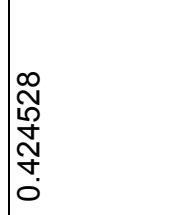 & 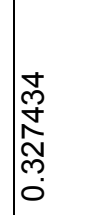 & $\begin{array}{l}\tilde{N} \\
\stackrel{\infty}{\infty} \\
\sim \\
\infty \\
0 \\
0 \\
0\end{array}$ & 0 & 0 & 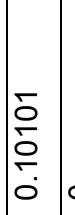 & 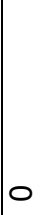 & 0 \\
\hline 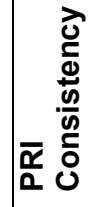 & 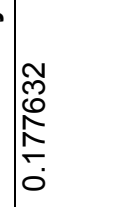 & 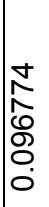 & 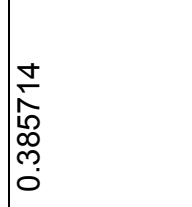 & 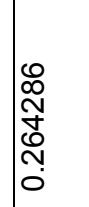 & $\begin{array}{l}\underset{N}{\mathbb{N}} \\
\underset{\dot{\sigma}}{\infty} \\
0 \\
0 \\
0\end{array}$ & 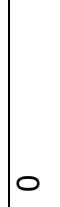 & 0 & $\begin{array}{l} \\
\frac{0}{0} \\
\frac{0}{0} \\
0\end{array}$ & 0 & 0 \\
\hline 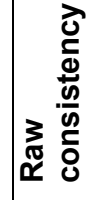 & $\begin{array}{l}\hat{N} \\
\tilde{N} \\
\tilde{N} \\
0 \\
0\end{array}$ & 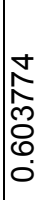 & 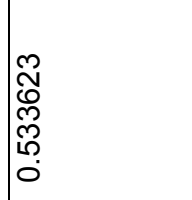 & 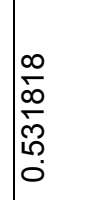 & \begin{tabular}{l}
5 \\
$\infty$ \\
\multirow{0}{0}{} \\
0 \\
0 \\
0
\end{tabular} & $\begin{array}{l}10 \\
2 \\
\infty \\
\infty \\
19 \\
0 \\
0\end{array}$ & 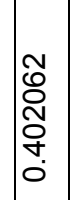 & 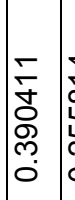 & 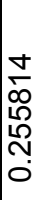 & 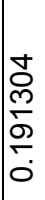 \\
\hline $\begin{array}{l}\mathscr{y} \\
\mathbb{8} \\
\mathscr{D} \\
\mathbb{J} \\
0\end{array}$ & 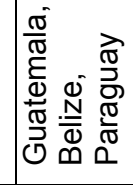 & 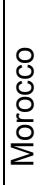 & 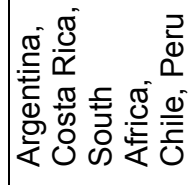 & 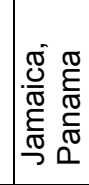 & 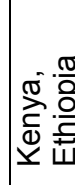 & $\mid \frac{\overline{2}}{\Sigma}$ & $\begin{array}{l}\stackrel{\bar{\Phi}}{\mathbf{\Phi}} \\
\overline{\mathbf{z}}\end{array}$ & $\underline{\underline{\underline{\sigma}}}$ & 离 & 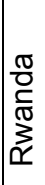 \\
\hline 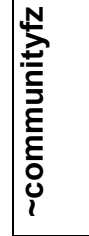 & 0 & 0 & 0 & 0 & 0 & 0 & 0 & 0 & 0 & 0 \\
\hline 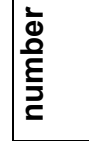 & $m$ & r & م & $N$ & $\sim$ & - & - & r & $r$ & $r$ \\
\hline 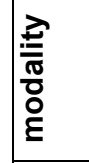 & 0 & $r$ & - & $r$ & $r$ & 0 & 0 & - & - & - \\
\hline 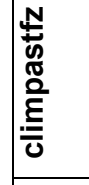 & - & 0 & 0 & 0 & 0 & 0 & 0 & - & 0 & 0 \\
\hline 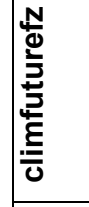 & 0 & 0 & 0 & 0 & - & - & - & - & 0 & - \\
\hline 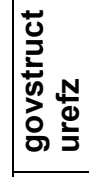 & - & - & - & 0 & $r$ & 0 & 0 & -0 & 0 & 0 \\
\hline \begin{tabular}{|l}
$\frac{N}{4}$ \\
\hdashline \\
\hdashline \\
0 \\
0 \\
0 \\
0
\end{tabular} & - & 0 & $r$ & - & 0 & $r$ & 0 & - & 0 & 0 \\
\hline
\end{tabular}




\section{Chapter 7: Do access modalities to international adaptation finance matter for the promotion of agricultural innovations?: An analysis of 36 Adaptation Fund projects}

\subsection{Introduction}

The agricultural sector in developing countries is vulnerable to climate change (IPCC, 2014b). Negative impacts are projected to affect the yields of crops such as rice, wheat, and maize (Auffhammer et al., 2012; Challinor et al., 2014; Lobell et al., 2011), which are important cash and food crops for a large number of developing countries. This implies that the income and livelihoods of rural and agriculture-dependent populations in these countries, which include $80 \%$ of the world's extreme poor, will also be highly vulnerable to climate shocks (FAO, 2018). Recognizing the need to reduce climate vulnerability of the rural poor, governments of developing countries have identified agriculture as a priority sector for climate change adaptation (Agarwal et al., 2012; Berrang-Ford et al., 2015).

Climate change presents new challenges for agricultural production, which in turn calls for innovations to adapt to their impacts (Aase et al., 2013; FAO, 2016). While farmers have always been responding to climate shocks, climate change presents three new challenges: 1) long-term change in average climatic conditions (e.g. rising temperatures, changes in precipitation patterns, sea level rise); 2) increased variation in weather conditions during a growing season (e.g. the start, duration, seasonal distribution of monsoons), and 3 ) increased frequency and magnitude of extreme weather events (e.g. floods, droughts, storms, heat waves, etc.) (IPCC, 2014a; Smit \& Skinner, 2002). To address these challenges, farmers will need to adopt new practices and technologies, such as production methods common to warmer or wetter 
regions, climate-tolerant crop varieties, and new scientific knowledge in crop and water management (FAO, 2014). More recently, literature stresses that agricultural innovations are not only important for climate change adaptation, but also for the sector to achieve the triple wins of climate-smart agriculture (CSA) i.e. increased productivity, reduced climate vulnerability (adaptation), and reduced GHG emissions (mitigation) (FAO, 2010; Zilberman et al., 2018).

It is well known that innovation in the agriculture sector is not only dependent on the knowledge and technological capabilities of the economic actors involved, but also on their access to finance to develop, test, and implement innovations (Moreddu \& Van Tongeren, 2013; World Bank, 2006). Within the context of global climate negotiations, it is also recognized that developed countries-whose historical emissions contributed disproportionally to today's climate change-have an obligation to assist developing countries with finance and technology transfer to introduce innovations to address climate challenges (UNFCCC, 2015). As the financing mechanisms of the UNFCCC, multilateral climate funds have been established to channel public climate finance from developed-country donors to climate-vulnerable developing countries. Such public climate finance is expected to a play a key role in supporting climate-related innovations by financing research and dissemination that would otherwise be under-provided by the private sector (Bowen, 2011), financing pilot experiments and/or subsidizing full projects (Bowen, 2011; Kotchen \& Costello, 2018), addressing systemic barriers to innovations (e.g. capital constraints, technical capacity, inadequate policy frameworks etc.) (Hogarth, 2012), and leveraging private financing for upscaling innovations (Bowen, 2011; Hogarth, 2012). While historically discussions on international climate finance for innovation and technology transfer focused on mitigation, the emphasis has shifted towards adaptation following the adoption of the 2007 Bali Action Plan at the UNFCCC COP13 (UNFCCC, 2007). 
Among major multilateral climate funds, the Adaptation Fund (AF) under the Kyoto Protocol has played an active role in financing agricultural innovations for climate change adaptation. Due to its mandate being focused on the most climate-vulnerable populations, the AF has financed a large portfolio of projects that introduce innovative agricultural practices and technologies to enhance the climate resilience of smallholder farmers. The AF is also seen as one of the most promising international climate financing sources for CSA, especially in the context of meeting the needs of vulnerable local communities (Lipper et al., 2014). In 2017, the AF launched a new mid-term operational strategy (2018-2020) which places innovation, along with action and learning, as the key pillars for its future operations (Adaptation Fund, 2017). In December 2018, the AF also launched innovation grants, with an objective to build national capacity to accelerate the deployment of innovative adaptation practices on the ground (Adaptation Fund, 2018a).

As discussed in the previous chapters, the AF currently finances adaptation projects in developing countries through the direct access and indirect access modalities, which represent two different governance models of international adaptation finance. Direct access projects are nationally implemented, while indirect access projects are implemented by international organizations on the behalf of the recipient countries. To date, there has been no research that systematically examines if these distinctive governance arrangements shape the utilization of international adaptation finance to promote innovations differently at the project level. In this chapter, I argue that addressing this knowledge gap is important for the global climate finance community to understand policy options to promote adaptation innovations for two reasons.

First, the 2017 Bali Action Plan calls for innovative financing mechanisms to accelerate innovative adaptation practices and technology transfer to vulnerable developing countries (UNFCCC, 2007). At the same time, the direct access modality to the AF is widely recognized as an innovative 
international adaptation finance mechanism pioneered by the AF (Brown et al., 2010). It is therefore relevant from a global climate finance policy perspective to develop insights on whether the direct access modality has made any difference in the way it promotes innovative adaptation actions on the ground. Second, given the different knowledge, capacity, and incentives of national versus international implementing entities of the $A F$, direct and indirect access adaptation projects could be designed in ways that represent different pathways to promote innovations for climate change adaptation. For example, multilateral implementing entities (MIEs) and regional implementing entities (RIEs) could be better positioned to facilitate international transfer of global knowledge and adaptation technologies, while national implementing entities (NIEs) could be endowed with more local knowledge that helps contextualize innovation for adoption. Understanding these pathway implications is highly relevant for the $A F$ to operationalize its innovation strategy, and will also provide valuable insights to other multilateral climate funds.

The objective of this chapter is to assess if and how the two access modalities to international adaptation finance shape the project design to promote agricultural innovations for local climate change adaptation. Using the AF as the case study, two specific research questions are answered in the chapter: 1) Are there differences in the project design of direct access and indirect access projects to promote adaptation innovations?; and 2) what explains differences in the project design, if they exist? While scholars have begun to analyze the role of climate finance in promoting climate-related innovations (Hogarth, 2012), to the best of my knowledge, this is the first study that aims to look deeper at how the access modalities to international adaptation finance could shape the promotion of agricultural innovations for local communities. 
The chapter is organized as follows. Section 7.2 develops a conceptual framework for the chapter. Section 7.3 describes the data and research methodology. Section 7.4. presents the results. Second 7.5 discusses the findings. The chapter then provides an overall conclusion in Section 7.6.

\subsection{Conceptual framework}

The conceptual framework for this chapter has three inter-related components. Component 1 defines the project design to promote agricultural innovations as the outcome of interest in this study. Component 2 focuses on the study's main explanatory variable-the access modalities to the AF. In particular, Component 2 expands the above initial observations on the potential implications of access modalities on the project design by drawing on literature to develop more theoretically informed hypotheses. However, it is recognized that any observed differences (or similarities) in the project design cannot be solely attributed to the role of access modalities. Component 3 of the conceptual framework therefore places the access modalities in the broader context of $\mathrm{AF}$ recipient countries, recognizing that such country context could also play a role in shaping the project design. Figure 7.1. depicts how the three components fit together. 


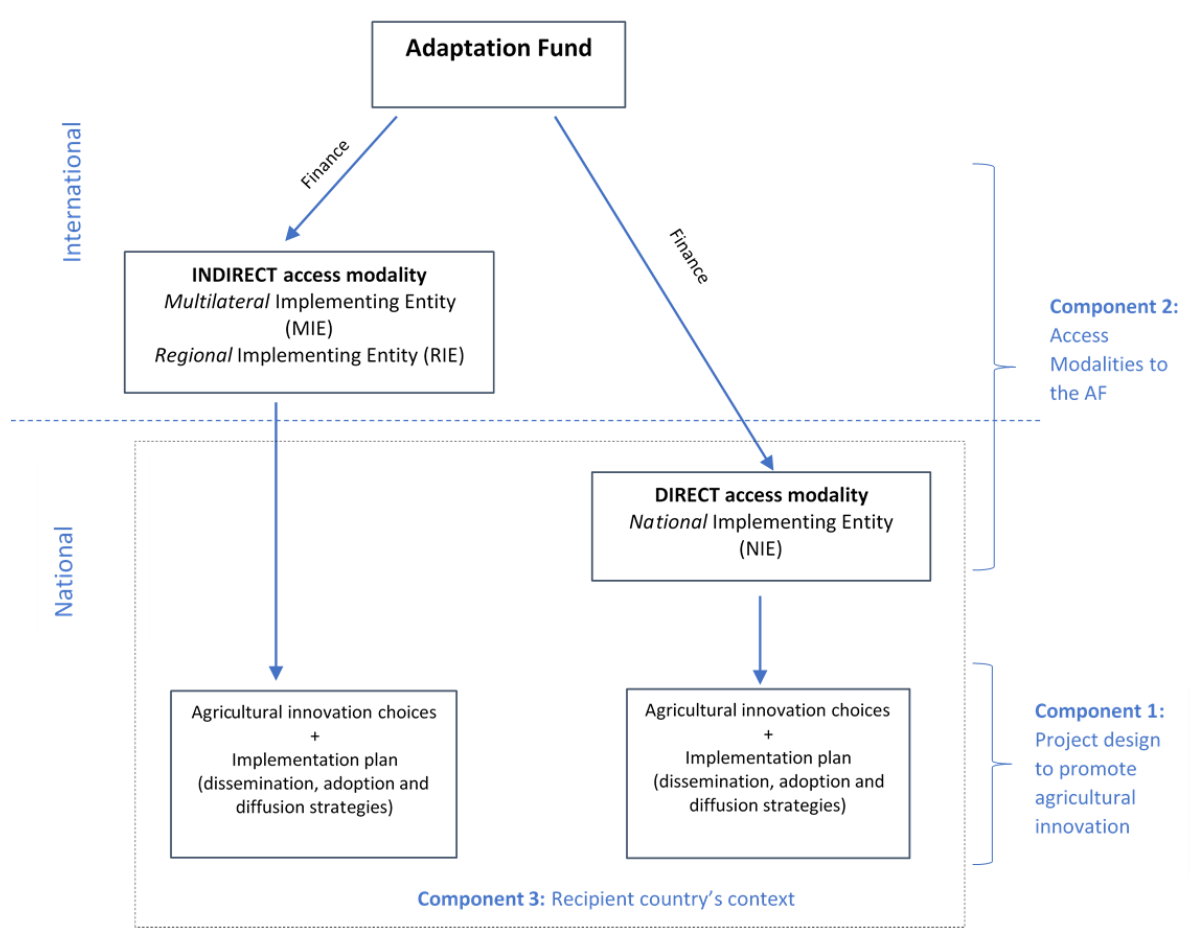

Figure 7.1. A conceptual framework on the potential role of access modalities to the $A F$ in shaping the project design to promote agricultural innovations. Source: Author.

The following sub-sections further elaborate on the three components of the conceptual framework and explain how they are used to guide the subsequent empirical analysis.

7.2.1. Component 1: Project design to promote agricultural innovations

For the purpose of this study, the project design to promote agricultural innovations is defined as a combination of two elements: the choice(s) of agricultural innovations financed by each AF project, and the project's implementation plan with regards to the innovations. 


\subsubsection{Agricultural innovation choices}

Innovation refers to an idea, practice, or object perceived as new by an individual or other unit of adoption (Rogers, 2003). This suggests that innovation is context-specific (Sørensen \& Torfing, 2011); a business-asusual product or practice in one context can become an innovation when introduced to other adopting systems and geographies. Building on this definition, an agricultural innovation for climate change adaptation is therefore understood in this chapter as anything new to the adopting units, systems, and geographies, which is introduced with an objective to reduce the vulnerability of the agricultural sector to climate change, including variabilities and extremes. In the context of AF projects, the adopting units of agricultural innovation generally refer to individual farmers, farm households and farmer groups who are the targeted project beneficiaries. Table 7.1. provides a typology of possible actions which could constitute agricultural adaptation innovations for the AF project beneficiaries if these actions are new to them (Bhatta et al., 2017; Rogers, 2003; World Bank, 2006). For the analysis in this chapter, I use the typology in Table 7.1. to classify and compare the agricultural innovation choice(s) financed by both direct access and indirect access AF projects (See Supplementary Material 4 for more detail). The result of this classification and comparison is presented in Section 7.4. 


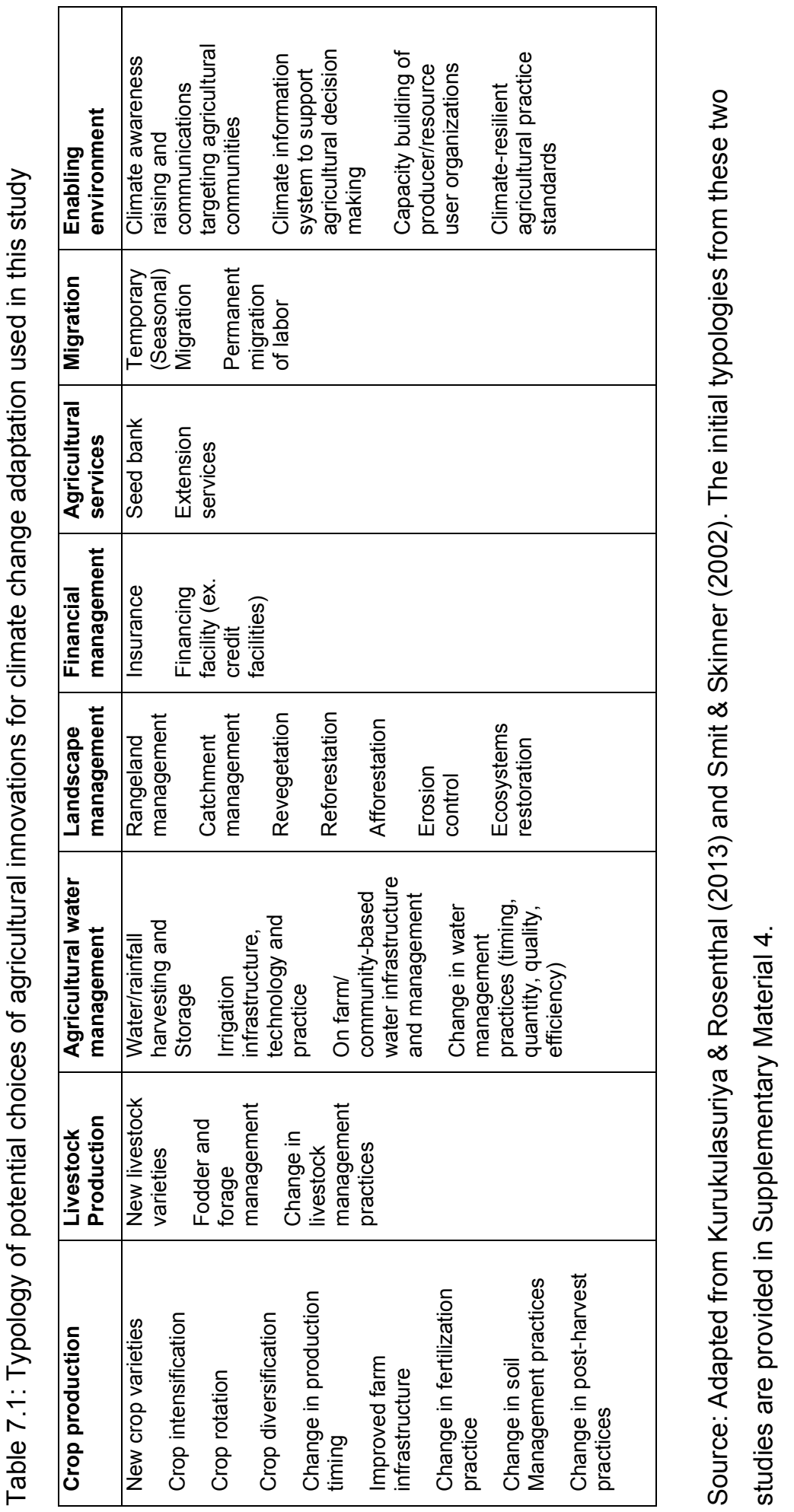




\subsubsection{Implementation plan}

For the purpose of this chapter, the implementation plan of an AF project to promote agricultural adaptation innovations is defined as a combination of the project's innovation dissemination, adoption and diffusion strategies.

Here, I use the term "dissemination" to refer to "a set of planned, systematic efforts designed to make a programme of innovation more widely available in practice" (Owen et al., 2006). This perspective on dissemination reflects the aspect of the innovation process that involves the intentionality and proactiveness to operationalize new ideas to catalyze change (Sørensen \& Torfing, 2011). Dissemination of innovation is often operationalized through targeted, publicly-financed intervention programs and often involves pilot experiments "to generate better information about whether a full project is likely to succeed or fail" (Kotchen \& Costello, 2018, p.2). In the context of AF projects, the dissemination of innovation takes place when the project implementing entities decide to pilot-test something new vis-a-via the adopting context and beneficiaries.

Following Rogers (2003), I define the "adoption" of innovation as a decision to make "full use of an innovation as the best course of action available", while rejection is a decision "not to adopt an innovation" (p.177). In other words, adoption refers to the uptake of a disseminated innovation by the targeted potential users. In the context of AF projects, the adoption process takes place if the intended project beneficiaries decide to adopt the innovation(s) disseminated by the projects.

Diffusion then takes place after adoption. Also following Rogers (2003), I use the term "diffusion" to refer to "the process in which an innovation is communicated thorough certain channels over time among the members of a social system" (p.5). This suggests that while adoption is an individual-level 
process, diffusion is a social process by which an innovation spreads from the early adopters to other groups in the same society and therefore reaches scale. In the context of AF projects, diffusion will occur if there is a spread of the adopted innovation from the direct beneficiaries of AF projects to the nonproject public. In other words, diffusion can be understood as the process of the innovations disseminated by AF projects, and adopted by the project beneficiaries, being upscaled. In this context, diffusion could be facilitated through actions such as planned geographical expansion beyond the AF's initial target areas, policy mainstreaming, and the spread of knowledge and information about the innovation through media and peer-to-peer exchange.

To understand the potential characteristics of the innovation dissemination, adoption and diffusion strategies of AF projects, I conducted a systematic literature review on agricultural innovations for climate change adaptation in developing countries. The objective is to develop an initial comprehensive list of drivers that could characterize each AF project's dissemination, adoption and diffusion strategies for agricultural innovations. The full methodology and results of the systematic literature review are beyond the scope of this chapter and presented as Supplementary Material 5 to this dissertation. Here, I summarize the key drivers documented in the literature (Table 7.2) and discuss them briefly. 
Table 7.2: Drivers for the dissemination, adoption and diffusion of agricultural innovations in developing countries

\begin{tabular}{|c|c|c|}
\hline Dissemination & Adoption & Diffusion \\
\hline 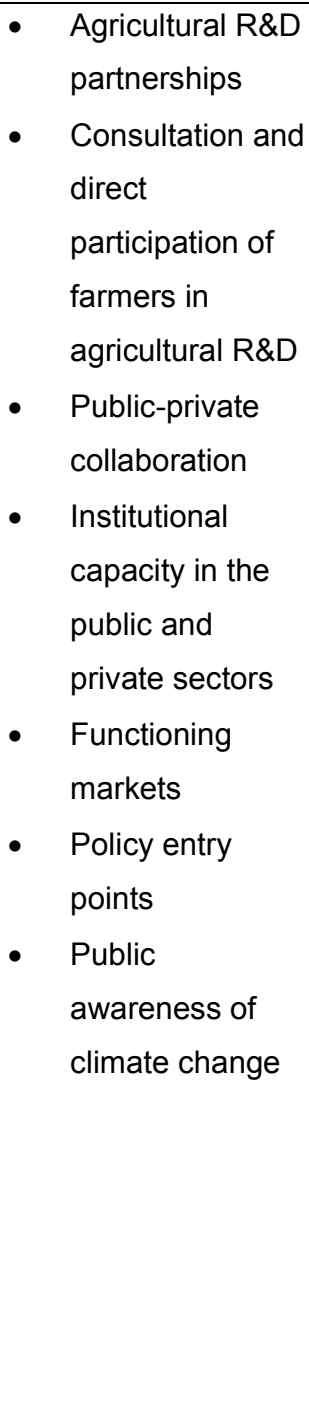 & $\begin{array}{cl}\text { Innovation characteristics } \\
\text { - } & \text { Relative advantage } \\
\text { - } & \text { Compatibility } \\
\text { - } & \text { Observability } \\
\text { - } & \text { Trialability } \\
\text { Adopter characteristics } \\
\text { - } & \text { Gender } \\
\text { - } & \text { Wealth } \\
\text { - } & \text { Education and } \\
& \text { awareness } \\
\text { - } & \text { Risk preference } \\
\text { - } & \text { Identity } \\
\text { - } & \text { Livelihood } \\
\text { - } & \text { diversification } \\
\text { - } & \text { Remittances } \\
\text { - } & \text { Fevel of food security } \\
\text { Enabling environment } \\
\text { - } \\
\quad \text { Informal community- } \\
\quad \text { level social groups } \\
\text { Formal institutions in } \\
\text { Functioning markets }\end{array}$ & $\begin{array}{l}\text { Interpersonal- } \\
\text { cosmopolite channels } \\
\text { - Staff of NGOs and } \\
\text { government projects } \\
\text { - } \quad \text { Government } \\
\text { extension officers } \\
\text { - } \text { Dialogue among } \\
\text { farmers and } \\
\text { researchers } \\
\text { Interpersonal- localite } \\
\text { channels } \\
\text { - Farmer groups } \\
\text { Farmer-supporting } \\
\text { institutions } \\
\text { - Community-based } \\
\text { fora } \\
\text { The mass-media } \\
\text { cosmopolite channels } \\
\text { radios) }\end{array}$ \\
\hline
\end{tabular}

Source: Author's summary of a systematic literature review (See Supplementary Material 5) 
The reviewed literature suggests that the following drivers could be influential in a project's strategy to disseminate agricultural innovations for climate change adaptation in developing countries. First, agricultural research and development $(R \& D)$ partnerships enable local research and government agencies to develop innovations that suit new local climatic conditions, and make them available for public dissemination (Chhetri \& Easterling, 2010; Moeletsi et al., 2013; Webersik \& Wilson, 2009). Second, consultation and direct participation of farmers in agricultural $R \& D$ provide key inputs for public agencies to disseminate the most locally appropriate innovations (Bocco \& Napoletano, 2017; Chhetri et al., 2012, 2013). Third, collaboration between public and private stakeholders beyond the R\&D and farmer communities creates a broader enabling environment for agricultural innovations (Bogale, 2015; Chhetri et al., 2012; Matsaert et al., 2011; Ojha et al., 2014; Röling, 2016; Webersik \& Wilson, 2009). Fourth, institutional capacity in public and private sectors needs to be strengthened to support public dissemination of agricultural innovations (Bhatta et al., 2017; Lybbert \& Sumner, 2012; Matsaert et al., 2011; Moreddu \& Van Tongeren, 2013; Popke et al., 2016). Fifth, public dissemination of several agricultural innovations, such as new seeds and new insurance products, requires functioning markets (Bogale, 2015; Lybbert \& Sumner, 2012; Ojha et al., 2014). Sixth, the identification of the right policy entry points contributes to successful innovation dissemination (Matsaert et al., 2011; Nyikahadzoi et al., 2017; Nzeadibe et al., 2012). Finally, public adaptation innovation programs benefit from sustained efforts in raising awareness on climate change among farming communities (Nzeadibe et al., 2012).

The adoption drivers of agricultural innovations for climate change adaptation in developing countries can be grouped into three main categories. The first group relates to innovation characteristics as perceived by the adopters. The four attributes highlighted in the literature are the relative advantage of the innovation vis-à-vis the idea it supersedes, the compatibility of the innovation 
with the norms, values, practices, and needs of the adopters, the level of complexity involved in using the innovation, and the observability of the benefits of the innovation (Rogers, 2003). Trialability, which refers to the notion that an innovation which can be experimented for a period of time is more likely to be adopted (Rogers, 2003), is the only Rogers' key attribute of innovation not highlighted in any of the reviewed articles. The second group of adoption drivers refers to adopter characteristics. Key characteristics highlighted in the literature are wealth (Adenle et al., 2015; Kolade \& Harpham, 2014; Nyongesa et al., 2017; Ojha et al., 2014; Popke et al., 2016), gender norms (Bunclark et al., 2018; Kolade \& Harpham, 2014; Nyongesa et al., 2017), livelihood diversification (Bhatta et al., 2017; Bogale, 2015; Bunclark et al., 2018), education and climate change awareness (Bhatta et al., 2017; Bogale, 2015; Bunclark et al., 2018), the availability of remittances (Bogale, 2015; Karanja Ng'ang'a et al., 2016), risk preference (Sibiko et al., 2018), identity (Bocco \& Napoletano, 2017) and the level of household food insecurity (Kristjanson et al., 2012). The third group of drivers relates to an enabling environment for innovation adoption, which results from the positive role of informal social institutions at the community level (Bunclark et al., 2018; Chhetri et al., 2013; Matsaert et al., 2011; Sibiko et al., 2018), of formal institutions in the agricultural sector, including government agencies (Chhetri et al., 2012, 2013; Nyikahadzoi et al., 2017), and of functioning market mechanisms, including access to agricultural credits (Adenle et al., 2015; Bhatta et al., 2017; Bogale, 2015) and the availability of markets to sell the increased outputs that result from innovation adoption (Lybbert \& Sumner, 2012).

For diffusion, the reviewed literature places more emphasis on the interpersonal channels of communication than on mass media as the key diffusion channel of agricultural innovations for climate change adaptation in developing countries. While interpersonal communication channels are classified as "cosmopolite" (linking the individual with external knowledge 
sources) and "localite" (linking the individual with local knowledge sources with the system under study), mass-media communication channels are always cosmopolite (Rogers, 2003, pp.207-208). The interpersonalcosmopolite communication channels mostly discussed in the reviewed literature involve information dissemination by staff of NGOs and government projects (Bunclark et al., 2018), government extension officers (Bunclark et al., 2018), and an ongoing dialogue among farmers and researchers as part of participatory R\&D (Chhetri et al., 2012). The mostly discussed interpersonal-localite communication channels are farmer groups (Sibiko et al., 2018), farmer-supporting institutions (Chhetri et al., 2013), and community-based fora such as local gender-based and faith-based organizations (Nzeadibe et al., 2012). The mass-media communication channels, such as radios and mobile phones, are also discussed as being key in disseminating public information to build climate change awareness important for agricultural innovation diffusion (Nzeadibe et al., 2012).

In the subsequent analysis, I use the list of drivers discussed above (Table 7.2) as a typology to analyze data from the interviews with the AF's national and international implementing entities. The objective is to understand the features of their implementation plan to promote agricultural innovations by characterizing and comparing the types of drivers for dissemination, adoption and diffusion that they pay most attention to in the project design. The result from this comparative analysis is presented in Section 7.4.

7.2.2. Component 2: Why access modalities matter for the promotion of agricultural innovations?

This study posits that the AF's direct access and indirect access modalities could influence the project design to promote agricultural adaptation innovations differently. To guide the empirical analysis on whether this is the case, I consult literature to develop initial theoretical expectations. While there 
are no existing theories on what different access modalities mean for project design, I draw on the broader literature on innovation studies, decentralization, aid effectiveness, and climate change adaptation to develop two initial theoretical perspectives and related hypotheses. A full discussion of the literature behind these perspectives was provided in Section 3.4. of Chapter 3. Here, I summarize the main arguments.

First, it can be argued that direct access projects represent more decentralized innovation platforms, and therefore have more potential to promote locally relevant agricultural innovations. An innovation platform convenes a wide range of public and private stakeholders to engage with local communities to identify problems and prioritize innovative solutions (Pamuk et al., 2014). Compared to an indirect access project, a direct access project represents an innovation platform which is structurally more decentralized to the national level. This helps create a shorter distance between the AF project and local realties. In turn, the shorter distance is likely to facilitate more active local consultation during the project design (Fenton et al, 2014), thereby enabling the project to better respond to heterogenous local preferences and different delivery challenges across localities. Given their embeddedness in the local context, NIEs of direct access projects are also likely better-placed to perform innovation brokering roles for the benefit of local communities, such as by connecting them to other actors to ensure that community members have the necessary resources and information to adopt innovation (Klerkx et al., 2012; Meinzen-Dick et al., 2013). Even when NIEs do not perform these innovation brokering roles themselves, they are likely endowed with a superior knowledge to identify those who can and engage them as project EEs. Such enhanced ability to identify the right local partners could help ensure that externally-funded projects make use of the most locallyrelevant global knowledge (Stott \& Huq, 2014). 
Based on the decentralized innovation platform perspective above, I therefore expect that direct access projects are more likely designed to promote locally relevant agricultural innovations. For example, direct access projects could be more likely to choose agricultural innovations developed by national or local research institutes. The projects could also be more likely to customize innovation dissemination using superior local knowledge, deliver scientific information to farmers in more local languages, and integrate the new science with indigenous knowledge and traditional practices to enhance innovation adoption and diffusion. On the other hand, indirect access projects could be considered as internationalized innovation platforms with more outreach to global and regional knowledge partnerships. As a result, they are likely better positioned to facilitate international transfer of new adaptation technologies and practices developed by global agricultural innovators, such as G-20 countries and international agricultural research consortia (Moreddu \& Van Tongeren, 2013), to AF recipient countries. Given this advantage of MIEs and RIEs, I therefore expect that indirect access projects are more likely to promote international transfer of adaptation technologies and practices in their innovation dissemination, adoption and diffusion strategies.

Second, from an aid effectiveness perspective, it can be argued that enhanced national ownership through direct access could ensure more continuation of country support for the long-term diffusion (up-scaling) of AFfinanced agricultural innovations. Such support can be reflected in two dimensions of policy mainstreaming: the alignment of AF-financed activities with national and sectoral policies, and the financial continuity plan for the AF projects by recipient governments. As policy alignment takes place at the domestic level, NIEs of direct access projects, many of which are government agencies themselves, are arguably better-positioned to influence the national and sectoral policy processes to mainstream innovations financed by multilateral climate funds (Hogarth, 2012), when compared to MIEs/RIEs of indirect access projects which are not part of the government system. For the 
financial continuity plan, enhanced project ownership through direct access likely ensures that externally funded interventions are considered national priorities, and therefore increases the likelihood that governments will continue to finance them with its own budgets. Given this aid effectiveness perspective, I therefore hypothesize that to see more policy mainstreaming of AF-financed agricultural innovations in the case of direct access projects. Key indicators of such policy mainstreaming are the alignment of AF-financed innovation promotion activities with national development or sectoral strategies, and a clear financial sustainability plan made by recipient governments for the continued diffusion of AF-disseminated innovations beyond the initial project period.

In the subsequent empirical analysis, I assess if direct access projects are indeed designed to promote more locally relevant agricultural innovations and more policy mainstreaming of AF-financed innovations when compared to indirect access projects, as suggested by the two theoretical perspectives above. The result from this comparative analysis is presented in Section 7.4. and reflected upon in the discussion section (Section 7.5).

\subsubsection{Component 3 : The role of recipient country context}

Given that innovation is highly context-specific, other contextual factors in AF recipient countries beyond the access modalities could also influence the design of AF projects to promote agricultural innovations (Manuamorn et al., 2020). For example, each project's choices of agricultural innovations and implementation strategies are likely shaped by each recipient country's specificities, such as unique agro-ecological settings (Bocco \& Napoletano, 2017), economic feasibility in implementation (Trærup \& Stephan, 2015), a national agricultural innovation strategy (Moreddu \& Van Tongeren, 2013), the capacities of national agricultural research and technological institutions (Adenle et al., 2015; Chhetri et al., 2012; World Bank, 2006), the extent of 
climate and agricultural policy integration (Brooks \& Loevinsohn, 2011; Leimona et al., 2015; Schmidt, 2019), and the prevailing forms of traditional knowledge and social institutions, which could enhance or constrain the hybridization of scientific and local knowledge through innovation and learning (Lebel, 2013). At the same time, each project could also be influenced by each recipient country's exposure to cross-scale knowledge flows between local and global knowledge systems (Lebel, 2013). Such knowledge flows could result from, for example, the presence of policy entrepreneurs connecting local and global actors in the CSA space (Faling et al., 2018), or the extensive experience of national institutions in collaborating with global institutions and experts. On the one hand, the recipient country's specificities could exacerbate the differences in AF project design across countries and access modalities, especially when the projects are designed by NIEs which are highly embedded in the local context. On the other hand, the presence of cross-scale knowledge flows could foster a mutually constructed understanding of adaptation and innovation between national and global institutions (Olwig, 2012), potentially reducing global-local differences in the project design.

Given the universe of potentially relevant country-level contextual factors, as well as this study's ultimate focus on the role of access modalities to multilateral climate funds, I do not develop specific hypotheses to test how each and every one factor plays a role in every AF project. Instead, I analyze data from semi-structured interviews with the AF's implementing entities to explore if and how some country-level contextual factors are directly mentioned, or could be interpreted, as shaping the project design. I reflect on how some of these factors contribute to the observed project design differences (or similarities) in the result section (Section 7.4). 


\subsection{Data and methods}

This chapter uses the AF as the case study and its projects as sub-units of analysis. I apply a three-step methodology to conduct the study: project sampling, systematic content analysis of project documents, and semistructured interviews. The following sub-sections describe each step.

\subsubsection{Sample}

A sample of AF projects for this study is selected using a three-step process. First, I review the list of all projects approved by May 2017 (when project data were collected for this dissertation). Second, out of all the 63 projects approved, I identify projects from sectors with agricultural relevance e.g. agriculture, rural development, food security, water management, and multisector. Third, I review a summary of the project objective and activities to ensure that they involve agricultural adaptation to climate change. Based on these steps, I select $36 \mathrm{AF}$ projects, comprising 15 direct access projects and 21 indirect access projects. (See the full list of projects in Supplementary Material 1). Full project proposal documents of the $36 \mathrm{AF}$ projects are then downloaded from the AF website. All project documents are in English and contain comparable content presented in the same format, thus facilitating a comparative analysis of information across projects (See Supplementary Material 2).

\subsubsection{Content analysis of AF project documents}

To identify and classify the choices of agricultural innovations disseminated by AF projects (section 7.2.1.1), I conduct a systematic content analysis of project documents of the 36 projects, using the typology of potential agricultural adaptation innovation choices in Table 7.1. I use the Atlas.ti program to extract information on the types of agricultural innovations 
disseminated by each project by using word searches that combine the key words for innovation used in the literature (e.g. innovative, pilot, new, experiment, trial, adopt, introduce, transfer etc.) with the typology of innovations (See the codebook in Supplementary Material 4). For example, a project that pilots a new species of drought-tolerant rice is coded as disseminating innovation for crop production, with a sub-code of new crop varieties. This process is repeated for all the 36 projects. Information extracted from the AF project documents is then used to generate the descriptive statistics on agricultural innovations disseminated through the projects. The result provides the answer to the first part of the project design to promote agricultural innovations (e.g. agricultural innovation choices), and is presented in Section 7.4.1.

\subsubsection{Semi-structured interviews}

I conduct semi-structured interviews with key informants to understand the key drivers behind their formulation of the AF projects' innovation dissemination, adoption and diffusion strategies. The interviews allow me to gain more in-depth understanding on the deeper rationale and motivations behind the project design, which could not be detected from the project document analysis. Three groups of informants are interviewed: 1) staff of international organizations that serve as MIEs or RIEs of indirect access AF projects; 2) staff of national organizations that serve as NIEs of direct access AF projects; and 3) staff of the AF Secretariat, who are involved in reviewing and monitoring all AF projects (See the invitation letter in Supplementary Material 6). I use the following strategy to identify specific informants from each group to interview.

First, the 15 direct access projects selected for this study are implemented by 13 NIEs; the NIE in India-the National Bank for Agriculture and Rural Development (NABARD)—implements three projects. All 13 NIEs are invited 
for the interview. For NABARD, I randomly select one project to be the subject of the interview. Out of the 13 invited NIEs, I receive a positive response from 6 NIEs (46\%) representing 6 direct access AF projects, with a total of 10 informants participating. Second, the 21 indirect access projects selected for this study are implemented by six MIEs and two RIEs. Three out of the six MIEs implement multiple projects; the United Nations Development Programme (UNDP) implement 10 projects, the United Nations Environment Programme (UNEP) implement three projects, and the United Nations World Food Programme (WFP) implement three projects. I invite all six MIEs and two RIEs to participate in the interview. For UNDP, I randomly select one project from each of the three regions (Asia, Africa, and Latin America) to be the subject of the interview. For WFP, one project is from Africa and two from Asia, so I randomly select one project from Asia, resulting two final projects as the subject of the interview. For UNEP, their three projects come from three different regions, so I include all of them in the interview invitations. Out of the invited eight international implementing entities (six MIEs and two RIEs) which represent 13 indirect access projects, I got a positive response from four MIEs $(50 \%)$ representing five projects, with a total of 7 informants participating. None of the two invited RIEs respond for the request for interview. Finally, I invite five staff of the AF Secretariat who have familiarity with both direct access and indirect access projects. I receive four positive responses (80\%) from the AF Secretariat. The above strategy results in 15 interviews conducted with a total of 21 key informants for this study. The interviews took place between May-June 2019. The interviews are conducted via skype (13), an MIE's videoconference program (1) and phone (1), and generally take between 50-75 minutes. One interviewee responds to the interview questions by providing written answers via email (Table 7.3). 
Table 7.3: Summary of conducted interviews.

\begin{tabular}{|c|c|c|c|c|}
\hline Number & Informant ID & $\begin{array}{l}\text { Number of } \\
\text { informants } \\
\text { in the } \\
\text { interview }\end{array}$ & $\begin{array}{l}\text { Date } \\
\text { conducted }\end{array}$ & Method \\
\hline 1 & AF1 & 1 & May 10,2019 & Skype \\
\hline 2 & NIE 8 & 1 & May 16,2019 & Skype \\
\hline 3 & AF2, AF3 & 2 & May 17,2019 & Skype \\
\hline 4 & MIE2 & 1 & May 21,2019 & Skype \\
\hline 5 & MIE3, MIE 4 & 2 & May 22,2019 & $\begin{array}{l}\text { MIE's } \\
\text { videoconference } \\
\text { program }\end{array}$ \\
\hline 6 & $\begin{array}{l}\text { NIE 2, NIE 3, } \\
\text { NIE 4, NIE 5, } \\
\text { NIE } 6\end{array}$ & 5 & May 22,2019 & Skype \\
\hline 7 & MIE1 & 1 & May 23,2019 & Phone \\
\hline 8 & MIE5 & 1 & May 24,2019 & Skype \\
\hline 9 & AF4 & 1 & May 29,2019 & Skype \\
\hline 10 & MIE 6 & 1 & May 29,2019 & Skype \\
\hline 11 & NIE 1 & 1 & May 29,2019 & Skype \\
\hline 12 & NIE 7 & 1 & May 30, 2019 & Skype \\
\hline 13 & NIE 10 & 1 & June 3, 2019 & Skype \\
\hline 14 & MIE7 & 1 & June 6, 2019 & Skype \\
\hline 15 & NIE 9 & 1 & June 11,2019 & $\begin{array}{l}\text { Written response to } \\
\text { translated } \\
\text { questions }\end{array}$ \\
\hline
\end{tabular}

Source: Author.

I take an exploratory approach to conduct the semi-structured interviews by pursuing a theoretically guided but open investigation, rather than strictly testing the pre-determined hypotheses only. While the interview questions are informed by the discussed theoretical perspectives, many are formulated in a relatively open way to encourage participants to highlight whatever drivers they considered most important when they designed the innovationrelated activities of the AF projects (See Supplementary Material 7 for the 
interview questions). I analyze the collected interview data by comparing them to the key innovation dissemination, adoption, and diffusion drivers, as well as the theoretical perspectives on the access modalities, discussed in the conceptual framework section (Section 7.2). I also take note of any new issues brought up by the informants. The result from the analysis of the interview data is presented in Sections 7.4.2., 7.4.3. and 7.4.4.

\subsubsection{Research limitations}

Some limitations of the study should be noted. First, AF project documents from different countries use inconsistent language when referring to what is innovative in each context, with some projects using the terms "innovative" and "innovation" rather loosely. As I code innovation-related keywords as per reported by the project documents, this inconsistency could lead to overreporting of innovations in some cases and under-reporting in others. Therefore, the descriptive results on the disseminated agricultural innovations derived from the project document analysis should be viewed as showing an overall qualitative picture of the dissemination efforts, rather than as a quantitative indicator of each project's innovativeness.

Second, the AF project document template does not contain a specific section on the design to promote innovations, making it difficult to identify information specific to how each project aims to encourage the adoption and diffusion of innovations (as opposed to other non-innovative project interventions). I address this issue by conducting semi-structured interviews with the AF's implementing entities to understand the project design approach specific to the promotion of agricultural innovations, but in doing so face the trade-offs of a reduced sample size (since not all NIEs and MIEs of the 36 AF projects participated in the interviews), and therefore reduced generalizability. 
Third, the semi-structured interviews were designed to encourage participants to highlight whatever drivers they consider most important in their efforts to promote agricultural innovations, rather than strictly testing the predetermined hypotheses. A more deductive or indicator-based design of the interview protocol may have allowed for a more advanced quantitative analysis of common drivers across projects.

Finally, the main interest of the study is to assess whether the access modalities ultimately matter for the project design to promote agricultural innovations. While recognizing that the design could also be shaped by contextual factors of each AF recipient country, it was not possible to examine them in detail as part of this study. Future research could build on this study by investigating more closely the broader country context in which an innovation is disseminated, adopted and diffused under both direct access and indirect access projects through in-depth case study.

\subsection{Results}

The project document analysis and semi-structured interviews lead to three key findings. First, both types of projects are similarly designed to prioritize investment in locally appropriate agricultural innovations for climate change adaptation, both in terms of the agricultural innovation choices and the implementation plan. This similarity is evidenced by the fact that both types of projects choose to distribute similar types of nationally developed agricultural innovations, while being aware of the need for further local customization. In terms of implementation, the two types of projects also employ similar innovation dissemination, adoption and diffusion strategies that build on close collaboration with locally-embedded partner institutions, and extensive use of community feedback and simplified communication technologies. Second, both types of projects also exhibit a similar pattern of policy mainstreaming. While staff of both NIEs and MIEs describe that their 
projects' innovation promotion activities are fully aligned with national and/or sectoral policies, both are similarly unsure of the recipient governments' financial continuation plan for the AF-financed innovations beyond the initial AF project implementation period. Third, while I find that NIEs and MIEs perceive their institutional strengths and weaknesses differently, these different perceptions did not lead them to design their projects to promote agricultural innovations differently in practice. The following sub-sections elaborate on these findings in more detail.

7.4.1. What kinds of agricultural innovations are disseminated through the AF projects?

My analysis of AF project documents shows that the top four areas of agricultural innovations disseminated through the 36 projects are crop production, agricultural water management, landscape and land use management, and the building of an enabling environment for climateresilient agriculture (Figure 7.2). The focus in disseminating innovations in these areas is similar under both access modalities. Both direct access and indirect access projects also target largely similar groups of beneficiaries i.e. Individual farmers and farmer groups. The most common sub-group of beneficiaries of both types of projects is also similarly women. 

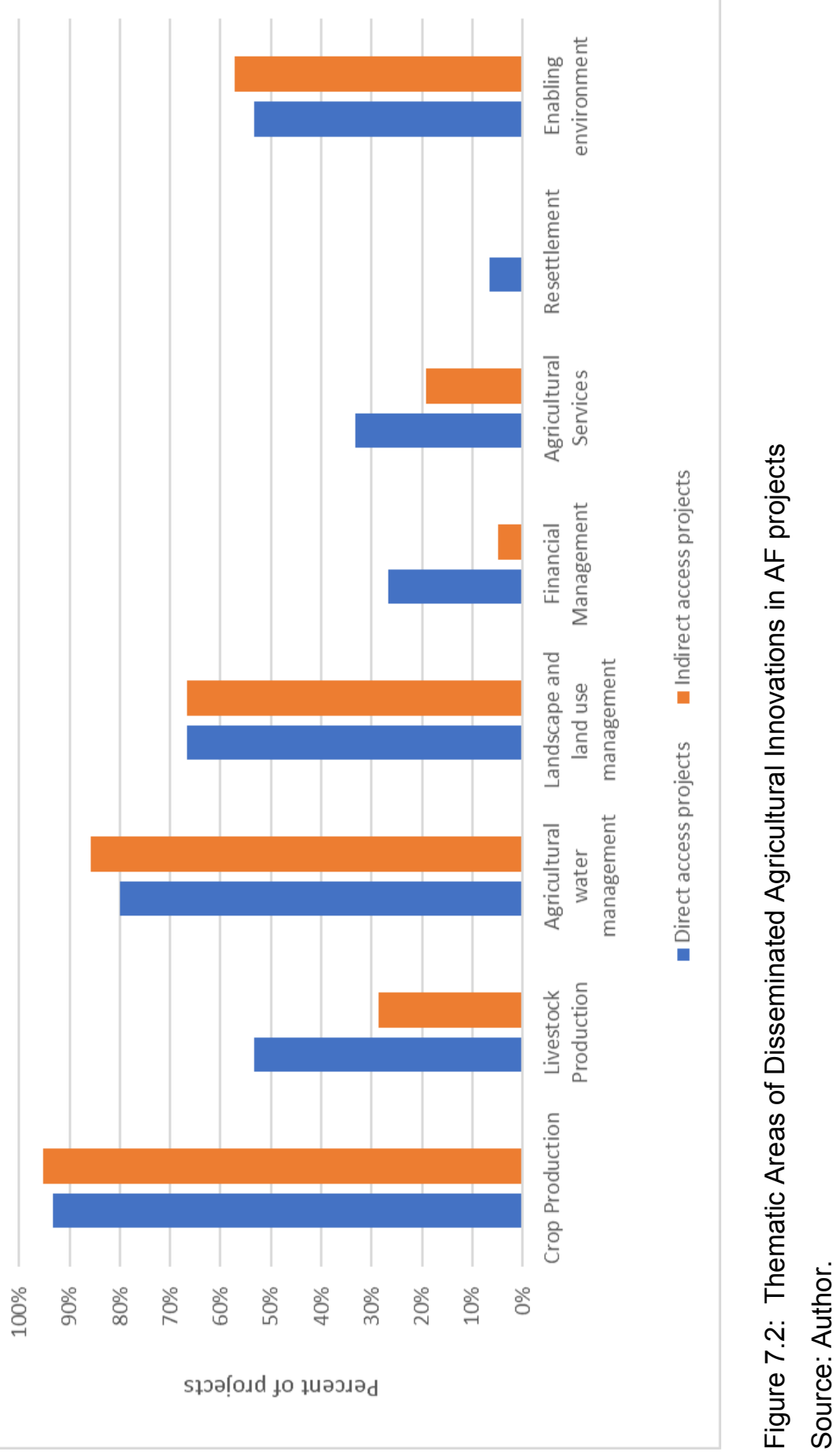
For crop production, new crop varieties (such as drought tolerant varieties) are by far the most disseminated innovation by both direct access and indirect access AF projects. For agricultural water management, new water and rainfall harvesting infrastructure (such as rooftop and runoff harvesting facilities) and new irrigation infrastructure, technology and practices (such as drip irrigation, micro irrigation, shallow well irrigation, low-cost pumps, and irrigation systems with incorporation of handling enclosures innovative for high altitude terrains) are the two most disseminated innovations by both types of projects. In addition, the same proportion (67\%) of projects under both access modalities disseminate new sustainable landscape and land use management practices in support of climate-resilient agricultural and livestock production. One of the most common innovative landscape approaches promoted by both types of projects is agroforestry. While some project documents mention other approaches such as revegetation, reforestation, catchment management and ecosystems restoration, overall the project documents do not provide enough detail to generate comparative descriptive statistics for all types of landscape approaches introduced by the 36 projects. To create an enabling environment for farmers to adopt climateresilient agricultural practices, a similar proportion of direct access projects $(20 \%)$ and indirect access projects (19\%) pilot innovative communication approaches to build stronger climate change awareness at the community level. These approaches include performance arts (e.g. community drama groups), radio programs, a local network for climate change monitoring, awareness and response, and climate innovation competitions. These innovative communication approaches are described in the project documents as innovations being tested themselves, not just as means to promote the adoption and diffusion of other types of innovations.

Only minor differences can be identified when comparing the choices of agricultural innovations disseminated through projects from both access modalities. First, the thematic areas of innovations which receive more 
attention (e.g. the difference in the number of projects is more than $50 \%$ ) from direct access projects relative to indirect access projects are livestock production, financial management (e.g. agricultural insurance, financing facility) and agricultural services (e.g. seed banks, extension services). On the other hand, managerial innovations in crop production (e.g. intercropping, change in production timing, and post-harvest practices), investment in new climate information systems for agricultural decision support (e.g. a local weather data-based crop advisory service, a participatory method of seasonal and longer-term adaptation planning based on downscaled weather forecasts and climate projections etc.) and investment in climate-resilient practice standards (e.g. a voluntary code of climate-resilient Good Agricultural Practices) are more frequently mentioned by indirect access projects. Finally, there are two types of innovations which are uniquely disseminated by projects from only one access modality: climate-resilient practice standards are only disseminated through two indirect access projects, while the resettlement of climate-vulnerable populations as an innovative solution to climate change for agricultural populations is only implemented in the direct access project in Rwanda.

7.4.2. How do AF projects plan to implement the promotion of agricultural adaptation innovations?

\subsubsection{Dissemination strategy}

In general, interviewees from the implementing entities of both types of projects highlight three similar major considerations driving their agricultural innovation dissemination strategies: 1) the strong institutional capacity of national research and technological institutions, 2) the extensive community participation in choosing locally appropriate innovations, and 3) the ability to make use of simplified communication technologies to reach farmers. 
First, both NIEs of direct access projects and MIEs of indirect access projects similarly decide to disseminate nationally developed agricultural innovations, a strategy enabled by the presence of strong institutional capacity of national research and technological institutions. In both types of projects, NIEs and MIEs engage in a similar strategy of identifying and collaborating with strong national technical partners, such as universities, research institutes and agrometeorological institutes, which have already developed new agricultural technologies and practices suited to each country's agricultural challenges. In many cases, these national technical partners serve as EEs of the AF projects. While the interviewees from both MIEs and NIEs mention that they have access to international knowledge and best practices, they intentionally choose to focus on nationally available agricultural innovations, which are considered more readily applicable to each country's context.

Second, as the disseminated innovations are nationally developed, they are generally not new to the country, but are still new to local communities and therefore need to be customized to suit local conditions across project sites. Both MIEs and NIEs report having used bottom-up inputs from extensive community consultations to identify the most suitable innovations to disseminate to different local communities, as well as to identify ways that new scientific information and practices embedded in the innovations could improve existing indigenous agricultural practices. As one interviewee noted:

"Community played the most important role in the selection of the disseminated innovations. The communities have to give us the green light. The innovations were selected by community members, $50 \%$ men and $50 \%$ women."

(Informant NIE1, from an NIE implementing a direct access project in Africa) 
The need for local customization of the nationally developed innovations also arises because most of them were not created with climate objectives at the onset. Both interviewees from MIEs and NIEs report that the extensive community feedback is also used to demonstrate to the national technical partners the relevance of their knowledge to local climate challenges. This is indicated by the following comment from an interviewee:

"Academic and research centers have played an important role in the choice of disseminated innovation. They developed so many technologies they did not know are climate relevant. We took these available solutions down to the fields then consulted with farmers. We discussed if these $x, y, z$ solutions would work, would you adopt these solutions."

(Informant MIE1, from a MIE implementing an indirect access project in Africa)

Third, while the project document analysis suggests that investment in strengthening climate information systems for agricultural decision support receives more attention from indirect access projects, the interviews reveal that such objective is embedded in the design of projects from both access modalities. Despite the varying levels of dedicated project resources, both direct access and indirect access projects incorporate support for translating weather forecasts and climate projections into tailored advice for farmers' decision-making on a real-time basis. Recognizing that the use of such realtime advice is innovative in the context of current farming practices, both direct and indirect access projects chose to disseminate this new information through communication methods, such as mobile phone-based applications and radio-based advisory messages, which are simple and already familiar to the farmers. An example is provided by the following interviewee: 
"Better information means better crops and better revenue for farmers. Farming communities need to be equipped with the most accurate information possible. While a lot of scientific information is already available at the national level, making this information reach the last mile is the critical part. Information needs to be processed in a way that farmers can understand. Mobile phones are not a new technology but can facilitate access to innovation."

(Informant MIE2, from a MIE implementing a regional indirect access project in three African countries)

I only observe one minor exception to the above pattern of similarity in the innovation dissemination strategies of direct and indirect access projects. There was one interviewee (informant NIE 7) from a NIE implementing a direct access project who emphasizes private sector collaboration as an important driver for the project's agricultural innovation dissemination strategy. Specifically, the private sector partnership was mentioned as crucial for the dissemination of market-based innovations such as weather insurance and new climate-related credit products. None of the interviewed informants from indirect access projects stresses the importance of private sector collaboration for determining their innovation dissemination design, but recognize the importance of bringing private sector, such as the agroindustry and supply chain actors, closer to the project activities during the implementation phase (Informants MIE 4 and MIE 6).

\subsubsection{Adoption strategy}

Based on the semi-structured interviews, I find that both direct access and indirect access projects are largely characterized by three similar adoption design principles: 1) the emphasis on trialability, observability, and relative advantage of innovation; 2 ) the maximization of the compatibility of innovation 
with socio-economic contexts; and 3) the use of informal community-level social groups to promote the adoption of agricultural innovations.

First, both types of projects are designed to primarily address three key adoption drivers related to innovation characteristics themselves. For trialability, both types of projects similarly set up demonstration plots or units - which build on the internationally established farmer field school approach popularized by the United Nations Food and Agriculture Organization (FAO) (FAO et al., 2011) - to trial innovative agricultural technologies and practices. In these plots, external technical experts provide hands-on advice to lead farmers to apply the innovative technologies and practices through learning by doing. The lead farmers are expected to gain familiarity with the innovation, witness its benefits, and disseminate the knowledge about the innovation among peers. For observability, all farmers in a village can come to directly observe the benefits of the trialed technologies and practices, a process which is expected to increase both group learning and trust in the innovation. As many of the demonstration plots are established side-by-side to normal plots, farmers are also able to compare the relative advantage of the innovation with their business-as-usual practices, especially by comparing the cost and yield performances of the two plots by the end of the production season.

Second, both types of projects are similarly designed to pay strong attention to indigenous agricultural practices and the broader socio-cultural contexts in which the innovation is introduced, reflecting a significant effort to disseminate locally appropriate innovations under both access modalities. In particular, the socio-cultural compatibility of innovation, which is also one of Rogers' five innovation attributes discussed earlier (see Section 7.2), is perceived by both NIEs and MIEs as a key driver for adoption, especially when the innovation involves diversification from current livelihood practices. The comment below 
from one interview demonstrates the emphasis on the socio-cultural compatibility of innovation:

"To enhance gender balance and also empower the women within the community, we've looked into activities that are culturally acceptable for a woman to take a role in. And those activities we found to be activities related to livestock/animal production, and agroprocessing. And for that, we also wanted to introduce diversified livelihood, so that the household would not rely only on crop production. So, we've introduced animal revolving loans that are managed by the local community organizations. The facility provides in-kind loans and family loans to the women primarily...

...Some gender theories say that you have to change the culture of the people and I do not agree with that. I think the best approach is to find what is culturally acceptable and try and mainstream your activities within the cultural setting. Otherwise, if you try and oppose what is culturally or normally acceptable, and we have seen that so many times in other projects, people would say "Okay, we accept it" and so on. As soon as the project goes, it collapses."

(Informant MIE1, from a MIE implementing an indirect access project in Africa)

Finally, both direct access and indirect access projects are also similarly designed to encourage agricultural innovation adoption through informal community-level social groups. While all projects aim to benefit individual farmers, the agricultural innovations and related capacity building activities were delivered to them through farmer groups, women groups, cooperatives, and community fora to encourage peer-to-peer exchange, with an aim to 
promote attitude change for innovation adoption. The comment below from an interviewee shows the emphasis in working with community-level groups:

"Our primary target beneficiaries on the agricultural innovation are individual farmers, but we also work with farmer groups. We will support group development and help them connect to markets."

(Informants MIE 4 from a MIE implementing an indirect access project in Asia)

In terms of the types of support for the groups, all projects invest in the development and strengthening of these groups by building their climaterelated skills (e.g. climate-resilient crop production, management, harvest etc.), and non-climate-related skills important for the groups' sustainability (e.g. financial and business management, conflict resolution etc.). The importance of these non-climate skills is highlighted by the following group of interviewees:

"Our project brings people from different cultures and background together to form groups and that could create conflicts. Groups require integration so that they can deal with climate and other situations sustainably. That's why we promote conflict resolution skills to encourage cohesion of the groups. These are skills that are not just relevant to conflicts on natural resource management, but conflict resolution more broadly."

(Informants NIE 2, NIE 3, NIE4, NIE 5, NIE 6 from an NIE implementing a direct access project in Central America) 


\subsubsection{Diffusion strategy}

As with the findings on the dissemination and adoption strategies, I also find that direct and indirect access projects are largely similar in their innovation diffusion strategies, which concern the long-term upscaling of the adoption of AF-financed innovations.

In terms of the communication channels used for diffusion, both staff of NIEs and MIEs mention that their projects use a combination of cosmopolite and localite channels to promote innovation diffusion. These include interpersonal-cosmopolite channels (e.g. extension services, educational institutions), interpersonal-localite channels (lead farmers, peer-to-peer exchanges, group training through farmer groups, farmer testimonials etc.), and mass-media channels (e.g. local radios, TV programs etc.). The interpersonal-localite communication channels are seen by the project implementing entities as key for innovation diffusion among community members and adjacent communities, and the interpersonal-cosmopolite and mass media channels for long-term and large-scale innovation diffusion within the country.

Another area of similarity in the diffusion strategies relates to two dimensions of policy mainstreaming of AF-financed innovations i.e. the alignment with national and sectoral policies, and the financial planning to geographically upscale the AF projects beyond the initial project period. Both MIEs and NIEs emphasize that their current AF projects are well-mainstreamed with national and sectoral policy priorities, and that the government of recipient countries are keen to up-scale the innovative activities. However, none have reported that the recipient governments have already allocated specific national budget amounts to geographically up-scale the AF projects. In the short run, more international financing, such as from the GCF, is the avenue similarly 
pursued by most of the interviewed NIEs and MIEs whose projects are reaching between the mid-term and completion stages.

Finally, both informants from NIEs and MIEs also mention that the support of private sector, such as agro-industries and producer organizations, is needed for the long-term diffusion of several market-based innovations such as new seeds, new crops, and new agricultural financial products.

7.4.3. The role of country context in explaining the similarities in project design

Overall, the findings on agricultural innovation choices and implementation plans above indicate that the access modalities to the AF does not matter for how AF projects are designed to promote agricultural innovations. What then could help explain the observed similarities in the project design between the direct and indirect access projects? The semi-structured interviews reveal the relevant roles of two types of recipient country contextual factors: 1 ) the preexisting institutional capacities of national and local institutions to develop agricultural innovations and customize them to local needs; and 2) their previous exposure to global knowledge on an internationally-recognized agricultural innovation dissemination approach. The importance of these two contextual factors could be seen in three ways.

First, both NIEs and MIEs were equally able to identify, and subsequently rely heavily on, national and local institutions with pre-existing strong institutional capacities, including staff, knowledge and networks, in designing the AF projects. With regards to the agricultural innovation promotion design, both staff of NIEs and MIEs confirm that they asked these institutions, which include national research institutes, universities, CBOs and others, to lead the framing the project's innovation agenda by considering government policy priorities, convening local stakeholders for bottom-up project priority setting, 
and brokering knowledge and information sharing between them. In most cases, these institutions serve as official project EEs, and in many, they are also the developers of the disseminated innovations. By partnering with these institutions, NIEs and MIEs essentially capitalize on the partners' pre-existing institutional capacities to promote locally appropriate agricultural innovations.

Second, many NIEs have a prior experience in collaborating with international development organizations and global experts and consultants. Apart from reflecting the strong capacities of these national institutions, such experience indicates that the institutions have been exposed to cross-scale knowledge flows between global and local knowledge systems. For example, the Jamaican NIE_-the Planning Institute of Jamaica (PIOJ)—has an extensive experience in obtaining development finance and managing projects and programs of international donors such as the European Union and UNDP (Bugler \& Rivard, 2012). The staff of NIEs in South Africa, Rwanda, Costa Rica, and Chile also mention that they possess similar international experience. According to the AF, such international experience is a key characteristic that increases the likelihood of national institutions being accredited as NIEs in the first place (Adaptation Fund, 2012). In the case of agricultural innovation promotion, such prior international experience likely has exposed the NIEs to internationally established innovation dissemination approaches, notably the farmer field school approach. This in turn helps explain why both NIEs and MIEs similarly apply this approach to their projects.

Finally, may other NIEs with less experience and technical capacity in designing and managing internationally funded development projects resort to replicating the project design of MIEs. The interviews with AF staff confirm that this replication is common in many direct access projects. From a knowledge flow perspective, such national replication of international project design could be considered another form of global-local knowledge transfer. 
7.4.4. Different perceptions on the advantages and constraints of the two access modalities

While I find no key differences in the project design to promote agricultural innovations between direct and indirect access projects, the semi-structured interviews reveal differences in the perceptions of staff of NIEs and MIEs on their institutional advantages and constraints as implementing entities of the AF.

\subsubsection{Self-perceptions of advantages}

The interviewees from MIEs generally see their comparative advantage in three areas: 1) developing project proposals and handling complicated procedures of multilateral climate funds; 2 ) facilitating the sharing of project experience through more diverse platforms; and 3) ensuring strong project management with regards to fiduciary and financial standards and social and environment safeguards. These self-perceived strengths also correspond with the general perception of the interviewed AF staff (informants AF2, AF3 and AF4) of stronger institutional capacity of MIEs when compared to NIEs. However, one interviewee from a MIE provides a different perspective on the advantage of a MIE. The interviewee argues that a MIE is more able to play the role of a "neutral convener" that helps overcome bureaucratic separation between government ministries. The interviewee also opines that the presence of such an international neutral convener could potentially open more space for civil society participation in the project design process when compared to a project which is entirely government-led. Specifically, the interviewee notes that:

"It's a little bit difficult for the government to implement such a project on its own. Sometimes you need an agency that is capacitated enough and neutral enough to bring all the different stakeholders 
together. The problem with the governments and line ministries in general is that sometimes their capacity is not that strong in terms of designing and implementing such activities. In many cases, when they work on developing activities like this, they do not capture or leverage the aspects that civil society can bring on board. I would be skeptical to what extent it would go into bringing civil society on board or leveraging other stakeholders like academia. So, I think this position of multinational or implementing entities like the UN or whatever other agency that is in the position to create the synergy amongst different stakeholders."

(Informant MIE1, from a MIE implementing an indirect access project in Africa)

On the other hand, staff of NIEs perceive their comparative advantage to come from their physical closeness to project beneficiaries, superior knowledge of local realities, a closer relationship with local organizations which helps build trust and local ownership, and the ability to create more national ownership in the direct access projects by setting own agenda. These self-perceived strengths of NIEs are reflected in the comments below from two interviewees:

"Being a NIE definitely makes a difference. We have more understanding of the reality and are more adaptive. We work very closely with local organizations so they feel ownership. There is no distance between us and them. They feel that they are part of the solution."

(Informant NIE7, from a NIE implementing a direct access project in Central America) 
"I don't think this project can be implemented by a MIE. You need to fully understand the language, culture and tradition of the beneficiaries. There is also the complicated involvement of local agencies. There is local politics. Farmers need to trust you to apply the knowledge. Being part of the same country is definitely better because you understand the politics, stakeholders, culture, and localities."

(Informant NIE 8, from a NIE implementing a direct access project in Latin America)

Staff of NIEs also highlight a financial value-added of the direct access modality. A group of NIE informants (NIE 2, NIE 3, NIE 4, NIE 5, and NIE 6) claim that the lower fees charged by NIEs when compared to MIEs allow direct access projects to spend more resources on capacity building when compared to indirect access projects.

For all the above reasons, all interviewees from NIEs strongly believe that the direct access modality will lead to more impact and sustainability of the disseminated agricultural innovations, and of overall AF-financed adaptation investment, in the long run.

\subsubsection{Self-perceptions of constraints}

Overall, MIEs did not perceive any major constraints in their ability to mainstream the indirect access projects with national and sectoral policy priorities and to build national ownership. All interviewees from MIEs are confident that they have achieved these mainstreaming and ownership objectives by conducting thorough national and local consultations, and partnering with strong national and local EEs. As noted by one MIE staff: 
"We work very closely with local government entities for AF projects. We don't see any path that we could have done better. As long as we work together, it's a win-win approach."

(Informant MIE3, from a MIE implementing an indirect access project in Asia)

The only area of potential constraints mentioned by one interviewee from a MIE (Informant MIE 7) is that sometimes the physical distances between a MIE and its EEs could be greater than between a NIE and its EEs, especially if the MIE has no country office within the project country. These distances could contribute to delays in information flows, but overall do not constitute a major obstacle for indirect access projects. On the other hand, staff of NIEs of direct access projects also do not perceive any major constraints in their ability to implement AF projects when compared to MIEs. The only issue mentioned by an NIE staff, as noted the comment below, is related to the perceived superiority of global experts over national ones. However, the NIE interviewee mentions that this issue could be addressed by building strong local reputation and implementing projects that deliver strong results.

"When somebody comes from the outside, it's easier to be heard. Sometimes external experts come in and they can go directly to see ministers. This has been a disadvantage for us. We need to have a good reputation in the country to be heard."

(Informant NIE3, from a NIE implementing a direct access project in Central America) 


\subsection{Discussion}

This study departed from an observation that different access modalities to multilateral climate funds could imply different pathways by which international adaptation finance is used to promote agricultural innovations for local communities. Building on the decentralization and innovation studies literature, I hypothesized that direct access projects, which represent more decentralized innovation platforms compared to indirect access projects, are more likely to promote locally appropriate agricultural innovations. Drawing on the aid effectiveness and climate change adaptation literature, I also posited that direct access projects are better positioned to promote policy mainstreaming of these adaptation innovations as a result of enhanced national ownership. By analyzing AF project documents and data from semistructured interviews, I however did not find key differences in the design of both types of projects along the two dimensions. Both direct and indirect access projects are similarly designed to prioritize investment in locally appropriate agricultural innovations. Both are also characterized by policy alignment but face similar uncertainties in terms of the availability of government financial resources for upscaling, indicating a similar pattern of policy mainstreaming.

The above findings offer three insights from a global climate finance policy perspective. First, locally relevant adaptation innovations could be promoted by multilateral climate funds through both access modalities, but this will require a meaningful involvement from capable and locally embedded partner institutions in project design from the onset. While the current study suggests that both NIEs and MIEs of the AF have the capacity to identify these institutions for partnership, new mechanisms could be considered to expand opportunities for these capable institutions to self-identify for involvement in future projects. Examples include open competitive community-level innovation grants and direct solicitation of specific adaptation solutions from 
national and local innovators. Second, the findings also imply that more care is needed to design internationally-financed innovative adaptation projects in recipient countries with weak national and local institutions. In this context, both NIEs and MIEs could take a different approach to project design by committing more resources to build capacities of potential partner EEs in the first place. Third, in addition to capacity support for partner EEs, both NIEs and MIEs must also pay attention to capacity building for local organizations further downstream. In practice, the EEs of AF projects also partner with these local actors as the actual interface with local communities. Therefore, localized institutional capacity building for these last-mile partners is also crucial, especially when they are on-granted the AF finance by the EEs as part of an enhanced direct access model (Informant AF 1).

The study's findings also contribute a new insight to the literature on agricultural innovations for climate change adaptation in developing countries. While much of this literature focuses on adoption and diffusion processes (Bunclark et al., 2018; G. E. Jones, 1967; Lybbert \& Sumner, 2012; Pamuk et al., 2014; Senyolo et al., 2018), this study has taken a broader view that also incorporates the dissemination perspective. In doing so, the study reveals how the documented drivers of these three innovation processes have been operationalized in developing countries through internationallyfunded adaptation projects.

In particular, this study finds that both MIEs and NIEs of the AF pay most attention to adoption drivers related to innovation attributes and the enabling environment, but not to adopter characteristics. The projects emphasize the four adoption drivers related to the innovation's own attributes i.e. observability, trialability, relative advantage, and compatibility. While the systematic literature review (see Section 7.2.1.2.) did not identify the trialability attribute to be important, the interview result shows that the trialability of innovation is central to the adoption design of AF projects. On 
the contrary, reducing the complexity of innovation, which was covered by the reviewed literature, was not mentioned by the interviewees as a key adoption design principle. For the enabling environment for innovation adoption, the AF projects pay strong attention to engaging with community-level informal social groups, supporting community consultation and participatory agricultural $R \& D$, identifying supportive market mechanisms (e.g. agricultural credit), raising climate change awareness, and building capacity of farmer institutions. On the other hand, neither direct nor indirect access projects were designed with a strong emphasis to encourage innovation adoption by targeting adopter characteristics. Except gender and the level of education and awareness on climate change, other key adopter characteristics were not highlighted during the interviews as being central to the projects' innovation adoption design. These characteristics are the adopters' wealth, risk preference, identity, degree of current livelihood diversification, reliance on remittances, the level of household food security and farm size. To promote agricultural innovations more effectively, the AF could consider requiring both NIEs and MIEs to explicitly address these adopter characteristics in the project design to maximize innovation adoption by different groups.

Future research could build on the findings of this study in several ways. First, while the study looks at the implications of the access modalities to international adaptation finance on the innovation promotion design in the short term, its findings should be complemented by studies with a long-term view. For example, the very process of an accredited NIE and domestic partners collaborating to access international climate finance could stimulate new R\&D. In reviewing the lessons learned on direct access from African countries, Schäfer et al. (2017) find that "in addition to institutional capacitybuilding as a direct positive impact of the accreditation process, respondents noted that accreditation had significant indirect co-benefits for catalysing and revitalising scientific research on mitigation and adaptation at the country level" (p.13). This could contribute to stimulating more home-grown climate 
innovations in the long run and will require further research to investigate. Second, future studies could also expand the emphasis on project design in this study to impact evaluation by examining whether there are differential innovation adoption and diffusion rates of the agricultural adaptation innovations between direct and indirect access projects following years of implementation. Finally, while the agricultural innovations studied in this chapter were financed by the AF with climate change adaptation as the main rationale, in practice they are not just a response to climate change, but also to the demand for higher productivity and more efficiency in agriculture. Therefore, the findings from this study could be equally relevant to the study of agricultural financing in general, even in a context where climate change is not the main concern for innovation.

Future studies on the role of $A F$ in promoting agricultural innovations could integrate a bottom-of-the pyramid (BoP) research perspective. The BoP stream of literature examines how the parameters of innovation adoption are different in the context of deep poverty (Ramani et al., 2012). In a BoP context, innovations "cater to the essential needs of the poor such as healthcare, housing, food, water and sanitation or enhance productivity and income-generation capacity" and the diffusion of these innovations "involves creating incentives for optimal adoption and effective utilization by the intended beneficiaries" (Ramani et al., 2012, p.678). This requires a consideration of the unique factors influencing the demand for BoP innovations, including financial constraints, limited knowledge, information and skills base, and limited access to complementary infrastructure (Ramani et al., 2012), and of the potential stratifying effects in introducing innovations (such as new technologies) to an environment of unequal level playing field between richer and poorer adopters (Mikulewicz, 2020). As the AF aims to reach the most vulnerable local communities in developing countries, the target beneficiaries of AF projects likely include the BoP. Integration of the BoP perspective in future research could therefore add valuable insights to 
the assessment of AF projects and inform policy recommendations to ensure that the benefits of innovation are equitably shared.

Finally, an interview conducted in this study reveals a claim that an external agent such as a MIE could be a neutral broker in project development and such neutrality could enhance civil society participation in internationally financed projects. This claim is interesting in light of the finding in Chapter 6 that the governance of civil society interacts with the access modalities to shape the level of community focus in the design of AF projects in some countries, and should therefore be investigated in future research.

\subsection{Conclusion}

This study aims to explain how distinctive governance arrangements through which developing countries access multilateral climate funds shape the utilization of international adaptation finance to promote innovations at the project level. To achieve this objective, I analyze the implications of the AF's direct access and indirect access modalities on how 36 AF projects are designed to promote agricultural innovations for local communities. While literature suggests that direct access projects could have more potential to promote locally relevant and policy-mainstreamed innovations, I do not find evidence that both types of projects are designed in to promote agricultural innovations differently along the two dimensions. The study highlights the important roles of two important contextual factors in AF recipient countriesthe pre-existing institutional capacities of national and local institutions to develop agricultural innovations and customize them to local needs, and their previous exposure to global knowledge on an internationally-recognized agricultural innovation dissemination approach-in explaining the observed similarities in project design. 
The study provides new empirical evidence to inform multilateral climate funds' strategy to catalyze innovations to address climate challenges. It demonstrates that internationally-financed adaptation projects under both direct and indirect access modalities could promote locally relevant agricultural innovations, but the ability to do so depends on collaboration between project implementing entities and capable, locally embedded partner institutions in the recipient countries from the onset. Expanding opportunities for these capable institutions to self-identify as project partners of multilateral climate funds, as well as dedicating more project resources to institutional capacity building where initial capacities are weak, are key policy implications. To complement the findings in this study, future research could build more insights on the long-term implications of the access modalities to international adaptation finance on local-level innovative adaptation investments. For example, future research could examine if the modalities have a differential impact in facilitating civil society participation in the implementation of publicly-financed innovative adaptation projects, and in achieving innovation adoption and diffusion rates among different social groups. 


\section{Chapter 8: Conclusions, discussion and reflections}

\subsection{Introduction}

This dissertation departed from the observation that there are four major knowledge gaps on how international adaptation finance has shaped local climate change adaptation in developing countries. First, little is known on how much international adaptation finance has reached local communities and in what manner the community-bound finance has been used. Second, one of the objectives of multilateral climate funds is to channel international adaptation finance to developing countries to stimulate community-focused adaptation, including by financing pilot experiments of innovations. But if, where and how these funds have done so remains under-researched. Third, whether climate finance governance models, defined in this dissertation as the direct access and indirect access modalities to multilateral climate funds, matters for international adaptation finance to stimulate community-focused and innovative adaptation is poorly understood. While literature suggests that direct access projects have more potential to be community focused and promote locally relevant and policy-mainstreamed innovations, there have been no studies that systematically compare direct access and indirect access projects. Fourth, as the direct access and indirect access modalities continue to operate in parallel, more knowledge is needed for multilateral climate funds and recipient governments to develop policy approaches to promote community-focused and innovative adaptation under both access modalities, while taking into account different recipient country contexts.

Given the knowledge gaps, this dissertation aims to understand and explain if and how the governance of international adaptation finance shapes local climate change adaptation actions at the project level in developing countries. To achieve this objective, I use a governance perspective to conceptualize 
the direct access and indirect access modalities to multilateral climate funds as different climate finance governance models, and I argue that they have the potential to shape the use of international adaptation finance for local adaptation differently. Three research strategies were pursued to achieve this objective. First, I conducted a comparative analysis of internationally-financed direct access and indirect access projects with regards to the communityfocused and innovative design characteristics. Second, I identified the mechanisms through which the two modalities could shape the communityfocused and innovative design of local adaptation actions differently and tested them empirically using project data. Third, I analyzed how the contextual conditions of recipient countries could play a role-by themselves or in conjunction with the access modalities-to shape the two design aspects of the projects. The following research questions were formulated to implement the above research strategies.

Main research question: How do access modalities to international adaptation finance shape the level of community focus and the promotion of adaptation innovations in the design of projects in recipient countries?

To answer this question, five research sub-questions (sub-RQ) were formulated:

1) Level of community focus in project investment

Sub-RQ1: How can the level of community focus in adaptation projects be defined and measured?

Sub-RQ2: Are direct access and indirect access projects equally communityfocused?

Sub-RQ3: What explains the difference in the level of community focus in direct access and indirect access adaptation projects? 
2) Promotion of adaptation innovations

Sub-RQ 4: Are there differences in the design of direct access and indirect access projects to promote adaptation innovations?

Sub-RQ 5: What explains differences in the design to promote adaptation innovations of direct access and indirect access projects, if they exist?

Figure 8.1. summarizes the four research gaps discussed in Chapter 1 and how they lead to the design of three research strategies and the research questions in this dissertation. 
framework for the dissertation (Chapter 3). Within the overall embedded case study research design (Chapter 1), I employed a multi-method approach to combine different research methods and data sources to answer the research questions.

This final chapter brings together the research findings into conclusions, discussion and reflections. Section 8.2. provides answers to the sub-research questions, highlights key insights from each answer, and synthesizes them into an overall answer to the main research question. Section 8.3. reflects on the scientific contributions of the dissertation's findings to the current literature. Section 8.4. reflects on the research design and methods used in this dissertation, and the limitations of this study. Section 8.5. identifies some areas of future research that can build on this study. Section 8.6 discusses the policy relevance of the dissertation to the governance of international adaptation finance for the benefits of local communities. Section 8.7 provides final remarks.

\subsection{Research findings and insights}

Sub-RQ1: How can the level of community focus in adaptation projects be defined and measured?

My research shows that defining the level of community focus in adaptation projects requires integrating the principles for local-level climate finance tracking with insights from the CBA literature. By reviewing the principles and the literature, I defined community-focused adaptation projects as ones with the following four essential characteristics (Chapter 5): 1) financial investment in activities that generate direct adaptation benefits for community-level beneficiaries, which include groups of households, villages, communes, neighborhoods, and settlements in climate-vulnerable locations; 2) active participation of community stakeholders throughout the project cycle; 3) 
devolution of decision-making power to the communities for them to determine the methods and goals of adaptation suitable for local needs and contexts; and 4) design from the onset to ensure the policy adoption and geographical replicability of community adaptation initiatives, which together represent the mainstreaming of adaptation benefits delivered to the communities.

Building on the above definition of community-focused adaptation, I developed a framework to measure the level of community-focused adaptation in project design using four main dimensions of indicators (Chapter 5): 1) the level of financial investment in adaptation actions at the community level; 2) the level of community participation in project design, implementation, and evaluation; 3) the level of devolution of project decisionmaking to local level; and 4) the mainstreaming of community adaptation priorities and practices in the national and sectoral policy processes, as well as geographically. Each of the four dimensions was further operationalized through a set of indicators. The indicators were subsequently used to assess and compare data from AF projects.

\begin{abstract}
Insight: A meaningful assessment of the level of community focus of adaptation projects requires combining the quantification of adaptation finance designated for community-level beneficiaries, with the indicator-based assessment of qualitative characteristics, including participation, devolution, and mainstreaming, that reflect the key design principles of community-level adaptation.
\end{abstract}

Sub-RQ2: Are direct access and indirect access projects equally communityfocused?

Chapter 5 answered the Sub-RQ 2 by applying the framework developed through the Sub-RQ1 to systematically assess the level of community focus 
of $63 \mathrm{AF}$ projects (22 direct access projects and 41 indirect access projects). By systematically reviewing the content of project documents, I found that direct access and indirect access projects are not equally community focused. On average, direct access projects are more community-focused than indirect access projects for the first three dimensions; direct access projects invest higher project budget at the community level, involve more community participation, and engages in more devolution of decision making to the local level. However, no difference exists with regards to the fourth dimension on the level of policy and geographical mainstreaming of the community adaptation actions financed by the two types of projects.

Insight: Direct access projects are on average more communityfocused than indirect access projects due to their financial, participatory and devolutionary characteristics. However, both adaptation projects with a strong and weak community focus are present under both access modalities to the AF.

Sub-RQ3: What explains the difference in the level of community focus in direct access and indirect access adaptation projects?

While the answer to the Sub-RQ 2 showed that direct access projects are on average more community-focused than indirect access projects, conclusions to the Sub-RQ3, which was addressed in Chapter 6, showed that the observed difference cannot be solely attributed to the role of access modalities. In practice, a different contextual factor, or a combination of factors, explain the different levels of community focus across projects in different groups of $\mathrm{AF}$ recipient countries.

In Chapter 6, I selected a sample of $30 \mathrm{AF}$ projects (13 direct access projects and 17 indirect access projects), and classified them into high, medium, and low community focus based on the aggregate financial, participation, and 
devolution scores derived from the answer to the Sub-RQ2. (The fourth score on policy and geographical mainstreaming was dropped due to no difference between the two types of projects). I then developed a fuzzy-set QCA model to explain the varying levels of community focus in project design as the outcome. Included in the QCA model were five contextual conditions that could explain the outcome: 1) the type of access modality that each recipient country uses to access the AF; 2) past climate-related losses; 3 ) exposure to projected future climate risks; 4 ) the level of government decentralization; and 5) the governance of civil society in AF recipient countries. It was hypothesized that direct access, higher past losses and future risks from climate change, more government decentralization, and an enabled civil society promote AF projects with a stronger community focus.

Based on the QCA results in Chapter 6, I found that the absence of high exposure to future climate risks is the necessary condition that explains the cases of AF projects with a weaker community focus. In other words, without a high degree of exposure to future climate harms, we can be nearly certain that countries would not have acted to direct more AF project financing towards local communities. However, given that there is no necessary condition for the presence of AF projects with a stronger community focus, the opposite is not the case; a higher degree of exposure to future climate harms does not guarantee the presence of a stronger community focus in AF projects. This means that whether or not AF projects would be designed to have a stronger community focus is not explained by one necessary condition, but by a configuration of sufficient conditions, within which the exposure to future climate risks may or may not play a role.

Insight: What explains a weaker community focus in AF projects is not automatically the negation of what explains the AF projects with a stronger community focus. 
I can further conclude that the presence of AF projects with a stronger community focus is explained by three configurations of contextual conditions, and the type of access modality to access the AF is part of two of them. First, in what could be called the "high future risk" countries, the presence of high exposure to future climate risks is individually sufficient to explain the presence of a stronger community focus in AF projects, regardless of the level of past climate-related losses, the decentralization characteristic of government structure, the governance of civil society, and the access modality to the AF. Second, in a group of "indirect access, strong civil society" countries, indirect access AF projects are designed to have a stronger community focus when there is a conducive civil society governance, regardless of the level of exposure to past and future climate risks and the prevailing level of government decentralization. Third, in "direct access, weak civil society" countries, direct access AF projects are designed to have a stronger community focus despite the absence of conducive civil society governance, regardless of the roles of past and future climate risks and the level of government decentralization. While the first group of countries highlights the role of exposure to future climate harms in shaping the high level of community focus in AF projects, the last two groups of countries indicate the complementary roles of civil society governance and access modalities in shaping such outcome.

There are two pathways of sufficient conditions that lead to a weaker community focus in AF projects, and the type of access modality is part of one of them. First, AF projects with a weaker community focus can be found in the context of recipient countries with weak civil society governance, despite these countries having decentralized governments and having experienced high losses from past climate-related extremes. Second, a combination of government centralization, low exposure to future climate risks, low past climate-related losses, and the use of the indirect access 
modality explains a weaker community focus in AF projects in another group of countries.

Insight: There are multiple pathways to internationally-financed adaptation projects with a stronger community focus. Choosing a particular access modality by itself is not sufficient to automatically result in a highly community-focused outcome. In some countries where the choice of access modality plays a role in delivering this outcome, it works in conjunction with the broader recipient country context i.e. the governance of civil society.

Sub-RQ 4: Are there differences in the design of direct access and indirect access projects to promote adaptation innovations?

This Sub-RQ 4 aimed to understand and compare the key design characteristics of direct access and indirect access projects with regards to the promotion of adaptation innovations for climate-vulnerable local communities. Based on the literature, I hypothesized that there could be two key differences between both types of projects. First, when compared to indirect access projects, direct access projects are likely to promote more locally relevant innovations due to their decentralization characteristics that in turn facilitate stakeholder participation and bottom-up identification of innovation needs. Second, direct access projects could also ensure more mainstreaming of AF-financed innovations with national policy processes due to the enhanced national ownership in the AF project preparation process. Chapter 7 answered the Sub-RQ 4 by testing if these two design differences exist, using project data from a subset of 36 AF projects (15 direct access projects and 21 indirect access projects) from sectors related to agriculture.

Based on project documents and semi-structured interviews, I did not find evidence of a difference in how the two types of projects are designed to 
promote agricultural innovations along the local relevance dimension. Both direct access and indirect access projects are similarly designed to prioritize investment in locally appropriate agricultural innovations. This is accomplished by:

- deliberately choosing to disseminate nationally developed, as opposed to internationally transferred, innovations, while recognizing the need for further local customization;

- relying on locally embedded technical partners, extensive community consultations and simplified communication technologies to disseminate the innovations;

- pursuing an innovation adoption strategy that maximizes the sociocultural compatibility of the innovations, while capitalizing on informal community-level social groups for attitude change.

I also did not find a difference in the policy mainstreaming aspect of innovation promotion activities financed through both type of AF projects. On the one hand, both the interviewed staff of the NIEs of direct access projects, and of the MIEs of indirect access projects, describe that the innovation promotion activities financed by their AF projects are fully aligned with national and/or sectoral policies. This similar description by NIEs and MIEs confirms the answer to the Sub-RQ 2 that direct access and indirect access projects do not differ along the mainstreaming dimension. On the other hand, both the staff of NIEs and MIEs are similarly unsure of the recipient governments' financial continuation plan for the AF-financed innovations beyond the initial AF project implementation period. This financial uncertainty for up-scaling despite the policy alignment indicates a similar pattern of policy mainstreaming in both types of AF projects.

While I found that staff of the NIEs and MIEs of the AF perceive their institutional advantages and constraints differently, these different 
perceptions did not lead them to design their projects to promote agricultural innovations differently along the two dimensions above.

Insight: Different self-perceptions of institutional strengths and weaknesses do not necessarily lead national and international project implementing entities of multilateral climate funds to design adaptation project interventions differently.

Sub-RQ 5: What explains differences in the design to promote adaptation innovations of direct access and indirect access projects, if they exist?

Given the answer to question 4 above, the answer to the sub-RQ 5 aimed to explain the lack of differences between direct access and indirect access projects with regards the agricultural innovation promotion design. Chapter 7 answered the sub-RQ 5 by turning to the influence of other recipient country contextual factors in shaping the project design similarities. Based on semistructured interviews, two such factors were identified: the pre-existing institutional capacities of national and local institutions to develop agricultural innovations and customize them to local needs, and their previous exposure to global knowledge on an internationally-recognized agricultural innovation dissemination approach. The importance of these two contextual factors could be seen in three ways.

First, the NIEs of direct access projects and MIEs of indirect access projects have pursued the same strategy in identifying national and local institutions with existing strong capacities in terms of staff, knowledge and networks, and partnering with them to design project interventions. In most cases, these institutions serve as official project EEs, and in many, they are also the developers of the disseminated innovations. These institutions, which include national research institutes, universities, $\mathrm{CBO}$ s and others, were then asked to play a leading role in framing the project's innovation agenda through 
extensive stakeholder consultations at the local level. Second, many NIEs of direct access projects have a prior experience in collaborating with international development organizations and global experts and consultants, therefore able to "strike the right note". Such experience also indicates that they have been exposed to global knowledge flows, which include the knowledge on an internationally established agricultural innovation dissemination approach i.e. the farmer field school approach (FAO et al., 2011). This in turn helps explain why both NIEs and MIEs similarly apply this approach to their projects. Finally, NIEs with less experience and technical capacity in designing and managing internationally funded development projects resort to replicating the project design of MIEs. From a knowledge flow perspective, such national replication of international project design could be considered another form of global-local knowledge transfer.

Insight: The design to promote innovations in internationallyfinanced adaptation projects is shaped by a combination of preexisting national and local institutional capacities and their exposure to established global knowledge on innovation dissemination, which is commonly held by both international and national organizations.

\section{Overall dissertation finding}

So, how do the above findings to the research sub-questions help answer the main research question: how do access modalities to international adaptation finance shape the level of community focus and the promotion of adaptation innovations in the design of projects in recipient countries? When taken together, the findings sum to a mixed answer. In short, the access modalities influence the design of AF projects with regards to the high level of community focus in only in a subset of AF recipient countries by working in conjunction with civil society, but do not affect how the 
projects are designed to promote agricultural adaptation innovations for community-level beneficiaries in any country.

The key implications from this overall dissertation finding are three-fold. First, while the governance of international adaptation finance could play a role is shaping local adaptation to climate change, the extent of such role does not extend equally across countries and across different project design aspects. Second, in the project design aspect where it does have some influence, as seen in this dissertation in the context of the level of community focus, the extent and direction of influence depends on its interaction with the prevailing recipient country context. Third, there is also project design aspect in which the role of the recipient country context prevails over how the access to funding is governed in shaping the project design. Such aspect refers to the promotion of agricultural innovations in the context of this dissertation.

Insight: The governance of international adaptation finance could play a role in shaping local level climate change adaptation, but the extent and direction of such role depends on the project design aspect as well as the recipient country's context.

\subsection{Scientific contributions}

Klein et al. (2017) identify four generations of research on climate change adaptation. The first-generation adaptation research was primarily concerned with describing the impacts of climate change as a basis to identify adaptation options. The second-generation adaptation research seeks to better define adaptation and related core concepts and begins to investigate the social and normative aspects of adaptation. The third-generation adaptation research has emerged with a growing concern with adaptation policy, while the fourthgeneration adaptation research, which is still evolving, is likely to be more implementation-oriented (Klein et al., 2017). This dissertation builds on the 
third-generation adaptation research by integrating two key cross-cutting policy-related themes of adaptation governance and adaptation finance (Biesbroek et al., 2014; Dzebo \& Stripple, 2015; Ensor \& Berger, 2009; Hall \& Persson, 2017; Lebel et al., 2017; Nieuwaal et al., 2009; Scoville-Simonds, 2016; Sharma et al., 2014). In particular, it contributes to advancing an understanding of the governance conditions-both related to climate finance governance and country governance-through which public international adaptation finance shapes the patterns of local climate change adaptation. The dissertation's findings also contribute to the fourth-generation research by providing new empirical insights on the delivery of international adaptation finance (Biagini et al., 2014; Chan and Amerasinghe, 2018; Donner et al., 2016; Fenton et al., 2014; Manuamorn et al., 2020; Micale et al., 2018; Parker et al., 2014; Peterson Carvalho and Terpstra, 2015; Terpstra et al., 2013). As the AF will continue to be a key financing mechanism of the Paris Agreement, the dissertation's findings from the AF case study are relevant for improving climate finance delivery in the context of the Agreement's global adaptation goal (Lesnikowski et al., 2017).

Within the above positioning of this dissertation in relation to adaptation research generations, this section highlights five key scientific contributions that emerge from the dissertation's overall findings. The policy contributions of the dissertation are discussed separately in Section 8.6.

First, a major contribution of this dissertation is to move away from simply describing the importance of climate finance governance arrangements towards explaining how they impact local climate change adaptation actions. While the subject of access modalities to multilateral climate funds have received considerable interest in the literature (Berliner et al., 2013; Bird et al., 2011; Brown et al., 2010b; Masullo et al., 2015; Schäfer et al., 2014), current scholarship has hardly moved beyond simple descriptions of their distinctive arrangements and empirical realities of selected direct access and 
indirect access projects, which in turn limits the analytical value of access modality as a construct. By using a governance lens, this dissertation has been able to unpack the access modalities more meaningfully and explore their importance in shaping local adaptation both theoretically and empirically. This is especially the case for the examination of the direct access modality. While previous studies generally highlight the potential of direct access in being favourable for local communities (Bosma et al., 2018; Fenton et al., 2014), this dissertation advances such claim by isolating the two relevant theoretical mechanisms-decentralization to the national level and policy mainstreaming induced by national ownership (Chapter 3), and found empirical evidence to support the former (Chapters $5,6,7$ ) but not the latter (Chapters 5 and 7). These findings, particularly on the mainstreaming issue, are novel to the literature on climate finance, which has until now largely equated the direct access modality with more national ownership (Müller, 2014), and by association, to more policy mainstreaming of internationallyfinanced adaptation actions (Amerasinghe et al., 2017; Hogarth, 2012). As such, the finding on the lack of a mainstreaming effect of direct access from this dissertation could help stimulate new scholarly debates in climate finance, particularly on the promises and limitations of the direct access modality. At the same time, the finding on decentralization also contributes to a better understanding of the role of democratic quality of climate finance governance in the process of addressing local climate change challenges.

Second, the dissertation's findings contribute new insights on how climate vulnerability is framed, and how adaptation project interventions are governed, in the context of internationally-financed adaptation projects. Earlier research on the AF found that its projects had limited focus on social aspects of vulnerabilities such as gender and ethnicity (Remling \& Persson, 2015). On the contrary, I found that, as of 2017 , the main vulnerable groups targeted by the AF projects in both access modalities are rural populations, particularly smallholder farmers, women, youth and the elderly, and that 
marginalized groups, including ethnic minorities, indigenous populations and low-caste communities, are explicitly targeted through numerous projects (Chapter 5). This finding reflects a growing recognition of the heterogeneity of vulnerabilities and adaptation needs, and indicates an increased adoption of the vulnerability-centric framing of adaptation (Dupuis \& Biesbroek, 2013; Hall, 2017) in the context of international adaptation finance. In terms of project governance, the dissertation also contributes to opening the black box of local stakeholder engagement in internationally-financed adaptation projects-a subject which has so far been under researched but recently gained more attention among scholars (Lebel et al., 2018; Sherman \& Ford, 2014; Sovacool et al., 2017). In particular, I found that direct access projects perform better than indirect access projects in engaging community-level stakeholders both as project beneficiaries and decision-makers (Chapter 5). For decision-making, direct access projects perform particularly well in engaging the stakeholders on vulnerability and adaptation assessment and project monitoring and evaluation. This finding is new to the literature on access modalities, and expands insights from recent research that evaluates the implications of stakeholder engagement on the actual implementation of adaptation initiatives (Sherman \& Ford, 2014).

Third, the dissertation contributes to highlighting the importance of macrolevel enabling conditions for community-level climate change adaptation. While much of the existing CBA literature emphasizes micro-level conditions such as community perceptions, local knowledge systems and capacity of local institutions (Alam et al. , 2017; Lebel, 2013; Sekine et al., 2009), the dissertation was motivated by the growing literature on how macro-level conditions, such the country's administrative tradition (Biesbroek et al., 2018) and level of country decentralization (Brockhaus \& Kambiré, 2009), affect the policy approach that governments take to support climate change adaptation across scales. As national governments still play a dominant role in the context of project development through multilateral climate funds, the 
influence of these macro-level governance factors could also be present when international adaptation finance is involved, but this has rarely been analyzed in the existing literature. By conducting such analysis, the dissertation offers new insights on key macro-level explanatory conditions, including the role of exposure to future climate risks, the governance of civil society and the access modality in enabling internationally-financed adaptation projects to be community-focused (Chapter 6), while identifying the pre-existing capacities of national and local institutions and their exposure to global knowledge as important in shaping these projects' innovation design (Chapter 7). These findings are novel to the studies on community-level adaptation and innovation in developing countries. By highlighting the role of these new conditions, this dissertation's findings expand the growing body of literature on enabling conditions for local adaptation (Adhikari \& Taylor, 2012; Archer et al., 2014; McNamara \& Buggy, 2017; Mimura et al., 2014; Regmi \& Star, 2015; Spires et al., 2014), and calls more scholarly attention to the role of conditions which may have been overlooked in the past.

Fourth, the dissertation also contributes to the debate and scholarship on local-level adaptation financing in ways that account for the interdependence among the enabling conditions by using the QCA methodology. While this dissertation adds to recent work that applies QCA to adaptation research (Pahl-Wostl \& Knieper, 2014), to the best of my knowledge, it is the first research to use it to study international adaptation finance. The use of QCA enabled the dissertation to investigate the interdependence of enabling conditions for local use on international adaptation finance explicitly and systematically. In turn, the dissertation demonstrated that some macro-level enabling conditions work in conjunction, as shown in the case of the complementary roles of access modality and civil society in shaping highly community-focused adaptation project design in some AF recipient countries (Chapter 6). On the other hand, another potential configuration of interdependent conditions-that the impact of direct access in enhancing 
highly community-focused adaptation could be magnified in recipient countries which are already decentralized-was not detected in this study. This finding adds a new empirical insight to inform the still nascent discussion in literature on the relationships between direct access to international adaptation finance and the contextual conditions of recipient developing countries (Duus-Otterström, 2016; Masullo et al., 2015; Schalatek, 2012). With all of these interesting findings from QCA, I hope that this dissertation sparks more scholarly interest in applying the configurational approach to future research on local-level adaptation financing, and on climate change adaptation more broadly.

Finally, the operational framework developed by this dissertation to define and measure the level of community focus in adaptation projects could facilitate a comparative assessment of projects from various funding sources. While previous studies have compared community-level adaptation across countries (Adhikari \& Taylor, 2012; McNamara, 2013), they hardly applied a systematic definition of what constitutes a community and what communitylevel adaptation entails across cases. Reflecting the well-known "dependent variable" problem in the study of climate change adaptation (Dupuis \& Biesbroek, 2013), this lack of a systematic definition has contributed to the concentration of knowledge on case-specific insights with limited crosscountry comparability and generalizability. The four-pronged framework developed in Chapter 5 contributes to addressing this problem by defining community-focused adaptation with tangible indicators, thus facilitating a comparative assessment of multiple cases. With the inclusion of a financial investment indicator, the framework could also be applied to track and compare community-bound international adaptation finance in other portfolios of projects beyond the $\mathrm{AF}$, thus contributing to advancing local-level climate finance tracking practices. 


\subsection{Reflections on the research design and study limitations}

This section reflects on the overall research design, including theoretical and methodological choices, and limitations of the study.

\subsubsection{Theoretical pluralism and multi-method research design}

Guided by a realist research approach, I intentionally used multiple strands of literature and theoretical perspectives to study the influence of governance of international adaptation finance on local climate change adaptation. This choice of theoretical pluralism was borne out of a recognition that a specific body of literature and a single theory will not provide me with adequate tools to examine the combined topics of governance of international adaptation finance, community-focused adaptation, and innovation, which by nature call for multi-disciplinary research. The choice also reflects a realization of the broader connections of research themes and issues; while there are no established theories on the influence of access modalities to multilateral climate funds on project-level actions per se, the underlying core contention of this topic-i.e. whether more participatory decision-making in the use of international development aid matters-is not new. With this realization, I therefore used a range of relevant theoretical perspectives, including participatory development, decentralization and aid effectiveness, as well as broader insights from the literature on climate change adaptation, governance, innovation and international development, to develop the theoretical framework (Chapter 3 ) to guide the empirical analyses (Chapters $5,6,7)$. Linking these multiple theoretical perspectives and insights was fundamental in helping me make sense of the new phenomenon under study and unravel the causal mechanisms behind it. While theoretical purists may argue that I have been too flexible in combining different ontological and epistemological assumptions, I would argue that this pragmatic approach has allowed me to conceptualize and examine the access modalities to 
international adaptation finance meaningfully, and led to research findings that are novel to the study on local-level adaptation financing.

The use of multiple methods for data collection and analysis contributes to the research validity of this dissertation and fits the overall epistemology chosen. For data collection, the dissertation made use of three sources of data: AF project documents (Chapters 5,6,7), global datasets (Chapter 6) and semi-structured interviews (Chapter 7). These multiple data sources contribute to research validity in three ways. First, the inclusion of $63 \mathrm{AF}$ project documents from 53 countries (Chapter 5), from which further subsamples were drawn (30 projects in Chapter 6 and 36 projects in Chapter 7), ensured that the three empirical studies in this dissertation are based on a relatively large sample size of cases. This, combined with the high level of quality and comparability of the information contained in the AF project documents, contributes to the systematic nature and generalizability of the dissertation's findings (Berrang-Ford et al., 2015; Biagini et al., 2014). Second, by operationalizing the outcome and conditions for the QCA model (Chapter 6) with project documents and global datasets, I essentially connected my analysis of the AF project data for the outcome to the established global research on the conditions (e.g. exposure to past and future climate change, decentralization, and civil society) that explain the outcome. This approach enhances the robustness in the scoring of the conditions, and thus in the analysis of their influence on the outcome. Third, the combined use of data from project documents and semi-structured interviews (Chapter 7) also facilitated iterative data examination and triangulation of the findings.

For data analysis, two methods-systematic methodology and QCA-deserve to be highlighted due to their transparent characteristics that increase the legitimacy of the research findings. 
The systematic methodology was applied in this dissertation in two ways. First, I conducted a content analysis of AF project documents using two codebooks, which are made available as Supplementary Materials 3 and 4 of this dissertation. This allows others to replicate and examine the analyses, and to expand them to projects financed by other funding sources. Second, as part of the analysis in Chapter 7, I also conducted a systematic literature review to synthesize and converge the literature on agricultural innovations for climate change adaptation in developing countries. The literature selection and review protocols are also made available as the Supplementary Material 5 of this dissertation. In applying the systematic review methodology, this dissertation in turn contributes to further expanding its use in cross-national climate change adaptation research (Berrang-Ford et al., 2011; Biagini et al., 2014; Lesnikowski et al., 2013).

The use of QCA enabled this dissertation to answer the research Sub-RQ 3 in a way that balances quantitative rigor with in-depth case knowledge. In the QCA model, the thresholds for membership, non-membership and cross-over points in the outcome and condition sets are determined by the researcher using both theory and empirical knowledge. The transparency required in choosing these thresholds allows the QCA results to be replicated and verified. Due to the dual focus in explaining the occurrence and nonoccurrence of the outcome, the QCA approach also enabled this dissertation to point out a causal asymmetry in the study of community focus in $A F$ projects, in that what explains the weaker outcome is not automatically the negation of the conditions, or configuration of conditions, that explains the stronger outcome. While conjunctural causality could also have been studied through other techniques (such as Partial Least Squares Structural Equation Modelling), this causal asymmetry cannot be captured easily by other data modelling techniques. 


\subsubsection{Study limitations}

Despite the methodological considerations discussed above, some limitations to this dissertation should be noted. While each empirical chapter (Chapters $5,6,7)$ had discussed limitations specific to each individual study, I discuss some overall research limitations of the dissertation here.

First, the dissertation's findings are largely based on a systematic assessment of project proposals which represent how the projects are designed but do not capture changes during project implementation or project outcomes. This design-centric approach was motivated by a recognition that previous adaptation studies tended to focus on outcomes and impacts without critically examining if project design is aligned with them. The focus on project design also reflects the fact that a large number of AF projects, particularly direct access projects, were still at the early stages when I collected project data in 2017 , and this data landscape would not have supported a meaningful assessment of the influence of access modalities on project implementation and outcomes across the AF portfolio. However, it is recognized that designcentric insights represent a snapshot rather than a longitudinal perspective, which would have provided a more dynamic understanding of communitylevel adaptation in developing countries.

Second, the reliance on content analysis of project documents means there are likely problems with under-reporting and over-reporting of information, which could bias the results. On the one hand, the low community focus scores in some AF projects may have reflected proposals which are less eloquently written with regards to their community-level activities. On the other hand, some projects also use the terms "innovative", "innovation", and related terms rather liberally, potentially contributing to over-reporting of what they claim as innovations. 
Third, the use of project documents and interviews with the AF Secretariat and implementing entities as the main data source means that community level perspectives are missing. To understand important questions-such as how much projects oversell the level of community engagement while in fact working with local elites, and whether international adaptation finance amplifies rather than transforms existing inequities-needs further in-depth research that examines the power and equity issues in adaptation at the local levels using a political ecology lens. More research that focuses on impact evaluation is also needed to assess the effectiveness of these project interventions for various groups within a community, and requires an explicit consideration of the unintended consequence of maladaptation.

Finally, the dissertation's focus on the macro-level enabling conditions across countries inevitably sacrifices an in-depth examination of the micro-level processes that also influence each internationally-financed adaptation project.

\subsection{Future research directions}

Based on the dissertation's findings, and some of the limitations discussed above, several topics merit further investigation. I discussed these specific topics in the three empirical chapters (Chapters 5,6,7). Here, I highlight some overarching areas for future research that emerge from the findings across chapters.

First, a consideration of more dimensions of governance could build additional insights on the access modalities to international adaptation finance. In this dissertation, I used the concepts of "decentralization" and "devolution" to characterize the access modalities and describe their potential differences (Chapters 3, 5, 6 and 7). However, other concepts, such as "multilevel governance" (Hooghe \& Marks, 2003) and "polycentric governance" 
(Ostrom, 2010; Pahl-Wostl \& Knieper, 2014), highlight different aspects as also being relevant. While multi-level governance presumes a strong role for government actors and their interdependence with other supra- and subnational actors, polycentric governance emphasizes multiple decision-making centres resulting from high autonomy and self-coordination-or even selfgovernance under the condition of trust-of societal actors (e.g. NGOs, private sector, citizens) (Wurzel et al., 2019). As such, multi-level governance and polycentric governance would highlight different dimensions of multilateral climate funds that could be empirically tested. While some scholars refer to the governance of adaptation projects financed by these funds as polycentric (Sovacool et al., 2017), other argue that it is multi-level but not necessarily polycentric (Lebel et al., 2017). This would require further theoretical and empirical analysis.

Second, research is needed to better understand the dynamics of adaptation policy and geographical mainstreaming processes in the context of local use of international adaptation finance. The analysis of policy and geographical mainstreaming in this dissertation was based on the content analysis of $\mathrm{AF}$ project documents (Chapters 5 and 7) and semi-structured interviews with staff of AF project implementing entities (Chapter 7). Relying on simple binary indicators, the dissertation assessed if considerations of policy and geographical mainstreaming were present or absent in the design of $\mathrm{AF}$ project activities under both access modalities. This binary analysis has led to the finding that there is no difference between direct access and indirect access projects at the design stage with regards to the mainstreaming characteristic. While providing a useful insight about AF projects, this analysis does not capture any qualitative differences in the mainstreaming processes between countries, or whether and how the processes evolve during implementation. Understanding these dynamics and how they unfold over time requires future research, for example, with an in-depth case study approach. As the adaptation mainstreaming literature still lacks a unified 
definition and framework to study the operationalization of mainstreaming and measure its effectiveness (Runhaar et al., 2018), future research could also develop new indicators to better analyze and compare mainstreaming both as policy outputs and outcomes in the context of adaptation finance.

Third, another major theme that emerges from this dissertation and could be further investigated is the importance of civil society in shaping local climate change adaptation. Several questions are worthy of more in-depth research. For example, why was there no configuration of "direct access, strong civil society" to explain the presence of AF projects with a stronger community focus? To the extent that the ability to gain direct access to multilateral climate funds reflect state capacity of recipient countries, what does the absence of the configuration indicate about the state-civil society relationship in shaping the use of international adaptation finance? In other words, does state capacity complement or substitute a strong civil society in this context? Is there empirical evidence to support the claim (Chapter 7 ) that an international organization could be a more neutral broker, and such neutrality could enhance more civil society participation in internationally-financed projects when compared to national government-led projects? These questions are worthy of scholarly investigation. They also call for a deeper dive into the rich literature on civil society, state capacity, international development aid and climate change adaptation.

Fourth, my dissertation started from country-level conditions, but the importance of regional and local conditions in shaping internationallyfinanced adaptation projects should not be overlooked. Future research could explore relevant regional and local conditions for community-level climate change adaptation, such as the nature of local adaptation plans (Cloutier et al., 2015; Measham et al., 2011; Reid \& Huq, 2014; Sharma et al., 2014), the availability and use of downscaled climate projections to reginal and local scales (Gustafson et al., 2017), and the role of social capital (Adger, 2003; 
Chantarat \& Barrett, 2012; Pelling \& High, 2005). and identify potential data sources for them. Adding multiple projects for each country would also bring the opportunity to assess the within-country variations of different projects.

Finally, future studies could compare direct access and indirect access projects within the same country to further isolate the influence of access modalities from that of the recipient country context. For the AF, such comparison is currently possible in Argentina and Peru which have recently used both modalities to access the AF financing. The comparison will also be possible as more developing countries begin to use multiple modalities to access the GCF in the near future.

\subsection{Policy implications and recommendations}

The dissertation's findings carry important policy implications for climate finance actors seeking to promote local use of international adaptation finance. Here, I discuss broad policy implications and recommendations for the $A F$, national governments, multilateral organizations and civil society.

For the AF, this dissertation findings demonstrated that community-focused and innovative adaptation could be promoted under both access modalities if the right enabling conditions are in place. While the AF cannot influence some enabling conditions such as the exposure of recipient countries to climate risks, it can address some others, including the role of civil society in shaping highly community-focused projects, and the capacity of national and local institutions in shaping the projects' innovation design. For example, in countries where the limited capacity of civil society has played a role in shaping projects with a weaker community focus, the AF can dedicate more attention to ensure that project implementing entities seek to engage civil society actors particularly CBOs more actively during project implementation and evaluation. Building on the current practice of knowledge exchange 
between $A F$ implementing entities, the $A F$ could also organize future exchanges on differentiated engagement strategies in countries with strong versus weak civil society capacities. For the design to promote innovations, the AF could consider using more mechanisms for capable national and local institutions to self-identify to be involved in AF projects. Examples include competitive community innovation grants and direct solicitation of specific adaptation solutions from national and local innovators, which have been used in other contexts (Cities Alliance, 2019; State Government of Victoria, 2020).

For national governments, my findings suggest that focusing policy attention on the role of access modality to multilateral climate funds alone is likely to have a limited impact in enhancing the local inclusiveness of international adaptation finance. While the direct access modality has garnered support from many developing countries as a more participatory, country-driven governance model of international adaptation finance that could be favourable for local communities, the dissertation finding shows that the modality by itself does not deliver the outcome of highly community-focused adaptation in all country contexts, and works in conjunction with the country context to deliver the outcome only in some countries. This means that even in developing countries with a capacity to use the direct access modality, more actions are needed to ensure that international adaptation finance truly reaches the most vulnerable. These actions could include active, top-down policy mainstreaming of community adaptation needs, support for local climate awareness campaigns, and capacity building for civil society, CBOs, and community members in climate finance readiness.

For multilateral organizations, the finding on the "indirect access, strong civil society" countries should serve as a reminder that indirect access AF projects were designed to have a stronger community focus with the presence of strong civil society able to advocate effectively for community priorities. This 
means that care is needed when multilateral organizations implement indirect access projects in an environment of weaker civil society. Given the longer distances between international project implementing entities and local civil society, multilateral organizations must make extra efforts in engaging them in the project design process, for example, by dedicating additional project financial, human, and time resources for civil society engagement.

Finally, it is clear from the dissertation that civil society is a key part of the enabling environment for community-focused adaptation. To play this enabling role effectively, CSOs need to be active in helping articulate the adaptation needs of community-level beneficiaries to the governments and multilateral climate funds. This in turn requires CSOs to acquire needed capacities, including government engagement, community mobilization, climate vulnerability assessment, project proposal development etc. In some cases, CSOs could submit project proposals on behalf vulnerable communities when calls for proposals are involved. In other cases, CSOs with project management capacities could seek to perform the role of executing entities of internationally-financed adaptation projects. As the dissertation shows that the higher exposure to climate risks could motivate policy makers to invest in community-focused adaptation, CSOs can help these policy makers by communicating how the risks affect different population groups locally, thus ensuring informed decision making on investment allocation.

\subsection{Final remarks}

The overall aim of this dissertation is to understand the role of international adaptation finance in supporting local climate change adaptation in developing countries. At the heart of this research is an investigation to better explain whether climate finance governance, as represented by the manner by which developing countries access multilateral climate funds, matters for the project-level use of international adaptation finance to stimulate 
community-focused and innovative adaptation. The overall conclusion of the dissertation is that access modalities have less influence than many have argued in terms of influencing the community focus in project design, and does not affect how projects are designed to promote adaptation innovations for local beneficiaries. The broader insight from this finding is that governance of international adaptation finance could play a role in shaping local adaptation, but the extent and direction of such role depends on the project design aspect, as well as the recipient country's context. I hope this dissertation contributes valuable new insights to the debate and scholarship on local-level adaptation financing, and help inform global efforts to effectively deliver international adaptation finance to those climate-vulnerable local communities that need it most. 


\section{References}

Aase, T. H., Chapagain, P. S., \& Tiwari, P. C. (2013). Innovation as an expression of adaptive capacity to change in Himalayan farming. Mountain Research and Development, 33(1), 4-10. https://doi.org/10.1659/MRD-JOURNAL-D-12-00025.1

Adaptation Fund. (2012). The Adaptation Fund and Direct Access: Supporting Developing Countries in Undertaking Concrete Measures to Adapt to the Adverse Effects of Climate Change. Adaptation Fund Board Secretariat.

Adaptation Fund. (2013). Enhancing Climate Resilience of Rural Communities Living in Protected Areas of Cambodia [Project document]. Adaptation Fund Board Secretariat. https://www.adaptation-fund.org/project/enhancing-climateresilience-of-rural-communities-living-in-protected-areas-ofcambodia/

Adaptation Fund. (2014). Reducing Vulnerability to Climate Change in North West Rwanda through Community Based Adaptation [Project document]. Adaptation Fund Board Secretariat.

https://www.adaptation-fund.org/project/reducing-vulnerability-toclimate-change-in-north-west-rwanda-through-community-basedadaptation/

Adaptation Fund. (2017). Medium-Term Strategy of the Adaptation Fund for the years 2018-2022. Adaptation Fund Secretariat. 
https://www.adaptation-fund.org/document/medium-term-strategy2018-2022/

Adaptation Fund. (2018a). Adaptation Fund Launches New Grant Funding Windows to Accelerate Action, Innovation and Learning in Adaptation. Adaptation Fund. https://www.adaptationfund.org/adaptation-fund-launches-new-grant-funding-windowsaccelerate-action-innovation-learning-adaptation/

Adaptation Fund. (2018b). Adaptation Fund Shall Serve the Paris Agreement, Starting on January 1st, 2019. Adaptation Fund. https://www.adaptation-fund.org/adaptation-fund-shall-serve-parisagreement-starting-january-1st-2019/

Adaptation Fund. (2019a). Adaptation Fund: Implementing Entities. https://www.adaptation-fund.org/apply-funding/implementingentities/national-implementing-entity/

Adaptation Fund. (2019b). Www.adaptation-fund.org/about/governance/.

Adaptation Fund. https://www.adaptationfund.org/about/governance/

Adaptation Fund NGO Network. (2012). Independent Insights from Vulnerable Developing Countries | adaptation fund network. Germanwatch e.V. http://af-network.org/5091

Adaptation Watch. (2015). Toward mutual accountability: The 2015 adaptation finance transparency gap report [Policy Briefing]. www.adaptationwatch.org 
ADB. (2012). Guidelines for Climate Proofing Investment in Agriculture, Rural Development, and Food Security. Asian Development Bank. https://www.adb.org/documents/guidelines-climate-proofinginvestment-agriculture-rural-development-and-food-security Adenle, A. A., Azadi, H., \& Arbiol, J. (2015). Global assessment of technological innovation for climate change adaptation and mitigation in developing world. Journal of Environmental Management, 161, 261-275. http://dx.doi.org/10.1016/j.jenvman.2015.05.040

Adger, W. N. (2003). Social capital, collective action, and adaptation to climate change. Economic Geography, 79(4), 387-404.

Adger, W. N. (2006). Vulnerability. Global Environmental Change, 16(3), 268-281. https://doi.org/doi:10.1016/j.gloenvcha.2006.02.006 Adger, W. N. (2010). Climate Change, Human Well-Being and Insecurity. New Political Economy, 15(2), 275-292. https://doi.org/10.1080/13563460903290912

Adger, W. N., Arnell, N. W., \& Tompkins, E. L. (2005). Successful adaptation to climate change across scales. Global Environmental Change, 15(2), 77-86. https://doi.org/10.1016/j.gloenvcha.2004.12.005

Adger, W. N., Huq, S., Brown, K., Conway, D., \& Hulme, M. (2003). Adaptation to climate change in the developing world. Progress in 
Development Studies, 3(3), 179-195.

https://doi.org/10.1191/1464993403ps060oa

Adger, W. N., Lorenzoni, I., \& O’Brien, K. L. (Eds.). (2009). Adapting to climate change: Thresholds, values, governance. Cambridge University Press.

Adhikari, B., \& Taylor, K. (2012). Vulnerability and adaptation to climate change: A review of local actions and national policy response. Climate and Development, 4(1), 54-65. https://doi.org/10.1080/17565529.2012.664958

AFB. (2008). Roles and Responsibilities of Implementing and Executing Entities Adaptation Fund Board First meeting Bonn, March 26-28, 2008 (AFB/B.1/6). Adaptation Fund Board. https://www.adaptationfund.org/wpcontent/uploads/2015/01/AFB.B.1.6_Roles_and_Responsibilities_of _the_IE_and_EE,_February_29,_2008.pdf

AFB. (2014). Multiple Executing Entities Partners for the Implementation of Local Adaptation Actions: Analysis of the Possible Effects on Administrative Costs Project and Programme Review Committee Fourteenth Meeting Bonn, Germany, 18-19 March 2014 (AFB/PPRC.14/14). Adaptation Fund. https://www.adaptationfund.org/wpcontent/uploads/2015/01/AFB.PPRC_.14.14\%20Effects\%20of\%20 
multiple\%20executing $\% 20$ entities\%20partners\%20on\%20administr ative $\% 20$ costs.pdf

AFB. (2015). Analysis of climate change adaptation reasoning in project and programme proposals approved by the Board (AFB/PPRC.17/5). Adaptation Fund Board. https://www.adaptation-fund.org/wpcontent/uploads/2015/12/AFB.PPRC_.17.5-Analysis-of-climatechange-adaptation-reasoning_final_Nov...pdf

AFB. (2017a). Operational Policies and Guidelines for Parties to Access Resources from the Adaptation Fund. https://www.adaptationfund.org/document/operational-policies-guidelines-parties-accessresources-adaptation-fund/

AFB. (2017b). Strategic priorities, policies, and guidelines of the Adaptation Fund adopted by the CMP (Annex I to the OPG) (Amended in October 2017) (AFB/B.33.b/3/Add.2). Adaptation Fund Board.

Agarwal, A., Perrin, N., Chhatre, A., Benson, C. S., \& Kononen, M. (2012). Climate policy processes, local institutions, and adaptation actions: Mechanisms of translation and influence. Wiley Interdisciplinary Reviews: Climate Change, 3(6), 565-579. https://doi.org/doi: 10.1002/wcc. 193

Agrawal, A. (2008). The role of local institutions in adaptation to climate change (Working Paper No. 69128). The World Bank.

Agrawal, A., \& Perrin, N. (2009). Climate adaptation, local institutions and rural livelihoods. In W. N. Adger, I. Lorenzoni, \& K. L. O’Brien 
(Eds.), Adapting to Climate Change: Thresholds, Values, Governance (pp. 350-367). Cambridge University Press.

Agrawal, A., \& Ribot, J. (1999). Accountability in decentralization: A framework with South Asian and West African cases. The Journal of Developing Areas, 33(4), 473-502.

Agrawala, S., \& Van Aalst, M. (2008). Adapting development cooperation to adapt to climate change. Climate Policy, 8(2), 183-193. https://doi.org/10.3763/cpol.2007.0435

Ahmed, F., Gersonius, B., Veerbeek, W., Alam Khan, M. S., \& Wester, P. (2015). The role of extreme events in reaching adaptation tipping points: A case study of flood risk management in Dhaka, Bangladesh. Journal of Water and Climate Change, 6(4), 729-742. https://doi.org/10.2166/wcc.2014.102

Alam, G. M. M., Alam, K., \& Mushtaq, S. (2017). Climate change perceptions and local adaptation strategies of hazard-prone rural households in Bangladesh. Climate Risk Management, 17, 52-63. https://doi.org/10.1016/j.crm.2017.06.006

Amerasinghe, N. M., Thwaites, J., Larsen, G., \& Ballesteros, A. (2017). Future of the Funds: Exploring the Architecture of Multilateral Climate Finance | World Resources Institute. World Resources Institute. https://www.wri.org/publication/future-of-the-funds 
Anheier, H. K., Carlson, L., Heinrich, V. F., \& Naidoo, K. (2001). The civil society diamond: A primer. CIVICUS Index on Civil Society Occasional Paper Series, 1(2), 1-17.

Archer, D., Almansi, F., DiGregorio, M., Roberts, D., Sharma, D., \& Syam, D. (2014). Moving towards inclusive urban adaptation: Approaches to integrating community-based adaptation to climate change at city and national scale. Climate and Development, 6(4), 345-356. https://doi.org/10.1080/17565529.2014.918868

Atteridge, A., \& Remling, E. (2018). Is adaptation reducing vulnerability or redistributing it? Wiley Interdisciplinary Reviews: Climate Change, 9(e500), 1-16. https://doi.org/doi: 10.1002/wcc.500

Auffhammer, M., Ramanathan, V., \& Vincent, J. R. (2012). Climate change, the monsoon, and rice yield in India. Climatic Change, 111(2), 411424. https://doi.org/10.1007/s10584-011-0208-4

Ayers, J. (2010). Understanding the adaptation paradox: Can global climate change adaptation policy be locally inclusive? [Thesis, The London School of Economics and Political Science]. http://etheses.Ise.ac.uk/393/

Ayers, J., \& Dodman, D. (2010). Climate change adaptation and development I: The state of the debate. Progress in Development Studies, 10(2), 161-168. https://doi.org/10.1177/146499340901000205 
Ayers, J., \& Forsyth, T. (2009). Community-based adaptation to climate change. Environment: Science and Policy for Sustainable Development, 51(4), 22-31. https://doi.org/10.3200/ENV.51.4.22-31

Ayers, J., \& Huq, S. (2009). Supporting Adaptation to Climate Change: What Role for Official Development Assistance? Development Policy Review, 27(6), 675-692. https://doi.org/10.1111/j.14677679.2009.00465.x

Ayers, J., Huq, S., Faisal, A. M., \& Hussain, S. T. (2014). Mainstreaming climate change adaptation into development: A case study of Bangladesh. Wiley Interdisciplinary Reviews: Climate Change, 5(1), 37-51. https://doi.org/10.1002/wcc.226

Baas, S., \& Ramasamy, S. (2008). Community based adaptation in action: A case study from Bangladesh (Environment and Natural Resources Management Series, p. 56) [Project Summary Report (Phase I) Improved Adaptive Capacity to Climate Change for Sustainable Livelihoods in the Agriculture Sector]. the Food and Agriculture Organization of the United Nations (FAO). http://www.unisdr.org/files/8311_i0481e.pdf

Bahadur, A. V., Ibrahim, M., \& Tanner, T. (2013). Characterising resilience: Unpacking the concept for tackling climate change and development. Climate and Development, 5(1), 55-65.

Ballesteros, A., Nakhooda, S., Werksman, J., \& Hurlburt, K. (2010). Power, responsibility, and accountability: Rethinking the legitimacy of 
institutions for climate finance. World Resources Institute. http://pdf.wri.org/power_responsibility_accountability.pdf

Bardhan, P. (2002). Decentralization of governance and development. Journal of Economic Perspectives, 16(4), 185-205. https://doi.org/10.1257/089533002320951037

Barnett, J. (2001). Adapting to Climate Change in Pacific Island Countries: The Problem of Uncertainty. World Development, 29(6), 977-993. https://doi.org/10.1016/S0305-750X(01)00022-5

Barnett, J. (2003). Security and climate change. Global Environmental Change, 13(1), 7-17. https://doi.org/10.1016/S0959$3780(02) 00080-8$

Barnett, J. (2011). Dangerous climate change in the Pacific Islands: Food production and food security. Regional Environmental Change, 11(1), 229-237. https://doi.org/10.1007/s10113-010-0160-2

Barnett, J., \& O'Neill, S. (2010). Maladaptation. Global Environmental Change, 2(20), 211-213. https://doi.org/doi:10.1016/j.gloenvcha.2009.11.004 Barrett, S. (2013a). The necessity of a multiscalar analysis of climate justice. Progress in Human Geography, 37(2), 215-233. https://doi.org/10.1177/0309132512448270

Barrett, S. (2013b). Local level climate justice? Adaptation finance and vulnerability reduction. Global Environmental Change, 23(6), 18191829. https://doi.org/10.1016/j.gloenvcha.2013.07.015 
Barrett, S. (2015). Subnational Adaptation Finance Allocation: Comparing Decentralized and Devolved Political Institutions in Kenya. Global Environmental Politics, 15(3), 118-139.

https://doi.org/doi:10.1162/GLEP_a_00314

Baumgartner, M., \& Thiem, A. (2017). Often Trusted but Never (Properly)

Tested: Evaluating Qualitative Comparative Analysis. Sociological Methods \& Research, 0049124117701487. https://doi.org/10.1177/0049124117701487

Bécault, E., \& Marx, A. (2017). The global governance system for climate finance: Towards greater institutional integrity? In Governing the Climate Change Regime: Institutional Integrity and Integrity Systems (pp. 93-1117). Routledge.

Berliner, J., Grüning, C., Menzel, C., \& Harmeling, S. (2013). Enhancing direct access to the Green Climate Fund [Policy Brief]. The Climate and Development Knowledge Network.

Berrang-Ford, L., Ford, J. D., Lesnikowski, A., Poutiainen, C., Barrera, M., \& Heymann, S. J. (2014). What drives national adaptation? A global assessment. Climatic Change, 124(1-2), 441-450. https://doi.org/10.1007/s10584-014-1078-3

Berrang-Ford, L., Ford, J. D., \& Paterson, J. (2011). Are we adapting to climate change? Global Environmental Change, 21(1), 25-33. https://doi.org/10.1016/j.gloenvcha.2010.09.012 
Berrang-Ford, L., Pearce, T., \& Ford, J. D. (2015). Systematic review approaches for climate change adaptation research. Regional Environmental Change, 15(5), 755-769. https://doi.org/10.1007/s10113-014-0708-7

Betsill, M. M., \& Bulkeley, H. (2006). Cities and the multilevel governance of global climate change. Global Governance, 12(2), 141-159. https://doi.org/10.1163/19426720-01202004

Betzold, C., \& Weiler, F. (2018). Development Aid and Adaptation to Climate Change in Developing Countries. Springer Nature.

Bhatta, G. D., Ojha, H. R., Aggarwal, P. K., Sulaiman, V. R., Sultana, P., Thapa, D., Mittal, N., Dahal, K., Thomson, P., \& Ghimire, L. (2017). Agricultural innovation and adaptation to climate change: Empirical evidence from diverse agro-ecologies in South Asia. Environment, Development and Sustainability, 19(2), 497-525. https://doi.org/DOI $10.1007 / s 10668-015-9743-x$

Biagini, B., Bierbaum, R., Stults, M., Dobardzic, S., \& McNeeley, S. M. (2014). A typology of adaptation actions: A global look at climate adaptation actions financed through the Global Environment Facility. Global Environmental Change, 25, 97-108. https://doi.org/10.1016/j.gloenvcha.2014.01.003

Biesbroek, R., Berrang-Ford, L., Ford, J. D., Tanabe, A., Austin, S. E., \& Lesnikowski, A. (2018). Data, concepts and methods for large-n comparative climate change adaptation policy research: A 
systematic literature review. Wiley Interdisciplinary Reviews:

Climate Change, e548. https://doi.org/10.1002/wcc.548

Biesbroek, R., Klostermann, J. E., Termeer, C. J., \& Kabat, P. (2013). On

the nature of barriers to climate change adaptation. Regional

Environmental Change, 13(5), 1119-1129.

https://doi.org/10.1007/s10113-013-0421-y

Biesbroek, R., Lesnikowski, A., Ford, J. D., Berrang-Ford, L., \& Vink, M. (2018). Do Administrative Traditions Matter for Climate Change Adaptation Policy? A Comparative Analysis of 32 High-Income Countries. Review of Policy Research, 35(6), 881-906. https://doi.org/10.1111/ropr.12309

Biesbroek, R., Termeer, C. J. A. M., Klostermann, J. E. M., \& Kabat, P. (2014). Analytical lenses on barriers in the governance of climate change adaptation. Mitigation and Adaptation Strategies for Global Change, 19(7), 1011-1032. https://doi.org/10.1007/s11027-013$9457-z$

Binternagel, N. B., Juhrbandt, J., Koch, S., Purnomo, M., Schwarze, S., Barkmann, J., \& Faust, H. (2010). Adaptation to climate change in Indonesia-livelihood strategies of rural households in the face of ENSO related droughts. In Tscharntke T., Leuschner C., Veldkamp E., Faust H., Guhardja E., Bidin A. (eds) Tropical rainforests and agroforests under global change (pp. 351-375). Springer. 
Bird, N. (2014). Improving access to international climate finance within subSaharan Africa [ODI Working Paper]. Overseas Development Institute. https://www.odi.org/sites/odi.org.uk/files/odiassets/publications-opinion-files/9142.pdf

Bird, N., Billett, S., \& Colón, C. (2011). Direct Access to Climate Finance: Experiences and Lessons Learned (p. 19) [Discussion Paper]. United Nations Development Programme. https://www.odi.org/publications/6150-direct-access-climatefinance-experiences-lessons-learned

Bird, N., \& Glennie, J. (2011). Going beyond aid effectiveness to guide the delivery of climate finance. Overseas Development Institute. http://www.odi.org/resources/docs/7106.pdf

Birdsall, N., \& De Nevers, M. (2012). Adaptation Finance How to Get Out from between a Rock and a Hard Place (Policy Paper No. 001). Center for Global Development.

Blumberg, B., Cooper, D. R., \& Schindler, P. S. (2011). Business research methods (Third Edition). McGraw-Hill Higher Education.

Bocco, G., \& Napoletano, B. M. (2017). The prospects of terrace agriculture as an adaptation to climate change in Latin America. Geography Compass, 11(10), e12330. https://doi.org/10.1111/gec3.12330

Bogale, A. (2015). Weather-indexed insurance: An elusive or achievable adaptation strategy to climate variability and change for smallholder 
farmers in Ethiopia. Climate and Development, 7(3), 246-256. https://doi.org/10.1080/17565529.2014.934769

Bohle, H. G., Downing, T. E., \& Watts, M. J. (1994). Climate change and social vulnerability: Toward a sociology and geography of food insecurity. Global Environmental Change, 4(1), 37-48.

Bosma, M., de Hon, M., Douma, A., Robben, D., Chhetri, R. P., Soentoro, T., \& Schalatek, L. (2018). Local actors ready to act: Six proposals to improve their access to the Green Climate Fund. Both ENDS; Heinrich Böll Sitftung North America; Aksi! for gender, social and ecological justice; Prakriti Resources Centre. https://us.boell.org/2018/06/13/local-actors-ready-act-six-proposalsimprove-their-access-green-climate-fund

Bowen, A. (2011). Raising climate finance to support developing country action: Some economic considerations. Climate Policy, 11(3), 1020-1036. https://doi.org/10.1080/14693062.2011.582388

Bowman, M., \& Minas, S. (2019). Resilience through interlinkage: The green climate fund and climate finance governance. Climate Policy, 19(3), 342-353. https://doi.org/10.1080/14693062.2018.1513358

Brockhaus, M., \& Kambiré, H. (2009). Decentralization: A window of opportunity for successful adaptation to climate change. In W. N. Adger \& I. Lorenzoni (Eds.), Adapting to climate change: Thresholds, values, governance (pp. 399-416). Cambridge University Press. 
Brooks, N., Neil Adger, W., \& Mick Kelly, P. (2005). The determinants of vulnerability and adaptive capacity at the national level and the implications for adaptation. Global Environmental Change, 15(2), 151-163. https://doi.org/10.1016/j.gloenvcha.2004.12.006

Brooks, S., \& Loevinsohn, M. (2011). Shaping agricultural innovation systems responsive to food insecurity and climate change. Natural Resources Forum, 35(3), 185-200. https://doi.org/10.1111/j.14778947.2011.01396.x

Brown, J., Bird, N., \& Schalatek, L. (2010a). Climate finance additionality: Emerging definitions and their implications (No. 2; Climate Finance Policy Brief, pp. 1-11). Heinrich Böll Stiftung North America and Overseas Development Institute.

Brown, J., Bird, N., \& Schalatek, L. (2010b). Direct access to the Adaptation Fund: Realising the potential of national implementing entities. Overseas Development Institute. http://www.boell.de/sites/default/files/assets/boell.de/images/downlo ad_de/2010-11-23_Direct_Access_to_the_Adaptation_Fund.pdf

Brown, L., Polycarp, C., \& Spearman, M. (2013). Within Reach:

Strengthening Country Ownership and Accountability in Accessing Climate Finance. World Resources Institute. https://www.wri.org/publication/ownership-and-accountability-inclimate-finance 
Brunner, S., \& Enting, K. (2014). Climate finance: A transaction cost perspective on the structure of state-to-state transfers. Global Environmental Change, 27, 138-143. https://doi.org/10.1016/j.gloenvcha.2014.05.005

Buchner, B., Trabacchi, C., Falconer, A., \& Wilkinson, J. (2012). Public climate finance: A survey of systems to monitor and evaluate climate finance effectiveness. Climate Policy Initiative.

Buchner, B., Trabacchi, C., Mazza, F., Abramskiehn, D., \& Wang, D. (2015). The Global Landscape of Climate Finance 2015. Climate Policy Initiative. https://climatepolicyinitiative.org/publication/globallandscape-of-climate-finance-2015/

Buggy, L., \& McNamara, K. E. (2016). The need to reinterpret "community" for climate change adaptation: A case study of Pele Island, Vanuatu. Climate and Development, 8(3), 270-280. https://doi.org/10.1080/17565529.2015.1041445

Bugler, W., \& Rivard, B. (2012). Direct access to the Adaptation Fund: Lessons from accrediting NIEs in Jamaica and Senegal (INSIDE STORIES on Climate Compatible Development). The Climate and Development Knowledge Network.

Bunclark, L., Gowing, J., Oughton, E., Ouattara, K., Ouoba, S., \& Benao, D. (2018). Understanding farmers' decisions on adaptation to climate change: Exploring adoption of water harvesting technologies in 
Burkina Faso. Global Environmental Change -Human and Policy Dimensions, 48, 243-254.

Burch, S., Mitchell, C., Berbes-Blazquez, M., \& Wandel, J. (2017). Tipping Toward Transformation: Progress, Patterns and Potential for Climate Change Adaptation in the Global South. Journal of Extreme Events, 4(01), 1750003.

Butler, J. R. A., Wise, R. M., Skewes, T. D., Bohensky, E. L., Peterson, N., Suadnya, W., Yanuartati, Y., Handayani, T., Habibi, P., Puspadi, K., Bou, N., Vaghelo, D., \& Rochester, W. (2015). Integrating TopDown and Bottom-Up Adaptation Planning to Build Adaptive Capacity: A Structured Learning Approach. Coastal Management, 43(4), 346-364. https://doi.org/10.1080/08920753.2015.1046802

Cameron, E., Shine, T., \& Bevins, W. (2013a). Climate Justice: Equity and Justice Informing a New Climate Agreement. [Working Paper]. World Resources Institute, and Mary Robinson Foundation Climate Justice.

Cameron, E., Shine, T., \& Bevins, W. (2013b). Climate justice: Equity and justice informing a new climate agreement [Working Paper]. World Resources Institute and Mary Robinson Foundation - Climate Justice.

Canales Trujillo, N., \& Nakhooda, S. (2013). The effectiveness of climate finance: A Review of the Adaptation Fund (Working Paper No. 373). Overseas Development Institute. 
CARE. (2010). Community Based Adaptation Toolkit. CARE International. http://www.careclimatechange.org/files/toolkit/CARE_CBA_Toolkit.p df

Carter, T., Jones, R. N., Lu, X., Bhadwal, S., Conde, C., Mearns, L. O., O’Neill, B., Rounsevell, M. D. A., \& Zurek, M. B. (2007). New Assessment Methods and the Characterisation of Future Conditions. Climate Change 2007: Impacts, Adaptation and Vulnerability. Contribution of Working Group II to the Fourth Assessment Report of the Intergovernmental Panel on Climate Change, M.L. Parry, O.F. Canziani, J.P. Palutikof, P.J. van der Linden and C.E. Hanson, Eds. (pp. 133-171). Cambridge University Press.

Casey, K. (2018). Radical Decentralization: Does Community-Driven Development Work? Annual Review of Economics, 10(1), 139-163. https://doi.org/10.1146/annurev-economics-080217-053339

Castán Broto, V., \& Bulkeley, H. (2013). A survey of urban climate change experiments in 100 cities. Global Environmental Change, 23(1), 92102. https://doi.org/10.1016/j.gloenvcha.2012.07.005

Castel-Branco, C. N. (2008). Aid dependency and development: A question of ownership? A critical view (Working Paper No. 01/2008; p. 56). Instituto de Estudos Sociais e Económicos. 
Cebotari, V., \& Vink, M. P. (2013). A configurational analysis of ethnic protest in Europe. International Journal of Comparative Sociology, 54(4), 298-324. https://doi.org/10.1177/0020715213508567

Challinor, A. J., Watson, J., Lobell, D. B., Howden, S. M., Smith, D. R., \& Chhetri, N. (2014). A meta-analysis of crop yield under climate change and adaptation. Nature Climate Change, 4(4), 287-291. https://doi.org/10.1038/nclimate2153

Chambers, R. (1983). Rural development: Putting the last first. Routledge.

Chambers, R. (1994). Participatory rural appraisal (PRA): Challenges, potentials and paradigm. World Development, 22(10), 1437-1454.

Chan, C., \& Amerasinghe, N. (2018). Deploying Adaptation Finance for Maximum Impact Moving Beyond the Adaptation v. Development False Dichotomy (p. 12). World Resources Institute.

Chantarat, S., \& Barrett, C. B. (2012). Social network capital, economic mobility and poverty traps. Journal of Economic Inequality, 10(3), 299-342. http://dx.doi.org/10.2139/ssrn.1151353

Chen, C., Noble, I., Hellmann, J., Coffee, J., Murillo, M., \& Chawla, N. (2015). University of Notre Dame Global Adaptation Index Country Index Technical Report. University of Notre Dame Global Adaptation Initiative (ND-GAIN). https://gainnew.crc.nd.edu/about/methodology

Chhetri, N., Chaudhary, P., Tiwari, P. R., \& Yadaw, R. B. (2012). Institutional and technological innovation: Understanding 
agricultural adaptation to climate change in Nepal. Applied Geography, 33, 142-150.

https://doi.org/10.1016/j.apgeog.2011.10.006

Chhetri, N., \& Easterling, W. E. (2010). Adapting to climate change:

Retrospective analysis of climate technology interaction in the ricebased farming system of Nepal. Annals of the Association of American Geographers, 100(5), 1156-1176.

https://doi.org/10.1080/00045608.2010.518035

Chhetri, N., Subedi, M., \& Ghimire, S. (2013). Niche-based responses in addressing the climatic constraints to farm production: Analogues to climate-change adaptation in Nepal. Climate and Development, 5(2), 174-181.

Christiansen, L., Martinez, G. S., \& Naswa, P. (2018). Adaptation metrics: Perspectives on measuring, aggregating and comparing adaptation results. UNEP DTU Partnership.

Chu, E., Anguelovski, I., \& Carmin, J. (2016). Inclusive approaches to urban climate adaptation planning and implementation in the Global South. Climate Policy, 16(3), 372-392.

https://doi.org/10.1080/14693062.2015.1019822

Ciplet, D., Roberts, J. T., \& Khan, M. (2013). The Politics of International Climate Adaptation Funding: Justice and Divisions in the Greenhouse. Global Environmental Politics, 13(1), 49-68. https://doi.org/10.1162/GLEP_a_00153 
Cities Alliance. (2019). Call for Proposals-Secure Tenure in African Cities: Micro Funds for Community Innovation. https://www.citiesalliance.org/newsroom/news/businessopportunities/secure-tenure-african-cities

Cleaver, F. (1999). Paradoxes of participation: Questioning participatory approaches to development. Journal of International Development, 11(4), 597-612.

Cloutier, G., Joerin, F., Dubois, C., Labarthe, M., Legay, C., \& Viens, D. (2015). Planning adaptation based on local actors' knowledge and participation: A climate governance experiment. Climate Policy, 15(4), 458-474. https://doi.org/10.1080/14693062.2014.937388

Colenbrander, S., Dodman, D., \& Mitlin, D. (2018). Using climate finance to advance climate justice: The politics and practice of channelling resources to the local level. Climate Policy, 18(7), 902-915. https://doi.org/10.1080/14693062.2017.1388212

Conde, C., Lonsdale, K., Nyong, A., \& Aguilar, I. (2005). Engaging stakeholders in the adaptation process. Cambridge University Press. http://www.adaptationundp.org/sites/default/files/downloads/adaptation_policy_framework s_for_climate_change__developing_strategies_policies_and_measures_0.pdf\#page $=51$

Conevska, A., Ford, J. D., \& Lesnikowski, A. (2019). Assessing the adaptation fund's responsiveness to developing country's needs. 
Climate and Development, 1-12.

https://doi.org/10.1080/17565529.2019.1638225

Conevska, A., Ford, J. D., Lesnikowski, A., \& Harper, S. (2018). Adaptation financing for projects focused on food systems through the UNFCCC. Climate Policy, 1-16. https://doi.org/10.1080/14693062.2018.1466682

Cooke, B., \& Kothari, U. (2001). Participation: The new tyranny? Zed books. Corbin, J., \& Strauss, A. (2008). Basics of Qualitative Research Techniques and Procedures for Developing Grounded Theory (Third Edition). Sage Publications.

Craeynest, L., Gallagher, L., \& Sharkey, C. (2010). Business as unusual. Direct Access: Giving power back to the poor? [Discussion paper]. CIDSE and Caritas Internationalis.

Creswell, J. W. (2003). Research design: Qualitative, quantitative, and mixed methods approaches (Second Edition). Sage publications.

Cutter, S., Osman-Elasha, B., Campbell, J., Cheong, S.-M., McCormick, S., Pulwarty, R., Supratid, S., \& Ziervogel, G. (2012). Managing the Risks from Climate Extremes at the Local Level. In Managing the Risks of Extreme Events and Disasters to Advance Climate Change Adaptation [Field, C.B., V. Barros, T.F. Stocker, D. Qin, D.J. Dokken, K.L. Ebi, M.D. Mastrandrea, K.J. Mach, G.-K. Plattner, S.K. Allen, M. Tignor, and P.M. Midgley (eds.)]. A Special Report of 
Working Groups I and II of the Intergovernmental Panel on Climate Change (IPCC). (pp. 291-338). Cambridge University Press.

D’Agostino, A. L., \& Sovacool, B. K. (2011). Sewing climate-resilient seeds: Implementing climate change adaptation best practices in rural Cambodia. Mitigation and Adaptation Strategies for Global Change, 16(6), 699-720. https://doi.org/10.1007/s11027-011-9289-7

Dannevig, H., Rauken, T., \& Hovelsrud, G. (2012). Implementing adaptation to climate change at the local level. Local Environment, 17(6-7), 597-611. https://doi.org/10.1080/13549839.2012.678317

Dasgupta, D., Ray, R., Shweta, \& Singh, S. S. (2015). Climate Change Finance, Analysis of a Recent OECD Report: Some Credible Facts Needed [Discussion Paper]. Government of India, Climate Change Finance Unit, Department of Economic Affairs.

Dasgupta, S., Huq, M., Khan, Z. H., Sohel Masud, Md., Ahmed, M. M. Z., Mukherjee, N., \& Pandey, K. (2011). Climate Proofing Infrastructure in Bangladesh: The Incremental Cost of Limiting Future Flood Damage. The Journal of Environment \& Development, 20(2), 167190. https://doi.org/10.1177/1070496511408401

de Coninck, H., Revi, A., Babiker, M., Bertoldi, P., Buckeridge, M., Cartwright, A., Dong, W., Ford, J., Fuss, S., Hourcade, J.-C., Ley, D., Mechler, R., Newman, P., Revokatova, A., Schultz, S., Steg, L., \& Sugiyama, T. (2018). Strengthening and Implementing the Global Response. In Global Warming of $1.5^{\circ} \mathrm{C}$. An IPCC Special Report on 
the impacts of global warming of $1.5^{\circ} \mathrm{C}$ above pre-industrial levels and related global greenhouse gas emission pathways, in the context of strengthening the global response to the threat of climate change, sustainable development, and efforts to eradicate poverty [MassonDelmotte, V., P. Zhai, H.-O. Pörtner, D. Roberts, J. Skea, P.R. Shukla, A. Pirani, W. Moufouma-Okia, C. Péan, R. Pidcock, S. Connors, J.B.R. Matthews, Y. Chen, X. Zhou, M.I. Gomis, E. Lonnoy, T. Maycock, M. Tignor, and T. Waterfield (eds.)]. In Press.

Dellink, R., Elzen, M. den, Aiking, H., Bergsma, E., Berkhout, F., Dekker, T., \& Gupta, J. (2009). Sharing the burden of financing adaptation to climate change. Global Environmental Change, 19(4), 411-421. https://doi.org/10.1016/j.gloenvcha.2009.07.009

Dodman, D., \& Mitlin, D. (2013). Challenges for Community-Based Adaptation: Discovering the Potential for Transformation. Journal of International Development, 25(5), 640-659.

https://doi.org/10.1002/jid.1772

Donner, S. D., Kandlikar, M., \& Webber, S. (2016). Measuring and tracking the flow of climate change adaptation aid to the developing world. Environmental Research Letters, 11(054006), 1-9. https://doi.org/doi:10.1088/1748-9326/11/5/054006

Doucouliagos, H., \& Paldam, M. (2009). The aid effectiveness literature: The sad results of 40 years of research. Journal of Economic 
Surveys, 23(3), 433-461. https://doi.org/10.1111/j.1467$6419.2008 .00568 . x$

Downing, T. E., Patwardhan, A., Klein, R. J., \& Mukhala, E. (2004). Technical Paper 3 Assessing Vulnerability for Climate Adaptation. In B. Lim \& E. Spanger-Siegfried (Eds.), Adaptation Policy Frameworks For Climate Change: Developing Strategies, Policies and Measures (pp. 67-89). Cambridge University Press. http://eportalafrica.com/pluginfile.php/74/mod_resource/content/1/Cl imate_vulnerabilty_and_adaptation.pdf

Druce, L., Grüning, C., \& Menzel, C. (2013). Direct access to international climate finance and associated fiduciary standards [Paper]. Frankfurt School - UNEP Collaborating Centre for Climate \& Sustainable Energy Finance. http://fs-unepcentre.org/publications/direct-access-international-climate-financeand-associated-fiduciary-standards

Dupuis, J., \& Biesbroek, R. (2013). Comparing apples and oranges: The dependent variable problem in comparing and evaluating climate change adaptation policies. Global Environmental Change, 23(6), 1476-1487. http://dx.doi.org/10.1016/j.gloenvcha.2013.07.022

Duus-Otterström, G. (2016). Allocating climate adaptation finance:

Examining three ethical arguments for recipient control. International Environmental Agreements: Politics, Law and 
Economics, 16(5), 655-670. https://doi.org/DOI 10.1007/s10784015-9288-3

Dzebo, A., \& Stripple, J. (2015). Transnational adaptation governance: An emerging fourth era of adaptation. Global Environmental Change, 35, 423-435. https://doi.org/10.1016/j.gloenvcha.2015.10.006

Eakin, H. C., Lemos, M. C., \& Nelson, D. R. (2014). Differentiating capacities as a means to sustainable climate change adaptation. Global Environmental Change, 27, 1-8. http://dx.doi.org/10.1016/j.gloenvcha.2014.04.013

Eckstein, D., Künzel, V., \& Schäfer, L. (2017). Global Climate Risk Index 2018 (p. 36) [Briefing paper]. Germanwatch e.V. http://germanwatch.org/de/14638

Eising, R., \& Kohler-Koch, B. (Eds.). (2003). The transformation of governance in the European Union. Routledge.

Engle, N. L. (2011). Adaptive capacity and its assessment. Global Environmental Change, 21(2), 647-656. https://doi.org/doi:10.1016/j.gloenvcha.2011.01.019

Ensor, J., \& Berger, R. (2009a). Community-based adaptation and culture in theory and practice. Cambridge University Press, New York.

Ensor, J., \& Berger, R. (2009b). Governance for Community Based Adaptation (p. 12) [Discussion paper]. Practical Action.

Ensor, J., Park, S. E., Attwood, S. J., Kaminski, A. M., \& Johnson, J. E. (2016). Can community-based adaptation increase resilience? 
Climate and Development, 1-18.

http://dx.doi.org/10.1080/17565529.2016.1223595

Eriksen, S., Aldunce, P., Bahinipati, C. S., Martins, R. D., Molefe, J. I., Nhemachena, C., O’brien, K., Olorunfemi, F., Park, J., \& Sygna, L. (2011). When not every response to climate change is a good one: Identifying principles for sustainable adaptation. Climate and Development, 3(1), 7-20. https://doi.org/10.3763/cdev.2010.0060

Faguet, J.-P. (2014). Decentralization and Governance. World Development, 53, 2-13. https://doi.org/10.1016/j.worlddev.2013.01.002

Faling, M., Biesbroek, R., \& Karlsson-Vinkhuyzen, S. (2018). The Strategizing of Policy Entrepreneurs towards the Global Alliance for Climate-Smart Agriculture. Global Policy, 9(3), 408-419. https://doi.org/10.1111/1758-5899.12547

Fankhauser, Sam, Sahni, A., Savvas, A., \& Ward, J. (2016). Where are the gaps in climate finance? Climate and Development, 8(3), 203-206. https://doi.org/10.1080/17565529.2015.1064811

Fankhauser, Samuel, \& Burton, I. (2011). Spending adaptation money wisely. Climate Policy, 11(3), 1037-1049. https://doi.org/10.1080/14693062.2011.582389

FAO. (2010). Climate-Smart agriculture: Policies, practice and financing for food security, adaptation and migration. The Food and Agriculture Organization of the United Nations. 
FAO. (2014). The state of food and agriculture: Innovation in family farming (p. 161). The Food and Agriculture Organization of the United Nations.

FAO. (2016). The State of Food and Agriculture 2016: Climate Change Agriculture, and Food Security (p. 173). The Food and Agriculture Organization of the United Nations. http://www.fao.org/3/ai6030e.pdf

FAO. (2018). Ending extreme poverty in rural areas- Sustaining livelihoods to leave no one behind. (p. 88). The Food and Agriculture Organization of the United Nations. http://www.fao.org/reduce-ruralpoverty/resources/resources-detail/en/c/1157795/

FAO, JICA, \& KFS. (2011). Farmer field school implementation guide: FARM FORESTRY AND LIVELIHOOD DEVELOPMENT (p. 353). The Food and Agriculture Organization of the United Nations, Japan International Cooperation Agency and Kenya Forest Service. http://www.fao.org/3/i2561e/i2561e00.htm

Faulkner, L., Ayers, J., \& Huq, S. (2015). Meaningful Measurement for Community-Based Adaptation. New Directions for Evaluation, 2015(147), 89-104. https://doi.org/10.1002/ev.20133

Fenton, A., Gallagher, D., Wright, H., Huq, S., \& Nyandiga, C. (2014). Upscaling finance for community-based adaptation. Climate and Development, 6(4, SI), 388-397. https://doi.org/10.1080/17565529.2014.953902 
Fenton, A., Reid, H., Wright, H., \& Huq, S. (2015). Ten principles to help assess funding for local climate adaptation (p. 4) [IIED Briefing]. International Institute for Environment and Development. http://pubs.iied.org/17323IIED/

Fetters, M. D., Curry, L. A., \& Creswell, J. W. (2013). Achieving Integration in Mixed Methods Designs_-Principles and Practices. Health Services Research, 48(6pt2), 2134-2156. https://doi.org/10.1111/1475-6773.12117

Few, R., Brown, K., \& Tompkins, E. L. (2007). Public participation and climate change adaptation: Avoiding the illusion of inclusion. Climate Policy, 7(1), 46-59. https://doi.org/10.1080/14693062.2007.9685637

Figueres, C. (2004). Plenary speech. 8th International Conference on Community Based Adaptation, 24-30 April 2014, Kathmandu, Nepal. https://pubs.iied.org/pdfs/G03809.pdf

Fioramonti, L., \& Kononykhina, O. (2015). Measuring the enabling environment of civil society: A global capability index. Voluntus, 26(2), 466-487. https://doi.org/10.1007/s11266-014-9444-3

Fisher, R. J. (1999). Devolution and decentralization of forest management in Asia and the Pacific. Unasylva: Decentralization and Devolution in Forestry, 50(199), 3-5. 
Flåm, K. H., \& Skjærseth, J. B. (2009). Does adequate financing exist for adaptation in developing countries? Climate Policy, 9(1), 109-114. https://doi.org/10.3763/cpol.2008.0568

Ford, J. D. (2007). Emerging trends in climate change policy: The role of adaptation. International Public Policy Review, 3, 5-15.

Ford, J. D., \& Berrang-Ford, L. (2016). The 4Cs of adaptation tracking: Consistency, comparability, comprehensiveness, coherency. Mitigation and Adaptation Strategies for Global Change, 21(6), 839859. https://doi.org/10.1007/s11027-014-9627-7

Ford, J. D., Berrang-Ford, L., Biesbroek, R., Araos, M., Austin, S. E., \& Lesnikowski, A. (2015). Adaptation tracking for a post-2015 climate agreement. Nature Climate Change, 5, 967-969.

https://doi.org/10.1038/nclimate2744

Ford, J. D., Berrang-Ford, L., Bunce, A., McKay, C., Irwin, M., \& Pearce, T. (2015). The status of climate change adaptation in Africa and Asia. Regional Environmental Change, 15(5), 801-814. https://doi.org/10.1007/s10113-014-0648-2

Ford, J. D., Berrang-Ford, L., Lesnikowski, A., Barrera, M., \& Heymann, S. (2013). How to Track Adaptation to Climate Change: A Typology of Approaches for National-Level Application. Ecology and Society, 18(3)(40). https://doi.org/10.5751/ES-05732-180340

Ford, J. D., Berrang-Ford, L., \& Paterson, J. (2011). A systematic review of observed climate change adaptation in developed nations: A letter. 
Climatic Change, 106(2), 327-336. https://doi.org/10.1007/s10584$011-0045-5$

Forsyth, T. (2013). Community-based adaptation: A review of past and future challenges. WIREs Climate Change, 4(5), 439-446. https://doi.org/10.1002/wcc.231

Fridahl, M., \& Linnér, B.-O. (2016). Perspectives on the Green Climate Fund: Possible compromises on capitalization and balanced allocation. Climate and Development, 8(2), 105-109. https://doi.org/10.1080/17565529.2015.1040368

Füssel, H.-M. (2010). How inequitable is the global distribution of responsibility, capability, and vulnerability to climate change: A comprehensive indicator-based assessment. Global Environmental Change, 20(4), 597-611. https://doi.org/10.1016/j.gloenvcha.2010.07.009

Gabrielsson, S., \& Ramasar, V. (2013). Widows: Agents of change in a climate of water uncertainty. Journal of Cleaner Production, 60, 3442. https://doi.org/10.1016/j.jclepro.2012.01.034

GCF. (2015). "Additional Modalities that Further Enhance Direct Access:

Terms of Reference for a Pilot Phase" Meeting of the Board 6-9 July 2015 Songdo, Republic of Korea Provisional Agenda item 10 (GCF/B.10/05). Green Climate Fund.

https://www.greenclimate.fund/documents/20182/24952/GCF_B.10 -05_- 
_Additional_Modalities_that_Further_Enhance_Direct_Access_Ter ms_of_Reference_for_a_Pilot_Phase.pdf/409c098e-60c2-45e98bea-4b2dba371ce1

GCF. (2018). Enhancing adaptive capacities of coastal communities, especially women, to cope with climate change induced salinity [Text]. Green Climate Fund.

https://www.greenclimate.fund/projects/fp069

GCF. (2019a). Adaptation Fund, Green Climate Fund Convene First

Community of Practice Meeting of Direct Access Entities to Climate Finance [Text]. Green Climate Fund.

https://www.greenclimate.fund/news/adaptation-fund-green-climatefund-convene-first-community-of-practice-meeting-of-direct-accessentities-to-climate-finan-1

GCF. (2019b). Strategic Programming for the Green Climate Fund First Replenishment (GCF/B.22/Inf.12). Green Climate Fund. https://www.greenclimate.fund/documents/20182/1424894/GCF_B. 22_Inf.12_-

_Strategic_Programming_for_the_Green_Climate_Fund_First_Repl enishment.pdf/9933d93d-2673-022c-8c1b-cd5213973674

GEF. (2011). Accessing Resources under the Least Developed Countries Fund. The Global Environment Facility Secretariat.

George, A. L., \& Bennett, A. (2005). Case studies and theory development in the social sciences. MIT Press. 
Ghuman, B. S., \& Singh, R. (2013). Decentralization and delivery of public services in Asia. Policy and Society, 32(1), 7-21. https://doi.org/10.1016/j.polsoc.2013.02.001

Gjaltema, J., Biesbroek, R., \& Termeer, K. (2019). From government to governance...to meta-governance: A systematic literature review. Public Management Review, 0(0), 1-21. https://doi.org/10.1080/14719037.2019.1648697

Gogoi, E., Dupar, M., Jones, L., Martinez, C., \& McNamara, L. (2014). Enablers for delivering community-based adaptation at scale. Climate and Development, 6(4), 368-371. https://doi.org/10.1080/17565529.2014.918869

Gough, D., Oliver, S., \& Thomas, J. (2012). An introduction to systematic reviews. Sage.

Government of Indonesia. (2016). First Nationally Determined Contribution. Republic of Indonesia.

Grasso, M. (2010). An ethical approach to climate adaptation finance. Global Environmental Change, 20(1), 74-81. https://doi.org/10.1016/j.gloenvcha.2009.10.006

Grasso, M. (2011). The role of justice in the North-South conflict in climate change: The case of negotiations on the Adaptation Fund. International Environmental Agreements: Politics, Law and Economics, 11(4), 361-377. https://doi.org/10.1007/s10784-010$9145-3$ 
Greene, J. C., Caracelli, V. J., \& Graham, W. F. (1989). Toward a Conceptual Framework for Mixed-Method Evaluation Designs. Educational Evaluation and Policy Analysis, 11(3), 255-274. https://doi.org/10.3102/01623737011003255

Grimm, J., Weischer, L., \& Eckstein, D. (2018). The future role of the Adaptation fund in the internatinal climate finance architecture ( $\mathrm{p}$. 36) [Study]. Germanwatch e. V. https://www.germanwatch.org/sites/germanwatch.org/files/The $\% 20$ \%20future $\% 2$ role $\% 20$ of $\% 20$ the $\% 20$ Adaptation $\% 20$ fund $\% 20 \mathrm{in} \% 20$ the\%20internatinal\%20climate\%20finance\%20architecture_1.pdf

Gustafson, S., Cadena, A. J., Ngo, C. C., Kawash, A., Saenghkaew, I., \& Hartman, P. (2017). Merging science into community adaptation planning processes: A cross-site comparison of four distinct areas of the Lower Mekong Basin. Climatic Change. https://doi.org/10.1007/s10584-016-1887-7

Ha, S., Hale, T., \& Ogden, P. (2016). Climate Finance in and between Developing Countries: An Emerging Opportunity to Build On. Global Policy, 7(1), 102-108. https://doi.org/10.1111/1758-5899.12293

Hall, N. (2017). What is adaptation to climate change? Epistemic ambiguity in the climate finance system. International Environmental Agreements: Politics, Law and Economics, 17(1), 37-53. https://doi.org/10.1007/s10784-016-9345-6 
Hall, N., \& Persson, A. (2017). Global climate adaptation governance: Why is it not legally binding? European Journal of International Relations, 24(3), 540-566.

Harmeling, S., \& Kaloga, A. O. (2010). Adaptation Fund under the KP:

Mature for Concrete Implementation of Projects and Direct access (European Capacity Building Initiative Policy Report).

Germanwatch.

Harmeling, S., \& Kaloga, A. O. (2011). Understanding the Political Economy of the Adaptation Fund. IDS Bulletin-Institute of Development Studies, 42(3), 23-32. https://doi.org/10.1111/j.1759-

5436.2011.00219.x

Heltberg, R., Siegel, P. B., \& Jorgensen, S. L. (2009). Addressing human vulnerability to climate change: Toward a 'no-regrets' approach. Global Environmental Change, 19(1), 89-99. https://doi.org/10.1016/j.gloenvcha.2008.11.003 Hesse, C. (2016). Decentralising climate finance to reach the most vulnerable (p. 4). International Institute for Environment and Development, the Near East Foundation, Innovation, Environnement et Développement en Afrique (IED Afrique),the Adaptation Consortium (ADA), the Adaptation Consortium (ADA), and the Local Climate Adaptive Living Facility of the UN Capital Development Fund (UNCDF-LoCAL). http://pubs.iied.org/G04103/ 
Hinkel, J. (2011). "Indicators of vulnerability and adaptive capacity":

Towards a clarification of the science-policy interface. Global Environmental Change, 21(1), 198-208.

https://doi.org/10.1016/j.gloenvcha.2010.08.002

Hogarth, J. R. (2012). The role of climate finance in innovation systems. Journal of Sustainable Finance \& Investment, 2(3-4), 257-274. Hooghe, L., \& Marks, G. (2003). Unraveling the central state, but how? Types of multi-level governance. American Political Science Review, 97(02), 233-243.

Horstmann, B. (2011). Operationalizing the Adaptation Fund: Challenges in allocating funds to the vulnerable. Climate Policy, 11(4), 10861096.

Horstmann, B., \& Abeysinghe, A. C. (2011). The Adaptation Fund of the Kyoto Protocol: A model for financing adaptation to climate change? Climate Law, 2(3), 415-437.

Huang, Y., \& Pascual, U. (2017). Aid Effectiveness for Environmental Sustainability. Springer.

Huq, S., \& Burton, I. (2003). Funding adaptation to climate change: What, who and how to fund (pp. 1-2) [Sustainable Development Opinion]. International Institute for Environment and Development.

Huq, S., \& Faulkner, L. (2013). Taking effective community-based adaptation to scale: An assessment of the GEF small grants programme community-based adaptation project in Namibia (p. 84). 
Global Environment Facility.

https://www.thegef.org/sites/default/files/publications/SGP_CBA_Pr oject_in_Namibia_0.pdf

Huq, S., \& Reid, H. (2007). Community-based adaptation: A vital approach to the threat climate change poses to the poor. International Institute for Environment and Development. http://dlc.dlib.indiana.edu/dlc/handle/10535/6228

Huq, S., \& Toulmin, C. (2006). Three eras of climate change (Sustainable Development Opinion). International Institute for Environment and Development. http://pubs.iied.org/pubs/pdfs/11060IIED.pdf IGES. (2011). Access Modalities for the Green Climate Fund: Lessons from the Existing Financial Mechanisms. UNFCCC AWG-KP16/AWGLCA14 Side event by IGES \& OECC "Climate Regime after Fukushima, New Market Mechanisms, and Support to Developing Countries," Singapore. https://iges.or.jp/en/pub/access-modalitiesgreen-climate-fund-lessons

IIED. (2014). Kathmandu Declaration on Financing Local Adaptation to Climate Change. International Institute for Environment and Development. http://pubs.iied.org/G03787/ IIED. (2015). Nairobi Declaration on Community-Based Adaptation to Climate Change. http://pubs.iied.org/G03919/ Inter-American Development Bank (IADB), World Bank (WB), European Bank for Reconstruction (EBRD), (first), European Investment Bank 
(EIB), Inter-American Investment Corporation (IIC), African

Development Bank (AfDB), \& Asian Development Bank (ADB).

(2017). 2016 Joint Report On Multilateral Development Banks'

Climate Finance. Inter-American Development Bank.

http://publications.iadb.org/handle/11319/8505

IPCC. (2007). Climate Change 2007: Impacts, Adaptation and Vulnerability,

Contribution of the Working Group II to the Fourth Assessment

Report of the IPCC, M.L. Parry, O.F. Canziani, J.P. Palutikof, P.J.

van der Linden and C.E. Hanson, Eds. Cambridge University Press.

https://www.ipcc.ch/site/assets/uploads/2018/03/ar4_wg2_full_repor

t.pdf

IPCC. (2014a). Climate Change 2014: Impacts, Adaptation, and

Vulnerability. Part A: Global and Sectoral Aspects. Contribution of

Working Group II to the Fifth Assessment Report of the

Intergovernmental Panel on Climate Change [Field, C.B., V.R.

Barros, D.J. Dokken, K.J. Mach, M.D. Mastrandrea, T.E. Bilir, M.

Chatterjee, K.L. Ebi, Y.O. Estrada, R.C. Genova, B. Girma, E.S.

Kissel, A.N. Levy, S. MacCracken, P.R. Mastrandrea, and L.L.

White (eds.)]. Cambridge University Press.

https://www.ipcc.ch/report/ar5/wg2/

IPCC. (2014b). Climate Change 2014: Synthesis Report. Contribution of

Working Groups I, II and III to the Fifth Assessment Report of the Intergovernmental Panel on Climate Change [Core Writing Team, 
R.K. Pachauri and L.A. Meyer (eds.)] (p. 151). Intergovernmetnal Panel on Climate Change.

https://www.ipcc.ch/site/assets/uploads/2018/02/AR5_SYR_FINAL_ SPM.pdf

IPCC. (2018a). Annex I: Glossary [Matthews, J.B.R. (ed.)]. In Global

Warming of $1.5^{\circ} \mathrm{C}$. An IPCC Special Report on the impacts of global warming of $1.5^{\circ} \mathrm{C}$ above pre-industrial levels and related global greenhouse gas emission pathways, in the context of strengthening the global response to the threat of climate change, sustainable development, and efforts to eradicate poverty [Masson-Delmotte, V., P. Zhai, H.-O. Pörtner, D. Roberts, J. Skea, P.R. Shukla, A. Pirani, W. Moufouma-Okia, C. Péan, R. Pidcock, S. Connors, J.B.R. Matthews, Y. Chen, X. Zhou, M.I. Gomis, E. Lonnoy, T. Maycock, M. Tignor, and T. Waterfield (eds.)]. In press. https://www.ipcc.ch/sr15/chapter/glossary/

IPCC. (2018b). Summary for Policymakers. In: Global Warming of $1.5^{\circ} \mathrm{C}$. An IPCC Special Report on the impacts of global warming of $1.5^{\circ} \mathrm{C}$ above pre-industrial levels and related global greenhouse gas emission pathways, in the context of strengthening the global response to the threat of climate change, sustainable development, and efforts to eradicate poverty [Masson-Delmotte, V., P. Zhai, H.O. Pörtner, D. Roberts, J. Skea, P.R. Shukla, A. Pirani, W. Moufouma-Okia, C. Péan, R. Pidcock, S. Connors, J.B.R. 
Matthews, Y. Chen, X. Zhou, M.I. Gomis, E. Lonnoy, T. Maycock, M. Tignor, and T. Waterfield (eds.)]. In Press.

https://www.ipcc.ch/site/assets/uploads/sites/2/2019/05/SR15_SPM _version_report_LR.pdf

Ivanyna, M., \& Shah, A. (2014). How close is your government to its people? Worldwide indicators on localization and decentralization. Economics: The Open-Access, Open-Assessment E-Journal, 8(2014-3), 1-61. http://dx.doi.org/10.5018/economicsejournal.ja.2014-3

Jagers, S. C., \& Stripple, J. (2003). Climate Govenance beyond the State. Global Governance, 9, 385-399. https://doi.org/10.1163/1942672000903009

Jones, B. D., \& Baumgartner, F. R. (2005). The politics of attention: How government prioritizes problems. University of Chicago Press.

Jones, G. E. (1967). The adoption and diffusion of agricultural practices. World Agricultural Economics and Rural Sociology Abstracts, 9, 134.

Jordan, A. J., Huitema, D., Hildén, M., van Asselt, H., Rayner, T. J., Schoenefeld, J. J., Tosun, J., Forster, J., \& Boasson, E. L. (2015). Emergence of polycentric climate governance and its future prospects. Nature Climate Change, 5, 977-982. https://doi.org/10.1038/NCLIMATE2725 
Juhola, S., \& Westerhoff, L. (2011). Challenges of adaptation to climate change across multiple scales: A case study of network governance in two European countries. Environmental Science \& Policy, 14(3), 239-247. https://doi.org/10.1016/j.envsci.2010.12.006

Karanja Ng'ang'a, S., Bulte, E. H., Giller, K. E., Mclntire, J. M., \& Rufino, M. C. (2016). Migration and self-protection against climate change: A case study of Samburu County, Kenya. World Development, 84, 55-68. http://dx.doi.org/10.1016/j.worlddev.2016.04.002

Kates, R. W., Travis, W. R., \& Wilbanks, T. J. (2012). Transformational adaptation when incremental adaptations to climate change are insufficient. Proceedings of the National Academy of Sciences, 109(19), 7156-7161. https://doi.org/10.1073/pnas.1115521109

Kates, Robert W. (2000). Cautionary tales: Adaptation and the global poor. Climate Change, 45, 5-17. https://doi.org/10.1023/A:1005672413880

Kepe, T. (1999). The problem of defining 'community': Challenges for the land reform programme in rural South Africa. Development Southern Africa, 16(3), 415-433.

https://doi.org/10.1080/03768359908440089

Kettle, N. P., Dow, K., Tuler, S., Webler, T., Whitehead, J., \& Miller, K. M. (2014). Integrating scientific and local knowledge to inform riskbased management approaches for climate adaptation. Climate Risk Management, 4, 17-31. 
Khan, M., Robinson, S., Weikmans, R., Ciplet, D., \& Roberts, J. T. (2019). Twenty-five years of adaptation finance through a climate justice lens. Climate Change, 161, 251-269. https://doi.org/10.1007/s10584-019-02563-x

Kirchherr, J., Charles, K. J., \& Walton, M. J. (2016). Multi-causal pathways of public opposition to dam projects in Asia: A fuzzy set qualitative comparative analysis (fsQCA). Global Environmental Change, 41, 33-45. https://doi.org/10.1016/j.gloenvcha.2016.08.001

Kirkby, P., Williams, C., \& Huq, S. (2015). A brief overview of CommunityBased Adaptation [Briefing paper]. International Center for Climate Change and Development (ICCCAD) at at the Independent University, Bangladesh (IUB). http://eprints.utas.edu.au/22473/

Kirkby, P., Williams, C., \& Huq, S. (2017). Community-based adaptation (CBA): Adding conceptual clarity to the approach, and establishing its principles and challenges. Climate and Development, 1-13. https://doi.org/10.1080/17565529.2017.1372265

Kjaer, A. M. (2004). Governance. Polity Press.

Klein, R. J. (2010). Mainstreaming climate adaptation into development: A policy dilemma. In Ansohn \& Pleskovic (Eds.), Climate governance and development (p. 157). The World Bank.

Klein, R. J., Adams, K. M., Dzebo, A., Davis, M., \& Siebert, C. K. (2017). Advancing climate adaptation practices and solutions: Emerging 
research priorities (Working Paper No. 2017-07). Stockholm Environment Institute.

Klerkx, L., Adjei-Nsiah, S., Adu-Acheampong, R., Saïdou, A., Zannou, E., Soumano, L., Sakyi-Dawson, O., van Paassen, A., \& Nederlof, S. (2013). Looking at agricultural innovation platforms through an innovation champion lens: An analysis of three cases in West Africa. Outlook on Agriculture, 42(3), 185-192. https://doi.org/10.5367/oa.2013.0137

Klerkx, L., Schut, M., Leeuwis, C., \& Kilelu, C. (2012). Advances in knowledge brokering in the agricultural sector: Towards innovation system facilitation. IDS Bulletin, 43(5), 53-60.

Kolade, O., \& Harpham, T. (2014). Impact of cooperative membership on farmers' uptake of technological innovations in Southwest Nigeria. Development Studies Research. An Open Access Journal, 1(1), 340-353. https://doi.org/10.1080/21665095.2014.978981

Kotchen, M. J., \& Costello, C. (2018). Maximizing the impact of climate finance: Funding projects or pilot projects? Journal of Environmental Economics and Management, 92, 270-281. https://doi.org/10.1016/j.jeem.2018.08.009

Kristjanson, P., Neufeldt, H., Gassner, A., Mango, J., Kyazze, F. B., Desta, S., Sayula, G., Thiede, B., Förch, W., \& Thornton, P. K. (2012). Are food insecure smallholder households making changes in their 
farming practices? Evidence from East Africa. Food Security, 4(3), 381-397. https://doi.org/10.1007/s12571-012-0194-z

Kurukulasuriya, P., \& Rosenthal, S. (2013). Climate change and agriculture: A review of impacts and adaptations (PAPER NO. 91; Climate Change Series, pp. 1-96). The World Bank.

Kuruppu, N., \& Willie, R. (2015). Barriers to reducing climate enhanced disaster risks in Least Developed Country-Small Islands through anticipatory adaptation. Weather and Climate Extremes, 7, 72-83. https://doi.org/10.1016/j.wace.2014.06.001

Lasage, R., Muis, S., Sardella, C. S. E., van Drunen, M. A., Verburg, P. H., \& Aerts, J. C. J. H. (2015). A Stepwise, Participatory Approach to Design and Implement Community Based Adaptation to Drought in the Peruvian Andes. Sustainability, 7(2), 1742-1773. https://doi.org/10.3390/su7021742

Lati, L. (2008). The Potential of Civil Society in Climate Change Adaptation Strategies. Political Science, 60(1), 19-30. https://doi.org/10.1177/003231870806000103

Lebel, L. (2013). Local knowledge and adaptation to climate change in natural resource-based societies of the Asia-Pacific. Mitigation and Adaptation Strategies for Global Change, 18(7), 1057-1076. https://doi.org/10.1007/s11027-012-9407-1

Lebel, L., Käkönen, M., Dany, V., Lebel, P., Thuon, T., \& Voladet, S. (2018). The framing and governance of climate change adaptation projects 
in Lao PDR and Cambodia. International Environmental Agreements: Politics, Law and Economics, 18(3), 429-446. https://doi.org/10.1007/s10784-018-9397-x

Lebel, L., Salamanca, A., \& Kallayanamitra, C. (2017). The governance of adaptation financing: Pursuing legitimacy at multiple levels. International Journal of Global Warming, 11(2), 226-245. https://doi.org/10.1504/IJGW.2017.10001237

Leimona, B., Amaruzaman, S., Arifin, B., Yasmin, F., Hasan, F., Agusta, H., Sprang, P., Jaffee, S., \& Frias, J. (2015). Indonesia's 'green agriculture'strategies and policies: Closing the gap between aspirations and application (Occasional Paper No. 22). World Agroforestry Center.

https://www.worldagroforestry.org/publication/indonesias-greenagriculture-strategies-and-policies-closing-gap-between-aspirationsand

Lemos, M. C., Lo, Y.-J., Nelson, D. R., Eakin, H., \& Bedran-Martins, A. M. (2016). Linking development to climate adaptation: Leveraging generic and specific capacities to reduce vulnerability to drought in NE Brazil. Global Environmental Change, 39, 170-179. http://dx.doi.org/10.1016/j.gloenvcha.2016.05.001

Lesnikowski, A., Ford, J. D., Berrang-Ford, L., Barrera, M., Berry, P., Henderson, J., \& Heymann, S. J. (2013). National-level factors affecting planned, public adaptation to health impacts of climate 
change. Global Environmental Change, 23(5), 1153-1163.

https://doi.org/10.1016/j.gloenvcha.2013.04.008

Lesnikowski, A., Ford, J. D., Berrang-Ford, L., Barrera, M., \& Heymann, J. (2013). How are we adapting to climate change? A global assessment. Mitigation and Adaptation Strategies for Global Change, 20(2), 277-293. https://doi.org/10.1007/s11027-013-9491$x$

Lesnikowski, A., Ford, J. D., Biesbroek, R., Berrang-Ford, L., Maillet, M., Araos, M., \& Austin, S. E. (2017). What does the Paris Agreement mean for adaptation? Climate Policy, 17(7), 825-831. https://doi.org/10.1080/14693062.2016.1248889

Lessmann, C., \& Markwardt, G. (2016). Aid, Growth, and Devolution: Considering Aid Modality and Different Types of Decentralization. World Development, 84, 118-130. https://doi.org/10.1016/j.worlddev.2016.03.018

Levaggi, M. (2014). Response to" Equity and cost-effectiveness of multilateral adaptation finance: Are they friends or foes?" In International Environmental Agreements: Politics, Law and Economics-Stadelmann et al.(2013). International Environmental Agreements: Politics, Law and Economics, 14(2), 121-123. https://doi.org/10.1007/s10784-014-9241-x 
Levy, B. S., \& Patz, J. A. (2015). Climate Change, Human Rights, and Social Justice. Annals of Global Health, 81(3), 310-322. https://doi.org/10.1016/j.aogh.2015.08.008

Lipper, L., Thornton, P., Campbell, B. M., Baedeker, T., Braimoh, A., Bwalya, M., Caron, P., Cattaneo, A., Garrity, D., Henry, K., Hottle, R., Jackson, L., Jarvis, A., Kossam, F., Mann, W., McCarthy, N., Meybeck, A., Neufeldt, H., Remington, T., ... Torquebiau, E. F. (2014). Climate-smart agriculture for food security. Nature Climate Change, 4(12), 1068-1072. https://doi.org/10.1038/nclimate2437

Lobell, D. B., Schlenker, W., \& Costa-Roberts, J. (2011). Climate trends and global crop production since 1980. Science, 333(6042), 616-620. https://doi.org/10.1126/science.1204531

Lybbert, T. J., \& Sumner, D. A. (2012). Agricultural technologies for climate change in developing countries: Policy options for innovation and technology diffusion. Food Policy, 37(1), 114-123. https://doi.org/10.1016/j.foodpol.2011.11.001

Madzwamuse, M. (2011). Climate governance in africa: Adaptation strategies and institutions (p. 110). Heinrich Böll Stiftung.

Magee, T. (2013). A Field Guide to Community Based Adaptation. Routledge.

Magnan, A. K., Schipper, E. L. F., Burkett, M., Bharwani, S., Burton, I., Eriksen, S., Gemenne, F., Schaar, J., \& Ziervogel, G. (2016). Addressing the risk of maladaptation to climate change. Wiley 
Interdisciplinary Reviews: Climate Change, 7(5), 646-665. https://doi.org/10.1002/wcc.409

Mansuri, G., \& Rao, V. (2003). Community-based and-driven Development: A Critical Review (pp. 1-39) [Working Paper]. The World Bank. Manuamorn, O. P., Biesbroek, R., \& Cebotari, V. (2020). What makes internationally-financed climate change adaptation projects focus on local communities? A configurational analysis of 30 Adaptation Fund projects. Global Environmental Change, 61, 102035.

Maru, Y. T., Langridge, J., \& Lin, B. B. (2011). Current and potential applications of typologies in vulnerability assessments and adaptation science (Working Paper No. 7; Climate Adaptation Flagship). CSIRO. http://www.csiro.au/resources/CAF-workingpapers.html

Masullo, I., Larsen, G., Brown, L., \& Dougherty-Choux, L. (2015). “Direct Access" to Climate Finance: Lessons Learned by National Institutions. World Resources Institute. http://www.wri.org/publication/direct-access

Matsaert, H., Kariuki, J., \& Mude, A. (2011). Index-based livestock insurance for Kenyan pastoralists: An innovation systems perspective. Development in Practice, 21(3), 343-356. https://doi.org/10.1080/09614524.2011.557423

McDonnell, S. (2019). Other dark sides of resilience: Politics and power in community-based efforts to strengthen resilience. Anthropological 
Forum, 30(1-2), 55-72.

https://doi.org/10.1080/00664677.2019.1647828

McEvoy, D., Matczak, P., Banaszak, I., \& Chorynski, A. (2010). Framing adaptation to climate-related extreme events. Mitigation and Adaptation Strategies for Global Change, 15(7), 779-795. https://doi.org/10.1007/s11027-010-9233-2

McGray, H., Anne Hamm ill, Rob Bradley, Schipper, E. L., \& Parry, J.-E. (2007). Weathering the Storm Options for Framing Adaptation and Development. World Resources Institute. http://www.wri.org/publication/weathering-storm McKendrick, J. H. (1999). Multi-Method Research: An Introduction to Its Application in Population Geography. The Professional Geographer, 51(1), 40-50. https://doi.org/10.1111/0033-0124.00143

McNamara, K. E. (2013). Taking stock of community-based climate-change adaptation projects in the Pacific. Asia Pacific Viewpoint, 54(3, SI), 398-405. https://doi.org/10.1111/apv.12033

McNamara, K. E., \& Buggy, L. (2017). Community-based climate change adaptation: A review of academic literature. Local Environment, 22(4), 443-460. https://doi.org/10.1080/13549839.2016.1216954

McNamara, K. E., Clissold, R., Westoby, R., Piggott-McKellar, A. E., Kumar, R., Clarke, T., Namoumou, F., Areki, F., Joseph, E., Warrick, O., \& Nunn, P. D. (2020). An assessment of community-based adaptation 
initiatives in the Pacific Islands. Nature Climate Change, 10(7), 628-639. https://doi.org/10.1038/s41558-020-0813-1

Mearns, R., \& Norton, A. (2010). Social dimensions of climate change: Equity and vulnerability in a warming world. The World Bank. Measham, T. G., Preston, B. L., Smith, T. F., Brooke, C., Gorddard, R., Withycombe, G., \& Morrison, C. (2011). Adapting to climate change through local municipal planning: Barriers and challenges. Mitigation and Adaptation Strategies for Global Change, 16(8), 889909. https://doi.org/10.1007/s11027-011-9301-2

Mehrotra, S. (2006). Governance and basic social services: Ensuring accountability in service delivery through deep democratic decentralization. Journal of International Development, 18(2), 263283. https://doi.org/10.1002/jid.1219

Meinzen-Dick, R., Bernier, Q., \& Haglund, E. (2013). The six "ins" of climate-smart agriculture: Inclusive institutions for information, innovation, investment, and insurance (pp. 1-27) [CAPRi Working Paper No. 114.]. International Food Policy Research Institute.

Mekonnen, A. (2014). Economic Costs of Climate Change and Climate Finance with a Focus on Africa. Journal of African Economies, 23(2), 50-82. https://doi.org/10.1093/jae/eju012

Mfitumukiza, D., Roy, A. S., Simane, B., Hammill, A., Rahman, M. F., \& Huq, S. (2020). Scaling local and community-based adaptation 
[Background Paper]. Global Commission on Adaptation. www.gca.org/global-commission-on-adaptation/report/papers Micale, V., Tonkonogy, B., \& Mazza, F. (2018). Understanding and Increasing Finance for Climate Adaptation in Developing Countries. Climate Policy Initiative. https://climatepolicyinitiative.org/publication/understanding-andincreasing-finance-for-climate-adaptation-in-developing-countries/

Michaelowa, A., \& Michaelowa, K. (2011). Coding Error or Statistical Embellishment? The Political Economy of Reporting Climate Aid. World Development, 39(11), 2010-2020. https://doi.org/10.1016/j.worlddev.2011.07.020

Mickwitz, P., Aix, F., Beck, S., Carss, D., Ferrand, N., Görg, C., Jensen, A., Kivimaa, P., Kuhlicke, C., Kuindersma, W., Manez, M., Melanen, M., Monni, S., Branth Pedersen, A., Reinert, H., \& van Bommel, S. (2009). Climate policy integration, coherence and governance (No. 2; PEER Report). Partnership for European Environmental Research. http://www.nab.vu/sites/all/files/documents/m235_peer_report21.pdf Mikulewicz, M. (2018). Politicizing vulnerability and adaptation: On the need to democratize local responses to climate impacts in developing countries. Climate and Development, 10(1), 18-34. https://doi.org/10.1080/17565529.2017.1304887 
Mikulewicz, M. (2020). Disintegrating labor relations and depoliticized adaptation to climate change in rural São Tomé and Príncipe. Area, 00, 1-9. https://doi.org/10.1111/area.12630

Mill, J. S. (1843). A System of Logic, Ratiocinative and Inductive: Being a Connected View of the Principles of Evidence, and Methods of Scientific Investigation, Volume 1. John W. Parker.

Mimura, N., Pulwarty, R. S., Duc, D. M., Elshinnawy, I., Redsteer, M. H., Huang, H. Q., Nkem, J. N., \& Rodriguez, R. S. (2014). Adaptation planning and implementation. In Climate Change 2014: Impacts, Adaptation, and Vulnerability. Part A: Global and Sectoral Aspects. Contribution of Working Group II to the Fifth Assessment Report of the Intergovernmental Panel on Climate Change [Field, C.B., V.R. Barros, D.J. Dokken, K.J. Mach, M.D. Mastrandrea, T.E. Bilir, M. Chatterjee, K.L. Ebi, Y.O. Estrada, R.C. Genova, B. Girma, E.S. Kissel, A.N. Levy, S. MacCracken, P.R. Mastrandrea, and L.L. White (eds.)]. (pp. 869-898). Cambridge University Press.

Ministry of Environment of Jordan. (2013). The National Climate Change Policy of the Hashemite Kingdom of Jordan 2013-2020 Sector Strategic Guidance Framework. http://www.Ise.ac.uk/Granthamlnstitute/wpcontent/uploads/laws/1417.pdf

Moeletsi, M. E., Mellaart, E. A. R., Mpandeli, N. S., \& Hamandawana, H. (2013). The use of rainfall forecasts as a decision guide for small- 
scale farming in Limpopo Province, South Africa. The Journal of Agricultural Education and Extension, 19(2), 133-145. https://doi.org/10.1080/1389224X.2012.734253

Mohan, G., \& Stokke, K. (2000). Participatory development and empowerment: The dangers of localism. Third World Quarterly, 21(2), 247-268. https://doi.org/10.1080/01436590050004346

Möhner, A., \& Klein, R. J. (2007). The Global Environment Facility: Funding for adaptation or adapting to funds (Climate and Energy Program Working Paper) [Working Paper]. Stockholm Environment Institute. https://mediamanager.sei.org/documents/Publications/Climate/the global_environment_facility_funding_adaptation.pdf

Moreddu, C., \& Van Tongeren, F. (2013). Improving agricultural productivity sustainably at global level: The role of agricultural innovation policies. EuroChoices, 12(1), 8-14.

Morgan, J., \& Waskow, D. (2014). A new look at climate equity in the UNFCCC. Climate Policy, 14(1), 17-22. https://doi.org/10.1080/14693062.2014.848096

Müller, B. (2006). Climate of distrust: The 2006 Bonn climate change adaptation fund negotiations. The Oxford Institute for Energy Studies, University of Oxford.

Müller, B. (2008). International adaptation finance: The need for an innovative and strategic approach. The Oxford Institute for Energy Studies, University of Oxford. 
Müller, B. (2011). Enhanced direct access: Submission to the Transitional Committee on the issue of Thematic Funding Windows (Workstreams II \& III). The Oxford Institute for Energy Studies, University of Oxford. http://eurocapacity.org/finance/documents/OIES\%20submission \%2 0on\%20Enhanced\%20Direct\%20Access\%20-\%20Final.pdf

Müller, B. (2013). Enhanced (Direct) Access' through '(National) Funding Entities'-Etymology and Examples: Information Note on the Green Climate Fund Business Model Framework. The Oxford Institute for Energy Studies, University of Oxford. https://www.oxfordenergy.org/wpcms/wpcontent/uploads/2013/05/Enhanced-Direct-Access-April-2013.pdf Müller, B. (2014). Enhancing direct access and country ownership: Status quo and the way forward [Discussion Note for the Sixth Meeting of the Green Climate Fund Board]. The Oxford Institute for Energy Studies, University of Oxford.

Müller, B., \& Pizer, W. (2014). Devolved Access Modalities: Lessons for the Green Climate Fund from existing practice (Working Paper NI WP 14-03). Duke University.

https://nicholasinstitute.duke.edu/sites/default/files/publications/dev olved_access_modalities.pdf 
Naess, L. O. (2013). The role of local knowledge in adaptation to climate change. Wiley Interdisciplinary Reviews: Climate Change, 4(2), 99106. https://doi.org/10.1002/wcc.204

Næss, L. O., Bang, G., Eriksen, S., \& Vevatne, J. (2005). Institutional adaptation to climate change: Flood responses at the municipal level in Norway. Global Environmental Change, 15(2), 125-138. https://doi.org/10.1016/j.gloenvcha.2004.10.003

Nakhooda, S. (2013). The effectiveness of international climate finance. Overseas Development Institute.

Nakhooda, S., Norman, M., Barnard, S., Watson, C., Greenhill, R., Caravani, A., Canales Trujillo, N., Hedger, M., \& Whitley, S. (2014). Climate finance: Is it making a difference? A review of the effectiveness of Multilateral Climate Funds. Overseas Development Institute. http://www.odi.org/sites/odi.org.uk/files/odiassets/publications-opinion-files/9358.pdf

Nakhooda, S., Watson, C., \& Schalatek, L. (2013). The Global Climate Finance Architecture (Climate Finance Fundamentals) [Briefing paper]. Overseas Development Institute and Heinrich Böll Foundation North America.

Nalau, J., Preston, B. L., \& Maloney, M. C. (2015). Is adaptation a local responsibility? Environmental Science \& Policy, 48, 89-98. https://doi.org/10.1016/j.envsci.2014.12.011 
Narain, U., Margulis, S., \& Essam, T. (2011). Estimating costs of adaptation to climate change. Climate Policy, 11(3, SI), 1001-1019. https://doi.org/10.1080/14693062.2011.582387

Nieuwaal, K. van, Driessen, P., Spit, T., \& Termeer, C. (2009). A state of the art of governance literature on adaptation to climate change: Towards a research agenda (KfC 003/2009; Knowledge for Climate Report). Utrecht University and Wageningen University. http://library.wur.nl/WebQuery/clc/1907502

Noble, I. R., Huq, S., Anokhin, Y. A., Carmin, J., Goudou, D., Lansigan, F. P., Osman-Elasha, B., \& Villamizar, A. (2014). Adaptation needs and options. In Climate Change 2014: Impacts, Adaptation, and Vulnerability. Part A: Global and Sectoral Aspects. Contribution of Working Group II to the Fifth Assessment Report of the Intergovernmental Panel on Climate Change [Field, C.B., V.R. Barros, D.J. Dokken, K.J. Mach, M.D. Mastrandrea, T.E. Bilir, M. Chatterjee, K.L. Ebi, Y.O. Estrada, R.C. Genova, B. Girma, E.S. Kissel, A.N. Levy, S. MacCracken, P.R. Mastrandrea, and L.L. White (eds.)]. (pp. 833-868). Cambridge University Press.

Nordgren, J., Stults, M., \& Meerow, S. (2016). Supporting local climate change adaptation: Where we are and where we need to go. Environmental Science \& Policy, 66, 344-352. https://doi.org/10.1016/j.envsci.2016.05.006 
Nunn, P. D. (2013). The end of the Pacific? Effects of sea level rise on Pacific Island livelihoods. Singapore Journal of Tropical Geography, 34(2), 143-171. https://doi.org/10.1111/sjtg.12021

Nyikahadzoi, K., Adekunle, A., Fatunbi, O., \& Zamasiya, B. (2017).

Promoting production and marketing of root crops in Southern Africa in a changing climate using integrated Agricultural Research for Development (IAR4d) pathway. African Journal of Food, Agriculture, Nutrition and Development, 17(1), 11787-11802. https://doi.org/10.18697/ajfand.77.13765

Nyongesa, D., Esilaba, A. O., Emongor, R., Bikketi, E., \& Were, K. (2017). Assessment of gender and innovations in climatesmart agriculture for food and nutrition security in Kenya: A case of Kalii watershed. International Journal of Agricultural Resources, Governance and Ecology, 13(2), 109-137.

Nzeadibe, T. C., Egbule, C. L., Chukwuone, N. A., Agwu, A. E., \& Agu, V. C. (2012). Indigenous innovations for climate change adaptation in the Niger Delta region of Nigeria. Environment, Development and Sustainability, 14(6), 901-914. https://doi.org/10.1007/s10668-0129359-3

O'Brien, K., Eriksen, S., Nygaard, L. P., \& Schjolden, A. (2007). Why different interpretations of vulnerability matter in climate change discourses. Climate Policy, 7(1), 73-88. https://doi.org/10.1080/14693062.2007.9685639 
OECD. (2016). Definition and Guidance for the Climate Rio Markers.

Organisation for Economic Co-operation and Development. http://www.oecd.org/dac/environmentdevelopment/Annex\%2018.\%20Rio\%20markers.pdf

OECD. (2018). Climate finance from developed to developing countries Public flows in 2013-17. OECD Publishing. http://www.oecd.org/environment/cc/Climate-finance-fromdeveloped-to-developing-countries-Public-flows-in-2013-17.pdf

OECD. (2019). Better Criteria for Better Evaluation Revised Evaluation Criteria Definitions and Principles for Use (p. 13). OECD/DAC Network on Development Evaluation, Organisation for Economic Co-operation and Development.

https://www.oecd.org/dac/evaluation/revised-evaluation-criteria-dec2019.pdf

Ojha, H. R., Sulaiman V, R., Sultana, P., Dahal, K., Thapa, D., Mittal, N., Thompson, P., Bhatta, G. D., Ghimire, L., \& Aggarwal, P. (2014). Is South Asian agriculture adapting to climate change? Evidence from the Indo-Gangetic Plains. Agroecology and Sustainable Food Systems, 38(5), 505-531. https://doi.org/10.1080/21683565.2013.841607

Oliver, P., Clark, A., \& Meattle, C. (2018). Global Climate Finance: An Updated View 2018. Climate Policy Initiative. 
https://climatepolicyinitiative.org/publication/global-climate-financean-updated-view-2018/

Olsson, L., Opondo, M., Tschakert, P., Agrawal, A., Eriksen, S. E., Ma, S., Perch, L. N., \& Zakieldeen, S. A. (2014). Livelihoods and poverty. In Climate Change 2014: Impacts, Adaptation, and Vulnerability. Part A: Global and Sectoral Aspects. Contribution of Working Group II to the Fifth Assessment Report of the Intergovernmental Panel on Climate Change [Field, C.B., V.R. Barros, D.J. Dokken, K.J. Mach, M.D. Mastrandrea, T.E. Bilir, M. Chatterjee, K.L. Ebi, Y.O. Estrada, R.C. Genova, B. Girma, E.S. Kissel, A.N. Levy, S. MacCracken, P.R. Mastrandrea, and L.L. White (eds.)]. (pp. 793-832).

Cambridge University Press.

Olwig, M. F. (2012). Multi-sited resilience: The mutual construction of "local" and "global" understandings and practices of adaptation and innovation. Applied Geography, 33, 112-118. https://doi.org/10.1016/j.apgeog.2011.10.007

Ostrom, E. (2010). Polycentric systems for coping with collective action and global environmental change. Global Environmental Change, 20(4), 550-557. https://doi.org/doi:10.1016/j.gloenvcha.2010.07.004

Owen, N., Glanz, K., Sallis, J. F., \& Kelder, S. H. (2006). Evidence-based approaches to dissemination and diffusion of physical activity interventions. American Journal of Preventive Medicine, 31(4), 3544. https://doi.org/10.1016/j.amepre.2006.06.008 
Paavola, J., \& Adger, W. N. (2006). Fair adaptation to climate change. Ecological Economics, 56(4), 594-609. https://doi.org/10.1016/j.ecolecon.2005.03.015

Pahl-Wostl, C. (2009). A conceptual framework for analysing adaptive capacity and multi-level learning processes in resource governance regimes. Global Environmental Change, 19(3), 354-365. https://doi.org/10.1016/j.gloenvcha.2009.06.001

Pahl-Wostl, C., \& Knieper, C. (2014). The capacity of water governance to deal with the climate change adaptation challenge: Using fuzzy set Qualitative Comparative Analysis to distinguish between polycentric, fragmented and centralized regimes. Global Environmental Change, 29, 139-154. https://doi.org/10.1016/j.gloenvcha.2014.09.003

Pamuk, H., Bulte, E., \& Adekunle, A. A. (2014). Do decentralized innovation systems promote agricultural technology adoption? Experimental evidence from Africa. Food Policy, 44, 227-236. https://doi.org/10.1016/j.foodpol.2013.09.015

Parker, C., Keenlyside, P., \& Conway, D. (2014). Early experiences in adaptation finance: Lessons from the four multilateral climate change adaptation funds. World Wildlife Fund. https://www.worldwildlife.org/publications/early-experiences-inadaptation-finance 
Pauw, W. P. (2015). Not a panacea: Private-sector engagement in adaptation and adaptation finance in developing countries. Climate Policy, 15(5), 583-603.

https://doi.org/10.1080/14693062.2014.953906

Pauw, W. P., Klein, R. J. T., Vellinga, P., \& Biermann, F. (2015). Private finance for adaptation: Do private realities meet public ambitions? Climatic Change, 134(4), 489-503. https://doi.org/10.1007/s10584$015-1539-3$

Pelling, M. (2011). Adaptation to climate change: From resilience to transformation. Routledge.

Pelling, M., \& High, C. (2005). Understanding adaptation: What can social capital offer assessments of adaptive capacity? Global Environmental Change, 15(4), 308-319. https://doi.org/10.1016/j.gloenvcha.2005.02.001

Pelling, M., O'Brien, K., \& Matyas, D. (2015). Adaptation and transformation. Climatic Change, 133(1), 113-127. https://doi.org/10.1007/s10584014-1303-0

Persha, L., \& Andersson, K. (2014). Elite capture risk and mitigation in decentralized forest governance regimes. Global Environmental Change, 24, 265-276. https://doi.org/10.1016/j.gloenvcha.2013.12.005

Persson, A. (2011). Institutionalising climate adaptation finance under the UNFCCC and beyond: Could an adaptation 'market'emerge 
[Working Paper]. Stockholm Environment Institute.

http://environmentportal.in/files/file/adaptation-commodification.pdf

Persson, A., \& Remling, E. (2014). Equity and efficiency in adaptation finance: Initial experiences of the Adaptation Fund. Climate Policy, 14(4), 488-506. https://doi.org/10.1080/14693062.2013.879514

Peterson Carvalho, A., \& Terpstra, P. (2015). Tracking adaptation finance:

An approach for civil society organizations to improve accountability for climate change adaptation. World Resources Institute and Oxfam.

Piccolella, A. (2013). Participatory mapping for adaptation to climate change: The case of Boe Boe, Solomon Islands. Knowledge Management for Development Journal, 9(1), 24-36.

Pickering, J., Betzold, C., \& Skovgaard, J. (2017). Special issue: Managing fragmentation and complexity in the emerging system of international climate finance. International Environmental Agreements: Politics, Law and Economics, 17(1), 1-16. https://doi.org/10.1007/s10784-016-9349-2

Pickering, J., Skovgaard, J., Kim, S., Roberts, J. T., Rossati, D., Stadelmann, M., \& Reich, H. (2015). Acting on Climate Finance Pledges: Inter-Agency Dynamics and Relationships with Aid in Contributor States. World Development, 68, 149-162. https://doi.org/10.1016/j.worlddev.2014.10.033 
Pielke, R., Prins, G., Rayner, S., \& Sarewitz, D. (2007). Lifting the taboo on adaptation. Renewed attention to policies for adapting to climate change cannot come too soon. Nature, 445(8), 597-598. https://doi.org/10.1038/445597a

Piggott-McKellar, A. E., McNamara, K. E., Nunn, P. D., \& Watson, J. E. (2019). What are the barriers to successful community-based climate change adaptation? A review of grey literature. Local Environment, 24(4), 374-390. https://doi.org/10.1080/13549839.2019.1580688

Popke, J., Curtis, S., \& Gamble, D. W. (2016). A social justice framing of climate change discourse and policy: Adaptation, resilience and vulnerability in a Jamaican agricultural landscape. Geoforum, 73, 70-80. http://dx.doi.org/10.1016/j.geoforum.2014.11.003

Pretty, J. N., Guijt, I., Thompson, J., \& Scoones. (1995). Participatory Learning and Action: A trainer's guide (IIED Participatory Methodology Series). International Institute for Environment and Development. http://pubs.iied.org/6021IIED/

Ragin, C. C. (2000). Fuzzy-set social science. University of Chicago Press.

Ragin, C. C. (2009). Redesigning social inquiry: Fuzzy sets and beyond. University of Chicago Press.

Ragin, C. C., \& Davey, S. (2016). Fuzzy-Set/Qualitative Comparative Analysis 3.0. 
Rai, N., Acharya, S., Bhushal, R., Chettri, R., Shamshudoha, M., Kallore, M. E., Kaur, N., Neupane, S., \& Tesfaye, L. (2015). Political economy of international climate finance: Navigating decisions in PPCR and SREP [Working Paper]. International Institute for Environment and Development. http://pubs.iied.org/10111IIED.html

Rai, N., Kaur, N., Greene, S., Wang, B., \& Steele, P. (2015). Topic Guide: A guide to national governance of climate finance. International Institute for Environment and Development (IIED). http://www.evidenceondemand.info/topic-guide-a-guide-to-nationalgovernance-of-climate-finance

Ramani, S. V., SadreGhazi, S., \& Duysters, G. (2012). On the diffusion of toilets as bottom of the pyramid innovation: Lessons from sanitation entrepreneurs. Technological Forecasting and Social Change, 79(4), 676-687. https://doi.org/10.1016/j.techfore.2011.06.007

Rawlani, A. K., \& Sovacool, B. K. (2011). Building responsiveness to climate change through community based adaptation in Bangladesh. Mitigation and Adaptation Strategies for Global Change, 16(8), 845863. https://doi.org/10.1007/s11027-011-9298-6

Reed, M. S. (2008). Stakeholder participation for environmental management: A literature review. Biological Conservation, 141(10), 2417-2431. https://doi.org/10.1016/j.biocon.2008.07.014

Regmi, B. R., \& Star, C. (2014). Identifying operational mechanisms for mainstreaming community-based adaptation in Nepal. Climate and 
Development, 6(4), 306-317.

https://doi.org/10.1080/17565529.2014.977760

Regmi, B. R., \& Star, C. (2015). Exploring the policy environment for mainstreaming community-based adaptation (CBA) in Nepal. International Journal of Climate Change Strategies and Management, 7(4), 423-441. https://doi.org/10.1108/IJCCSM-042014-0050

Reid, H. (2016). Ecosystem-and community-based adaptation: Learning from community-based natural resource management. Climate and Development, 8(1), 4-9. https://doi.org/10.1080/17565529.2015.1034233

Reid, H., Alam, M., Berger, R., Cannon, T., Huq, S., \& Milligan, A. (2009). Community-based adaptation to climate change: An overview. In $\mathrm{H}$. Ashley, N. Kenton, A. Milligan, H. Reid, T. Cannon, R. Berger, M. Alam, \& A. Milligan (Eds.), Participatory Learning and Action 60 (pp. 11-33). International Institute for Environment and Development. http://www.iied.org/pla-60-community-based-adaptation-climatechange

Reid, H., \& Huq, S. (2014). Mainstreaming community-based adaptation into national and local planning. Climate and Development, 6(4), 291292. https://doi.org/10.1080/17565529.2014.973720 
Reid, H., Huq, S., \& Murray, L. A. (2010). Community champions: Adapting to climate challenges. International Institute for Environment and Development. https://pubs.iied.org/pdfs/10028IIED.pdf

Remling, E., \& Persson, A. (2015). Who is adaptation for? Vulnerability and adaptation benefits in proposals approved by the UNFCCC Adaptation Fund. Climate and Development, 7(1), 16-34. https://doi.org/10.1080/17565529.2014.886992

Ribot, J. (2010). Vulnerability does not fall from the sky: Toward multiscale, pro-poor climate policy. In R. Mearns \& A. Norton (Eds.), Social dimensions of climate change: Equity and vulnerability in a warming world (Vol. 2, pp. 47-74). The World Bank.

Roberts, J. T., \& Weikmans, R. (2017). Postface: Fragmentation, failing trust and enduring tensions over what counts as climate finance. International Environmental Agreements: Politics, Law and Economics, 17(1), 129-137. https://doi.org/10.1007/s10784-016$9347-4$

Robinson, S., \& Dornan, M. (2017). International financing for climate change adaptation in small island developing states. Regional Environmental Change, 17(4), 1103-1115. https://doi.org/10.1007/s10113-016-1085-1

Rogers, E. M. (2003). Diffusion of innovations (Fifth Edition). Free Press. 
Röling, N. (2016). Institutions: Lessons from West Africa. Outlook on Agriculture, 45(4), 220-224. https://doi.org/10.1177/0030727016675105

Roncoli, C., Orlove, B. S., Kabugo, M. R., \& Waiswa, M. M. (2011). Cultural styles of participation in farmers' discussions of seasonal climate forecasts in Uganda. Agriculture and Human Values, 28(1), 123138. https://doi.org/10.1007/s10460-010-9257-y

Runhaar, H., Wilk, B., Persson, A.., Uittenbroek, C., \& Wamsler, C. (2018). Mainstreaming climate adaptation: Taking stock about "what works" from empirical research worldwide. Regional Environmental Change, 18(4), 1201-1210. https://doi.org/10.1007/s10113-017$1259-5$

Sabates-Wheeler, R., Mitchell, T., \& Ellis, F. (2008). Avoiding repetition: Time for CBA to engage with the livelihoods literature? IDS Bulletin, 39(4), 53-59.

Saito, N. (2013). Mainstreaming climate change adaptation in least developed countries in South and Southeast Asia. Mitigation and Adaptation Strategies for Global Change, 18(6), 825-849. https://doi.org/10.1007/s11027-012-9392-4

Saldaña, J. (2013). The Coding Manual for Qualitative Reseachers (Second Edition). Sage Publications.

Sayer, A. (2000). Realism and social science. Sage Publications. 
Scanlon, J., \& Nobbe, C. (2010). Creating the Capacity for Decentralized, Self-Governing Adaptations to Climate Change. In Ansohn \& Pleskovic (Eds.), Climate Governance and Development. The World Bank.

Schäfer, L., Kaloga, A., Kreft, S., Jennings, M., Schalatek, L., \& Munyaradzi, F. (2014). Learning from Direct Access Modalities in Africa. Germanwatch e.V. www.germanwatch.org/en/9475

Schalatek, L. (2012). Democratizing climate finance governance and the public funding of climate action. Democratization, 19(5, SI), 951973. https://doi.org/10.1080/13510347.2012.709690

Schalatek, L., Bird, N., \& Brown, J. (2010). Where's the money? The status of climate finance post-Copenhagen (Climate Finance Policy Brief No.1). Overseas Development Institute and Heinrich Böll Foundation North America. http://www.odi.org/resources/docs/5844.pdf

Schipper, E. L. F. (2006). Conceptual History of Adaptation in the UNFCCC Process. Review of European Community \& International Environmental Law, 15(1), 82-92. https://doi.org/10.1111/j.14679388.2006.00501.x

Schipper, E. L. F. (2007). Climate change adaptation and development: Exploring the linkages (Working Paper No. 107; pp. 1-13). Tyndall Centre for Climate Change Research. 
https://www.researchgate.net/publication/228391167_Climate_chan ge_adaptation_and_development_Exploring_the_linkages

Schipper, E. L. F., Ayers, J., Reid, H., Huq, S., \& Rahman, A. (2014).

Community-based adaptation to climate change: Scaling it up. Routledge.

Schmidt, N. M. (2019). Late bloomer? Agricultural policy integration and coordination patterns in climate policies. Journal of European Public Policy, O(0), 1-19. https://doi.org/10.1080/13501763.2019.1617334

Schneider, A. (2003). Decentralization: Conceptualization and measurement. Studies in Comparative International Development, 38(3), 32-56. https://doi.org/10.1007/BF02686198

Schneider, C. Q., \& Wagemann, C. (2010). Standards of good practice in qualitative comparative analysis (QCA) and fuzzy-sets. Comparative Sociology, 9(3), 397-418. https://doi.org/10.1163/156913210X12493538729793

Schneider, C. Q., \& Wagemann, C. (2012). Set-theoretic methods for the social sciences: A guide to qualitative comparative analysis. Cambridge University Press.

Scholz, R. W., \& Tietje, O. (2002). Embedded case study methods: Integrating quantitative and qualitative knowledge. Sage Publications.

Scoville-Simonds, M. (2016). The governance of climate change adaptation finance-An overview and critique. International Development 
Policy | Revue Internationale de Politique de Développement [Online], 7.1. https://doi.org/10.4000/poldev.2243

Sekine, H., Fukuhara, K., Uraguchi, A., Tan, C. K., Nagai, M., \& Okada, Y. (2009). The effectiveness of community-based adaptation (CBA) to climate change-from the viewpoint of social capital and indigenous knowledge (No. 2009-001; GEIC Working Paper). Mitsubishi Research Institute and United Nations University - Institute for Sustainability and Peace (UNU-ISP).

https://www.researchgate.net/profile/Chun_Knee_Tan/publication/2 55758881_The_Effectiveness_of_Communitybased_Adaptation_CBA_to_Climate_Change_From_the_Viewpoint _of_Social_Capital_and_Indigenous_Knowledge/links/00b49520a5 d0e6b4f3000000/The-Effectiveness-of-Community-basedAdaptation-CBA-to-Climate-Change-From-the-Viewpoint-of-SocialCapital-and-Indigenous-Knowledge.pdf

Senyolo, M. P., Long, T. B., Blok, V., \& Omta, O. (2018). How the characteristics of innovations impact their adoption: An exploration of climate-smart agricultural innovations in South Africa. Journal of Cleaner Production, 172, 3825-3840. https://doi.org/10.1016/j.jclepro.2017.06.019

Sharma, V., Orindi, V., Hesse, C., Pattison, J., \& Anderson, S. (2014). Supporting local climate adaptation planning and implementation through local governance and decentralised finance provision. 
Development in Practice, 24(4), 579-590.

https://doi.org/10.1080/09614524.2014.907240

Sherman, M. H., \& Ford, J. D. (2014). Stakeholder engagement in adaptation interventions: An evaluation of projects in developing nations. Climate Policy, 14(3), 417-441. https://doi.org/10.1080/14693062.2014.859501

Sibiko, K. W., Veettil, P. C., \& Qaim, M. (2018). Small farmers' preferences for weather index insurance: Insights from Kenya. Agriculture \& Food Security, 7(53), 1-14.

Sietz, D., Boschütz, M., \& Klein, R. J. T. (2011). Mainstreaming climate adaptation into development assistance: Rationale, institutional barriers and opportunities in Mozambique. Environmental Science \& Policy, 14(4), 493-502. https://doi.org/10.1016/j.envsci.2011.01.001

Simane, B., \& Zaitchik, B. F. (2014). The Sustainability of Community-Based Adaptation Projects in the Blue Nile Highlands of Ethiopia.

Sustainability, 6(7), 4308-4325. https://doi.org/10.3390/su6074308

Simiti, M. (2017). Civil Society and the Economy: Greek Civil Society During the Economic Crisis. Journal of Civil Society, 13(4), 357-373. https://doi.org/10.1080/17448689.2017.1355033

Smit, B., Burton, I., Klein, R. J., \& Wandel, J. (2000). An anatomy of adaptation to climate change and variability. Climatic Change, 45, 223-251. https://doi.org/10.1023/A:1005661622966 
Smit, B., \& Skinner, M. W. (2002). Adaptation options in agriculture to climate change: A typology. Mitigation and Adaptation Strategies for Global Change, 7, 85-114. https://doi.org/10.1023/A:1015862228270

Smit, B., \& Wandel, J. (2006). Adaptation, adaptive capacity and vulnerability. Global Environmental Change, 16(3), 282-292. https://doi.org/10.1016/j.gloenvcha.2006.03.008

Smith, J. B., Dickinson, T., Donahue, J. D. B., Burton, I., Haites, E., Klein, R. J. T., \& Patwardhan, A. (2011). Development and climate change adaptation funding: Coordination and integration. Climate Policy, 11(3), 987-1000. https://doi.org/10.1080/14693062.2011.582385

Soanes, M., Rai, N., Steele, P., Shakya, C., \& Macgregor, J. (2017).

Delivering real change: Getting international climate finance to the local level [IIED Working Paper]. International Institute for Environment and Development.

Soora, N. K., Aggarwal, P. K., Saxena, R., Rani, S., Jain, S., \& Chauhan, N. (2013). An assessment of regional vulnerability of rice to climate change in India. Climatic Change, 118(3-4), 683-699. https://doi.org/10.1007/s10584-013-0698-3

Sørensen, E., \& Torfing, J. (2011). Enhancing collaborative innovation in the public sector. Administration \& Society, 43(8), 842-868. https://doi.org/10.1177/0095399711418768 
Sovacool, B. K., Baker, L., Martiskainen, M., \& Hook, A. (2019). Processes of elite power and low-carbon pathways: Experimentation, financialisation, and dispossession. Global Environmental Change, 59, 101985. https://doi.org/10.1016/j.gloenvcha.2019.101985

Sovacool, B. K., Tan-Mullins, M., Ockwell, D., \& Newell, P. (2017). Political economy, poverty, and polycentrism in the Global Environment Facility's Least Developed Countries Fund (LDCF) for Climate Change Adaptation. Third World Quarterly, 38(6), 1249-1271. https://doi.org/10.1080/01436597.2017.1282816

Spires, M., Shackleton, S., \& Cundill, G. (2014). Barriers to implementing planned community-based adaptation in developing countries: A systematic literature review. Climate and Development, 6(3), 277287. https://doi.org/10.1080/17565529.2014.886995

Sprain, L. (2017). Paradoxes of Public Participation in Climate Change Governance. The Good Society, 25(1), 62-80. https://doi.org/10.5325/goodsociety.25.1.0062

Stadelmann, M., Michaelowa, A., Butzengeiger-Geyer, S., \& Köhler, M. (2015). Universal Metrics to Compare the Effectiveness of Climate Change Adaptation Projects. In W. Leal Filho (Ed.), Handbook of Climate Change Adaptation (pp. 2143-2160). Springer. https://doi.org/10.1007/978-3-642-38670-1_128

Stadelmann, M., Persson, Å., Ratajczak-Juszko, I., \& Michaelowa, A. (2013). Equity and cost-effectiveness of multilateral adaptation 
finance: Are they friends or foes? International Environmental Agreements: Politics, Law and Economics, 14(2), 101-120. https://doi.org/10.1007/s10784-013-9206-5

Stadelmann, M., Roberts, J. T., \& Michaelowa, A. (2011a). New and additional to what? Assessing options for baselines to assess climate finance pledges. Climate and Development, 3(3), 175-192.

Stadelmann, M., Roberts, J. T., \& Michaelowa, A. (2011b). New and additional to what? Assessing options for baselines to assess climate finance pledges. Climate and Development, 3(3), 175-192. https://doi.org/10.1080/17565529.2011.599550

State Government of Victoria. (2020). Community Innovation Grant Program. http://www.vic.gov.au/community-innovation-grantprogram

Stern, N. (2007). The Economics of Climate Change The Stern Review. Cambridge University Press.

Stott, C., \& Huq, S. (2014). Knowledge flows in climate change adaptation: Exploring friction between scales. Climate and Development, 6(4), 382-387. https://doi.org/10.1080/17565529.2014.951014

Streck, C. (2012). Struggling With Expectations and Changing Realities: International Climate Negotiations. Journal of Environment \& Development, 21(1, SI), 52-56. https://doi.org/10.1177/1070496512436425 
Szabo, S., Nicholls, R. J., Neumann, B., Renaud, F. G., Matthews, Z., Sebesvari, Z., AghaKouchak, A., Bales, R., Ruktanonchai, C. W., Kloos, J., Foufoula-Georgiou, E., Wester, P., New, M., Rhyner, J., \& Hutton, C. (2016). Making SDGs Work for Climate Change Hotspots. Environment: Science and Policy for Sustainable Development, 58(6), 24-33. https://doi.org/10.1080/00139157.2016.1209016

Tacconi, L. (2007). Decentralization, forests and livelihoods: Theory and narrative. Global Environmental Change, 17(3), 338-348. https://doi.org/10.1016/j.gloenvcha.2007.01.002

TANGO International and ODI. (2015). First Phase Independent Evaluation of the Adaptation Fund. The World Bank. https://www.adaptationfund.org/document/evaluation-of-the-fund-stage-1/

Terpstra, P., Carvalho, A. P., \& Wilkinson, E. (2013). The plumbing of adaptation finance: Accountability, transparency and accessibility at the local level. World Resources Institute.

Thomalla, F., Downing, T., Spanger-Siegfried, E., Han, G., \& Rockström, J. (2006). Reducing hazard vulnerability: Towards a common approach between disaster risk reduction and climate adaptation. Disasters, 30(1), 39-48. https://doi.org/10.1111/j.14679523.2006.00305.x 
Thompson, G., Frances, J., Levačić, R., \& Mitchell, J. (Eds.). (1991).

Markets, hierarchies and networks: The coordination of social life. Sage Publications.

Titz, A., Cannon, T., Krüger, F., Titz, A., Cannon, T., \& Krüger, F. (2018). Uncovering 'Community': Challenging an Elusive Concept in Development and Disaster Related Work. Societies, 8(3), 71. https://doi.org/10.3390/soc8030071

Tompkins, E. L., \& Eakin, H. (2012). Managing private and public adaptation to climate change. Global Environmental Change, 22(1), 3-11. https://doi.org/10.1016/j.gloenvcha.2011.09.010

Torfing, J. (2012). Interactive Governance: Advancing the Paradigm. Oxford University Press.

Totin, E., Roncoli, C., Traoré, P. S., Somda, J., \& Zougmoré, R. (2018). How does institutional embeddedness shape innovation platforms? A diagnostic study of three districts in the Upper West Region of Ghana. NJAS-Wageningen Journal of Life Sciences, 84, 27-40. http://dx.doi.org/10.1016/j.njas.2017.07.002

Trærup, S., \& Stephan, J. (2015). Technologies for adaptation to climate change. Examples from the agricultural and water sectors in Lebanon. Climatic Change, 131(3), 435-449. https://doi.org/10.1007/s10584-014-1158-4 
Tranter, B., \& Booth, K. (2015). Scepticism in a changing climate: A crossnational study. Global Environmental Change, 33, 154-164. https://doi.org/10.1016/j.gloenvcha.2015.05.003

Treisman, D. (2002). Defining and measuring decentralization: A global perspective [Working Paper]. University of California.

Treisman, D. (2008). Decentralization Dataset (Tiers of government). http://www.sscnet.ucla.edu/polisci/faculty/treisman/

Uittenbroek, C. J., Janssen-Jansen, L. B., \& Runhaar, H. A. C. (2013). Mainstreaming climate adaptation into urban planning: Overcoming barriers, seizing opportunities and evaluating the results in two Dutch case studies. Regional Environmental Change, 13(2), 399411. https://doi.org/10.1007/s10113-012-0348-8

UNDP. (2010a). Designing Climate Chnage Adaptation Initiatives: A UNDP Toolkit for Practitioners. United Nations Development Programme. http://www.undp.org/content/undp/en/home/librarypage/environment -energy/low_emission_climateresilientdevelopment/designingadaptation-initiatives-toolkit.html

UNDP. (2010b). Gender, Climate Change and Community Based Adaptation Guidebook. United Nations Development Programme. http://www.undp.org/content/undp/en/home/librarypage/environment -energy/climate_change/gender/gender-climate-change-andcommunity-based-adaptation-guidebook-.html 
UNDP. (2012). Readiness for Climate Finance. A Framework for Understanding What It Means to be Ready to Use Climate Finance. United Nations Development Programme.

http://www.tr.undp.org/content/dam/turkey/docs/Publications/EnvSu st/UNDP-Readiness_for_Climate_Finance.pdf

UNDP. (2014). Guidance Note on How to Plan and Mainstream CommunityBased Adaptation at the Local, Sub-National and National Levels. United Nations Development Programme. https://sgp.undp.org/index.php?option=com_docman\&view=docume nt\&layout=default\&alias=499-guidance-note-on-how-to-plan-andmainstream-community-based-adaptation-at-the-local-sub-nationaland-national-levels\&category_slug=globalpublications\&Itemid=289\#.WH4iofl95m8 UNDP. (2015). A Practitioners Guide to Establishing A Community-Based Adaptation Programme Recommendations Based on A UNDP-GEF Community-based adaptation Pilot Project. United Nations Development Programme. https://sgp.undp.org/index.php?option=com_docman\&view=docume nt\&layout=default\&alias=562-a-practitioners-guide-to-establishinga-community-based-adaptation-programme-recommendationsbased-on-a-undp-gef-community-based-adaptation-pilotproject\&category_slug=globalpublications\&ltemid=289\#.WH4gwPI95m8 
UNEP. (2016). The Adaptation Gap Report 2016. United Nations Environment Programme. /publications/2016/the-adaptation-gapreport-2016/

UNFCCC. (1992). United Nations Framework Convention on Climate Change. United Nations. https://unfccc.int/resource/docs/convkp/conveng.pdf

UNFCCC. (2005). Buenos Aires programme of work on adaptation and response measures (Decision 1/CP.10) (FCCC/CP/2004/10/Add.1). UNFCCC. https://unfccc.int/resource/docs/cop10/10a01.pdf UNFCCC. (2007). Bali Action Plan (Decision 1/CP.13) (FCCC/CP/2007/6/Add.1*). UNFCCC. https://unfccc.int/resource/docs/2007/cop13/eng/06a01.pdf UNFCCC. (2008a). Report of the Conference of the Parties serving as the meeting of the Parties to the Kyoto Protocol on its third session. Addendum Decision 1/CMP.3 Adaptation Fund (FCCC/KP/CMP/2007/9/Add.1). UNFCC. http://unfccc.int/resource/docs/2007/cmp3/eng/09a01.pdf\#page=3

UNFCCC. (2008b). Review of the financial mechanism referred to in decision 6/CP.13 (FCCC/SBI/2008/MISC. 3). UNFCCC. http://unfccc.int/resource/docs/2008/sbi/eng/misc03.pdf UNFCCC. (2009). Report of the conference of the parties serving as the meeting of the parties to the Kyoto Protocol on its fourth session. Addendum. Decision 1/CMP.4, Adaptation Fund 
(FCCC/KP/CMP/2008/11/Add.2.). UNFCCC.

http://unfccc.int/resource/docs/2008/cmp4/eng/11a02.pdf\#page=1

UNFCCC. (2010a). G-77 and China Proposal Financial Mechanism for

Meeting Financial Commitments under the Convention. UNFCCC.

http://unfccc.int/files/kyoto_protocol/application/pdf/g77_china_finan cing_1.pdf

UNFCCC. (2010b). The Cancun Agreements: Outcome of the work of the Ad Hoc Working Group on Long-term Cooperative Action under the Convention (FCCC/CP/2010/7/Add.1).

https://unfccc.int/resource/docs/2010/cop16/eng/07a01.pdf

UNFCCC. (2010c). Synthesis report on efforts undertaken to assess the costs and benefits of adaptation options, and views on lessons learned, good practices, gaps and needs (FCCC/SBSTA/2010/3). UNFCCC. http://unfccc.int/resource/docs/2010/sbsta/eng/03.pdf UNFCCC. (2013). Adaptation Fund Board.

https://unfccc.int/process/bodies/constituted-bodies/adaptationfund-board-afb

UNFCCC. (2015a). Paris Agreement.

https://unfccc.int/sites/default/files/english_paris_agreement.pdf UNFCCC. (2015b). Synthesis report on the aggregate effect of the intended nationally determined contributions (FCCC/CP/2015/7). UNFCCC. http://unfccc.int/resource/docs/2015/cop21/eng/07.pdf 
UNFCCC. (2016). Report of the Conference of the Parties on its twenty-first session, held in Paris from 30 November to 11 December 2015. (FCCC/CP/2015/10/Add.1; p. 36). UNFCCC.

UNFCCC. (2018). Third Biennial Assessment and Overview of Climate Finance Flows. UNFCCC Standing Committee on Finance. https://unfccc.int/topics/climate-finance/resources/biennialassessment-of-climate-finance

UNFCCC. (2020). Nairobi work programme on impacts, vulnerability and adaptation to climate change. https://unfccc.int/topics/adaptationand-resilience/workstreams/nairobi-work-programme-on-impactsvulnerability-and-adaptation-to-climate-change\#eq-1

United Nations. (2008). Participatory governance and the millennium development goals (MDGs) (ST/ESA/PAD/SER.E/119; Publication Based on the Expert Group Meeting on Engaged Governance: Citizen Participation in the Implementation of the Developmental Goals Including the Millennium Development Goals (MDGs) 1-2 November 2006 New York). United Nations.

van Aalst, M. K., Cannon, T., \& Burton, I. (2008). Community level adaptation to climate change: The potential role of participatory community risk assessment. Global Environmental Change, 18(1), 165-179. https://doi.org/10.1016/j.gloenvcha.2007.06.002 
V-Dem Institute. (2018). V-Dem [Country-Year/Country-Date] Dataset v8" Varieties of Democracy (V-Dem) Project. University of Gothenburg. https://www.v-dem.net/en/

weADAPT. (n.d.). What is a Community-Based Adaptation Project? Retrieved January 18, 2017, from https://www.weadapt.org/knowledge-base/global-initiative-oncommunity-based-adaptation-gicba/what-is-a-community-basedadaptation-project

Webb, J., Vorbach, D., Boydell, E., Mcnaught, R., \& Sterrett, C. (2015). Tools for CBA: Lessons from NGO Collaboration in Vanuatu. Coastal Management, 43(4), 407-423. https://doi.org/10.1080/08920753.2015.1046807

Webersik, C., \& Wilson, C. (2009). Achieving environmental sustainability and growth in Africa: The role of science, technology and innovation. Sustainable Development, 17(6), 400-413.

Wilkinson, E., Caravani, A., Canales Trujillo, N., Nakhooda, S., Terpstra, P., \& Peterson Carvalho, A. (2014). Going in the right direction? Tracking adaptation finance at the subnational level. Overseas Development Institute.

Winkler, H., \& Beaumont, J. (2010). Fair and effective multilateralism in the post-Copenhagen climate negotiations. Climate Policy, 10(6), 638654. https://doi.org/10.3763/cpol.2010.0130 
Winkler, H., \& Dubash, N. K. (2016). Who determines transformational change in development and climate finance? Climate Policy, 16(6), 783-791. https://doi.org/10.1080/14693062.2015.1033674

Wong, S. (2016). Can Climate Finance Contribute to Gender Equity in Developing Countries? Journal of International Development, 28(3, SI), 428-444. https://doi.org/10.1002/jid.3212

Work, C., Rong, V., Song, D., \& Scheidel, A. (2019). Maladaptation and development as usual? Investigating climate change mitigation and adaptation projects in Cambodia. Climate Policy, 19(sup1), S47S62. https://doi.org/10.1080/14693062.2018.1527677

World Bank. (2006). Enhancing agricultural innovation: How to go beyond the strengthening of research systems. [Economic and Sector Work paper]. The World Bank. http://siteresources.worldbank.org/INTARD/Resources/Enhancing_ Ag_Innovation.pdf

World Bank. (2007). World Development Report 2008: Agriculture for Development. The World Bank. https://doi.org/10.1596/978-0-8213$6807-7$

World Bank. (2009). World development report 2010: Development and climate change. The World Bank.

World Bank. (2010). Economics of Adaptation to Climate Change: Synthesis Report (World Bank Other Operational Studies No. 12750). The 
World Bank.

http://econpapers.repec.org/paper/wbkwboper/12750.htm

World Bank. (2020). Financial Intermediary Funds (FIFs): Adaptation Fund.

https://fiftrustee.worldbank.org/en/about/unit/dfi/fiftrustee/funddetail/adapt

Wright, H., Vermeulen, S., Laganda, G., Olupot, M., Ampaire, E., \& Jat, M. L. (2014). Farmers, food and climate change: Ensuring communitybased adaptation is mainstreamed into agricultural programmes.

Climate and Development, 6(4), 318-328.

https://doi.org/10.1080/17565529.2014.965654

Wurzel, R. K. W., Liefferink, D., \& Torney, D. (2019). Pioneers, leaders and followers in multilevel and polycentric climate governance.

Environmental Politics, 28(1), 1-21.

https://doi.org/10.1080/09644016.2019.1522033

Zadek, S. (2011). Beyond climate finance: From accountability to productivity in addressing the climate challenge. Climate Policy, 11(3, SI), 1058-1068.

https://doi.org/10.1080/14693062.2011.582288

Zilberman, D., Lipper, L., McCarthy, N., \& Gordon, B. (2018). Innovation in Response to Climate Change. In L. Lipper, N. McCarthy, D. Zilberman, S. Asfaw, \& G. Branca (Eds.), Climate Smart Agriculture. Natural Resource Management and Policy (Vol. 52, pp. 49-74). Springer. https://doi.org/10.1007/978-3-319-61194-5_4 


\section{Annex A. Supplementary Material 1: Adaptation Fund Projects Included in Analysis}

Belonging to the following chapters:

Chapter 4: Case Study

Chapter 5: Do direct access and indirect access adaptation projects differ in their focus on local communities? A systematic analysis of 63 Adaptation Fund projects

Chapter 6: What makes internationally-financed climate change adaptation projects focus on local communities? A configurational analysis of 30 Adaptation Fund projects

Chapter 7: Do access modalities to international adaptation finance matter for the promotion of agricultural innovations?: An analysis of 36 Adaptation Fund projects 


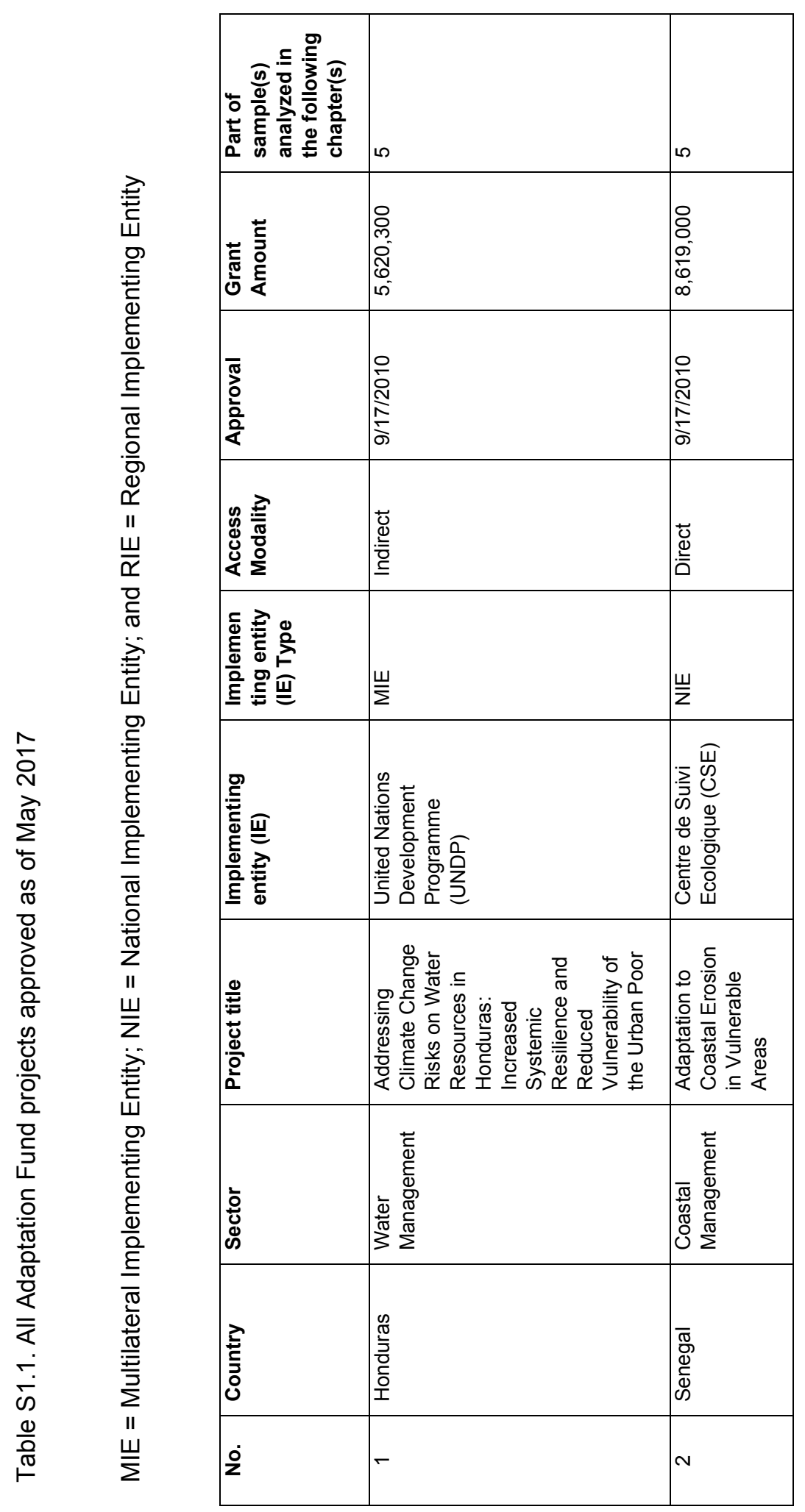

品 


\begin{tabular}{|c|c|c|c|}
\hline 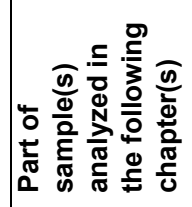 & $\hat{i}$ & ما & ما \\
\hline 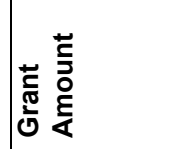 & $\begin{array}{l}8 \\
0 \\
0 \\
8 \\
0 \\
10 \\
15\end{array}$ & $\begin{array}{l}8 \\
8 \\
0 \\
8 \\
8 \\
\infty \\
\text { m. }\end{array}$ & 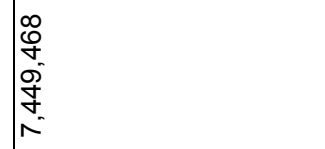 \\
\hline $\begin{array}{l}\bar{\pi} \\
\frac{\pi}{2} \\
\frac{0}{2} \\
\frac{2}{2}\end{array}$ & 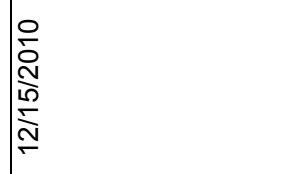 & 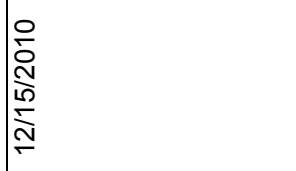 & 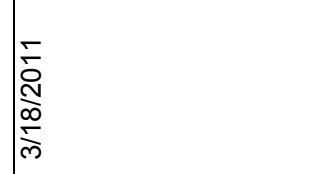 \\
\hline 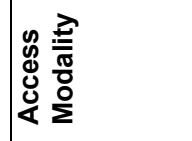 & 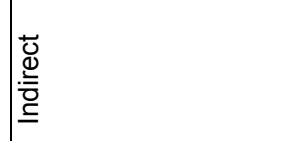 & 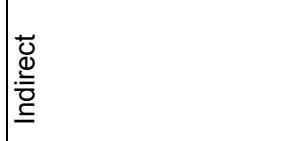 & 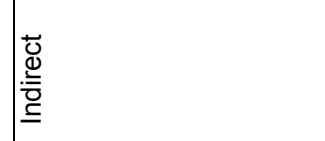 \\
\hline 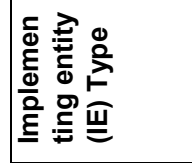 & $\frac{w}{\Sigma}$ & $\frac{\omega}{\bar{\Sigma}}$ & $\frac{\omega}{\Sigma}$ \\
\hline 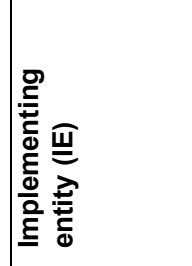 & @ٍ & ڤ̀ & 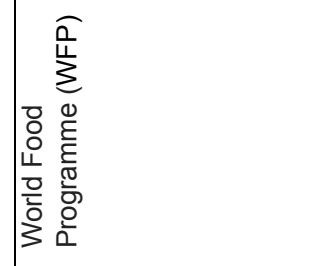 \\
\hline 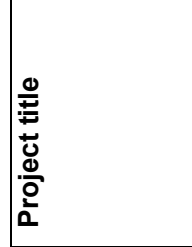 & 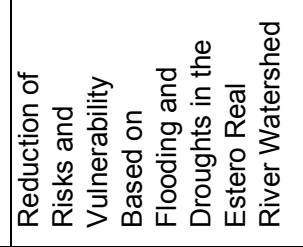 & 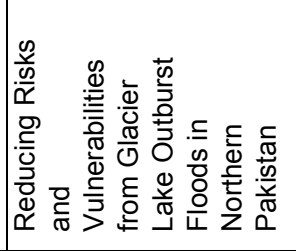 & 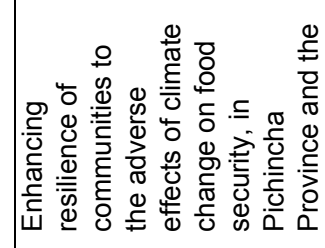 \\
\hline |̀ & 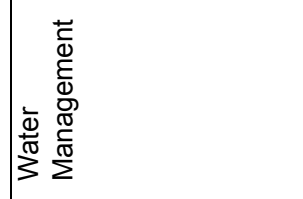 & 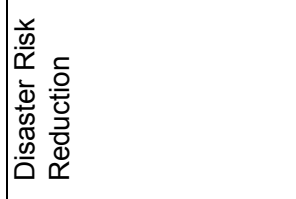 & 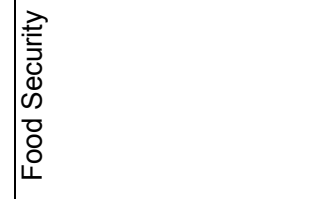 \\
\hline ن & 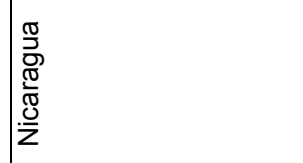 & 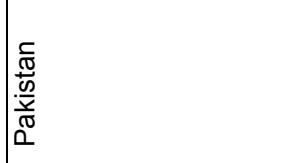 & 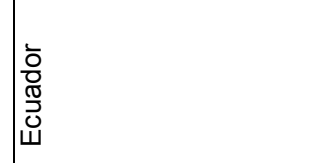 \\
\hline ì & m & $\nabla$ & L \\
\hline
\end{tabular}

ஸे 


\begin{tabular}{|c|c|c|c|c|}
\hline 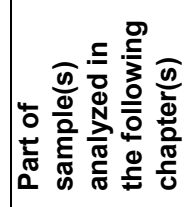 & & $\hat{10}$ & $\hat{i}$ & م \\
\hline 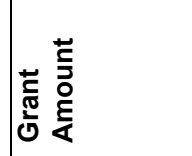 & & $\begin{array}{l}0 \\
10 \\
\infty \\
0 \\
01 \\
10 \\
0\end{array}$ & $\begin{array}{l}8 \\
0 \\
\infty \\
\infty \\
0 \\
0 \\
15\end{array}$ & $\begin{array}{l}\stackrel{2}{1} \\
\text { N } \\
\infty \\
\infty \\
\infty \\
\infty \\
\infty\end{array}$ \\
\hline $\begin{array}{l}\bar{\pi} \\
\frac{\pi}{2} \\
\frac{0}{2} \\
\frac{0}{\alpha}\end{array}$ & & $\begin{array}{l}\frac{5}{2} \\
\stackrel{N}{N} \\
\frac{\infty}{\infty} \\
\frac{0}{m}\end{array}$ & 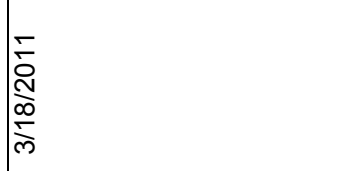 & 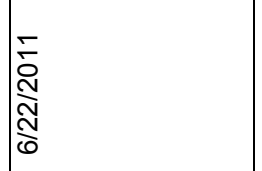 \\
\hline 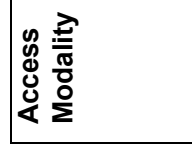 & & 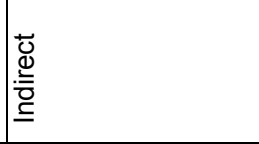 & 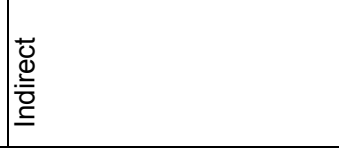 & 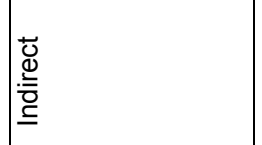 \\
\hline 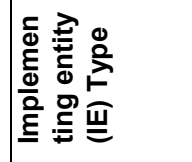 & & $\frac{\mathrm{W}}{\Sigma}$ & $\mid \underline{\Sigma}$ & $\underline{\bar{\Sigma}}$ \\
\hline 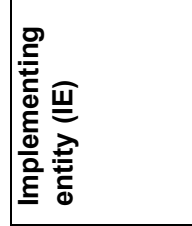 & & 高 & @̣ & 高 \\
\hline 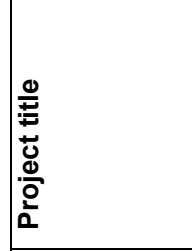 & 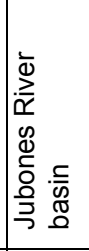 & 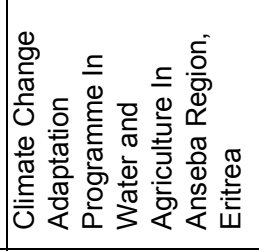 & 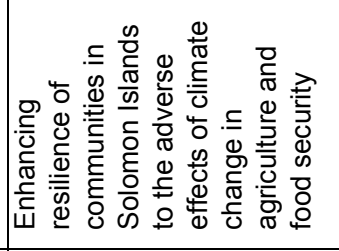 & 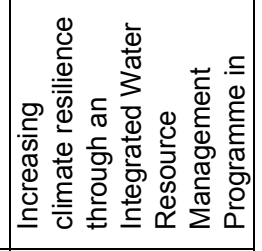 \\
\hline के & & $\begin{array}{l}0 \\
\frac{0}{3} \\
\frac{1}{5} \\
\cdot \frac{0}{5} \\
\frac{9}{4}\end{array}$ & 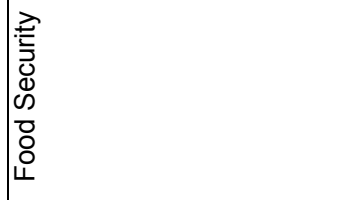 & 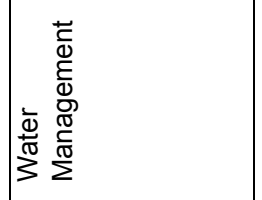 \\
\hline 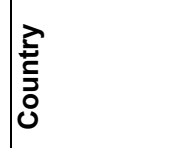 & & 忍 & 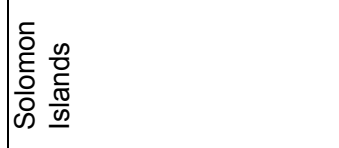 & 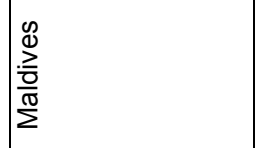 \\
\hline ì & & 0 & $\wedge$ & $\infty$ \\
\hline
\end{tabular}

กำ 


\begin{tabular}{|c|c|c|c|c|}
\hline 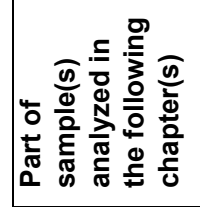 & & م & $\hat{\omega}$ & ما \\
\hline 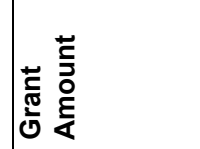 & & $\begin{array}{l}8 \\
8 \\
80 \\
0 \\
0 \\
15\end{array}$ & 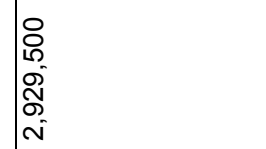 & 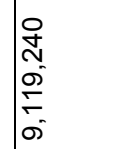 \\
\hline $\begin{array}{l}\overline{10} \\
\frac{0}{0} \\
\frac{0}{20} \\
\frac{2}{4}\end{array}$ & & $\mid \begin{array}{c}\bar{\Sigma} \\
\substack{\text { N̦ } \\
\text { G }}\end{array}$ & 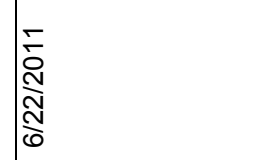 & 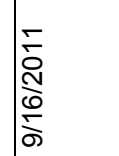 \\
\hline 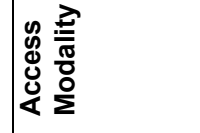 & & 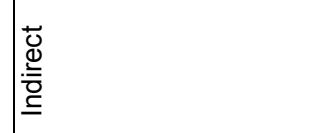 & 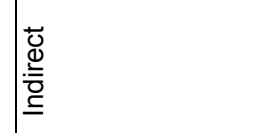 & 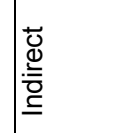 \\
\hline 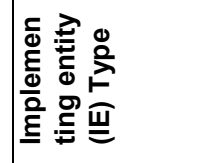 & & $\frac{\omega}{\Sigma}$ & $\underline{\bar{\Sigma}}$ & $\underline{\bar{\Sigma}}$ \\
\hline 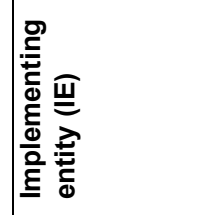 & & 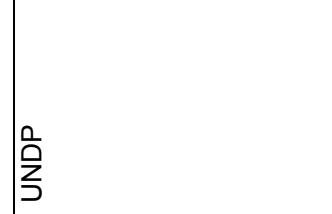 & 离 & $\sum_{\text {In }}$ \\
\hline 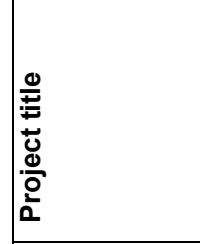 & 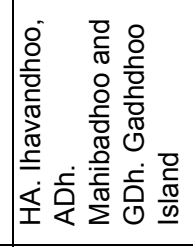 & 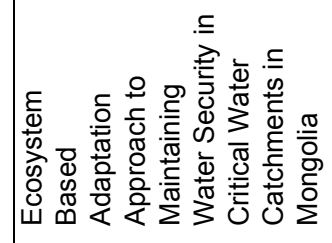 & 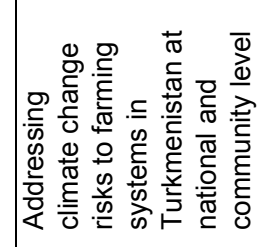 & 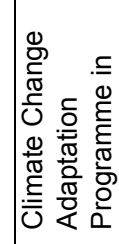 \\
\hline | & & 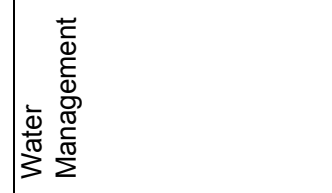 & 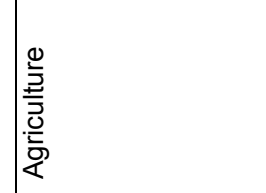 & 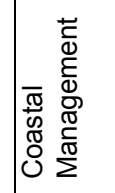 \\
\hline ن & & 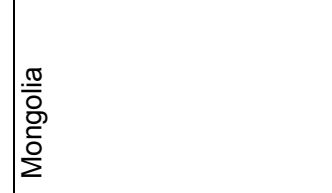 & 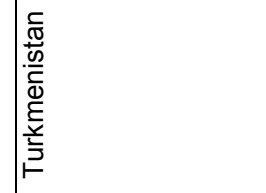 & 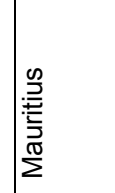 \\
\hline ì & & o & $\circ$ & $\leftleftarrows$ \\
\hline
\end{tabular}

$\stackrel{\bullet}{\mathrm{n}}$ 


\begin{tabular}{|c|c|c|c|c|}
\hline 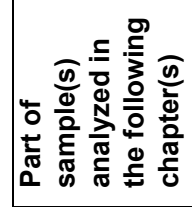 & & م & م & $\hat{s}$ \\
\hline 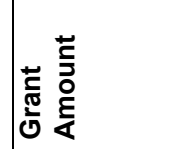 & & $\begin{array}{l}8 \\
8 \\
0 \\
\infty \\
0 \\
0 \\
0 \\
15\end{array}$ & $\begin{array}{l}8 \\
0 \\
0 \\
0 \\
0 \\
0 \\
0 \\
50\end{array}$ & $\begin{array}{l}\stackrel{2}{0} \\
\sigma \\
0 \\
0 \\
0 \\
i\end{array}$ \\
\hline \begin{tabular}{|l}
$\bar{\pi}$ \\
$\frac{\pi}{2}$ \\
$\frac{0}{2}$ \\
$\frac{0}{\alpha}$
\end{tabular} & & 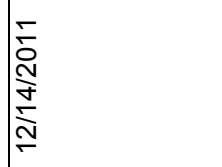 & 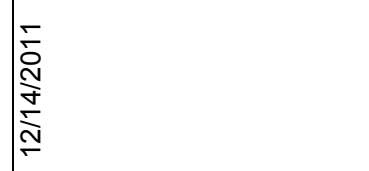 & 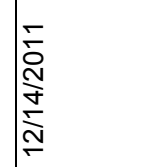 \\
\hline 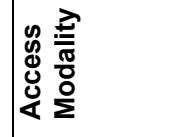 & & 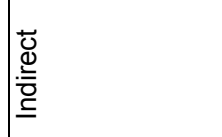 & 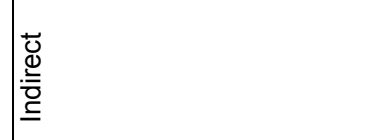 & $\begin{array}{l}\overrightarrow{\breve{d}} \\
: \underline{\overline{\bar{\Xi}}} \\
\underline{\underline{\Xi}}\end{array}$ \\
\hline 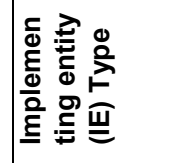 & & $\mid \underline{\bar{\Sigma}}$ & $\frac{\omega}{\Sigma}$ & $\frac{\omega}{\Sigma}$ \\
\hline 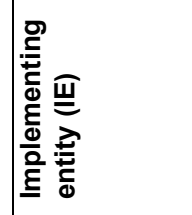 & & 产 & 高 & 离 \\
\hline 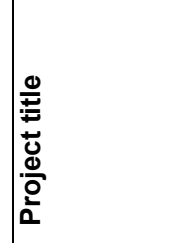 & 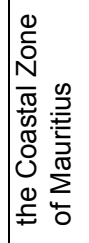 & 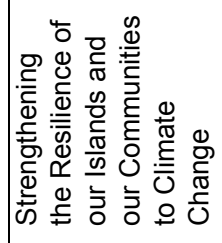 & 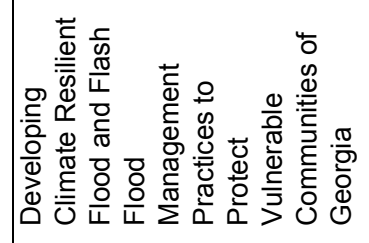 & 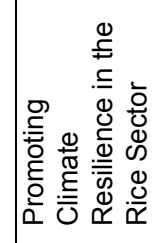 \\
\hline 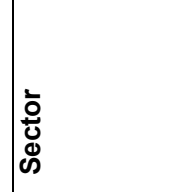 & & 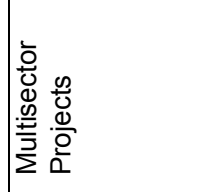 & 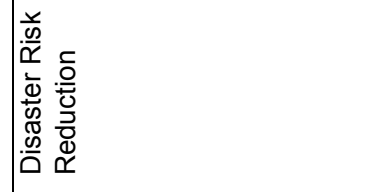 & 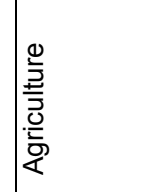 \\
\hline 童 & & 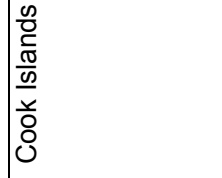 & $\mid$ & 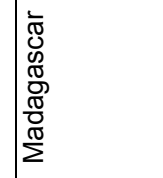 \\
\hline$\dot{\partial}$ & & $\cong$ & $\stackrel{2}{-}$ & 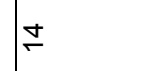 \\
\hline
\end{tabular}

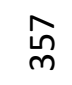




\begin{tabular}{|c|c|c|c|}
\hline 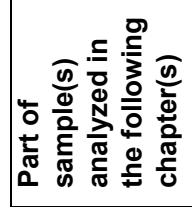 & م & م & $\hat{5}$ \\
\hline 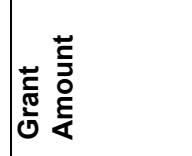 & $\begin{array}{l}\bar{n} \\
\tilde{m} \\
\tilde{N} \\
\hat{N} \\
\infty \\
\infty\end{array}$ & $\begin{array}{l}10 \\
0 \\
0 \\
o n \\
8 \\
0 \\
i n\end{array}$ & $\begin{array}{l}\infty \\
0 \\
0 \\
0 \\
0 \\
0 \\
0\end{array}$ \\
\hline 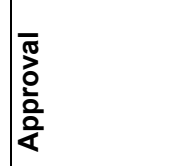 & 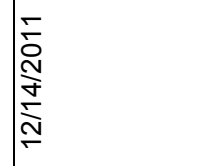 & 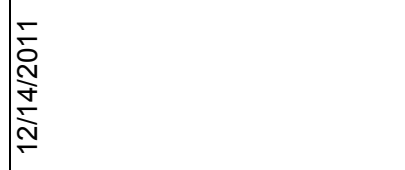 & 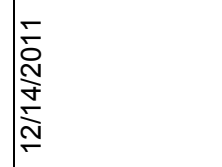 \\
\hline 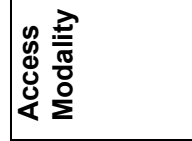 & 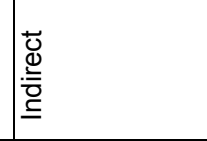 & $\begin{array}{l}\underline{\underline{U}} \\
\underline{\underline{\underline{E}}} \\
\underline{\underline{\underline{E}}} \\
\underline{\underline{E}}\end{array}$ & 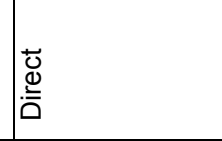 \\
\hline 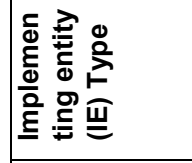 & $\frac{\omega}{\Sigma}$ & $\frac{\omega}{\bar{\Sigma}}$ & $\frac{w}{\bar{z}}$ \\
\hline 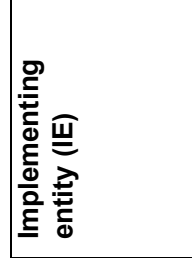 & ฏ & 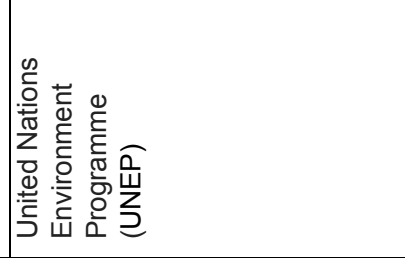 & 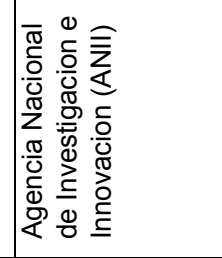 \\
\hline 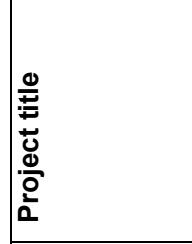 & 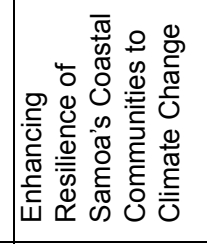 & 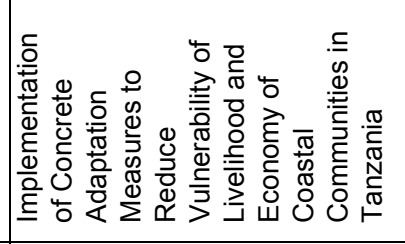 & 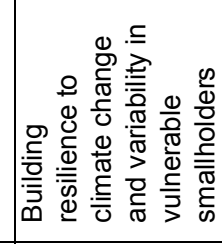 \\
\hline 离 & 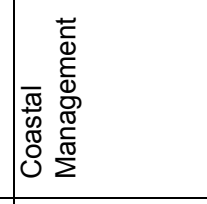 & 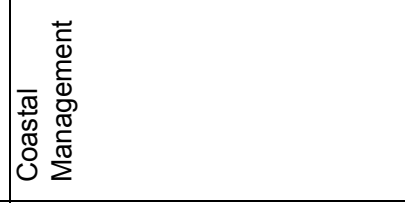 & $\begin{array}{l}0 \\
\frac{0}{3} \\
\frac{2}{3} \\
\frac{0}{5} \\
\frac{9}{4}\end{array}$ \\
\hline 全 & 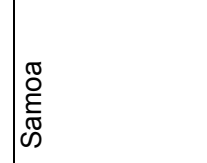 & 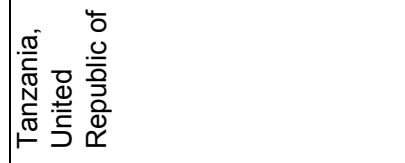 & 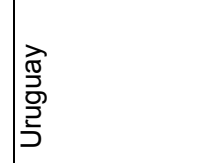 \\
\hline$\dot{0}$ & $\stackrel{2}{\sim}$ & 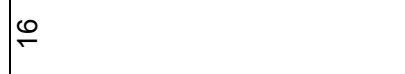 & $₹$ \\
\hline
\end{tabular}




\begin{tabular}{|c|c|c|c|}
\hline 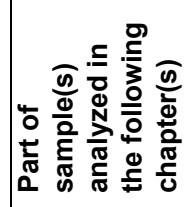 & ڤ & $\mid \begin{array}{l}\hat{0} \\
\hat{\sigma}^{0}\end{array}$ & $\mid \begin{array}{l}0 \\
b^{\circ}\end{array}$ \\
\hline 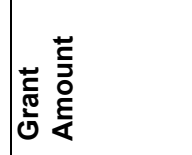 & $\begin{array}{l}0 \\
0 \\
0 \\
0 \\
0 \\
0 \\
0 \\
0\end{array}$ & 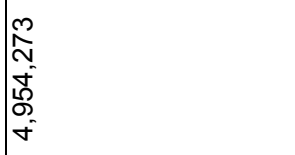 & $\mid \begin{array}{l}\hat{0} \\
0 \\
\infty \\
\infty \\
\infty \\
\infty \\
\infty \\
\infty\end{array}$ \\
\hline $\begin{array}{l}\bar{\pi} \\
\frac{\pi}{2} \\
\frac{0}{2} \\
\frac{2}{2}\end{array}$ & $\begin{array}{l}\mathfrak{N} \\
\stackrel{D}{N} \\
\frac{D}{\infty} \\
\frac{m}{\infty}\end{array}$ & 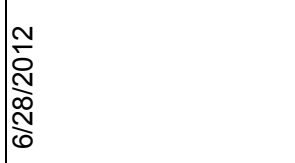 & 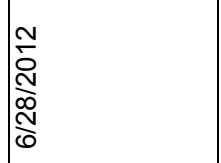 \\
\hline 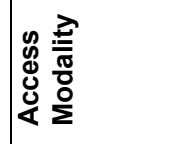 & 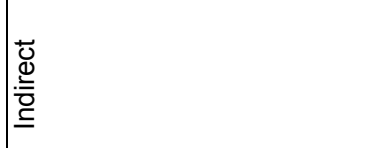 & 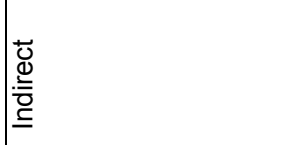 & 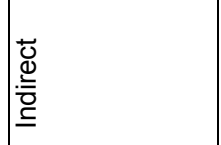 \\
\hline 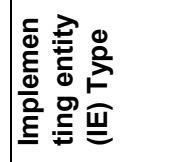 & $\frac{\omega}{\Sigma}$ & $\mid \frac{w}{\Sigma}$ & $\mid \frac{\omega}{\bar{\Sigma}}$ \\
\hline 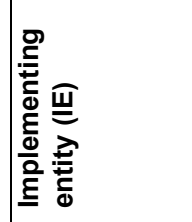 & ฏ̊ & $\frac{a}{\underline{u}}$ & 高 \\
\hline 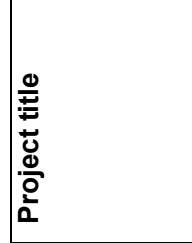 & 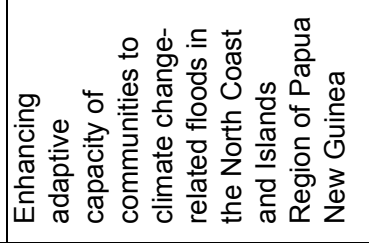 & 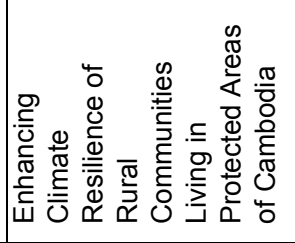 & 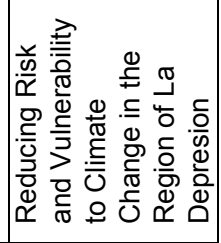 \\
\hline | & 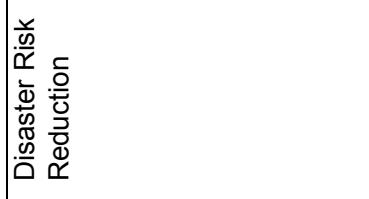 & 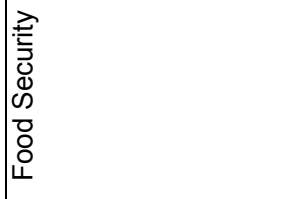 & 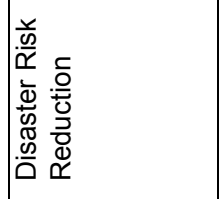 \\
\hline 量 & 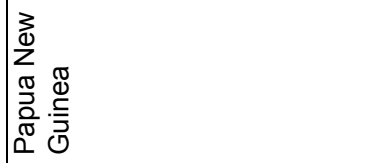 & 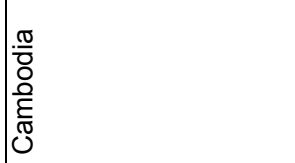 & $\mid \begin{array}{l}\frac{0}{0} \\
\frac{0}{2} \\
\frac{0}{0} \\
0\end{array}$ \\
\hline ì & $\stackrel{\infty}{\leftarrow}$ & I9 & 尺ి \\
\hline
\end{tabular}

品 


\begin{tabular}{|c|c|c|c|c|}
\hline 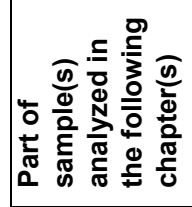 & & $\hat{i}$ & $\begin{array}{l}\hat{0} \\
0 \\
0\end{array}$ & $\begin{array}{l}\hat{0} \\
0 \\
0\end{array}$ \\
\hline 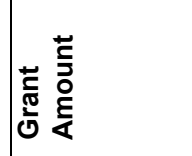 & & $\begin{array}{l}0 \\
0 \\
0 \\
0 \\
0 \\
0 \\
0 \\
0 \\
f\end{array}$ & 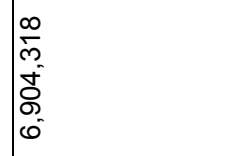 & $\begin{array}{l}8 \\
8 \\
10 \\
0 \\
0 \\
0 \\
\sigma\end{array}$ \\
\hline 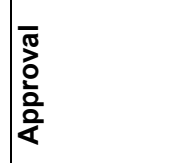 & & 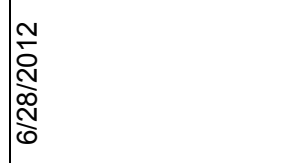 & $\begin{array}{l}\mathfrak{N} \\
\stackrel{N}{N} \\
\mathcal{D} \\
\stackrel{0}{0}\end{array}$ & 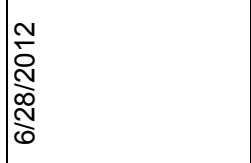 \\
\hline 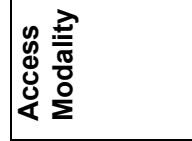 & & 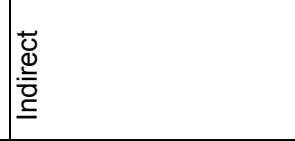 & 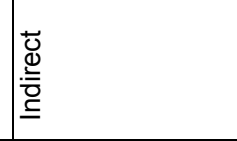 & 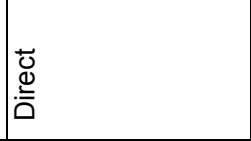 \\
\hline 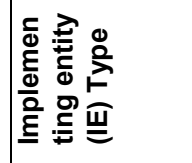 & & $\frac{\omega}{\bar{\Sigma}}$ & $\frac{\omega}{\Sigma}$ & $\frac{\omega}{z}$ \\
\hline 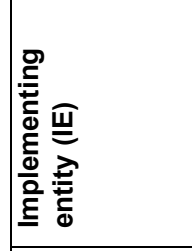 & & ל, & $\frac{0}{3}$ & 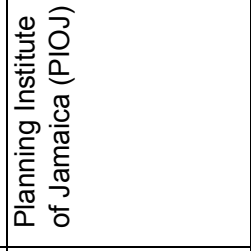 \\
\hline 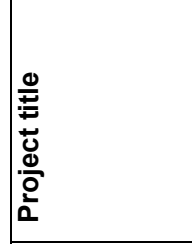 & 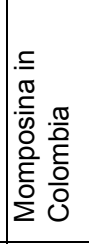 & 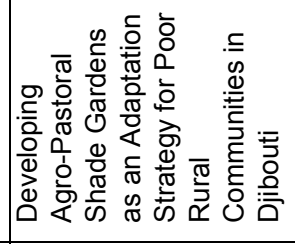 & 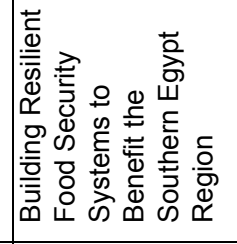 & 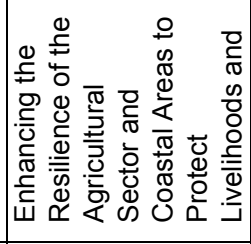 \\
\hline 离 & & 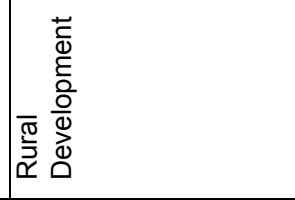 & 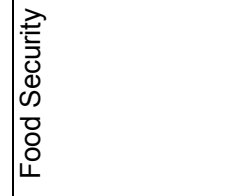 & 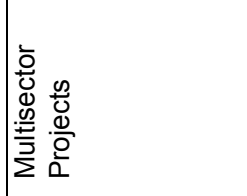 \\
\hline 胥 & & 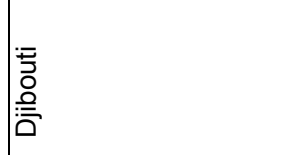 & 蔏 & 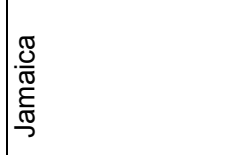 \\
\hline ì & & $\bar{N}$ & $\approx$ & $\stackrel{N}{N}$ \\
\hline
\end{tabular}

ঃ 


\begin{tabular}{|c|c|c|c|c|}
\hline 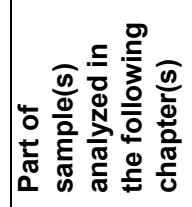 & & $\begin{array}{l}\hat{0} \\
\hat{0} \\
\delta^{\circ}\end{array}$ & $\begin{array}{ll}0 \\
0\end{array}$ & $\hat{i}$ \\
\hline 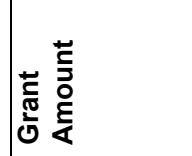 & & 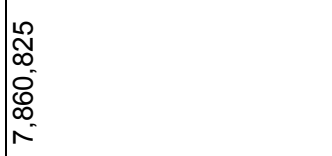 & 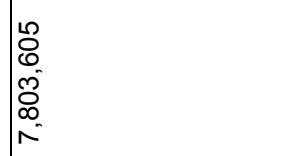 & 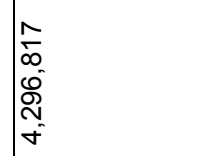 \\
\hline $\begin{array}{l}\bar{\pi} \\
\frac{\pi}{2} \\
\frac{0}{2} \\
\frac{2}{2}\end{array}$ & & 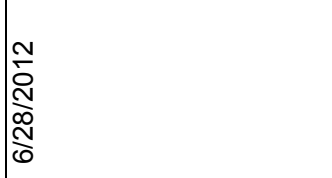 & 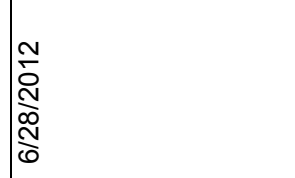 & 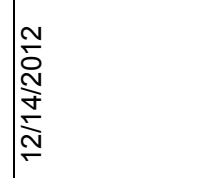 \\
\hline 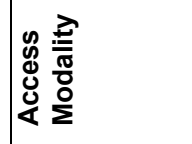 & & 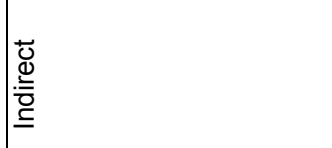 & 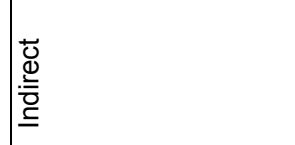 & 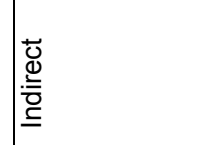 \\
\hline 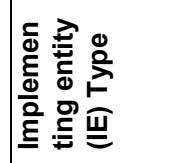 & & $\overline{\underline{\Sigma}}$ & $\mid \frac{\omega}{\Sigma}$ & $\frac{\omega}{\Sigma}$ \\
\hline 趇 & & 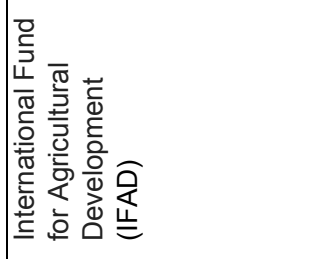 & $\frac{0}{3}$ & 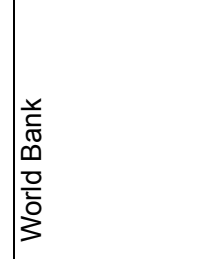 \\
\hline 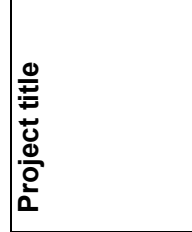 & 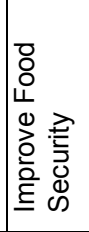 & 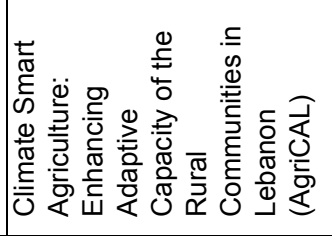 & 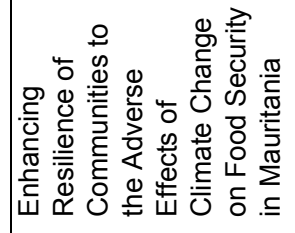 & 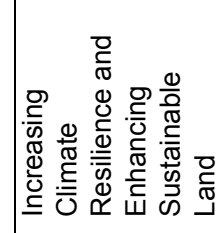 \\
\hline | & & 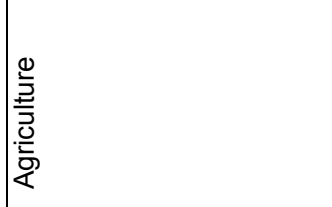 & 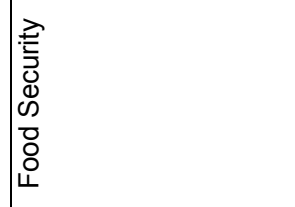 & 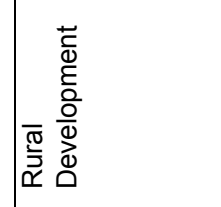 \\
\hline ن & & 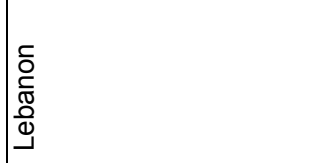 & 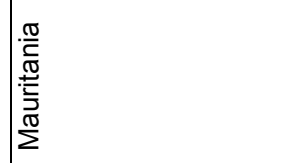 & 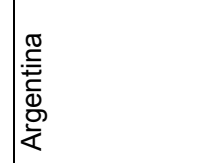 \\
\hline io & & d & 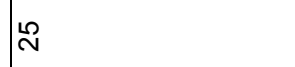 & 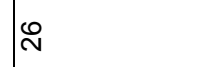 \\
\hline
\end{tabular}

후 


\begin{tabular}{|c|c|c|c|}
\hline 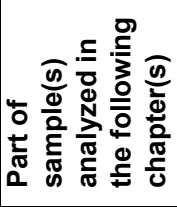 & & $\begin{array}{l}\hat{0} \\
0 \\
i^{\circ}\end{array}$ & $\begin{array}{l}\hat{0} \\
0 \\
i s\end{array}$ \\
\hline 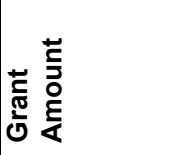 & & $\begin{array}{l}\hat{N} \\
\hat{N} \\
0 \\
0 \\
0 \\
N \\
N\end{array}$ & $\begin{array}{l}8 \\
8 \\
0 \\
0 \\
0 \\
0 \\
15\end{array}$ \\
\hline 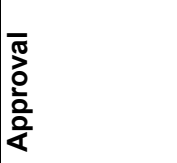 & & 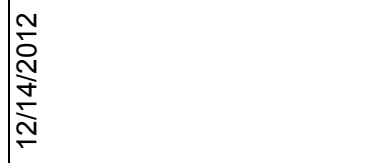 & 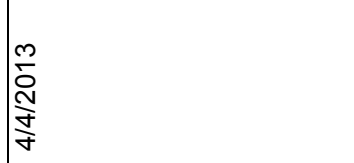 \\
\hline 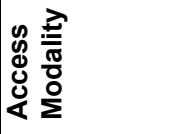 & & 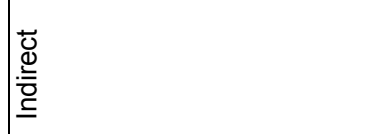 & 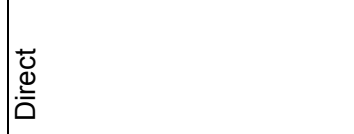 \\
\hline 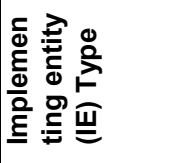 & & $\frac{\omega}{\Sigma}$ & $\frac{w}{z}$ \\
\hline 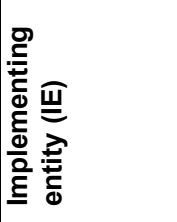 & & $\frac{0}{14}$ & 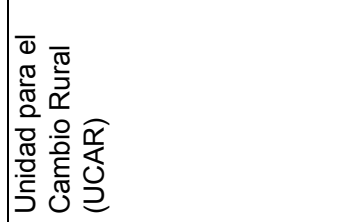 \\
\hline 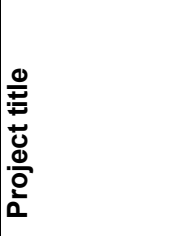 & 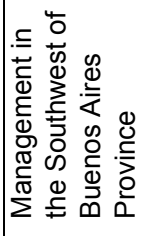 & 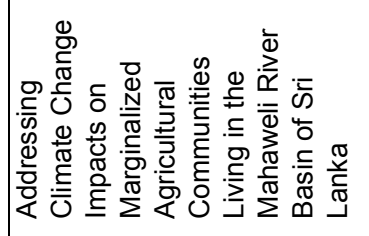 & 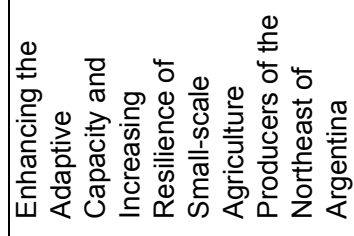 \\
\hline | & & 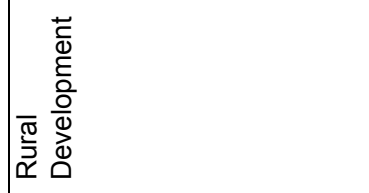 & 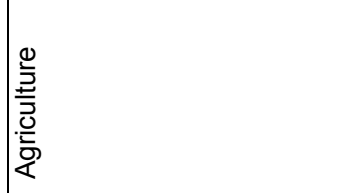 \\
\hline 薏 & & $\mid$ & 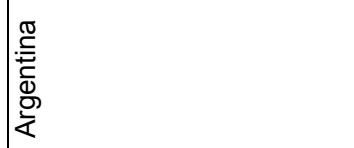 \\
\hline ì & & $\hat{N}$ & $\stackrel{\infty}{\sim}$ \\
\hline
\end{tabular}

ธ్ 


\begin{tabular}{|c|c|c|c|}
\hline 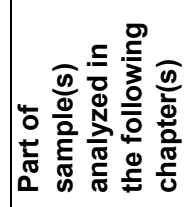 & $\begin{array}{l}\hat{0} \\
\hat{0} \\
\omega^{\circ}\end{array}$ & $\mid \begin{array}{l}\hat{0} \\
\hat{\sigma}^{\circ}\end{array}$ & ما \\
\hline 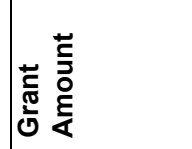 & 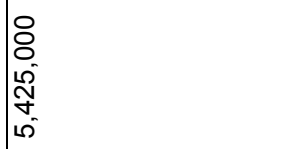 & $\begin{array}{l}0 \\
0 \\
0 \\
0 \\
8 \\
0 \\
0\end{array}$ & 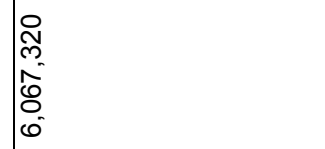 \\
\hline $\begin{array}{l}\bar{\pi} \\
\frac{\pi}{2} \\
\frac{0}{2} \\
\frac{2}{2}\end{array}$ & 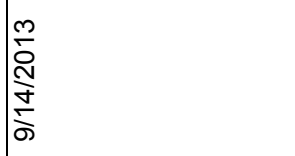 & $\underset{\substack{m \\
\stackrel{m}{N} \\
⿱ 亠 䒑}}{\vdots}$ & 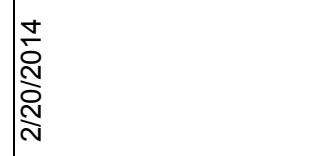 \\
\hline 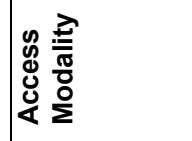 & 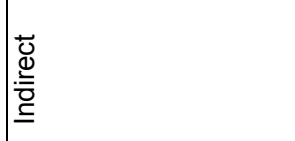 & 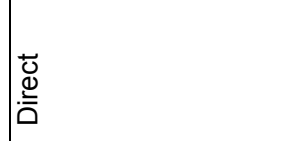 & 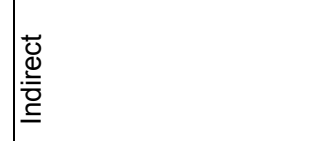 \\
\hline 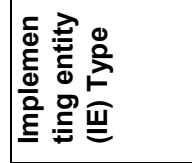 & $\frac{\omega}{\Sigma}$ & $\frac{\omega}{\bar{z}}$ & $\frac{\omega}{\Sigma}$ \\
\hline 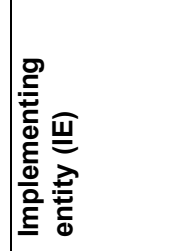 & ఏ̊ & 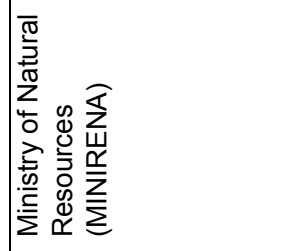 & ఏ \\
\hline 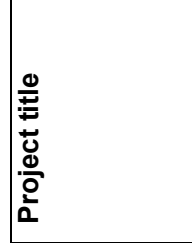 & 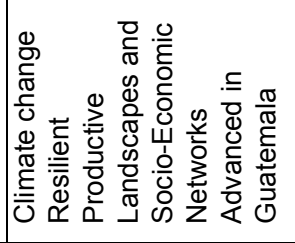 & 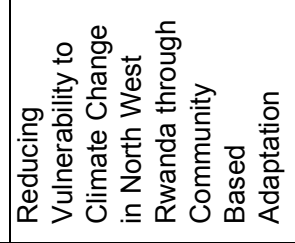 & 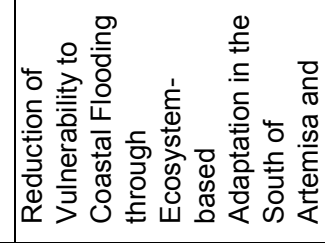 \\
\hline | & 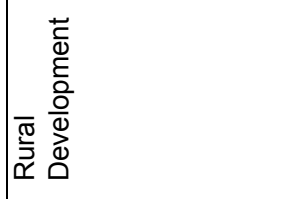 & 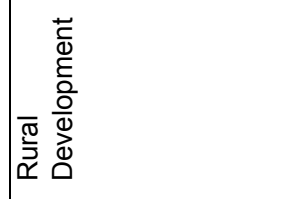 & 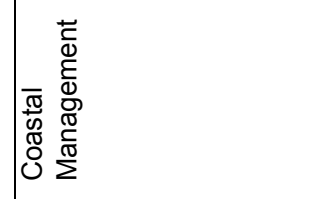 \\
\hline ن & 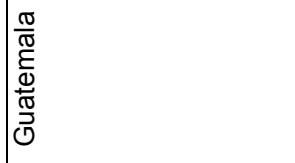 & 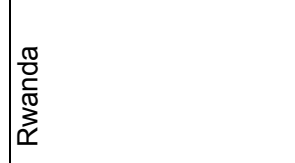 & $\begin{array}{l}\pi \\
\\
0 \\
0\end{array}$ \\
\hline ì & $\stackrel{\sim}{\text { N }}$ & ஓ্ল & $\bar{m}$ \\
\hline
\end{tabular}

足 


\begin{tabular}{|c|c|c|c|c|c|}
\hline 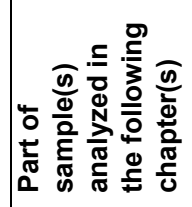 & & م & $\mid \begin{array}{l}\hat{0} \\
\hat{0} \\
\omega^{\circ}\end{array}$ & is & $\begin{array}{l}0 \\
0\end{array}$ \\
\hline 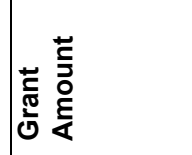 & & 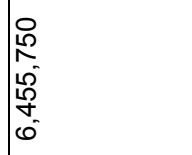 & 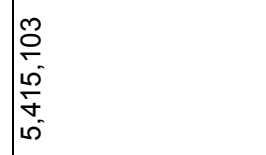 & 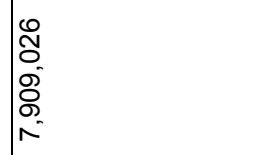 & $\begin{array}{l}0 \\
8 \\
0 \\
8 \\
0 \\
0\end{array}$ \\
\hline $\begin{array}{l}\bar{\pi} \\
\frac{\pi}{2} \\
\frac{0}{2} \\
\frac{2}{2}\end{array}$ & & 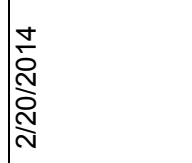 & 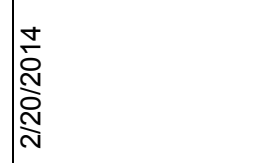 & $\begin{array}{l}\text { N } \\
\stackrel{N}{N} \\
\text { N } \\
\text { N }\end{array}$ & 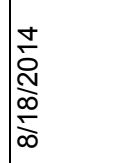 \\
\hline 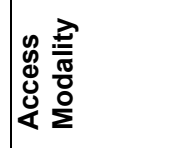 & & 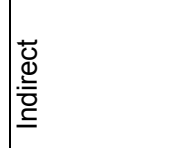 & 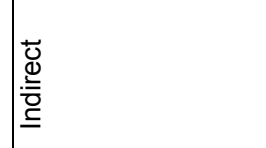 & 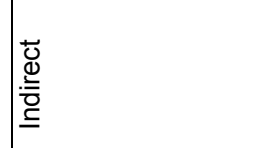 & 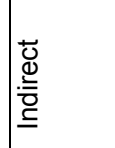 \\
\hline 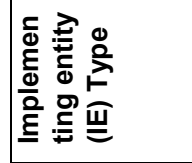 & & $\frac{\omega}{\Sigma}$ & $\mid \frac{\omega}{\Sigma}$ & $\frac{\omega}{\bar{\Sigma}}$ & $\frac{\omega}{\bar{\Sigma}}$ \\
\hline 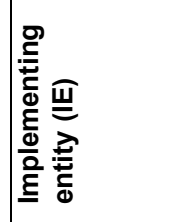 & & ఏ̆ & 高 & 彥 & 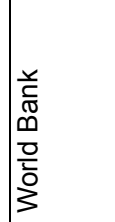 \\
\hline 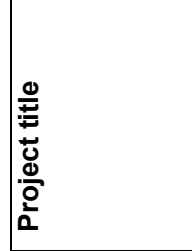 & 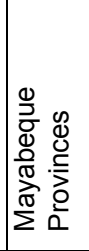 & 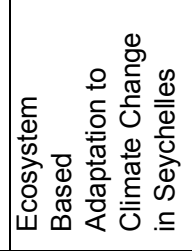 & 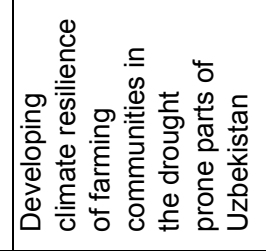 & 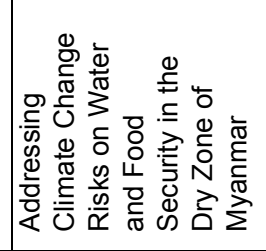 & 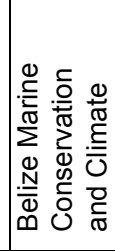 \\
\hline | & & 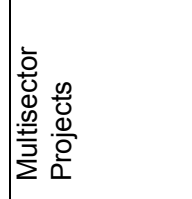 & 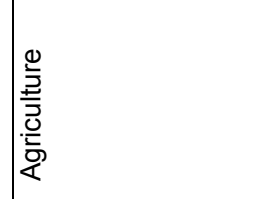 & 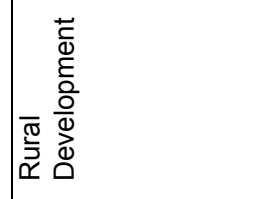 & 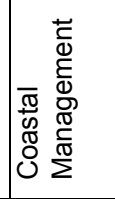 \\
\hline ن & & 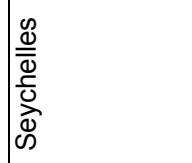 & 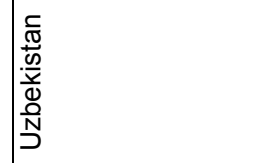 & 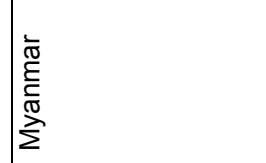 & 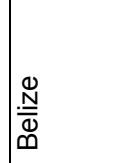 \\
\hline io & & స్ల & $m$ & 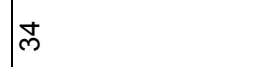 & œ \\
\hline
\end{tabular}




\begin{tabular}{|c|c|c|c|}
\hline 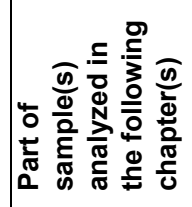 & & $\mid \begin{array}{l}\hat{0} \\
\hat{\sigma}^{\circ}\end{array}$ & is \\
\hline 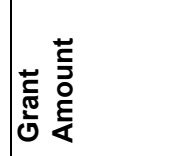 & & $\begin{array}{l}8 \\
8 \\
0 \\
0 \\
0 \\
0 \\
0\end{array}$ & $\begin{array}{l}0 \\
\infty \\
\infty \\
0 \\
0 \\
i n \\
i \\
0\end{array}$ \\
\hline $\begin{array}{l}\overline{0} \\
\frac{\pi}{0} \\
\frac{0}{2} \\
\frac{0}{4}\end{array}$ & & 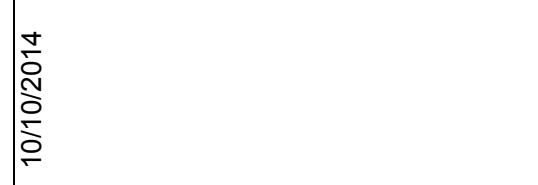 & 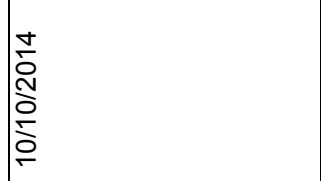 \\
\hline 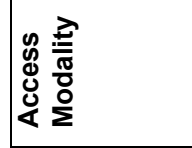 & & 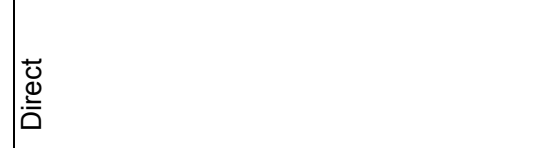 & 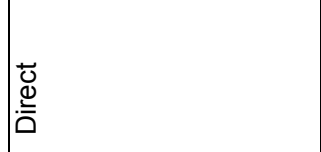 \\
\hline 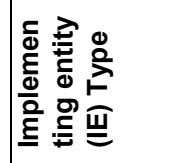 & & $\mid \frac{\omega}{z}$ & $\frac{\omega}{z}$ \\
\hline 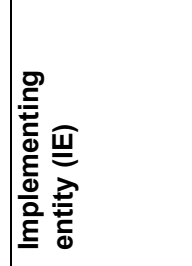 & & 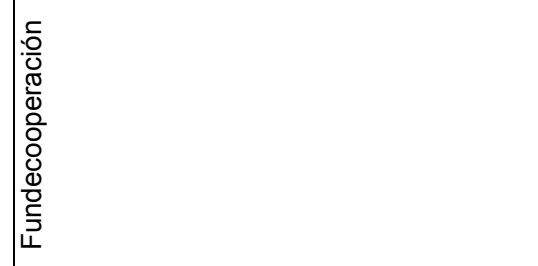 & 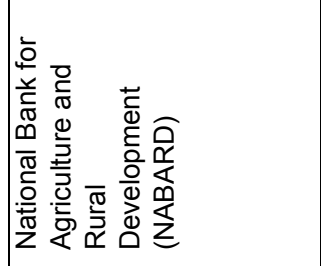 \\
\hline 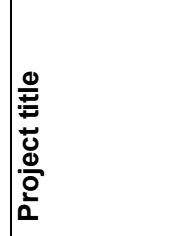 & 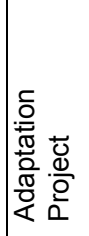 & 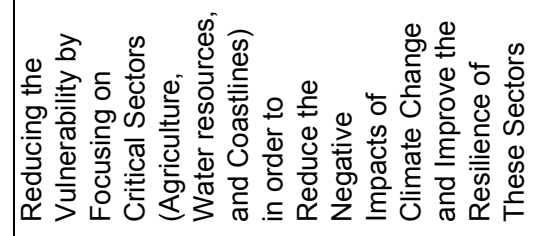 & 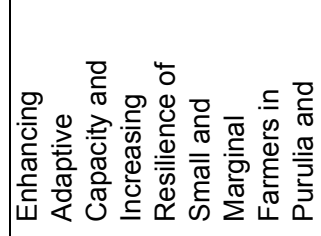 \\
\hline |̀ & & 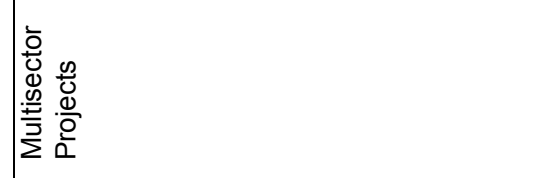 & 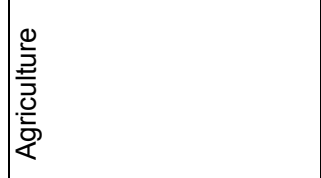 \\
\hline نे & & 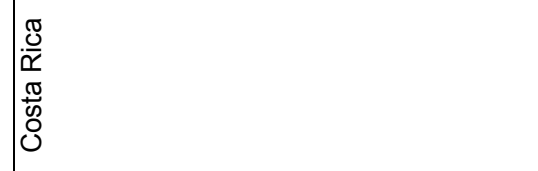 & 产 \\
\hline$\dot{0}$ & & @ & $\hat{m}$ \\
\hline
\end{tabular}




\begin{tabular}{|c|c|c|c|c|}
\hline 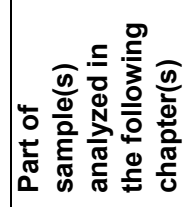 & & ڤ & $\mid \begin{array}{l}\hat{0} \\
\hat{\sigma}^{\circ}\end{array}$ & ڤ \\
\hline 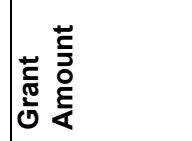 & & 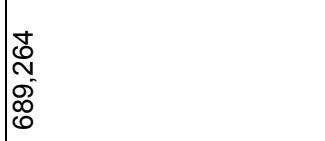 & 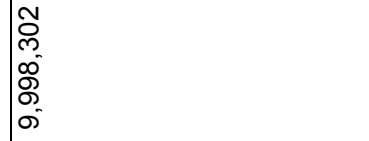 & 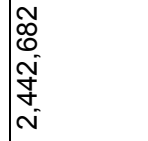 \\
\hline $\begin{array}{l}\overline{1} \\
\frac{10}{2} \\
\frac{0}{2} \\
\frac{2}{2}\end{array}$ & & 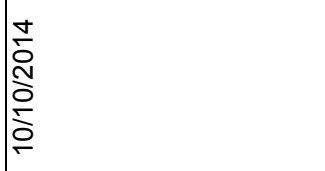 & 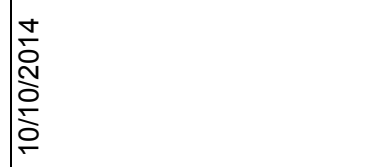 & $\begin{array}{l}\frac{0}{0} \\
\frac{0}{2} \\
\frac{0}{2} \\
\frac{0}{2}\end{array}$ \\
\hline 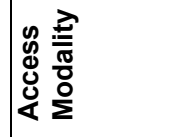 & & 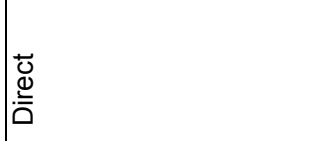 & 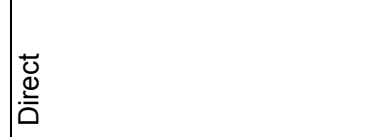 & 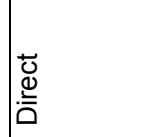 \\
\hline 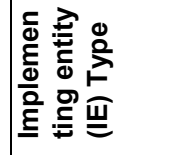 & & $\mid \underline{\bar{z}}$ & $\frac{\omega}{z}$ & $\frac{w}{z}$ \\
\hline 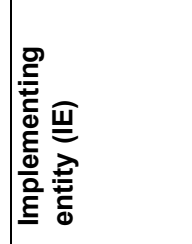 & & $\begin{array}{l}\frac{\partial}{\frac{\alpha}{\alpha}} \\
\frac{1}{\alpha} \\
\frac{1}{z}\end{array}$ & 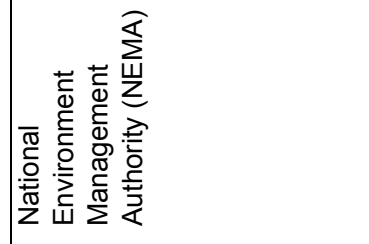 & 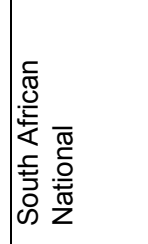 \\
\hline 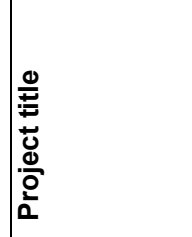 & 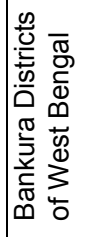 & 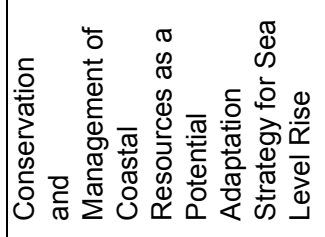 & 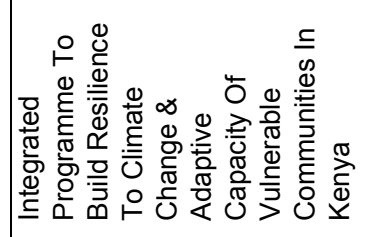 & 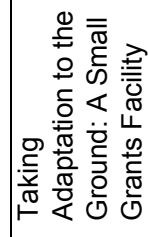 \\
\hline | & & 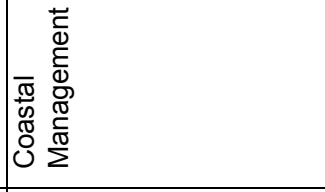 & 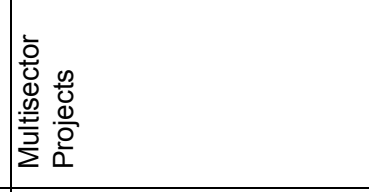 & 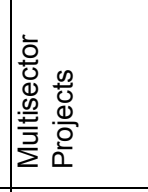 \\
\hline ن & & 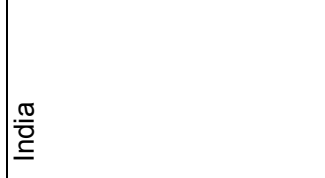 & 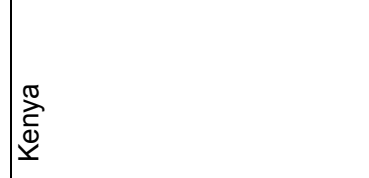 & 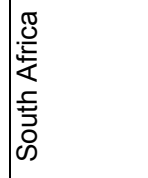 \\
\hline ì & & œ & ৪্ & g \\
\hline
\end{tabular}




\begin{tabular}{|c|c|c|c|c|}
\hline 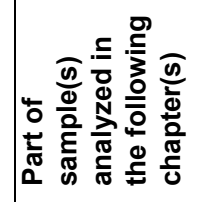 & & $\begin{array}{l}\hat{0} \\
\hat{s}^{\circ}\end{array}$ & $\begin{array}{l}\hat{0} \\
\hat{0} \\
\hat{s}\end{array}$ & $\mid \begin{array}{l}\hat{0} \\
\hat{s}^{\circ}\end{array}$ \\
\hline 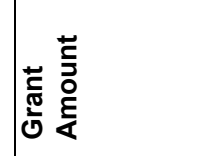 & & 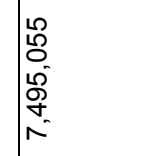 & $\mid \begin{array}{l}\tilde{N} \\
\hat{N} \\
\tilde{N} \\
\tilde{N} \\
\infty \\
\infty\end{array}$ & 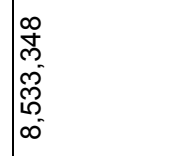 \\
\hline 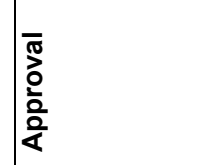 & & 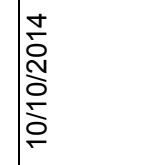 & $\mid \begin{array}{c}\frac{n}{2} \\
\substack{N \\
\frac{N}{m}}\end{array}$ & 胫 \\
\hline 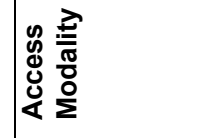 & & $\begin{array}{l}\overrightarrow{\breve{d}} \\
\underline{\underline{\underline{a}}}\end{array}$ & \begin{tabular}{|l}
$\underline{\underline{\underline{w}}}$ \\
$\underline{\underline{\underline{\underline{z}}}}$ \\
$\underline{\underline{x}}$
\end{tabular} & 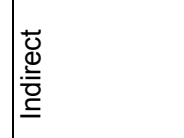 \\
\hline 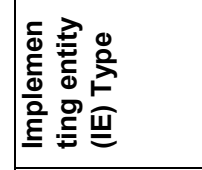 & & $\frac{\omega}{\underline{z}}$ & $\frac{\omega}{\Sigma}$ & $\frac{\omega}{\Sigma}$ \\
\hline 喔 & 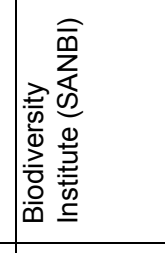 & 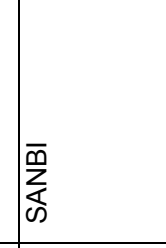 & 商 & 产 \\
\hline 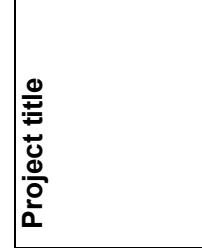 & 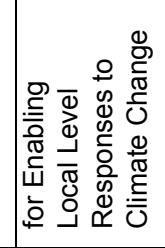 & 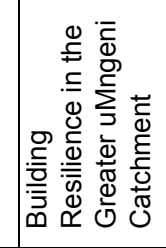 & 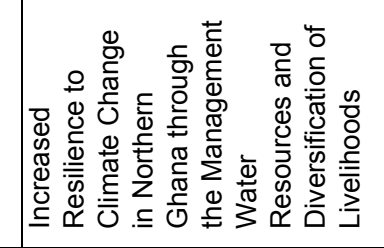 & 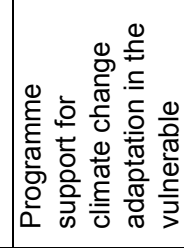 \\
\hline 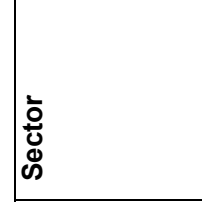 & & 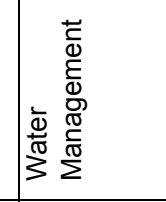 & 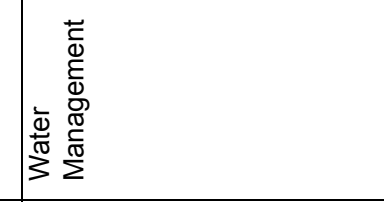 & 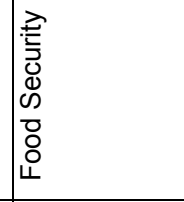 \\
\hline 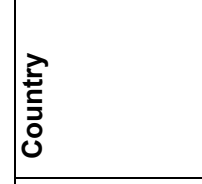 & & 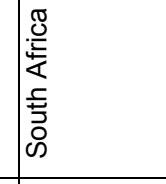 & 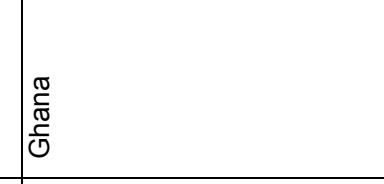 & $\frac{\overline{\bar{w}}}{\Sigma}$ \\
\hline$\stackrel{\dot{q}}{z}$ & & $\bar{\tau}$ & ₹ & g \\
\hline
\end{tabular}

চ 


\begin{tabular}{|c|c|c|c|}
\hline 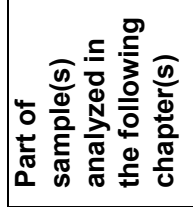 & & $\begin{array}{l}\hat{0} \\
\hat{\theta} \\
\delta^{\circ}\end{array}$ & م \\
\hline 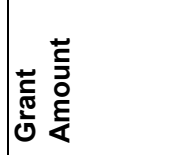 & & 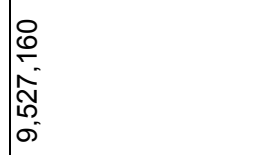 & \begin{tabular}{l}
8 \\
0 \\
0 \\
8 \\
0 \\
1 \\
\hdashline
\end{tabular} \\
\hline \begin{tabular}{|l|l}
$\overline{0}$ \\
$\frac{0}{0}$ \\
$\frac{0}{2}$ \\
$\frac{2}{4}$
\end{tabular} & & 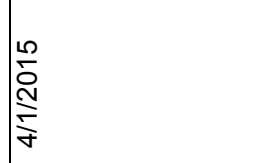 & 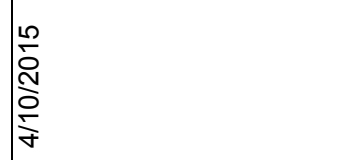 \\
\hline 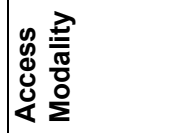 & & 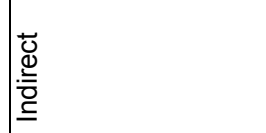 & 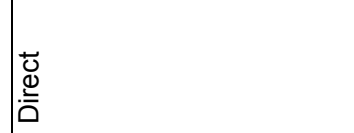 \\
\hline 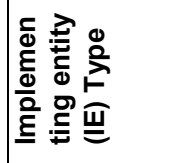 & & $\frac{\omega}{\Sigma}$ & $\frac{w}{\bar{z}}$ \\
\hline 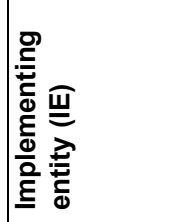 & & $\frac{0}{3}$ & 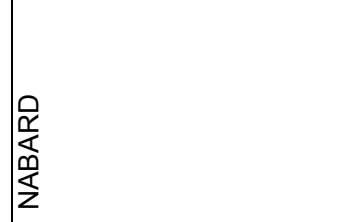 \\
\hline 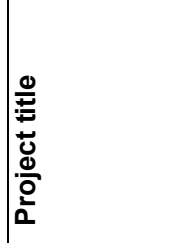 & 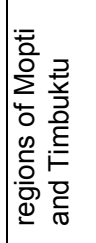 & 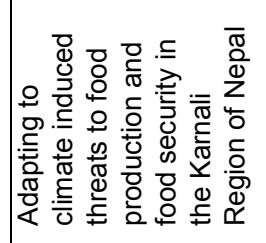 & 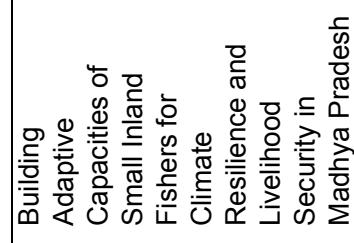 \\
\hline | & & 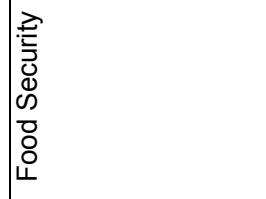 & 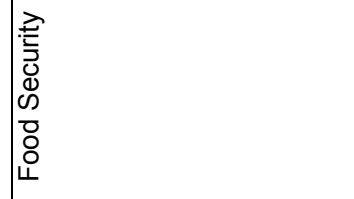 \\
\hline نे & & \begin{tabular}{|l}
$\overline{\bar{\sigma}}$ \\
$\frac{Q}{\bar{Q}}$
\end{tabular} & $\frac{\underline{\underline{\pi}}}{\underline{\underline{0}}}$ \\
\hline ì & & A & $\stackrel{8}{\&}$ \\
\hline
\end{tabular}




\begin{tabular}{|c|c|c|c|}
\hline 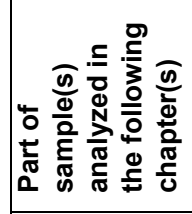 & $\begin{array}{l}\hat{0} \\
\hat{\theta}^{\circ}\end{array}$ & $\begin{array}{l}\hat{0} \\
0^{\circ}\end{array}$ & $\begin{array}{l}\hat{0} \\
0^{\circ}\end{array}$ \\
\hline 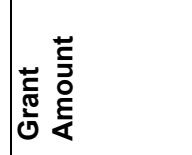 & 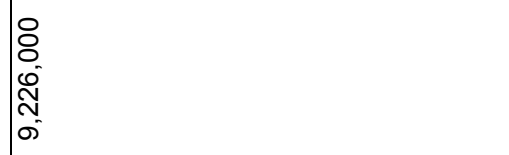 & $\begin{array}{l}8 \\
8 \\
0 \\
0 \\
0 \\
0 \\
0\end{array}$ & $\begin{array}{l}8 \\
8 \\
0 \\
0 \\
8 \\
0 \\
\sigma\end{array}$ \\
\hline $\begin{array}{l}\bar{\pi} \\
\frac{\pi}{2} \\
\frac{0}{2} \\
\frac{2}{2}\end{array}$ & $\begin{array}{l}\frac{1}{D} \\
\frac{N}{8} \\
\frac{\gamma}{7}\end{array}$ & 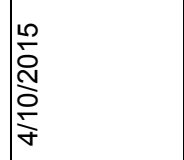 & 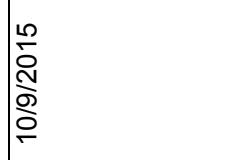 \\
\hline 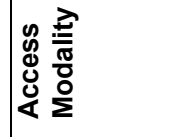 & 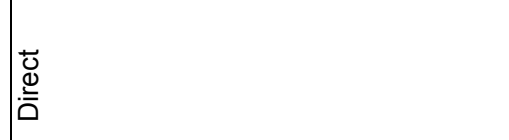 & 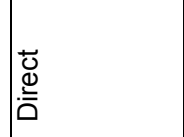 & 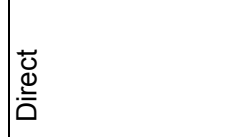 \\
\hline 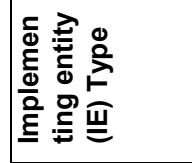 & $\frac{\omega}{z}$ & $\frac{\omega}{z}$ & $\mid \frac{\omega}{z}$ \\
\hline 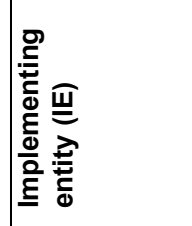 & 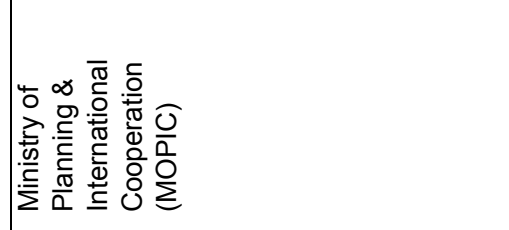 & 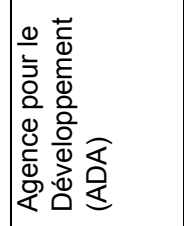 & 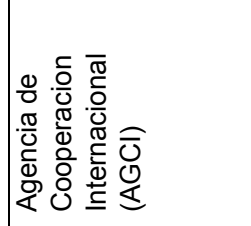 \\
\hline 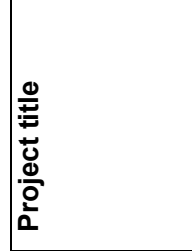 & 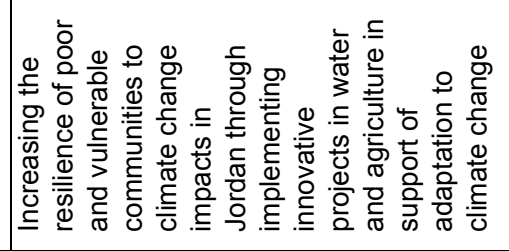 & 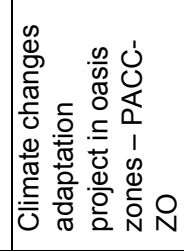 & 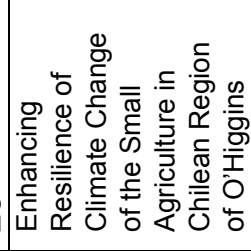 \\
\hline के & 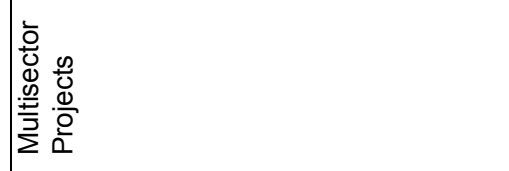 & 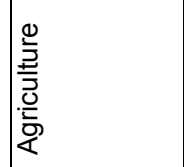 & 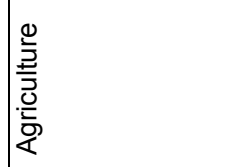 \\
\hline 童 & 동 & 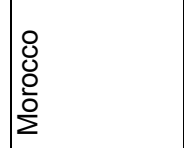 & $\stackrel{Ð}{\frac{\partial}{\bar{\nu}}}$ \\
\hline ì & g & $\hat{f}$ & $\stackrel{\infty}{+}$ \\
\hline
\end{tabular}

吕 


\begin{tabular}{|c|c|c|c|}
\hline 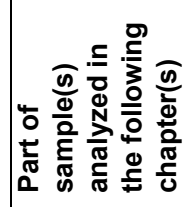 & $\begin{array}{l}\hat{0} \\
0 \\
i \infty\end{array}$ & is & $\mid \begin{array}{l}0 \\
00^{\circ}\end{array}$ \\
\hline 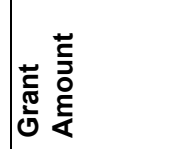 & $\begin{array}{l}8 \\
15 \\
08 \\
8 \\
8\end{array}$ & 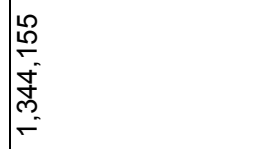 & 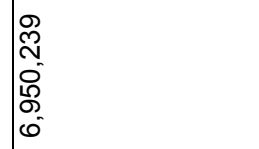 \\
\hline 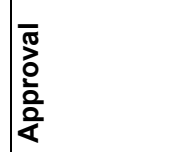 & 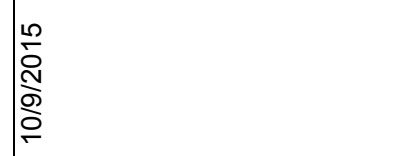 & 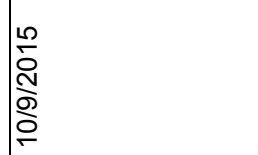 & 产 \\
\hline 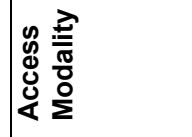 & 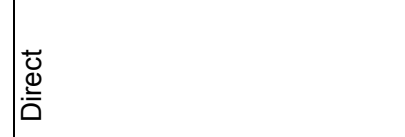 & 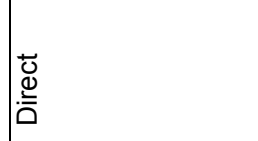 & 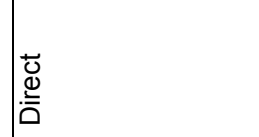 \\
\hline 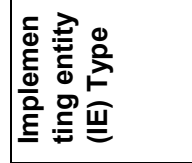 & $\frac{\omega}{z}$ & $\frac{\omega}{z}$ & $\frac{w}{z}$ \\
\hline 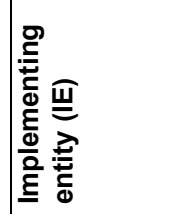 & $\begin{array}{l}\frac{Q}{\frac{\alpha}{\alpha}} \\
\frac{1}{\alpha} \\
\frac{\alpha}{z}\end{array}$ & $\begin{array}{l}\frac{Q}{\frac{\alpha}{\alpha}} \\
\frac{\alpha}{\alpha} \\
\frac{\alpha}{z}\end{array}$ & 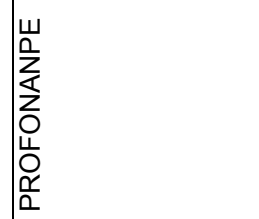 \\
\hline 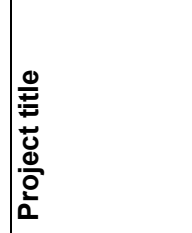 & 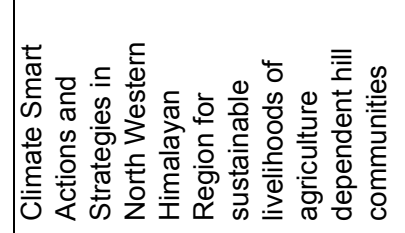 & 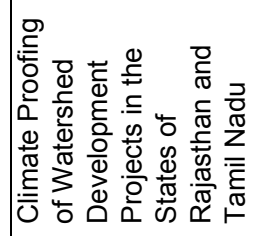 & 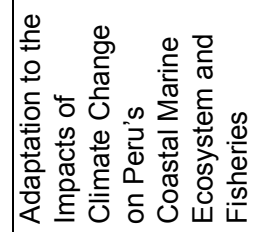 \\
\hline '̀ & 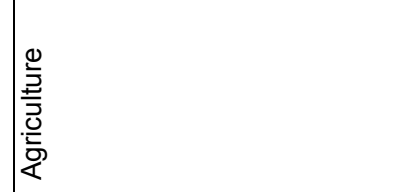 & 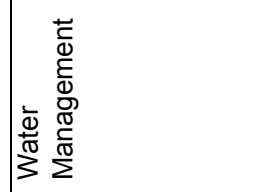 & 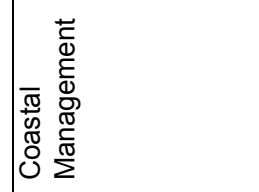 \\
\hline ن & $\begin{array}{l}\underline{\underline{\sigma}} \\
\underline{\underline{\underline{\sigma}}}\end{array}$ & 覓 & $\begin{array}{l} \\
\frac{2}{0} \\
0 \\
0\end{array}$ \\
\hline ì & g & i & is \\
\hline
\end{tabular}




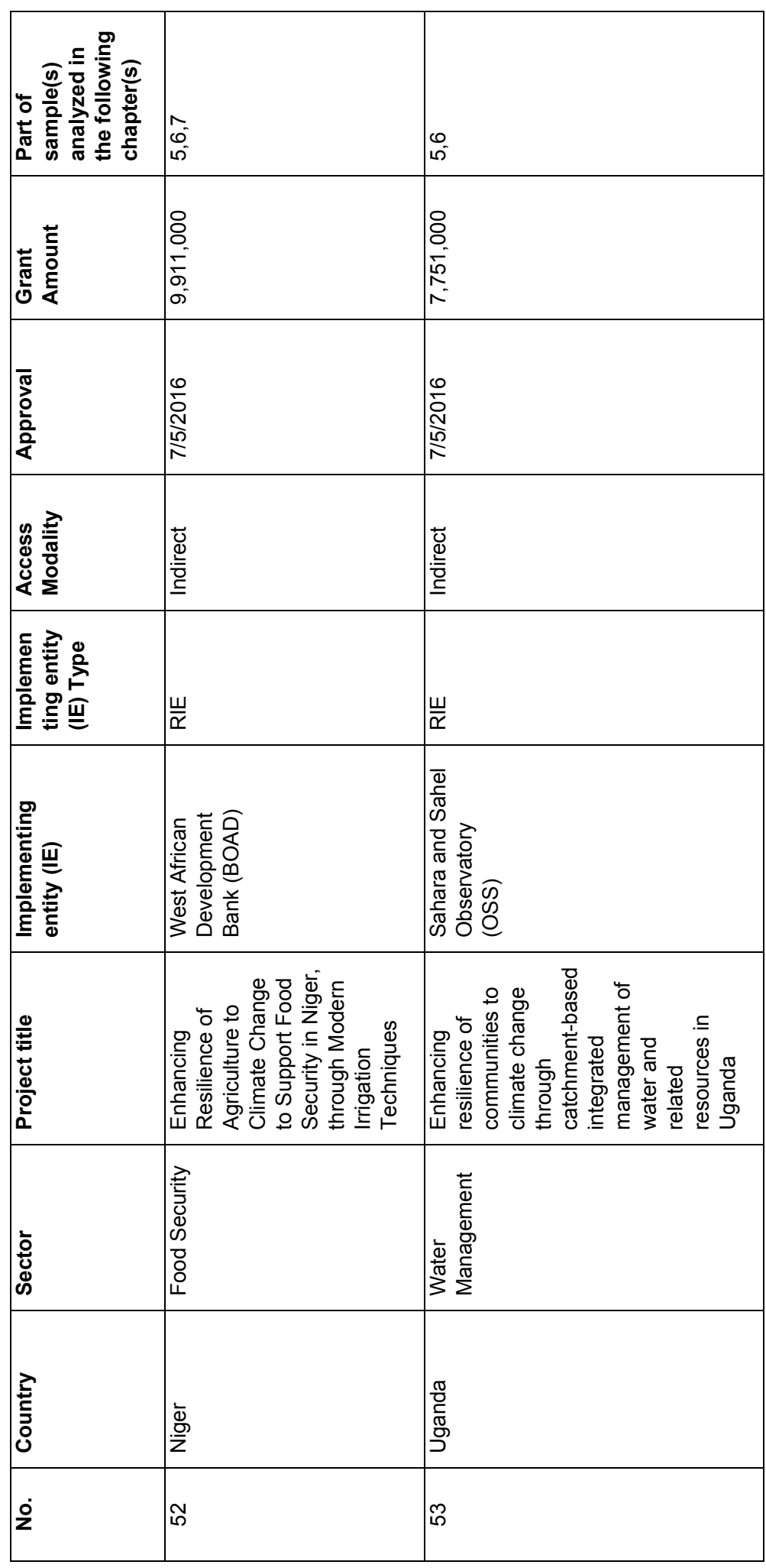

공 


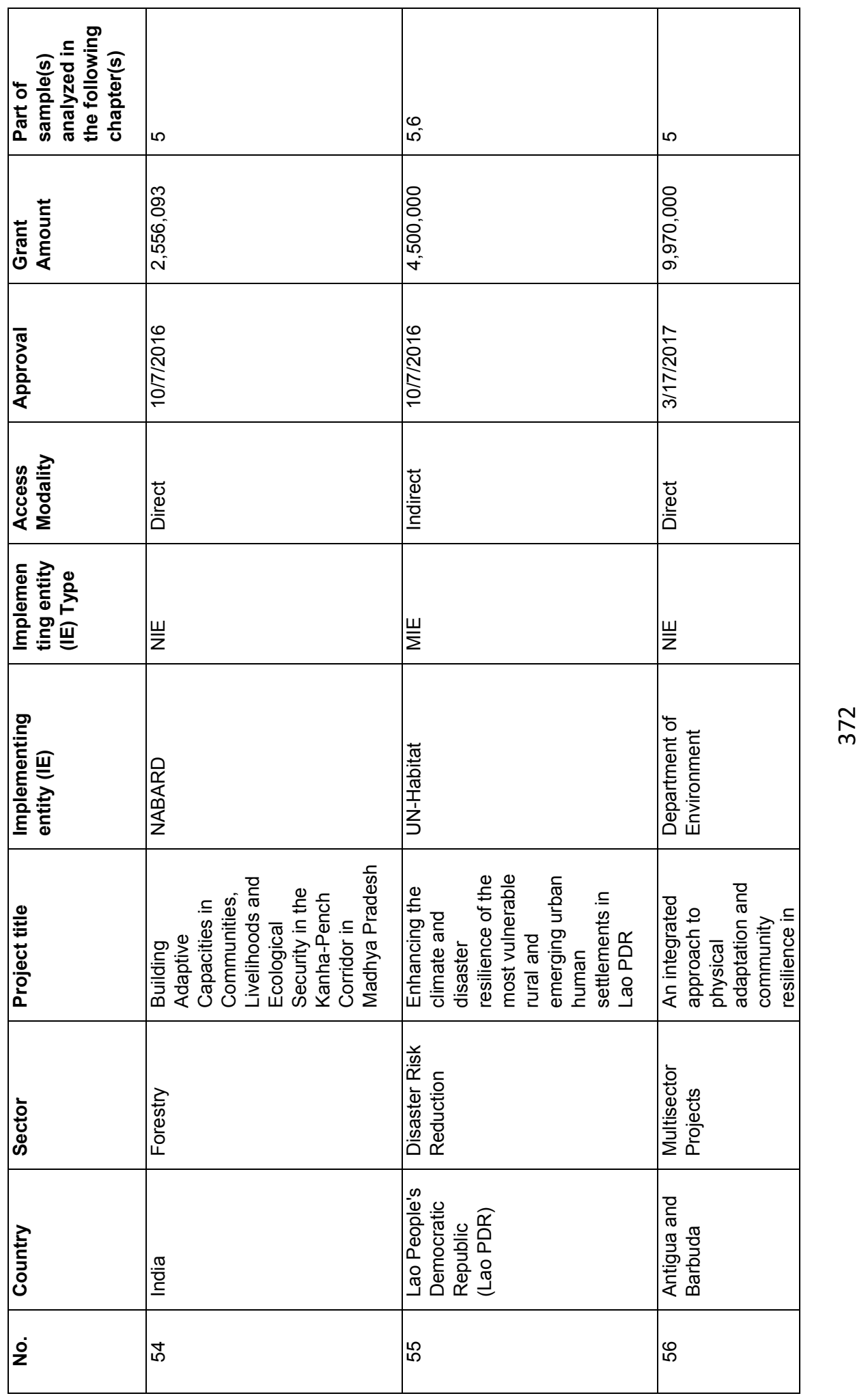




\begin{tabular}{|c|c|c|c|c|}
\hline 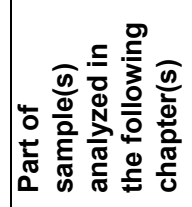 & & $\mid \begin{array}{l}\hat{0} \\
0 \\
0\end{array}$ & $\begin{array}{l}0 \\
i^{\circ}\end{array}$ & L \\
\hline 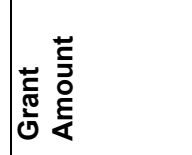 & & $\begin{array}{l}0 \\
0 \\
0 \\
0 \\
0 \\
0 \\
0 \\
0\end{array}$ & 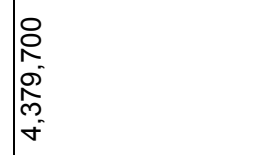 & $\begin{array}{l}8 \\
0 \\
0 \\
8 \\
0 \\
0\end{array}$ \\
\hline $\begin{array}{l}\bar{\pi} \\
\frac{\pi}{2} \\
\frac{0}{2} \\
\frac{0}{2}\end{array}$ & & 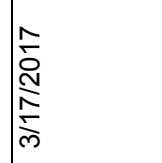 & 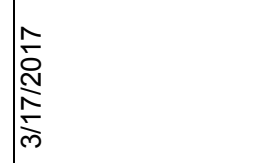 & 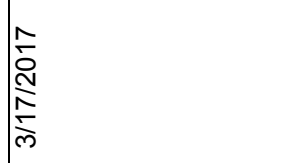 \\
\hline 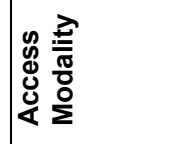 & & 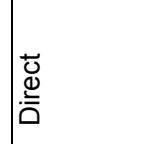 & 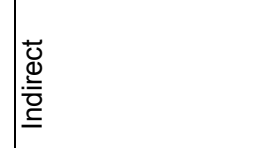 & 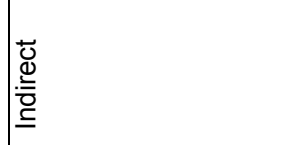 \\
\hline 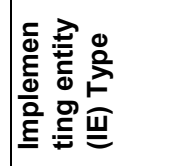 & & $\mid \frac{\omega}{z}$ & $\frac{\omega}{\Sigma}$ & $\frac{\omega}{\bar{\alpha}}$ \\
\hline 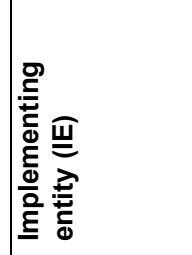 & & 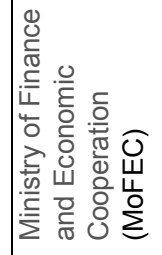 & $\varliminf_{3}^{0}$ & 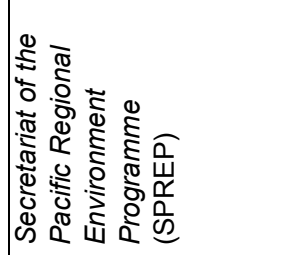 \\
\hline 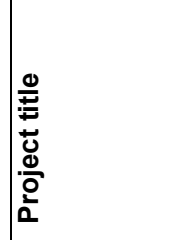 & 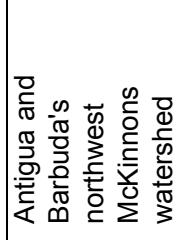 & 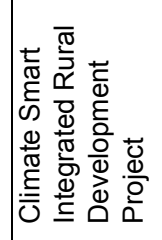 & 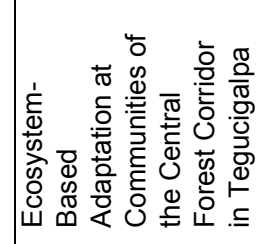 & 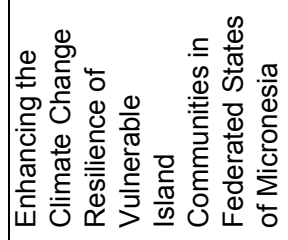 \\
\hline '. & & 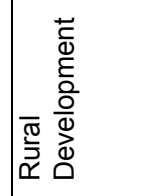 & 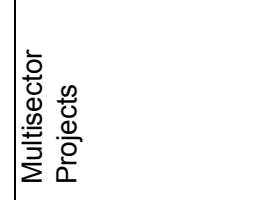 & 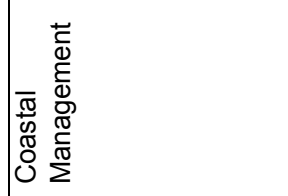 \\
\hline ن & & 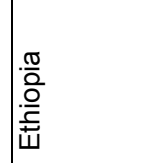 & 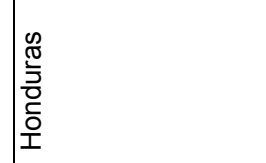 & 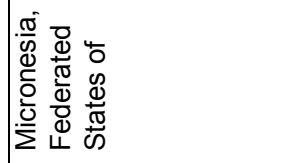 \\
\hline ì & & is & $\stackrel{\infty}{\infty}$ & סי \\
\hline
\end{tabular}




\begin{tabular}{|c|c|c|c|}
\hline 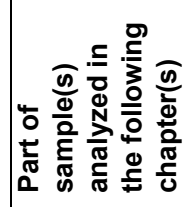 & $\begin{array}{l}\hat{0} \\
\hat{0} \\
\omega^{\circ}\end{array}$ & $\begin{array}{l}\hat{0} \\
0 \\
i 0^{\circ}\end{array}$ & is \\
\hline 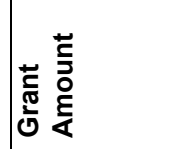 & $\begin{array}{l}\infty \\
0 \\
0 \\
\infty \\
\infty \\
0 \\
0 \\
0 \\
0\end{array}$ & 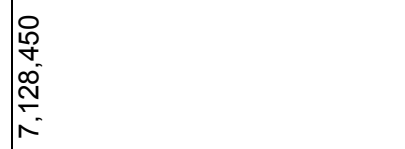 & 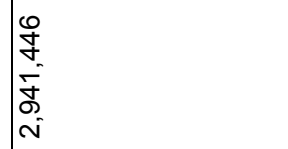 \\
\hline $\begin{array}{l}\bar{\pi} \\
\frac{\pi}{2} \\
\frac{0}{2} \\
\frac{2}{2}\end{array}$ & $\underset{\substack{\stackrel{N}{N} \\
\stackrel{N}{m}}}{\stackrel{N}{N}}$ & $\begin{array}{l}\hat{N} \\
\stackrel{N}{N} \\
\stackrel{N}{N}\end{array}$ & $\begin{array}{l}\hat{N} \\
\stackrel{N}{N} \\
\stackrel{N}{m} \\
\text { N }\end{array}$ \\
\hline 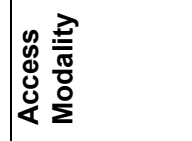 & 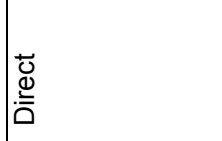 & 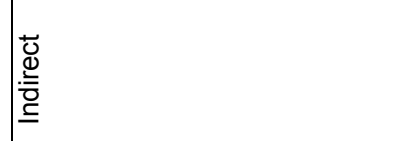 & 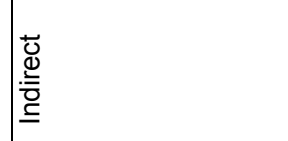 \\
\hline 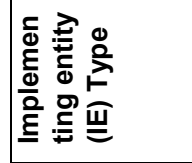 & $\frac{\omega}{z}$ & $\frac{\omega}{\Sigma}$ & $\frac{w}{\bar{\alpha}}$ \\
\hline 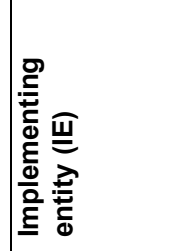 & 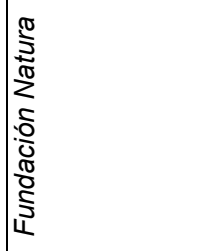 & $\frac{n}{\underline{u}}$ & 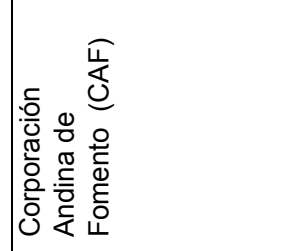 \\
\hline 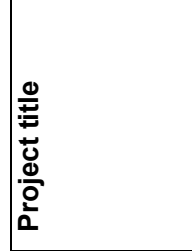 & 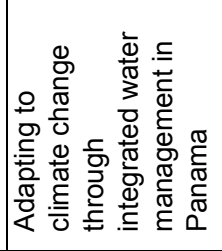 & 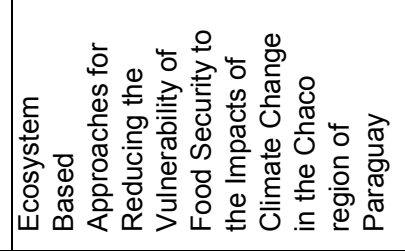 & 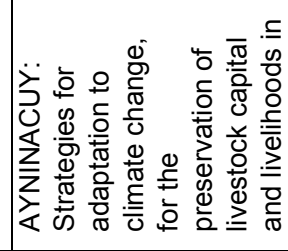 \\
\hline के & 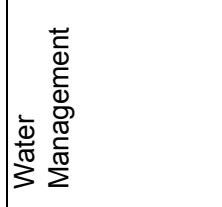 & 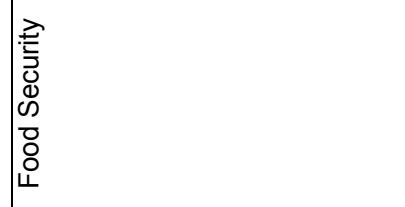 & 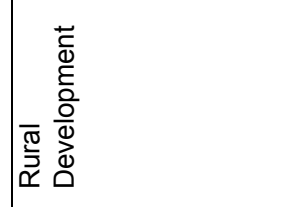 \\
\hline 量 & 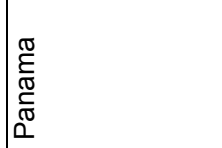 & $\begin{array}{l}\vec{\sigma} \\
\frac{\sigma}{3} \\
\frac{\pi}{\pi} \\
\frac{\pi}{0} \\
0\end{array}$ & $\begin{array}{l}2 \\
\frac{2}{0} \\
0 \\
0\end{array}$ \\
\hline ì & 8 & $\bar{\emptyset}$ & $\widehat{్}$ \\
\hline
\end{tabular}

ก 

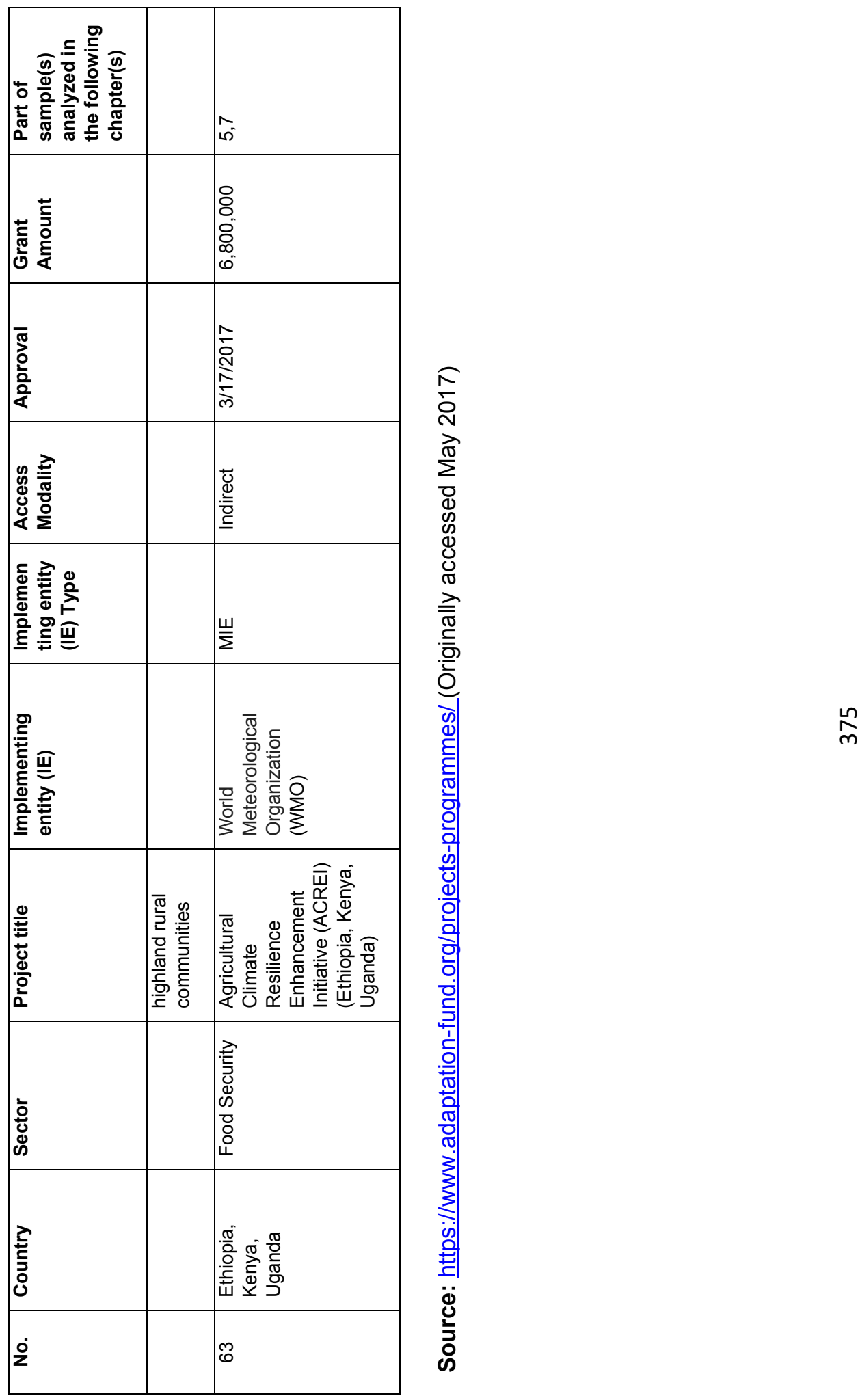


\section{Annex B. Supplementary Material 2: Adaptation Fund Project/ Programme Proposal Template}

Belonging to the following chapters:

Chapter 5: Do direct access and indirect access adaptation projects differ in their focus on local communities? A systematic analysis of 63 Adaptation Fund projects

Chapter 6: What makes internationally-financed climate change adaptation projects focus on local communities? A configurational analysis of 30 Adaptation Fund projects

Chapter 7: Do access modalities to international adaptation finance matter for the promotion of agricultural innovations?: An analysis of 36 Adaptation Fund projects 


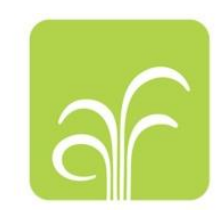

\section{ADAPTATION FUND}

\section{PROJECT/PROGRAMME PROPOSAL TO THE ADAPTATION FUND}

\section{PART I: PROJECT/PROGRAMME INFORMATION}

Project/Programme Category:

Country/ies:

Title of Project/Programme:

Type of Implementing Entity:

Implementing Entity:

Executing Entity/ies:

Amount of Financing Requested: $\quad$ (in U.S Dollars Equivalent)

\section{Project / Programme Background and Context:}

Provide brief information on the problem the proposed project/programme is aiming to solve. Outline the economic social, development and environmental context in which the project would operate.

\section{Project / Programme Objectives:}

List the main objectives of the project/programme.

\section{Project / Programme Components and Financing:}

Fill in the table presenting the relationships among project components, activities, expected concrete outputs, and the corresponding budgets. If necessary, please refer to the attached instructions for a detailed description of each term. 
For the case of a programme, individual components are likely to refer to specific sub-sets of stakeholders, regions and/or sectors that can be addressed through a set of well defined interventions / projects.

\begin{tabular}{|l|l|l|l|}
\hline \multicolumn{1}{|c|}{$\begin{array}{c}\text { Project/Programme } \\
\text { Components }\end{array}$} & $\begin{array}{c}\text { Expected Concrete } \\
\text { Outputs }\end{array}$ & $\begin{array}{c}\text { Expected } \\
\text { Outcomes }\end{array}$ & $\begin{array}{c}\text { Amount } \\
\text { (US\$) }\end{array}$ \\
\hline 1. & & & \\
\hline 2. & & & \\
\hline 3. & & & \\
\hline 4. & & & \\
\hline 5. & & \\
\hline 6. Project/Programme Execution cost & \\
\hline 7. Total Project/Programme Cost & \\
\hline 8. Project/Programme Cycle Management Fee charged by the \\
Implementing Entity (if applicable)
\end{tabular}

\section{Projected Calendar:}

Indicate the dates of the following milestones for the proposed project/programme

\begin{tabular}{|l|c|}
\hline \multicolumn{1}{|c|}{ Milestones } & \multicolumn{1}{|c|}{$\begin{array}{c}\text { Expected } \\
\text { Dates }\end{array}$} \\
\hline Start of Project/Programme Implementation & \\
\hline Mid-term Review (if planned) & \\
\hline Project/Programme Closing & \\
\hline Terminal Evaluation & \\
\hline
\end{tabular}




\section{PART II: PROJECT / PROGRAMME JUSTIFICATION}

A. Describe the project / programme components, particularly focusing on the concrete adaptation activities of the project, and how these activities contribute to climate resilience. For the case of a programme, show how the combination of individual projects will contribute to the overall increase in resilience.

B. Describe how the project / programme provides economic, social and environmental benefits, with particular reference to the most vulnerable communities, and vulnerable groups within communities, including gender considerations. Describe how the project / programme will avoid or mitigate negative impacts, in compliance with the Environmental and Social Policy of the Adaptation Fund.

C. Describe or provide an analysis of the cost-effectiveness of the proposed project/programme.

D. Describe how the project/programme is consistent with national or sub-national sustainable development strategies, including, where appropriate, national or sub-national development plans, poverty reduction strategies, national communications, or national adaptation programs of action, or other relevant instruments, where they exist.

E. Describe how the project / programme meets relevant national technical standards, where applicable, such as standards for environmental assessment, building codes, etc., and complies with the Environmental and Social Policy of the Adaptation Fund.

F. Describe if there is duplication of project / programme with other funding sources, if any.

G. If applicable, describe the learning and knowledge management component to capture and disseminate lessons learned.

H. Describe the consultative process, including the list of stakeholders consulted, undertaken during project preparation, with particular reference to vulnerable groups, including gender considerations, in compliance with the Environmental and Social Policy of the Adaptation Fund. 
I. Provide justification for funding requested, focusing on the full cost of adaptation reasoning.

J. Describe how the sustainability of the project/programme outcomes has been taken into account when designing the project / programme.

K. Provide an overview of the environmental and social impacts and risks identified as being relevant to the project / programme.

\begin{tabular}{|l|l|l|}
\hline $\begin{array}{c}\text { Checklist of environmental } \\
\text { and social principles }\end{array}$ & $\begin{array}{c}\text { No further } \\
\text { assessment required } \\
\text { for compliance }\end{array}$ & $\begin{array}{c}\text { Potential impacts } \\
\text { and risks - further } \\
\text { assessment and } \\
\text { management } \\
\text { required for } \\
\text { compliance }\end{array}$ \\
\hline Compliance with the Law & & \\
\hline Access and Equity & & \\
\hline $\begin{array}{l}\text { Marginalized and Vulnerable } \\
\text { Groups }\end{array}$ & & \\
\hline Human Rights & & \\
\hline $\begin{array}{l}\text { Gender Equity and Women's } \\
\text { Empowerment }\end{array}$ & & \\
\hline Core Labour Rights & & \\
\hline Indigenous Peoples & & \\
\hline Involuntary Resettlement & & \\
\hline Protection of Natural Habitats & & \\
\hline $\begin{array}{l}\text { Conservation of Biological } \\
\text { Diversity }\end{array}$ & & \\
\hline Climate Change & & \\
\hline $\begin{array}{l}\text { Pollution Prevention and } \\
\text { Resource Efficiency }\end{array}$ & & \\
\hline Public Health & & \\
\hline Physical and Cultural Heritage & & \\
\hline Lands and Soil Conservation & & \\
\hline
\end{tabular}




\section{PART III: IMPLEMENTATION ARRANGEMENTS}

A. Describe the arrangements for project / programme implementation.

B. Describe the measures for financial and project / programme risk management.

C. Describe the measures for environmental and social risk management, in line with the Environmental and Social Policy of the Adaptation Fund.

D. Describe the monitoring and evaluation arrangements and provide a budgeted M\&E plan.

E. Include a results framework for the project proposal, including milestones, targets and indicators.

F. Demonstrate how the project / programme aligns with the Results Framework of the Adaptation Fund

\begin{tabular}{|l|l|l|l|l|}
\hline $\begin{array}{l}\text { Project } \\
\text { Objective(s) }\end{array}$ & $\begin{array}{l}\text { Project Objective } \\
\text { Indicator(s) }\end{array}$ & $\begin{array}{l}\text { Fund } \\
\text { Outcome }\end{array}$ & $\begin{array}{l}\text { Fund } \\
\text { Outcome } \\
\text { Indicator }\end{array}$ & $\begin{array}{l}\text { Grant } \\
\text { Amount } \\
\text { (USD) }\end{array}$ \\
\hline & & & & \\
\hline & & & & \\
\hline $\begin{array}{l}\text { Project } \\
\text { Outcome(s) }\end{array}$ & $\begin{array}{l}\text { Project Outcome } \\
\text { Indicator(s) }\end{array}$ & $\begin{array}{l}\text { Fund } \\
\text { Output }\end{array}$ & $\begin{array}{l}\text { Fund Output } \\
\text { Indicator }\end{array}$ & $\begin{array}{l}\text { Grant } \\
\text { Amount } \\
\text { (USD) }\end{array}$ \\
\hline & & & & \\
\hline & & & & \\
\hline
\end{tabular}

5 The AF utilized OECD/DAC terminology for its results framework. Project proponents may use different terminology but the overall principle should still apply 
G. Include a detailed budget with budget notes, a budget on the Implementing Entity management fee use, and an explanation and a breakdown of the execution costs.

H. Include a disbursement schedule with time-bound milestones.

\section{PART IV: ENDORSEMENT BY GOVERNMENT AND CERTIFICATION BY THE} IMPLEMENTING ENTITY

A. Record of endorsement on behalf of the government ${ }^{6}$ Provide the name and position of the government official and indicate date of endorsement. If this is a regional project/programme, list the endorsing officials all the participating countries. The endorsement letter(s) should be attached as an annex to the project/programme proposal. Please attach the endorsement letter(s) with this template; add as many participating governments if a regional project/programme:

(Enter Name, Position, Ministry) $\quad$ Date: (Month, day, year)

B. Implementing Entity certification Provide the name and signature of the Implementing Entity Coordinator and the date of signature. Provide also the project/programme contact person's name, telephone number and email address

I certify that this proposal has been prepared in accordance with guidelines provided by the Adaptation Fund Board, and prevailing National Development and Adaptation Plans (...... list here.....) and subject to the approval by the Adaptation Fund Board, commit to implementing the project/programme in compliance with the Environmental and Social Policy of the Adaptation Fund and on the understanding that the Implementing Entity will be fully (legally and financially) responsible for the implementation of this project/programme.

Name \& Signature

Implementing Entity Coordinator

6. Each Party shall designate and communicate to the secretariat the authority that will endorse on behalf of the national government the projects and programmes proposed by the implementing entities. 
Project Contact Person:

Tel. And Email: 


\section{Annex C. Supplementary Material 3: Codebook for the Assessment of the Level of Community Focus in Adaptation Fund projects}

Belonging to the following chapters:

Chapter 5: Do direct access and indirect access adaptation projects differ in their focus on local communities? A systematic analysis of 63 Adaptation Fund projects

Chapter 6: What makes internationally-financed climate change adaptation projects focus on local communities? A configurational analysis of 30 Adaptation Fund projects 


\section{Introduction to the codebook}

The coding scheme below is designed to extract information from $63 \mathrm{AF}$ project documents to measure the varying degrees of community focus in the project's adaptation investment. The four dimensions of community-focused adaptation defined in the Chapter 5 of this dissertation are: 1) the level of financial investment in community-level adaptation activities; 2 ) the level of community participation in project design and implementation; 3 ) the level of devolved decision-making to the community level; and 4) the design for policy adoption and replicability of community-level adaptation actions, which together represent the mainstreaming of adaptation benefits delivered to the communities.

Part 1 of the coding scheme helps differentiate the 63 AF projects into direct access and indirect access projects. Part 2 contains the coding scheme to measure the level of community-focused adaptation of these projects along the four dimensions.

I use the following process to develop the second part of the codebook. First, I consult the literature to develop relevant typologies for each dimension of community-focused adaptation and its indicators. The typologies are then translated into codes and sub-codes to extract information for each indicator. Second, I look at a sample of six AF projects to identify relevant sections of information for each indicator. I pilot-test the coding scheme with these sample projects to ensure the scheme's applicability to the project documents. The pilot leads to the fine-tuning and finalization of all codes and sub-codes, including the incorporation of some new codes emerging from the project document data. Third, for the codes and sub-codes that require a general search of the whole project document, I develop a list of key terms for free searches, drawing on the terms used in the literature and the common terms used on that topic in the sample AF project documents. 
The codebook forms the basis for my extraction of data from AF project documents using Atlas.ti. 
PART 1: Differentiation between direct access vs indirect access AF

\section{projects}

\begin{tabular}{|l|l|l|l|l|}
\hline Category & $\begin{array}{l}\text { Code options } \\
\text { (Exclusive) }\end{array}$ & Definition & $\begin{array}{l}\text { Source of } \\
\text { information }\end{array}$ & Coding procedure \\
\hline $\begin{array}{l}\text { Access } \\
\text { modality }\end{array}$ & $\begin{array}{l}\text { Direct } \\
\text { access (1) } \\
\text { Indirect } \\
\text { access (0) }\end{array}$ & $\begin{array}{l}\text { Direct access } \\
\text { A project which } \\
\text { has a national } \\
\text { implementing } \\
\text { entity (NIE) } \\
\text { Document- } \\
\text { Part I } \\
\text { (Project/Progr } \\
\text { amme } \\
\text { Information) }\end{array}$ & $\begin{array}{l}\text { I. Look at "Type of } \\
\text { Implementing } \\
\text { Entity" mentioned } \\
\text { in the mentioned } \\
\text { section of the } \\
\text { project document. }\end{array}$ \\
& $\begin{array}{l}\text { Indirect access } \\
\text { A project which } \\
\text { has a multilateral } \\
\text { implementing } \\
\text { entity (MIE) or a } \\
\text { regional } \\
\text { implementing } \\
\text { entity (RIE) }\end{array}$ & $\begin{array}{l}\text { 2. If it is national } \\
\text { institution (NIE), } \\
\text { then code "direct } \\
\text { access". If it is a } \\
\text { multilateral } \\
\text { institution (MIE) or } \\
\text { regional institution } \\
\text { (RIE), then code }\end{array}$ \\
& & & "indirect access" \\
& & $\begin{array}{l}\text { 3. Direct access } \\
\text { projects are } \\
\text { assigned the value } \\
\text { of 1, while indirect } \\
\text { access projects are } \\
\text { assigned the value } \\
\text { of 0. }\end{array}$ \\
\hline
\end{tabular}


Example 1: The following project is coded as "indirect access" (0)

\section{PART I: PROJECT/PROGRAMME INFORMATION}

Project/PRogramme CATEgory: COUNTRY/IES:

TITLE OF PROJECT/PROgRAMME:

TYPE OF IMPLEMENTING ENTITY: IMPLEMENTING ENTITY:

EXECUTING ENTITY/IES:

AMOUNT OF FINANCING REQUESTED:
Regular

Honduras

Addressing Climate Change Risks on Water Resources in Honduras: Increased Systemic Resilience and Reduced Vulnerability of the Urban Poor

(UNDP PIMS 4399; Atlas IDs - Proposal 00060323, Project 00075904, HND10)

Multilateral Implementing Entity

United Nations Development Program

Secretariat for Natural Resources and

Environment (SERNA)

$\$ \mathbf{5 , 6 2 0 , 3 0 0}$ (In U.S Dollars Equivalent)

Example 2: The following project is coded as "direct access" (1)

\section{PART I: PROJECT/PROGRAMME INFORMATION}

\begin{tabular}{|c|c|}
\hline Project Category: & REgular PROJECT \\
\hline COUNTRY: & RWANDA \\
\hline \multicolumn{2}{|l|}{ SECTOR/s: } \\
\hline \multirow[t]{2}{*}{ Title of Project: } & REDUCING VULNERABILITY TO CLIMATE CHANGE IN \\
\hline & $\begin{array}{l}\text { NORTH WEST RWANDA THROUGH COMMUNITY BASED } \\
\text { ADAPTATION }\end{array}$ \\
\hline TYPE 0F IMPLEMENTING ENTITY: & NATIONAL IMPLEMENTING ENTITY \\
\hline IMPLEMENTING ENTITY: & MinisTRY of NATURAL RESOURCES (MINIRENA) \\
\hline EXECUTING ENTITY: & RWANDA NATURAL RESOURCES AuTHORITY (RNRA) \\
\hline Amount of Financing REQUESTED: & 9,969,619 (IN U.S DoLLARS EQUIVALENT) \\
\hline
\end{tabular}




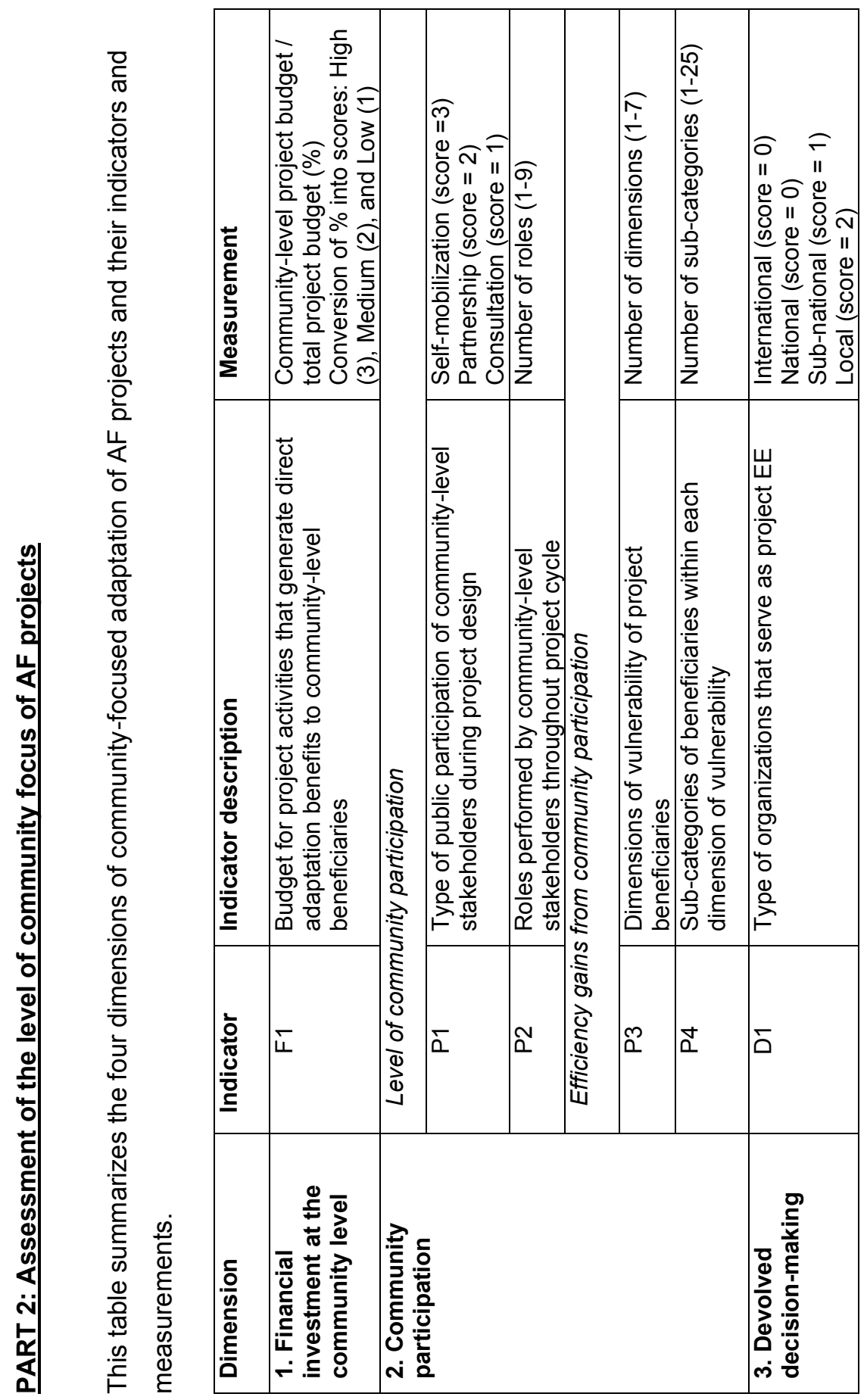

ळ 

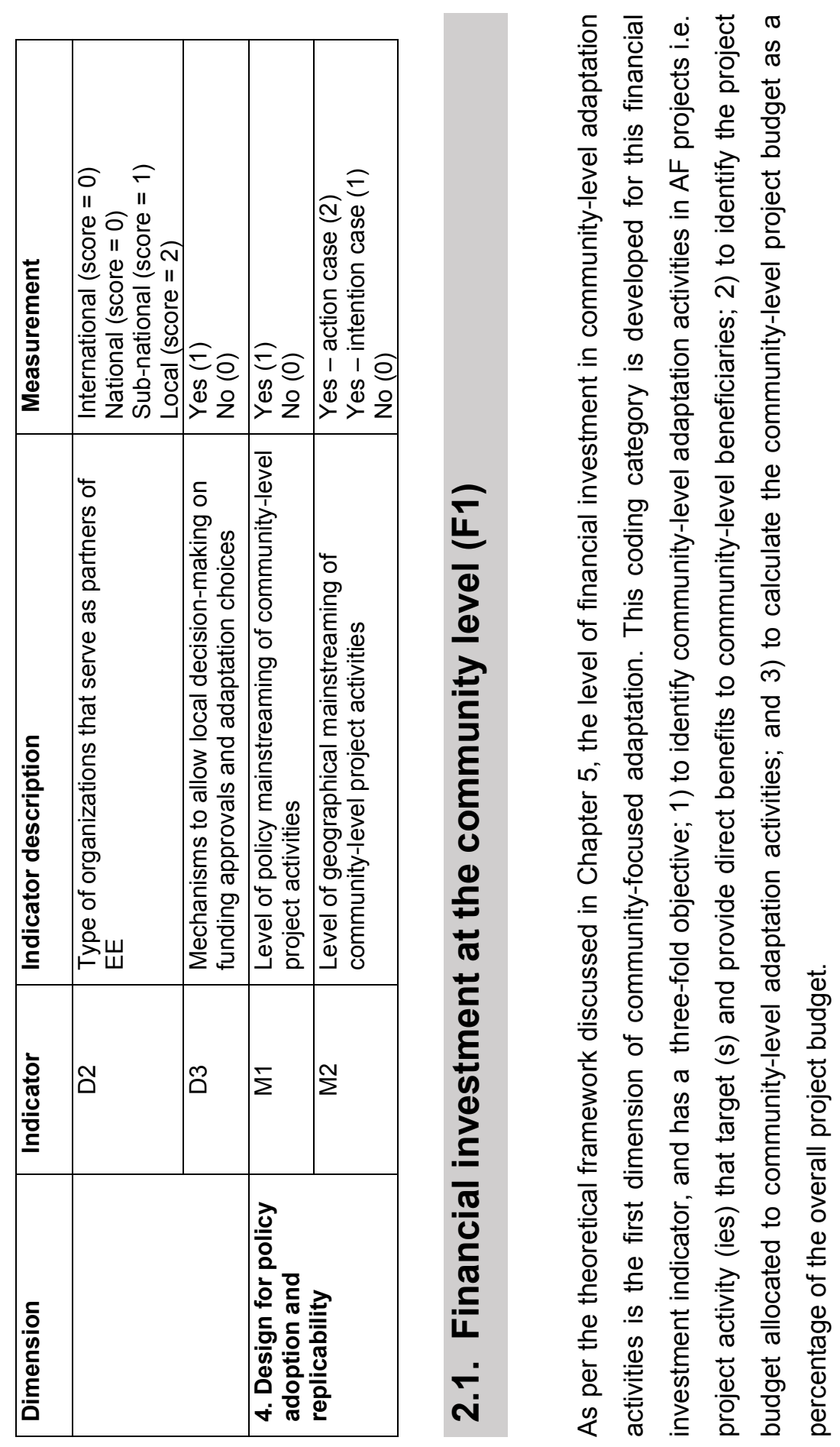

용 


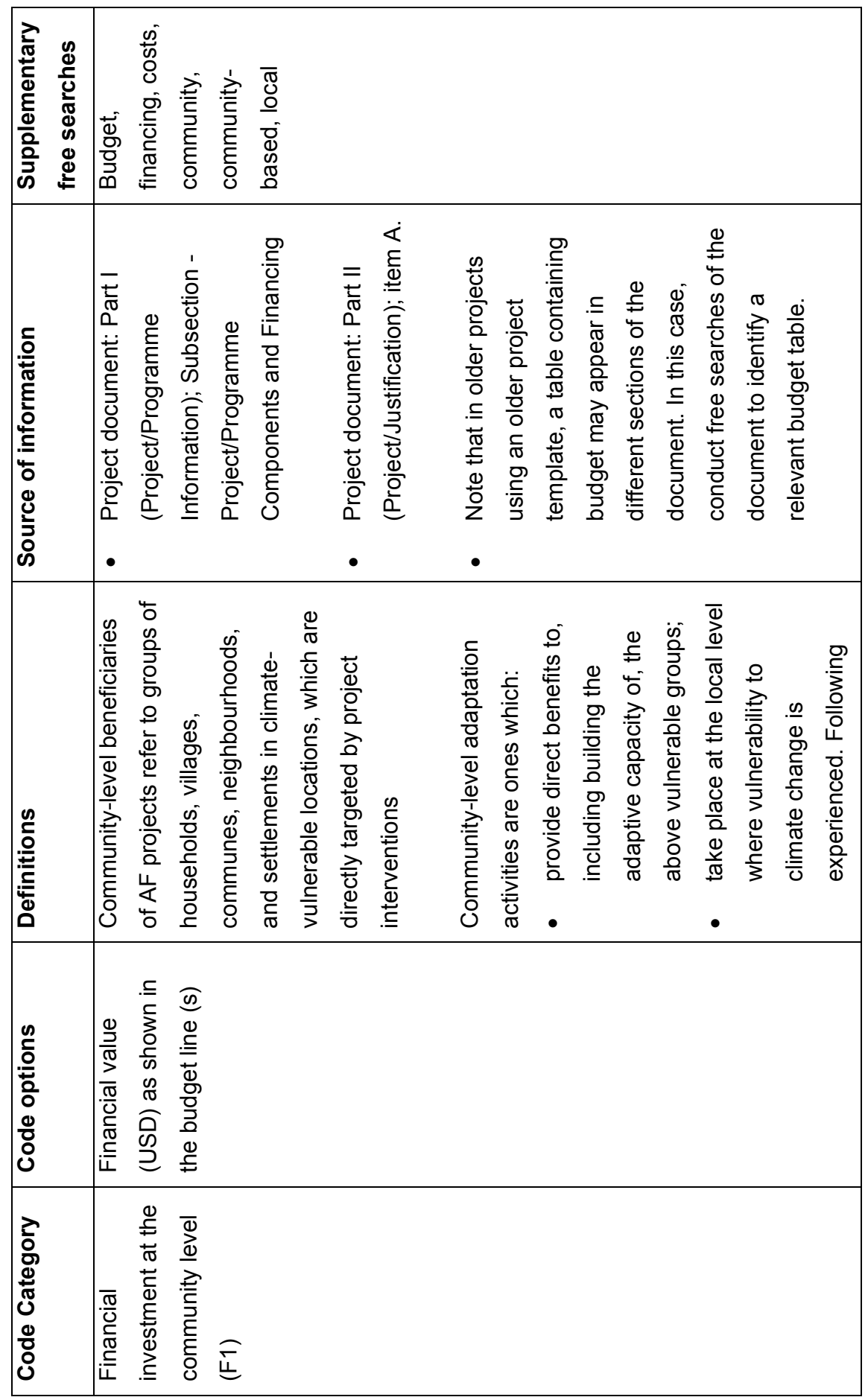




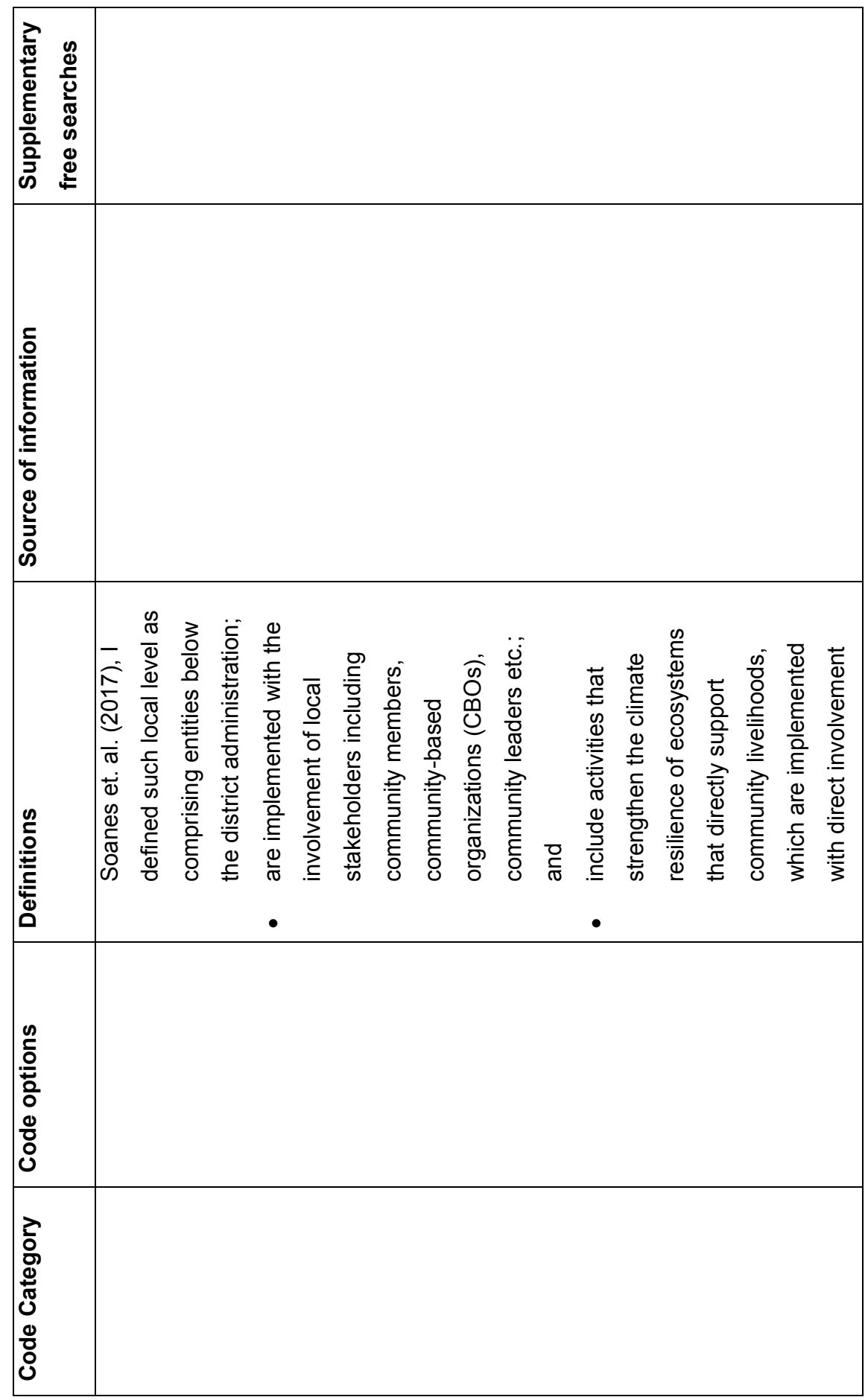

స్ 


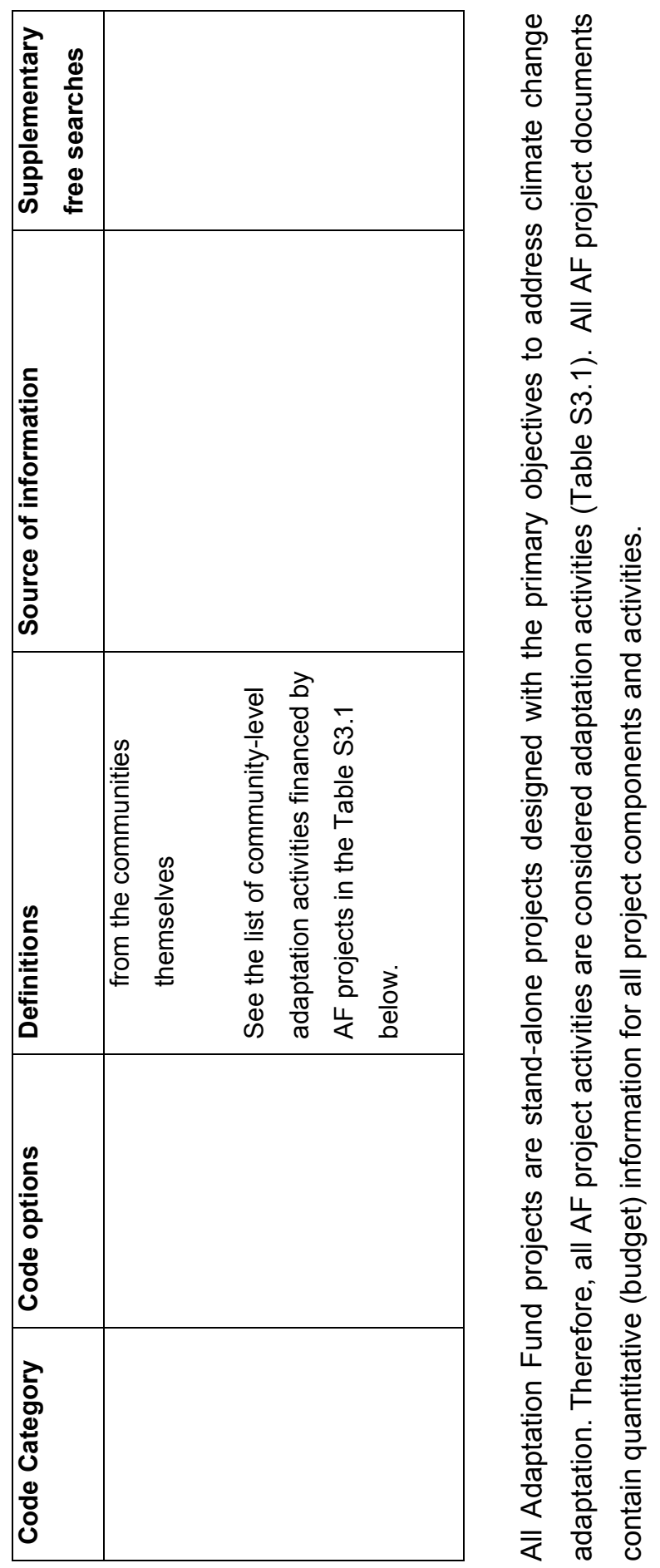




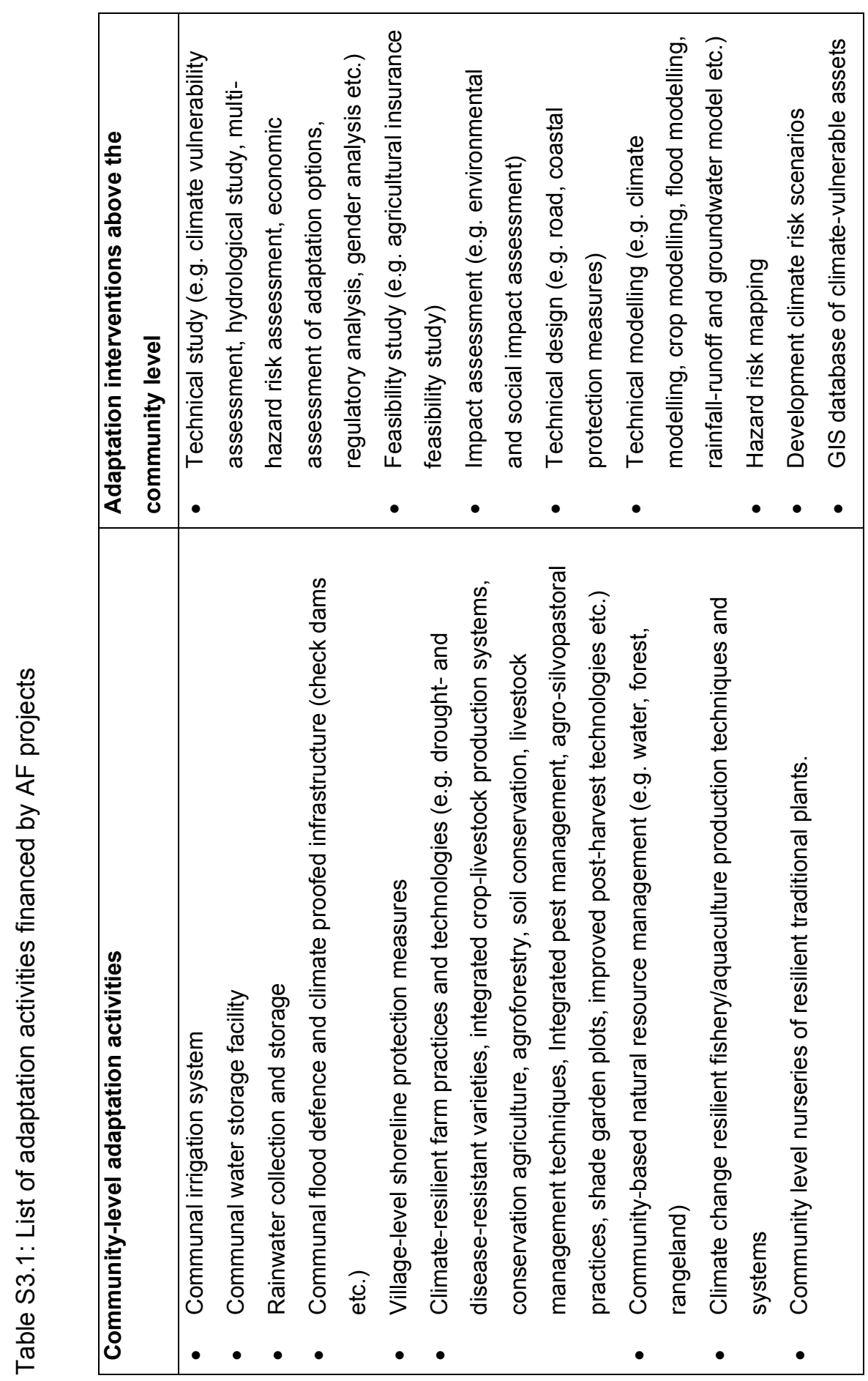

๖ 


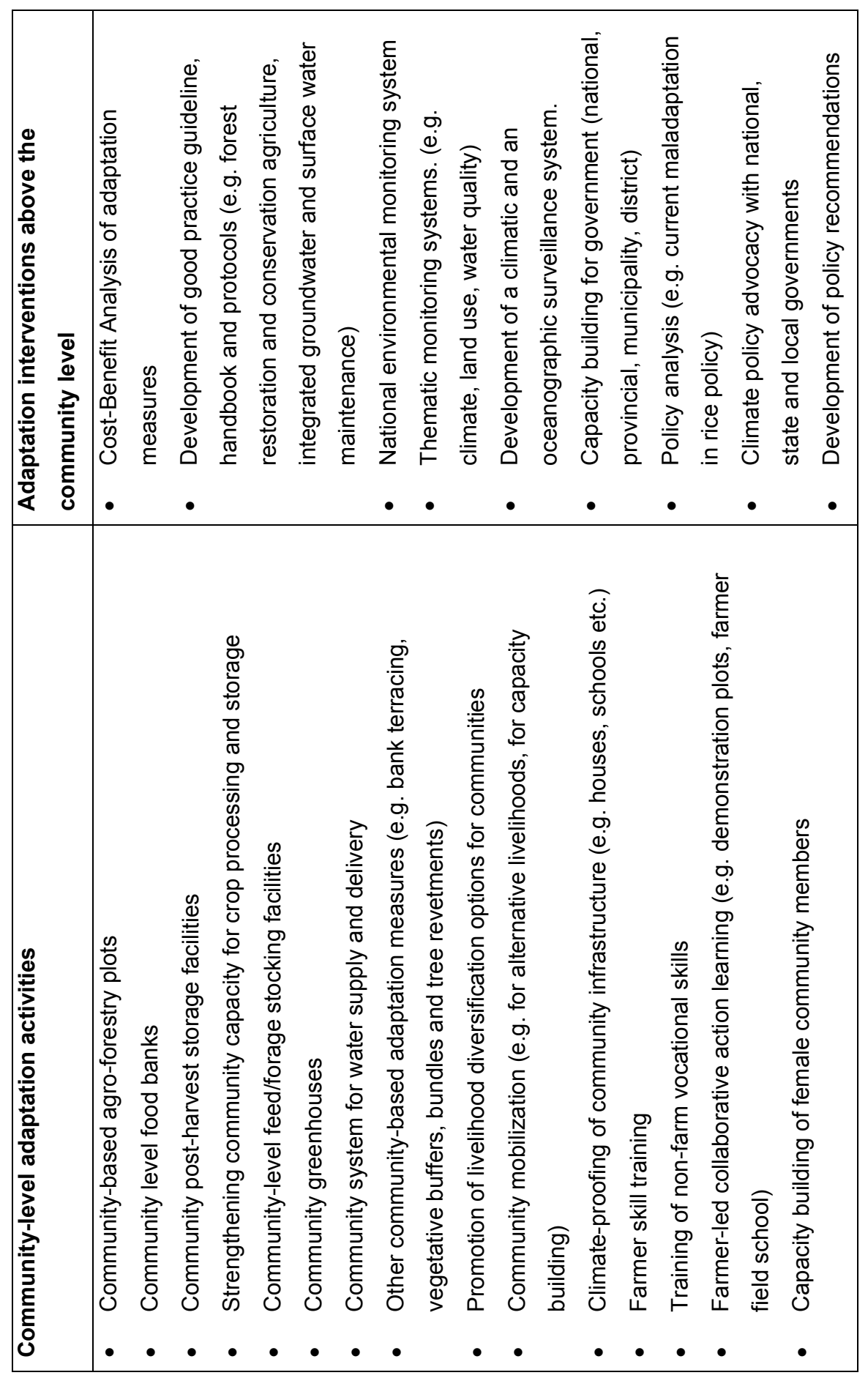

ก) 


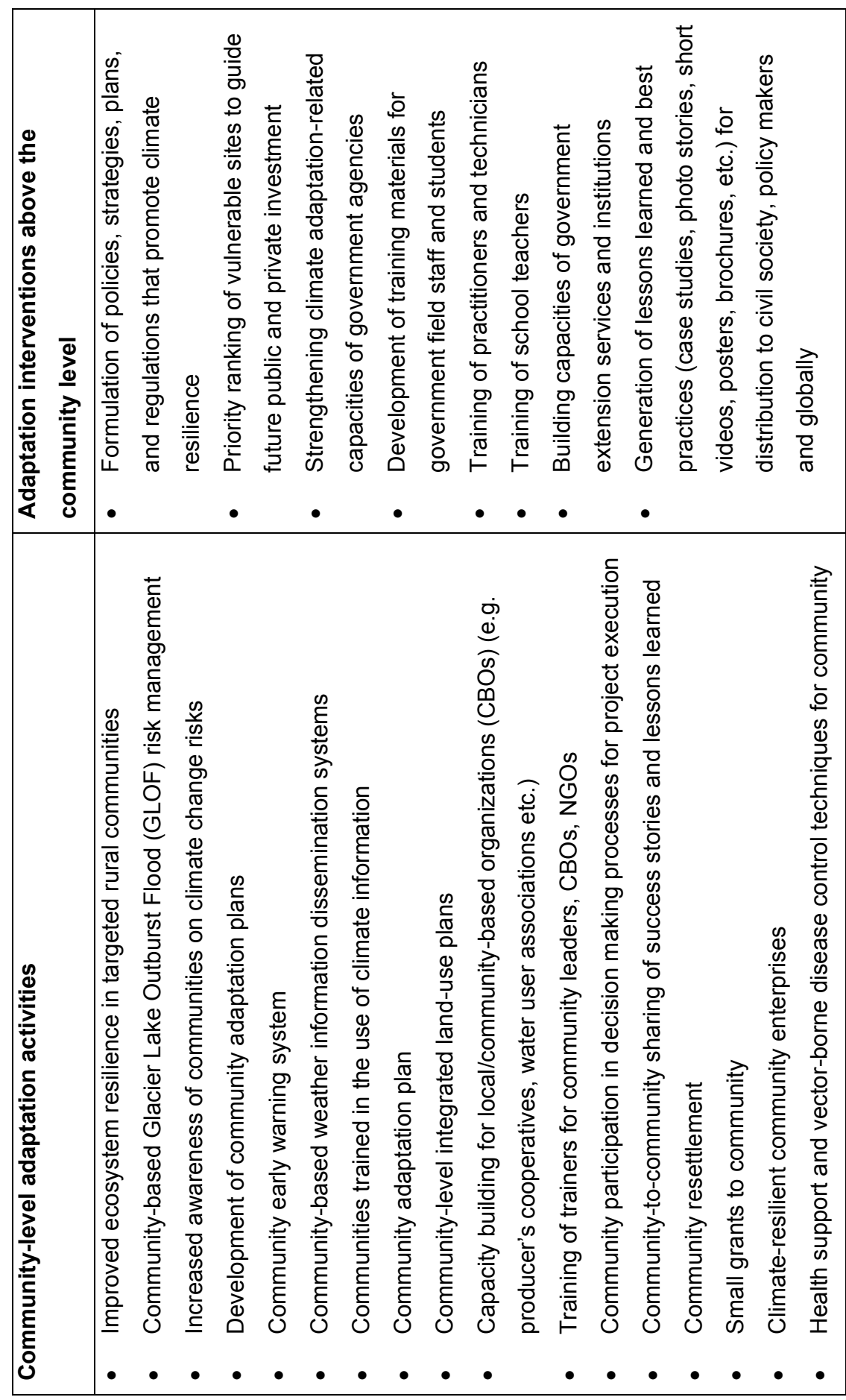

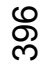




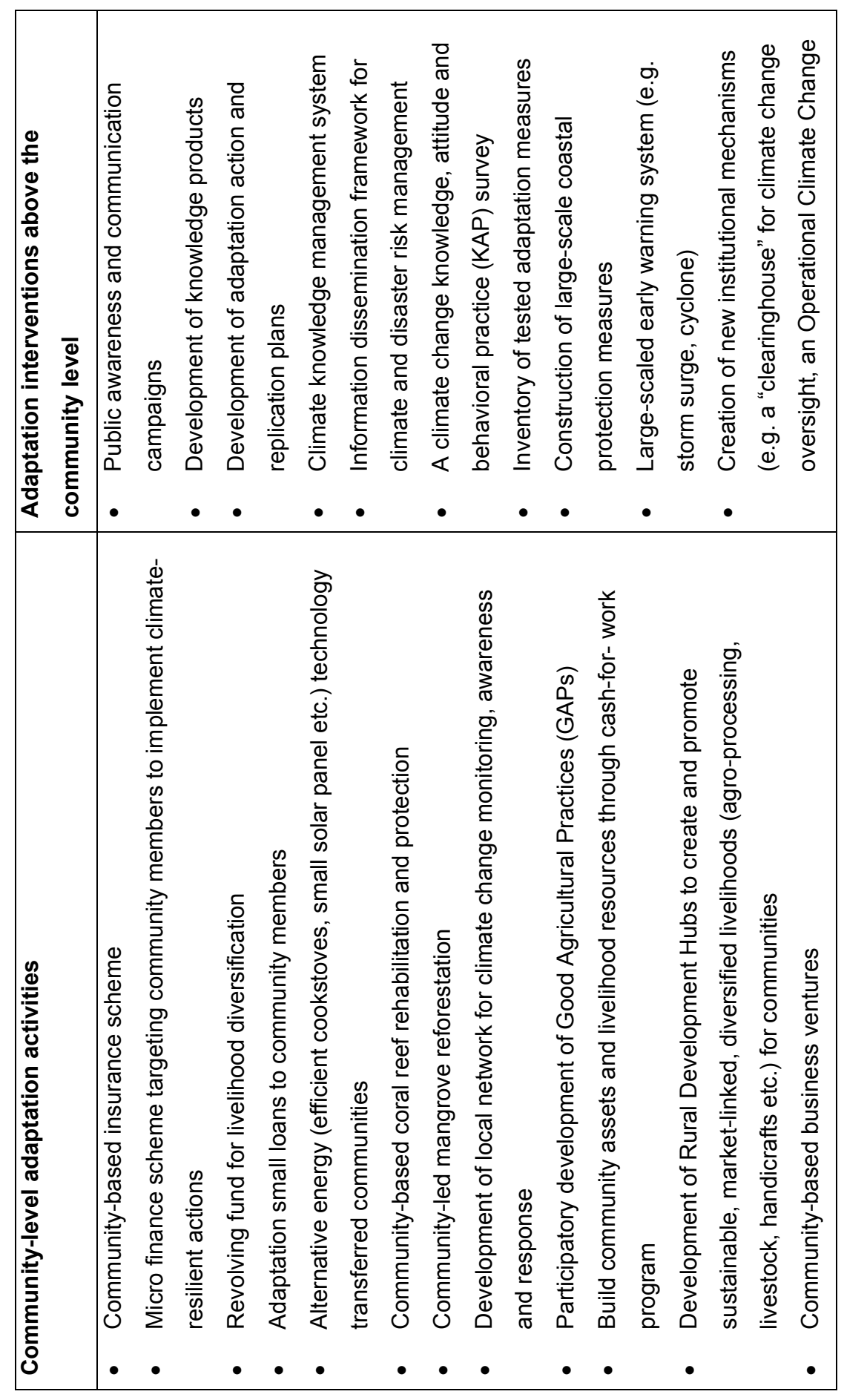

กิ 


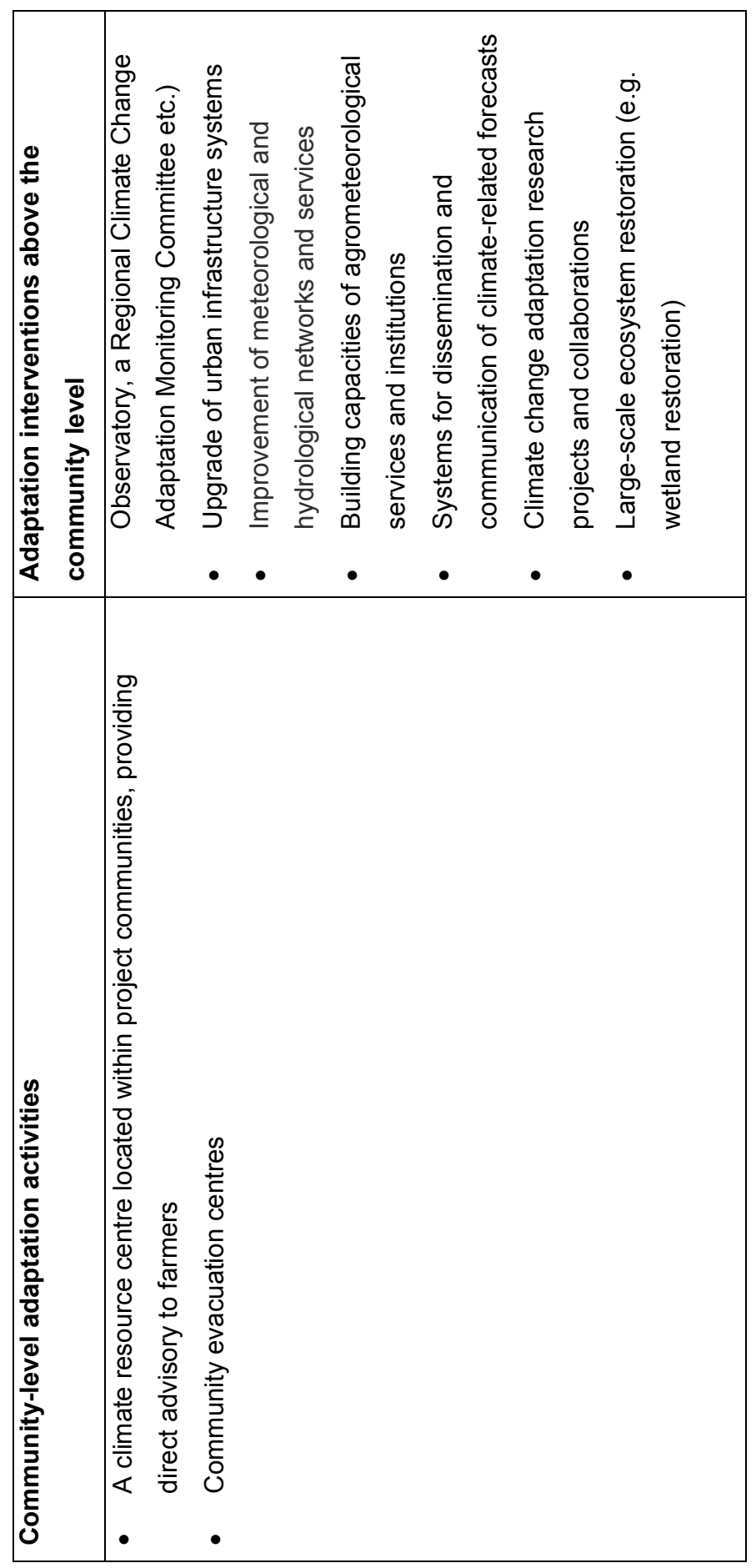

న 


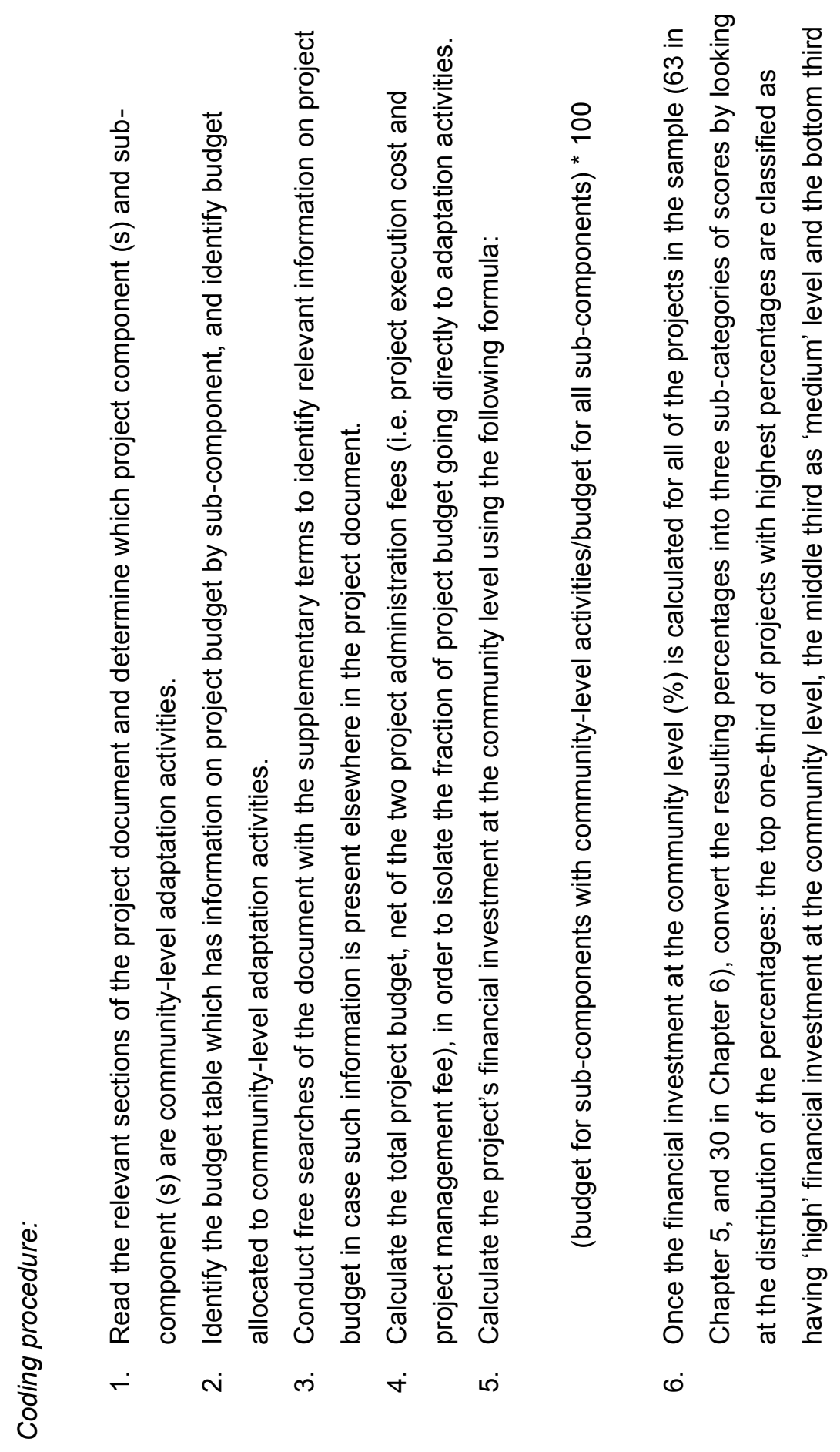

হ 

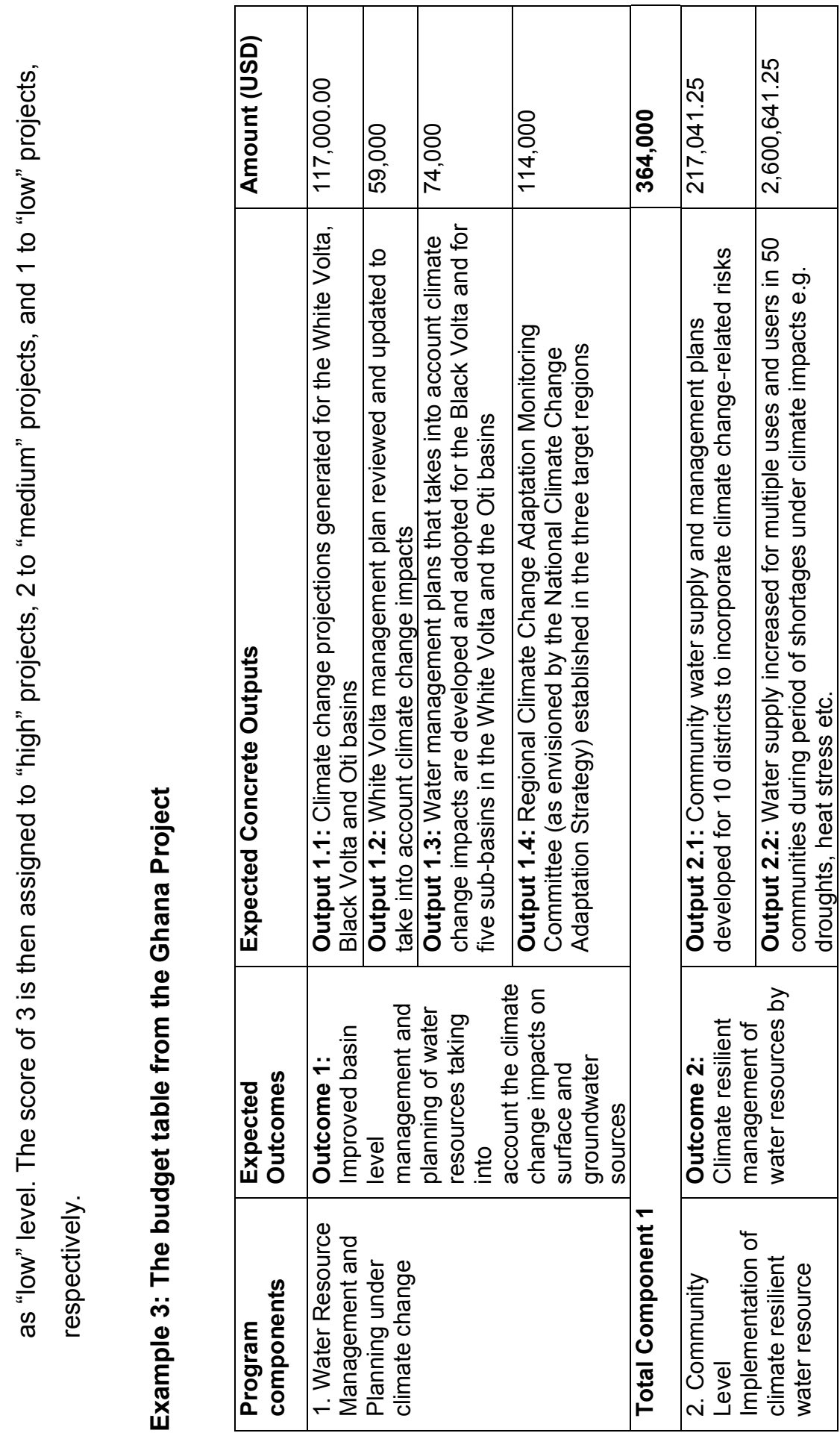

ㅇํㅇ 


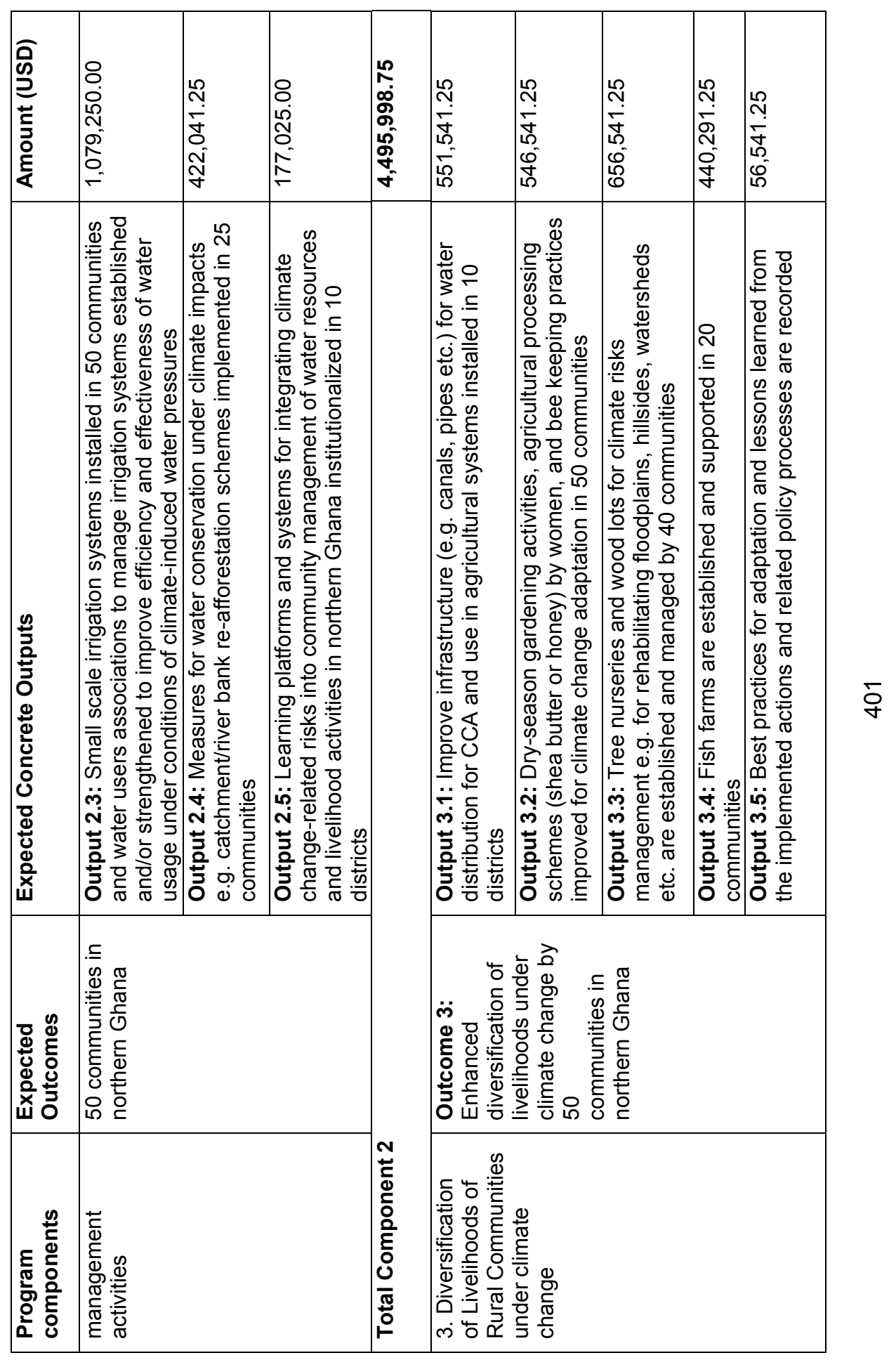



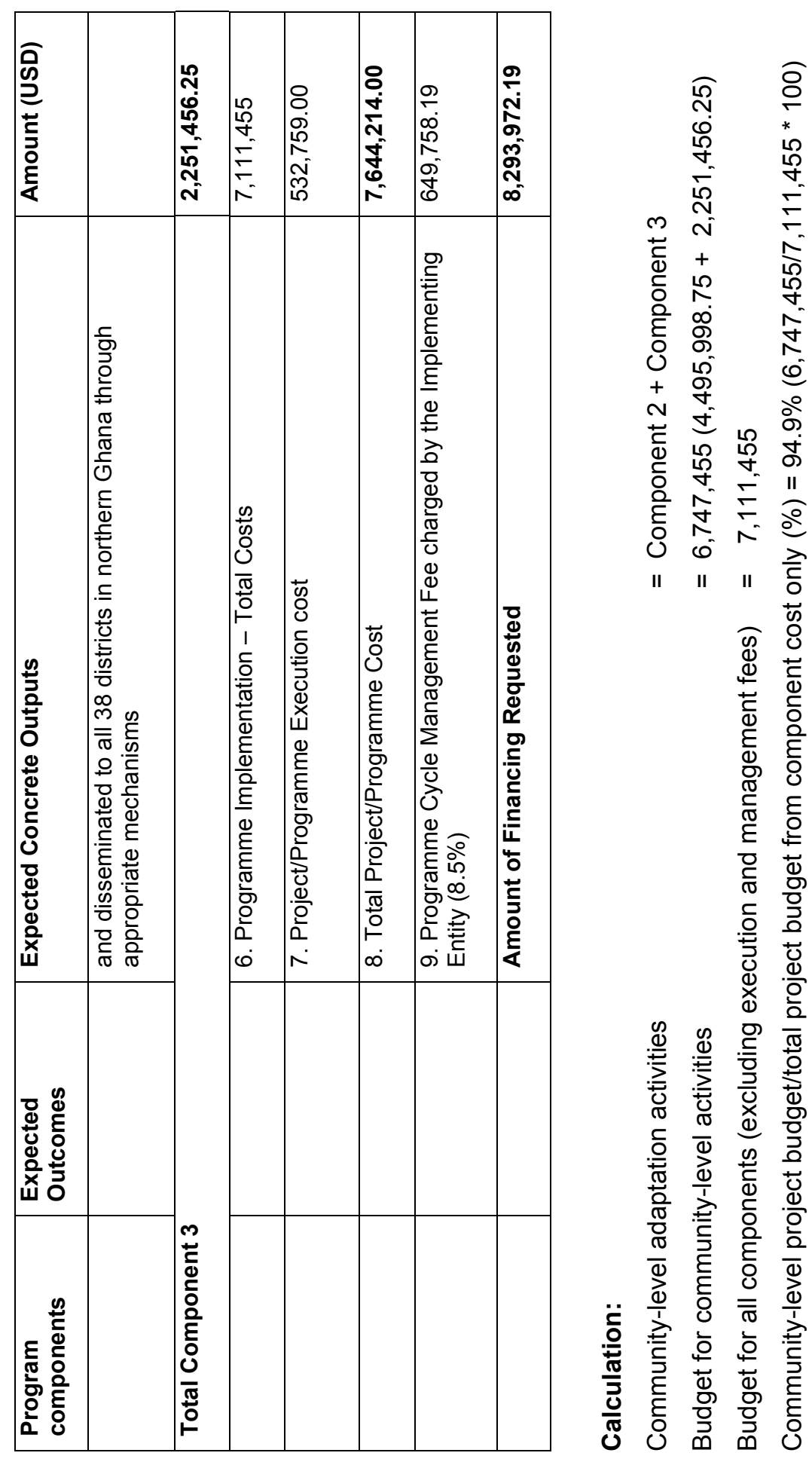


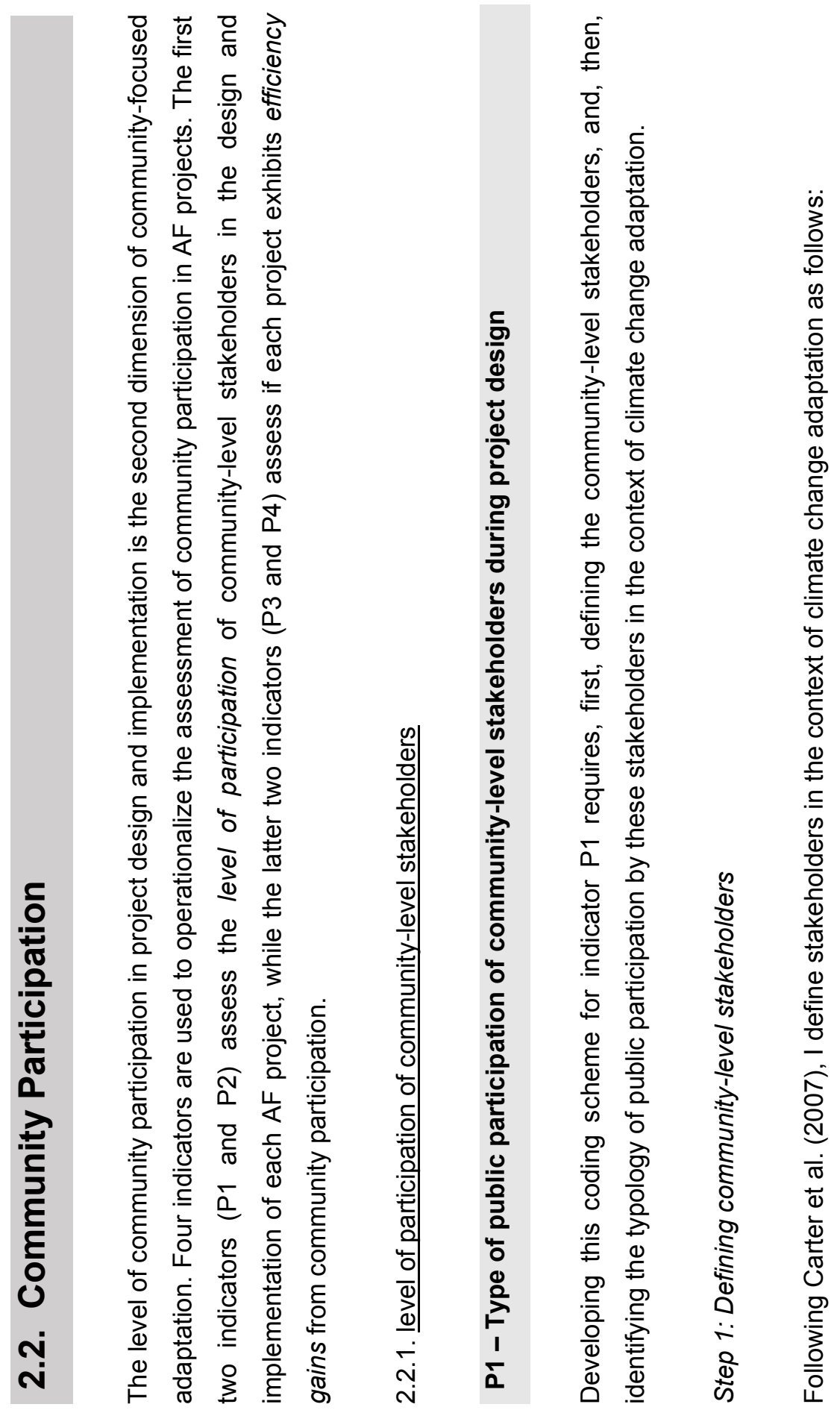



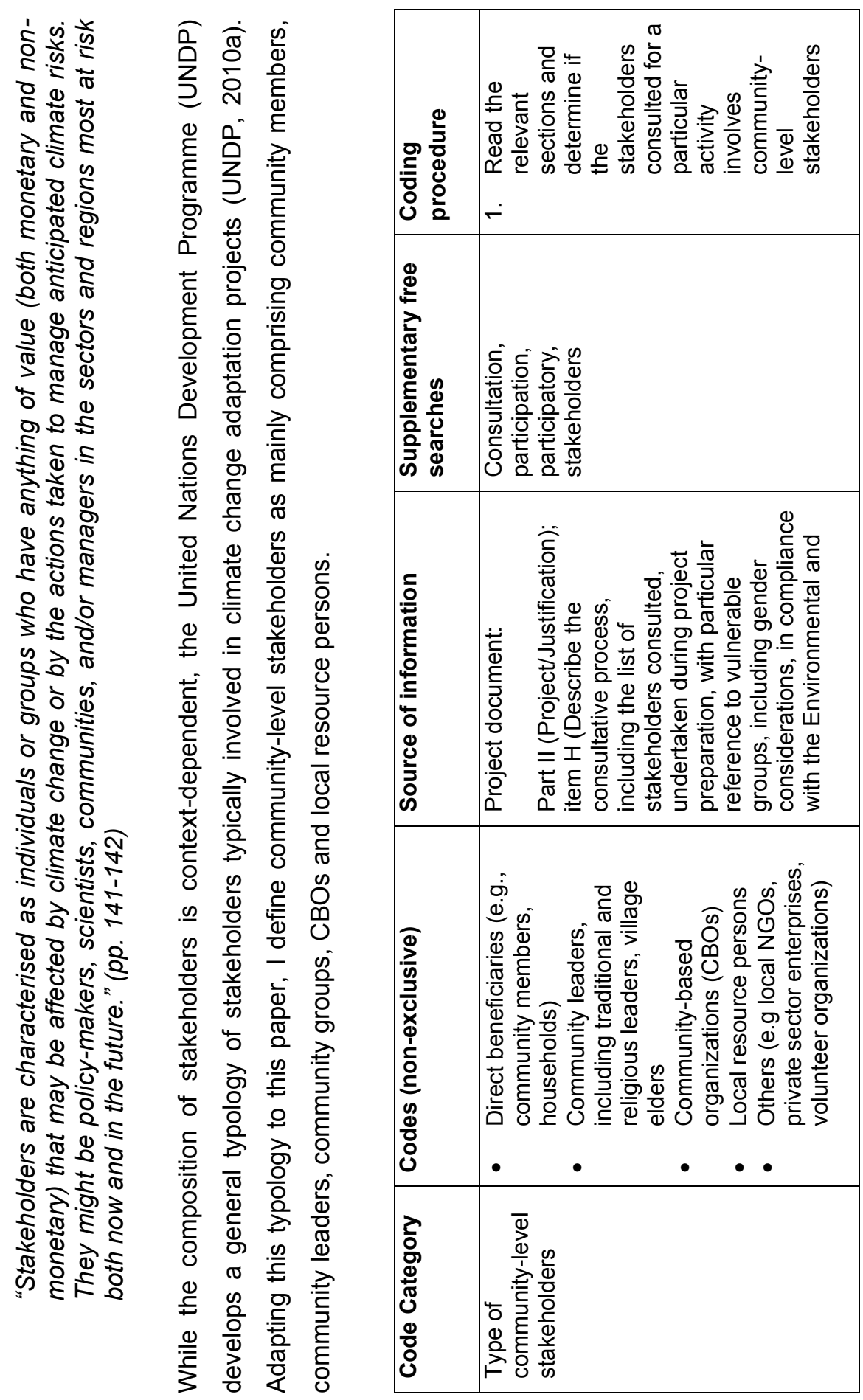

ஓ 

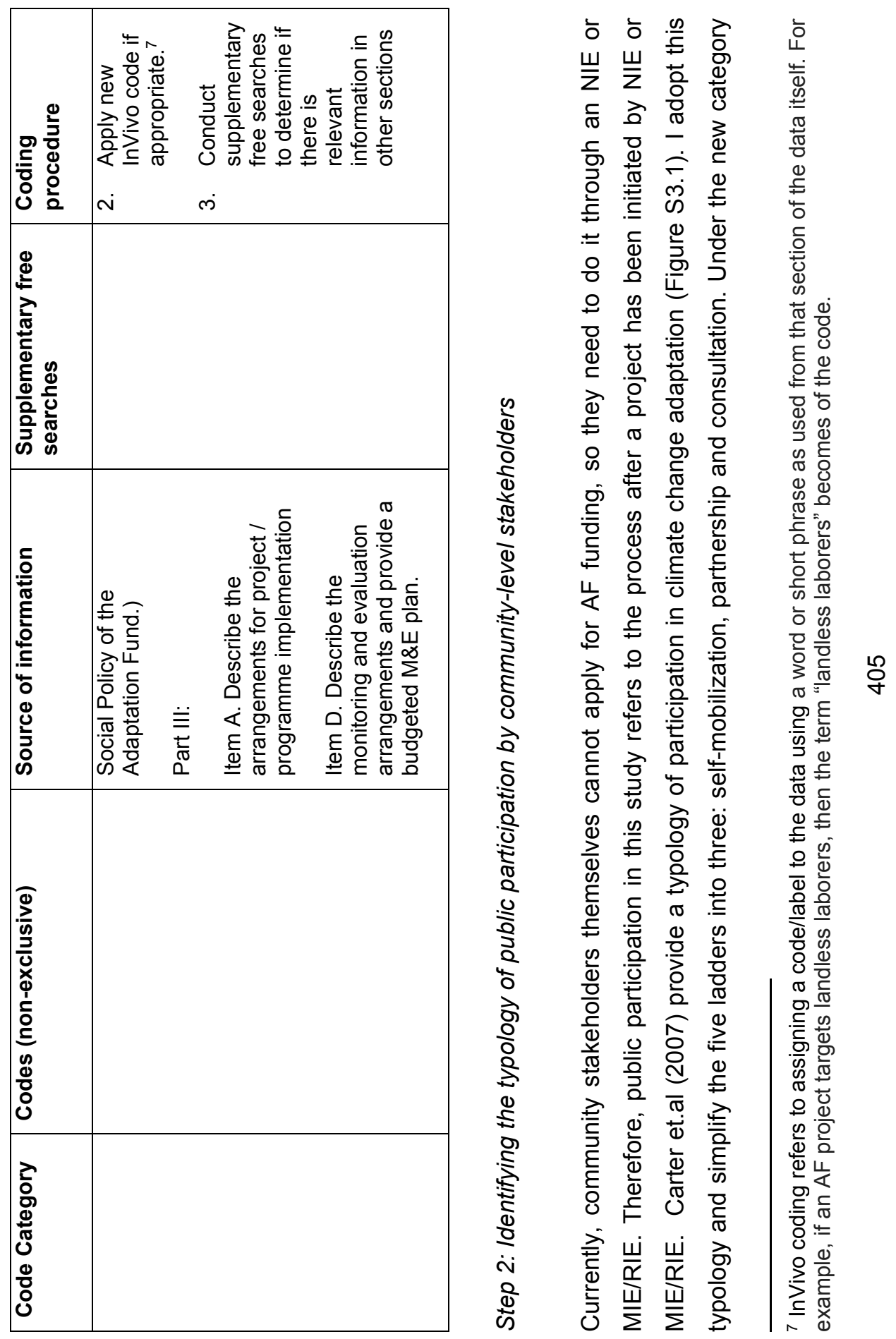


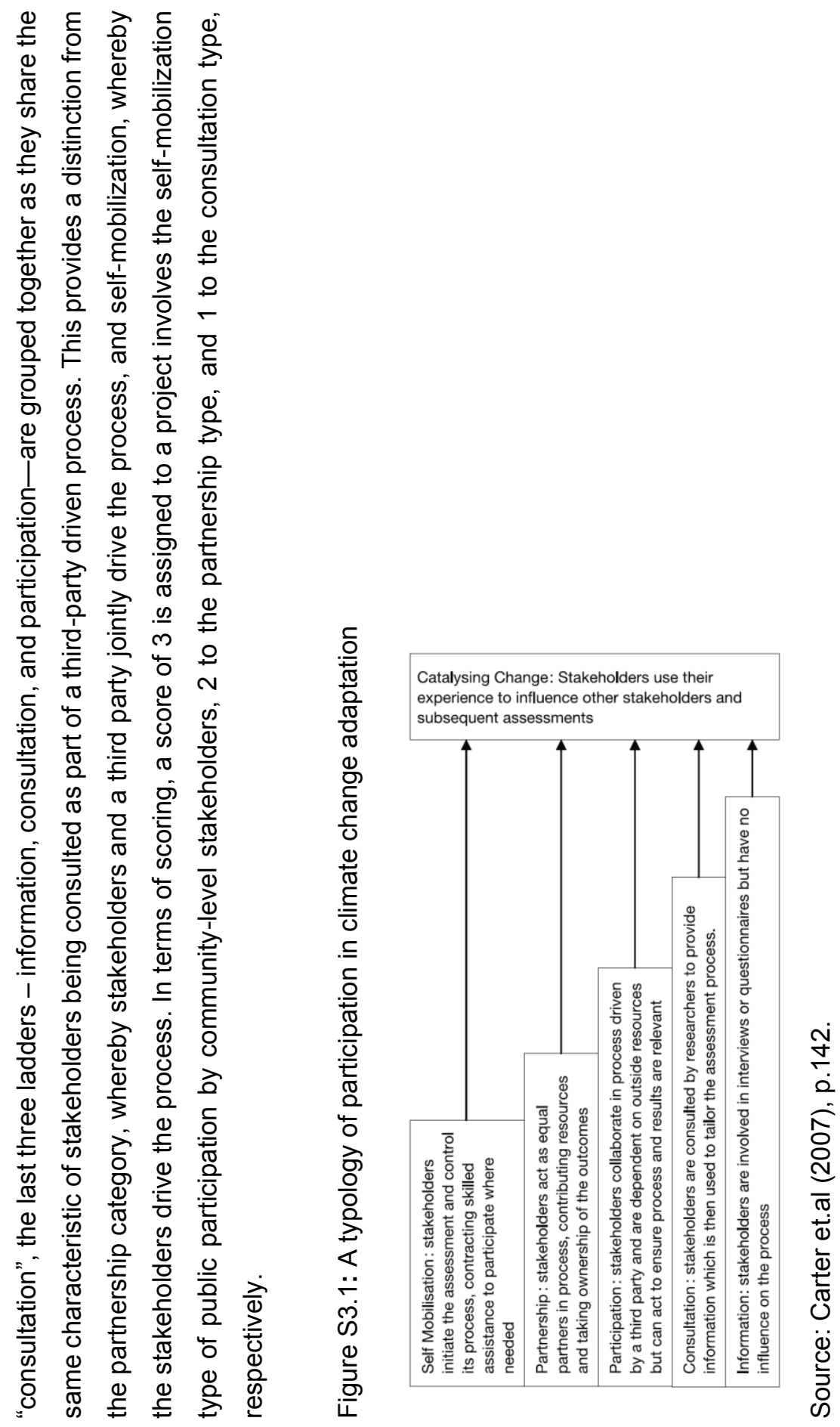




\begin{tabular}{|c|c|c|c|}
\hline 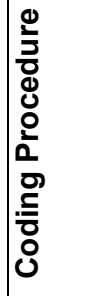 & \multicolumn{3}{|c|}{ 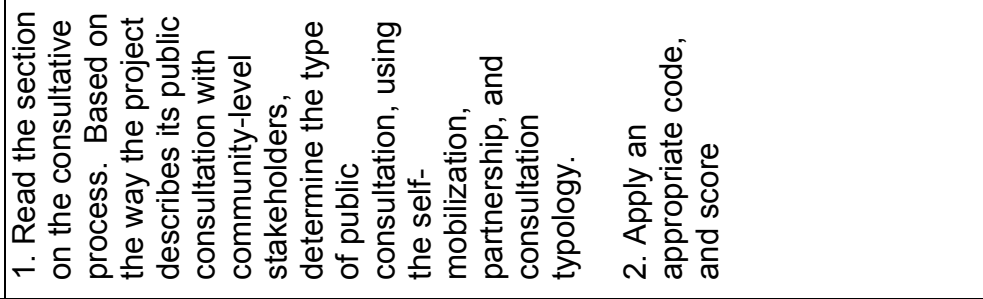 } \\
\hline 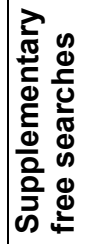 & \multicolumn{3}{|l|}{ 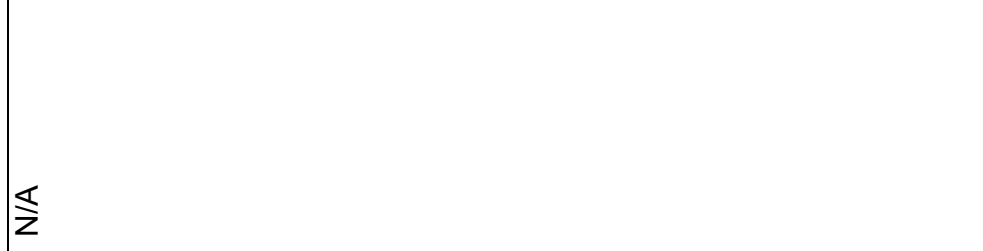 } \\
\hline 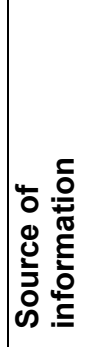 & \multicolumn{3}{|c|}{ 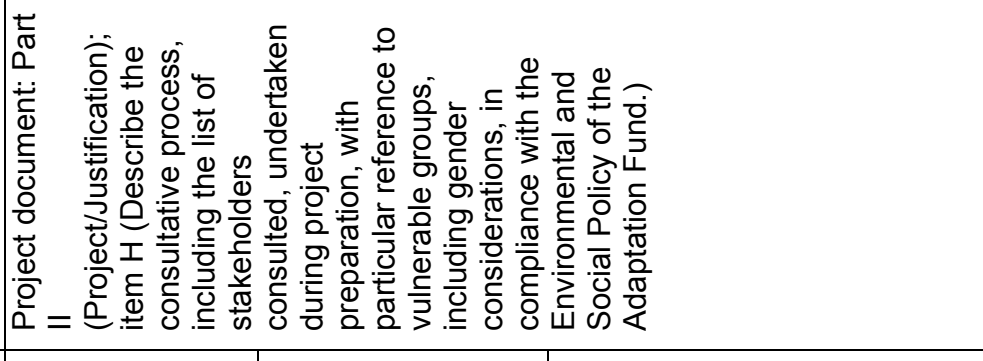 } \\
\hline 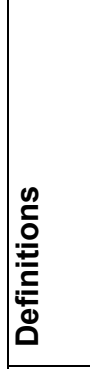 & 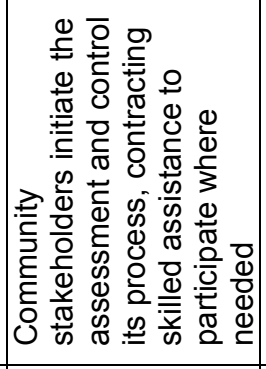 & 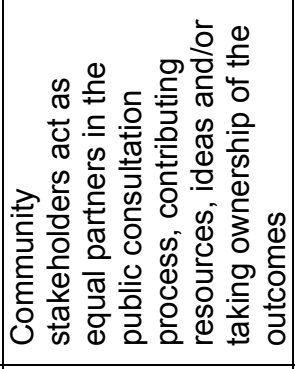 & 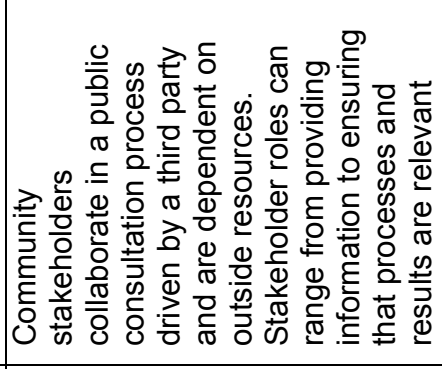 \\
\hline 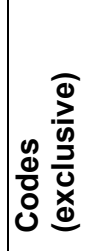 & 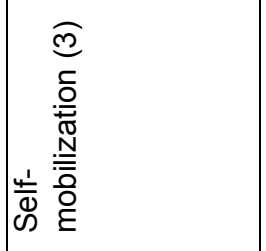 & 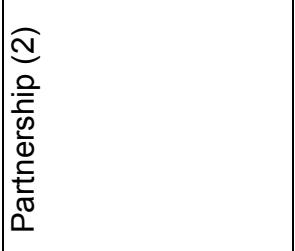 & 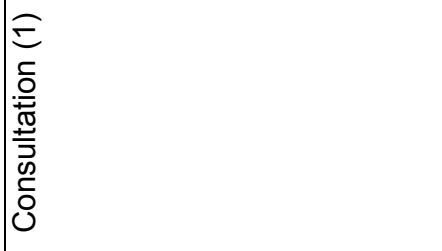 \\
\hline 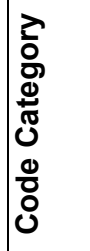 & \multicolumn{3}{|l|}{ 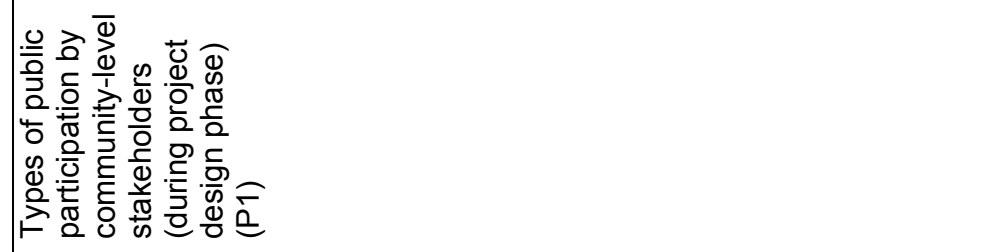 } \\
\hline
\end{tabular}



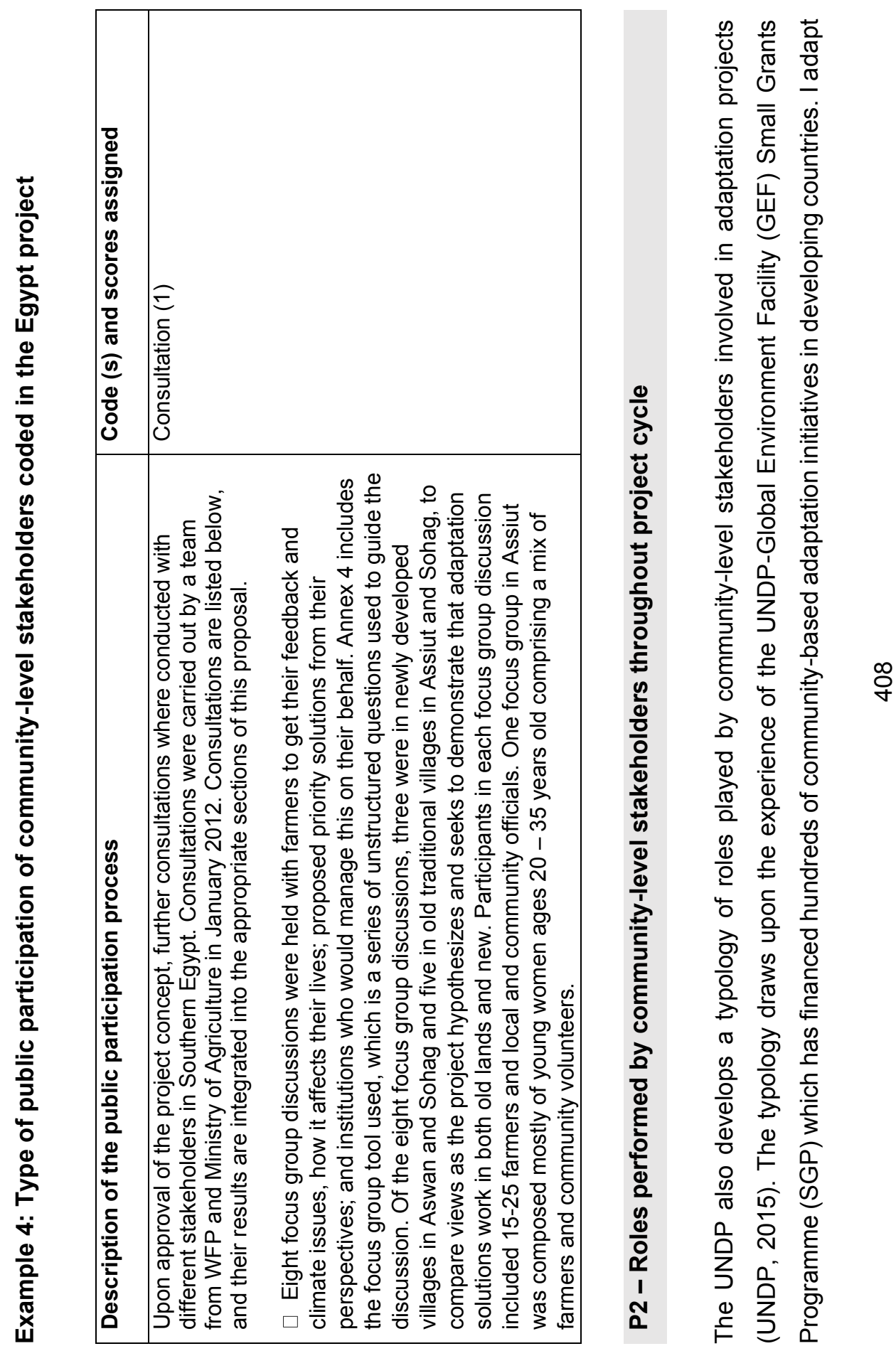


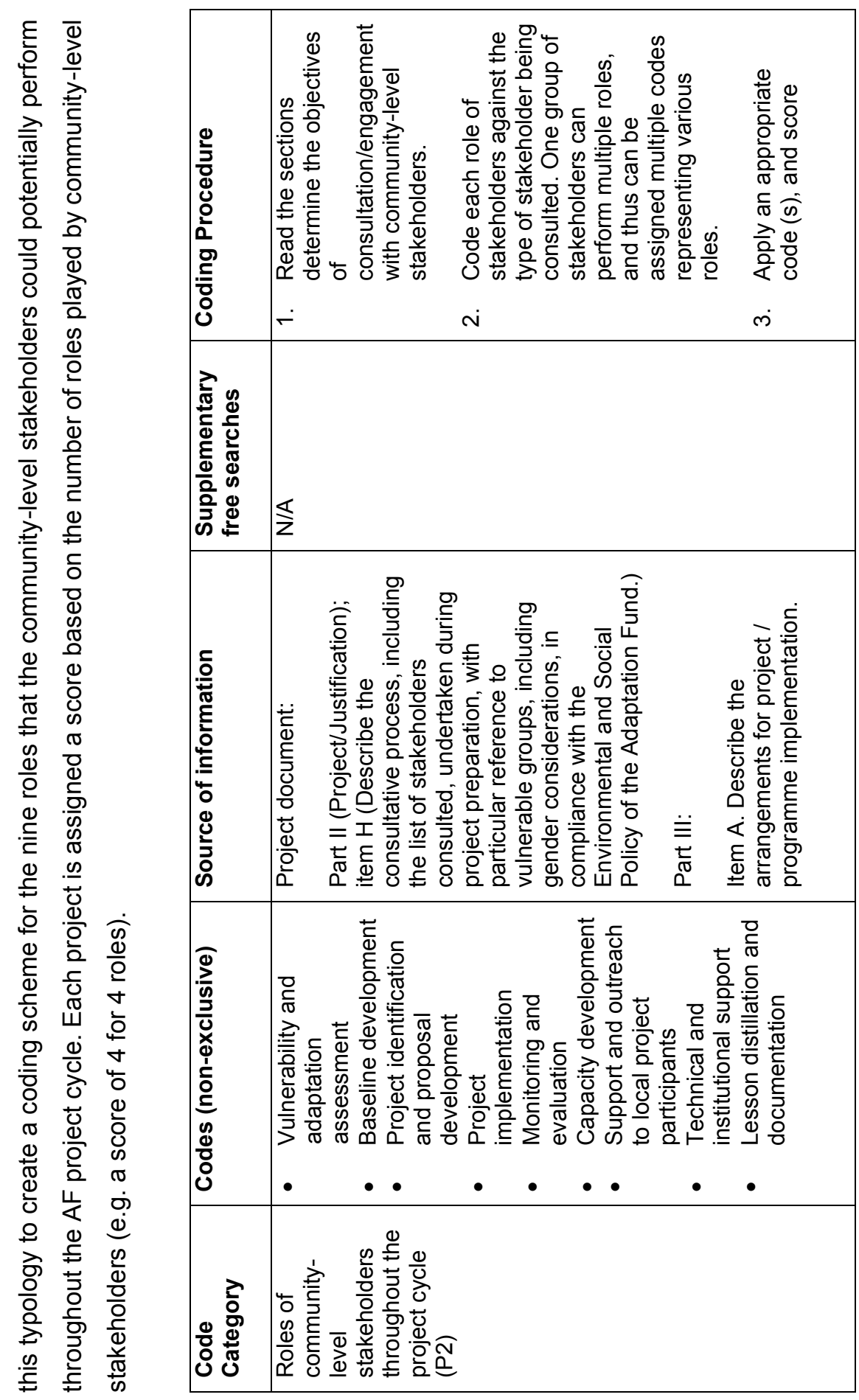



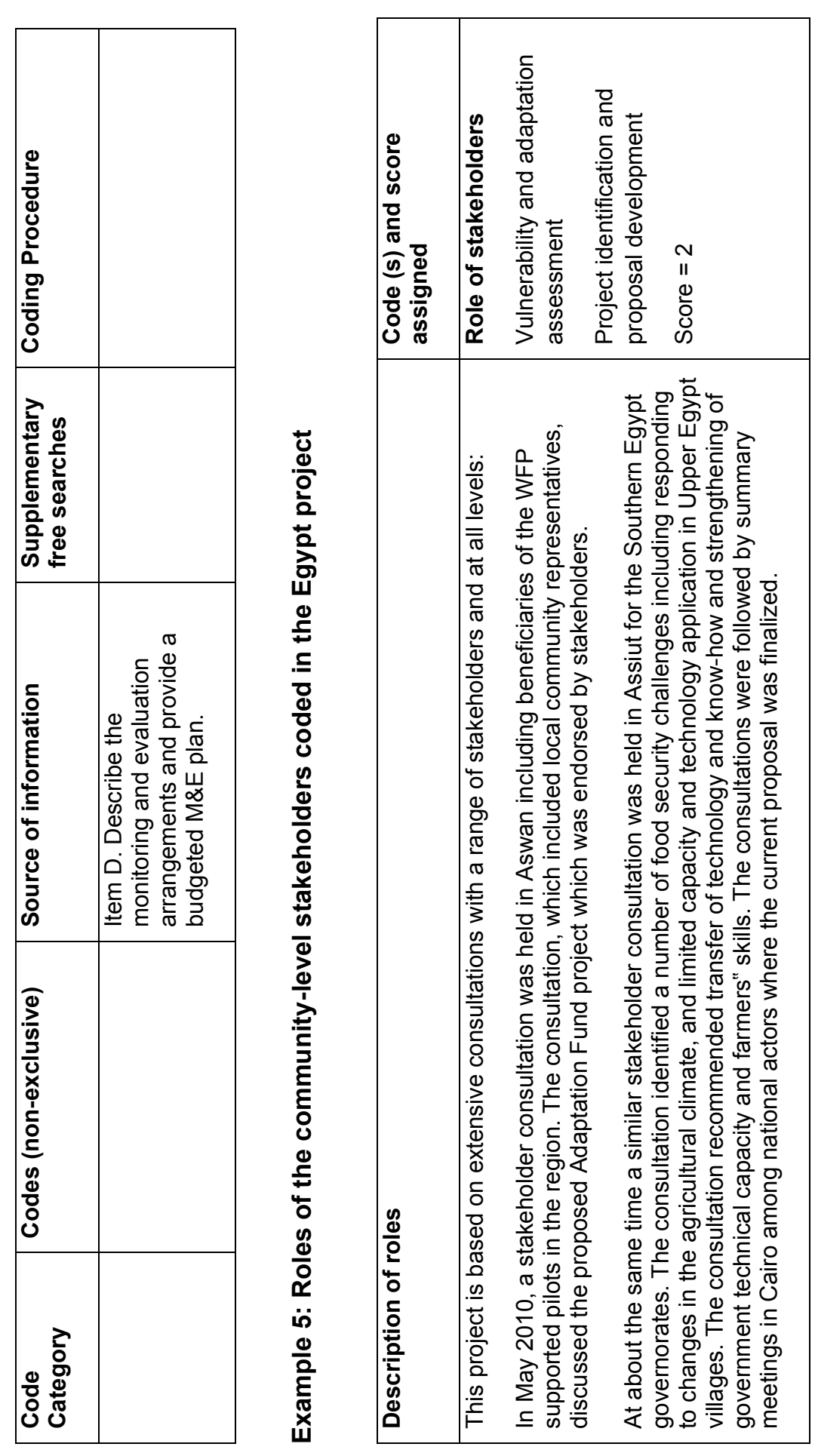

$\frac{8}{8}$ 


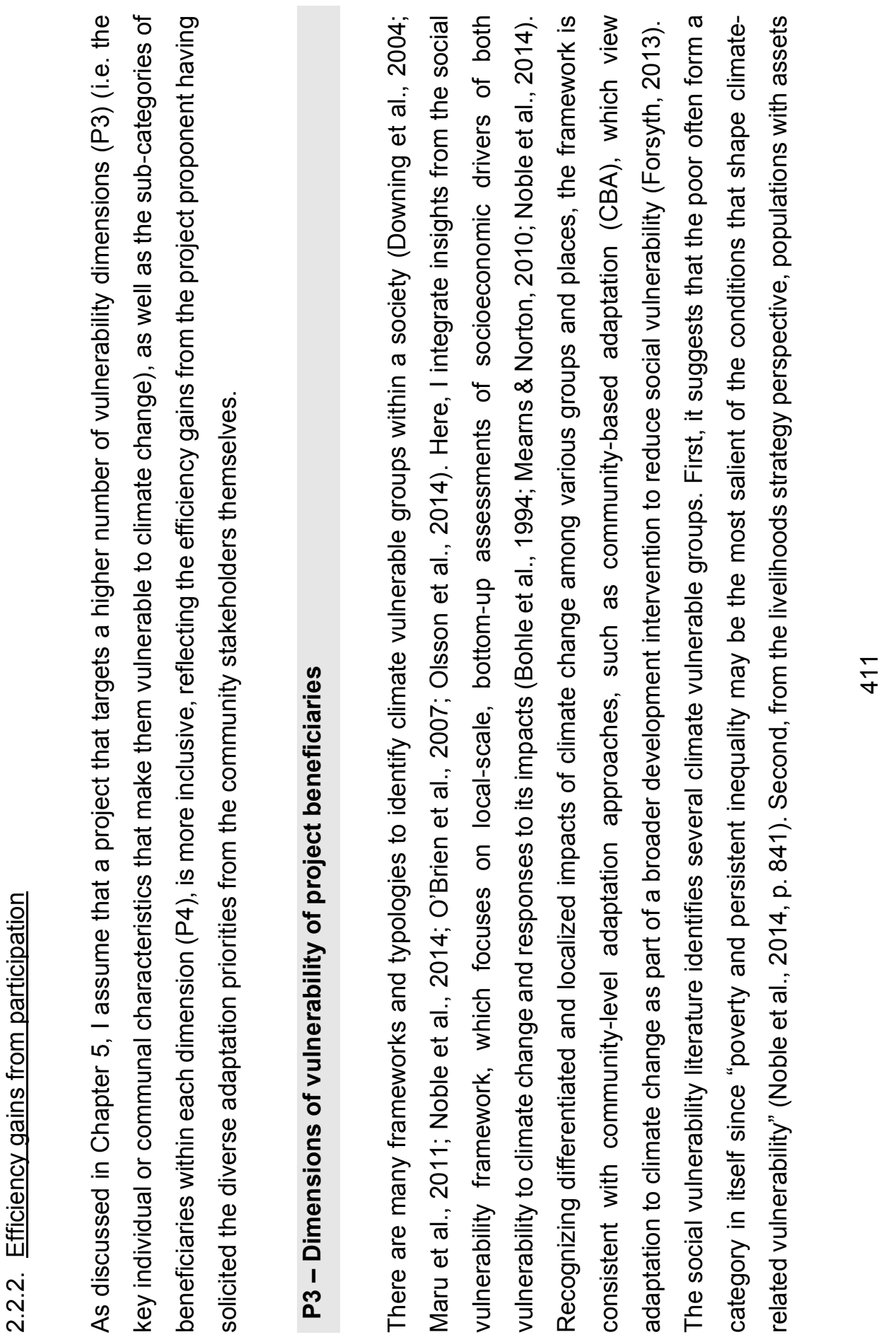




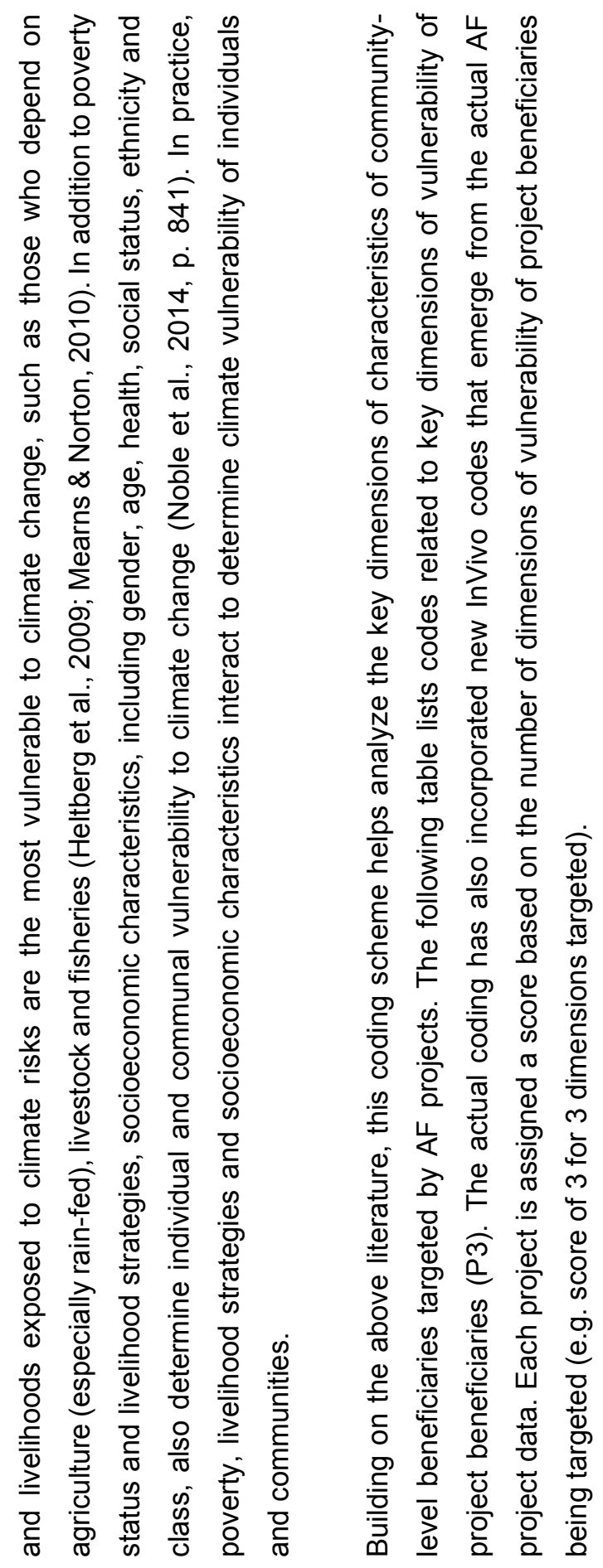



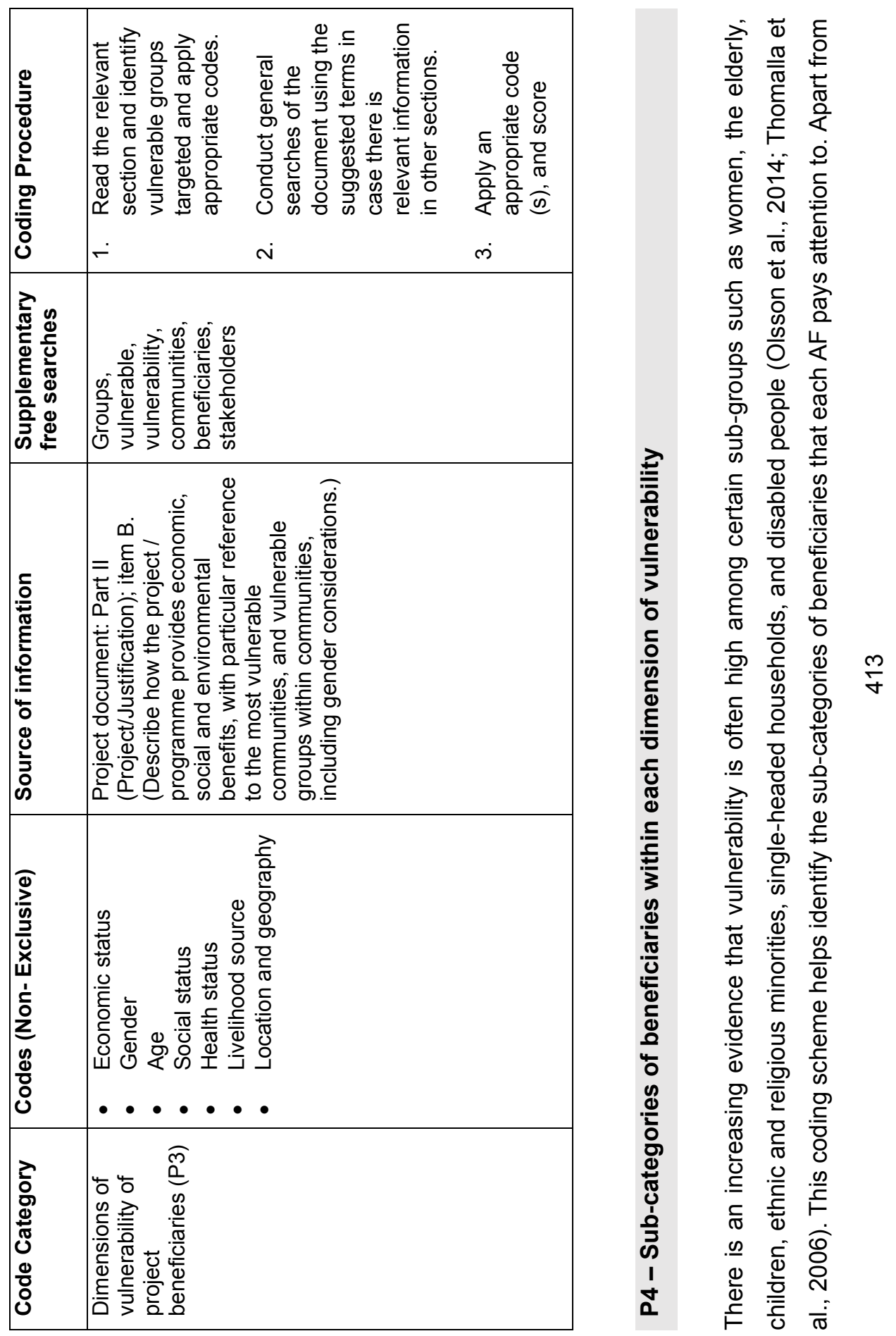


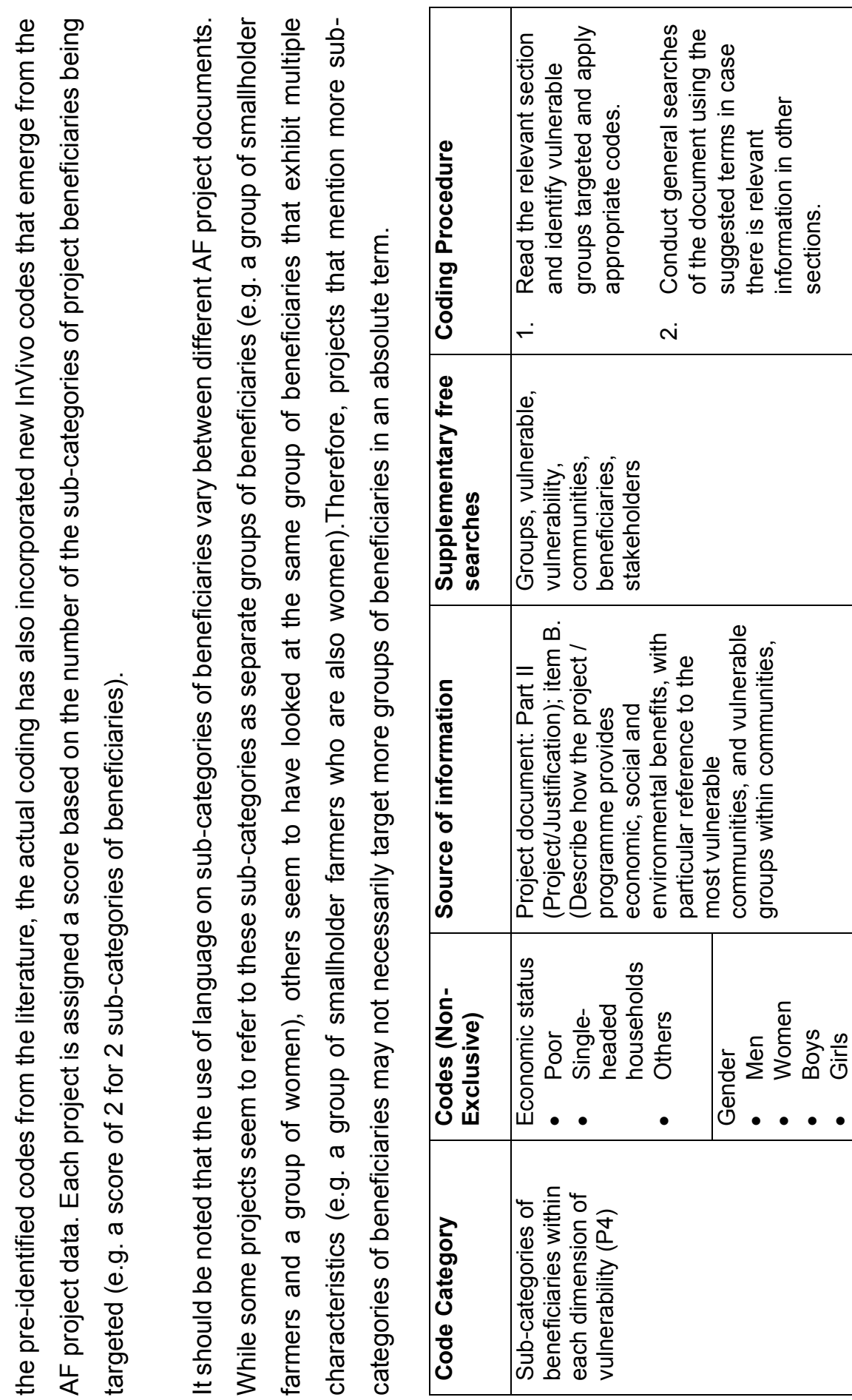




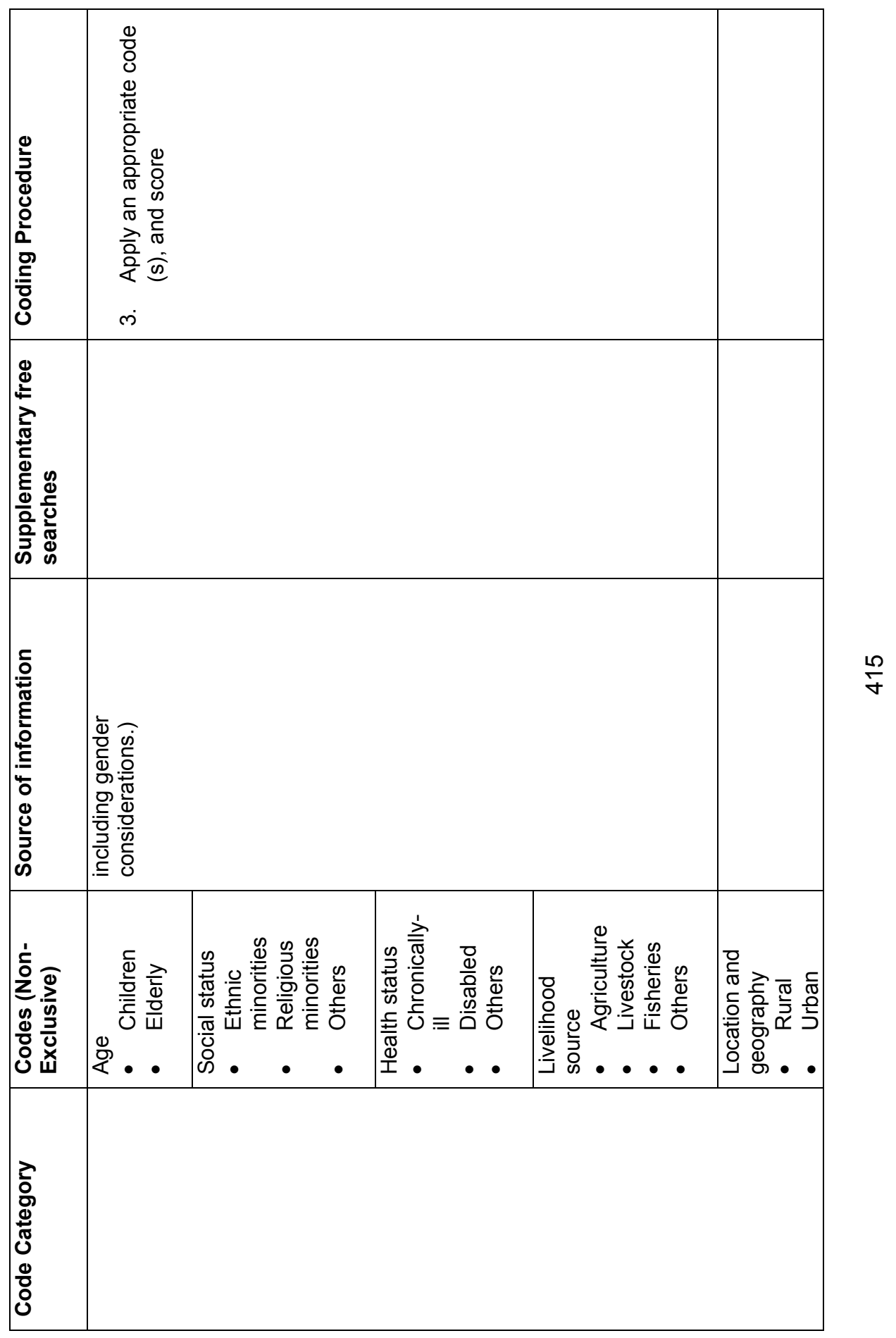



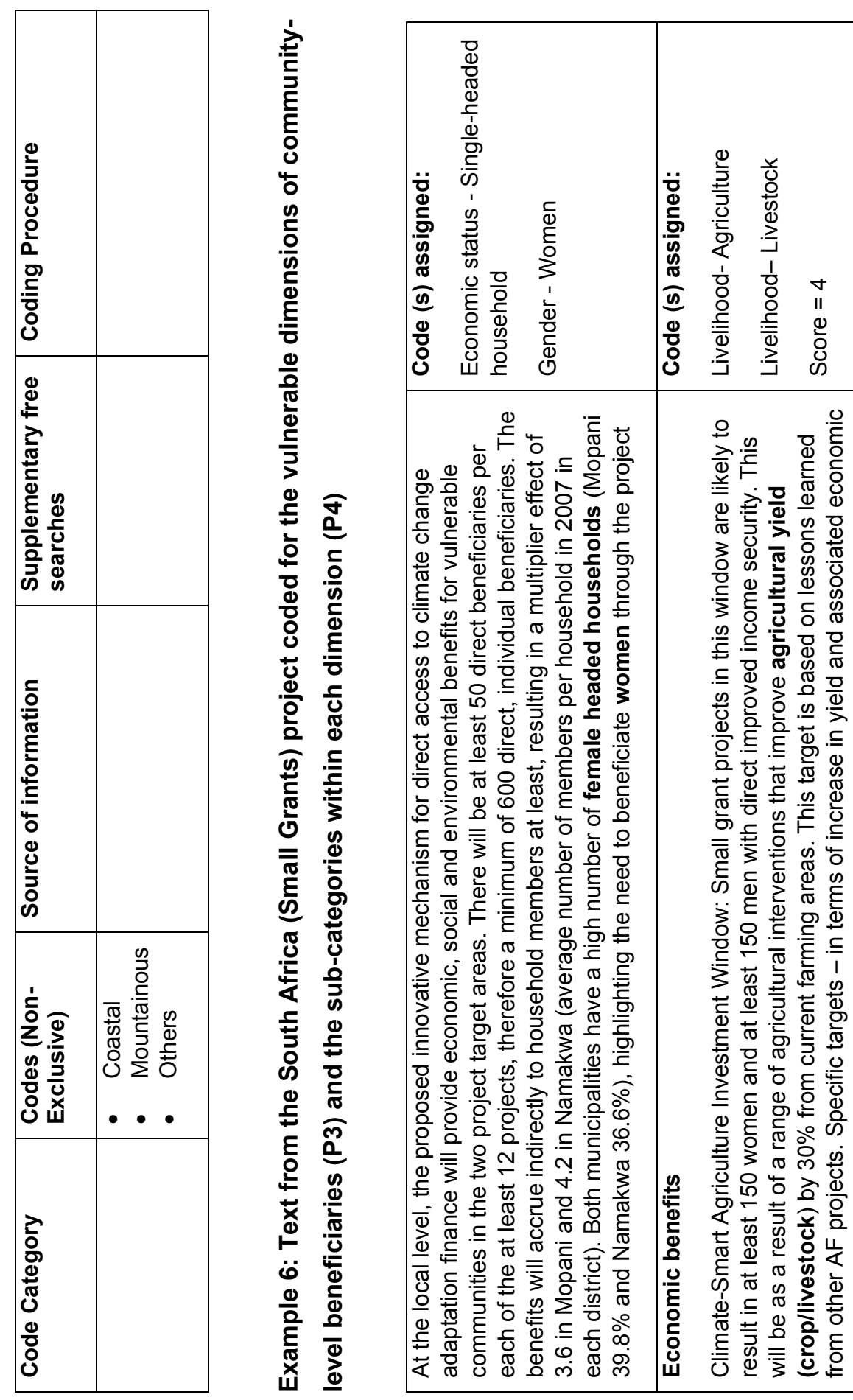

$\stackrel{0}{\frac{\sigma}{\gamma}}$ 

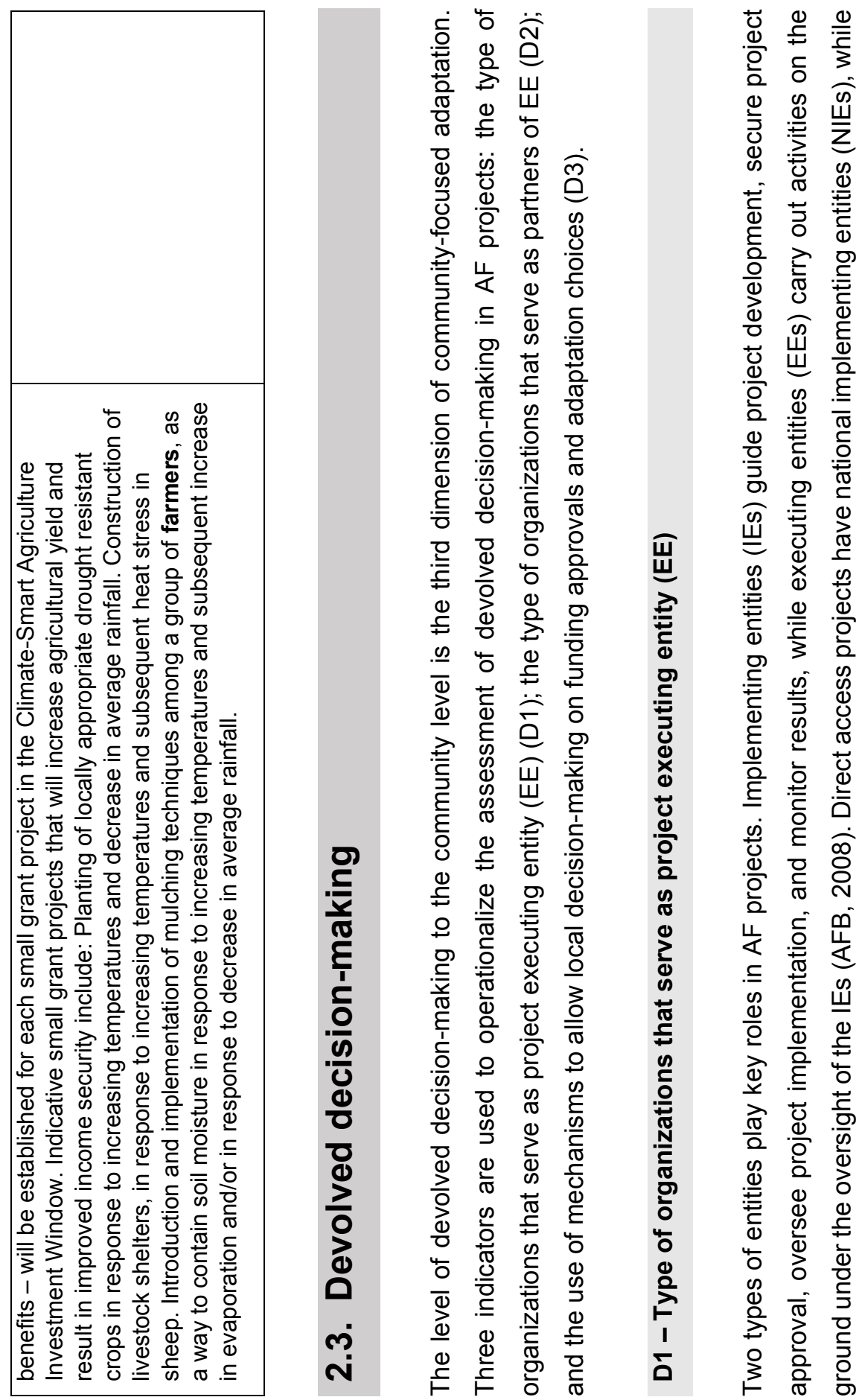

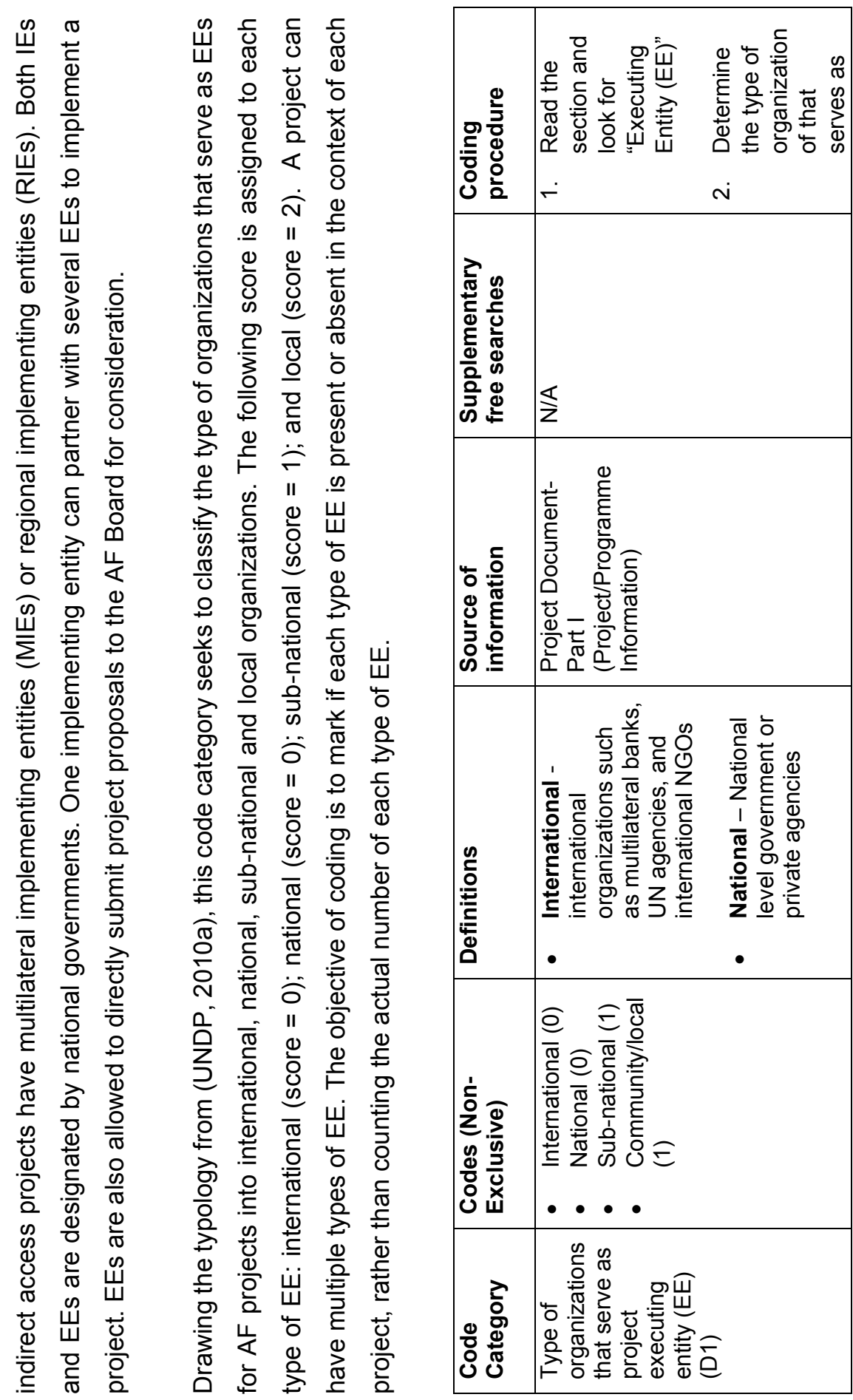


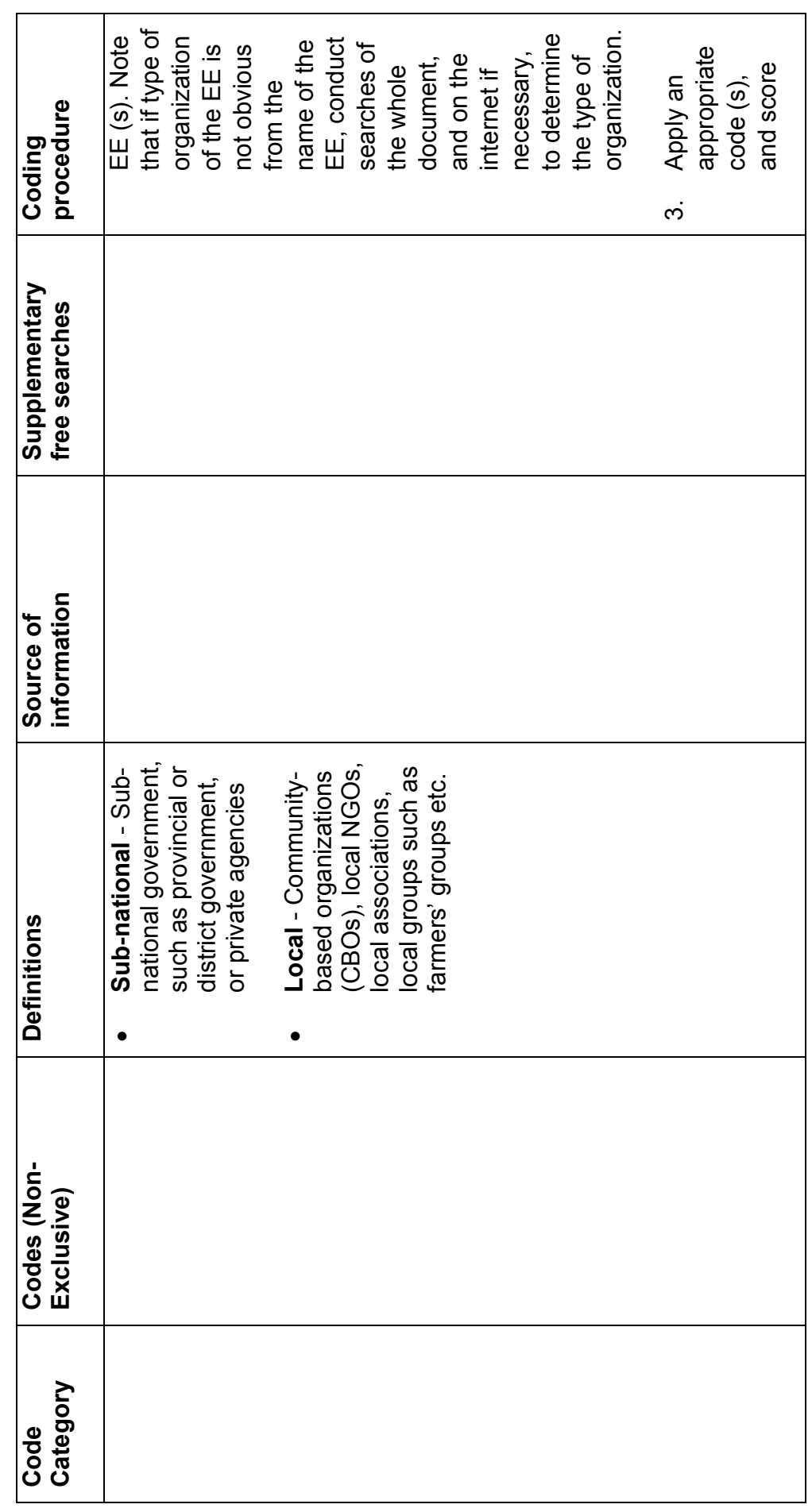



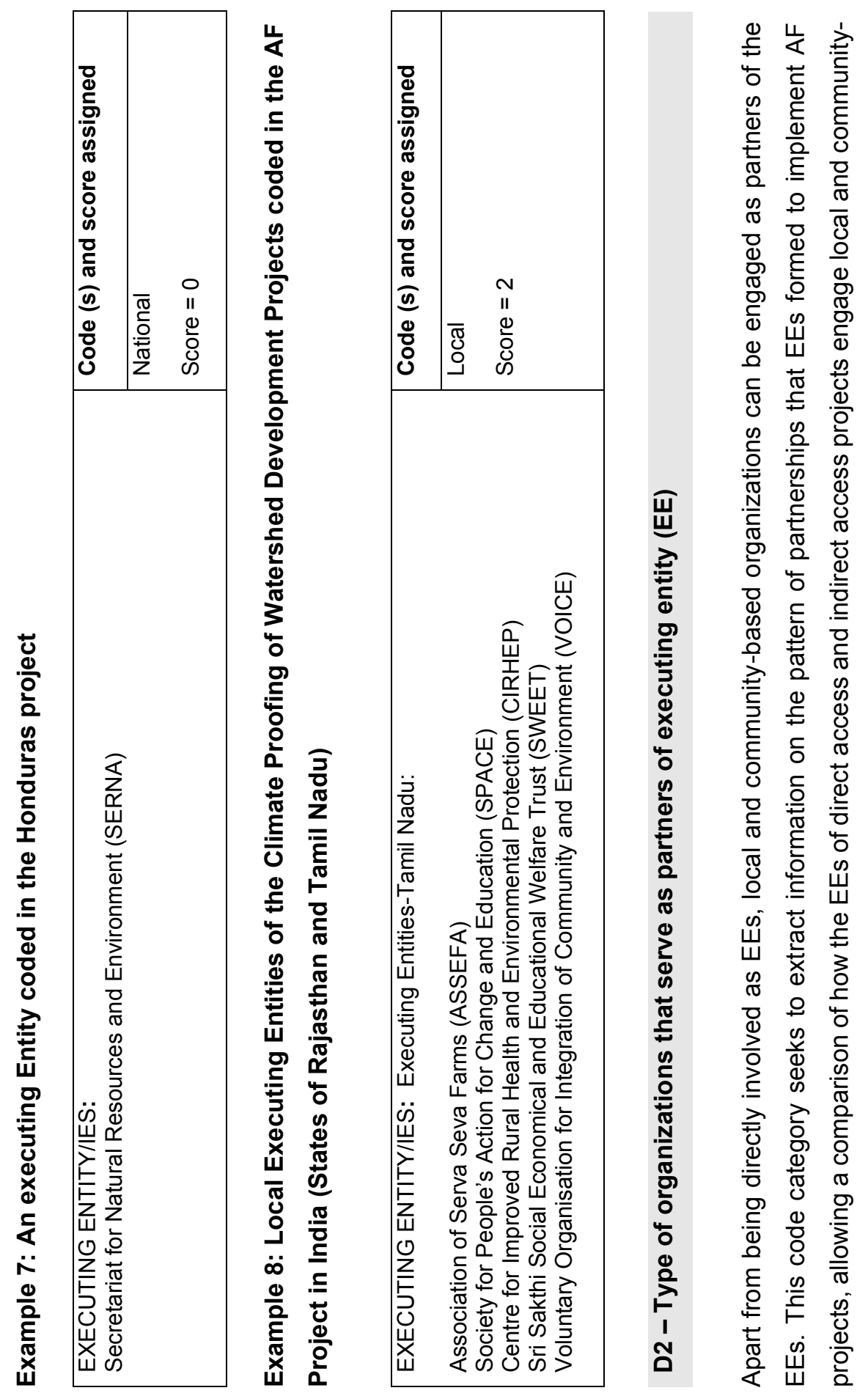

엉

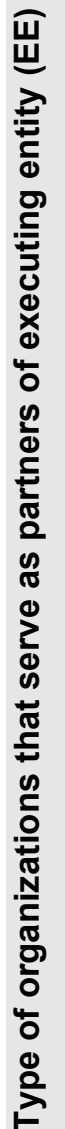

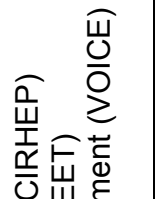
ভய Е

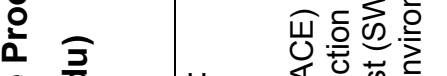

$\stackrel{0}{\stackrel{0}{0}} \frac{\pi}{2}$

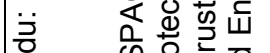

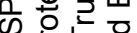

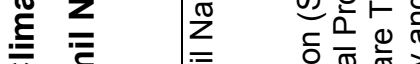

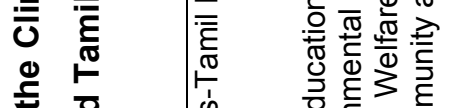

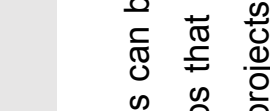

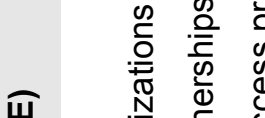

யU.

김

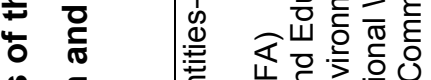

\& 든

岌

잉

$\leq \frac{1}{\sqrt{0}}$ 宁

을

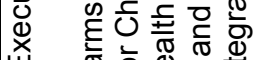

山

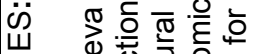

这

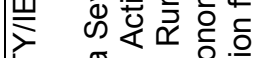

స

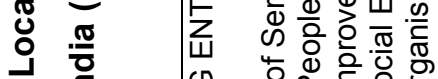

$\ddot{\infty}$ 으

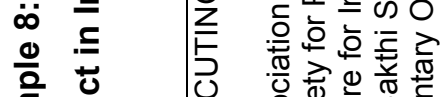

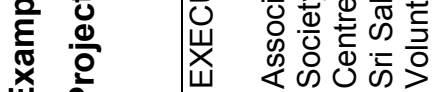

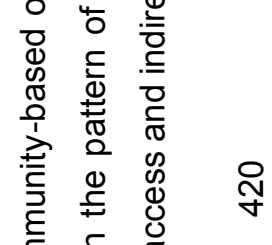

है ธ

○ 월

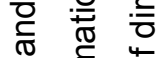

$\frac{\sigma}{\pi}$ है

으. 놀

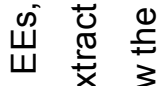

(1)

웅

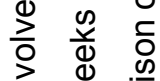

$\stackrel{\infty}{.} \stackrel{\infty}{\frac{0}{\pi}}$

ते

ब ब 0

융

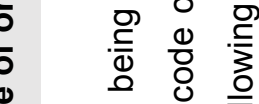

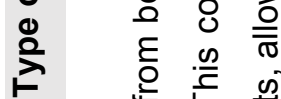

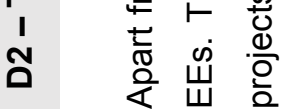




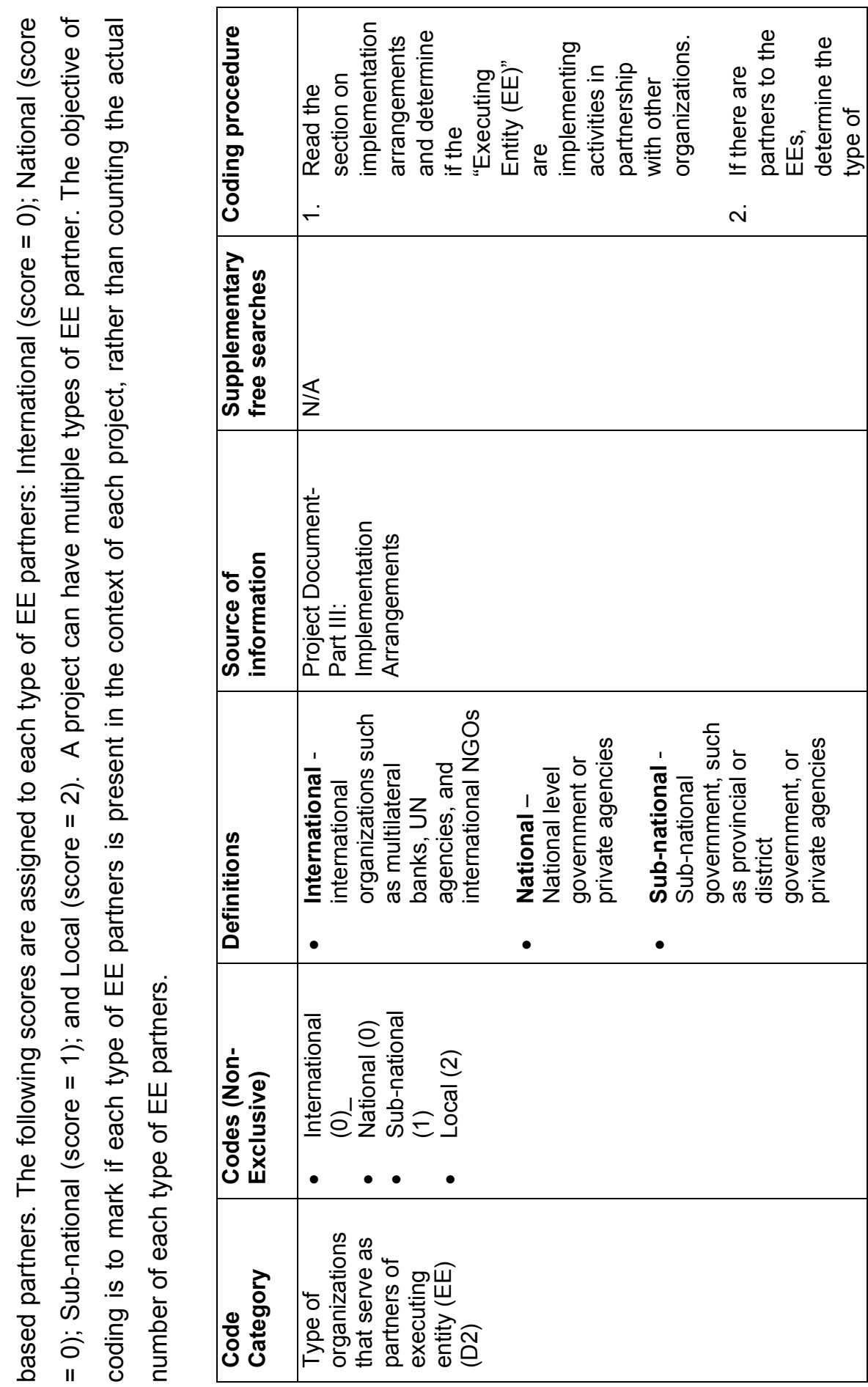

$\underset{\text { พ }}{ }$ 


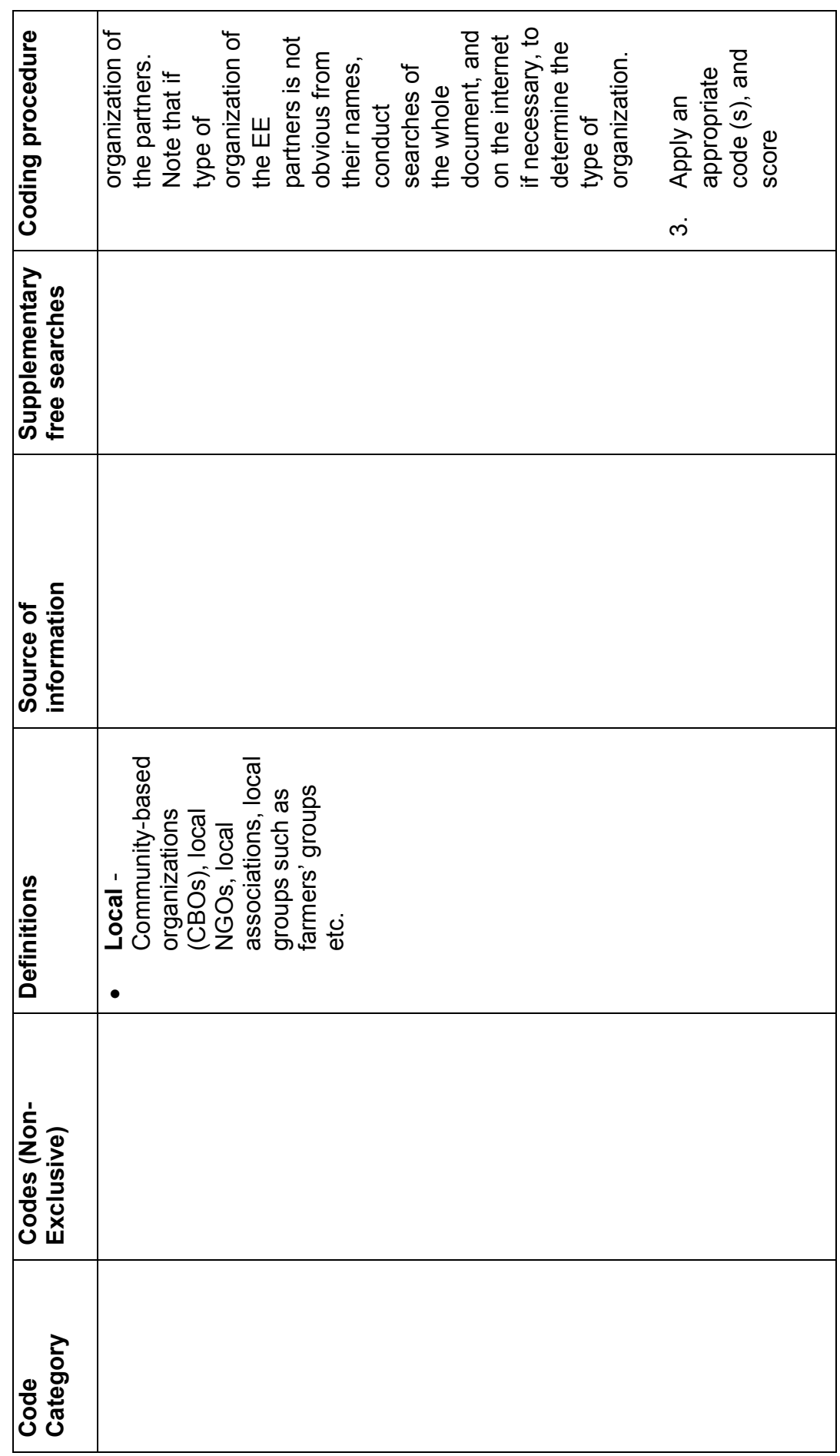

N 

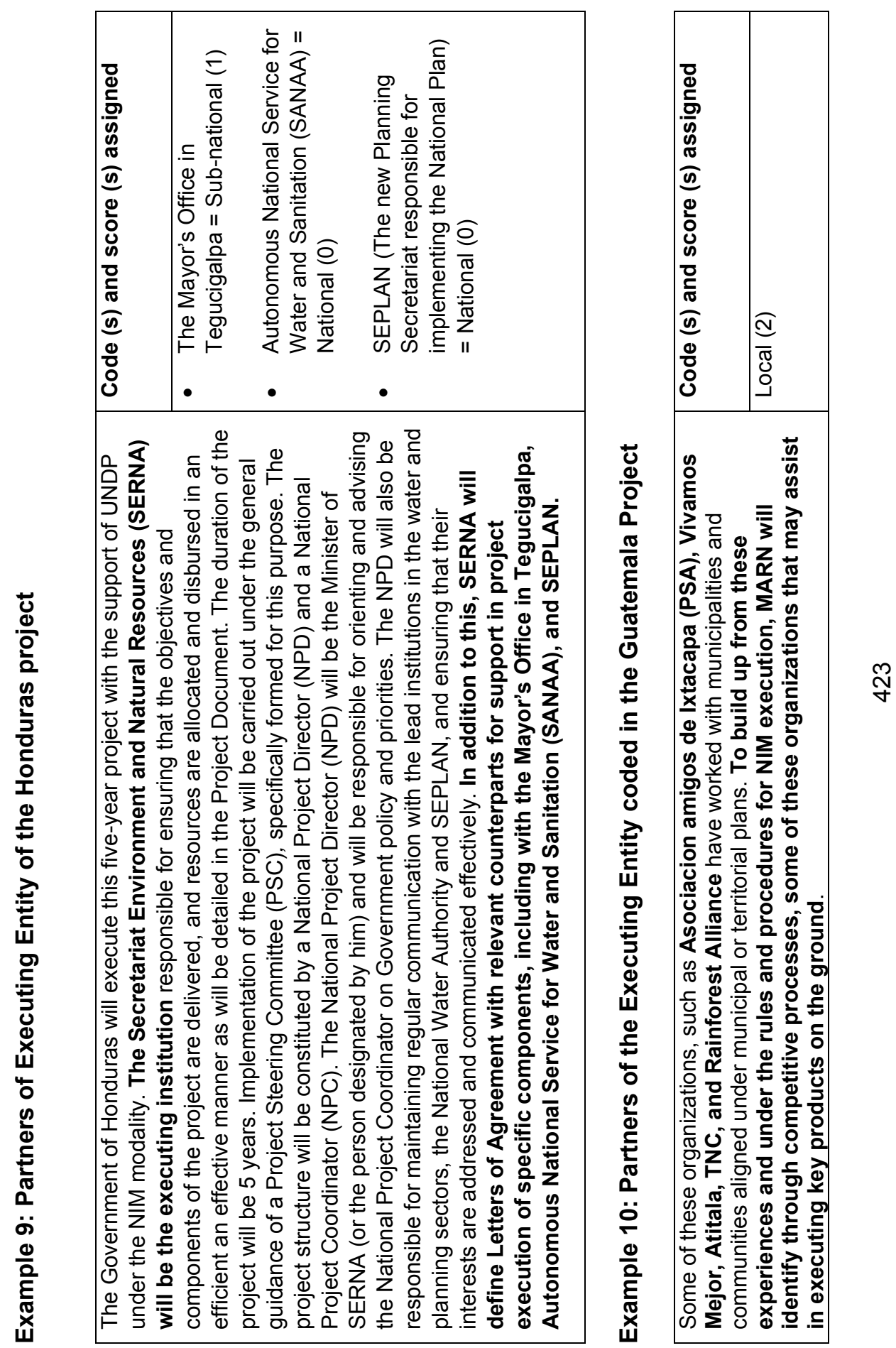


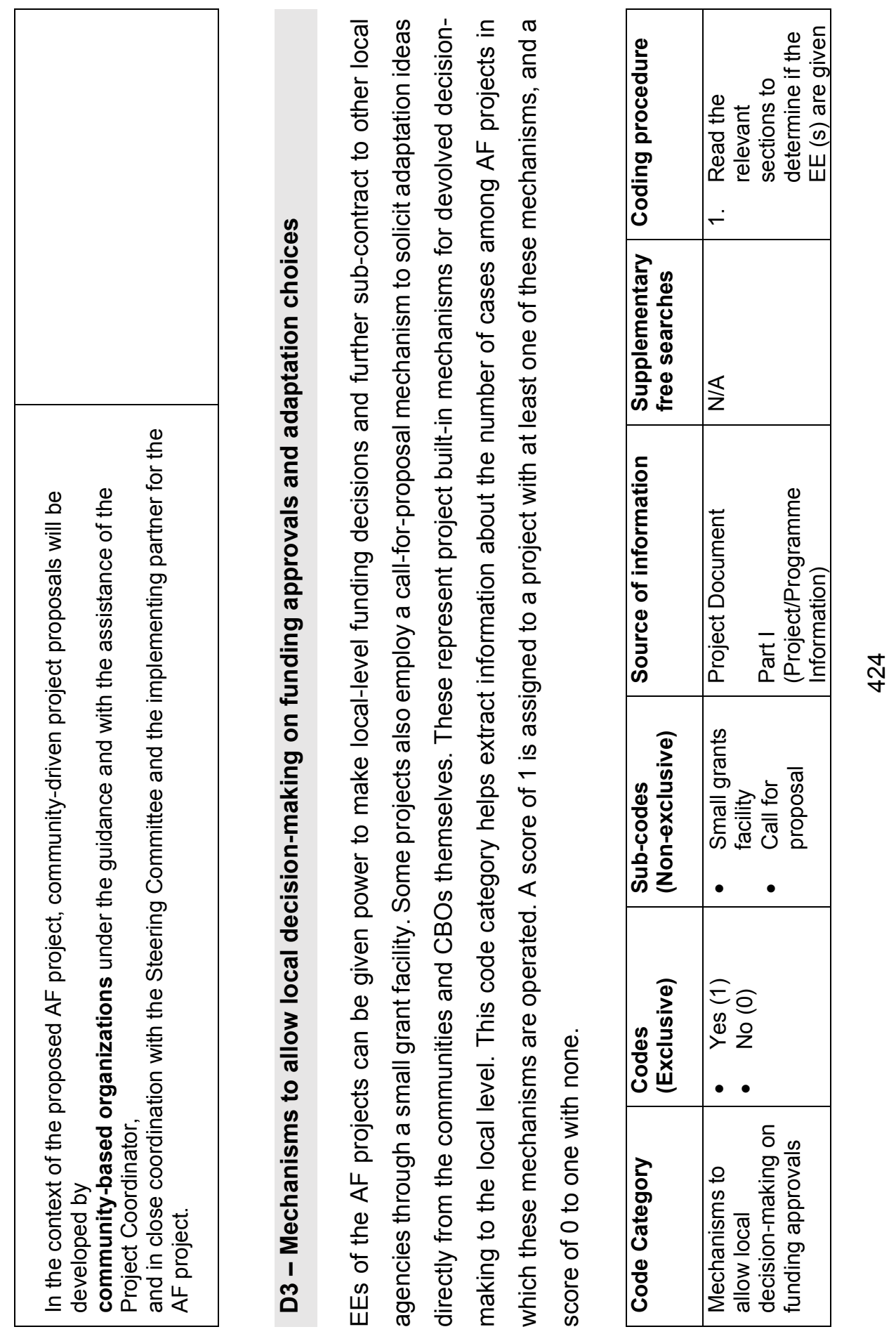




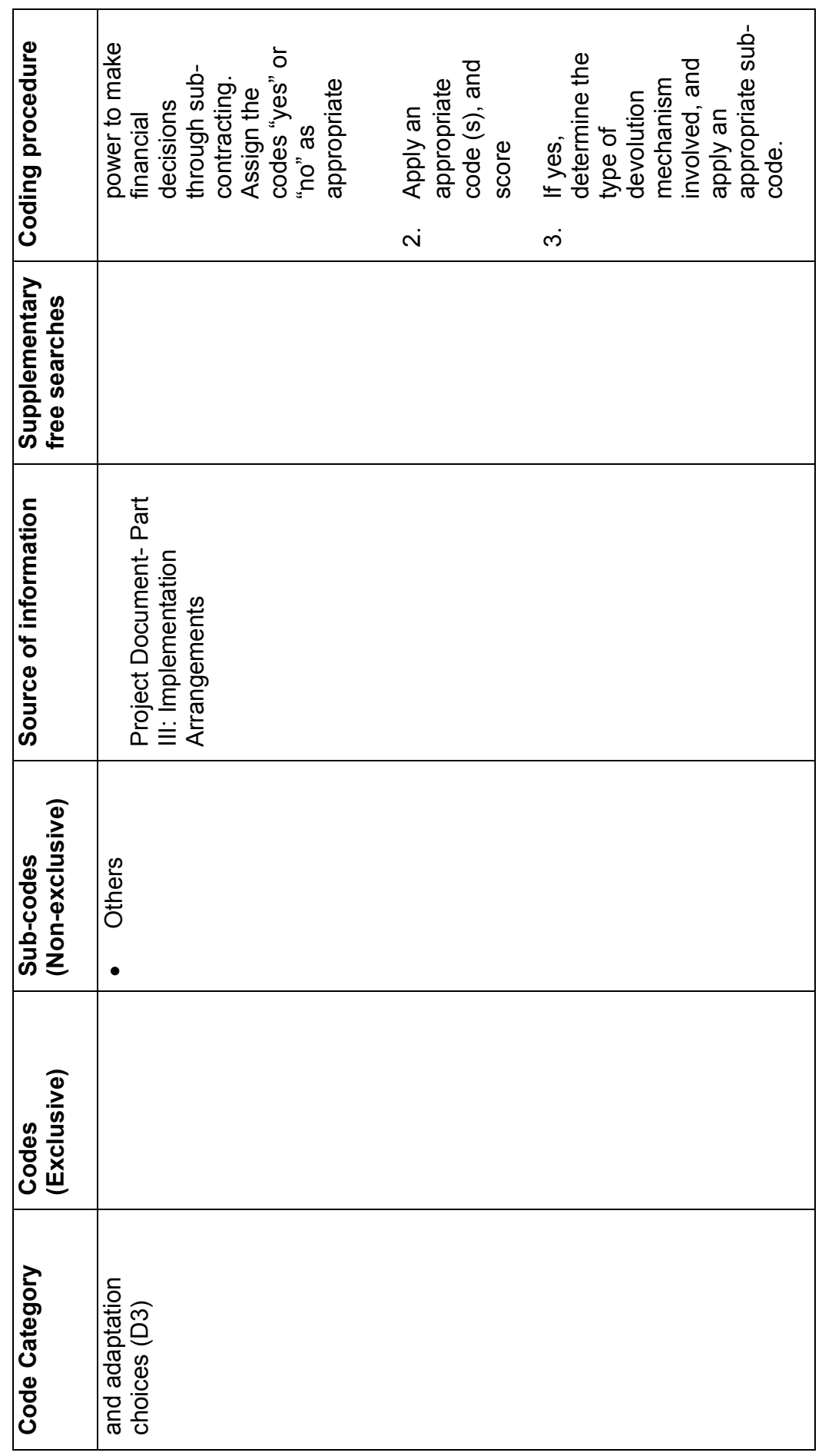

$\stackrel{\text { ำ }}{7}$ 

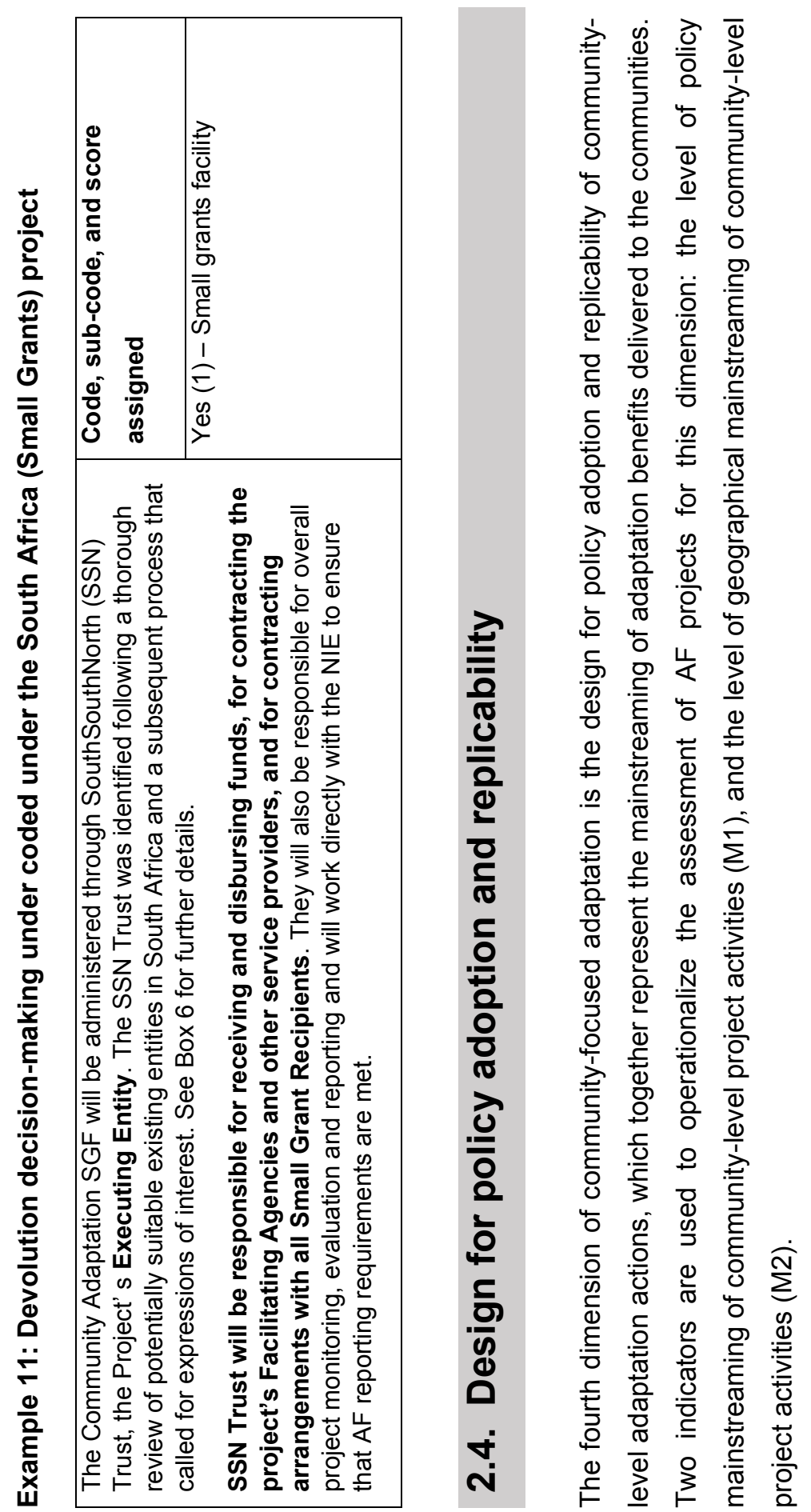

$\stackrel{\vartheta}{\vee}$ 


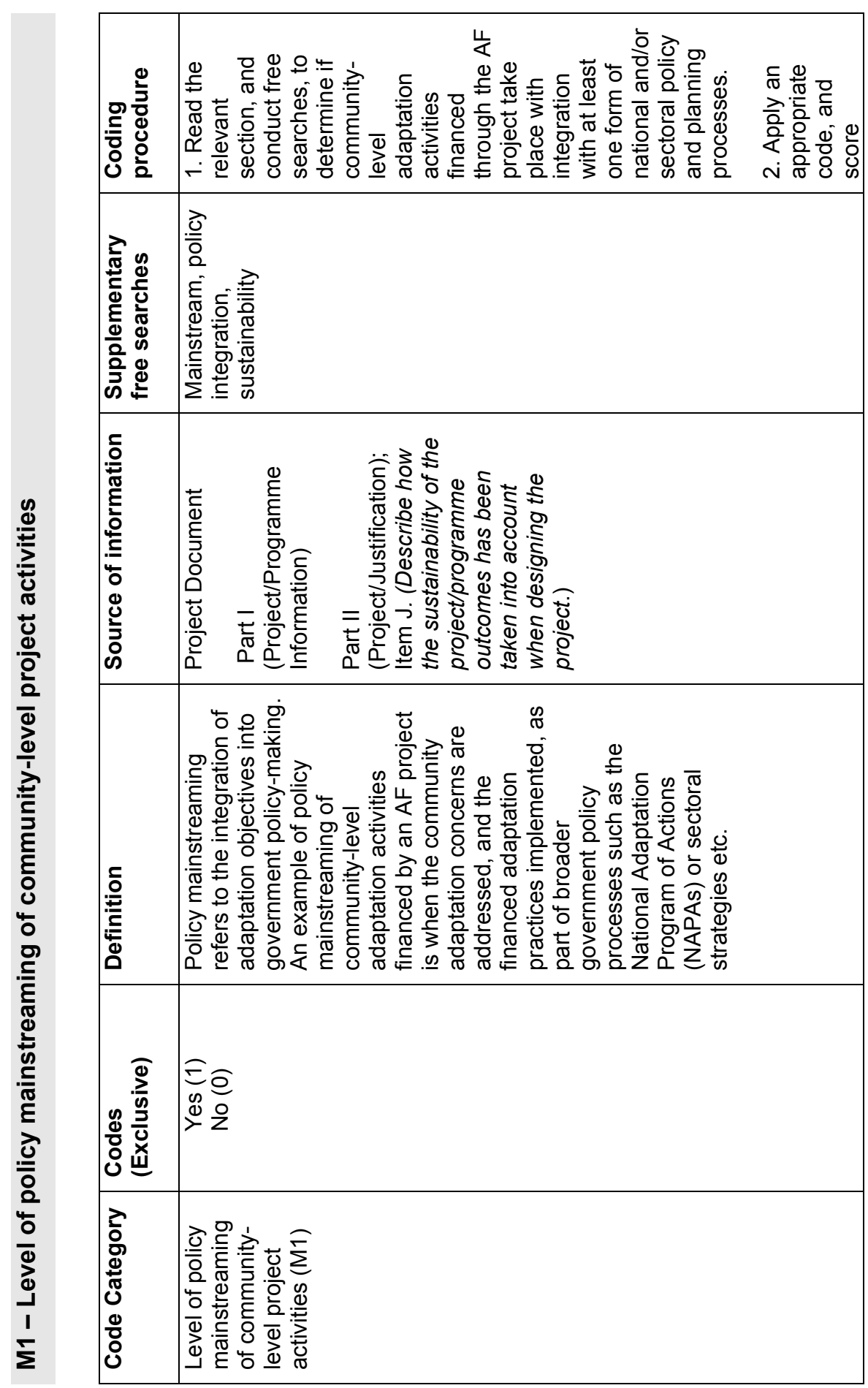

ฟ 


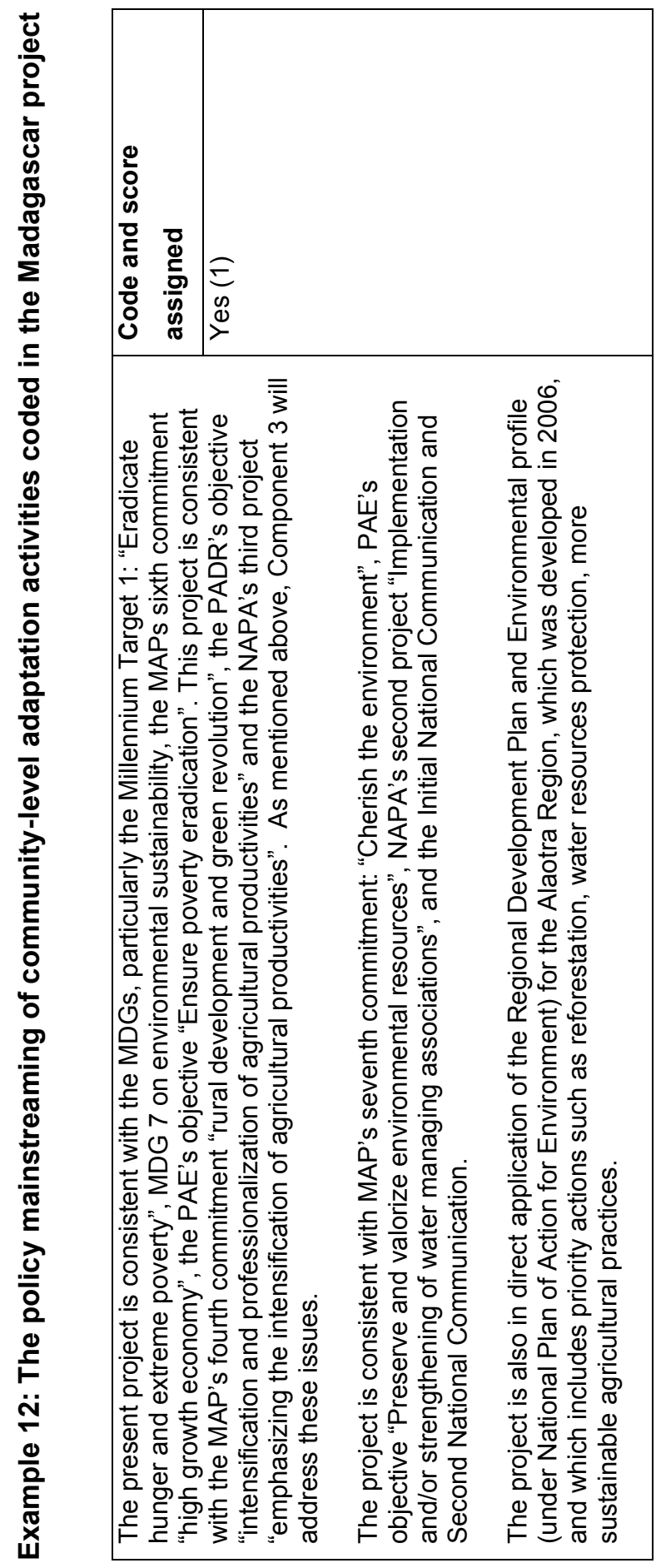

$\stackrel{\infty}{\vee}$ 


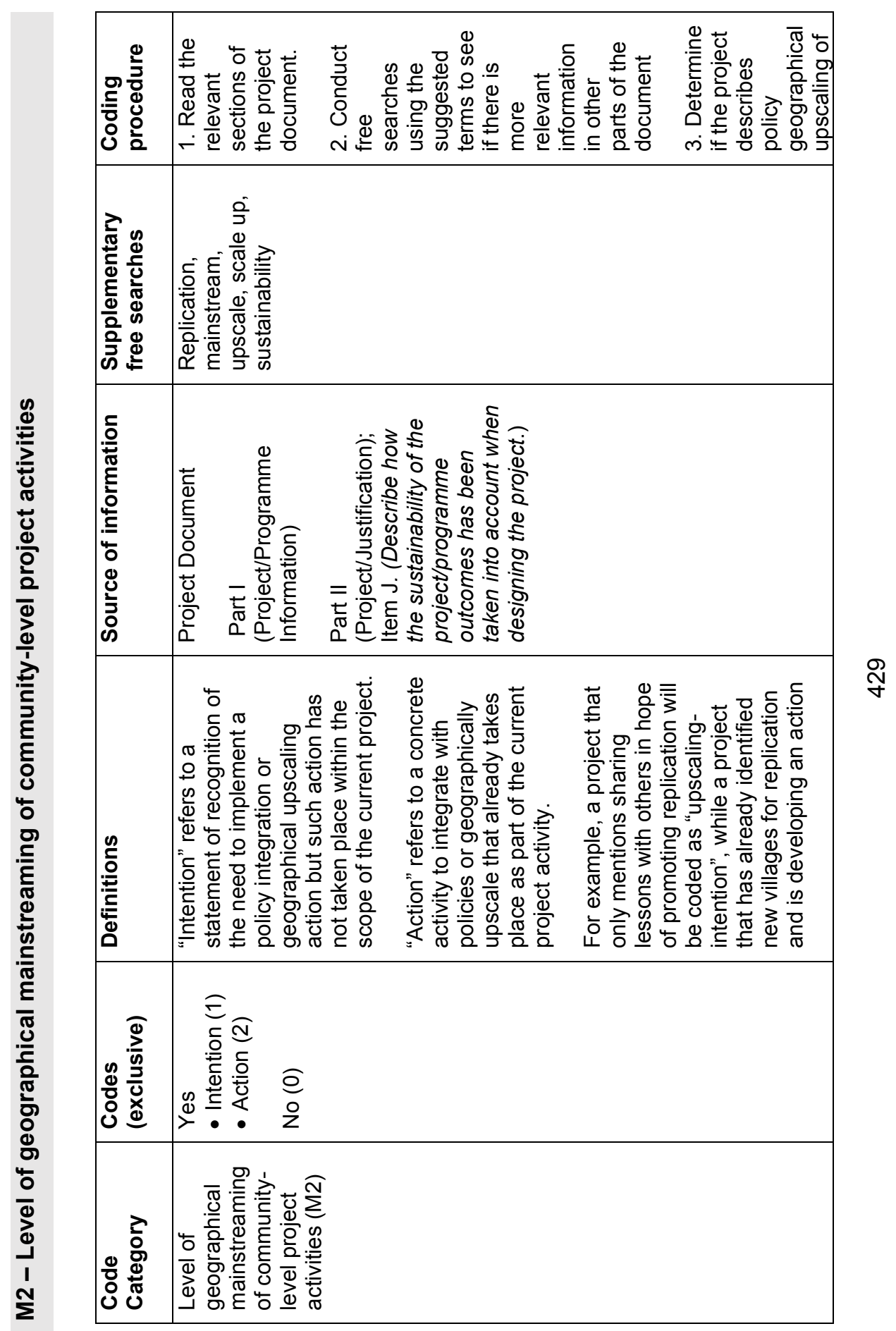



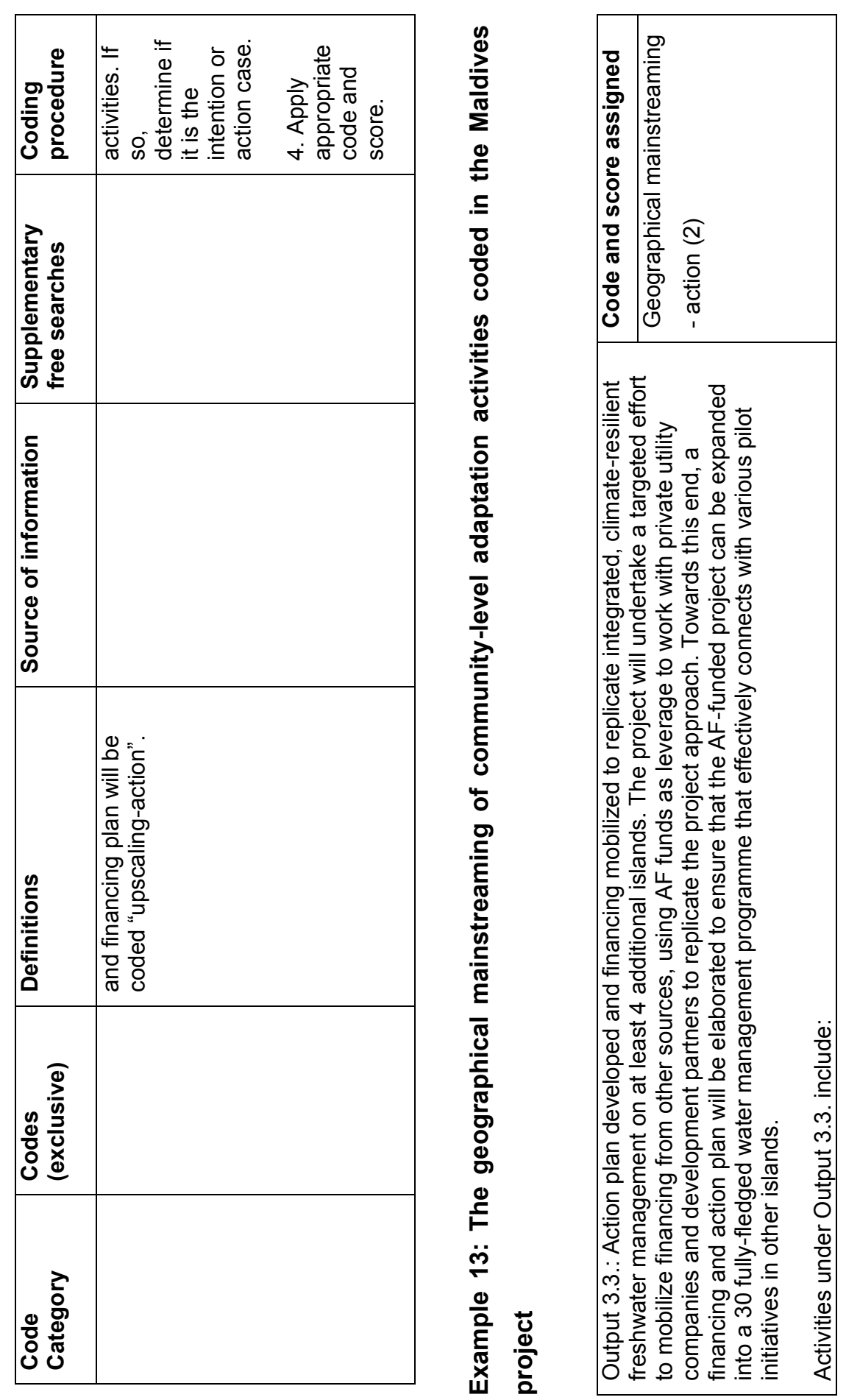

움 


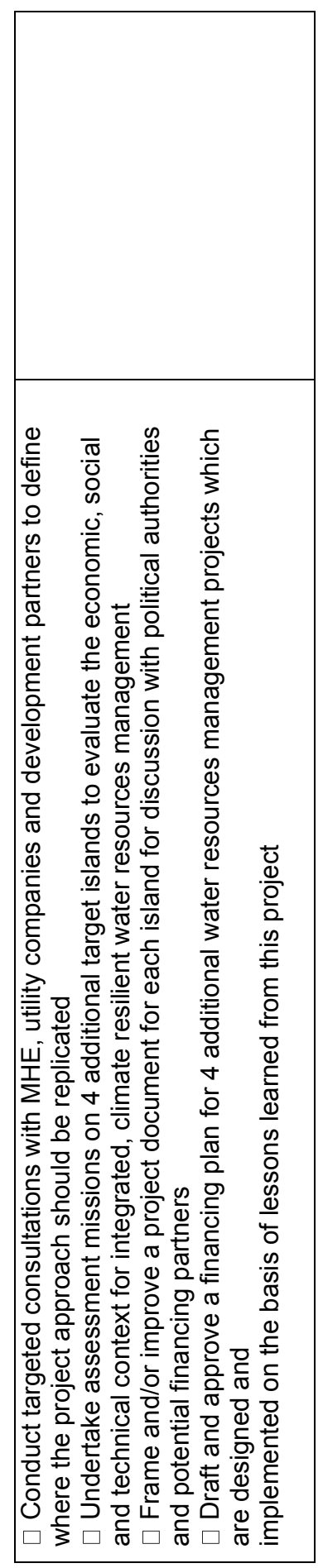

ซ্ 


\section{Annex D. Supplementary Material 4: Codebook for classifying the choices of agricultural innovations for climate change adaptation financed by Adaptation Fund Projects}

Belonging to the following chapter:

Chapter 7: Do access modalities to international adaptation finance matter for the promotion of agricultural innovations?: An analysis of 36 Adaptation Fund projects 


\section{Introduction to the codebook}

This coding scheme is part of the analysis in Chapter 7. It is designed to extract information from $36 \mathrm{AF}$ project documents from the agriculture-related sectors. The objective is to classify the choices of agricultural innovations for climate change adaptation financed by the projects.

I use the following process to develop this codebook. First, I consult the literature to identify examples of typologies of climate change adaptation options in the agricultural sector. I identify a typology of such actions in developed countries (Smit \& Skinner, 2002), and another in developing countries (Kurukulasuriya \& Rosenthal, 2013). I then use these two typologies as the initial list of codes and sub-codes (Table S4.1) to explore and extract information from AF project documents.

Table S4.1: Examples of typologies of climate change adaptation actions in the agricultural sector

Smit \& Skinner, 2002

(1) Technological developments

- Crop development

- Weather and climate information systems

- Resource management innovations

(2) Government programs and insurance

- Agricultural subsidy and support programs

- $\quad$ Private insurance

- Resource management programs

(3) Farm production practices

- Farm production

- Land Use
Kurukulasuriya \& Rosenthal, 2013

(1) Short-Term Adaptations

- Farm Responses

- Temporary Migration

- Insurance

(2) Long-Term Adaptations

- Changing Crop Type and Location

- Development of New Technologies and Modernization

- Improving Water Management

- Permanent Migration of Labor

(3) Adaptations Irrespective of the Temporal Dimension of Climate Impacts

- Investment and Accumulation of Capital 


\begin{tabular}{|c|c|c|}
\hline (4) & $\begin{array}{l}\text { - } \quad \text { Land topography } \\
\text { - } \quad \text { Irrigation } \\
\text { Farming of operations } \\
\text { - } \quad \text { Crop insurance } \\
\text { - } \quad \text { Income stabilization programs } \\
\text { Household income } \\
\text { Diversify source of household } \\
\text { income in order to address the } \\
\text { risk of climate-related income } \\
\text { loss. }\end{array}$ & $\begin{array}{l}\text { Reform of Pricing Schemes, } \\
\text { Development of Open Markets, } \\
\text { and other Reforms } \\
\text { - } \quad \text { Adoption of New Technologies } \\
\text { - } \quad \text { Promotion of Trade } \\
\text { - } \quad \text { Extension Services } \\
\text { Diversification of Income-Earning } \\
\text { and Employment Opportunities } \\
\text { - } \quad \text { Dissemination of Climate Data } \\
\text { Institutional Planning and } \\
\text { Implementation }\end{array}$ \\
\hline
\end{tabular}

Second, I identify the keywords used in the literature and AF project documents to signify when an action, product or practice constitutes an innovation in the adopting agricultural context. As discussed in Chapter 7, an agricultural innovation is understood in this dissertation as any action, product or practice which is new to the farm households, irrespective of whether it is new elsewhere (Bhatta et al., 2017; Rogers, 2003; World Bank, 2006). Agricultural innovations for climate change adaptation are therefore anything new to the farm households, which is introduced with an objective to reduce the vulnerability of agricultural production to climate change, including variabilities and extremes. Drawing from this definition, as well as a systematic review of literature (see Supplementary Material 5) and an examination of AF project documents, I develop a list of keywords that indicate the newness of an action, product or practice vis-à-vis the adopting agricultural context (e.g. pilot, innovation, innovative, new, novel, experiment, learn, transfer, adopt, test, trial, and introduce). There keywords are then used as a typology of innovation keywords to extract information from AF project documents.

Third, to identify agricultural innovations for climate change adaptation in AF project documents, I then combine the typology of agricultural adaptation actions in Table S4.1 with the typology of innovation keywords above to code 
the data. For example, a project that "pilots" a new species of drought-tolerant rice is initially coded as disseminating innovation for "farm production practice". I pilot-test this initial coding scheme with six sample AF projects to ensure the scheme's applicability to the project documents.

Fourth, the pilot-testing of the initial coding scheme leads to more fine-tuning and finalization of all codes and sub-codes, which incorporate some new codes emerging from the project document data. Through this iterative process, I reorganize the initial codes from Table S4.1 into the final coding scheme for the analysis in Chapter 7 . The final coding scheme, presented as Table 7.1 in Chapter 7 , is then used to code all the 36 AF projects using Atlas.ti. Information extracted is then used to generate the descriptive statistics on the choices of agricultural innovations disseminated through the $36 \mathrm{AF}$ projects.

The following table summarizes the final coding scheme and the coding procedure and provides an example of how it is applied to AF project data. 


\begin{tabular}{|c|c|c|c|c|c|}
\hline 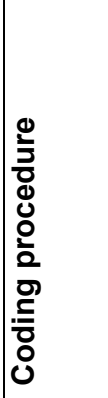 & \multicolumn{5}{|c|}{ 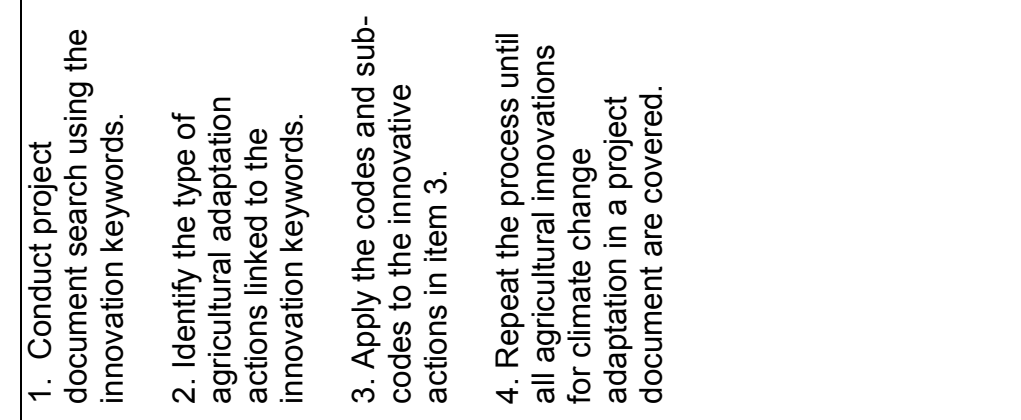 } \\
\hline 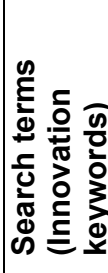 & \multicolumn{5}{|c|}{ 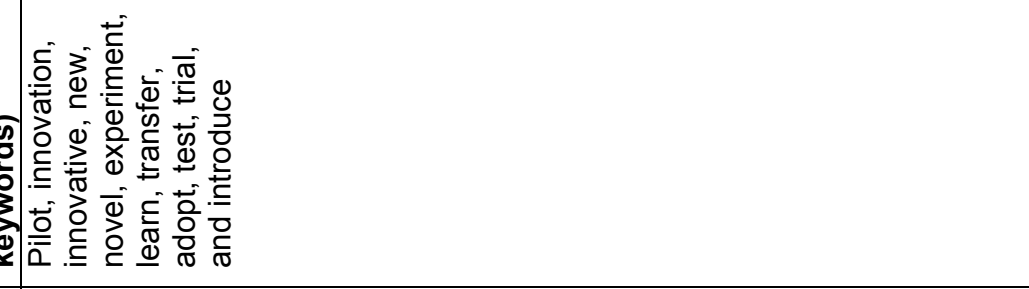 } \\
\hline 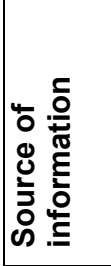 & \multicolumn{5}{|l|}{ 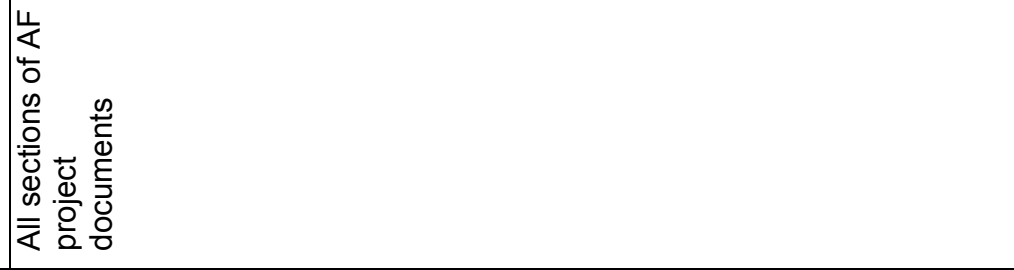 } \\
\hline 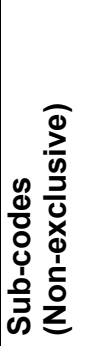 & \multicolumn{3}{|c|}{ 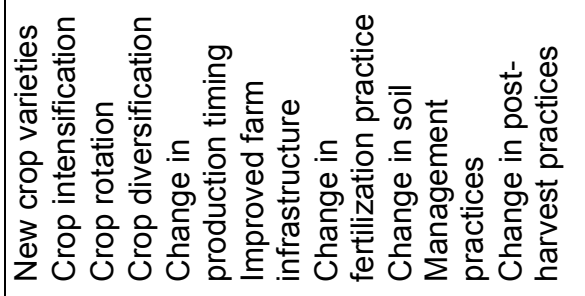 } & 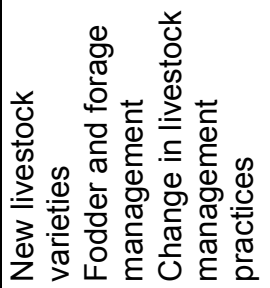 & 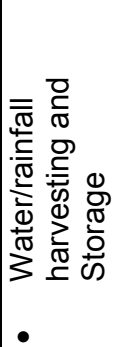 \\
\hline 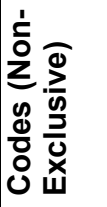 & 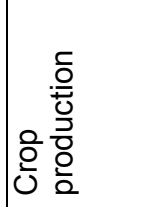 & & & 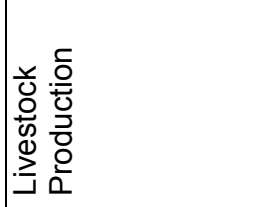 & 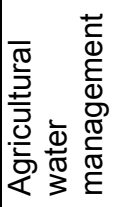 \\
\hline 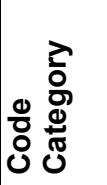 & 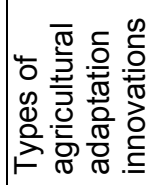 & & & & \\
\hline
\end{tabular}




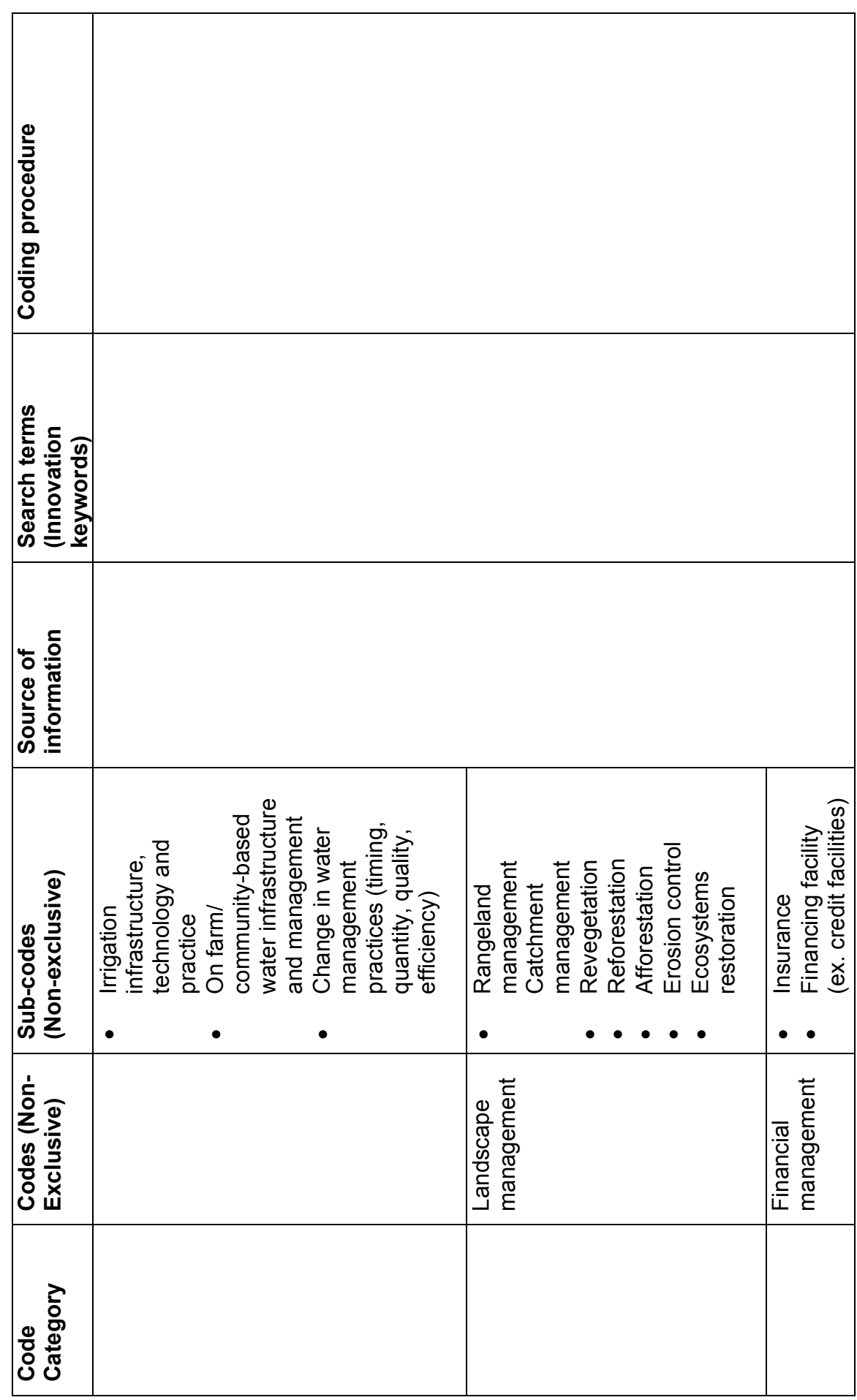

 


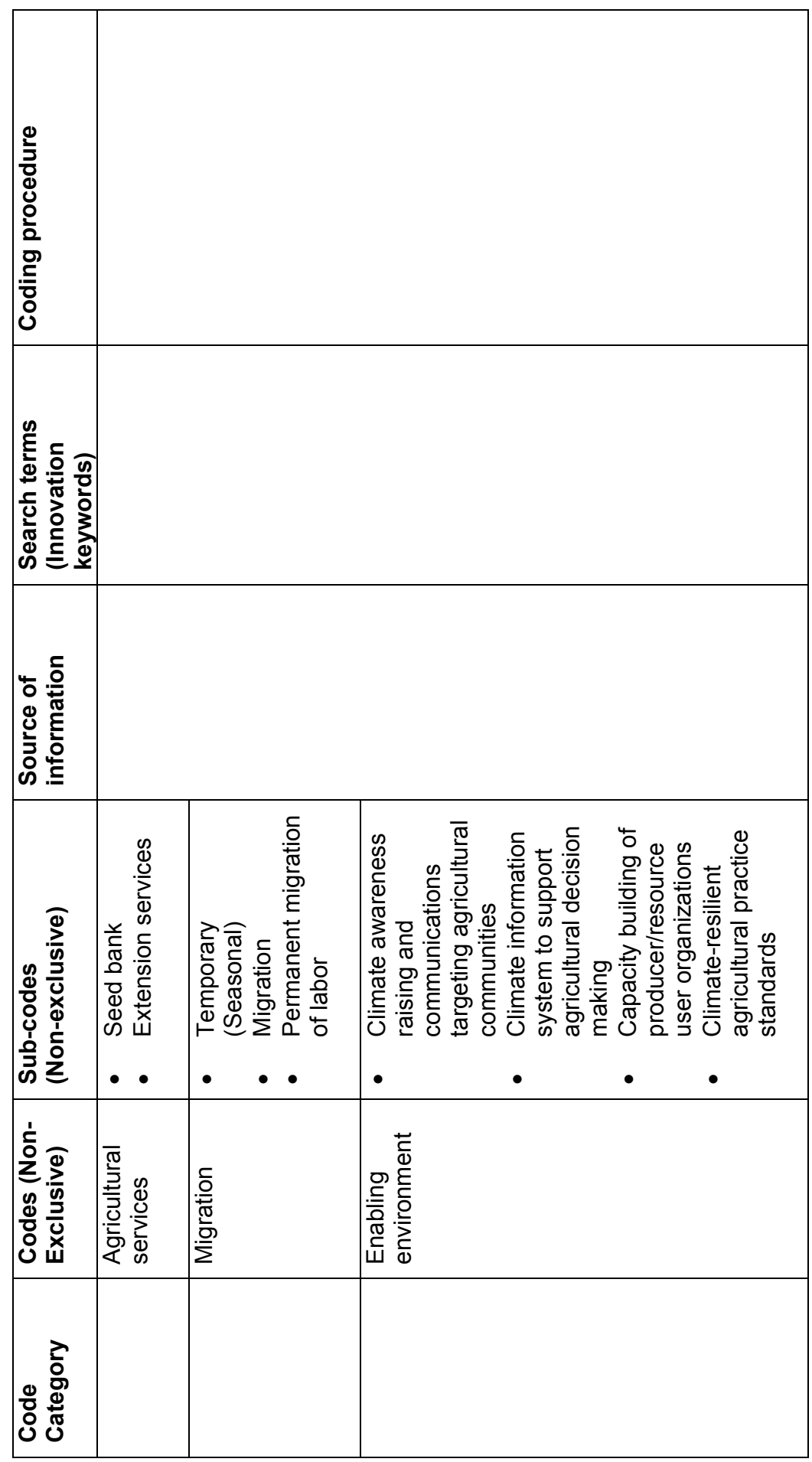

$\stackrel{\infty}{\sim}$ 


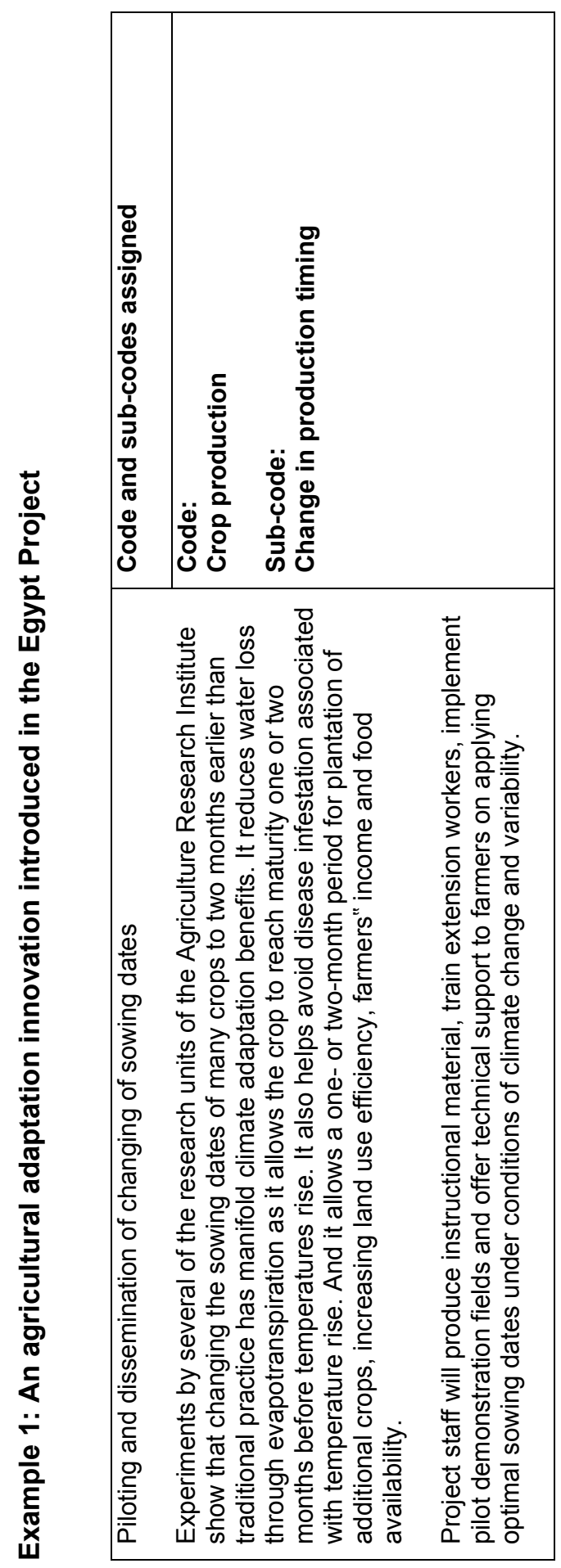

ก 


\section{Annex E. Supplementary Material 5: A systematic literature review of the drivers of dissemination, adoption and diffusion of agricultural innovations for climate change adaptation}

Belonging to the following chapter:

Chapter 7: Do access modalities to international adaptation finance matter for the promotion of agricultural innovations?: An analysis of 36 Adaptation Fund projects 


\section{Introduction}

This systematic literature review aims to identify the drivers of innovation dissemination, adoption, and diffusion in the specific context of agricultural innovations for climate change adaptation in developing countries. Given that the initial level of agricultural technological sophistication is generally higher in developed countries, focusing on studies from developing countries helps identify the innovation drivers in the context of lower initial technological development which generally characterizes AF recipient countries.

\section{Methodology}

Drawing on the methodologies of Berrang-Ford et al. (2015), Biesbroek et al. (2013); Ford et al. (2011), I conduct a systematic search of the Scopus database to select the most relevant articles for this literature analysis. First, I focus the search on the literature from environmental and social sciences published on the year 2008 onwards. The year 2008 is the period after agricultural climate vulnerability was recognized as a global development agenda (World Bank, 2007), leading to the proliferation of articles on the role of agricultural innovations for climate change adaptation and/or climate-smart agriculture in developing countries. Second, I conduct an initial assessment of the adaptation literature to identify keywords and a synonyms list, which I subsequently use to develop a configuration of search query for the Scopus database (Table S5.1). The search query yields an initial list of 396 articles.

Table S5.1: Configuration of the search query

\begin{tabular}{|c|}
\hline Search query for Scopus \\
\hline 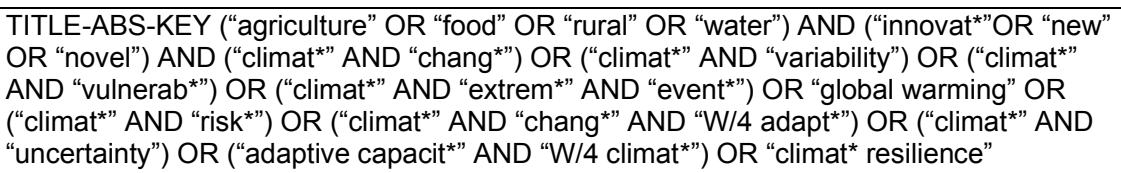 \\
\hline
\end{tabular}


Third, I review the abstracts of the 396 articles against the inclusion and exclusion criteria to identify the final corpus of 32 most relevant articles (Table S5.2).

Table S5.2: Inclusion and exclusion criteria for the selection of articles

\begin{tabular}{l}
\hline Inclusion criteria used for screening titles, abstracts and keywords \\
\hline I1. Explicit mentioning of adaptation to climate change as the main context of the article \\
I1. Focus on adaptation actions to respond the impacts of climate change \\
I3. The agricultural sector, including relevant issues such as livestock, food security, water \\
management in agricultural use, as the main sector under the investigation \\
I4. Understanding innovations in the context of the agriculture's sector adaptation to climate \\
change should be the main aim to the paper, not a side observation \\
I5. Of relevance to developing countries \\
\hline Exclusion criteria used for screening titles, abstracts and keywords \\
\hline E1: Not relevant topics: mitigation, reducing emissions from deforestation and forest \\
degradation (REDD), energy, deforestation, biodiversity, conservation, climate change \\
adaptation in the urban sector, general environmental management, environmental impact \\
and pollution, ecosystem, ecological change, agri-food system, general agricultural policy and \\
management, land use, crop modeling, water modeling, general water management. social \\
change, and intellectual property rights. \\
E2. Exclusive focus on climate science (climate change modelling and projections) \\
E3. Exclusive focus on the building of climate-related data infrastructure \\
E4. Methodological frameworks and techniques to study aspects and impacts of climate \\
change (ex. modelling, computerized general equilibrium model, participatory assessment, \\
scenario-based planning, remote sensing, trend analysis, decision support tools etc.) \\
E5. Focus on climate impact and vulnerability assessment not adaptation actions \\
E6. Natural climate change adaptation processes not involving human response \\
E7: Climate justice \\
E8: Description of climate change or adaptation research collaboration
\end{tabular}

Finally, I review the full content of the 32 articles to identify the drivers of dissemination, adoption and diffusion of agricultural innovations for climate change adaptation in developing countries which have been documented in the literature. Figure S5.1 summarizes the whole literature review process. 


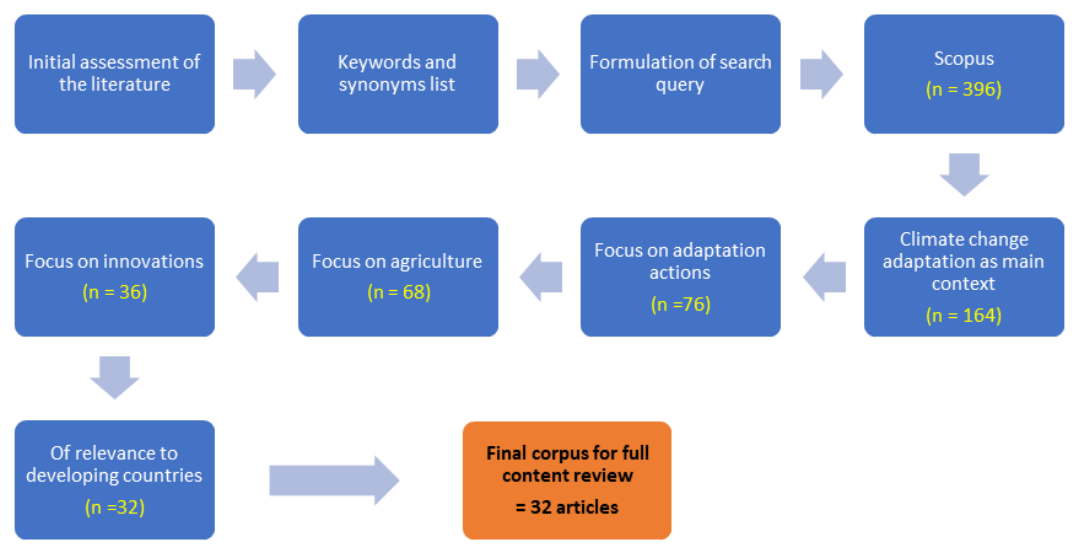

Figure S5.1: A systematic literature review to identify the divers of dissemination, adoption, and diffusion of agricultural innovations for climate change adaptation in development countries

Source: Author.

\section{Review findings}

\subsection{Dissemination drivers}

Sixteen out of the 32 articles I reviewed discuss the dissemination aspect of agricultural innovations for climate change adaptation in developing countries. Seven dissemination drivers are highlighted in these articles (Table S5.3). First, agricultural research and development (R\&D) partnerships enable local research and government agencies to develop innovations that suit new local climatic conditions, and make them available for public dissemination (Chhetri \& Easterling, 2010; Moeletsi et al., 2013; Webersik \& Wilson, 2009). Second, consultation and direct participation of farmers in agricultural $R \& D$ provide key inputs for public agencies to disseminate the most locally appropriate innovations (Bocco \& Napoletano, 2017; Chhetri et al., 2012, 2013). Third, collaboration between public and private stakeholders 
beyond the R\&D and farmer communities creates a broader enabling environment for agricultural innovations (Bogale, 2015; Chhetri et al., 2012; Matsaert et al., 2011; Ojha et al., 2014; Röling, 2016; Webersik \& Wilson, 2009). Fourth, institutional capacity in public and private sectors needs to be strengthened to support public dissemination of agricultural innovations (Bhatta et al., 2017; Lybbert \& Sumner, 2012; Matsaert et al., 2011; Moreddu \& Van Tongeren, 2013; Popke et al., 2016). Fifth, public dissemination of several agricultural innovations, such as new seeds and new insurance products, requires functioning markets (Bogale, 2015; Lybbert \& Sumner, 2012; Ojha et al., 2014). Sixth, the identification of the right policy entry points contributes to successful innovation dissemination (Matsaert et al., 2011; Nyikahadzoi et al., 2017; Nzeadibe et al., 2012). Finally, public adaptation innovation programs benefit from sustained efforts in raising awareness on climate change among farming communities (Nzeadibe et al., 2012).

Table S5.3: Factors influencing the dissemination of agricultural innovations for climate change adaptation through public programs in developing countries.

\begin{tabular}{|l|l|l|}
\hline Factor & Examples & References \\
\hline $\begin{array}{l}\text { Agricultural } \\
\text { R\&D } \\
\text { partnerships }\end{array}$ & $\begin{array}{l}\text { The Coordinated Rice Research Program (CRRP) } \\
\text { coordinated with the International Rice Research } \\
\text { Institute to new cultivars and improved agronomic } \\
\text { management practices in Nepal }\end{array}$ & $\begin{array}{l}\text { Chhetri \& } \\
\text { Easterling (2010) }\end{array}$ \\
\cline { 2 - 3 } & $\begin{array}{l}\text { The African Rice Centre, supported by the United } \\
\text { Nations Development Programme and the Japanese } \\
\text { government, developed the New Rice for Africa } \\
\text { (NERICA) technology adapted to thrive in harsh } \\
\text { growing and low-input conditions in several African } \\
\text { countries }\end{array}$ & $\begin{array}{l}\text { Webersik \& } \\
\text { Wilson (2009) }\end{array}$ \\
\cline { 2 - 4 } & $\begin{array}{l}\text { The Agricultural Research Council (ARC) partnered } \\
\text { with EcoLink to develop a farmer-tailored } \\
\text { agrometeorology service for the Limpopo Province in } \\
\text { South Africa }\end{array}$ & $\begin{array}{l}\text { Moeletsi et al. } \\
\text { (2013) }\end{array}$ \\
\hline $\begin{array}{l}\text { Consultation } \\
\text { and direct }\end{array}$ & $\begin{array}{l}\text { Participatory Variety Selection (PVS) and } \\
\text { Participatory Plant Breeding (PPB) in Nepal }\end{array}$ & $\begin{array}{l}\text { Chhetri et al. } \\
\text { (2012, 2013) }\end{array}$ \\
\hline
\end{tabular}




\begin{tabular}{|c|c|c|}
\hline Factor & Examples & References \\
\hline $\begin{array}{l}\text { participation of } \\
\text { farmers in } \\
\text { agricultural } \\
\text { R\&D }\end{array}$ & $\begin{array}{l}\text { Terrace agriculture for climate change adaptation in } \\
\text { Latin America }\end{array}$ & $\begin{array}{l}\text { Bocco \& } \\
\text { Napoletano } \\
\text { (2017) }\end{array}$ \\
\hline \multirow[t]{4}{*}{$\begin{array}{l}\text { Public-private } \\
\text { collaboration }\end{array}$} & $\begin{array}{l}\text { The Participatory Technology Development (PTD) } \\
\text { approach in Nepal involves NGOs, CBOs, and private } \\
\text { enterprises in agricultural R\&D }\end{array}$ & $\begin{array}{l}\text { Chhetri et al. } \\
\text { (2012) }\end{array}$ \\
\hline & $\begin{array}{l}\text { Multi-stakeholder innovation platforms helped promote } \\
\text { hybrid palm oil in West Africa }\end{array}$ & Röling (2016) \\
\hline & $\begin{array}{l}\text { Weather index-based insurance for livestock in Kenya } \\
\text { and for smallholder farmers in Ethiopia was } \\
\text { introduced through public-private partnerships }\end{array}$ & $\begin{array}{l}\text { Matsaert et al. } \\
\text { (2011), Bogale, } \\
\text { (2015) }\end{array}$ \\
\hline & $\begin{array}{l}\text { The African Agricultural Technology Foundation } \\
\text { (AATF) are promoting partnerships to remove barriers } \\
\text { that have prevented smallholder farmers from } \\
\text { accessing existing agricultural technologies }\end{array}$ & $\begin{array}{l}\text { Webersik \& } \\
\text { Wilson (2009) }\end{array}$ \\
\hline \multirow[t]{5}{*}{$\begin{array}{l}\text { Institutional } \\
\text { capacity }\end{array}$} & $\begin{array}{l}\text { Limited local research capacity constrains the transfer } \\
\text { of agricultural research to inform local practice }\end{array}$ & $\begin{array}{l}\text { Lybbert \& } \\
\text { Sumner (2012) }\end{array}$ \\
\hline & $\begin{array}{l}\text { The Jamaican government has facilitated the } \\
\text { development of drip irrigation to field crops through } \\
\text { the use of solar pumps, but access is limited to only } \\
\text { certain areas. }\end{array}$ & $\begin{array}{l}\text { Popke et al. } \\
(2016)\end{array}$ \\
\hline & $\begin{array}{l}\text { Meso- and higher-level institutions could act as the } \\
\text { means of delivery for external resources to facilitate } \\
\text { adaptation and up-scaling of innovations at the local } \\
\text { level }\end{array}$ & $\begin{array}{l}\text { Bhatta et al. } \\
(2017)\end{array}$ \\
\hline & $\begin{array}{l}\text { A new generation of agricultural specialists, scientists } \\
\text { and service providers with adequate technical } \\
\text { knowledge and professional skills are needed. }\end{array}$ & $\begin{array}{l}\text { Moreddu \& Van } \\
\text { Tongeren, } \\
\text { (2013) }\end{array}$ \\
\hline & $\begin{array}{l}\text { Donor-funded pilot programs, with support from } \\
\text { researchers, could create a critical mass of } \\
\text { knowledge within private insurance companies }\end{array}$ & $\begin{array}{l}\text { Matsaert et al. } \\
(2011)\end{array}$ \\
\hline \multirow[t]{3}{*}{$\begin{array}{l}\text { Function } \\
\text { markets }\end{array}$} & $\begin{array}{l}\text { Local seed dealers helped introduce new high- } \\
\text { yielding vegetable varieties to local farmers in Nepal, } \\
\text { Bangladesh and India }\end{array}$ & $\begin{array}{l}\text { Ojha et al. } \\
(2014)\end{array}$ \\
\hline & $\begin{array}{l}\text { Limited private sector investment and involvement in } \\
\text { the seed sector can severely limit farmers' access to } \\
\text { new varieties }\end{array}$ & $\begin{array}{l}\text { Lybbert \& } \\
\text { Sumner (2012) }\end{array}$ \\
\hline & $\begin{array}{l}\text { Strong marketing channel and intermediary are } \\
\text { needed for dissemination of insurance products }\end{array}$ & Bogale (2015) \\
\hline Entry points & $\begin{array}{l}\text { The development of a social-protection safety net, } \\
\text { and the ongoing dialogue and product development }\end{array}$ & $\begin{array}{l}\text { Matsaert et al. } \\
(2011)\end{array}$ \\
\hline
\end{tabular}




\begin{tabular}{|c|c|c|}
\hline Factor & Examples & References \\
\hline & $\begin{array}{l}\text { between insurance companies, banks, and } \\
\text { agribusiness could provide the right entry points for } \\
\text { disseminating weather index insurance. }\end{array}$ & \\
\hline & $\begin{array}{l}\text { An integrated agricultural research for development } \\
\text { approach could provide an entry point for } \\
\text { disseminating agriculture adaptation strategies }\end{array}$ & $\begin{array}{l}\text { Nyikahadzoi et } \\
\text { al. (2017) }\end{array}$ \\
\hline $\begin{array}{l}\text { Public } \\
\text { awareness of } \\
\text { climate } \\
\text { change }\end{array}$ & $\begin{array}{l}\text { Policy makers could make use of the mass media, } \\
\text { community-based and faith-based organizations, } \\
\text { mobile phones for awareness raising on climate } \\
\text { change. }\end{array}$ & $\begin{array}{l}\text { Nzeadibe et al. } \\
\text { (2012) }\end{array}$ \\
\hline
\end{tabular}

\subsection{Adoption drivers}

What influences famers' adoption of agricultural innovations for climate change adaptation receives attention in 24 out of the 32 reviewed articles. The articles discuss a long list of Influential factors for innovation adoption, which I group into three main categories: innovation characteristics, adopter characteristics and an enabling environment (Table S5.4).

For innovation characteristics, the reviewed literature highlights factors which correspond to four out of five key attributes of innovations (as perceived by the adopters) which Rogers (2003) identifies as having an important impact on adoption. The four attributes are the relative advantage of the innovation vis-à-vis the idea it supersedes (Rogers, 2003), the compatibility of the innovations with the norms, values, practices, needs of the adopters (p.240), the level of complexity involved in using the innovation (p. 257), and the observability of the benefits of the innovation. The importance of the relative advantage characteristic (Bocco \& Napoletano, 2017; Bogale, 2015; Bunclark et al., 2018; Röling, 2016) and the compatibility characteristic (Bhatta et al., 2017; Bunclark et al., 2018; Moeletsi et al., 2013; Nzeadibe et al., 2012) of the innovation for adoption were discussed in more articles, when compared to the innovation's complexity characteristic (Moeletsi et al., 2013; Sibiko et al., 2018) and observability characteristic (Moeletsi et al., 2013; Sibiko et al., 
2018). Trialability, which refers to the notion that an innovation which can be experimented for a period of time is more likely to be adopted (Rogers, 2003), is the only Rogers' key attribute of innovation which was not highlighted in any of the reviewed articles.

For adopter characteristics, the role of wealth in positively influencing farmers' decision to adopt agricultural innovations for climate change adaptation was highlighted in a highest number of articles (Adenle et al., 2015; Kolade \& Harpham, 2014; Nyongesa et al., 2017; Ojha et al., 2014; Popke et al., 2016). This is followed by the role of gender norms in household decision-making and crop production (Bunclark et al., 2018; Kolade \& Harpham, 2014; Nyongesa et al., 2017) and the degree of livelihood diversification (Bhatta et al., 2017; Bogale, 2015; Bunclark et al., 2018), both of which could encourage or discourage adoption of agricultural innovations in different contexts. The level of education and climate change awareness is also found in three articles to encourage innovation adoption (Bhatta et al., 2017; Bogale, 2015; Bunclark et al., 2018). A smaller number of articles also identify the availability of remittances (Bogale, 2015; Karanja Ng'ang'a et al., 2016), risk preference (Sibiko et al., 2018), the role of identity (Bocco \& Napoletano, 2017) and the level of food insecurity of farmers and farm households (Kristjanson et al., 2012) as influencing their decision to adopt agricultural innovations.

The reviewed articles also identify three aspects of an enabling environment for farmers' adoption of agricultural innovations for climate change adaptation. The first aspect, which receives most support from the literature, relates to the positive role of informal social institutions at the community level. It is found that farmers' membership in groups which are based on livelihood strategies (Bunclark et al., 2018; Chhetri et al., 2013; Matsaert et al., 2011; Sibiko et al., 2018), gender (Chhetri et al., 2013; Gabrielsson \& Ramasar, 2013), and ethnic ties (Binternagel et al., 2010; Gabrielsson \& Ramasar, 2013) help facilitate the adoption of innovations. Active CBOs, 
NGOs, and cooperatives in the farming communities also help build necessary capacity for farmers to adopt innovations (Aase et al., 2013; Bhatta et al., 2017; Bocco \& Napoletano, 2017; Chhetri et al., 2012; Kolade \& Harpham, 2014). The second aspect of an enabling environment refers to the role of formal institutions in the agricultural sector. Specifically, direct participation of farmers in agricultural R\&D (Chhetri et al., 2012, 2013; Nyikahadzoi et al., 2017) and other forms of government support (such as insurance subsidy) (Matsaert et al., 2011; Sibiko et al., 2018) positively impact the farmers' adoption of agricultural innovations. The third aspect of an enabling environment refers to the role of functioning market mechanisms in promoting agricultural innovation adoption, including by enabling farmers to access agricultural credits (Adenle et al., 2015; Bhatta et al., 2017; Bogale, 2015) and sell the increased outputs that result from the adoption of new production technology and practices (Lybbert \& Sumner, 2012).

Table S5.4: Factors influencing the adoption of agricultural innovations for climate change adaptation through public programs in developing countries

\begin{tabular}{|l|c|l|l|}
\hline $\begin{array}{l}\text { Factor } \\
\text { category }\end{array}$ & $\begin{array}{l}\text { Relation } \\
\text { ship } \\
\text { with } \\
\text { adoption }\end{array}$ & Examples & References \\
\hline 1. Innovation characteristics & & $\begin{array}{l}\text { Early adopters associate positive value } \\
\text { to, and earn more income from } \\
\text { innovation. Dis-adopters perceive the } \\
\text { innovation as being ineffective in } \\
\text { reducing production risks from multiple } \\
\text { climate hazards, and/or unable to } \\
\text { generate long-term benefits compared } \\
\text { to other livelihood options. }\end{array}$ & $\begin{array}{l}\text { (Bocco \& Napoletano, } \\
\text { 2017; Bogale, 2015; } \\
\text { Bunclark et al., 2018; } \\
\text { Röling, 2016) }\end{array}$ \\
\hline Relative & + & $\begin{array}{l}\text { Innovations which are more compatible } \\
\text { to indigenous knowledge, practices, } \\
\text { and norms (such as agronomic } \\
\text { practices, labour use norms etc.) and } \\
\text { existing farm assets, and work as "add- } \\
\text { on" tools to them, are more adopted. }\end{array}$ & $\begin{array}{l}\text { (Bhatta et al., 2017; } \\
\text { Bunclark et al., 2018; } \\
\text { Moeletsi et al., 2013; } \\
\text { Nzeadibe et al., 2012) }\end{array}$ \\
\hline Compatibility & + & \multicolumn{2}{|l}{} \\
\hline
\end{tabular}




\begin{tabular}{|c|c|c|c|}
\hline $\begin{array}{l}\text { Factor } \\
\text { category }\end{array}$ & $\begin{array}{l}\text { Relation } \\
\text { ship } \\
\text { with } \\
\text { adoption }\end{array}$ & Examples & References \\
\hline Complexity & - & $\begin{array}{l}\text { Limited understanding of innovations, } \\
\text { such as the function of a weather index } \\
\text { insurance contract or the meaning of } \\
\text { SMS messages containing } \\
\text { agrometeorological information, } \\
\text { constrains adoption. }\end{array}$ & $\begin{array}{l}\text { (Moeletsi et al., 2013; } \\
\text { Sibiko et al., 2018) }\end{array}$ \\
\hline Trialability & + & $\mathrm{N} / \mathrm{A}$ & $\mathrm{N} / \mathrm{A}$ \\
\hline Observability & + & $\begin{array}{l}\text { Farmers adopt a new crop variety when } \\
\text { they observe better performance of the } \\
\text { variety in a neighbouring farm. Adoption } \\
\text { is delayed if farmers cannot observe the } \\
\text { performance of the new variety due to } \\
\text { the competing influence of multiple } \\
\text { production factors. }\end{array}$ & $\begin{array}{l}\text { (Moeletsi et al., 2013; } \\
\text { Sibiko et al., 2018) }\end{array}$ \\
\hline \multicolumn{4}{|c|}{ 2. Adopter characteristics } \\
\hline \multicolumn{4}{|c|}{ 2.1. Individual and household characteristics } \\
\hline Gender & $+/-$ & $\begin{array}{l}\text { Gender roles influence innovation } \\
\text { adoption. For example, (Bunclark et al., } \\
\text { 2018) studied adoption of water } \\
\text { harvesting technology in Bukina Faso, } \\
\text { and found that men and women } \\
\text { dominate decision-making on different } \\
\text { livelihood activities, and male heads of } \\
\text { household were more active adopter of } \\
\text { innovation compared to their wives. The } \\
\text { physical nature of applying and } \\
\text { maintaining a certain innovation (such } \\
\text { as tractor) also accounts for } \\
\text { comparatively higher male adopters in } \\
\text { Southwest Nigeria. (Kolade \& Harpham, } \\
\text { 2014) }\end{array}$ & $\begin{array}{l}\text { (Bunclark et al., 2018; } \\
\text { Kolade \& Harpham, } \\
\text { 2014; Nyongesa et al., } \\
\text { 2017) }\end{array}$ \\
\hline Wealth & + & $\begin{array}{l}\text { Wealthier farmers, including those who } \\
\text { own land, can access grants and loans } \\
\text { as upfront capital and have more labor, } \\
\text { adopt more innovations }\end{array}$ & $\begin{array}{l}\text { (Adenle et al., 2015; } \\
\text { Kolade \& Harpham, } \\
\text { 2014; Nyongesa et al., } \\
\text { 2017; Ojha et al., 2014; } \\
\text { Popke et al., 2016) }\end{array}$ \\
\hline $\begin{array}{l}\text { Education } \\
\text { and } \\
\text { awareness }\end{array}$ & + & $\begin{array}{l}\text { Farmers with higher level of education, } \\
\text { more awareness of climate change are } \\
\text { more likely to adopt agricultural } \\
\text { innovations for adaptation (such as } \\
\text { paying for the premium of weather } \\
\text { insurance) }\end{array}$ & $\begin{array}{l}\text { (Bogale, 2015; Kolade \& } \\
\text { Harpham, 2014; } \\
\text { Nzeadibe et al., 2012) }\end{array}$ \\
\hline $\begin{array}{l}\text { Risk } \\
\text { preference }\end{array}$ & + & $\begin{array}{l}\text { Risk-averse farmers were found to have } \\
\text { a low preference for WII contracts, even }\end{array}$ & (Sibiko et al., 2018) \\
\hline
\end{tabular}




\begin{tabular}{|c|c|c|c|}
\hline $\begin{array}{l}\text { Factor } \\
\text { category }\end{array}$ & $\begin{array}{l}\text { Relation } \\
\text { ship } \\
\text { with } \\
\text { adoption }\end{array}$ & Examples & References \\
\hline & & $\begin{array}{l}\text { though they are actually the main target } \\
\text { group of insurance products }\end{array}$ & \\
\hline Identity & - & $\begin{array}{l}\text { Association of individual identity with } \\
\text { the production of certain crop type } \\
\text { make farmers unwilling to adopt new } \\
\text { crop variety }\end{array}$ & $\begin{array}{l}\text { (Bocco \& Napoletano, } \\
\text { 2017) }\end{array}$ \\
\hline $\begin{array}{l}\text { Livelihood } \\
\text { diversification }\end{array}$ & $+/-$ & $\begin{array}{l}\text { Studies from Ethiopia (Bogale, 2015) } \\
\text { and Burkina Faso (Bunclark et al., } \\
\text { 2018) found that farmers with more } \\
\text { non-farm income are less likely to adopt } \\
\text { innovation (such as insurance, water } \\
\text { harvesting technology), while ather } \\
\text { study from South Asia (Bhatta et al., } \\
\text { 2017) founds that farm households with } \\
\text { more livelihood sources are adopting } \\
\text { more new agricultural practices. }\end{array}$ & $\begin{array}{l}\text { (Bhatta et al., 2017; } \\
\text { Bogale, 2015; Bunclark } \\
\text { et al., 2018) }\end{array}$ \\
\hline Remittances & $+/-$ & $\begin{array}{l}\text { Bogale (2015) found that households } \\
\text { with more remittances are less likely to } \\
\text { pay for the indexed insurance in } \\
\text { Ethiopia, while Karanja Ng'ang'a et al. } \\
\text { (2016) remittances from migrant } \\
\text { household members enable the uptake } \\
\text { of new agricultural technologies, } \\
\text { potentially by relaxing the capital } \\
\text { constraint of the adopting household. }\end{array}$ & $\begin{array}{l}\text { (Bogale, 2015; Karanja } \\
\text { Ng'ang'a et al., 2016) }\end{array}$ \\
\hline $\begin{array}{l}\text { Level of food } \\
\text { security }\end{array}$ & - & $\begin{array}{l}\text { Higher level of food insecurity is } \\
\text { strongly negatively correlated with } \\
\text { adoption agricultural innovations, } \\
\text { though, the direction of causality is } \\
\text { unclear. }\end{array}$ & (Kristjanson et al., 2012) \\
\hline \multicolumn{4}{|l|}{ 2.2. Farm size } \\
\hline Farm size & + & $\begin{array}{l}\text { Large farm size is positively correlated } \\
\text { with adoption of agricultural } \\
\text { innovations. }\end{array}$ & $\begin{array}{l}\text { (Aase et al., 2013; } \\
\text { Bhatta et al., 2017; } \\
\text { Lybbert \& Sumner, } \\
\text { 2012; Popke et al., } \\
\text { 2016) }\end{array}$ \\
\hline \multicolumn{4}{|c|}{ 3. Enabling environment } \\
\hline \multicolumn{4}{|c|}{ 3.1. Informal social institutions at the community level } \\
\hline $\begin{array}{l}\text { Livelihood- } \\
\text { based groups }\end{array}$ & + & $\begin{array}{l}\text { Informal exchange of knowledge and } \\
\text { assets (such as labour, ploughs and } \\
\text { carts) between farmer, pastoralist, and } \\
\text { self-help groups encourage uptake of } \\
\text { innovations. }\end{array}$ & $\begin{array}{l}\text { (Bunclark et al., 2018; } \\
\text { Chhetri et al., 2013; } \\
\text { Matsaert et al., 2011; } \\
\text { Sibiko et al., 2018) }\end{array}$ \\
\hline
\end{tabular}




\begin{tabular}{|c|c|c|c|}
\hline $\begin{array}{l}\text { Factor } \\
\text { category }\end{array}$ & $\begin{array}{l}\text { Relation } \\
\text { ship } \\
\text { with } \\
\text { adoption }\end{array}$ & Examples & References \\
\hline $\begin{array}{l}\text { Gender } \\
\text { groups }\end{array}$ & + & $\begin{array}{l}\text { Widow and married women groups } \\
\text { strengthening of collaborative ties } \\
\text { among community members and } \\
\text { facilitate introduction of new } \\
\text { technologies }\end{array}$ & $\begin{array}{l}\text { (Chhetri et al., 2013; } \\
\text { Gabrielsson \& Ramasar, } \\
\text { 2013) }\end{array}$ \\
\hline Ethnic groups & + & $\begin{array}{l}\text { Farmer-to-farmer knowledge transfer, } \\
\text { which promotes adaptation through } \\
\text { innovation, is mainly taking place along } \\
\text { ethnic lines and local institutions. }\end{array}$ & $\begin{array}{l}\text { (Binternagel et al., 2010; } \\
\text { Gabrielsson \& Ramasar, } \\
\text { 2013) }\end{array}$ \\
\hline $\begin{array}{l}\text { Civil society } \\
\text { organizations }\end{array}$ & + & $\begin{array}{l}\text { Active CBOs, NGOs, and cooperatives } \\
\text { play a key role in raising climate } \\
\text { awareness, providing technical } \\
\text { information and training, and supporting } \\
\text { experimentations that lead to farmers' } \\
\text { adoption of innovations }\end{array}$ & $\begin{array}{l}\text { (Aase et al., 2013; } \\
\text { Bhatta et al., 2017; } \\
\text { Bocco \& Napoletano, } \\
\text { 2017; Chhetri et al., } \\
\text { 2012; Kolade \& } \\
\text { Harpham, 2014) }\end{array}$ \\
\hline \multicolumn{4}{|c|}{ 3.2. Agricultural institutions } \\
\hline $\begin{array}{l}\text { Participatory } \\
\text { agricultural } \\
\text { R\&D }\end{array}$ & + & $\begin{array}{l}\text { Widespread participation of } \\
\text { stakeholders in the R\&D process to } \\
\text { develop location-specific technologies } \\
\text { (such as a new local crop variety) } \\
\text { encourages adoption. }\end{array}$ & $\begin{array}{l}\text { (Chhetri et al., 2012, } \\
\text { 2013; Nyikahadzoi et al., } \\
\text { 2017) }\end{array}$ \\
\hline $\begin{array}{l}\text { Government } \\
\text { support }\end{array}$ & + & $\begin{array}{l}\text { Government support, such as insurance } \\
\text { premium subsidies and regular } \\
\text { provision of rainfall measurements, } \\
\text { could encourage adoption of weather } \\
\text { index insurance. }\end{array}$ & $\begin{array}{l}\text { (Matsaert et al., 2011; } \\
\text { Sibiko et al., 2018) }\end{array}$ \\
\hline \multicolumn{4}{|c|}{ 3.3. Market institutions } \\
\hline $\begin{array}{l}\text { Access to } \\
\text { credits }\end{array}$ & + & $\begin{array}{l}\text { Lack of access to credits inhibit } \\
\text { adoption of agricultural innovations }\end{array}$ & $\begin{array}{l}\text { (Adenle et al., 2015; } \\
\text { Bhatta et al., 2017; } \\
\text { Bogale, 2015) }\end{array}$ \\
\hline $\begin{array}{l}\text { Functioning } \\
\text { markets }\end{array}$ & + & $\begin{array}{l}\text { Poorly integrated output markets can } \\
\text { discourage farmers from adopting more } \\
\text { productive technologies by reducing } \\
\text { transmission of price signals and } \\
\text { introducing substantial market risk. }\end{array}$ & $\begin{array}{l}\text { (Lybbert \& Sumner, } \\
\text { 2012) }\end{array}$ \\
\hline
\end{tabular}




\subsection{Diffusion drivers}

Rogers (2003) categorizes communication channels for the diffusion of innovations as: 1) either interpersonal (e.g. face-to-face) or mass media in nature, and 2) either localite (e.g. linking the individual with local sources with the system under study) or cosmopolite (e.g. linking the individual with outside sources). Interpersonal channels can be both localite (e.g. farmers' peer-topeer exchange) and cosmopolite (e.g. farmers attending a farmer gathering outside his/her community), while all mass media channels are cosmopolite. Mass media channels more relatively more important in creating the knowledge of innovations, and inter-personal channels in influencing attitudes toward adopting or rejecting the innovations (Rogers 2003).

I find that only five out of the reviewed 32 articles discuss communication channels for the diffusion of agricultural innovations for climate change adaptation in developing countries. The articles place more emphasis on the interpersonal channels when compared to mass media. While interpersonalcosmopolite channels and interpersonal-localite channels are discussed in three articles each, mass-media cosmopolite channels are emphasized in only one article. The main interpersonal-cosmopolite channels discussed are external priming agents such as staff of NGOs and government projects (Bunclark et al., 2018), government extension officers (Bunclark et al., 2018), and an ongoing dialogue among farmers and researchers as part of participatory R\&D (Chhetri et al., 2012). The main interpersonal-localite channels discussed are farmer groups (Sibiko et al., 2018), farmer-supporting institutions (Chhetri et al., 2013), and community-based fora such as local gender-based and faith-based organizations (Nzeadibe et al., 2012). The mass-media cosmopolite channels discussed are mass media and mobile phones, which could be harnessed to disseminate information to build climate change awareness (Nzeadibe et al., 2012). 


\section{Annex F. Supplementary Material 6: Letter of invitation for semi-structured interview}

Belonging to the following chapter:

Chapter 7: Do access modalities to international adaptation finance matter for the promotion of agricultural innovations?: An analysis of 36 Adaptation Fund projects 


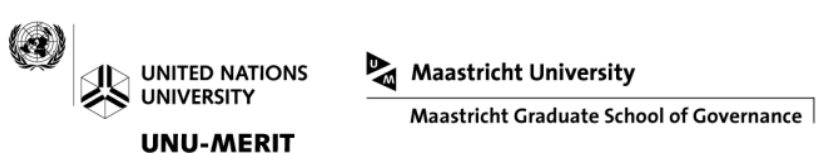

UNU-MERIT

Maastricht Graduate School of Governance

Subject: Request for interview for a Ph.D. study on the role of international adaptation finance in promoting agricultural innovations

Date: $(\ldots)$

$\operatorname{Dear}(\ldots \ldots)$

Ms. Ornsaran Pomme Manuamorn is a Ph.D. fellow in the Doctoral Programme in Governance and Policy Analysis at Maastricht Graduate School of Governance /UNU-MERIT at the Maastricht University in the Netherlands. As a paper under her Ph.D. dissertation, she is conducting a study entitled "Do access modalities to international adaptation finance matter for the promotion of agricultural innovations?: An analysis of 36 Adaptation Fund projects".

The purpose of the study is to explore the role of international climate finance in promoting agricultural innovations for climate change adaptation in developing countries. Using projects from the Adaptation Fund as case study, the paper will also analyze the implications of investments under the Fund's two access modalities on agricultural innovations. Specifically, the paper will investigate if there are differences in how direct access and indirect access projects are designed to disseminate agricultural innovations and encourage their adoption and diffusion for climate change adaptation, and if so, what are the policy implications.

This study will contribute to the growing body of research that examines how institutional arrangements of climate finance influence the pattern of climate change adaptation actions that take place in developing countries. It will also inform the policy discussion on how international adaptation finance could effectively promote agricultural innovations through investments under both access modalities.

Ms. Manuamorn is interested in interviewing you because as a (staff of an Adaptation Fund's implementing entity/ staff of the Adaptation Fund Secretariat), you are knowledgeable about the topic and could provide a highly valuable perspective for this research. 
Your participation in this research is entirely voluntary. Should you accept to participate, the interview will be conducted either in person or via audio or videoconference and will take approximately 45-60 minutes. During the interview, you are free to end your participation at any time without giving any reason. With your permission, the interview will be audio-recorded. The record will be immediately delated after the data is transcribed. If you prefer not to be recorded, interview notes will be taken. In either case, the transcription or notes will be shared with you should you wish to review to ensure the accuracy. All collected data will be treated anonymously and confidentially, stored in Maastricht University's password-secured research drive, and only be used for the purpose of academic research.

Both the research plan and methodology were developed in line with the Dutch code of conduct for researchers, and conform to the ethical and data management codes to which every researcher at Maastricht University is committed.

As the supervisor of this research, I kindly ask you to consider the collaboration with Ms. Manuamorn for this requested interview. Should you have any questions, please feel free to contact me (ramani@merit.unu.edu) and Ms. Manuamorn (o.manuamorn@student.maastrichtuniversity.nl) directly.

Yours sincerely,

Prof. Dr. Shyama Ramani

Professorial Fellow, UNU-MERIT, Maastricht University http://www.merit.unu.edu/about-us/profile/?staff id $=1126$

Tel. $+\operatorname{xxxx}$

skypeid: $x x x x$ 


\section{Annex G. Supplementary Material 7: Semi- structured interview guides}

Belonging to the following chapter:

Chapter 7: Do access modalities to international adaptation finance matter for the promotion of agricultural innovations?: An analysis of 36 Adaptation Fund projects 


\section{A. Interview protocol}

The following protocol will be discussed with each research informant prior to the interview.

\section{Introduction}

Thank you for agreeing to participate in this interview. My name is Ornsaran Manuamorn, or Pomme for short, and I am a research fellow at the Maastricht Graduate School of Governance of Maastricht University. As indicated in the information sheet, this study is part of my Ph.D. research paper entitled " $D o$ access modalities to international adaptation finance matter for the promotion of agricultural innovations?: An analysis of 36 Adaptation Fund projects"

The purpose of this interview today is to learn about the role of Adaptation Fund projects in promoting agricultural innovations for climate change adaptation in developing countries. Specifically, the interview aims to gain more insights on whether there are key differences in the approach by which direct access and indirect access projects use to disseminate agricultural innovations and ensure their adoption and diffusion, what might explain the differences in case they exist, and what are the policy implications. The interview will last about 45-60 minutes.

\section{Consent form}

[Option 1] Thank you for signing the consent form and sending it to me earlier [Option 2] Did you read the consent form that was sent to you? Do you have any questions? Do you agree to sign the consent form and return it to me via email?

\section{Ground rules}

Everything you tell me will be confidential. The information you provide during the interview will be only be used for the purpose of research. To protect your privacy, I will not connect your name with anything that you say.

During our conservation, please feel free to let me know if you have any questions or if you would rather not answer any specific question. Responses are based on your opinion and that there are no right or wrong answers. You can also stop the interview at any time for any reason.

The data from this interview will be stored in the Maastricht University's password-protected secured research drive, and will only be used for academic research purposes.

Are there any questions regarding what I explained? 
With your permission, I will audio-record this interview. The audio recording will be deleted as soon as the interview is transcribed. If you prefer not to be recorded, I will only take notes. In either case, the transcription or notes could be shared with you if you wish to review the accuracy.

[Option 1] Is it ok if I audiotape this interview today? If yes, [Turn on recoding equipment. Ask participants to confirm consent on tape]

[Option 2] If no, start the interview and only take notes 
B. Guide for with interviews with staff of Adaptation Fund's national implementing entities - NIEs (for direct access projects) or Multilateral Implementing Entities (MIEs) and Regional Implementing Entities (RIEs) (for indirect access projects)

\section{Introductory questions}

1.1. Please tell me a little bit about yourself. How long have you worked for the organization? What are your responsibilities?

1.2. How long has your organization been an implementing entity of the Adaptation Fund?

1.3. What were your personal responsibilities with regards to the Adaptation Fund project your organization is implementing?

1.4. Could you tell me more about the Adaptation Fund project implemented by your organization? It is at which stage? [approval, implementation, completion, impact evaluation]

2. Topic: Dissemination of agricultural innovations in Adaptation Fund projects

Definition of key concepts:

"Innovation" refers to "a product, process, and practice (e.g. organizational routine, governance routine, community practice etc.) that are new to an individual, community or an organization"

"Dissemination" of innovations refers to "the planned, systematic efforts designed to make innovation more widely available through a targeted program"

2.1. What agricultural innovations are disseminated through your project?

2.2. What makes the disseminated agricultural product, process, and/or practice "innovative" in the context of your project?

2.3. Why were these agricultural innovations considered needed in the context of your project?

2.4. Who are the target beneficiaries of these innovations? [individual farmers, farmer groups, farmer institutions etc.) 
2.5. Did stakeholder consultations influence the choice of disseminated agricultural innovations?

a. If so, how?

b. Which stakeholders played the most important role in the selection of innovations to be disseminated?

2.6. From your perspective, does being [an National Implementing Entity (NIE) or Multilateral Implementing Entity (MIE) or Regional Implementing Entity (RIE)] make a difference in the dissemination of agricultural innovations? If so, how?

3. Topic: Perceived drivers of adoption of agricultural innovations in Adaptation Fund projects

Definition of key concept:

"Adoption" of innovation refers to "an individual process concerned with the stages that the potential user of innovation goes through to decide to accept or reject an innovation".

In this study, the potential user of innovation is understood as the direct beneficiaries targeted by the Adaptation Fund projects.

For projects at the project approval stage:

3.1. What factors do you think drive the decision of project beneficiaries to adopt or reject the agricultural innovations disseminated through your project?

3.2. How does the project design address these drivers of innovation adoption?

3.3. Did international experiences inform the project's design to enhance adoption of the innovations? If so, how?

3.4. Did local or indigenous knowledge inform the project's design to enhance adoption of the innovations? If so, how?

For projects at the implementation, completion or impact evaluation stages:

3.5. What has been the response of project beneficiaries in terms of adopting or rejecting the disseminated agricultural innovations? 
3.6. Has the project made any changes after implementation to encourage adoption of the disseminated agricultural innovations?
a. If yes, what?
b. What has been the response from project beneficiaries to the changes?

3.7. Do you think being [an NIE, MIE or RIE] makes a difference for the adoption of agricultural innovations? If so, how?

\section{Topic: Perceived drivers of diffusion of agricultural innovations in Adaptation Fund projects}

Definition of key concept:

"Diffusion" of innovation refers to a social process by which an adopted innovation is communicated through certain channels over time among the members of a social system, and as a result, makes the adoption reaches a large scale.

In this study, diffusion is understood as the spread of an adopted innovation from the direct beneficiaries targeted by the Adaptation Fund projects to the non-project public.

In other words, diffusion refers to the "scaling up" of the disseminated innovations to more adopters beyond the Adaptation Fund's initial target beneficiaries and areas.

4.1. What do you think will enable the diffusion (scaling-up) of the disseminated agricultural innovations?

4.2. Does the project design pay attention to promoting the diffusion of agricultural innovations?

- To more beneficiaries in the same context?

- To other contexts/areas?

4.3. From your perspective, does being [an NIE, MIE or RIE] make a difference in the diffusion of agricultural innovation? If so, how? 
5. Topic: Differences between direct access and indirect access projects

Definition of key concept:

"Promotion" of agriculture innovations is understood in the context of this research to result from a combination of approaches to pursue dissemination, adoption and diffusion of agricultural innovations

5.1. What are the advantages of being an NIE or MIE/RIE in promoting agricultural innovations in the context of an Adaptation Fund project?

5.2. What are the disadvantages of being an NIE or MIE/RIE in promoting agricultural innovations in the context of an Adaptation Fund project?

\section{Closing questions}

6.1. Is there anything else you would like to add about any of the topics we have discussed?

6.2. Are there any other issues we didn't discuss but you think important to mention?

6.3. If you know of any documents, reports or resources that may be useful to complement this interview, please share or send them to me.

Thank you for your time and participation in this interview. The information you have provided will be analyzed for the research. I will be happy to share with you the findings from this part of the research.

Thank you. 


\section{Guide for with interviews with staff of the Adaptation Fund Secretariat}

\section{Introductory questions}

1.1. Please tell me a little bit about yourself. How long have you worked for the AF? What are your responsibilities?

1.2. Could you share some general thoughts about the experience having worked with the AF?

1.3. What are your specific responsibilities in relation of Adaptation Fund projects?

1.4. Are you involved with the development of the Fund's strategy to promote innovations for climate change adaptation? If so, how?

2. Topic: Dissemination of agricultural innovations in Adaptation Fund projects

Definition of key concepts:

“Innovation" refers to "a product, process, and practice (e.g. organizational routine, governance routine, community practice etc.) that are new to an individual, community or an organization"

"Dissemination" of innovations refers to "the planned, systematic efforts designed to make innovation more widely available through a targeted program"

2.1. Why is dissemination of agricultural innovations important to the objective of the Adaptation Fund?

2.2. What makes a disseminated agricultural product, process, and/or practice "innovative" from the Fund's perspective?

2.3. What are key examples of agricultural innovations disseminated through Adaptation Fund projects? Who are the target beneficiaries?

2.4. What do you think are the key reasons these innovations were chosen by the NIEs/MIEs/RIEs?

2.5. Do you think stakeholder consultations influence the choice of agricultural innovations disseminated by NIEs and MIEs/RIEs? If so, how? 
2.6. Do you think being an NIE or MIE/RIE matter for the dissemination of agricultural innovations?

\section{Topic: Perceived drivers of adoption of agricultural innovations in} Adaptation Fund projects

Definition of key concept:

"Adoption" of innovation refers to "an individual process concerned with the stages that the potential user of innovation goes through to decide to accept or reject an innovation".

In this study, the potential user of innovation is understood as the direct beneficiaries targeted by the Adaptation Fund projects.

3.1. Does the Adaptation Fund require the NIEs and MIEs/RIEs to address key drivers of adoption of agricultural innovations through project design? If so, how?

3.2. Could you give an example of an Adaptation Fund project implemented by an NIE which successfully promotes adoption of agricultural innovations? What have been the contributing factors to the success?

3.3. Could you give an example of an Adaptation Fund project implemented by an MIE/RIE which successfully promotes adoption of agricultural innovations? What have been the contributing factors to the success?

3.4. Have you experienced the cases of the agricultural innovations disseminated through the Adaptation Fund projects being "disadopted" after the initial project implementation? If so, what have been the contributing factors to the dis-adoption?

3.5. Do you think being an NIE or MIE/RIE matter for adoption of agricultural innovations? 
4. Topic: Perceived drivers of diffusion of agricultural innovations in Adaptation Fund projects

Definition of key concept:

"Diffusion" of innovation refers to a social process by which an adopted innovation is communicated through certain channels over time among the members of a social system, and as a result, makes the adoption reaches a large scale.

In this study, diffusion is understood as the spread of an adopted innovation from the direct beneficiaries targeted by the Adaptation Fund projects to the non-project public.

In other words, diffusion refers to the "scaling up" of the disseminated innovations to more adopters beyond the Adaptation Fund's initial target beneficiaries and areas.

4.1. What do you think will enable the diffusion (scaling-up) of the disseminated agricultural innovations?

4.2. Does the Adaptation Fund require project design to ensure the diffusion of agricultural innovations beyond the project's life in the target project areas? If so, how?

4.3. Does the Adaptation Fund require project design to ensure the diffusion of agricultural innovations beyond the initial target project areas? If so, how?

4.4. Do you think being an NIE or MIE/RIE matter for diffusion of agricultural innovations?

\section{Topic: Differences between direct access and indirect access projects}

Definition of key concept:

"Promotion" of agriculture innovations is understood in the context of this research to result from a combination of approaches to pursue dissemination, adoption and diffusion of agricultural innovations

5.1. What are the advantages of being an NIE or MIE/RIE in promoting agricultural innovations in the context of an Adaptation Fund project? 
5.2. What are the disadvantages of being an NIE or MIE/RIE in promoting agricultural innovations in the context of an Adaptation Fund project?

\section{Closing questions}

6.1. Is there anything else you would like to add about any of the topics we have discussed?

6.2. Are there any other issues we didn't discuss but you think important to mention?

6.3. If you know of any documents, reports or resources that may be useful to complement this interview, please share or send them to me.

Thank you for your time and participation in this interview. The information you have provided will be analyzed for the research. I will be happy to share with you the findings from this part of the research.

Thank you. 


\section{Annex H. Summary of the Dissertation}

Local communities in developing countries are facing a disproportionate burden in adapting to the negative impacts of climate change. As these impacts are localized, adaptation actions must be tailored to their contextspecific needs. As climate change presents new challenges to these communities, innovations are also needed to enhance the effectiveness of local adaptation actions. There is much scholarly and policy interest in the role that multilateral climate funds could play in reducing climate vulnerability of these communities, particularly by channeling international adaptation finance towards community-focused and innovative adaptation actions. Despite this, little is known on how much international adaptation finance channeled by these funds has reached local communities to date. Whether climate finance governance matters for how internationally-financed adaptation projects are designed to stimulate community-focused and innovative adaptation is also poorly understood.

Given these knowledge gaps, the dissertation seeks to understand and explain how the governance of international adaptation finance influences the design of internationally-financed adaptation projects. To this end, the dissertation conceptualizes the direct access and indirect access modalities to multilateral climate funds as two governance models of international adaptation finance-whereby direct access projects are implemented by national institutions and indirect access projects by international organizations for the recipient countries-and examine how they shape the community-focused and innovative aspects of project design under different recipient country contexts. The dissertation uses the Adaptation Fund (AF) established under the Kyoto Protocol as the case study and its projects as sub-units of analysis. 
The dissertation demonstrates that direct access projects are on average more community-focused than indirect access projects due to their financial, participatory and devolutionary characteristics. However, both adaptation projects with a strong and weak community focus are present under both access modalities. It also finds that choosing a particular access modality by itself is not sufficient to automatically result in a highly or weakly communityfocused outcome, and that there are multiple pathways to projects with a stronger and weaker community focus. In particular, AF projects with a stronger community focus are stimulated by the sole presence of higher exposure to projected future climate risks in a group of countries, and by the complementary roles of civil society governance and the access modality to the $A F$ in others. On the other hand, AF projects with a weaker community focus can be found in the context of recipient countries with weak civil society governance, and ones with a combination of government centralization, low exposure to future climate risks, low past climate-related losses, and the use of the indirect access modality.

As for the innovative aspect of project design, the dissertation finds no evidence that the type of access modalities matters, both in terms of the choices of agricultural innovations financed by each AF project, and the implementation plan to disseminate the innovations and encourage adoption and diffusion. While the national and multilateral project implementing entities perceive their institutional strengths and weaknesses differently, these divergent perceptions did not lead them to design AF projects differently. The dissertation highlights the roles of two country-level contextual factors-the pre-existing institutional capacities of national and local institutions, and their previous exposure to global knowledge on agricultural innovation dissemination-in explaining the observed similarities in project design. It also demonstrates that multilateral climate funds can promote locally relevant innovations through both access modalities, but this requires strong 
collaboration between the project implementing entities and capable and locally embedded partners from the onset.

Overall, the dissertation concludes that access modalities have less influence than many have argued in terms of influencing the community focus in project design, and do not affect how projects are designed to promote adaptation innovations for local beneficiaries. The broader implication of this finding is that the governance of international adaptation finance could play a role in shaping local level climate change adaptation, but the extent and direction of such role depends on the project design aspect as well as the recipient country's context.

The dissertation brings the under-researched governance aspects of international adaptation finance to the center of the discussion on local level adaptation. Its key contributions lie in moving from descriptive to explanatory analyses on how adaptation finance governance affects adaptation actions, and in advancing the scholarship on local-level adaptation financing in ways that account for the interdependence of climate finance governance and other country-level enabling conditions. From the policy perspective, the dissertation identifies different pathways to promote internationally-financed, community-focused adaptation, while also contributing to the development of an indicator-based methodology to systematically track community-bound international adaptation finance. 


\section{Annex I. Addendum on Valorization of the Dissertation}

This addendum discusses how the dissertation creates social value by making relevant knowledge available for translation into use by different audiences.

Reducing the impacts of climate change on vulnerable local populations in developing countries is widely recognized as an urgent task in the international development community. A key question that has grabbed the attention of global policy makers is how to get more adaptation finance to where it is needed most i.e. peoples and communities at the frontlines. Reflecting the high-level pollical recognition for the need to address this problem, the Global Commission on Adaptation (GCA) recently establishes "locally-led action" as a priority action track and calls for "significant increases in the volume of devolved and decentralized funding available to local governments, community-based organizations, and others working at the local level to identify, prioritize, implement, and monitor climate adaptation solutions." timely to inform this policy dialogue led by the GCA, and participated by key global players including climate funds, development banks, UN agencies, bilateral donors, national and local governments, private sector, civil society representatives etc.

The results of this research are shared with the above audiences and the public at large by several means. First, I made a summary presentation to the Adaptation Fund Secretariat, highlighting the findings from Chapter 7 on the role of the Fund in promoting agricultural innovations for climate change adaptation. The presentation led to an engaging discussion of the results.

${ }^{8}$ https://gca.org/global-commission-on-adaptation/action-tracks/locally-led-action 
According to the Fund's staff, the findings resonate with their experience and feedback from recipient countries, but also raise new perspectives, for example, on the important role of local research institutes and universities in developing homegrown innovations, and the usefulness of integrating a more poverty-sensitive lens (i.e. the bottom of yramid) to innovation promotion and project evaluation. Given that innovation is a key pillar of the Fund's strategy, the dissertation's findings are valuable inputs to the ongoing strategy implementation and its future revision.

Second, by collaborating with Prof. Shyama Ramani, I am confident that the findings from this dissertation will be disseminated by SITE4Society. ${ }^{9}$ Through its activities including briefs, action research, workshops and training programmes, SITE4Society aims to connect and mobilize academia and society towards solving local and global challenges and contribute to all SDGs as set by the United Nations in 2015.

Third, the key findings of this dissertation have been published as journal articles. Chapter 6 presents a very novel finding to the study of and policy discourse on international adaptation finance for local actions-that access modalities to climate funds have less influence than many have argued in terms of driving the community focus in project design, and other enabling conditions, especially the conducive governance of civil society, are also at play. This Chapter has been published in the journal Global Environmental Change. Within the short period since it was released in March 2020, the article has been widely read and shared among researchers (e.g. through ResearchGate) and practitioners (e.g. through Linkedin) and is beginning to receive citations. Chapter 5 has also been accepted for publication in the journal Regional Environmental Change, and Chapter 7 will be submitted for publication shortly.

\footnotetext{
${ }^{9}$ http://site4society.merit.unu.edu/
} 
Last but not least, this research has shaped my own thinking as a development practitioner, and therefore informed my professional work on climate change adaptation and climate finance at the World Bank. In particular, the knowledge and perspectives I gained through this research has been translated into my technical advice to teams to mainstream the adaptation perspective in lending projects. These projects come from sectors that highly matter for the welfare of local and marginalized populations, including agriculture, water and sanitation, social protection and urban development, and I am grateful for the opportunity to contribute to them. I also had the opportunity to shape the design of analytical studies within the World Bank, and in the process, helped raise the profile of climate vulnerability and adaptation as an urgent development challenge, as well as emphasizing the critical role of financing, governance and community participation in addressing it. 


\section{Annex J. Curriculum Vitae}

Ornsaran Pomme Manuamorn was born on 21 November 1980 in Bangkok, Thailand. She obtained B.A. in Political Science (summa cum laude) from Chulalongkorn University, Thailand. After completing her undergraduate studies, she obtained M.Phil. in International Relations from Cambridge University, England, with a Gates Cambridge Scholarship, and MPA in International Development from Princeton University, USA, with a Fulbright Scholarship. She also attended the Oxford Adaptation Academy in 2014.

As a development professional, Pomme has more than 16 years of international experience working at the intersection of livelihood, environment, natural resource governance, and broader development issues. She had worked full-time for the World Bank, the Asian Development Bank (ADB), and AECOM International Development (for USAID-funded regional environment programs in Asia), and more recently served as an expert consultant for various organizations, including DAI (for USAID), World Wildlife Fund, ADB, and the World Bank. Through these assignments, she has worked, both analytically and operationally, on climate change adaptation and mitigation, access to climate finance, environmental and natural resource governance, and agricultural (weather) insurance and risk financing for climate-vulnerable rural communities. Her country experience includes Bangladesh, Cambodia, China, India, Indonesia, Lao PDR, Myanmar, Philippines, Samoa, Tanzania, Thailand, and Viet Nam. She is currently a senior specialist consultant (climate change and environmental governance) with the World Bank, working on Indonesia and South Asia.

Pomme has lived in Thailand, USA, India, and Indonesia. Her languages include Thai, English and Portuguese. 


\section{UNU-MERIT/MGSoG Dissertation Series}

2020

\section{Gillian McFarland}

Doing policy in Further Education

An exploration of the enactment of the

GCSE resits policy in Further

Education colleges in England

UNU-MERIT/MGSoG Dissertation

Series № 249

\section{Omar Rodriguez Torres}

Essays on Entrepreneurship in

Colombia

UNU-MERIT/MGSoG Dissertation

Series № 248

\section{Elaine Lebon-McGregor}

International Organizations and

Global Migration Governance

UNU-MERIT/MGSoG Dissertation

Series № 247

\section{Janyl Moldalieva}

Playing the 'Game' of Transparency and Accountability in Kyrgyzstan's

Resource Governance

UNU-MERIT/MGSoG Dissertation

Series № 246

\section{Kaleab Kebede Haile}

Essays on Rural Household Decision-

Making under Climate Risk

UNU-MERIT/MGSoG Dissertation

Series № 245

\section{Nora Jasmin Ragab}

Diaspora Mobilisation in a Conflict

Setting

UNU-MERIT/MGSoG Dissertation

Series № 244

\section{Mary Kaltenberg}

From Micro to Macro: Essays on

Technological Change and Income

Divergence

UNU-MERIT/MGSoG Dissertation

Series № 243

\section{Ayla E. Bonfiglio}

Student migrant, refugee or both?

Exploring Refugee Agency and

Mobility through Tertiary Education

in Kenya, South Africa and Uganda

UNU-MERIT/MGSoG Dissertation

Series № 242

\section{Danilo Sartorello Spinola}

Cycles, Economic Structures and

External Constraints.

A Structuralist study on the causes of economic volatility in Latin America UNU-MERIT/MGSoG Dissertation Series № 241 
Shellie E. Solomon

Neighborhoods Matter:

Jemal Adem

Livelihood Vulnerability to Shocks,

Behaviour and Investment in

Education: Essays in Behavioural

Development Economics

UNU-MERIT/MGSoG Dissertation

Series № 240

\section{Davina Osei}

Corrupt or corrupted networks?

An empirical enquiry

UNU-MERIT/MGSoG Dissertation

Series № 239

\section{Patima Chongcharoentanawat}

Beyond Static Inequality

Public policies and economic mobility

in Thailand

UNU-MERIT/MGSoG Dissertation

Series № 238

\section{Charlotte Guillard}

Rethinking economic growth

and structural change.

The role of boundaries and linkages

between industries

UNU-MERIT/MGSoG Dissertation

Series № 237

\section{Nicolas Echarti}

Employment Effects or Vocational

Rehabilitation in Germany:

A quantitative analysis

UNU-MERIT/MGSoG Dissertation

Series № 236
Crime, collective efficacy and

foreclosures in Miami

UNU-MERIT/MGSoG Dissertation

Series № 235

Michał Kazimierczak

Regional Innovation and

Entrepreneurship

Patents, trade marks, entry and

entrants' growth in European

manufacturing industries

UNU-MERIT/MGSoG Dissertation

Series № 234

\section{Fernanda Soares}

The Influence of Within School and Across Schools' Collaborative Practices on Student Learning and Teaching

Outcomes in West Africa

UNU-MERIT/MGSoG Dissertation

Series № 233

\section{Mira Bierbaum}

New Mindsets to Innovate Activation

UNU-MERIT/MGSoG Dissertation

Series № 232

\section{Norman Dytianquin}

Technology in the Asian Miracle and

Crisis Debates: Applications of and

Insights from the Field of Influence

Approach to Input-Output Analysis

UNU-MERIT/MGSoG Dissertation

Series № 231 
Nga Le

The implications of health insurance for the labour market and patient satisfaction with medical care in Vietnam

UNU-MERIT/MGSoG Dissertation Series № 230

\section{Jinhyuck Park}

Intellectual Property right protection and cross-border RED investments by multinational enterprises

UNU-MERIT/MGSoG Dissertation Series № 229

\section{Richard de Groot}

Show me the Money:

Essays on the Impact of Cash Transfers on Child Nutrition and the Role of Intra-Household Dynamics UNU-MERIT/MGSoG Dissertation Series № 228

\section{Catie Lott}

Diamonds are a Women's Best Friend Broadening Measures of Women's Access to Formal Political DecisionMaking

UNU-MERIT/MGSoG Dissertation Series № 227

\section{Ana Cristina Calderon Ramirez}

Public Management Reforms

Three stories about public procurement agencification in Latin America UNU-MERIT/MGSoG Dissertation Series № 226

\section{Camilo Nicanor Carrillo Purin}

Teachers' in-service training and student achievement:

The effect of in-service training of Peruvian teachers on student achievement UNU-MERIT/MGSoG Dissertation Series № 225

\section{Hugo Confraria}

Developing scientific capacity in the

Global South

UNU-MERIT/MGSoG Dissertation

Series № 224

\section{Alison Cathles}

Educational Pathways and Skills:

Past, Present, and Future

UNU-MERIT/MGSoG Dissertation

Series № 223

\section{Ibrahima Sory Kaba}

Aggregate Fluctuations and

Development: Essays on

Macroeconomic Volatility and

Economic Growth

UNU-MERIT/MGSoG Dissertation

Series № 222

\section{Charlotte Keijser}

Firm Participation, Learning and

Innovation in Heterogenous Value

Chains of IT-enabled Services

UNU-MERIT/MGSoG Dissertation

Series № 221 


\section{Salih Çevikarslan}

Innovation Strategies and Their

Implications for Technological Change

and Market Outcomes:

An Evolutionary Multi-Agent Based

Modelling Approach

UNU-MERIT/MGSoG Dissertation

Series № 220

\section{Wondimagegn Mesfin Tesfaye}

Essays on the Impacts of Climate-

Smart Agricultural Innovations on

Household Welfare

UNU-MERIT/MGSoG Dissertation

Series № 219

\section{Tatevik Poghosyan}

How Board Networks Affect Firm

Performance and Innovation Incentives

in Transition Economies: The Case of

Armenia

UNU-MERIT/MGSoG Dissertation

Series № 218

\section{Arip Muttaqien}

Essays on Inequality and Polarization:

Empirical Studies in Developing Asia

UNU-MERIT/MGSoG Dissertation

Series № 217

2018

\section{Katrin Marchand}

Essays on Forced Migration and

Labour Market Participation in

Developing Countries

UNU-MERIT/MGSoG Dissertation

Series № 216

\section{Ortrun Merkle}

The Myth of Gender Neutral Power:

Corruption and Gender Norms

UNU-MERIT/MGSoG Dissertation

Series № 215

\section{Biljana Meshkovska}

Life after Trafficking:

(re)integration processes of women that have been trafficked for the purpose of sexual exploitation in Europe

UNU-MERIT/MGSoG Dissertation

Series № 214

\section{Vincenzo Vinci}

The Relevance of Institutions and

People's Preferences for Social

Protection

UNU-MERIT/MGSoG Dissertation

Series № 213

\section{Silke Heuser}

The Effectiveness of Environmental Policies on Reducing Deforestation in the Brazilian Amazon

UNU-MERIT/MGSoG Dissertation

Series № 212

\section{Jennifer Waidler}

Social Assistance and Remittances and Their Role in the Fight Against

Poverty

UNU-MERIT/MGSoG Dissertation

Series № 211

\section{Choolwe Muzyamba}

The role of community mobilization in the promotion of maternal health of women living with HIV in Zambia UNU-MERIT/MGSoG Dissertation Series № 210 
Juan Carlos A. Castillo Sánchez

Assessing the Role of the Export Sector in Mexican Economic

Development,1965-2014

UNU-MERIT/MGSoG Dissertation

Series № 209

\section{Tareq Abuelhaj}

Food Security Policy Impact Analysis:

The Econometrics of Cash and Food

Assistance Cost Effectiveness

UNU-MERIT/MGSoG Dissertation

Series № 208

Marta Férnandez de Arroyabe

Arranz

Essays on MEAS and Innovation

UNU-MERIT/MGSoG Dissertation

Series № 207

\section{Clotilde Mahé}

Essays on Migration and Occupational

Choice

UNU-MERIT/MGSoG Dissertation

Series № 206

\section{Simone Sasso}

Talent on the move. Essays on Human

Capital, Graduate Mobility and

Economic Development

UNU-MERIT/MGSoG Dissertation

Series № 205

\section{Khaled Walid Rajab}

Strategic Planning under Fragility

UNU-MERIT/MGSoG Dissertation

Series № 204

\section{Mutinta Hambayi Nseluke}

A Tall Order: Improving Child Linear

Growth

UNU-MERIT/MGSoG Dissertation

Series № 203

\section{Elvis Korku Avenyo}

Innovations and Firm Performance

in sub-Saharan Africa: Empirical

Analyses

UNU-MERIT/MGSoG Dissertation

Series № 202

\section{Ni Zhen}

Employment Dynamics, Firm

Performance and Innovation

Persistence in the Context of

Differentiated Innovation Types:

Evidence from Luxembourg

UNU-MERIT/MGSoG Dissertation

Series № 201

\section{Caroline Wehner}

Too Scared to Achieve: The Relation

Between Neuroticism,

Conscientiousness

and Socioeconomic Outcomes

UNU-MERIT/MGSoG Dissertation

Series № 200

\section{Stefania Innocenti}

On Institutional Persistence

UNU-MERIT/MGSoG Dissertation

Series № 199

\section{Hassen Abda Wako}

Economic Globalization, Institutions and Development: Essays on Aid, Foreign Direct Investment and Trade UNU-MERIT/MGSoG Dissertation Series № 198 


\section{Michael Verba}

Hans-Erik Edsand

Winds of Change

UNU-MERIT/MGSoG Dissertation

Series № 197

\section{Ana Patricia Silva Vara}

Redressing the Gender Gap

UNU-MERIT/MGSoG Dissertation

Series № 196

\section{Andrés Iván Mideros Mora}

Essays on the Economic Effects of Noncontributory Social Protection

UNU-MERIT/MGSoG Dissertation Series № 195

\section{Tobias Broich}

New Actors in the Global Economy UNU-MERIT/MGSoG Dissertation Series № 194

\section{Bernard Nikaj}

From No-government to E-government UNU-MERIT/MGSoG Dissertation Series № 193

\author{
Ali Safarnejad \\ Prioritizing the HIV Response \\ UNU-MERIT/MGSoG Dissertation \\ Series № 192

\section{Clovis Freire} \\ Diversification and Structural \\ Economic Dynamics \\ UNU-MERIT/MGSoG Dissertation \\ Series № 191
}

Innovation and Knowledge Dynamics: Essays on the Knowledge Economy UNU-MERIT/MGSoG Dissertation Series № 190

\section{Pui Hang Wong}

The Hearts and Minds in Conflict and Peace: The Economics of

Counterinsurgency and the Psychology of Reconstruction

UNU-MERIT/MGSoG Dissertation Series № 189

\section{Brenda Yamba}

Schooling Despite All Odds: Evidence from Lesotho on Female Child Carers who Stayed in School UNU-MERIT/MGSoG Dissertation Series № 188

\section{Sheng Zhong}

Moving towards An Energy Efficient Future: Essays on Energy Efficiency, Technology and Development UNU-MERIT/MGSoG Dissertation Series № 187

\section{Julieta Marotta}

Access to Justice and Legal

Empowerment of Victims of Domestic

Violence through Legal Organizations in the City of Buenos Aires: A

Qualitative Empirical Legal Study

UNU-MERIT/MGSoG Dissertation

Series, № 186 


\section{Andrea Franco-Correa}

On the Measurement of

Multidimensional Poverty as a Policy

Tool: Empirical Applications to Chile,

Colombia, Ecuador and Peru

UNU-MERIT/MGSoG Dissertation

Series, № 185

2016

Yesuf Awel

Insurance for Growth: Empirical

Essays on Insurance Demand and

Impacts in Africa

UNU-MERIT Dissertation Series,

№ 108

Tigist Mekonnen Melesse

Grow More Food using Fewer

Resources: Agricultural Technology

Adoption and Innovation Practices for

Inclusive and Sustainable

Development

UNU-MERIT Dissertation Series,

№ 107

\section{Eleni Yitbarek}

Getting Ahead or left Behind? Essays on Poverty Dynamics and Social

Mobility in Africa

UNU-MERIT Dissertation Series, № 106

\section{Thuy Dieu Nguyen}

Firm-Level Theory and Evidence of

Corruption

UNU-MERIT Dissertation Series, № 105

\section{Raquel Tsukada Lehman}

Essays on Household Production with

Labor-Saving Technology

UNU-MERIT Dissertation Series,

№ 104

\section{Eva Barteková}

Multi-Problem Challenges for a

Renewable Future: Empirical Studies

on Competitive Disadvantages from

Electricity Price Differentials and

Mineral Supply Risk in an Open

Economy

UNU-MERIT Dissertation Series,

№ 103

\section{Jocelyn Olivari}

Entrepreneurial Traits and Innovation:

Evidence from Chile

UNU-MERIT Dissertation Series,

№ 102

\section{Muhammad Shafique}

Essays on the role of knowledge, RED, and Technology-based Firms in the Evolution of Socio-techno-economic System

UNU-MERIT Dissertation Series, № 101

\section{Serdar Türkeli}

Governance of Innovation Policy:

Empirical Studies on Applied Political Economy by Multi-Methods Analysis UNU-MERIT Dissertation Series, № 100 


\section{Ayokunu Adedokun}

Pathways to Sustainable Peace

building in Divided Societies: Lessons

and Experiences from Mozambique

MGSoG Dissertation Series, № 75

\section{Luiz Rothier Bautzer}

Organizing Concurrent Engineering

through ICT Platforms

Blueprinting Product Lifecycle

Management Platforms across

Disciplinary Agencies

MGSoG Dissertation Series, № 74

\section{Natalia Popova}

Migration in the Periphery of the

European Union:

Determinants of Successful and

Sustainable Labour Market Integration of Return Migrants in Albania, Egypt, Moldova and Tunisia

MGSoG Dissertations Series, № 73

\section{Richard A. Martina}

Uncertainty and Resource Constraint in the Small Island Developing States: Essays in Entrepreneurial Cognition MGSoG Dissertations Series, № 72

\section{Cécile Cherrier}

The Expansion of Basic Social

Protection in Low-income Countries:

An Analysis of Foreign Aid Actors'

Role in the Emergence of Social

Transfers in Sub-Saharan Africa

MGSoG Dissertations series, № 71

\section{Paul Caldron}

The Tacit Bargain in Short-Term

Medical Missions: Why U.S.

physicians go and what it costs

MGSoG Dissertation Series, № 70

\section{Mahmut Kobal}

Customs \& Excellence: A Comparative Approach on Administrative and Regulatory Compliance Perspectives of the EU-Turkey Customs Union

MGSoG Dissertation Series, № 69

\section{Craig Loschmann}

Essays on Conflict-related Migration

and Development in the Case of

Afghanistan

MGSoG Dissertations Series, № 68

\section{Andrea Milan}

Rural Livelihoods, Location and

Vulnerable Environments: Approaches to Migration in Mountain areas of

Latin America

MGSoG Dissertation Series, № 67

\section{Farida Lada}

On Guarding the Welfare of Clinical

Trial Subjects While Promoting Novel

Drug Innovation

A Game Theoretical Approach

MGSoG Dissertation Series, № 66

\section{5}

\section{Hibret Belete Maemir}

Dissecting Aggregate Productivity:

International Integration and Growth with Heterogeneous Firms

UNU-MERIT Dissertation Series, № 96 


\section{Giorgio Triulzi}

Looking for the Right Path: Technology

Dynamics, Inventive Strategies and

Catching-up in the Semiconductor

Industry

UNU-MERIT Dissertation Series, № 95

\section{Abdul Baseer Qazi}

Knowledge flows and networks in the

ICT sector: The case of Pakistan

UNU-MERIT Dissertation Series, № 94

\section{Ajay Thutupalli}

Technology Paradigm Shifts in

Agriculture: Drivers of Sustainability

and Catch up

UNU-MERIT Dissertation Series, № 93

\section{Eduardo Urias}

Improving access to HIVIAIDS

treatment in Brazil: When are

Compulsory Licenses effective in Price

Negotiations?

UNU-MERIT Dissertation Series, № 92

\section{Francesca Guadagno}

Why have so few Countries

Industrialised?

UNU-MERIT Dissertation Series, № 91

\section{Daniel Opolot}

The Evolution of Beliefs and Strategic

Behaviour

UNU-MERIT Dissertation Series, № 90
Alejandro Lavopa

Structural Transformation and

Economic Development: Can

Development Traps be Avoided

UNU-MERIT Dissertation Series, № 89

\section{Jinjin Zhao}

Urban water management reform: The

Case of China

UNU-MERIT Dissertation Series,

№ 88

\section{Simona Vezzoli}

Borders, Independence and Post-

colonial Ties: the Role of the State in

Caribbean Migration

MGSoG Dissertation Series, № 65

\section{Silvia Consuelo Gómez Soler}

Civil Conflict and Education: How

Does Exposure to Civil Conflict Affect

Human Capital Accumulation?

Evidence from Standardized Exit

Exams in Colombia

MGSoG Dissertation Series, № 64

\section{Paula Nagler}

Occupational Choice in the Developing World

MGSoG Dissertation Series, № 63

\section{Jasmin Kientzel}

Determinants of Professional

Commitment to Environmental

Sustainability

MGSoG Dissertation Series, № 62 


\section{Mehmet Güney Celbiş}

Regional Policies: Convergence, Trade, and the Allocation of Public Capital

MGSoG Dissertation Series, № 61

\section{Florian Henning}

Living Up to Standard:

Interoperability Governance and

Standards Adoption in Government

Information Networks

MGSoG Dissertation Series, № 60

\section{Niels P. Groen}

The Never-Ending Project

Understanding E-Government Project

Escalation

MGSoG Dissertation Series, № 59

\section{Derek Copp}

Teacher-Based Reactivity to Provincial

Large-scale Assessment in Canada

MGSoG Dissertation Series, № 58

\section{Michaella Vanore}

Family-Member Migration and the

Psychosocial Health Outcomes of

Children in Moldova and Georgia

MGSoG Dissertation Series, № 57

\section{Sonja Fransen}

The Economic and Social Effects of

Remittances and Return Migration in

Conflict-Affected Areas: The Case of

Burundi

MGSoG Dissertation Series, № 56

\section{Ibrahim Khalil Conteh}

The Impact of Floods on Primary

School Education in Zambia

MGSoG Dissertation Series, № 55

\section{Richard Bluhm}

Growth Dynamics and Development Essays in Applied Econometrics and Political Economy

MGSoG Dissertation Series, № 54

\section{Nevena P. Zhelyazkova}

Work-Family Reconciliation and Use of Parental Leave in Luxembourg:

Empirical Analysis of Administrative Records

MGSoG Dissertation Series, № 53

2014

\section{Dirk Crass}

The Impact of Brands on Innovation and Firm Performance: Empirical Evidence from Germany UNU-MERIT Dissertation Series, № 87

\section{Samyukta Bhupatiraju}

The Geographic Dimensions of Growth and Development

UNU-MERIT Dissertation Series, № 86

\section{François Lafond}

The Evolution of Knowledge Systems UNU-MERIT Dissertation Series, № 85 


\section{Annalisa Primi}

Promoting Innovation in Latin

America: What Countries Have

Learned (and What They Have Not) in

Designing and Implementing

Innovation and Intellectual Property

Policies

UNU-MERIT Dissertation Series, № 84

Fatoumata Lamarana Diallo

Evaluation of Meal and Deworming

Programs for Primary Schools in Rural

Senegal

UNU-MERIT Dissertation Series, № 83

\section{Sachin Kumar Badkas}

Metachoice and Metadata: Innovating with Environmental Policy Analysis in Europe

MGSoG Dissertation Series, № 52

Irina S. Burlacu

An Evaluation of Tax-Benefit Systems Impact on the Welfare of Frontier

Worker:

The Case of Luxembourg and Belgium MGSoG Dissertation Series, № 51

\section{Özge Bilgili}

Simultaneity in Transnational

Migration Research: Links Between

Migrants' Host and Home Country

Orientation

MGSoG Dissertation Series, № 50

\section{Yulia Privalova Krieger}

Reshaping the Big Agenda:

Transnational Politics and Domestic

Resistance Financial crisis and social protection reform in Bosnia and

Herzegovina

MGSoG Dissertation Series, № 49

\section{Marieke van Houte}

Moving Back or Moving Forward?

Return migration after Conflict

MGSoG Dissertation Series, № 48

\section{Oxana Slobozhan}

Global Governance in the Management of Natural Resources: The Case of the Extractive Industries Transparency Initiative (EITI)

MGSoG Dissertation Series, № 47

\section{Luis Bernardo Mejia Guinand}

The Changing Role of the Central

Planning Offices in Latin America: A

Comparative Historical Analysis

Perspective (1950-2013)

MGSoG Dissertation Series, № 46

\section{Cheng Boon Ong}

Ethnic Segregation in Housing, Schools and Neighbourhoods in the Netherlands

MGSoG Dissertation Series, № 45

\section{Luciana V. Cingolani}

Bureaucracies for Development:

Oxymoron or Reality? Studies on State

Capacity in Challenging Governance

Contexts

MGSoG Dissertation Series, № 44 


\section{Carlos Cadena Gaitán}

Green Politics in Latin American

Cities - Sustainable Transport Agendas

MGSoG Dissertation Series, № 43

\section{Katie Kuschminder}

Female Return Migration and

Reintegration Strategies in Ethiopia

MGSoG Dissertation Series, № 42

\section{Metka Hercog}

Highly-Skilled Migration and New

Destination Countries

MGSoG Dissertation Series, № 41

\section{Margaret Agaba Rugadya}

Can Remittances Influence the Tenure and Quality of Housing in Uganda?

MGSoG Dissertation Series, № 40

\section{Ilire Agimi}

New Governance Under Limited

Statehood: The Case of Local

Government Reform in Kosovo

MGSoG Dissertation Series, № 39

2013

\section{Anant Kamath}

Information Sharing through Informal

Interaction in Low-Tech Clusters

UNU-MERIT Dissertation Series, № 82

\section{Flavia Pereira de Carvalho}

What we talk about when we talk about Brazilian Multinationals: An Investigation on Brazilian FDI, Economic Structure, Innovation and the Relationship between them UNU-MERIT Dissertation Series, № 81

\section{Jun Hou}

Complementarity in Innovation and Development: A Cross-country Comparison

UNU-MERIT Dissertation Series, № 80

\section{Rufin Baghana}

Impacts of Government Incentives to $R \mathcal{E} D$, Innovation and Productivity: A Microeconometric Analysis of the Québec Case UNU-MERIT Dissertation Series, № 79

\section{Lilia I. Stubrin}

High-Tech Activities in Emerging Countries: A Network perspective on the Argentinean Biotech Activity UNU-MERIT/MGSoG Dissertation Series, № 78

\section{Kristine Farla}

Empirical Studies on Institutions, Policies and Economic Development MGSoG Dissertation Series, № 38 
Marina Petrovic

Social Assistance and Activation in the Pursuit of Happiness: Shedding New

Light on Old Policy Solutions to Social Exclusion

MGSoG Dissertation Series, № 37

\section{Laura Torvinen}

Assessing Governance Assessments:

The Case of Mozambique: Governance

Assessments in the Context of Aid

Effectiveness Discourse

MGSoG Dissertation Series, № 36

\section{Biniam Egu Bedasso}

Institutional Change in the Long

Shadow of Elite: Essays on

Institutions, Human Capital and

Ethnicity in Developing Countries

MGSoG Dissertation Series, № 35

\section{Sepideh Yousefzadeh Faal}

Deghati

Childhoods Embargoed: Constructing

and Reconstructing Multidimensional

Child Poverty in Iran 1984-2009

MGSoG Dissertation Series, № 34

\section{Robert Bauchmüller}

Investing in Early Childhood Care and

Education: The Impact of Quality on

Inequality

MGSoG Dissertation Series, № 33

\section{Martin Rehm}

Unified Yet Separated: Empirical

Study on the Impact of Hierarchical

Positions within Communities of

Learning

MGSoG Dissertation Series, № 32
2012

\author{
Abdul Waheed \\ Innovation Determinants and \\ Innovation as a Determinant: Evidence \\ from Developing Countries \\ UNU-MERIT Dissertation Series, \\ № 77
}

\section{Bilal Mirza}

Energy Poverty and Rural Energy

Markets in Pakistan

UNU-MERIT Dissertation Series, № 76

\section{Benjamin Engelstätter}

Enterprise Software and Video Games:

An Empirical Analysis

UNU-MERIT Dissertation Series, № 75

\section{Fulvia Farinelli}

Natural Resources, Innovation and Export Growth: The Wine Industry in Chili and Argentina

UNU-MERIT Dissertation Series

\section{Rodolfo Lauterbach}

Innovation in Manufacturing: From

Product Variety and Labor

Productivity Growth to Economic

Development in Chile

UNU-MERIT Dissertation Series

\section{Kirsten Wiebe}

Quantitative Assessment of

Sustainable Development and Growth in Sub-Saharan Africa

UNU-MERIT Dissertation Series, № 74 


\section{Julio Miguel Rosa}

Organizational Strategies, Firms'

Performance and Spatial Spillovers:

The Canadian Case in Research and

Development.

UNU-MERIT Dissertation Series, № 73

Johannes Wilhelmus Marie Boels

Joseph Schumpeter, Honderd Jaar

Economische Ontwikkeling: Een

Historisch-theoretische Beschouwing.

UNU-MERIT Dissertation Series

\section{Dorcas Mbuvi}

Utility Reforms and Performance of the

Urban Water Sector in Africa

MGSoG Dissertation Series, № 31

\section{Lina Salanauskaite}

Distributional Impacts of Public

Policies: Essays in Ex-Ante and Ex-

Post Evaluation

MGSoG Dissertation Series, № 30

\section{Esther Schüring}

To Condition or not - is that the

Question?

An Analysis of the Effectiveness of ExAnte and Ex-Post Conditionality in

Social Cash Transfer Programs

MGSoG Dissertation Series, № 29

\section{Joe Abah}

Strong Organisations in Weak States:

Atypical Public Sector Performance in

Dysfunctional Environments

MGSoG Dissertation Series, № 28

\section{Zina Samih Nimeh}

Social Citizenship Rights: Inequality

and Exclusion

MGSoG Dissertation Series, № 27

2011

\section{Daniel Vertesy}

Interrupted Innovation: Emerging

Economies in the Structure of the

Global Aerospace Industry

UNU-MERIT Dissertation Series, № 72

\section{Tina Saebi}

Successfully Managing Alliance

Portfolios: An Alliance Capability

View

UNU-MERIT Dissertation Series, № 71

\section{Nora Engel}

Tuberculosis in India: A Case of Innovation and Control

UNU-MERIT/MGSoG Dissertation Series, № 70

\section{Evans Mupela}

Connectivity and growth in Sub-

Saharan Africa: The Role of

Communication Satellites

UNU-MERIT Dissertation Series, № 69

\section{Nantawan Kwanjai}

Cross Cultural Intelligence amid Intricate Cultural Webs: A Tale of the UnDutchables in the Land of 1002 Smiles

UNU-MERIT Dissertation Series, № 68 


\section{Lina Sonne}

Innovation in Finance to Finance Innovation: Supporting Pro-poor

Entrepreneur-based Innovation

UNU-MERIT Dissertation Series, № 67

\section{Lenka Eisenhamerová}

Legitimacy of 'Humanitarian Military

Intervention'

MGSoG Dissertation Series, № 26

\section{Sonila Tomini}

Informal Payments for Health Care

Services in Albania

MGSoG Dissertation Series, № 25

\section{Jinjing Li}

Dynamic Microsimulation in Public

Policy Evaluation

MGSoG Dissertation Series, № 24

\section{Aziz Atamanov}

Rural Nonfarm Employment and

International Migration as

Alternatives to Agricultural

Employment: The Case of Kyrgyzstan

MGSoG Dissertation Series, № 23

\section{Frieda Vandeninden}

Poverty Alleviation: Aid and Social

Pensions

MGSoG Dissertation Series, № 22

\section{Juliana Nyasha Tirivayi}

The Welfare Effects of Integrating

AIDS Treatment with Food Transfers:

Evidence from Zambia

MGSoG Dissertation Series, № 21

\section{Agnieska Ewa Sowa}

Who's Left Behind? Social Dimensions

of Health Transition and Utilization of

Medical Care in Poland

MGSoG Dissertation Series, № 20

\section{Emmanaouil Sfakianakis}

The Role of Private Actors in the

Provision of Public Goods with

Applications to Infrastructure and

Financial Stability

MGSoG Dissertation Series, № 19

\section{Siu Hing Lo}

White Collars Green Sleeves: An Interorganizational Comparison of Determinants of Energy-Related Behaviors among Office Workers MGSoG Dissertation Series, № 18

\section{Treena Wu}

Constraints to Human Capital Investment in Developing Countries: Using the Asian Financial Crisis in Indonesia as a Natural Experiment MGSoG Dissertation Series, № 17

\section{Henry Espinoza Peña}

Impact Evaluation of a Job-Training

Programme for Disadvantaged Youths:

The Case of Projoven

MGSoG Dissertation Series, № 16 


\section{Fernando Santiago}

Human Resources Management

Practices and Learning for Innovation

in Developing Countries:

Pharmaceutical Firms in Mexico

UNU-MERIT Dissertation Series, № 66

\section{Zakaria Babutsidze}

Essays on Economies with

Heterogeneous Interacting Consumers

UNU-MERIT Dissertation Series, № 65

\section{Bertha Vallejo}

Learning and Innovation Under

Changing Market Conditions: The

Auto Parts Industry in Mexico

UNU-MERIT Dissertation Series,

№ 64

\section{Donatus Ayitey}

Technical Change, Competitiveness

and Poverty Reduction: A Study of the

Ghanaian Apparel Industry

UNU-MERIT Dissertation Series,

№ 63

\section{Sergey Filippov}

Multinational Subsidiary Evolution:

Corporate Change in New EU Member States

UNU-MERIT Dissertation Series, № 62

\section{Asel Doranova}

Technology Transfer and Learning under the Kyoto Regime: Exploring the Technological Impact of CDM Projects in Developing Countries

UNU-MERIT Dissertation Series, № 61

\section{Florian Tomini}

Between Family and Friend:

Understanding the Interdependency of Private Transfers

MGSoG Dissertation Series, № 15

\section{Michał Polalowski}

The Institutional Transformation of

Social Policy in East Central Europe:

Poland and Hungary in Comparative and Historical Perspective

MGSoG Dissertation Series, № 14

\section{Maha Ahmed}

Defining, Measuring and Addressing

Vulnerability: The Case of Post

Conflict Environments

MGSoG Dissertation Series, № 13

\section{Pascal Beckers}

Local Space and Economic Success:

The Role of Spatial Segregation of Migrants in the Netherlands

MGSoG Dissertation Series, № 12

\section{Victor Cebotari}

Conflicting Demands in Ethnically

Diverse Societies: Ethno political

Contention and Identity Values in

Europe

MGSoG Dissertation Series, № 11 
Dennis Gyllensporre

Competing and Complementary

Perspectives on the EU as a Crisis

Management Actor:

An Examination of the Common

Security and Defence Policy through

the Lenses of Idealism and Realism

MGSoG Dissertation Series, № 10

Judit Vall Castello

Business Cycle and Policy Effects on Labour Market Transitions of Older and Disabled Workers in Spain

MGSoG Dissertation Series, № 9

\section{Keetie Roelen}

False Positives or Hidden Dimensions:

The Definition and Measurement of

Child Poverty

MGSoG Dissertation Series, № 8

Denisa Maria Sologon

Earning Dynamics in Europe

MGSoG Dissertation Series, № 7

\section{Melissa Siegel}

Money and Mobility: Migration and

Remittances

MGSoG Dissertation Series, № 6

Jessica S. Hagen-Zanker

Modest Expectations: Causes and

Effects of Migration on Migrant

Households inSource Countries

MGSoG Dissertation Series, № 5
2009

\begin{abstract}
Alexis Habiyaremye
From Primary Commodity Dependence to Diversification and Growth:

Absorptive Capacity and Technological Catch Up in Botswana and Mauritius.

UNU-MERIT Dissertation Series, № 60
\end{abstract}

\section{Yoseph Getachew}

The Role of Public Capital in Economic Development

UNU-MERIT Dissertation Series, № 59

\section{Sandra Leitner}

Embodied Technological Change and

Patterns of Investment in Austrian

Manufacturing

UNU-MERIT Dissertation Series, № 58

\section{Semih Akçomak}

The Impact of Social Capital on Economic and Social Outcomes UNU-MERIT Dissertation Series, № 57

\section{Abraham Garcia \\ The Role of Demand in Technical \\ Change \\ UNU-MERIT Dissertation Series, № 56}

\section{Saurabh Arora}

Coherence in Socio-technical Systems:

A Network Perspective on the Innovation Process

UNU-MERIT Dissertation Series, № 55 


\section{Mirtha R. Muniz Castillo}

Human Development and Autonomy

in Project Aid: Experiences from four

bilateral projects in Nicaragua and $E l$

Salvador

MGSoG Dissertation Series, № 4

\section{Christiane Arndt}

Governance Indicators

MGSoG Dissertation Series, № 3

\section{Britta Augsburg}

Microfinance: Greater Good or Lesser

Evil?

MGSoG Dissertation Series, № 2

2008

\section{Rutger Daems}

Medicines for the Developing World

UNU-MERIT Dissertation Series, № 54

\section{Johannes Hanel}

Assessing Induced Technology:

Sombart's Understanding of Technical

Change in the History of Economics

UNU-MERIT Dissertation Series,

№ 53

\section{Rifka Weehuizen}

Mental Capital: the Economic

Significance of Mental Health

UNU-MERIT Dissertation Series,

№ 52

\section{Danielle Cloodt}

The Relationship between RED

Partnership Formation, Social

Embeddedness and Innovative

Performance

UNU-MERIT Dissertation Series, № 51

\section{Sabine Fuss}

Sustainable Energy Development

under Uncertainty

UNU-MERIT Dissertation Series,

№ 50

\section{Geranda Notten}

Measuring and Managing Poverty

Risks

MGSoG Dissertation Series, № 1

2007

\section{Tobias Kronenberg}

Reconciling Environmental

Conservation with Economic

Prosperity: The Feasibility of Double

Dividends in the Short and Long Run

UNU-MERIT Dissertation Series,

№ 49

\section{Viktoria Kravtsova}

Assessing the Impact of Foreign Direct Investment in Transition Economies UNU-MERIT Dissertation Series, № 48 


\section{Suhail Sultan}

The Competitive Advantage of Small and Medium Sized Enterprises: The Case of Jordan's Natural Stone Industry

UNU-MERIT Dissertation Series, № 47

2006

\section{Bulat Sanditov}

Essays on Social Learning and Imitation

UNU-MERIT Dissertation Series, № 46

\section{Mamata Parhi}

Dynamics of New Technology Diffusion: A Study of the Indian Automotive Industry

UNU-MERIT Dissertation Series, № 45

\section{Andreas Reinstaller}

Social Structures and the Innovation Process: Their Role in the Demand of Firms and Consumers

UNU-MERIT Dissertation Series, № 44

\section{Rose Kiggundu}

Innovation systems and Development:

The Journey of a Beleaguered Nile

Perch Fishery in Uganda

UNU-MERIT Dissertation Series, № 43

\section{Thomas Pogue}

The Evolution of Research

Collaboration in South African Gold Mining: 1886-1933

UNU-MERIT Dissertation Series, № 42

\section{Geoffrey Gachino}

Foreign Direct Investment, Spillovers and Innovation: The Case of Kenyan Manufacturing Industry

UNU-MERIT Dissertation Series, № 41

\section{Önder Nomaler}

Technological Change, International

Trade and Growth: An Evolutionary, Multi-Agents-Based Modeling

Approach

UNU-MERIT Dissertation Series, № 40

2005

Samia Satti Osman Mohamed-

Nour

Change and Skill Development in the Arab Gulf Countries

UNU-MERIT Dissertation Series, № 39

\section{Elad Harison}

Intellectual Property Rights:

Economics and Policy Analysis

UNU-MERIT Dissertation Series, № 38 


\section{Daniel Dalohoun}

Learning to innovate: agricultural innovation and entrepreneurship: the case of Songhai farmers in Benin

UNU-MERIT Dissertation Series, № 37

\section{Müge Ozman}

Networks, Organizations and

Knowledge

UNU-MERIT Dissertation Series, № 36

\section{Bas Straathof}

Product Variety and Economic

Growth: The Counteracting Effects of

Scale and Idiosyncrasy

UNU-MERIT Dissertation Series, № 35

\section{Wilfred Schoenmakers}

Knowledge Flows between

Multinational Companies: A Patent

Data Analysis

UNU-MERIT Dissertation Series, № 34

\section{Myriam Cloodt}

Mergers and Acquisitions ( $M$ and As) in High-Tech Industries: Measuring the Post-M and A Innovative

Performance of Companies

UNU-MERIT Dissertation Series, № 33
2004

\section{Paola Criscuolo}

RED Internationalisation and

Knowledge Transfer: Impact on MNEs and their Home Countries

UNU-MERIT Dissertation Series, № 32

\section{Maarten Verkerk}

Trust and Power on the Shop Floor UNU-MERIT Dissertation Series, № 31

\section{Gottfried Leibbrandt}

Adoption, Harmonization and Succession of Network Technologies across Countries

UNU-MERIT Dissertation Series, № 30

\section{Mark Sanders}

Skill Biased Technical change: Its Origins, the Interaction with the Labour Market and Policy Implications UNU-MERIT Dissertation Series, № 29

2003

\section{Nadine Roijakkers}

Inter-firm Cooperation in High-tech Industries: a Study of RED

Partnerships in Pharmaceutical Biotechnology

UNU-MERIT Dissertation Series, № 28 
Viki Sonntag

Speed, Scale and Sustainability

UNU-MERIT Dissertation Series, № 27

\section{Masaru Yarime}

From End-of-Pipe Technology to Clean

Technology

UNU-MERIT Dissertation Series,

№ 26

\section{Stéphane Malo}

The Combinatorial Chemistry

Revolution: Sustaining a Superior

Performance Position through

Technological Learning

UNU-MERIT Dissertation Series,

№ 25

\section{2}

\section{Annelies Hogenbirk}

Determinants of Inward Foreign

Direct Investment: the Case of the

Netherlands

UNU-MERIT Dissertation Series, № 24

\section{Bastiaan Johan terWeel}

The Computerization of the Labour Market

UNU-MERIT Dissertation Series
2001

\section{John Adeoti}

Technology Investment in Pollution Control in Sub-Saharan Africa: The Case of the Nigerian Manufacturing Industry

UNU-MERIT Dissertation Series, № 23

\section{Edward Huizenga}

Innovation Management: How

Frontrunners Stay Ahead: An

Empirical Study on Key Success

Factors in the ICT sector

UNU-MERIT Dissertation Series, № 22

\section{0}

\section{Machiel van Dijk}

Technological Change and the Dynamics of Industries: Theoretical Issues and Empirical evidence from Dutch Manufacturing UNU-MERIT Dissertation Series, № 21

\section{9}

\section{Jan Cobbenhagen}

Managing Innovation at the Company Level: A Study on Non-Sector-Specific Success Factors UNU-MERIT Dissertation Series, № 20 
Marjolein Caniëls

Regional Growth Differentials: The

Impact of Locally Bounded Knowledge

Spillovers

UNU-MERIT Dissertation Series, № 19

1998

\begin{abstract}
Aldo Geuna
Resource Allocation and Knowledge production: Studies in the Economics of University Research UNU-MERIT Dissertation Series, № 18
\end{abstract}

1996

\section{Reinoud Joosten}

Dynamics, Equilibria, and Values UNU-MERIT Dissertation Series, № 17

\section{Hugo Kruiniger}

Investment, $R \mathcal{E} D$, and the Financing

Decisions of the Firm

UNU-MERIT Dissertation Series, № 16

\section{5}

\section{Hans van Meij1}

Endogenous Technological Change:

The Case of Information Technology,

Theoretical Considerations and

Empirical Results

UNU-MERIT Dissertation Series, № 15

\section{René Kemp}

Environmental Policy and Technical

Change: A Comparison of the

Technological Impact of Policy

Instruments

UNU-MERIT Dissertation Series, № 14

\section{Rohini Acharya}

The Impact of New Technologies on Economic Growth and Trade: A Case Study of Biotechnology

UNU-MERIT Dissertation Series, № 13

\section{Geert Duysters}

The Evolution of Complex Industrial Systems: The Dynamics of Major IT Sectors

UNU-MERIT Dissertation Series, № 12

\section{Marjan Groen}

Technology, Work and Organisation: A Study of the Nursing Process in Intensive Care Units

UNU-MERIT Dissertation Series, № 11

\section{4}

\section{Huub Meijers}

On the Diffusion of Technologies in a Vintage Framework: Theoretical Considerations and Empirical Results UNU-MERIT Dissertation Series, № 10 
Theon van Dijk

The Limits of Patent Protection: Essays on the Economics of Intellectual

Property Rights

UNU-MERIT Dissertation Series, № 9

\section{Hans Voordijk}

Naar Integrale Logistiek in

Bedrijfsketens: Ontwikkelingen in de Bouw

UNU-MERIT Dissertation Series, № 8

1993

\section{Paul Diederen}

Technological Progress in Enterprises and Diffusion of Innovation:

Theoretical Reflections and Empirical

Evidence

UNU-MERIT Dissertation Series, № 7

\section{Ben Dankbaar}

Economic Crisis and Institutional Change: The Crisis of Fordism from the Perspective of the Automobile Industry UNU-MERIT Dissertation Series, № 6

\section{Hanno Roberts}

Accountability and Responsibility: The Influence of Organisation Design on Management Accounting UNU-MERIT Dissertation Series, № 5
1992

\section{Bart Verspagen}

Uneven Growth between

Interdependent Economies: An

Evolutionary View on Technology

Gaps, Trade and Growth

UNU-MERIT Dissertation Series,

№ 4

\section{Sjoerd Romme}

A Self-organization Perspective on

Strategy Formation

UNU-MERIT Dissertation Series, № 3

\section{9}

\section{John Spangenberg}

Economies of Scale, and Atmosphere in Research Organisations

UNU-MERIT Dissertation Series, № 2

1988

\section{John Hagedoorn}

Evolutionary and Heterodox

Innovation Analysis: A Study of

Industrial and Technological

Development in Process Control and

Information Technology

UNU-MERIT Dissertation Series, № 1 